\title{
What works to make EU law work? An analysis of the usefulness of national, transnational, and supranational compliance instruments
}

Citation for published version (APA):

Polak, J. J. C. (2015). What works to make EU law work? An analysis of the usefulness of national, transnational, and supranational compliance instruments. [Doctoral Thesis, Maastricht University]. Maastricht University. https://doi.org/10.26481/dis.20151016jp

Document status and date:

Published: 01/01/2015

DOI:

10.26481/dis.20151016jp

Document Version:

Publisher's PDF, also known as Version of record

Please check the document version of this publication:

- A submitted manuscript is the version of the article upon submission and before peer-review. There can be important differences between the submitted version and the official published version of record.

People interested in the research are advised to contact the author for the final version of the publication, or visit the DOI to the publisher's website.

- The final author version and the galley proof are versions of the publication after peer review.

- The final published version features the final layout of the paper including the volume, issue and page numbers.

Link to publication

\footnotetext{
General rights rights.

- You may freely distribute the URL identifying the publication in the public portal. please follow below link for the End User Agreement:

www.umlib.nl/taverne-license

Take down policy

If you believe that this document breaches copyright please contact us at:

repository@maastrichtuniversity.nl

providing details and we will investigate your claim.
}

Copyright and moral rights for the publications made accessible in the public portal are retained by the authors and/or other copyright owners and it is a condition of accessing publications that users recognise and abide by the legal requirements associated with these

- Users may download and print one copy of any publication from the public portal for the purpose of private study or research.

- You may not further distribute the material or use it for any profit-making activity or commercial gain

If the publication is distributed under the terms of Article 25fa of the Dutch Copyright Act, indicated by the "Taverne" license above, 


\section{What works to make EU law work?}

An analysis of the usefulness of national, transnational, and supranational compliance instruments

Josine Polak

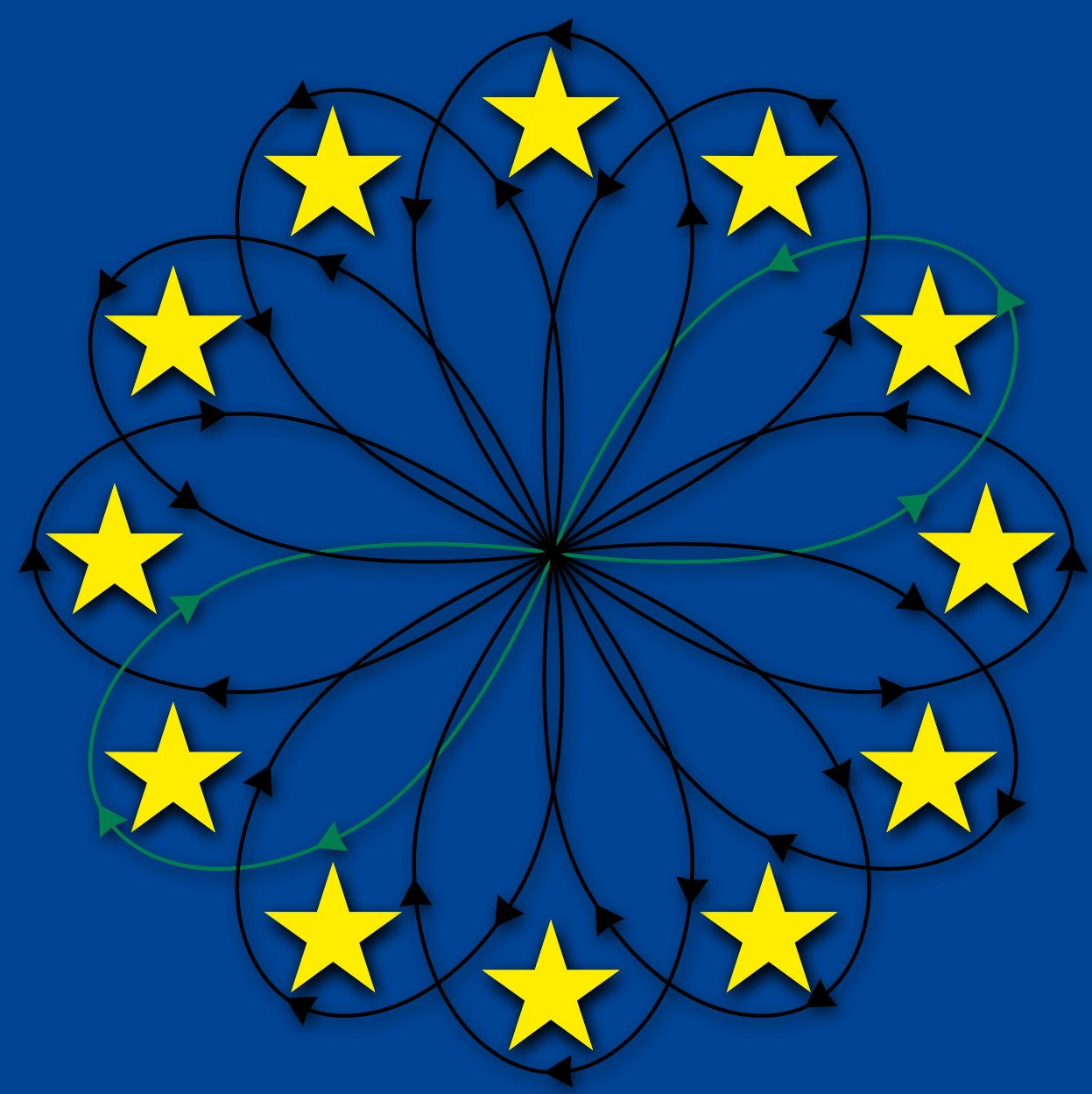


๑) Copyright Josine Polak 2015 


\title{
What works to make EU law work?
}

\section{An analysis of the usefulness of national, transnational, and supranational compliance instruments}

\author{
DISSERTATION \\ to obtain the degree of Doctor at Maastricht University, \\ on the authority of the Rector Magnificus Prof. dr. L.L.G. Soete, \\ in accordance with the decision of the Board of Deans, \\ to be defended in public on Friday 16 October 2015, at 16.00 hours \\ by
}

Josina Johanna Cornelia Polak 
Maastricht University, Faculty of Law

Supervisors:

Prof. dr. Chris Backes

Prof. dr. Esther Versluis

Co-supervisor:

Dr. Mariolina Eliantonio

Assessment Committee:

Prof. dr. Ellen Vos (Chair)

Prof. dr. Tanja Börzel, Freie Universität Berlin

Dr. Elissaveta Radulova

Prof. dr. Frans van Waarden, Utrecht University

Prof. dr. Bruno de Witte 


\section{Preface}

This thesis is the product of a journey that I originally embarked on, not only out of an intrinsic interest in the subject of compliance in the EU, but also out of a wish to challenge myself professionally. Having previously studied and worked at the Faculty of Arts and Social Sciences, moving to the Faculty of Law indeed seemed to pose the perfect professional challenge. And a challenge it was at times, with some unforeseen bumps on the road and detours to take. But here we are, after nearly six years, with the product of this journey in front of you.

I would first of all like to wholeheartedly thank my supervisors, Chris Backes and Esther Versluis, for their enduring support on this journey. Thank you for your constructive feedback, patience, constant practical support, and trust that I would finish this work. I have been very fortunate to have you as my supervisors, not in the least since you complement each other perfectly. I would also like to thank my co-supervisor Mariolina Eliantonio. Thank you for your detailed and constructive comments and for the encouraging and helpful 'Yummy coffees' we had in Brussels.

I would also like to thank the members of the Assessment Committee, for their willingness to take some time out of their busy schedules to read my thesis and to provide valuable feedback.

I also received valuable feedback on certain chapters of my manuscript from Paolo Graziano and Phedon Nicolaides, which I thankfully made use of. This also applies to the comments provided by Francisco Pereira Coutinho, who reviewed some of my writing about Portuguese law.

This work would have been impossible to carry out without the help of the national and EU officials who were so kind to free some, and sometimes a considerable amount, of their valuable time to meet me for an interview and to share their views and experiences with me. Let me therefore take this opportunity to transmit, once again, my thanks to all of my interviewees. Special thanks go to Ernst, Jose Manuel, Jakub Skorupski, Marina, and Spencer for their great efforts in helping me to better understand the subject matter of my thesis and - in some cases - for acting as translators during interviews. Special thanks also go to Daniel and Lénia, who were invaluable for putting me in touch with respondents in Portugal, and to Bartek and Dariusz, who were greatly helpful for establishing interview contacts in Poland. I owe much to Dariusz in particular, who acted not only as a great guide in Warsaw, but also as my 'hotline' back home whenever I had technical questions about Polish administrative law or implementation in Poland.

Having come from 'the other side of the Vrijthof', conducting my research at the Law Faculty has allowed, not only for interesting academic endeavours, but also for a 
cultural exploration. I would like to thank my former colleagues at the Department of Public Law, whom I thankfully resorted to for questions about the intricacies of Dutch law in particular. I would also like to thank Peggy van Wersch for her great help with practical matters during all of these years, and Licette Poll for being so helpful during the last stages of the process. I am also much indebted to Ubbo Noordhof at Datawyse, whose support in relation to the publishing of this book was invaluable. Finally, I would like to wholeheartedly thank Bas Swaen at SCRiBBR for his great support, Melissa Winterbottom for her generosity in carrying out the language check of my work, and Tiara Patel for some last-minute linguistic assistance. All remaining errors are my own.

This - amongst others - is also the place to thank my friends, for all their patience during these last years. To Nina and Suzanne: many thanks for your willingness to act as paranymphs. Thank you for being such great friends, for your pep talks when things were not going so smoothly, and for our many moments 'away from everything'. Marianne, thank you for your wise words, and Tiara, thank you for our Indian evenings and for sharing brownies and mattresses whenever I had to come over to Maastricht for meetings. In Brussels, I have been very happy to meet Pedro and Eveline, Jacqui, and Peter, who always understood that I could not always be there and who miraculously kept up with my complaints. I am very grateful to Sjoerd for his help with the technical issues of my manuscript that - unavoidably - turned up 'five minutes to twelve'. Leon, the golden medal for having saved my manuscript goes to you!

I would also like to express my gratitude to my family, particularly my parents - for everything. It might not always have been obvious to you what I was doing and why I was doing it, and I must have tested your patience at times. Special thanks go to my father, who has managed to symbolically convey the red thread of this study in the front cover design, which he conceived.

Finally, I would not have been able to bring this work to its completion without $o$ meu amorzão. Daniel, my interview with you in Brussels on that rainy autumn day in 2012, on which everything initially seemed to go wrong, has definitely produced the best 'output' of my research project. I cannot even find the words to thank you for your patience, your encouragement, your interest in my work, and your attempts to convince me of its usefulness. Without your love, I would not have been able to finish this journey.

Josine Polak

Brussels, September 2015 


\section{Outline contents}

Abbreviations $\quad 21$

Tables $\quad 25$

Figures $\quad 26$

PART I PURPOSE, RELEVANCE, THEORY, AND METHODOLOGY 27

Chapter 1 Making EU law work: A problem in need of a solution 29

Chapter 2 Implementation in the EU: Same rules, divergent practices 41

$\begin{array}{lll}\text { Chapter } 3 & \text { Approach and methodology } & 67\end{array}$

PART II SUPRANATIONAL COMPLIANCE INSTRUMENTS 103

$\begin{array}{lll}\text { Chapter } 4 \text { Monitoring and sanctions } & \mathbf{1 0 5}\end{array}$

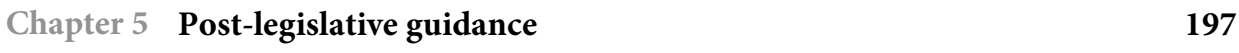

PART III TRANSNATIONAL COMPLIANCE INSTRUMENTS 255

$\begin{array}{lll}\text { Chapter } 6 & \text { Transnational networks } & 257\end{array}$

PART IV NATIONAL COMPLIANCE INSTRUMENTS 321

$\begin{array}{lll}\text { Chapter } 7 & \text { Civil society } & \mathbf{3 2 3}\end{array}$

$\begin{array}{lll}\text { Chapter } 8 \text { Case law } & 373\end{array}$

PART V CONCLUSIONS AND RECOMMENDATIONS 465

Chapter 9 What works to make EU law work? Conclusions and $\begin{array}{ll}\text { recommendations } & 467\end{array}$

Summary $\quad 521$

Annex I Valorisation $\quad 531$

Annex II List of interviews

Literature $\quad 543$

International, EU, and national measures and documents $\quad 564$

Case law $\quad \mathbf{5 7 0}$

Websites $\quad 576$ 


\section{Detailed contents}

Preface $\quad 5$

Outline contents $\quad 7$

Detailed contents 9

Abbreviations $\quad 21$

Tables $\quad 25$

Figures $\quad 26$

PART I PURPOSE, RELEVANCE, THEORY, AND METHODOLOGY 27

Chapter 1 Making EU law work: A problem in need of a solution 29

1. The problem: Ensuring compliance with EU law 31

2. Towards a solution? Studying the usefulness of compliance instruments 33

3. A preliminary note on methodology 36

4. Outline of this study $\quad 38$

$\begin{array}{ll}\text { 4.1. Part I } & 38\end{array}$

4.2. Parts II, III, and IV 39

$\begin{array}{ll}\text { 4.3. Part V } & 40\end{array}$

Chapter 2 Implementation in the EU: Same rules, divergent practices 41

Introduction $\quad 42$

1. What's in a name? About implementation, compliance, and effectiveness 43

1.1. Defining implementation, compliance, and effectiveness 44

1.2. Implementation and compliance in the EU 45

2. The implementation of EU directives: obligations of member states 47

2.1. Transposition 48

2.2. Operationalisation 48

2.3. Application $\quad 49$

2.4. Enforcement 51

3. The implementation deficit in the EU: Attempts to shed light on the

3.1. Of information and implementation deficits 52

3.2. How to explain variance in implementation processes and outcomes? 54

3.2.1. Domestic implementation research 55

3.2.2. EU implementation research 56

3.2.2.1. Member state specific variables: the worlds of compliance

typology 57 
3.2.2.2.1. Goodness of fit 60

3.2.2.2.2. Salience $\quad 62$

3.2.2.2.3. Preferences 63

3.2.2.2.4. Synthesis 64

3.3. Problems with EU implementation research 65

\section{$\begin{array}{lll}\text { Chapter } 3 & \text { Approach and methodology } & 67\end{array}$}

Introduction $\quad 68$

1. From studying implementation problems towards examining possible $\begin{array}{ll}\text { solutions } & 69\end{array}$

1.1. An exploration of the compliance instruments included in this study $\quad 70$

1.2. An exploration of the interrelations of compliance instruments 71

2. Why should compliance instruments work? $\quad 72$

2.1. The rationalist answer: enforcement 73

2.2. The managerial answer: capacity building, rule clarification, and $\begin{array}{ll}\text { transparency } & 74\end{array}$

2.3. The constructivist answer: socialisation $\quad 75$

3. Towards an actor-based typology of compliance instruments 76

$\begin{array}{ll}\text { 3.1. Why existing typologies do not work } & 77\end{array}$

3.2. A pragmatic approach: an actor-based typology of compliance instruments 80

4. Methodology 83

4.1. Case studies $\quad 83$

4.1.1. The selection of directives 84

4.1.1.1. The GPS Directive $\quad 86$

4.1.1.2. The IPPC Directive $\quad 87$

4.1.1.3. The SAFA Directive $\quad 88$

4.1.2. The selection of member states 90

$\begin{array}{ll}\text { 4.2. Sources } & 92\end{array}$

4.2.1. Survey 93

4.2.2. Elite interviews 95

4.2.2.1. The definition of the target population 95

4.2.2.2. The selection of interviewees 96

4.2.2.3. The completion, processing, analysis, and validation of interviews $\quad 98$

5. Synthesis 99 
$\begin{array}{ll}\text { Chapter } 4 \text { Monitoring and sanctions } & \mathbf{1 0 5}\end{array}$

$\begin{array}{ll}\text { Introduction } & 106\end{array}$

1. Monitoring and sanctions as compliance instruments 109

$\begin{array}{ll}\text { 1.1. Why monitoring and sanctions? } & 109\end{array}$

$\begin{array}{ll}\text { 1.1.1. Monitoring } & 109\end{array}$

1.1.1.1. Police-patrol oversight $\quad 110$

$\begin{array}{ll}\text { 1.1.1.2. Fire-alarm oversight } & 112\end{array}$

1.1.2. Sanctions 113

1.1.2.1. Naming and shaming $\quad 113$

1.1.2.2. Infringement proceedings 114

1.1.2.2.1. Article 258 TFEU proceedings $\quad 115$

A. Commencement 115

B. Pre-contentious and administrative stages $\quad 116$

C. Litigation stage 117

1.1.2.2.2. Article $260 \mathrm{TFEU}$ proceedings 119

$\begin{array}{ll}1.1 .2 .2 .3 \text {. Recent developments } & 120\end{array}$

1.1.2.2.4. Beyond correction: the preventive effect of infringement proceedings $\quad 122$

1.2. Limitations of monitoring and sanctions as compliance instruments $\quad 123$

$\begin{array}{ll}\text { 1.2.1. } \text { Monitoring } & 124\end{array}$

1.2.1.1. Incomplete information $\quad 124$

1.2.1.2. Insufficient resources for verifying information $\quad 126$

$\begin{array}{ll}\text { 1.2.2. Sanctions } & 128\end{array}$

1.2.2.1. Restraint with the imposition of sanctions $\quad 128$

1.2.2.2. Variable impact of sanctions 131

1.2.2.2.1. Internal factors 131

1.2.2.2.2. External factors 133

2. Monitoring and sanctioning instruments relevant to this study 134

$\begin{array}{ll}\text { 2.1. Monitoring instruments } & 134\end{array}$

2.1.1. The GPS Directive 134

2.1.2. The IPPC Directive 135

2.1.3. The SAFA Directive 135

2.2. Naming and shaming 138

2.2.1. General Commission reports 138

2.2.2. The GPS Directive 139

2.2.3. The IPPC Directive 141

2.2.4. The SAFA Directive 143

$\begin{array}{ll}\text { 2.3. Infringement proceedings } & 145\end{array}$ 
2.3.2. Findings 147

3. The usefulness of monitoring and sanctions as compliance instruments $\quad 151$

3.1. Inspections carried out by EASA 151

3.1.1. Poland: EASA as a policeman 152

3.1.2. The Netherlands: EASA as a policeman and as a facilitator 154

3.1.3. Portugal: EASA as a (bad) teacher vs. a reassuring agent 155

3.1.4. Synthesis 158

3.2. Naming and shaming 158

3.2.1. Naming and shaming: EU reports 159

3.2.1.1. Variable familiarity with EU reports 159

3.2.1.2. The meaningfulness of information 161

3.2.1.2.1. Objectivity of information 161

3.2.1.2.2. Understandability of information that 'bites' 165

3.2.1.2.3. Relevance of information 168

3.2.1.3. Capacity-building effects of EU reports $\quad 170$

3.2.2. Naming and shaming 'amongst intimae' 171

$\begin{array}{ll}\text { 3.2.3. Issue salience } & 174\end{array}$

3.2.4. Synthesis 176

$\begin{array}{ll}\text { 3.3. Infringement proceedings } & 177\end{array}$

$\begin{array}{ll}\text { 3.3.1. Intensity of enforcement activity } & 177\end{array}$

3.3.1.1. Availability of information $\quad 178$

3.3.1.2. Clarity and binding effect of rules $\quad 180$

3.3.1.3. Political and pragmatic considerations 181

3.3.2. Between (much) frustration and (little) appreciation 183

3.3.2.1. The Commission's use of discretion 184

3.3.2.2. A useful 'stick in the cupboard'? $\quad 187$

$\begin{array}{ll}\text { 3.3.3. Synthesis } & 188\end{array}$

4. Concluding remarks: how and when do monitoring and sanctions work? $\quad 190$

4.1. Inspections by EU regulatory agencies 190

4.2. Naming and shaming 192

$\begin{array}{ll}\text { 4.3. Infringement proceedings } & 194\end{array}$

$\begin{array}{lll}\text { Chapter } 5 & \text { Post-legislative guidance } & 197\end{array}$

$\begin{array}{ll}\text { Introduction } & 199\end{array}$

1. Post-legislative guidance as a compliance instrument 203

1.1. Why post-legislative guidance? 203

1.1.1. Smoothing and prevention of infringement proceedings 204

1.1.2. Reassurance 205

1.1.3. Information exchange 205 
1.2. Limitations of post-legislative guidance as a compliance instrument

1.2.2. Consultation and legitimacy

1.2.2.1. National competent authorities

1.2.2.2. The European Parliament

1.2.2.4. Adverse effects of a lack of consultation

1.2.3.1. The European Commission and national competent authorities

1.2.3.2. The CJEU and national courts

1.2.3.3. Incidental effects of interpretative rules

2. Post-legislative guidance relevant to this study

2.1. The GPS Directive

2.1.1. The RAPEX Guidelines

2.1.2. Other guidance

2.2. The IPPC Directive

2.2.1. The BREFs

2.2.2. Other guidance

2.3. The SAFA Directive

2.3.1. The SAFA Guidance Materials

2.3.2. Other guidance

3. The usefulness of post-legislative guidance as a compliance instrument

3.2. Quality of guidance

3.2.2. Nature of the policy issue

3.3. The (legal) effect of post-legislative guidance

3.3.1. The BREF guidance documents

3.3.2. The SAFA guidance materials

3.3.3. The GPS Directive

3.4. Requests for binding guidance: a question of culture?

3.4.1. Guidance in the area of IPPC

3.4.2. Guidance in the area of GPS

3.4.3. Guidance in the area of SAFA

3.4.4. Binding guidance: a choice between the devil and the deep blue sea 
$\begin{array}{lll}\text { Chapter } 6 & \text { Transnational networks } & \mathbf{2 5 7}\end{array}$

$\begin{array}{ll}\text { Introduction } & 258\end{array}$

1. Networks as compliance instruments $\quad 261$

$\begin{array}{ll}\text { 1.1. Why networks? } & 261\end{array}$

1.1.1. Actor-centred institutionalism: resource sharing and mutual trust 264

1.1.2. Learning theories: mutual learning 265

1.1.3. Constructivism: socialisation 267

1.2. Limitations of networks as compliance instruments 267

1.2.1. The dependence of networks on interdependence 267

1.2.2. Output legitimacy: an institutional design and capacity perspective 268

$\begin{array}{ll}\text { 1.2.2.1. Trust } & 269\end{array}$

1.2.2.2. Size of networks $\quad 270$

$\begin{array}{ll}\text { 1.2.2.3. Goal consensus } & 270\end{array}$

1.2.2.4. Network-level competencies $\quad 271$

1.2.2.5. Synthesis 272

1.2.3. Output legitimacy: a participant-level perspective 272

1.2.4. Input legitimacy: accountability, transparency, and participation 274

2. Networks relevant to this study 276

2.1. The GPS Directive $\quad 277$

2.1.1. The Consumer Safety Network 280

2.1.2. Prosafe 281

2.2. The IPPC Directive $\quad 281$

2.2.1. IMPEL 284

2.3. The SAFA Directive $\quad 285$

2.3.1 The European SAFA Steering Group 286

3. The usefulness of networks as compliance instruments 287

\begin{tabular}{ll}
3.1. & Perceived interdependence \\
\hline 3.2. & 287
\end{tabular}

3.2. The virtues of transnational cooperation 291

3.2.1. Mutual learning: about teachers and students 291

3.2.2. Mutual trust: about leaders and laggards 294

3.2.3. Resource sharing: the importance of money 295

3.2.4. Conflict resolution: 'bottom-up' coordination in the presence of interdependence 298

3.3. Informality: the key to making cooperation work? 300

3.3.1. Informality: key to openness, key to mutual trust 300

3.3.2. What really matters: the perception of cooperation as informal 304

3.4. Pitfalls of cooperation 307

3.4.1. Incomplete participation 307 


\section{Chapter 7 Civil society}

1. Civil society as a compliance instrument

1.1. Why civil society?

1.1.1. Cooperation

1.1.2. Multi-level pressure

1.2. Limitations of civil society as a compliance instrument

1.2.1. Civil society preferences

1.2.2. Strength of civil society

1.2.2.1. Between cooperation and conflict, between institutional and organisational capacity

1.2.2.2. Institutional path dependence and fault lines in the EU

2. Civil society actors relevant to this study

2.1. The GPS Directive

2.1.1. The Netherlands

2.1.2. Poland

2.1.3. Portugal

2.2. The IPPC Directive

2.2.1. The Netherlands

2.2.2. Poland

2.2.3. Portugal

2.3. The SAFA Directive

3. The usefulness of civil society as a compliance instrument

3.1. The SAFA Directive: low salience, lack of civil society involvement

3.2. The GPS Directive

3.2.1. The Netherlands: civil society in a complementary role

3.2.2. Poland: negative perceptions of civil society

3.2.3. Portugal: mixed perceptions of civil society

3.2.4. Synthesis

3.3 The IPPC Directive

3.3.1. The Netherlands: ambivalent perceptions of constructive pressure 
1. Case law as a compliance instrument 376

1.1. Why case law? 376

1.1.1. Domestic case law 376

1.1.2. Preliminary rulings 377

1.2. Limitations of case law as a compliance instrument 380

1.2.1. Domestic case law 381

1.2.1.1. Access to justice $\quad 382$

1.2.1.1.1 Standing 383

A. Actio popularis proceedings 383

B. Concept of party in other proceedings 384

1.2.1.1.2. Time limits 387

A. Time limits for persons to bring a claim 388

B. Time (limits) for courts to deliver a judgement 388

1.2.1.1.3. Costs 390

A. Court fees 390

B. Experts 393

C. Attorneys 394

D. Compensation of costs for winning parties $\quad 395$

E. Financial assistance 397

F. Requests for a preliminary ruling $\quad 397$

1.2.1.2. Remedies 398

A. Interim relief 398

B. Remedies if a claim is upheld 399

$\begin{array}{ll}\text { 1.2.1.3. Synthesis } & 402\end{array}$

1.2.1.4. Capacity of civil society to engage in litigation 404

1.2.2. The preliminary ruling procedure 405

1.2.2.1. Preliminary ruling requests: cross-issue, cross-country, and cross-court variation 406

1.2.2.2. Compliance with preliminary rulings $\quad 408$

2. Case law relevant to this study 409

2.1. National case law 410

2.2. Preliminary rulings 413

3. The usefulness of case law as a compliance instrument 414

3.1. National case law 414

3.1.1. Explaining the prevalence of case law 414

3.1.1.1. Capacity and motivation of potential litigants 415

3.1.1.2. The performance of prejudicial problem-solving mechanisms 417 
3.1.1.3. Interests of potential litigants

3.1.1.4. Rules for access to justice

3.1.1.4.1. Standing

3.1.1.4.2. Length of proceedings

3.1.1.4.3. Costs

425

3.1.1.4.4. Remedies

426

A. Expertise of judges

426

B. Relativiteitsvereiste

427

3.1.1.5. Litigation culture

428

3.1.1.6. Synthesis

429

3.1.2. The usefulness of national case law

3.1.2.1. The GPS Directive

430

3.1.2.1.1. Poland

430

A. Contents 430

B. Usefulness 433

3.1.2.2. The IPPC Directive 437

3.1.2.2.1. The Netherlands 438

A. Contents 438

B. Usefulness 440

3.1.2.2.2. Poland 442

A. Contents 442

B. Usefulness 445

3.1.2.2.3. Synthesis 446

3.1.2.3. Case law on SAFA inspections $\quad 447$

3.1.2.3.1. The Netherlands 448

A. Contents 448

B. Usefulness 448

$\begin{array}{ll}\text { 3.1.3. Synthesis } & 448\end{array}$

3.2. Preliminary rulings $\quad 449$

3.2.1. Preliminary rulings for the GPS Directive 449

A. Contents 449

B. Usefulness 450

3.2.2. Preliminary rulings for the IPPC Directive 454

A. Contents 454

B. Usefulness 456

3.2.3. Synthesis 458

4. Concluding remarks: how and when does case law work? $\quad 459$

4.1. National case law 459

4.2. Preliminary rulings 462 


\section{Chapter 9 What works to make EU law work? Conclusions and} recommendations

1. What this study set out to do 469

2. Approach and methodology 470

3. What this study has not done 473

4. What works to make EU law work? 476

4.1. Mixing compliance instruments 476

4.2. Flexibility: why a one-size-fits-all approach may not fit anyone 479

4.2.1. Monitoring and sanctions (Chapter 4) 479

$\begin{array}{ll}\text { 4.2.1.1. Inspections } & 479\end{array}$

4.2.2.2. Naming and shaming $\quad 480$

4.2.2.3. Infringement proceedings 483

4.2.2. Post-legislative guidance (Chapter 5) 485

4.2.3. Transnational networks (Chapter 6) 488

4.2.4. Civil society (Chapter 7) 492

4.2.5. Case law (Chapter 8) 495

4.2.5.1. Domestic case law 495

4.2.5.2. Preliminary rulings $\quad 498$

4.2.6. Synthesis 500

Intermezzo: Implications for EU implementation research 502

The findings of this study and international relations studies 503

The findings of this study and EU application research 505

Understanding and theorizing EU law application: what way to go? 509

5. Recommendations 511

5.1. The Commission should gain more insight into the functioning of $\begin{array}{ll}\text { compliance instruments } & 512\end{array}$

5.2. The Union's enforcement strategy must be reformed 513

5.1.1. The problem of double-hatting 514

5.1.2. A call for increased transparency 514

5.1.3. 100\% compliance? $\quad 515$

5.1.4. A call for increased efficiency 515

5.3. The Commission should be more of a guide of the treaties 517

5.4. The Commission should facilitate 'informal' transnational cooperation $\quad 518$

5.5. Member states should take responsibility and make the most of compliance instruments 
Annex II List of interviews

Literature $\quad \mathbf{5 4 3}$

International, EU, and national measures and documents $\quad 564$

Case law $\quad \mathbf{5 7 0}$

Websites $\quad 576$

$\begin{array}{lr}\text { Curriculum vitae } & 579\end{array}$ 



\section{Abbreviations}

\begin{tabular}{|c|c|}
\hline ANAC & $\begin{array}{l}\text { Autoridade Nacional da Aviação Civil (National Civil Aviation } \\
\text { Authority) }\end{array}$ \\
\hline APA & Agência Portuguesa do Ambiente (Portuguese Environment Agency) \\
\hline ASAE & $\begin{array}{l}\text { Autoridade de Segurança Alimentar e Económica (Food and Economic } \\
\text { Safety Authority) }\end{array}$ \\
\hline BAT & best available techniques \\
\hline BAT-AEL & best available techniques - associated emission level \\
\hline BEUC & $\begin{array}{l}\text { Bureau Européen des Unions de Consommateurs (European Consumer } \\
\text { Organisation) }\end{array}$ \\
\hline BREF & best available techniques reference document \\
\hline Chw & Crisis- en herstelwet (Crisis and Recovery Act) \\
\hline $\mathrm{CI}$ & Consumers International \\
\hline CIRCABC & $\begin{array}{l}\text { Communication and Information Resource Centre for Administrations, } \\
\text { Businesses, and Citizens }\end{array}$ \\
\hline CJEU & Court of Justice of the European Union \\
\hline CRD & comment response document \\
\hline CSN & Consumer Safety Network \\
\hline CSSBC & $\begin{array}{l}\text { Comissão de Segurança de Serviços e Bens de Consumo (Consumer } \\
\text { Goods and Services Safety Commission) }\end{array}$ \\
\hline DECO & $\begin{array}{l}\text { Associação Portuguesa para a Defesa do Consumidor (Portuguese } \\
\text { Association for the Defence of the Consumer) }\end{array}$ \\
\hline DG SANCO & Directorate-General for Health and Consumers (Barroso Commission) \\
\hline DG ENV & Directorate-General for the Environment (Barroso Commission) \\
\hline DG MOVE & Directorate-General for Mobility and Transport (Barroso Commission) \\
\hline DG SANCO & Directorate-General for Health and Consumers (Barroso Commission) \\
\hline DGC & Direção-Geral do Consumidor (Consumer Directorate-General) \\
\hline DR & Diário da República (Official Gazette) \\
\hline Dz. U. & Dziennik Ustaw (Journal of Laws) \\
\hline EASA & European Aviation Safety Agency \\
\hline EMSA & European Maritime Safety Agency \\
\hline
\end{tabular}


EC European Commission

ECAC European Civil Aviation Conference

EEC European Economic Community

EFTA European Free Trade Area

EIA environmental impact assessment

EIONET European Environment Information and Observation Network

EIPPCB European IPPC Bureau

ELV emission limit value

E-PRTR European Pollution Release and Transfer Register

ESSG European SAFA Steering Group

EU

European Union

GDP gross domestic product

GEOTA Grupo de Estudas de Ordenamento do Território e Ambiente (Study Group of Spatial Planning and the Environment)

GM guidance material

GPS general product safety

GPSD General Product Safety Directive

GSK Gospodarcza Sąd Kasacyjny (Economical Cassation Court)

ICAO International Civil Aviation Organisation

ICSMS Information and Communication System for Market Surveillance

IED Industrial Emissions Directive

IEF Information Exchange Forum

IEG IPPC Expert Group

IGAMAOT Inspeção-Geral da Agricultura, do Mar, do Ambiente e do

Ordenamento do Território (Inspectorate-General for Agriculture, Sea, Environment, and Spatial Planning)

IMPEL European Union Network for the Implementation and Enforcement of Environmental Law

ILenT Inspectie Leefomgeving en Transport (Human Environment and Transport Inspectorate)

IPPC integrated pollution prevention and control

IRIS Industrial Emissions Reporting Information System

JAA-NC Joint Aviation Authorities-National Coordinators

Łd Lodz 
LPN

MIenM

MOB

MoS

MSZ

N.

N\&M

$\mathrm{NAO}$

NCA

NGO

NLF

NVWA

OJ

OSK

PDFs

Prosafe

RAPEX

R\&TTE

RvS

SA

SAC

SAFA

Stb.

Stcr.

$\mathrm{Sz}$

TEC

TEEC

TEU

TFEU

TWG

Liga para a Proteç̧ão da Natureza (Alliance for the Protection of Nature)

Ministerie van Infrastructuur en Milieu (Ministry of Infrastructure and the Environment)

Coöperatie (Cooperative) MOBilisation for the Environment

Ministerstwo Środowiska (Ministry of the Environment)

Ministerstwo Spraw Zagranicznych (Ministry of Foreign Affairs)

number

Natuur \& Milieu (Nature\&Environment)

network administrative organisation

national competent authority

non-governmental organisation

New Legislative Framework

Nederlandse Voedsel- en Warenautoriteit (Netherlands Food and Consumer Product Safety Authority)

Official Journal of the European Communities/European Union

Ogólnoadministracyjna Sąd Kasacyjny (General Administrative Cassation Court)

pre-described findings

Product Safety Enforcement Forum of Europe

rapid alert system for non-food dangerous products

Radio and Telecommunications Terminal Equipment

Raad van State (Council of State)

Sąd administracyjny (administrative court)

supreme administrative court

safety assessment of foreign aircraft

Staatsblad (Official Journal)

Staatscourant (Official Journal)

Szczecin

Treaty establishing the European Community

Treaty establishing the European Economic Community

Treaty on European Union

Treaty on the Functioning of the European Union

technical working group 
UDFs user-defined findings

ULC Urząd Lotnictwa Cywilnego (Civil Aviation Authority)

UNECE United Nations Economic Commission for Europe

UOKiK Urząd Ochrony Konkurencji I Konsumentów (Office of Competition and Consumer Protection)

VNO- Verbond Nederlandse Ondernemingen/Nederlands Christelijk

NCW/MKB- Werkgeversverbond/Midden- en Klein Bedrijf Nederland

Nederland (Confederation of Netherlands Industry and Employers/Royal Association MKB Nederland)

VROM Volksgezondheid, Ruimtelijke Ordening en Milieu (Public Health, Spatial Planning and Environment)

VWS Volkgezondheid, Welzijn en Sport (Public Health, Welfare and Sport)

Wa Warsaw

WIOS Wojewódzki Inspektorat Ochrony Środowiska (Regional Inspectorate for Environmental Protection) 


\section{Tables}

Table 1 Structure of this thesis $\quad 35$

Table 2 Variables explaining application and enforcement 57

Table 3 Existing instruments that aim to improve the application of EU law $\quad 70$

Table 4 The presence of compliance instruments across the selected directives 86

Table $5 \quad N$. surveys sent out, responded to, and completed 94

Table 6 Interviewed entities $\quad 97$

$\begin{array}{lll}\text { Table } 7 & \text { Monitoring mechanisms } & 134\end{array}$

Table 8 Naming and shaming mechanisms 138

Table 9 Numbers and sources of infringements 148

Table 10 Infringement proceedings 150

Table 11 Conditions for EU inspections to be useful compliance instruments 190

Table 12 Conditions for naming and shaming to be a useful compliance instrument 192

Table 13 Conditions for infringement proceedings to be useful compliance $\begin{array}{ll}\text { instruments } & 194\end{array}$

Table 14 Post-legislative guidance relevant to the context of this study 217

Table 15 Conditions for post-legislative guidance to be a useful compliance $\begin{array}{ll}\text { instrument } & 250\end{array}$

Table 16 Networks focused on in this study 277

$\begin{array}{lll}\text { Table } 17 \text { Civil society strategies } & 328\end{array}$

Table 18 Factors shaping the interaction between state and civil society 333

Table 19 Conditions for civil society to be a useful compliance instrument 368

Table 20 Existence of actio popularis principle 383

Table 21 Concept of party in other proceedings 384

Table 22 Time to lodge an appeal 388

Table 23 Time (limits) to decide on an appeal 389

Table 24 Court fees for actio popularis proceedings 390

Table 25 Court fees for proceedings other than actio popularis proceedings 392

Table 27 Attorneys 394

Table 28 Compensation of costs for winning parties 395

Table 29 Financial assistance $\quad 397$

Table 30 Costs for preliminary ruling requests 397

Table 31 Injunctive relief 399

Table 32 Remedies when the appeal is upheld 400

Table 33 Comparative overview of effectiveness of judicial protection 403 
Table 34 Relevant administrative authorities

Table 35 Administrative courts relevant to the context of this study

Table 36 Search terms used for finding relevant jurisprudence

Table 37 National case law

Table 38 Preliminary rulings

Table 39 Conditions for national case law to be a useful compliance instrument

Table 40 Compliance instruments for the directives and member states included in this study

\section{Figures}

Figure 1 Implementation, compliance, and policy effectiveness

Figure 2 The categorisation of compliance instruments used in this study

Figure 3 Monitoring and sanctions

Figure 4 EASA standardisation inspections

Figure 5 Types and features of post-legislative guidance

Figure 6 Possible effects of interpretative rules

Figure 7 Schematics of the information exchange - 'Seville' - process

Figure 8 Distinctions between different forms of transnational networks

Figure 9 The usefulness of networks

Figure 10 Networks in the context of the GPS Directive

Figure 11 Networks in the context of the IPPC Directive

Figure 12 Networks in the context of the SAFA Directive

Figure 13 Incentives and prime virtues of cooperation present interdependence

Figure 14 Incentives and perceived virtues of cooperation without interdependence

Figure 15 Conceptualisations of civil society

Figure 16 Compliance instruments: categorisation and specification 


\section{PART I}

\section{PURPOSE, RELEVANCE, THEORY, AND METHODOLOGY}





\section{Chapter 1}

Making EU law work:

A problem in need of a solution 



\section{The problem: Ensuring compliance with EU law}

What works to make EU law work? This may be one of the most important questions facing the European Union in view of the nearly axiomatic implementation deficit that it is confronted with. ${ }^{1}$ EU directives are "notorious" for not being incorporated into the national legal order correctly or in due time. ${ }^{2}$ Implementation problems take on "quite dramatic proportions" if one looks beyond the stage of transposition, into the application of national transposing provisions - and of directly applicable EU measures - by administrative authorities across member states. ${ }^{3}$ While it is not possible to grasp the exact size of the implementation deficit in the $\mathrm{EU},{ }^{4}$ the notion that gaps between the law on paper and the law in practice are problematic is a truism. Implementation gaps not only reduce legal certainty for individuals and legal persons, they also undermine EU policy objectives and hamper the efficiency of the single market. Finally, implementation gaps threaten the sustainability, credibility, and legitimacy of the European Union as a whole. ${ }^{5}$ Without the correct application of democratically adopted rules by the member state authorities, the EU is bound to appear as a "travesty of governance", 6 which is an unsettling idea for a political system as young as the European Union.

In view of the adverse consequences of the problems with the application of EU law, there is a good reason that the EU institutions have attached great priority to ensuring that EU law is applied effectively throughout the Union. The Council did this already in its Declaration on the Implementation of Community Law, annexed to the Maastricht Treaty. ${ }^{7}$ In this declaration, the Council indicates that it "considers it essential for the proper functioning of the Community that the measures taken by the different member states should result in Community law being applied with the same effectiveness and rigor as in the application of their national law". ${ }^{8}$ The need to ensure effective application also comes to the fore in the Commission's White Paper on European Governance, ${ }^{9}$ and it takes centre stage in the Commission's Communication A Europe

\footnotetext{
${ }^{1}$ Adriaanse et al., 2008; Ballesteros et al., 2013: 16; Börzel, 2001; Curtin and Heukels, 1994: 426; Krislov et al., 1986; Mendrinou, 1996; Snyder, 1993; Tallberg, 1999; Voermans, 2015.

2 Prechal, 2005: 131.

${ }^{3}$ Toshkov et al., 2010: 18; also Treib, 2008: 9.

${ }^{4}$ For an elaboration, see Chapter 2 on implementation in the EU: same rules, divergent practices, Section 3.1.

${ }^{5}$ Versluis, 2012: 180; for the credibility issue, see also e.g. Commission, 'Monitoring the application of EU law. 2014 Annual Report' (Report) COM (2015) 329 final, p. 4.

${ }^{6}$ Williams, 2005: 88.

${ }^{7}$ Treaty on European Union - Declaration on the implementation of Community law, OJ [1992] OJ C $191 / 102$.

${ }^{8}$ Ibid.: para. 1. Also see Council, 'Effective implementation and enforcement of Community legislation in the area of social affairs' (Conclusions) [1993] OJ C 49/6; Council, 'The effective uniform application of Community Law and the penalties applicable for breaches of Community law in the internal market' (Resolution) [1995] OJ C 188/1.

${ }^{9}$ Commission, 'European Governance' (White Paper) COM (2001) 428 final, pp. 20-22.
} 
of Results - Applying Community Law. In this communication, the Commission highlights that "it is necessary to attach high priority to the application of the law, to identify why difficulties in implementation and enforcement may have arisen and to assess whether the present approach towards handling issues of application and enforcement can be improved". ${ }^{10}$ This communication is integrated in the Commission's Communication Smart Regulation in the European Union, ${ }^{11}$ in which the Commission emphasises that regulation "is about the whole policy cycle" recalls the importance of proper implementation, and requires that investments in improving law making are matched with efforts to implement existing legislation. ${ }^{12}$

More recent Commission documents highlight that the gap between the law on paper and the law in practice has not been closed. One only need to examine the latest annual reports on monitoring the application of EU law to see that insufficient application of EU law continues to be (regarded as) an issue in need of a solution. ${ }^{13}$ The Commission's latest annual report, for example, indicates that "[e]ffective application of EU law [has] continued to face major challenges". ${ }^{14}$ The idea that application issues, therefore, continue to require the Commission's attention also appears from the Commission's 2015 Work Programme, which "confirms that the Commission will continue working actively to ensure that EU law is properly applied implemented and enforced so it delivers real benefits to citizens" $[$ sic $] .{ }^{15}$ In other words, there seems to be recognition in all of these documents that the application of EU law is often inadequate, and continuous attention to application issues is therefore needed. These documents also recognise that the approach towards solving application issues requires review and, where necessary, improvement. ${ }^{16}$

\footnotetext{
${ }^{10}$ Commission, 'A Europe of Results - Applying Community Law' (Communication) COM (2007) 502 final, p. 1. Also see Commission, 'Better Monitoring of the Application of Community Law' (Communication) COM (2002) 725 final.

${ }^{11}$ Commission, 'Smart Regulation in the European Union' (Communication) COM (2010) 543 final.

${ }^{12}$ Ibid., p. 3.

${ }^{13}$ Annual reports are available on European Commission, 'Annual reports on monitoring the application of EU law', <http://ec.europa.eu/atwork/applying-eu-law/infringements-proceedings/annual-reports>.

${ }^{14}$ See COM (2015) 329 final, p. 25. This Annual Report indicates that 223 infringement proceedings were started against member states throughout 2014. The number of open infringement cases by the end of 2014 was 1,347. For these figures, see ibid., p. 9, 14. Note that not all of these cases lead to an infringement being confirmed by the Commission and/or by the Court. Also note that these figures do not cover all existing infringements; for the idea that Commission data on infringement proceedings underestimate the number of actually existing infringements, see Chapter 2 on implementation in the EU: same rules, divergent practices, Section 3.1.

${ }^{15}$ Commission, 'Commission Work Programme 2015 - A New Start' (Work Programme) COM (2014) 910 final. Quote from COM (2015) 329 final, p. 25.

${ }^{16}$ For a recent academic source highlighting the importance for the Commission to review its implementation management system, see Voermans, 2015.
} 


\section{Towards a solution? Studying the usefulness of compliance instruments}

In contrast to the emphasis that EU institutions have put on the issue of (effective) EU law application, is the relative neglect of the application phase of the implementation process in EU implementation studies. The majority of such studies focus on the transposition of the provisions of EU directives by member states. ${ }^{17}$ What these studies have in common is a focus on transposition problems. In view of the sometimes-divergent transposition records of member states, they identify variables - from domestic veto points to Chinese Walls and from misfits to salience, to name a few - that explain why some member states lead and others lag behind in fulfilling their obligation to transpose directives correctly and in due time. This type of "misery research" regarding the transposition of EU directives is paired by few studies that focus on the application of EU legislation in practice. ${ }^{18}$ What these studies share with transposition research is a problem-oriented focus. When they do identify ways towards improved application practices, ${ }^{19}$ these studies remain rather general, theoretical, and abstract. Comprehensive empirical research on the usefulness of mechanisms that have been put in place to support the application of EU law by the member states does not seem to exist. ${ }^{20}$

This study aims to shed light on this latter issue. It does this by studying the usefulness of mechanisms that have been put in place to support, or that may otherwise be

\footnotetext{
${ }^{17}$ See e.g. Baratta 2014; Berglund et al., 2006b; Borghetto and Franchino, 2010; Bursens, 2002; Ciavarini Azzi, 2000; Dimitrakopoulos, 2001; Dimitrova and Rhinard, 2005; Dimitrova and Steunenberg, 2000; Duina, 1997; Falkner et al., 2004; Giuliani, 2003; Haverland and Romeijn, 2007; Haverland et al., 2011; Hille and Knill, 2006; Kaeding, 2008; Knill and Tosun, 2009; König, 2013; König and Lütgert, 2009; König and Mäder, 2013, 2014; Lampinen and Uusikylä, 1998; Leventon and Antypas, 2012; Linos, 2007; Luetgert and Dannwolf, 2009; Mastenbroek, 2003; Steunenberg and Toshkov, 2009; Sverdrup, 2004; Thomson, 2009, 2010; Treib, 2003; Steunenberg, 2006; Thomann, 2015; Toshkov, 2007b, 2008; Thomson, 2007; Versluis and Spendzharova, 2013; Zhelyazkova, 2013; Zhelyazkova and Torenvlied, 2009; Zhelyaskova and Yordanova, 2015; Zubek, 2005, 2011; Zubek and Staronova, 2010.

${ }^{18}$ The notion "misery research" was coined first by Rothstein, 1998: 62. Examples of studies that focus specifically on the application and/or the enforcement of EU law are Versluis, 2003, 2004, 2007; Zürn and Joerges, 2005; Demmke, 2001; Luetgert, 2011; Leventon, 2015. For 'mixed' studies, see e.g. Börzel, 2003; Falkner et al., 2005; Bugdahn, 2005; Knill and Lenschow, 1998; Duina, 1999; Siedentopf and Ziller, 1988; Dimitrova and Steunenberg, 2013.

${ }^{19}$ E.g. Falkner, 2010; Tallberg, 2002; Börzel et al., 2010.

${ }^{20}$ This does not mean that related research is absent. For example, the chapters in the volume edited by Cremona, 2012, provide a review of several compliance instruments. These instruments are, however, exclusively of a legal nature; they address the infringement procedure and the role of national (constitutional) courts 'only'. Panke focuses on the effectiveness of the CJEU at restoring compliance with EU law; see Panke, 2010. Groenleer et al., 2010 and Versluis and Tarr, 2013 focus on the role of agencies in ensuring compliance. What seems to be lacking is empirical research with a more comprehensive, cross-instrument focus. Ballesteros et al., 2013, seem to provide the most comprehensive study on the effectiveness of, what they call, "compliancepromoting tools" to date. This study focuses on transposition and does not examine in detail the underlying dynamics that make these compliance instruments work.
} 
expected to have the effect of contributing to, the correct application of EU law by the competent administrative authorities ('competent authorities') of the member states. These mechanisms, which throughout this thesis are referred to as 'compliance instruments, ${ }^{21}$ are categorised on the basis of an assessment of the institutional level harbouring the actors in control of the relevant instruments. Monitoring and sanctioning strategies employed by the European Commission are thus classified as supranational compliance instruments. The same classification applies to post-legislative guidance, which is usually issued by the Commission, sometimes after a deliberation process involving member states. Networks for administrative cooperation amongst member states are transnational instruments. In view of the lack of a veritable European civil society and the entrenchment of non-governmental organisations (NGOs) at the national level, civil society activism belongs to the national level. This also applies to national case law and preliminary rulings. While preliminary rulings are issued by the Court of Justice of the European Union (CJEU), they are requested by national courts, and they acquire meaning within the national implementation context by virtue of the compliance of national courts with such rulings.

The chapters at the core of this thesis are structured in line with the actor-based categorisation of compliance instruments discussed in the previous paragraph. Table 1 outlines the structure of the entire thesis, which may serve as a signpost for the reader.

The focus of this thesis on the usefulness of compliance instruments means that rather than approaching the topic of implementation in the EU from a problemoriented perspective, this thesis takes a solution-focused approach. The added value of this reversed angle is, first, that it precludes the addition of a forty-eighth variable to "the theory [on EU implementation] of forty-seven variables that completely explain five case studies" ${ }^{22}$ Indeed, after three decades of research focusing on implementation failure in the EU, explanatory power for variation in the implementation of EU legislation has been attributed to a number of variables. Until now, most research has done little to contribute to a general theory of implementation in the EU. It is questionable whether or not establishing an overarching theory is possible. What seems certain, however, is that seeking to explain implementation failure by reference to another set of cases - and possibly another set of variables - is likely to contribute little to theory building on implementation in the EU. This is why this study does not engage in such an endeavour.

\footnotetext{
${ }^{21}$ For an explication of the exact relationship between implementation and compliance (and policy effectiveness), see Chapter 2 on implementation in the EU: same rules, divergent practices, Section 1.

${ }^{22}$ Meier, 1999: 5; similar Goggin, 1986. This applies to domestic implementation studies as well. Sverdrup refers to Mazmanian and Sabatier, 1981, who list seventeen key variables critical for implementation, and to O'Toole, 1986, who found that researchers were using more than 300 variables when studying implementation. See Sverdrup, 2007: 198.
} 
Table 1 Structure of this thesis

Part I

Purpose, relevance, theory, and methodology

Supranational compliance instruments

Transnational compliance instruments

Part IV

National compliance instruments

$$
\begin{array}{ll}
\text { Chapter } 7 & \text { Civil society } \\
\text { Chapter } 8 & \text { National case law } \\
& \text { Preliminary rulings }
\end{array}
$$

Chapter 6 Transnational networks

\author{
Chapter 1 Making EU law work: A problem in need of a solution \\ Chapter 2 Implementation in the EU: Same rules, divergent practices \\ Chapter 3 Approach and methodology
}

Part V

Conclusions and recommendations Chapter 9 What works to make EU law work? Conclusions and recommendations

Second, this 'reversed angle' promises to be relevant to determining what works to make EU law work better in practice. One can only agree that a better understanding of the dynamics at work in the implementation process is indispensable for designing strategies to improve the implementation of EU law. ${ }^{23}$ At the same time, however, it seems that because of their focus on 'what went wrong' instead of on 'what went right', implementation studies have overlooked the fact that "every day and on every level of government, new programs are introduced that, to some degree or another, work" ${ }^{24}$ The focus of this study on the usefulness of instruments that have been introduced to ensure the correct application of EU law, or that may otherwise be expected to have this effect, addresses this concern. Presenting recommendations that may be of use to practitioners seeking to improve the application of EU law, this study hopes to be relevant not only to academic scholarship, but to these practitioners as well.

\footnotetext{
${ }^{23}$ Falkner, 2007: 1019.

${ }^{24}$ DeLeon, 1999: 321.
} 


\section{A preliminary note on methodology}

The act of applying a law involves "more than meets the lawyer's eye". ${ }^{25}$ Studying law application similarly requires more than a lawyer's perspective. The same goes for examining the usefulness of compliance instruments that are used to make the law work better. This is why the current study takes an interdisciplinary research approach that combines perspectives and methods from legal science with those pertaining to political science, in particular public administration. While legal perspectives have much to say about the details of the infringement procedure and the normative implications of networks, political science perspectives are particularly useful for analysing why instruments work - that is, why they may be useful for supporting the application of EU law by the competent authorities of the member states - or why they do not work at all.

This study follows a case-study method and analyses the selected cases by means of case law analysis, literature and policy document analysis, survey analysis (77 completed surveys), and qualitative interviewing (91 interviewed officials). Our goal of answering the question of how and why compliance instruments work (or why they fail to do so) explains why this study opts for a few cases for detailed qualitative analysis, rather than many instances for statistical analysis. Case law analysis and literature and policy document analysis are needed to obtain insights into the practical and political contexts in which compliance instruments exist, the design and contents of these instruments, and the theoretical debate on implementation in the EU. A survey and qualitative interviews are required to gain insight into the perceptions of national officials.

Studying perceptions is useful, first, because it is impossible to evaluate the usefulness of compliance instruments objectively, by establishing causal relationships between concrete compliance instruments and (improved) application practices. This is partly because instruments are interrelated and because they interact with, and are influenced by, factors of a circumstantial nature. Moreover, the quality of law application practices is generally difficult to assess. ${ }^{26}$ Second, the perceptions of actors whom compliance instruments are supposed to affect play an important mediating role in the how these instruments are used and the impact that they have. Indeed, if "mediating between opportunity and action are people and the subjective meanings that they attach to their situations", ${ }^{27}$ the impact of compliance instruments may be studied by examining the subjective elements that play a role in this. For these reasons the preferences and beliefs of actors involved in the application of EU law, when explored through qualitative interviews, are a relevant and potentially rich source of information.

Using preferences as a yardstick to measure phenomena is not self-evident. Hooghe, who studies preferences of Commission officials, points out that preferences

\footnotetext{
${ }^{25}$ Treib and Falkner, 2008: 157.

${ }^{26}$ See Chapter 2 on implementation in the EU: same rules, divergent practices, Section 1.2.

${ }^{27}$ McAdam, 1999: 48, in a different context, namely in relation to the mobilisation of civil rights activism.
} 
and beliefs "pose a serious research challenge to social scientists". ${ }^{28}$ In brief, the problem is a perceived gap between preferences and behaviour. While some observers think of preferences as "rationalisations for emotional impulses", others argue that they "simply [cloak] self-interest". ${ }^{29}$ Still, others are "skeptical about the value of researching preferences because they harbor unrealistic expectations about their causal power" ${ }^{30}$ Hooghe argues that these scholars aim too high. According to her:

Preferences are general guidelines - heuristic aids to action - not a set of algorithms. They are context-sensitive propensities to action... Basic orientations serve as 'bounded rationalities' or 'prisms' through which individuals conceive and respond to objective facts. They profoundly influence, but do not determine, action. ${ }^{31}$

Beliefs and preferences thus shape action; they "serve as cognitive and normative frames for action, rendering it more likely than not that particular behavioural dynamics are associated with certain perceptional patterns" ${ }^{32}$ Thus, it makes little sense to attempt to infer beliefs and preferences from action. ${ }^{33}$ For this reason this study, in line with the research conducted by Hooghe, is empirical rather than deductive, and studies preferences on the basis of elite interviews that enable a direct examination of preferences independent of how actors behave. ${ }^{34}$ In elite interviews, the respondents are treated as experts on the topic at hand, ${ }^{35}$ and "the investigator is willing, and often eager, to let the interviewee teach him what the problem, the question, the situation is". ${ }^{36}$ As such, elite interviews give privileged access to the experiences, perspectives, and understanding of interviewees, which makes them suitable for exploring and describing under-researched phenomena. $^{37}$

In order to arrive at a sound and simultaneously in-depth picture of preferences and beliefs regarding the usefulness of compliance instruments, this study uses a casestudy methodology that involves a limited number of EU measures and a limited number of member states. The measures selected for study are three EU directives: Directive 2001/95/EC on general product safety (GPS Directive), Directive 2008/1/EC on inte-

\footnotetext{
${ }^{28}$ Hooghe, 2001: 10.

${ }^{29}$ Ibid.: 11.

${ }^{30}$ Ibid.

${ }^{31}$ Ibid.

${ }^{32}$ Egeberg and Trondal, 2011: 874.

${ }^{33}$ Hooghe, 2001: 11.

${ }^{34}$ The methodology used in the current study does, however, deviate from the methodology used by Hooghe in that it does not use structured interviews, rather it uses semi-structured interviews. For an elaboration on the motivation of this choice, see section 2.2. below.

${ }^{35}$ Leech, 2002a: 663.

${ }^{36}$ Dexter, 2006: 6.

${ }^{37}$ Kvale and Brinkmann, 2009: 169-171.
} 
grated pollution prevention and control (IPPC Directive), and Directive 2004/36/EC on the safety of third-country aircraft using Community airports (SAFA Directive). The member states selected for study are the Netherlands, Poland, and Portugal. This case selection and the other (methodological) choices made in the context of this study are elaborated on in Chapter 3 on approach and methodology.

\section{Outline of this study}

\subsection{Part I}

This chapter outlines the relevance of this study, by referencing the real-world challenge of making EU law work on the ground and the simultaneous absence of comprehensive empirical studies investigating the usefulness of compliance instruments in supporting the application of EU law. This chapter also identifies the research question and provides preliminary insight into the methodology used in the context of this study.

Chapter 2 on Implementing EU law: same rules, divergent practices sets out, first, to elaborate on the main implementation-related terminology and on the legal rules that apply to the national competent authorities in the implementation of EU directives. It then reflects on the implementation deficit that the EU is confronted with, and in particular on the explanations advanced by EU implementation studies on the sometimesdivergent implementation, particularly application, performances of member states. It argues that although EU implementation studies have provided valuable insight into the nature of implementation - mostly transposition - problems in the EU, these insights do not provide concrete answers as to what makes EU law work better in practice. Therefore, this study proposes a reversed angle to study implementation in the EU, as suggested above.

Chapter 3 on Approach and methodology sets out to explore this reversed angle in detail. It first, outlines the compliance instruments included in this study. Relying on the perspectives on compliance presented in international relations studies, it then reflects on the question of why these instruments may be expected to be useful for making EU law work better in practice. Seeking to categorise compliance instruments in a sensible way and establishing that existing typologies are hardly suitable in the context of this study, the chapter subsequently proposes a rather a-theoretical, actor-based categorisation of compliance instruments. It concludes by reflecting on the selection of EU directives and member states included in this study, and by accounting for the sources used to study the research question. 


\subsection{Parts II, III, and IV}

Parts II, III, and IV, which comprise the empirical chapters of this book, are structured on the basis of the actor-based categorisation of the compliance instruments introduced in Chapter 3. Part II deals with supranational compliance instruments, comprising monitoring and sanctions (Chapter 4) and post-legislative guidance (Chapter 5). Part III focuses on transnational instruments, and particularly on transnational networks (Chapter 6). Part IV, finally, examines national compliance instruments; namely, civil society (Chapter 7) and case law, including domestic case law and preliminary rulings provided by the CJEU (Chapter 8 ).

All empirical chapters follow the same internal structure. Each chapter begins with a reflection on why the compliance instrument(s) that are the focus of that particular chapter are expected to contribute to a better application of EU law by the competent authorities of the member states. This first section also reflects on the limitations that are expected to hinder the usefulness of the relevant mechanism(s) as (a) compliance instrument(s). The reflections presented in this first section mainly draw on analyses of the relevant secondary literature and policy documents. They are necessary in view of the fact that this study constitutes an interpretative study; for a proper understanding of the usefulness of compliance instruments, the reader must acquire some insight into the way that compliance instruments may support member states in the application of EU law, and the limitations that are thought to exist in this regard.

Section 2 of each chapter provides a comparative overview of the compliance instruments present in the context of the three directives discussed in this study, and where relevant, also for individual member states. The latter is the case for civil society activism and national case law. The compilation of compliance instruments included in this section and the description of the design and/or contents of these instruments are based primarily on policy document, case law, and interview analysis.

Section 3 of each chapter, then analyses the usefulness of the relevant compliance instrument(s) for supporting the application of the three directives in the three member states included in this study. Here, the interviews conducted for this study are particularly relevant. Note that since this study is neither deductive nor inductive, but interested in 'the case as such' - that is, the usefulness of compliance instruments - it is the information retrieved from these interviews that greatly determines the structure and the substance of this third section. This does not mean that the theoretical concepts coined in the first part of the chapter are absent; it only means that these concepts do not guide the analysis and are not necessarily reflected on in detail. Also note that the interview results are complemented with document analyses of the functioning of the relevant compliance instruments (for example, through a discussion of the relevant guidance documents and case law) and by the results of the survey conducted for this study. These results are presented in in-text boxes. Comparisons between the survey and interview results are provided in the main text of the section. 
Each chapter ends by presenting concluding remarks on the usefulness of the compliance instrument(s) studied. The focus of this section is not only on the extent to which these instruments are useful and why this is the case, but also on the conditions that need to be present in order for such instruments to deliver the benefits that they are associated with. When relevant - compliance instruments hardly ever act in isolation from one another - links with instruments studied in other empirical chapters are established as well.

\subsection{Part $V$}

Part V concludes this study. Chapter 9 on What works to make EU law work? Conclusions and recommendations aims to bring this study full circle by presenting conclusions on the usefulness of the compliance instruments examined in the empirical chapters and on the conditions under which such instruments seem to work best. Chapter 9 also aims to discuss the links between this study and EU implementation research. The chapter finally presents recommendations that are geared towards practitioners for how member states can be (better) supported in the application of EU law, in order to make EU law work better for citizens and for business actors alike. As such, this study hopes to be of practical relevance as well. 


\section{Chapter 2}

\section{Implementation in the EU:}

Same rules, divergent practices 


\section{Introduction}

The first chapter of this study suggests that the EU faces an implementation, or compliance, deficit that threatens the effectiveness of EU law. This suggestion raises a number of questions that the current Chapter aims to answer. The first set of questions is of a conceptual nature. What is implementation? What does compliance mean? And, how do implementation and compliance relate to the notion of effectiveness? Section 1 attempts to distinguish between these notions, and to define them. It also reflects on the meaning of these notions specifically regarding the implementation of EU law.

The second set of questions relates to what member states need to do to implement EU law correctly. Section 2 outlines the obligations of member states at each of the four stages that compose the implementation process. Knowledge about the obligations imposed on the member states in the implementation of EU directives is indispensable in view of the interest of this study regarding what works to make member states better fulfil their obligations. Even though the current study is interested in the usefulness of compliance instruments for improving the application of EU directives, and the focus of this section is accordingly on that same stage of the implementation process, it is logical to contextualise such obligations by including the other stages of the implementation process as well.

Section 3 reflects on the nature and the size of the EU's implementation deficit, and on the reasons for variation in implementation, particularly application, processes and outcomes in the EU. It does this, primarily by drawing on the EU implementation literature. The reflection presented here is pertinent in view of the interpretative nature of the current study; explaining 'where we are and where we have come from' in EU implementation studies clarifies how the current study fits into existing studies - and how it differs from these studies. By discussing the problems that $\mathrm{EU}$ implementation research is associated with, this section also intends to highlight the added value of the 'reversed angle' of this study in relation to the existing literature. 


\section{What's in a name? About implementation, compliance, and effectiveness}

The term 'implementation' has been used previously in this thesis, but it has not been defined. The definition of this term varies depending on the literature one looks at - if a definition is actually provided, since many studies on policy implementation fail to stipulate the meaning of implementation in their specific case. ${ }^{1}$ In studies that do attempt to define the term, 'implementation' is regularly used as an umbrella concept containing several sub-stages that, together, comprise the implementation process. ${ }^{2}$ Other studies, explicitly or implicitly, refer to one of these sub-stages. In the latter case, international relations studies usually seem to refer to 'implementation' as the incorporation of international commitments to national law. ${ }^{3}$ In line with this, in the domain of $\mathrm{EU}$ implementation studies, the term often refers to the transposition of EU directives by the competent authorities of the member states. ${ }^{4}$

The noted inconsistency of the implementation-related jargon used in (EU) implementation studies is paired by a lack of coherence in the terminology used by the EU institutions. In contrast to what one would expect from a Union "that is sophisticated enough to make clear and precise distinctions between day-old chicks, breeding poultry, productive poultry and slaughter poultry in its secondary legislation", ${ }^{5}$ the terminology employed by the EU institutions appears to be imprecise when it comes to these basic concepts of the policy cycle. The Commission's annual reports on monitoring the application of EU law review more than the application of EU law by the member states. And one only needs to consult the Commission's Communication A Europe of Results Applying Community Law to see that the terms implementation, application, and enforcement are used in a manner that is difficult to follow in other instances as well. ${ }^{6}$ In view of the resultant lack of clarity in both the literature and EU policy documents, the term implementation - and what is meant by it - deserves further exploration.

\footnotetext{
${ }^{1}$ Sinclair, 2001.

${ }^{2}$ E.g. Prechal, 2005; Curtin and Heukels, 1994.

${ }^{3}$ E.g. Van den Bossche, 1996; Haas, 1998.

${ }^{4}$ Jans et al., 2007: 13.

${ }^{5}$ Curtin and Heukels, 1994: 427.

${ }^{6}$ As referred to in the previous chapter, in this communication, the Commission underlines that "it is necessary to attach high priority to the application of the law, to identify why difficulties in implementation and enforcement may have arisen and to assess whether the present approach towards handling issues of application and enforcement can be improved". See COM (2007) 502 final; italics inserted. The reader is left confused as to the meaning attached to these terms by the Commission.
} 


\subsection{Defining implementation, compliance, and effectiveness}

In domestic implementation research, implementation has, generally, been referred to as "the actual process of translating policy into action", ${ }^{7}$ as "what happens after a bill becomes a law", ${ }^{8}$ or as "the carrying out of a basic policy decision". ${ }^{9}$ Implementation is not the same as compliance, which is a question of "the extent to which agents act in accordance with and fulfilment of the prescriptions contained in rules and norms". ${ }^{10}$ While the measures taken by actors to implement rules may result in adherence to the prescribed provisions, this is not necessarily the case. Compliance can occur also without the adaptation of the implementation practice to a newly adopted rule; namely, where pre-existing practices are already in conformity with international rules that states have committed to. ${ }^{11}$ In fact, implementation and compliance could be seen as two sides of the same coin, with implementation referring to the process of translating a policy into action, and compliance relating to the conforming outcome of this process. ${ }^{12}$

Compliance does not equal policy effectiveness; even when member states adhere to prescribed rules, the efficacy of these rules for solving the political problem that they were designed for is not guaranteed. ${ }^{13}$ This is because there may be a mismatch between means and ends: the concrete rules that are set may aim too low to achieve the policy objectives that these rules were designed for in the first place. If this is the case, effective implementation will not lead to effective policy. ${ }^{14}$ Reversely, policies can be effective without perfect implementation or universal compliance ${ }^{15}$ if the means are too farreaching in view of the policy objectives set. In this case, what may be considered 'implementation failure' need not defy the achievement of policy objectives and, therefore, policy effectiveness. Despite the lack of a causal relationship between compliance and policy effectiveness, one may assume that in most cases, "compliance will correlate sufficiently with effectiveness to make more compliance preferable to less". ${ }^{16}$

At this point it must be emphasised that 'effective implementation', or compliance, is neither easily defined nor easily determined. Such difficulties are expressed in the notions that there are variable understandings and ways of measuring implementation, ${ }^{17}$ and that many studies fail to specify what is actually meant by 'effective implementa-

\footnotetext{
${ }^{7}$ Barrett, 2004: 251.

${ }^{8}$ Bardach, 1977.

${ }^{9}$ Sabatier and Mazmanian, 1981: 5.

${ }^{10}$ Checkel, 1999; similar Young, 1979: 3; Raustiala and Slaughter, 2002: 539.

${ }^{11}$ Underdal, 1998: 6.

${ }^{12}$ Treib, 2008: 4; Hartlapp and Falkner, 2009: 283.

${ }^{13}$ For the notion of efficacy, see Neyer and Zürn, 2001.

${ }^{14}$ Simmons, 1998: 77-78; Mitchell, 1996: 25.

${ }^{15}$ DeLeon, 1999; Haas, 1998; Mitchell, 1996: 25.

${ }^{16}$ Mitchell, 1996: 6; italics in original.

${ }^{17}$ Giuliani, 2005.
} 
tion'. ${ }^{18}$ Defining compliance is difficult because rules are often ambiguous or general about what targets are actually expected, and because the normative content of the language may not be clear. ${ }^{19}$ Research on decision making in the EU suggests that higher levels of policy conflict during negotiation processes are associated with higher levels of discretion in the resultant act, ${ }^{20}$ meaning that the more controversial legislative proposals are, the greater the room for member states to manoeuvre in the implementation process, and the more difficult it is to establish whether member states comply or defect. Furthermore, compliance is rarely a transparent, binary choice - and this already connects to the following paragraph - and actors often intentionally behave in an ambiguous, dilatory, or confusing manner. ${ }^{21}$

Determining compliance is not easy since the EU is a pre-eminent example of an implementation system featuring considerable linguistic, socio-cultural, and geographical differences throughout that may increase ambiguity. ${ }^{22}$ Determining whether or not states comply requires deep knowledge about relevant country-specific characteristics; knowledge that may not always be readily available. In addition, causal relationships are often incomplete or difficult to describe. ${ }^{23}$ This difficulty is partly explained by the fact that data on the application and enforcement of EU law in member states are "tremendously hard to gather" ${ }^{24}$ This may be the case particularly when the authority for ensuring the application of the law lies with local government levels, which may be difficult to study. ${ }^{25}$

All of the above factors make it difficult to define and determine compliance. These difficulties, partly, explain why this study refrains from attempting to establish causal relationships between compliance instruments and compliance levels, and why it attaches significant value to the perceptions of national civil servants on the usefulness of compliance instruments for supporting law application instead.

\subsection{Implementation and compliance in the $E U$}

The previous section suggests that implementation is neither compliance nor policy effectiveness; rather it is the carrying out of a policy decision. What is needed to translate a policy into action depends on the level that has produced the relevant policy decision in the first place. Since the focus of this thesis is on the implementation of EU law -

\footnotetext{
${ }^{18}$ Lester and Goggin, 1998: 5.

${ }^{19}$ Haas, 1998: 18-19; Chayes et al., 1998: 39; Mitchell, 1996: 7; Dimotrakopoulos, 2001: 4 (on vagueness in EU legislation).

${ }^{20}$ Franchino, 2004.

${ }^{21}$ Simmons, 1998: 78; see also Mitchell, 1996: 6; Young, 1979: 105, in Underdal, 1998: 6, who argues that compliance is a "matter of degree".

${ }^{22}$ Sverdrup, 2007: 208.

${ }^{23}$ Ibid.: 206.

${ }^{24}$ Mastenbroek, 2003: 1114.

${ }^{25}$ Haas, 1998: 18-19; Sverdrup, 2007: 206.
} 
rather than on the process of translating originally national policy into action - we now shift our focus exclusively to the meaning of implementation in the EU policy context. Adapted to this particular context, implementation is understood as the process of giving effect to EU policy. The actors responsible for effectuating this process vary with the EU rule at stake. In some areas - the EU's common commercial and fishery policies are prominent examples - this responsibility lies exclusively with the European Commission. The implementation system in the EU has, however, essentially remained decentralised, with the member states having been assigned the responsibility of implementation for the majority of policy decisions impinging on individuals. ${ }^{26}$

The nature of the obligations of member states in the implementation of EU rules depends on the type of rule at stake, and on the legally binding force that such rules may or may not have. In this regard, it is useful to distinguish between soft law and hard law rules. Soft law rules - for instance recommendations, opinions, and interpretative guidance issued by the European Commission - are not attributed with legally binding force as an inherent feature, which means that they are in principle not binding to member states. This means that the implementation of soft law rules by the member states is in principle voluntary. ${ }^{27}$ Hard law rules - EU treaties, EU legislative acts, and delegated and implementing acts adopted by the European Commission - in contrast, do have inherent legally binding force, which means that the member states (concerned) have no choice but to implement them dutifully and to comply with them. ${ }^{28}$ Pursuant to the duty of loyal cooperation outlined in Article 4(3) of the Treaty on European Union (TEU), member states must take the appropriate measures to ensure fulfilment of the obligations arising from the relevant acts. This requirement involves a positive duty that requires member states to facilitate the achievement of the tasks outlined in these acts, and a negative duty to abstain from any action that could jeopardize the achievement of such objectives.

What concrete actions from member states the duty of loyal cooperation should entail depends on the act at stake. Of the two most 'general' measures in the EU - regulations and directives ${ }^{29}$ regulations are directly applicable in all member states, ${ }^{30}$ meaning that they do not need to be incorporated into the national legal order. In fact, it is not permitted for member states to do so. ${ }^{31}$ Directives, in contrast, must be translated

\footnotetext{
${ }^{26}$ Jans et al., 2007: 199.

${ }^{27}$ Exceptions to this general rule include situations in which soft law rules are attributed indirect legally binding force; on this issue, see Chapter 5 on post-legislative guidance.

${ }^{28}$ While treaties and regulations bind all member states alike, directives and decisions bind only those member states to which they are addressed; see consolidated version on the Treaty on the Functioning of the European Union [2012] OJ C326/47 [TFEU], Art. 288.

${ }^{29}$ Toshkov, n.d; Curtin and Heukels, 1994: 439.

${ }^{30}$ TFEU, Art. 288, second indent.

${ }^{31}$ Case 34/73 Variola v. Amministrazione delle Finanze [1973] ECR 981. Note that this prohibition does not preclude the necessity of modifying pre-existing national rules in case of a conflict between such rules and the newly applicable regulation; see Prechal, 2005: 14; Craig and De Burca, 2011: 105.
} 
into national rules. ${ }^{32}$ Moreover, in order for them to be applied and enforced, rules for the operationalisation of transposition measures may need to be adopted. ${ }^{33}$ What regulations and directives have in common is that they both must be applied and enforced by the member states; the legal rules need to be administered in individual situations, and member states must seek to "ensure compliance and bring those responsible for noncompliance into line". ${ }^{34}$

The relationship between the notions of implementation, compliance, and effectiveness that the foregoing subsection refers to, and the four stages that the previous sentences suggest are relevant for the implementation of EU directives are visualised in Figure 1. These four stages are discussed in detail below.

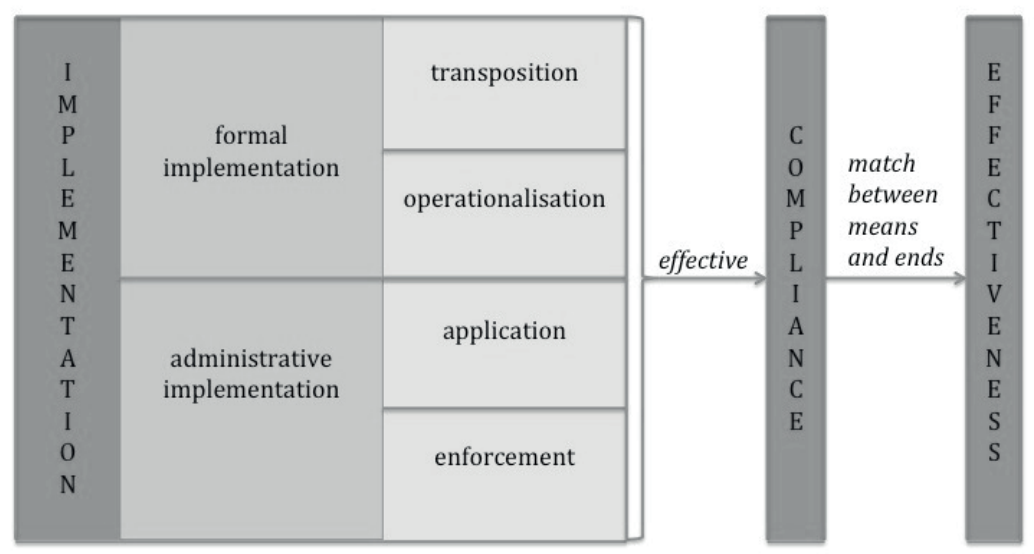

Figure 1 Implementation, compliance, and policy effectiveness $s^{35}$

\section{The implementation of EU directives: obligations of member states}

The current section moves away from the theoretical discussion presented in the previous section, towards an exploration of the concrete legal obligations of member states in the implementation process. In view of the interest of this study in EU directives, all four phases outlined above - transposition, operationalisation, application, and enforcement - are relevant to address in this regard. While they partly overlap in practice - implementation is referred to as a messy process for a good reason - these stages are conceptually distinct. Therefore, this section takes a closer look at each of these stages.

\footnotetext{
32 TFEU, Art. 288, third indent. See further Section 3.2.1. below.

${ }^{33}$ Jans et al., 2007:14.

${ }^{34}$ For this definition, see Matthews, 1993: 2.

${ }^{35}$ For the distinction between "formal" and "administrative" implementation, see e.g. From and Stava, 1993; Versluis, 2007.
} 
In view of the centrality of the application phase of the implementation process in this study, attention is paid to this phase in particular.

\subsection{Transposition}

Regarding the implementation of EU directives, member states are required to incorporate and translate the provisions outlined therein into national measures, ${ }^{36}$ and to do so timely and correctly. The modality of transposition is left to the member states; ${ }^{37}$ essentially, directives are tools of flexibility that allow each member state to choose the methods and means that suit their political, social, administrative, regulatory, and legal systems best. ${ }^{38}$ Self-evidently, these methods and means must be suitable to achieve "the legal and factual situation as determined by the substantive and ancillary provisions of the directive at issue" ${ }^{39}$ Ensuring that transposing measures are sufficiently clear and precise is deemed essential in this regard, particularly if the directive is intended to create rights for individuals. ${ }^{40}$ Member states are also obliged to give effect to the provisions of a directive by means of national provisions of a binding nature; ${ }^{41}$ this is a necessity both in view of the desired continuous application of the legal rules by the administration, and with a goal of ensuring legal certainty and effective judicial protection for individuals. $^{42}$

\subsection{Operationalisation}

The legal implementation phase also requires member states to adopt measures for the operationalisation of directives. This phase of the implementation process usually involves the designation of national authorities responsible for the further application of the rules, the adoption of procedural and enforcement measures, and the introduction

\footnotetext{
${ }^{36}$ For this definition of the notion of transposition, see Curtin and Heukels, 1994: 427.

${ }^{37}$ Art. 288, third paragraph, TFEU. For an overview of the transposition practices across member states, see e.g. Berglund et al., 2006a; Batta, 2007.

${ }^{38}$ Van den Bossche, 1996: 397. Note that the exact degree of flexibility allowed to member states depends on the degree of harmonisation that is foreseen. It has been argued that the earlier preference for minimum harmonisation has recently given way to a move in favour of maximum harmonisation, implying exhaustive regulation of a policy issue; see Steiner and Woods, 2009: 368; also Prechal, 2005: 14. This must be considered to have a limiting effect on the discretion that is left to member states in the implementation of directives.

${ }^{39}$ Prechal, 2005: 51.

${ }^{40}$ E.g. case C-131/88 Commission v. Germany [1991] ECR-I 825.

${ }^{41}$ Case 96/81 Commission v. Netherlands [1982] ECR 1791.

${ }^{42}$ Prechal, 2005: 82-83. In relation to this, the CJEU has ruled that reliance of member states on whimsical administrative practices does not suffice for a directive to be transposed properly; see case 96/81 Commission v. Netherlands [1982] ECR 1791. This does not mean that legislative action is necessary in each member state. In particular, when general principles of constitutional and administrative law exist that guarantee that the national authorities will apply the directive fully, the enactment of specific legislation may be superfluous; see case Case 29/84 Commission v. Germany [1985] ECR 1661.
} 
of other tools necessary for the competent authorities to administer the law. ${ }^{43}$ Directives often include an explicit requirement for such measures to be adopted. ${ }^{44}$ When a directive is silent in this regard, the duty for member states to adopt such measures may be inferred from Article 4(3) TEU. ${ }^{45}$ Note that the integration of directives into national law generally implies that existing authorities are granted further powers under the legislation that already applies, and that enforcement provisions and other procedural provisions become almost automatically applicable ${ }^{46}$ - unless the relevant authorities and the necessary provisions do not exist, one might add, in which case new (delegated) acts must be adopted.

\subsection{Application}

While the Court has repeatedly held that member states must ensure that directives are applied fully in law and not only in fact, ${ }^{47}$ the reverse is true as well; legislation is bound to remain ineffectual until it is given practical effect. The third phase of the implementation process involves the administration of the national transposition measures in concrete cases. It is here that the precision, the clarity, and the legally binding nature of these measures are important; where such measures are imprecise, unclear, or lack binding nature, the rules of a directive may be misapplied or not applied at all. ${ }^{48}$ When it comes to the timing of application, it is assumed that when directives do not outline an explicit time limit for application of the norms contained therein, all provisions should be translated into national measures, and be fully applied in practice from the end of the transposition deadline. ${ }^{49}$

It is by virtue of the principles of direct effect and indirect effect, which have been developed in CJEU case law, that the failure of member states to transpose a directive correctly or in due time must not deprive individuals from the rights that they derive from a directive. The provisions of a directive have direct effect if they are sufficiently clear, precise, and unconditional, such that they are capable of being applied directly by a national court. ${ }^{50}$ Since directly effective provisions are immediately enforceable by individual applicants in national courts, ${ }^{51}$ directives may produce similar effects to regu-

\footnotetext{
${ }^{43}$ Jans et al., 2007: 14.

${ }^{44}$ Case C-494/01 Commission v. Ireland [2001] ECR 2005 I-03331, opinion of AG Geelhoed, para. 26.

${ }^{45}$ Ibid.

${ }^{46}$ Jans et al., 2007: 14-15.

${ }^{47}$ E.g. case C-361/99 Commission v. Germany [1991] ECR I-2576; Case C-339/87 Commission v. The Netherlands [1990] ECR I-851.

${ }^{48}$ Prechal, 2005: 87.

${ }^{49}$ Kurcz and Lazowski, 2006: 186-187.

${ }^{50}$ Case 41/74 Van Duyn v Home Office [1974] ECR 1337; Case 148/78 Pubblico Ministero v Tullio Ratti [1979] ECR 1629; Case 152/84 Marshall v Southampton and South-West Hampshire Area Health Authority (Teaching) [1986] ECR 723. See more recently e.g. case C-226/07 Flughafen Köln/Bonn GmbH v Hauptzollamt Köln [2008] ECR I-5999.

${ }^{51}$ Craig and De Burca, 2011: 185.
} 
lations after the time limit for their implementation has expired and the state has not properly implemented them..$^{52}$ The Court has also held that although member states are not obliged to implement a directive prior to the expiry of the transposition deadline outlined in the directive, they must refrain from adopting any measures that may seriously compromise the result prescribed by the directive. ${ }^{53}$ This applies to all state entities (including national courts) that must refrain from interpreting national law in such a way as to prejudice the attainment of the objectives of the directive, ${ }^{54}$ and set aside any provision of national law that may conflict with EU law, even if the transposition deadline of the directive has not yet expired. ${ }^{55}$ When national legislation and jurisprudence do not conform to the requirements of the directive, all national authorities are obligated to set aside the relevant provisions and to apply the provisions of the directive instead. ${ }^{56}$ The Court has also declared that individuals can continue to rely on the provisions of a directive against the state if it is not properly applied in practice, even when the directive has been correctly transposed into national law. ${ }^{57}$

If directives are not sufficiently clear, precise, and unconditional to have direct effect, national competent authorities are subject to the doctrine of indirect effect. Also known as the principle of harmonious interpretation, this doctrine requires all competent authorities to interpret national law to the greatest extent possible - that is, within the limits of general principles of law, notably legal certainty - and for matters within their jurisdiction, in conformity with the wording and the purpose of specific directives. ${ }^{58}$ Compliance with the principle of consistent interpretation implies that it is not the provisions of the directive that apply directly to the case, but the provisions of the national law as interpreted in the light of directives. ${ }^{59}$ The obligation of national authorities to interpret national law in conformity with an indirectly effective directive, applies only once the transposition deadline has passed. ${ }^{60}$ However, national authorities must refrain, as far as possible, from interpreting domestic law in a manner that may seriously compromise the attainment of the objectives envisaged by a directive after the transposition period has expired. ${ }^{61}$

\footnotetext{
${ }^{52}$ Ibid.: 194.

${ }^{53}$ E.g. case C-129/96 Inter-Environnement Wallonie ASBL v Région Wallone [1997] ECR I-7411.

${ }^{54}$ Cases C-261 and 299/07 VTB-VAB NV v. Total Belgium NV [2009] ECR I-2949.

${ }^{55}$ Case C-144/04 Mangold v Helm [2005] ECR I-9981.

${ }^{56}$ Case C-103/88 Fratelli Costanzo SpA v Comune di Milano [1989] ECR 1839.

${ }^{57}$ Case C-62/00 Marks \& Spencer plc v Commissioners of Customs \& Excise [2002] ECR I-6325.

${ }^{58}$ Case 14/83 Von Colson [1984] ECR 1891; Case C-106/89 Marleasing [1990] ECR I-4135; Case C-218/01

Henkel KGaA [2004] ECR I-1725. The duty of consistent interpretation was laid down already in Von Colson, with Marleasing adding the 'as far as possible' clause, and Henkel setting out that the obligation applies not only to national courts, but to all national competent authorities called upon to interpret the law.

${ }^{59}$ Prechal, 2005: 213.

${ }^{60}$ Case C-212/04 Konstantinos Adeneler et al v Ellinikos Organismos Galaktos (ELOG) [2006] ECR I-6057.

${ }^{61}$ Case C-129/96 Inter-Environnement Wallonie ASBL v Région Wallone [1997] ECR I-7411.
} 


\subsection{Enforcement}

The fourth and final stage of the implementation process involves the enforcement of EU rules by the relevant competent authorities, meaning - as we have seen above - that authorities must seek to ensure compliance on the part of the regulated by monitoring the observance of the law and bringing those responsible for noncompliance into line. In some cases, EU measures outline specific rules related to the monitoring by member states of compliance with EU rules and to the imposition of sanctions. Regardless of whether such rules exist, national enforcement rules must comply with certain minimum requirements outlined in CJEU case law. The Court has ruled that, in the enforcement of EU law fundamental rights, the general principles of EU law and the treaty freedoms must be obeyed..$^{62}$ Moreover, it has held that national enforcement measures must fulfil the requirements of equivalence, effectiveness, dissuasiveness and proportionality. ${ }^{63}$ Since enforcement is not the focus of this study, these requirements are not further elaborated on here. ${ }^{64}$

\section{The implementation deficit in the EU: Attempts to shed light on the unknown}

Legal obligations are there to be complied with, but the implementation deficit in the EU highlights the veracity of the notion that compliance cannot be taken for granted. This section addresses the size and cause of the implementation deficit in the EU. Note that the term implementation used here is in line with the definition provided in Section 1 above; it is understood to concern the entire implementation process, from transposition to enforcement. Where addressing a specific stage in the implementation process which is the case in Section 3.2 that focuses on application - reference is made to that specific stage. The section concludes by reflecting on the problems inherent in EU implementation research. This reflection will serve as a prelude to the next chapter, which outlines the approach used in this study to examine implementation in the EU.

\footnotetext{
${ }^{62}$ See case C-112/00 Schmidberger [2003] ECR I-5659 and case C-94/00 Roguette Frères [2002] ECR I-9011.

${ }^{63}$ For the requirements of equivalence and effectiveness, see, initially, case 33/76, Rewe-Zentralfinanz eG and Rewe-Zentral AG v. Landwirtschaftskammer für das Saarland [1976] ECR 1989 and case C-45/76 Comet BV v Produktschap voor Siergewassen [1976] ECR 2043. For the principle of proportionality, see, initially, case 8/77 Sagulo, Brenca, and Bakhouce [1977] ECR 1495, 12-13. Case 14/83 Von Colson and Kamann v. Land Nordrhein-Westfalen [1984] ECR 1891 added the requirement of adequacy and effectiveness of national remedies to the requirement of proportionality and the principles of effectiveness and equivalence. For the idea that sanctions must be effective, proportional, and dissuasive, see case C-68/88 Commission $v$ Greece (Greek Maize) [1989] ECR 2965. For the idea that these requirements apply to both positive and negative integration measures, see case C-265/95 Commission v. France (Spanish strawberries) [1997] ECR I-6959.

${ }^{64}$ For a synthesis, see e.g. Ottow and Weers, 2011; Jans et al., 2007: $201 \mathrm{ff}$.
} 


\subsection{Of information and implementation deficits}

The notion that the European Union faces an implementation deficit is nearly axiomatic. ${ }^{65}$ While it has been argued that "implementation almost everywhere encounters formidable barriers", ${ }^{66}$ the decentralised implementation system in the EU is considered to put exceptional strains on the effectiveness of implementation. ${ }^{67}$ The extent to which these strains actually inhibit effective implementation is, however, unclear. The EU suffers from a deficit not only when it comes to the implementation of EU law, but also regarding information about the nature and the seriousness of the gap between EU law on paper and EU law in practice. ${ }^{68}$ The reasons for this information deficit are briefly summarised below.

The first reason for the lack of information about the state of implementation in the $\mathrm{EU}$ is that it is impossible for the Commission to detect all instances of violations of EU law committed by the member states. This is because of the limited police-patrol powers that the Commission has at its disposal and because of the suboptimal functioning of the fire-alarm mechanisms that it relies on. ${ }^{69}$ Second, not all presumed or identified instances of noncompliance are acted on because the Commission does not possess the material resources to verify the veracity of each piece of information that it receives. Moreover, the Commission explicitly reserves the right to act on identified infringements as it pleases; it may decide to take action against member states that it knows have infringed an EU law provision, but it may also decide not to. ${ }^{70}$ Third, even when an infringement is known and acted upon, one cannot be certain that it will end up in Commission reports. This is because the Commission pledges to inform the public, "unless it decides otherwise". ${ }^{71}$ Put briefly, public reports only include those instances of noncompliance that the Commission is aware of, that it decides to take action on, and that it wants the general public to see. ${ }^{72}$ The result is that these reports underestimate the

\footnotetext{
${ }^{65}$ See the references cited in Chapter 1 on making EU law work: a problem in need of a solution, Section 1.

${ }^{66}$ Ibid.: 192.

${ }^{67}$ Harding and Swart, 1996: 1 . This does not mean that implementation is equally bad throughout the EU or across policy domains. The Commission's annual reports on monitoring the application of EU law show great disparities between member states and between policy domains regarding the extent to which the Commission pursues violations of EU law. These reports are available on European Commission, 'Annual reports on monitoring the application of EU law', <http://ec.europa.eu/atwork/applying-eu-law/infringementsproceedings/annual-reports $>$.

${ }^{68}$ E.g. Voermans, 2015: 345.

${ }^{69}$ See Chapter 4 on monitoring and sanctions, Section 1.2.

${ }^{70}$ See ibid., Section 1.1.2.2.

${ }^{71}$ E.g. European Commission, 'Infringement decisions', <http://ec.europa.eu/atwork/applying-eu-law/ infringements-proceedings/infringement_decisions $>$. See also Chapter 4 on monitoring and sanctions, Section 3.3. See

${ }^{72}$ See Sverdrup, 2007: 209; Falkner et al., 2005: Chapter 11; Börzel, 2001; Thomson et al., 2007: 686. See Chapter 3 on the approach and methodology of this thesis. The unreliability of infringement data has not withheld scholars from using them; see e.g. Börzel 2001; Mbaye, 2001; Tallberg, 2002; Mendrinou, 1996; Perkings and Neumayer, 2007. Börzel et al., 2010, also rely on infringement data provided by the European Commission.
} 
number of instances of noncompliance ${ }^{73}$ and the extent to which this is the case is unclear.

The incompleteness of Commission reports particularly applies to the application and enforcement stages of the implementation process. Indeed, whereas member state notifications regarding the measures adopted to transpose EU directives provide the Commission with "very precise information" regarding the transposition performance of member states, ${ }^{74}$ reliable data on member state performances regarding the implementation of EU rules in practice are "tremendously hard" to gather. ${ }^{75}$ This latter difficulty also explains why EU implementation studies generally focus on the transposition phase of the implementation process, and why contributions that concern application and enforcement are relatively few. Scientific progression on these latter issues has recently even decreased compared to the progress made during earlier years of EU implementation research ${ }^{76}$ the result is that issues of application and enforcement have remained "severely under-researched". ${ }^{77}$

What the few existing studies indicate is that application and enforcement are problematic; in $97 \%$ of the cases, studies report that practical implementation is "incorrect, insufficient, or faces problems" ${ }^{78}$ What is also problematic, however, is that such studies do not depict a representative picture of application in the EU. This inaccurate representation is due to the fact that those studies are usually small $N$-studies that suffer from problems with generalisability and over-determination..$^{79}$ Moreover, these studies display a bias regarding the choice of countries and the choice of policy domains. ${ }^{80}$ Finally, since compliance by administrative agencies (and private actors) is more difficult to investigate than the more general features of administrative and court systems, most studies that focus on the practical implementation of EU law examine enforcement

However, they had access to the Commission's own infringement database rather than to the publicly available information on infringement proceedings initiated against member states. This cancels out the third limiting factor referred to in the text (i.e. the dependence of researchers of the Commission's willingness to share information with the public).

${ }^{73}$ Thomson et al., 2007: 691; Börzel et al., 2010: 1374.

${ }^{74}$ Ciavarini Azzi, 2000: 53-54.

${ }^{75}$ Mastenbroek, 2005: 1114. Regarding the idea that data on application and enforcement are more difficult to gather than information on transposition, see also Voermans, 2015: 348-49. See also Chapter 4 on monitoring and sanctions, Section 3, for the idea that the difficulty to gather reliable data is still relevant.

${ }^{76}$ Treib, 2008: 17; 2014: 15.

77 Treib, 2014: 15.

${ }^{78}$ Toshkov et al., 2010: 17.

${ }^{79}$ Versluis, 2007.

${ }^{80}$ The majority of studies deal with either environmental or social policies; these topics cannot be accounted for by the (in particular in relation to social policy) relatively small number of legal acts adopted by the EU in these policy domains. Big member states receive the bulk of attention, and countries with a rather "aberrant" behaviour in terms of implementation patterns remain understudied; see Toshkov et al., 2010: 12-14. Similar Angelova et al., 2012: 1280-81. 
rather than application. ${ }^{81}$ The result is that the application of EU law has remained much of a "black box". 82

\subsection{How to explain variance in implementation processes and outcomes?}

While the previous section suggests that the EU suffers, not only from an implementation deficit, but also from an information deficit regarding the performance of member states, analyses of existing EU implementation studies suggest that explanations for implementation problems are abundant. The eighty qualitative studies on implementation that existed in 2010 cover 350 policy implementation cases, track more than 70 explanatory variables, and list 1,100 relationships between a variable and a specific outcome. ${ }^{83}$ Implementation studies have therefore, euphemistically, been described as "the theory of forty-seven variables that completely explain five case studies". ${ }^{84}$ Since most studies focus on the formal phase of the implementation process, many of these variables explain transposition processes and outcomes. Since the interest of this study lies not in transposition but in application, the variables that apply to transposition (only) are not explored further at this point. ${ }^{85}$

Particularly earlier implementation research does not systematically distinguish between factors that influence transposition and factors that affect application and enforcement. ${ }^{86}$ To assume that the factors that explain application and enforcement processes and outcomes are the same as those that account for transposition processes and outcomes is, however, misguided. The actors that have a role to play at each stage of the implementation process are, at least partially, different; while administrative entities have a crucial role in the application of EU law on the ground, government representatives and political parties may, depending on the legal instrument chosen to transpose the provisions of a directive, ${ }^{87}$ play a pivotal role in the transposition process. ${ }^{88}$ In view of this conceptual problem that is inherent in early implementation studies, the findings of these studies do not identify the specificities of implementation at individual stages of the process. ${ }^{89}$

\footnotetext{
${ }^{81}$ Treib, 2014: 29.

${ }^{82}$ Versluis, 2007.

${ }^{83}$ Toshkov et al., 2010: 5.

${ }^{84}$ Meier, 1999: 5; similar Goggin, 1986.

${ }^{85}$ For comprehensive reviews of the EU implementation literature, see e.g. Mastenbroek, 2005; Toshkov, 2010; Toshkov et al., 2010; Angelova et al., 2012; Treib, 2014. Where relevant or logical in the context of the current section, references to transposition are made in the main text or in the footnotes.

86 Treib, 2014: 8, 10.

${ }^{87}$ Studies show that since it determines the type of actor(s) involved in transposition, the type of legal instrument chosen for transposition influences the transposition process; see e.g. Haverland et al., 2011; Berglund et al., 2006b; Steunenberg, 2006.

88 Treib, 2014: 10.

${ }^{89}$ Ibid.
} 
The conceptual distinction between the legal and practical stages of the implementation process does appear in later implementation studies. In line with earlier research, these recent studies suggest that, since civil servants who are tasked with the application of EU measures on the ground are generally not aware of the European origins of norms, "[EU] law, once it has been incorporated [into national law], is applied neither better nor worse than national law". ${ }^{90}$ This suggestion seems to imply that studies regarding the application of EU law can build on the insights offered by domestic implementation research. ${ }^{91}$ Before exploring the factors that, according to EU implementation research, explain application processes and outcomes in the EU, the following subsections first describe the tenets of domestic implementation research.

\subsubsection{Domestic implementation research}

Domestic implementation studies broadly conform to one of two perspectives on implementation: top-down perspectives, or bottom-up perspectives. One of the earliest proponents of the former take on implementation is Pressman and Wildavsky's famous study Implementation, ${ }^{92}$ which has set the stage for implementation research and which has greatly inspired early EU implementation studies as well. This study posits that the success of implementation is highly contingent on the length of the vertical "chain" reaching down from top-level policymakers all the way to street-level implementing actors. It proposes an inverted relationship between the number of clearances in this chain and the probability of implementation that is congruent with the policy intentions. Communication and coordination problems in the policy chain inhibit policyconforming implementation. ${ }^{93}$ Other studies that have a top-down perspective of implementation have additionally emphasised factors, such as a lack of clear policy objectives and a lack of control over implementing agencies, as inhibiting successful implementation. These studies also consider differences between and within organisations regarding values, interests, priorities, and motivations for implementation as capable of causing implementation problems. ${ }^{94}$

Top-down perspectives on implementation are juxtaposed to bottom-up perspectives, which start from the presumption that "all politics are local". ${ }^{95}$ In line with this presumption, bottom-up perspectives consider that implementation is dependent on the

\footnotetext{
${ }^{90}$ Ciavarini Azzi, 1988: 199, in Treib, 2014: 8.

91 Treib, 2014: 29.

${ }^{92}$ Pressman and Wildavsky, 1973. Full title: Implementation: How Great Expectations in Washington are Dashed in Oakland; or, Why It's Amazing that Federal Programs Work at All, This Being a Saga of the Economic Development Administration as Told by Two Sympathetic Observers Who Seek to Build Morals on a Foundation of Ruined Hopes.

${ }^{93}$ Pressman and Wildavsky, 1984: xxiii-xxv. For a summary, see e.g. Hupe, 2011.

${ }^{94}$ E.g. Dunsire, 1978; Hanf and Scharpf, 1978; Hood, 1976; Mazmanian and Sabatier, 1981.

${ }^{95}$ DeLeon, 1999: 317.
} 
implementation structures that put policies into effect. ${ }^{96}$ The centrality of implementation structures leads one to believe that "policy implementation in the end comes down to the people who actually implement it"; those people are practitioners or "street-level bureaucrats". ${ }^{97}$ Such street-level bureaucrats act within a certain margin of discretion and with a certain interpretative ability that allows them to re-invent policies on the ground. Reflecting the values, interests, and understanding of street-level bureaucrats rather than the will of policymakers, the outcome of policy implementation is uncertain..$^{98}$ Put briefly, bottom-up perspectives posit that, while policymakers may design what policy should be, what policy will be is determined by the actions of street-level bureaucrats.

\subsubsection{EU implementation research}

EU implementation studies have borrowed from the two seemingly competing approaches described in the previous section..$^{99}$ In the vein of top-down perspectives, the implementation of EU law is perceived as an apolitical, hierarchical process, the success of which mainly depends on clearly defined policy intentions and a well-organised administrative apparatus. ${ }^{100}$ Bottom-up oriented studies, in contrast, regard the implementation of EU law as a process requiring both the involvement of all relevant domestic stakeholders in the policy cycle from early on, and the coordination of policy negotiation and implementation tasks within domestic administration. ${ }^{101}$ Elements from both approaches return in later studies. The variables that these studies argue have explanatory power for practical implementation processes and outcomes primarily seem to fit top-down perspectives on implementation and compliance, and are understood either as state specific or as case specific. ${ }^{102}$ While state-specific variables explain cross-country variation in implementation performances, case-specific variables explain why member states comply with certain EU measures more often than with others. These variables, which are discussed in the following subsections, are listed in Table 2 and classified based on the two types of distinctions mentioned above.

\footnotetext{
${ }^{96}$ E.g. Hjern and Porter, 1981; Berman, 1978.

${ }^{97}$ Lipsky, 1980.

${ }^{98}$ Ibid.; Prottas, 1979. More recently, see e.g. Maynard-Moody and Musheno, 2003. For a critique, see e.g. Evans and Harris, 2004

${ }^{99}$ Note that attempts to reconcile them have been made; see e.g. Sabatier, 1986.

${ }^{100}$ Falkner et al., 2008: 8-9.

${ }^{101}$ Ibid.

102 This classification links in with the one proposed by Treib, 2014, and partly relates to the distinction between state and preference-based factors proposed by Thomson et al., 2007. The following discussion builds on Treib, 2014.
} 
Table 2 Variables explaining application and enforcement

\begin{tabular}{ll}
\hline State specific & Case specific \\
\hline - compliance culture & $\bullet$ goodness of fit (and mediating factors) \\
- effectiveness and efficiency of administrations & $\bullet$ issue salience \\
- effectiveness of judiciaries & $\bullet$ preferences of political principals \\
- national arrogance & \\
- strength of civil society & \\
\hline
\end{tabular}

\subsubsection{Member state specific variables: the worlds of compliance typology}

The most well-known advocate of a member state specific approach to analysing compliance problems is the worlds of compliance typology proposed by Falkner et al. ${ }^{103}$ The authors argue that there is "not a single overriding factor which determines the compliance performance of member states"; ${ }^{104}$ this is why they do not propose a meta-theory of implementation and compliance in the EU, but four (initially three) different worlds of compliance that each show "a specific typical pattern of reacting to EU-induced reform requirements". ${ }^{105}$ This typology does not only suggest the possible causes underlying implementation problems; it also implicates the remedies that should, accordingly, be implemented to solve such problems, as the following paragraphs clarify. ${ }^{106}$

According to the worlds of compliance typology, in countries characterised by a compliance culture and an effective administrative and court system, both the legal and practical phases of the implementation process are usually successful. ${ }^{107}$ Implementation problems in countries belonging to this world of law observance (namely, the Scandinavian member states) could be remedied by close contacts during the policy preparation phase between negotiators in Brussels and implementing actors at home, in order to avoid unnecessary misfit. ${ }^{108}$ Aspirations to comply with EU measures are "fragile" in countries clustered into the world of domestic politics (that is, a number of west and ('old') central European countries and Spain). ${ }^{109}$ Government resistance to EU rules may override such aspirations, which produces problems at the transposition stage. ${ }^{110}$ These problems may be solved by the exercise of EU pressure and awareness-raising activities

\footnotetext{
${ }^{103}$ Falkner et al., 2005, 2008; Falkner and Treib, 2008.

${ }^{104}$ Falkner et al., 2005: 317.

${ }^{105}$ Ibid.: 318.

${ }^{106}$ Note that since this typology concerns both the formal and the practical stages of the implementation process, the following discussion examines its postulations in relation to both transposition and application/enforcement.

${ }^{107}$ Falkner and Treib, 2008: 296-97.

${ }^{108}$ Falkner, 2010: 9. For an elaboration of the concept of 'goodness of fit', see Section 3.2.2.1 below.

${ }^{109}$ Falkner and Treib, 2008: 297.

${ }^{110}$ Ibid.
} 
aimed at promoting whistle blowing and court cases. ${ }^{111}$ Given the effectiveness of administration and judiciaries, application and enforcement in these countries usually work well. ${ }^{112}$

Application and enforcement are expected to be mixed or weak in the two remaining worlds of compliance. Depending on the prevalent political constellation amongst domestic actors, countries characterised as belonging to the world of dead letters (some of the 2004 entrants into the EU, plus Ireland and Italy) may or may not transpose directives smoothly. ${ }^{113}$ Shortcomings in the court systems and weak civil societies explain why the subsequent application and enforcement of the law are weak. ${ }^{114}$ Structural reforms regarding the administrative and court system, as well as strengthening cooperative governance and civil society, are referred to as solutions to such problems. ${ }^{115}$ Finally, for countries belonging to the world of transposition neglect (France, Greece, Luxembourg, and Portugal), implementation is "not a goal in itself". ${ }^{116}$ National arrogance and administrative inefficiency are said to explain why such countries score weakly on the transposition of EU directives and mixed on the subsequent application and enforcement of the relevant national measures. ${ }^{117}$ Administrative reforms, training programs for civil servants, tight control during the transposition phase, and speedy initiation of infringement proceedings, are potential solutions for implementation problems experienced in such countries. ${ }^{118}$

The notion that the worlds of compliance model has made "significant advances" in the study of noncompliance in the EU is juxtaposed with criticism of the usefulness of this model as a guideline for explaining implementation performance in the EU. ${ }^{119}$ It has been argued that contrary to the basic postulations of the worlds of compliance typolo-

\footnotetext{
${ }^{111}$ Falkner, 2010: 10-11.

${ }^{112}$ Falkner and Treib, 2008: 297. For the importance of administrative capability in the implementation of EU law more generally, see e.g. Mbaye, 2001; Linos, 2007; Borghetto et al., 2006; Boh, 2004; Maniokas, 2009; Bugdahn, 2005; Berglund et al., 2006b. For government effectiveness, see Steunenberg and Toshkov, 2009; Berglund et al., 2006b; Börzel et al., 2010; Haverland and Romeijn, 2007; Toshkov, 2008; Thomson, 2007. For administrative coordination capabilities, see Dimitrova and Toskhov, 2009; Steunenberg, 2006; McNally, 2009; Dimitrakopoulos, 2001. The factor of government capacity also returns in Börzel et al., 2010, who have suggested that states with high bureaucratic efficiency and low political power violate EU law less frequently than member states for which the opposite is the case.

${ }^{113}$ Ibid.: 308.

${ }^{114}$ Ibid.: 309 . Note that the strength of civil society and the degree to which potential litigants may gain access to justice are identified as important, particularly when the state relies on fire-alarm oversight; that is, when it does not have direct monitoring powers but relies on societal monitoring instead. For an elaboration of the notion of fire-alarm oversight in the supranational enforcement context, see Chapter 4 on monitoring and sanctions, Section 1.

${ }^{115}$ Falkner, 2010: 15-17.

${ }^{116}$ Falkner and Treib, 2008: 297-98.

117 Ibid.

${ }^{118}$ Falkner, 2010: 11-12.

${ }^{119}$ Toshkov, 2007a; Thomson, 2007; Thomson et al., 2007; Thomson, 2009. Quote at Toshkov, 2007a: 933. Similar Thomson, 2007: 988.
} 
gy, attitudes towards law-abidingness and rule following and the influence of domestic politics do not differ across the different worlds. ${ }^{120}$ In contrast to the demise by Falkner et al. of misfit as a "master variable" that explains compliance, ${ }^{121}$ misfit has a consistently negative effect on timely transposition in all worlds. ${ }^{122}$ And although not the essence of the worlds of compliance typology, ${ }^{123}$ variations in transposition outcomes are not significant across the different worlds. ${ }^{124}$ Overall, the critics of the worlds of compliance typology argue that there is no evidence that the effects of variables that are critical to the typology differ across member states. These contributions consider the validity of the typology in relation to transposition in particular, and conclusions about the validity of the typology in relation to application processes and outcomes cannot be drawn.

Such criticism has, on several occasions, been countered by the architects of the worlds of compliance typology, primarily on the basis of theoretical, methodological, and data-related arguments. ${ }^{125}$ Falkner argues that the typology has found broad acceptance amongst scholars and practitioners alike; according to her, "it has been welcomed... by hundreds of bureaucrats and politicians and European integration scholars who... agreed to the classification of countries they know best". ${ }^{126}$ The most vocal critics of the typology have, as suggested previously, stated that the appearance of the worlds of compliance typology has made for marked progress in the domain of EU implementation studies. ${ }^{127}$ Regardless of one's position on the debate about the validity of the tenets of the worlds of compliance typology, one can safely agree that this typology, as all others, "can only serve as a starting point for further refinement and, most importantly, theory building". ${ }^{128}$

\footnotetext{
${ }^{120}$ Toshkov, 2007a; Thomson, 2009. In contrast, Falkner et al. argue that a culture of law abiding and rule following is a feature more of the world of law observance than of the other two worlds. They also argue that domestic politics influences compliance in a different way across the worlds of compliance. See Falkner et al., 2005: 321-326.

${ }^{121}$ Falkner, 2007: 1012. For the concept of misfit see below.

${ }^{122}$ Thomson, 2009. Falkner et al. argue that their results disprove the misfit hypothesis. See Falkner et al., 2005: 291. They suggest that "all things being equal, larger misfit will not generally increase delay in compliance (but only under some specific framework conditions, which are typical only in one group of countries and depend on the specific ideology of the government in office)". Falkner, 2007: 1012; italics in original.

${ }^{123}$ Falkner et al.'s work is about variation in national implementation styles, not variation in implementation outcomes. This does not mean that the authors do not expect implementation outcomes to be different: transposition in the world of law observance is expected to be "on time and correct (even where conflicting domestic interests exist)"; in the world of domestic politics it is expected to be "correct and on time only if there is no conflict with domestic concerns"; and in the world of neglect it is expected to be "late and/or pro forma". See Falkner et al., 2005: 322.

${ }^{124}$ Toshkov, 2007a; Thomson, 2007, 2009; and Thomson et al., 2007.

${ }^{125}$ Falkner, 2007; Falkner et al., $2007 b$.

${ }^{126}$ Falkner, 2007: 1018.

${ }^{127}$ Toshkov, 2007a; Thomson, 2007.

${ }^{128}$ Falkner, 2007: 1018.
} 


\subsubsection{Case-specific variables}

Next to the variables that the worlds of compliance typology proposes influence implementation processes and outcomes across member states, are case-specific variables that have not yet found a 'theoretical umbrella'. Since they highlight that the effectiveness of practical implementation depends on the features of (the circumstantial factors present in relation to) the policy issue at hand, these variables implicitly question the validity of the arguably somewhat static image of implementation transmitted by the worlds of compliance typology. These variables seem to be partly intertwined and partly in contradiction to one another, as we see below.

\subsection{Goodness of fit}

The first case-specific variable concerns goodness of fit, a concept that was central to early Europeanisation research. ${ }^{129}$ This concept postulates that, whereas the implementation of supranational norms and practices that match domestic norms and practices is not expected to be problematic, the implementation of mismatching norms and practices is bound to be fraught with difficulties. In the latter case, it is only under high adaptation pressure that positive domestic change may be triggered and implementation may take place. ${ }^{130}$ Note that accounts of the validity of the goodness of fit hypothesis for explaining implementation are contradictory; while some studies have drawn positive conclusions in this regard, ${ }^{131}$ others have criticised the thesis as having limited explanatory power. ${ }^{132}$

Proponents of the latter conclusion have indicated that the static nature of the hypothesis - which is guided by the expectation that domestic governments and admin-

\footnotetext{
${ }^{129}$ In general terms, the notion of Europeanisation refers to the process of "domestic adaptation to European regional integration"; see Vink and Graziano, 2007: 7. This broad definition enables an understanding of Europeanisation as a horizontal process, referring to changes at the domestic level induced by transnational influences; see Radaelli, 2006; Börzel, 2002; Haggard and Moravcsik, 1997; Haggard et al., 1997. It also enables a perception of Europeanisation in terms of 'downloading' EU norms and 'uploading' national preferences; for this perception, see further below.

${ }^{130}$ E.g. Börzel, 2000; Börzel and Risse, 2003; Duina, 1997; Risse et al., 2001; Leiber, 2007; Knill and Lenschow, 1998. Note that some of these authors only discuss misfit in passing.

${ }^{131}$ The validity of the goodness of fit hypothesis has been confirmed by a number of quantitative studies and by a review study carried out by Angelova et al., 2012. Compare, however, the review study by Toshkov et al., 2010, which draws the opposite conclusion. Treib notes several problems with quantitative studies examing the validity of the goodness of fit hypothesis. One of these problems lies in the idea that the conceptualisations used by many quantitative studies differ from the original argument, meaning that such studies may not have tested what they meant to test. Another problem concerns the indicators used to measure the fit between EU norms and pre-existing domestic practices. See Treib, 2014: 23-24.

${ }^{132}$ This is the case in particular for qualitative studies; see e.g. Haverland, 2000; Héritier, 2001; Falkner et al., 2005. Toshkov et al., 2010, find that few qualitative studies that look at the degree of misfit find that it plays a significant explanatory role. Where it is found to play a role, the effect of misfit is deemed negative; unlike the goodness of fit hypothesis would expect, high adaptation pressure resulting from a high degree of misfit does not always lead to domestic change; see Toshkov et al., 2010: 32 .
} 
istration act as "guardians of the status quo" rather than as agents of change $\mathrm{e}^{133}-\mathrm{ac}$ counts for its alleged limitations. In response to these limitations, a number of studies have introduced auxiliary variables "bringing domestic politics back in". ${ }^{134}$ These studies argue that high adaptation pressures are necessary, but not sufficient, for domestic change to occur, and that when high pressure is present, mediating variables are necessary to make that change happen. ${ }^{135}$ Such factors fall under either rational choice institutionalism, which invokes a logic of consequences, or sociological institutionalism, which invokes a logic of appropriateness. The former poses that in a situation of misfit, multiple veto points and facilitating formal institutions may empower societal actors to exploit new opportunities to pursue their interests and trigger change. ${ }^{136}$ The logic of appropriateness, in contrast, endows persuasive change agents and informal cooperative institutions with an important role in triggering change through processes of socialisation and social learning. ${ }^{137}$

A recent study combines the notion of goodness of fit with the structural features of national governance systems. ${ }^{138}$ This study suggests that when misfit between transposition measures (which reflect government preferences) and preferences of (subnational) implementation agencies is present, the formal powers of national supervisory institutions to enforce compliance on the part of administrative entities are crucial to ensure the effective application of transposition measures. Since the supervisory powers of institutions may vary across issue areas, this variable explains case-specific - rather than state-specific - variation in implementation processes. ${ }^{139}$

While early studies that developed the misfit argument do not distinguish between the different stages of the implementation process, the image that appears from these studies is that misfits in the implementation process often concern the (subnational) application of EU rules in practice. ${ }^{140}$ It is argued that the misfit argument is most plausible in relation to the application of EU law, since "it is much easier to find a coalition of political actors to support the enactment of a major piece of new legislation than to

\footnotetext{
${ }^{133}$ Duina, 1997: 157.

${ }^{134}$ And some studies discard it altogether, e.g. Mastenbroek and Kaeding, 2006.

${ }^{135}$ Risse et al., 2001: 9.

${ }^{136}$ For the influence of veto players on transposition, see e.g. Giuliani, 2003; Borghetto et al., 2006; Kaeding, 2008; Lampinen and Uusikylä, 1998; Linos, 2007; Giuliani, 2003; Mbaye, 2001; Toshkov, 2007a. Note that the influence of veto players does not seem consistent; while some studies find a significantly negative effect of veto players on legal compliance (e.g. Kaeding, 2008; Perkins and Neumayer, 2007; Lampinen and Uusikylä, 1998; Linos, 2007; Giuliani, 2003), others do not find evidence of such an effect at all (Mbaye, 2001; Toshkov, 2007a; Borghetto et al.).

${ }^{137}$ Börzel and Risse, 2003; Risse et al., 2001.

${ }^{138}$ Leventon, 2015.

${ }^{139}$ Although one could imagine that structural features of national governance systems as a whole play a mediating role in this regard as well; it is in this context that we move from case to state-specific thinking on implementation.

${ }^{140}$ Angelova et al., 2012: 1274-75; Treib, 2014: 30. For such studies, see e.g. Knill and Lenschow, 1998; Börzel, 2000; Leventon, 2015.
} 
make a large state machinery fundamentally change its bureaucratic routines". ${ }^{141}$ This argument finds support in research on policy styles, which posits that institutions are 'sticky'; that is, that policy traditions and administrative routines may be so deeply entrenched as to make it difficult for them to change swiftly. ${ }^{142}$ Indeed, instead of simply 'copying in' external demands for change, member state institutions adapt to external pressures "primarily by approaching 'reality' by means of their own standard operating procedures, institutional repertoire and codes"; ${ }^{143}$ all of this limits the costs of adaptation. ${ }^{144}$

The idea that member states may aim to limit the costs of adaptation underlines the relevance of a conceptualisation of Europeanisation as a 'two-way process', according to which states aim to minimise the costs of 'downloading' European practices - that is, at avoiding costly misfit - by trying to 'upload' their policy preferences to the EU level. ${ }^{145}$ Note that for this process to be successful, close contact between national decision makers and implementing agencies in the context of EU policy-making processes must exist; where such contacts are absent and Chinese Walls exist in their place, ${ }^{146}$ the preferences uploaded by national decision makers may not match those held by the relevant national implementing actors. In this situation, the reflection of national preferences in newly adopted EU norms may still require considerable change from the administrative entities responsible for the application of such norms on the ground.

\subsection{Salience}

A second variable that is proposed to explain variation in the application and enforcement of EU law across cases concerns the degree of salience of a policy issue. Issue salience refers to the relative importance attached to a policy subject within society; ${ }^{147}$ put simply, it refers to whether an issue is regarded as 'hot or not'. Salience comes with visi-

\footnotetext{
${ }^{141}$ Treib, 2014: 30.

${ }^{142}$ See e.g. March and Olsen, 1989, DiMaggio and Powell, 1991; and Pierson, 2000, on historical/institutionalist accounts of organisational change. See Van Waarden, 1995: 333ff, on regulatory styles.

${ }^{143}$ Dimitrakopoulos, 2001: 3.

${ }^{144}$ For studies showing that this is the case, see e.g.Versluis, 2007; Dimitrova and Steunenberg, 2013.

${ }^{145}$ E.g. Börzel, 2002. For an understanding of Europeanisation as a process of 'downloading' EU settings, rules and practices by the member states, see e.g. Ladrech, 1994; Buller and Gamble, 2002. For studies examining the impact of EU membership on the member states, see e.g. Radaelli, 2000; Andersen and Burns, 1996; Featherstone, 1998; Goetz, 1995; Börzel, 1999; Weiler, 1994; Stone Sweet and Brunell, 1998; Shaw and More, 1995; Green Cowles et al., 2001; Goetz and Hix, 2000; Featherstone and Kazamias, 2001; Börzel and Risse, 2003. For a conceptualisation of Europeanisation as 'uploading' national policy preferences, see e.g. Börzel, 2002; Bulmer and Burch, 2001. For studies taking a bottom-up perspective, see e.g. McCauley, 2011; Wallace and Wallace, 1996; Stone Sweet and Sandholtz, 1998; Moravcsik, 1998; Héritier, 1999; Constantelos, 2004; Fairbrass and Jordan, 2002; Warleigh, 2001. For the idea that the line between these two conceptualisations of Europeanisation is blurred, see e.g. Quaglia et al., 2007; similar Howell, 2002.

${ }^{146}$ For the notion of Chinese Walls, see e.g. Mastenbroek, 2003.

${ }^{147}$ Spendzharova and Versluis, 2013.
} 
bility, in particular with the visibility of events that do not agree with perceptions of 'what ought to be'. Such events - risks, accidents, disasters, and crises - draw societal attention to certain policy issues at the expense of others. ${ }^{148}$ Since policy makers are likely to prioritise issues that society accords prominence to, salience may play an important role in explaining (positive) change in the domestic policy process. ${ }^{149}$

Studies indicate that this logic applies to the practical implementation process as well; higher degrees of salience have been found to correspond to better application and enforcement, because implementing agencies are more likely to dedicate their limited resources to issues that enjoy considerable societal - and therefore political - salience than issues that are not at the centre of societal attention. ${ }^{150}$ Note that interest groups may play a mediating role in increasing the degree of issue salience by raising societal awareness of a certain policy issue. ${ }^{151}$ In addition, low issue salience may be compensated for - and implementation success in low-salience cases accounted for - by the existence of tools that reduce the discretionary room for street-level implementing actors, such as centralised enforcement structures. ${ }^{152}$ At this point reference may be made to top-down perspectives in domestic implementation research, which, as stated above, refer to the degree of control over administrative agencies as relevant to explaining implementation processes.

\subsection{Preferences}

Finally, a more recent study suggests that the constellations of preferences of political principals explain inter-case variety regarding the effectiveness of application. ${ }^{153}$ This study starts from the assumption that application can be effective only if the policy preferences held by the domestic political principals responsible for transposition are uniform and administrative agencies responsible for application share these preferences. Self-evidently, in order for application to be effective in view of the EU norms, these preferences should be congruent with the norms outlined in the respective directive. ${ }^{154}$ If

\footnotetext{
${ }^{148}$ Such events are, hence, coined "focusing events"; see e.g. Kingdon, 1995 and Birkland, 1997 (on focusing events and agenda setting).

${ }^{149}$ Some studies show that a high degree of salience may speed up the transposition process (e.g. Bursens and Deforche, 2008; Kaeding, 2007; Spendzharova and Versluis, 2013); others argue that it may trigger domestic conflicts causing delay (e.g. Dimitrova and Toshkov, 2009).

${ }^{150}$ Versluis, 2003, 2004, 2007.

${ }^{151}$ E.g. Börzel and Buzogany, 2010: 166. For the influence of non-governmental organisations on application, see Chapter 7 on civil society.

152 Versluis, 2007.

${ }^{153}$ Dimitrova and Steunenberg, 2013. Note that government preferences have been suggested to mediate implementation in the EU more generally (that is, in relation to transposition) as well; see e.g. Mastenbroek and Van Keulen, 2006; Treib, 2003; Linos, 2007; Zhelyazkova and Torenvlied, 2009; Thomson et al., 2007; Falkner et al., 2004; Zhelyazkova, 2013.

${ }^{154}$ Dimitrova and Steunenberg, 2013: 251. Note that non-governmental actors could act as informal veto players'; given the possible involvement of such actors in implementation processes, the perceptions of these
} 
the latter is not the case, the European Commission may force the domestic political principals to transpose directives correctly, but - especially where subsequent supranational enforcement is weak ${ }^{155}$ - political principals may allow administrative implementation agencies to reverse the transposed norms and follow a course that is congruent with domestic preferences instead. When the domestic political principals that are responsible for transposition display a heterogeneous set of preferences - and are too divided to press for compliance - administrative agencies are given the discretion to shape application practices in accordance with their own preferences. ${ }^{156}$ In both of these cases, the application performance of the administration is bound to be ineffective in view of the EU rules that are set.

\subsection{Synthesis}

Similar to the worlds of compliance typology, case-specific explanations of application processes and outcomes have weaknesses. One of these is that they do little to contribute to establishing a theory of application in the EU. This is partly because there are few studies that examine how these variables influence application and because they display selection based on the dependent variable, ${ }^{157}$ both of which make it difficult to determine the general validity of these variables for explaining variation in the application of EU law. Problematic in terms of theory building is also that the variables that, according to the literature, explain variation are partly contradictory. For example, if high issue salience causes better application, whether or not a misfit between EU and domestic norms exists should be irrelevant. Likewise, if the effectiveness of application is determined by the degree of fit between EU and domestic norms, misfit may hinder domestic change even when high issue salience is present.

Note that tension exists in relation to the worlds of compliance typology as well; this is logical because while the typology perceives variation in application as dependent on member state characteristics, case-specific thinking perceives of such variation as dependent on the specificities of individual issues. Whereas the worlds of compliance typology seems to present a rather static picture of application processes - as if application in individual worlds follows a similar pattern regardless of the policy issue at hand - case-specific variables seem to disregard the potential capacity of state-specific structures to mediate or overcome inertia owing to a lack of issue salience or misfit. As there may be truth in both conceptions of compliance, it may be promising for EU implementation research to examine whether it is possible to combine state and case-specific variables within a coherent conceptual framework.

\footnotetext{
actors are relevant to attempts to understand (the formation of) preferences of political principals. Ibid.: 257.

155 This is not unthinkable, as Section 3.1 shows and as Chapter 4 on monitoring and sanctions shows in detail.

${ }^{156}$ For the importance of discretion in the transposition of directives, see Dimitrova and Steunenberg, 2000; Thomson, 2007; Thomson et al., 2007; Keading, 2008a; Steunenberg and Toshkov, 2009; Zhelyazkova, 2013.

${ }^{157}$ For this point see Section 3.1 above.
} 
Finally, the case-specific variables discussed above may not only contradict each other, they may also be closely intertwined. Salience might act as an impetus to bring heterogeneous preferences into line (which might be the case in crisis situations requiring a quick reaction, which do not allow for turf battles to be fought) or in contrast, reinforce heterogeneity (which might be the case where politicians exploit the opportunities for political profiling offered by crisis situations). Similar interconnections seem to involve the concept of goodness of fit, which earlier research has, as explained above, identified as unlikely to explain domestic change alone. Whether these (and other) interconnections exist, and what form they take, may be an equally interesting matter for EU implementation research.

\subsection{Problems with EU implementation research}

In view of the discussion presented in the previous sections, a number of problems with EU implementation research must be noted. First of all, EU implementation studies focus primarily on explaining divergent performance records of member states regarding the transposition of EU directives. The phase during which EU rules are administered in concrete situations on the ground has remained a black box. We know little about the extent to which such rules are applied and about the problems that street-level actors experience in the application process. This limited attention to the application phase of the implementation process may be explicable in view of the fact that it is "exceedingly difficult" to monitor the application of EU rules on the ground. ${ }^{158}$ However, since applying EU rules is essential if these rules are to achieve their full effect, and since we cannot understand member state behaviour in the implementation of EU law by examining the transposition of directives alone, this lack of attention is a cause for concern.

Second, and as referred to in the previous subsection, the abundance of factors that are proposed to explain variation in implementation patterns has done little to contribute to theory building on implementation in the EU. Studies continue to add new causal factors or establish new causal relationships that seem to explain implementation (in particular transposition) and compliance in the cases subject to investigation. Rather than proposing a model with general explanatory potential, the existing literature proposes "sometimes-true theories" 159 - models that explain variation in implementation processes across cases by reference to differences across these same cases. Theory building, however, should aim to establish causal relationships between variables that are generalised explanations of a phenomenon. Overall, despite the existence of some studies that have created order out of the chaos of EU implementation research, after three decades of EU implementation research, we are still unable to provide a generally appli-

\footnotetext{
158 Tallberg, 2002: 624 .

${ }^{159}$ Falkner et al., 2007a.
} 
cable, straightforward explanation for implementation patterns in the EU. The question is whether or not such an ambition is realistic - a question that the concluding chapter of this thesis returns to.

Third, the excessive focus of implementation studies on implementation failure has created a bias in implementation research; it is as though all policies are bound to fail, and member states act in a vacuum when implementing EU law. The majority of implementation studies overlook the fact that mechanisms to support a correct implementation of EU law exist. ${ }^{160}$ Moreover, when studies do suggest remedies for implementation problems, the respective proposals usually mirror the nature of implementation problems that must be tackled. Civil society does not function well and more civil society activism is required to improve implementation. The administration does not function effectively and a more effective administration is necessary. And this continues. Such proposals do not quite provide concrete tools for taking implementation to a higher level. For example, there is a consensus that establishing a well-functioning civil society in countries featuring weak civil society activism may take longer than a generation. ${ }^{161}$ And in view of the 'stickiness' of member state institutions, it is unlikely that dramatic institutional change will occur overnight. Because of the limited attention to 'what is out there' - instead of what should be there - to remedy compliance problems, there is little knowledge about the functioning of existing 'could-be solutions'.

This criticism does not make EU implementation research irrelevant for solving compliance problems. For practitioners attempting to close the implementation gap, knowledge about variables that explain implementation problems is highly relevant. This also applies to knowledge about variables that practitioners cannot manipulate, "since it enables them to focus their efforts on cases that are likely to raise compliance problems". ${ }^{162}$ However, it seems that in order to focus their efforts efficiently, practitioners would benefit not only from knowledge about 'what goes wrong' in the implementation of EU law, but also from knowledge about 'what goes right'. In view of this consideration, it seems promising to delve into the usefulness of concrete instruments for supporting the competent authorities of the member states in the application of EU law. It is this issue that this study focuses on, as the following chapter outlines in more detail.

\footnotetext{
${ }^{160}$ For exceptions, see e.g. Panke, 2010 (for a study on the effectiveness of the CJEU for restoring compliance with EU law), Cremona, 2012 (for a review of several legal compliance instrument), and Tallberg, 2002 (for a review of the instruments that the European Commission has at its disposal in the implementation of EU law). ${ }^{161}$ See Chapter 7 on civil society.

${ }^{162}$ Thomson, 2009: 15.
} 
Chapter 3

Approach and methodology 


\section{Introduction}

Recognising the criticism of EU implementation studies outlined in the previous chapter, the current study proposes a different perspective on the topic of implementation in the EU. Instead of focusing on the transposition phase of the implementation process, it turns its attention to the stage at which EU directives must be applied by the competent administrative authorities of the member states. Rather than aiming to explain problems experienced at this stage, its purpose is to examine instruments that may be thought of as useful for correcting application problems or for preventing such problems from occurring. Chapters 1 and 2 have elaborated on the advantages of this reversed angle in light of the one-sided focus of EU implementation studies, and the practical relevance of a shift in focus for EU practitioners. This chapter elaborates on the operationalisation of the approach to this study and explains the methodological choices that were made in this regard.

Section 1 explains the selection of compliance instruments included in this study and briefly describes each of these instruments. Elaborate descriptions are found in the relevant empirical chapters of this thesis. The question of why compliance instruments are expected to be useful for supporting the application of EU law is reflected on in Section 2, which relies on perspectives of compliance offered by the rationalist, managerialist, and constructivist schools in international relations studies. While at first sight, they seem to offer a useful framework for the categorisation of compliance instruments, a second glance suggests that these schools are not suitable for this purpose. This also applies to notable alternatives that should be considered in the framework of this study. Section 3 elucidates why this is the case. This elucidation serves as a precursor to understanding the pragmatic choice of this study to categorise instruments based on an assessment of the institutional level harbouring the main actors responsible for making the relevant instruments work. Finally, Section 4 aims to explain the choice of qualitative case studies and to identify the sources used in this study. 


\section{From studying implementation problems towards examining possible solutions}

If there is one message that EU implementation studies convey, it is that noncompliance is a complex phenomenon - a phenomenon, therefore, that must be addressed by a variety of remedies if implementation problems are to be solved effectively. Analysis suggests that the European implementation context features a variety of instruments that aim to ensure the correct application of EU rules by the competent authorities of the member states, or that may otherwise be expected to have this effect. These instruments can be found at the supranational governance level, and at the transnational, national, and subnational governance levels. Ideally, an analysis of the 'compliance toolbox' should cover instruments at each of these levels. Practical constraints have, however, made this infeasible and forced us to select compliance instruments wisely.

The primary methodological reason for choosing not to study a sole mechanism, but a wide a variety of compliance instruments, is that a patchwork of instruments exists and these instruments are not isolated from one another. Focusing on a single instrument not only prevents us from understanding the full picture of 'what is out there', in order to support the application of EU law; in view of the interrelationships between compliance instruments, a single-instrument focus also makes it impossible to understand both the place of this single instrument in the patchwork of compliance instruments, and the usefulness of this instrument in relation to that of other instruments. For these reasons, a comprehensive approach to studying the usefulness of compliance instruments is preferable to a single-instrument approach.

Since the interest of this study lies in examining the usefulness of principal compliance instruments, including the interactions amongst those instruments, the focus of this study is on instruments that exist at all, bar the subnational, governance levels. The exclusion of instruments at the subnational governance level has not been motivated by the idea that such instruments would not be interesting to study; it has been opted for because the inclusion of subnational instruments at the expense of that of instruments at the other governance levels would have created 'missing links' or left major lacunae. The former would have been the case if the national governance level, which connects the supranational to the subnational governance level, had been left out. The latter would have been the case if supranational instruments had been excluded; in view of the importance attached to the European Commission as guardian of the treaties, the exclusion of the tasks exercised by the Commission in this regard has been deemed undesirable. The relatively recent surge of transnational instruments as important compliance instruments makes it imperative to include such instruments in our examination as well.

Finally, the instrument selection has also been guided by a desire to include instruments that may theoretically apply to all member states, and across policy domains. This selection criterion is important, since it allows this study to arrive at recommendations 
that may be useful for improving the application of EU law more generally. It has resulted in the inclusion of the compliance instruments listed in Table 3. An exploration of these instruments and of their interrelationships follows in Sections 1.1 and 1.2 below.

Table 3 Existing instruments that aim to improve the application of EU law

The right of the European Commission to launch infringement proceedings against noncomplying member states

Naming and shaming strategies implemented by the Commission and/or by EU agencies

Post-legislative guidance issued by the Commission and/or by EU agencies

Inspection tasks of EU regulatory agencies

Preliminary rulings given by the Court of Justice of the European Union

Transnational cooperation amongst administrative authorities of the member states

National case law

Civil society activism

\subsection{An exploration of the compliance instruments included in this study}

As each of the compliance instruments listed above are examined in detail in the empirical chapters of this study, it is currently sufficient to describe their features succinctly. Some of these instruments are longstanding. The most notable example of this seems to be the Commission's power to pursue member states for violating EU law, which has been assigned to it since the inception of the European Economic Community (EEC), by the Treaty of Rome. Infringement proceedings usually start with informal negotiations between the Commission and member states in order to arrive at an amicable solution to the dispute at stake, but they may end with a formal ruling of the CJEU requiring member states to comply and (since approximately two decades ago) eventually result in the imposition of financial sanctions on member states. National case law on the application of national measures adopted for the transposition of directives into national law, and the right for national courts to ask the CJEU for a preliminary ruling on questions of EU law have existed since the early years of the European integration process as well. One only needs to recall the famous Van Gend \& Loos and Costa $v$ Enel judgements in this respect, ${ }^{1}$ which were handed down by the European Court following a request for a preliminary ruling submitted by national courts in the context of domestic court proceedings.

In addition, post-legislative guidance has been a feature of EU law from early on, which - in view of the complexity of legal provisions and because of the increasing amount of supranational jurisprudence on the interpretation of EU measures - has been increasingly used over time; this is similar to transnational administrative cooperation. In many policy areas, transnational cooperation has existed for decades, either within or

\footnotetext{
${ }^{1}$ Case 26/62 NV Algemene Transport- en Expeditie Onderneming van Gend \& Loos v. Netherlands Inland Revenue Administration [1963] ECR 1; case 6/64 Flaminio Costa v. E.N.E.L. [1964] ECR 585.
} 
outside of the EU institutional framework. Over time however, networks have increasingly made their appearance in the European policy and implementation context, with the currently existing multitude of networked forms of cooperation being a novel phenomenon.

Other instruments have been considered capable of making a positive contribution to the application of EU law by the member states - or emphasised by EU institutions as essential - only later. Naming and shaming strategies, according to which the Commission publicly benchmarks the performance of member states with the aim of compelling badly performing countries into compliance, have been used by the Commission since the early 1990s. The Commission's White Paper on European Governance has been critical for emphasising the contribution that non-governmental organisations - and other societal actors - can make to improve the application of EU law on the ground. ${ }^{2}$ It must be emphasised that the reference is to national non-governmental organisations. This is the case, since a true "European civil society" - a "singular transnational civil society" that is a "unified and coherent entity" rather than "an assemblage of most Europeanized national publics" - does not (yet) exist. ${ }^{3}$ Citizens may be organising themselves transnationally, but considerable transaction costs force most social actors to resort to domestic resources and opportunities rather than cross-border forms of operation. ${ }^{4}$ And while associations at the European level do exist, they are often created in a top-down manner with EU funding, and as a result they may be geared more towards lobbying the EU institutions than maintaining close relations with organisations rooted in the national level. ${ }^{5}$ Thus, it is not EU-level associations, but national-level organisations, that are the most close - and most relevant - to the national implementation practice. This is why this study focuses on the latter type of organisations.

Note that the question of why these compliance instruments are thought to improve the application of EU law, and how they are supposed to do this, is discussed in the first section of each empirical chapter. To attain a balanced picture of the extent to which compliance instruments are expected to be useful for improving law application, the respective sections also discuss the factors that limit the usefulness of the studied instruments for ensuring compliance.

\subsection{An exploration of the interrelations of compliance instruments}

As explained above, one reason for including the multitude of compliance instruments listed above, is that compliance instruments are interrelated and are, therefore, difficult to study in isolation. In order to clarify this argument - and to underline the added

\footnotetext{
${ }^{2}$ COM (2001) 428 final.

${ }^{3}$ Heidbreder, 2012: 27-28; quotes on p. 27. For an overview of different contributions on the shape of a 'European civil society', see Finke, 2007.

${ }^{4}$ Bar business actors, one might argue. Tarrow, 2001: 237.

${ }^{5}$ Smismans, 2003: 493; also Kohler-Koch, 2009: 54.
} 
value of taking a multi-instrument approach to the study of compliance instruments - it may be worthwhile to explore some of these interrelations at this point.

An initial exploration of these instruments' intended purpose suggests that compliance instruments may depend on one another to function effectively, or reinforce one another. Interdependencies seem to exist in particular between preliminary rulings, national case law, and civil society activism. Without civic organisations that understand how to start and argue a case in court, litigation seems - especially in areas regulating public goods - unlikely to enter the picture as an often used and helpful compliance instrument. Without national case law triggering issues of interpretation of EU law, it is difficult to expect national judges to submit questions about the interpretation of EU law to the CJEU. Similar interdependencies exist for other combinations of compliance instruments. The elaboration of guidelines, for example, may be triggered by the Commission's monitoring activities highlighting diverging interpretations of the same legal provision across member states. The initiation of infringement proceedings and the implementation of naming and shaming strategies depend on the information gathered by the European Commission through its monitoring activities. In all of these cases, the effective functioning of certain compliance instruments is conditional to the effective functioning of others.

Note that the effective functioning of certain compliance instruments may also have the opposite effect and reduce the necessity or prevalence of others. For example, when national case law is successful at solving instances of noncompliance, infringement proceedings might be avoided. If guidelines effectively clarify questions regarding the interpretation of EU law, domestic court proceedings may be prevented and preliminary rulings regarded as unnecessary. And if violations of EU law are prevented or solved by instruments other than the infringement procedure, the burden on the Commission as guardian of the treaties is reduced.

The features of these (and other) interdependencies will be examined in more detail in the empirical chapters of this study. Clearly, the added value of studying multiple compliance instruments within the same study is that it allows one to attain insight into the functioning of individual instruments that together comprise the 'compliance package', and develop a better understanding of the manner in which these instruments relate to, and depend on, one another. Such an understanding seems useful for developing recommendations for how the application of EU law can be improved.

\section{Why should compliance instruments work?}

Why should compliance instruments be helpful for supporting the application of EU law? The simple answer would be: because they are introduced for that purpose, or because there is a suspicion that they may otherwise have the 'right' characteristics to do 
so. A more precise answer is that these instruments may be useful if they address the underlying dynamics of noncompliance. From international relations studies we learn that compliance problems may be derived from unwillingness on the part of states to comply (rationalism), state-capacity problems or rule ambiguity (management perspectives), or weak internationalisation of norms of appropriate behaviour (constructivism). These schools also introduce instruments that, according to each of them, work to address compliance problems successfully.

The tenets of these three schools have been applied to EU implementation studies as well. ${ }^{6}$ Studying the sometimes-divergent performance records of member states in the implementation of EU law, Börzel et al. identified strong interaction effects between the enforcement and management approaches of international relations studies. The authors accordingly suggest that the combination of management and enforcement instruments should be an effective way to improve compliance. ${ }^{7}$ This latter suggestion is aligned with propositions put forward by others, not only within the area of EU implementation studies, ${ }^{8}$ but within the general domain of international relations studies. While the logics of compliance proposed by the three schools were initially seen as mutually exclusive, ${ }^{9}$ it is now more and more accepted that the relevant question is not "which model is 'true', but rather how much of the observed variance each of them can account for". ${ }^{10}$

The following subsections examine each these three schools' conceptions of the roots of implementation problems and the solutions that they suggest should be employed to fight these problems.

\subsection{The rationalist answer: enforcement}

According to the rationalist school of international relations studies, compliance is a matter of preferences. States are perceived as rational actors that make decisions to comply - or to defect - out of self-interest, ${ }^{11}$ based on a consideration of the costs and benefits of compliance and of the costs and benefits of defection. It follows that compli-

\footnotetext{
${ }^{6}$ See Tallberg, 2002, and Börzel et al., 2010, for an analysis of which strategies proposed by the three schools in international relations studies work to address compliance problems in the EU.

${ }^{7}$ Börzel et al., 2010. Note that this study considers implementation as a whole; the findings do not specifically concern the application phase of the implementation process.

${ }^{8}$ E.g. Tallberg, 2002.

${ }^{9}$ E.g. Raustiala and Victor, 1998; Raustiala and Slaughter, 2002.

${ }^{10}$ Underdal, 1998: 5-6; italics in original. Also Simmons, 1998: 76; Sverdrup, 2007: 207, 210. See e.g. Checkel, 1999 and Zürn and Checkel, 2005, for an attempt to 'build bridges' between constructivism and rationalism. See Börzel et al., 2010 for an attempt to explain diverging compliance records of member states by reference to the three approaches. See Beach, 2005, on an attempt to bridge the gap between instrumental and normative models of compliance (on the compliance of member states with ECJ judgements). See Tallberg, 2002, for the argument that enforcement and management are complementary and mutually reinforcing mechanisms to achieve compliance.

${ }^{11}$ Mitchell, 1996: 8.
} 
ance is a matter of willingness, and noncompliance a matter of ill will to bear the costs of compliance on the part of states. ${ }^{12}$ States are likely to implement if there is an expected utility, for example because rules reduce uncertainty or transaction costs. ${ }^{13}$ When the benefits of noncompliance exceed the costs of defection, states will choose to defect. ${ }^{14}$ Since the benefits of compliance differ across countries, countries' responses to rules are also expected to vary. ${ }^{15}$

In view of the centrality of unwillingness on the part of states as an explanatory factor for noncompliance, the rationalist school advances a coercive strategy of monitoring and sanctioning as the most effective method of solving compliance problems. ${ }^{16}$ In order for such a strategy to alter the cost-benefit calculations of states in favour of compliance, the likelihood of noncompliance being detected must be as high as possible. ${ }^{17}$ Transparency is essential in this regard, since it makes the detection of violations easier. ${ }^{18}$ In addition, the costs of noncompliance must be as high as possible. ${ }^{19}$ Since states vary in terms of their vulnerability to costs, ${ }^{20}$ international regimes should ideally be able to impose them flexibly. Sanctions may be of a financial or a reputational nature; they may come in the form of fines, or in the form of diplomatic or public pressure. ${ }^{21}$ Strict enforcement is needed when compliance requires states to deviate further from their preferences, since it is in such cases that the temptation to violate the relevant rules is greatest and noncompliance is most harmful. ${ }^{22}$

\subsection{The managerial answer: capacity building, rule clarification, and transparency}

In contrast to rationalist perspectives of implementation, the managerial school of international relations studies assumes that member states are basically willing to comply. The argument of managerialists is that compliance is a matter of possibility rather than of preference; "compliance problems often do not reflect a deliberate decision to violate an international undertaking on the basis of a calculation of interests", ${ }^{23}$ and are deviant and endemic instead. According to management perspectives, compliance problems are

\footnotetext{
${ }^{12}$ Mitchell, 1996; Tallberg, 2002: 611; Joachim et al., 2008: 179.

${ }^{13}$ E.g. Keohane, 1984.

${ }^{14}$ Downs et al., 1996. For a nuance of this basic argument, see Mitchell, 1996: 11.

${ }^{15}$ Fearon, 1998: 276-277.

${ }^{16}$ At least in which policy problems resemble collaboration games; that is, situations in which joint compliance is preferred to joint violation, but in which each state's dominant strategy is to violate even if others comply. In coordination games, on the other hand, each actor prefers compliance as long as other actors comply. In this case, enforcement is unlikely to be needed (Mitchell, 1996: 9-10).

${ }^{17}$ Fearon, 1998; Mitchell, 1996: 14.

${ }^{18}$ Mitchell, 1996: 18-19.

${ }^{19}$ Fearon, 1998; Mitchell, 1996: 14.

${ }^{20}$ Haas, 1998: 29.

${ }^{21}$ Mitchell, 1996: 21; Keohane, 1984: 105-106; Downs and Jones, 2002.

${ }^{22}$ Downs et al., 1996.

${ }^{23}$ Chayes and Chayes, 1993: 176.
} 
caused by capacity limitations, rule ambiguity, and uncontrollable social or economic changes. ${ }^{24}$ Capacity limitations may come in various forms. Governments may, for example, not dispose of the legal authority, the administrative efficiency, or the financial, technical, and human resources to implement a policy, ${ }^{25}$ or they may face domestic opposition. ${ }^{26}$ Rules may be ambiguous because the language lacks clarity and precision, leading to interpretations on the part of states that may not be consistent with the intention of the rule at stake. ${ }^{27}$

In the vein of management perspectives, solving implementation problems through "coercive enforcement is as misguided as it is costly". ${ }^{28}$ Instead, management perspectives argue that compliance problems must be coped with by "focusing on and improving the mundane, day-today interactions and discussions that persuade actors to comply" ${ }^{29}$ Capacity building, rule interpretation, and transparency measures are proposed as important mechanisms in this regard. ${ }^{30}$ While measures such as technical, educational, and financial assistance may address capacity shortages, ${ }^{31}$ authoritative rule interpretation - for example through case law or through informal processes - may clarify the meaning of norms for all parties and specify the performance required from states. ${ }^{32}$ Transparency is important since "for a party deliberately contemplating violation, the high probability of discovery reduces the expected benefits rather than increasing the costs and would thus deter violation regardless of the prospect of sanctions". ${ }^{33}$ Transparency also provides reassurance to actors that they are not being cheated, ${ }^{34}$ thus contributing to mutual trust, and it permits actors to coordinate their behaviour. ${ }^{35}$

\subsection{The constructivist answer: socialisation}

While rationalist and management perspectives are often presented as opposite ends of a spectrum when theorizing compliance, constructivism is less concerned with the question of whether compliance problems are intentional or capacity related. Analysing compliance from a normative angle, constructivists argue that the behaviour of states is rule governed and driven by a logic of appropriateness. ${ }^{36}$ This does not mean that states do not pursue interests; it means that states act not on the basis of material incentives -

\footnotetext{
${ }^{24}$ Chayes and Chayes, 1993.

${ }^{25}$ Young, 1992: 183; Haas, 1998: 19-20; Mitchell, 1996: 12.

${ }^{26}$ Young, 1992: 184-185.

${ }^{27}$ Chayes and Chayes, 1993: 188-189.

${ }^{28}$ Chayes and Chayes, 1998: 22.

${ }^{29}$ Chayes et al., 1998: 62.

${ }^{30}$ E.g. Chayes and Chayes, 1998: 22ff; Chayes et al., 1998: 52ff; Young, 1992.

${ }^{31}$ Chayes et al., 1998: 52-54; Mitchell, 1996: 14, $20-21$.

${ }^{32}$ Chayes et al., 1998: 54-56.

${ }^{33}$ Chayes and Chayes, 1998: 153; Chayes et al., 1998: 43-44.

${ }^{34}$ Chayes et al., 1998: 43-44.

${ }^{35}$ Ibid.

${ }^{36}$ Checkel, 1999.
} 
as rationalism would propose - but on the basis of the meaning that objects or actors have for them. ${ }^{37}$ In this perspective, states comply with a rule if this rule is considered legitimate; that is, if a state holds a normative belief that a rule ought to be obeyed. ${ }^{38}$ Legitimacy may be derived from the contents of a rule, or from the procedure or source by which it was generated. ${ }^{39}$ According to constructivists, the perception of rules or of institutions as legitimate tends to increase over the course of time; the longer a state is a member of an organisation or the longer it is subjected to rules, the more this state internalises the relevant rules as appropriate and compliance as 'the right thing to do'. ${ }^{40}$

Constructivists argue that compliance problems must be addressed through socialisation; that is, through mechanisms that allow for the internalisation of norms and standards of behaviour. ${ }^{41}$ Socialisation may occur through social protest and through social learning. Social protest involves non-state actors and policy networks attempting to persuade state actors into compliance by exercising soft pressure, for example through campaigns and incriminating press releases. Social learning may occur when individuals change their allegiances, values, and objective functions as they are exposed to norms, through interaction in the context of social structures. ${ }^{42}$ The design of these social structures depends on the design of international institutions themselves. Changes in individual allegiances are most likely to occur in highly specific international institutions, which are relatively isolated from domestic politics and have a primary affiliation of all individual members. It has been suggested that the intensity of contact and career level are more important than the duration of contact in this regard. When it comes to altering domestic beliefs at the state level, socialisation is said to have the greatest effect when domestic opposition to change is weak and when the state sees itself as a student in a teacher-student relationship. ${ }^{43}$

\section{Towards an actor-based typology of compliance instruments}

The three strands of international relations studies discussed above provide useful tools for understanding the dynamics underlying compliance problems and the appropriate remedies to solve these problems, both generally and in the EU. ${ }^{44}$ These schools do,

\footnotetext{
${ }^{37}$ Hurd, 2008: 300, 310-311.

${ }^{38}$ Hurd, 1999: 381; Koh, 1997.

${ }^{39}$ Hurd, 1999: 381; Raustiala and Slaughter, 2002: 546.

${ }^{40}$ Raustiala and Slaughter, 2002: 546. Not all norms are equally internalised, though. The effectiveness of internalisation depends on the characteristics of the norm at stake, i.e. on their substance and the way in which they are legalised. For an overview, see ibid.

${ }^{41}$ Zürn and Checkel, 2005: 1045; Koh, 1997.

${ }^{42}$ Checkel, 1999; Mitchell, 1996: 24. Norm entrepreneurs and issue networks have already early been identified as playing an important role in this context, see e.g. Keck and Sikkink, 1998.

${ }^{43}$ Zürn and Checkel, 2005:1056.

${ }^{44}$ In fact, many variables advanced by EU implementation studies as explaining compliance problems seem
} 
however, fail to provide an adequate conceptual framework for categorising the compliance instruments examined in the context of this study. This section first explains why this is the case and why pre-eminent typologies of public policy instruments are also not sufficient. It then proposes an actor-based typology as a tool to order compliance instruments, and as a guiding structure for this study.

\subsection{Why existing typologies do not work}

The problem with a categorisation of compliance instruments along the lines described in Section 2 above is that these instruments rarely fit a single logic of compliance. In principle, certain instruments may be categorised as belonging to either logic based on an assessment of their prime purpose. In this vein, one may classify EU monitoring activities and national case law as enforcement instruments, and the preliminary ruling system as a capacity-building mechanism. However, the effect of these instruments goes beyond enforcing member states into compliance or supporting them in the application of EU law. For example, case law may sanction a member state or authority into compliance while at the same time clarifying the relevant legal provisions for this state or authority (and for others). Preliminary rulings may support courts - and authorities - in the implementation of EU law by removing instances of confusion, but the intention is that these courts and authorities also act in compliance with such rulings. And while monitoring activities are an essential element of an effective enforcement strategy, they may lead to the production of interpretative guidance in view of apparent misunderstandings.

One may argue that a model is not a perfect depiction of reality - and that partial misfits should therefore not be considered to compromise its suitability as a tool for the classification of phenomena, in this case compliance instruments. However, if there are numerous misfits one must conclude that a model cannot constitute a credible tool for depicting reality. The idea that numerous misfits exist in the context of this study is clarified when other compliance instruments are considered. For both transnational networks and civil society activism, their prime purpose cannot be easily determined. Non-governmental organisations may apply pressure to national governments by acting as watchdogs, strengthen the capacity of authorities by providing knowledge and expertise, engage in both activities simultaneously, or shift their emphasis over time. Networked cooperation may socialise national officials into certain norms by facilitating social learning processes, and help officials improve their performances by enabling mutual learning and resource sharing. In these cases it is particularly difficult to identify the prime purpose of the relevant instruments.

capable of being categorised as belonging to (either of) those schools, in particular those of rationalism (preference-based accounts) and managerialism (state-based accounts). 
Note that the idea that the three logic of compliance theories fail to provide an adequate framework for categorising compliance instruments is not something that these logics should (or could) be blamed for. This is the case, since these logics are not intended to offer an encompassing framework for the classification of compliance instruments; rather, each of these logics speak to the underlying compliance problems and the solutions to such problems. In other words, while an attempt to classify compliance instruments by reference to these logics of compliance may seem natural at first sight, the fact that such an attempt fails is not a reflection of the validity of these models.

Models that come closer to being intended as classification tools do not seem to work well either. A prime example of such alternatives is the enforcement pyramid, which proposes that supervisory authorities resort to enforcement instruments only to coerce persistent non-compliers into compliance, after persuasion has been attempted. ${ }^{45}$ In the European context, a management-enforcement ladder has been envisaged; that is, a ladder featuring preventive capacity building and rule interpretation measures at the bottom, and monitoring and enforcement instruments at the top. ${ }^{46}$ Both models overlook the fact that in a multi-level governance system, ${ }^{47}$ compliance mechanisms may exist at several levels of governance. The Commission's activities as guardian of the treaties may fit into the logic of the enforcement pyramid and of the managementenforcement ladder - but transnational and national-level activities do not fit into these models.

In addition, the distinction between persuasive (or preventive) compliance instruments at the bottom of the pyramid (or ladder) and enforcing (or corrective) compliance instruments at the top is misleading; an idea that relates to the notions put forward at the beginning of this subsection. Infringement proceedings started by the Commission against noncomplying member states are aimed at correcting existing instances of compliance, but the prospect of negotiations with the Commission and the eventuality of financial sanctions being imposed may prevent member states from infringing EU law in the first place. Post-legislative guidance may aim to prevent member states from violating EU law provisions, but the interpretation of EU rules outlined therein may also correct existing instances of noncompliance. Financial inducements may be aimed at influencing actors who want, but are unable, to comply, but they may also provide incentives for countries to re-examine the costs of compliance. ${ }^{48}$ Put briefly, while instruments may, at first sight, appear to be aimed at sanctioning or correcting instances of noncompliance, closer examination suggests that they simultaneously have a persuasive or preventive effect - or vice versa.

\footnotetext{
${ }^{45}$ E.g. Ayres and Braithwaite, 1992.

${ }^{46}$ Tallberg, 2002.

${ }^{47}$ For an early contribution using the multi-level governance approach to analyse the EU, see Marks et al., 1996.

${ }^{48}$ For this latter point, see Mitchell, 1996: 21.
} 
The main typologies proposed in the policy-instrument literature do not seem to work either. One of these typologies proposes that government authorities exercise power to support and affect social change through three sorts of public policy instruments. ${ }^{49} \mathrm{Gov}$ ernments may adopt binding rules in order to influence people or administrative actors in the public sector (sticks); they may allocate subsidies or withdraw grants from them (carrots); or they may influence behaviour through the transfer of knowledge, the communication of reasoned argument, and persuasion (sermons). ${ }^{50}$ Governments may also combine several of these instruments. ${ }^{51}$ Then there is the NATO taxonomy of substantive and procedural public policy instruments. ${ }^{52}$ NATO is an acronym that sums up four basic resources "that governments tend to possess by virtue of being governments"; each of these resources give governments different capabilities of addressing public problems. ${ }^{53}$ These resources are information that governments, as central actors, possess (nodality); legal or official power to "demand, forbid, guarantee, adjudicate" (authority); money or other exchangeable resources (treasure); and formal arrangements, people, materials, and such available to government (organisations). ${ }^{54}$

Both models are problematic if used in the context of this study. First, the relevant typologies seem to address questions on policy-making, or more specifically: on the policy mixes that governments have at their disposal to achieve defined policy objectives (for example, less environmental pollution, safer consumer products, and safer airplanes). In particular, the aim of the relevant literature is to understand why policy makers utilise certain instruments, or why a particular combination of instruments is utilised in a specific sector. ${ }^{55}$ The relevant classifications do not focus on the specific options available to governments regarding policy implementation and compliance, or about implementation and compliance in a decentralised system such as the EU.

Second, the policy instruments proposed by these taxonomies are typically those that nation-state governments dispose of. An analysis of the policy tools available to the EU administration demonstrates that not all of these instruments exist at the EU level. The EU is constrained by budget appropriations; this is an issue that has limited the involvement of the Union in non-regulatory, direct-expenditure programs, and that has forced the Commission to expand the scope of its regulatory activities instead. ${ }^{56}$ The complexity of the policy sub-system - that is, the number and type of actors that the EU

\footnotetext{
${ }^{49}$ Bemelmans-Videc, 1998: 3.

${ }^{50}$ Ibid.: 11-12.

${ }^{51}$ Van der Doelen, 1998.

${ }^{52}$ For the NATO model on substantive policy instruments, see, initially, Hood, 1983, and more recently, Hood and Margetts, 2007. For the application of the NATO model to procedural policy instruments, see Howlett, 2000. For an overview of the different classifications of policy instruments in the literature over time, see Howlett, 2005.

${ }^{53}$ Hood and Margetts, 2007: 5; italics in original.

${ }^{54}$ Ibid.: 5-6.

${ }^{55}$ Howlett, 2005: 45-46.

${ }^{56}$ E.g. Majone, 1994.
} 
must affect in order to implement legislation - contributes to the flight of the Commission to regulation (and information). ${ }^{57}$ What all of this means is that 'carrots' and 'treasure' are not instruments that the EU has abundantly at its disposal to address implementation problems. ${ }^{58}$

Third, the focus of these models on tools that government authorities have at their disposal makes them ill-suited to capture the variety of compliance instruments covered in the current study - instruments that may be controlled by actors such as courts or civil society organisations instead of by government actors. In fact, national governments command none of the national-level compliance instruments included in this study (namely, case law and civil society activism). At the supranational level, European jurisprudence is not under the control of the European Commission; the Commission cannot force the Court to further its own interests. Overall then, while certainly useful in another context - for example if one is interested in the question of why national governments choose certain policy mixes to further their policy objectives at the expense of others $^{59}$ - these models do not work as structuring tools in the context of this study.

\subsection{A pragmatic approach: an actor-based typology of compliance instruments}

The message that the above section aims to transmit is clear: while the above referenced taxonomies may be helpful for understanding the choices that governments have or make in the public policy process (carrots, stick, and sermons; NATO); for guiding governments in their choice of how to induce the regulated into compliance (enforcement pyramid); for describing the Commission's resources in order to induce member states into compliance (management-enforcement ladder); or for understanding the different dynamics that compliance instruments may address (rationalism, management perspectives, and constructivism), neither of them seems suited to provide an adequate conceptual framework in the context of this study. Therefore, this study proposes an alternative categorisation of compliance instruments, along the lines set out in Figure 2.

\footnotetext{
${ }^{57}$ Howlett and Ramesh model policy instrument choice on the basis of an assessment of the level of state capacity to affect societal actors and policy subsystem complexity. While geared at policy instrument choice on the national level, their taxonomy seems an apt description of instrument choice in the EU. See Howlett and Ramesh, 2009.

${ }^{58}$ A main example of a 'carrot' is the instrument of EU conditionality, which is known in particular for its use in relation to the accession of states into the EU; see e.g. Schimmelfennig and Sedelmeier, 2005. Sverdrup qualifies the EU's ability to link issues or set conditions on implementation in one policy field for participation in other policy fields as 'positive incentives' as well. See Sverdrup, 2007: 203-204.

${ }^{59}$ For a criticism on the use of the instrument-choice approach to policy-making - and a call to venture into the domain of governance and governance strategies - see Part III in Eliadis et al., 2005.
} 


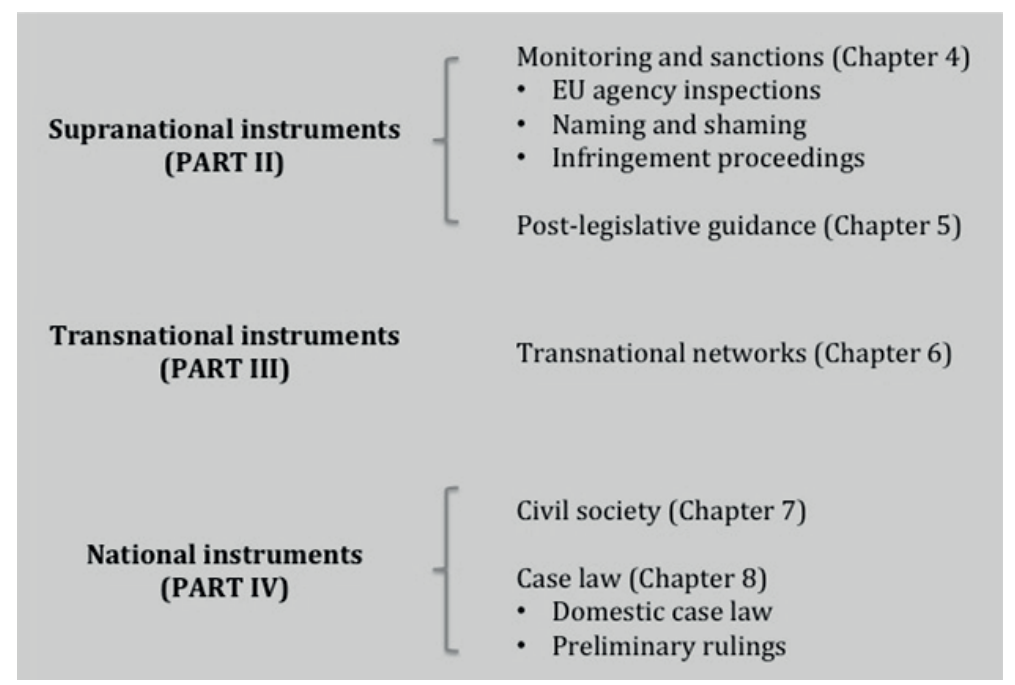

Figure 2 The categorisation of compliance instruments used in this study

The categorisation outlined in Figure 2 is based on an appreciation of the institutional context embedding the main actors involved in making the respective compliance instruments work. The starting point for this categorisation is, thus, not the institutional context in which these instruments are formally anchored, although both dimensions may overlap. For example, the initiation of monitoring activities, naming and shaming strategies, and infringement proceedings is clearly controlled by the European Commission acting as guardian of the treaties. Member states are involved in the relevant activities by virtue of their being subject to such activities, but they are not in control of them. ${ }^{60}$ Hence, the three instruments referred to are firmly anchored at the supranational level.

This is not the case for post-legislative guidance. Such guidance may be authored by the European Commission or by an EU agency, but it may also be authored by (the) member states acting in concert, or by the Commission - or an agency - and the member states together. The various ways in which guidance is developed in practice may make it difficult to decide whom the 'ownership rights' of guidance documents should pertain to. Such decisions are delicate affairs from a legal perspective, for reasons that Chapter 5 on post-legislative guidance clarifies. At this point - that is, when it comes to the classification of post-legislative guidance as a supranational, transnational, or national compliance instrument - a pragmatic approach suffices. Since the main authors of the guidance documents discussed in this study are considered the European Commission or an EU agency - all relevant guidance documents are published as Commission decisions, as executive decisions of an EU agency, or as Commission documents on

\footnotetext{
${ }^{60}$ At least not formally. How great the influence of member states on such instruments may be in practice becomes clear from Chapter 4 on monitoring and sanctions.
} 
the Commission's website - post-legislative guidance is considered a supranational compliance instrument.

What applies to guidance similarly applies to networks facilitating administrative cooperation amongst member states; such networks may be institutionally anchored at the supranational level or be established by member state authorities. The networks included in this study exemplify both variants. Important for their categorisation as transnational instruments, is that regardless of the institutional context in which they are anchored, networks thrive on the input provided by the network participants. Thus, even when formal control over the network lies with the European Commission or with an EU agency, the control of their functioning - their de facto control - lies with the member states acting in concert.

In view of the role of national courts as adjudicators in domestic legal disputes, the categorisation of national case law as a national-level instrument is not surprising. Regarding civil society activism, even though citizens and non-governmental organisations may 'take the European route' to try to improve the application of EU law by the national administration, they remain embedded in the national context. ${ }^{61}$ The choice to categorise the preliminary ruling mechanism as a national-level instrument is derived from the fact that national courts are prime actors for making this instrument work; the CJEU would not deliver preliminary rulings if national courts did not submit requests. The fact that the TFEU requires national courts, against whose decision there is no judicial remedy under national law, to take recourse to the CJEU when questions on interpretation are raised, further underlines the essential role of national courts in the system. ${ }^{62}$

The advantage of the actor-based typology outlined above is not only that it allows us to eliminate the conceptual difficulties associated with alternative taxonomies. Since it does not associate certain instruments with pre-fixed benefits and drawbacks, it also allows us to study the functioning of individual compliance instruments with an open mind. This does not mean that theory is absent. The previous chapter has sketched the theoretical background of this study. Moreover, note that while the actor-based categorisation of compliance instruments forms the structure of this study, each empirical chapter starts with a theoretical reflection on why the compliance instrument(s) addressed in that particular chapter may be expected to work to make EU law work better. In addition, the concluding chapter discusses the implications of the empirical findings of this study for (EU) implementation research. Thus, while theory may not be a strong guiding force, concepts, models, and theories relevant to EU implementation research are certainly indispensable reference points.

\footnotetext{
${ }^{61}$ See Section 1 of this chapter.

${ }^{62}$ This requirement is outlined in Article 267 TFEU. See Chapter 8 on case law, Section 1.1.2.
} 


\section{Methodology}

In view of its aim to assess the usefulness of compliance instruments for supporting national competent authorities in the application of EU law, this study could be considered to belong to the realm of evaluation studies. Note that this study does not aim to conduct an effectiveness evaluation; its purpose is not to examine the extent to which compliance instruments have contributed to a better application of EU law on the ground. Establishing causal relationships is not possible since it is - as we may recall from the previous chapter ${ }^{63}$ - difficult to verify the status of application of EU law in the member states. The interrelationships amongst compliance instruments, and the difficulty of isolating such instruments from other - circumstantial - factors that exercise an influence in the implementation process, make it hard to establish causal relationships as well.

The focus of this study on the functioning of compliance instruments in terms of their usefulness for supporting the application of EU law implies that this study aims to conduct research that is similar to an organisational evaluation. ${ }^{64}$ This evaluation seems to be conducted most effectively using a combination of legal and political science methods; this is a necessity given the research question and the varied nature of the compliance instruments included in this study. In order to arrive at a sound and indepth picture of the usefulness of compliance instruments, this study uses a case-study methodology involving three EU directives and three EU member states. The following subsections elaborate on the choices that were made in the selection of case studies and in the use of sources, particularly in relation to the use of interviews as tools to assess the usefulness of compliance instruments.

\subsection{Case studies}

This study uses a case-study method to analyse the functioning and usefulness of compliance instruments. The case-study method has been subject to criticism, in particular on the part of proponents of large- $N$, or statistical, studies. A predominant point of criticism relates to the incapability of case studies to constitute a basis for valid generalisation; this makes case studies a somewhat ambiguous method, one has argued, since scientific research is eventually "all about generalization". ${ }^{65}$ Next to the questionable validity of the presumption that case studies are by definition not able to produce generalisable results, is the misguided belief that the only aim of scientific research is, or should be, generalisation. The creation of knowledge is not preconditioned on generalisation; "[ $[$ ]hat knowledge cannot be formally generalised does not mean that it cannot

\footnotetext{
${ }^{63}$ See Chapter 2 on implementation in the EU: same rules, divergent practices, Section 3.1.

${ }^{64}$ Leeuw, 2011.

${ }^{65}$ Lijphart, 1971: 691.
} 
enter into the collective process of knowledge accumulation in a given field or in a society" ${ }^{66}$ In other words, when carried out adequately, case-study research may make a valuable contribution to science.

Depending on the researcher's question of interest, case studies may even be preferable to large- $N$ studies, since they may provide insights that large- $N$ studies are not capable of providing. Certainly, the latter have the advantage of incorporating a large number of cases, which may allow them to identify whether a hypothesis is true. However, large- $N$ studies are not capable of providing insight into why that hypothesis is true or not. ${ }^{67}$ The notion that the current study is interested in answering the latter question, explains why this study opts for few cases for detailed qualitative analysis, rather than for many instances for statistical analysis.

The selection of cases included in this study has been guided by the fact that the focus of this study is not on theory building or theory testing, but on the case - the usefulness of compliance instruments - per se. This does not mean that this study is void of theoretical reflections; as Chapter 2 shows and the following chapters of this thesis demonstrate, this study makes explicit use of theory in order to provide insight into the cases included herein. In fact, this study is possible only with reference to existing theories on implementation and compliance and concepts relevant to the compliance instruments examined. In view of these considerations, this study may be seen as a study in applied science and as taking an interpretative approach to case studies. ${ }^{68}$

Analysing the usefulness of compliance instruments for supporting the application of EU law by the national competent authorities of the member states requires one to select EU measures and member states. With more than 6,100 regulations and over 1,800 directives in force in a Union with 27 member states at the time of the case selection, ${ }^{69}$ the case selection possibilities were endless. Eventually, three directives and three countries were chosen for study.

\subsubsection{The selection of directives}

The rationale underlying the choice of regulations instead of directives, is that it is interesting to examine the usefulness of compliance instruments in situations with significant inter-country variation in implementation practices; if compliance instruments have the ability to effectively support the application of EU measures in situations of great diversity, they are expected to have a positive effect in situations without this diversity as well. The reverse is less likely to hold true. As inter-country variation in im-

\footnotetext{
${ }^{66}$ Flyvberg, 2001: 76.

${ }^{67}$ See Van Evera 1997: 55.

${ }^{68}$ Lijphart, 1971: 691-692.

${ }^{69}$ For these numbers, see Commission, '2 $7^{\text {th }}$ Annual report on monitoring the application of EU law' (Report) COM (2010) 538 final, p. 2. The case selection was conducted in 2010, when Croatia was not yet an EU member state.
} 
plementation practices tends to be greater in situations where member states are given room to manoeuvre, than in situations where this is not the case, directives enter the picture as more interesting objects of study than regulations. Indeed, whereas regulations are adopted with the aim of limiting room for inter-country variation in their application, directives are intended to be mechanisms of flexibility. The generally technical, detailed nature of regulations and the idea that regulations do not exist in all policy domains explain the choice of directives as well. Note that the term 'directive' refers to Council (and Parliament) directives, not to directives adopted by the Commission on the basis of its implementing powers. Such directives 'merely' amend or supplement parent legislation; therefore, they do not fall within the scope of interest of this study. This does not mean that they do not enter the picture at all; they are referred to where relevant.

The selection of directives was guided by three criteria. First, in order to ensure the feasibility of comparing the usefulness of instruments across directives, an attempt was made to include directives that score positively on the variety of instruments selected for study. Note that the compliance instruments relevant at this stage of the case selection process are only those of a supranational and transnational nature. Second, since existing studies focusing on cross-sectoral policy issues are relatively few, ${ }^{70}$ and in order to increase the generalisability of the results of this study, an effort was made to select directives from different policy areas, including those that are studied less frequently in EU implementation studies. ${ }^{71}$ Third, in order to increase the wider relevance of this study, the objective of these directives must be societally relevant and not too obscure.

Based on these criteria, the directives selected for study are the Directive on general product safety (Directive 2011/95/EC; hereafter referred to as GPS Directive); ${ }^{72}$ the Directive on integrated pollution prevention and control (Directive 96/61/EC, as replaced by Directive 2008/1/EC; IPPC Directive); ${ }^{73}$ and the Directive on the safety of thirdcountry aircraft using Community airports (Directive 2004/36 EC; SAFA Directive). ${ }^{74}$

\footnotetext{
${ }^{70}$ For the idea that this is still the case, see Treib, 2014: 16-17.

${ }^{71}$ Toshkov et al. (2010) point out that the social policy sector accounts for half of all cases analysed in the literature. The environmental domain accounts for 30\%; the field of transport and communications and the domain of internal market for less than $10 \%$ each; and the domains of energy and agriculture for less than $5 \%$ each. Figures calculated on the basis of the data provided in Toshkov, 2010: 12.

${ }^{72}$ Directive 2001/95/EC of the European Parliament and of the Council of 3 December 2001 on general product safety, [2001] OJ L 11/4. Note that this directive is supposed to be replaced by a regulation, which is now being negotiated in Council and Parliament.

${ }^{73}$ Council Directive 96/61/EC of 24 September 1996 on integrated pollution prevention and control [1996] OJ L 257/26, and its successor, Directive 2008/1/EC of the European Parliament and of the Council of 15 January 2008 concerning integrated pollution prevention and control (codified version) OJ, L 24/8. Note that this Directive has been replaced by Directive 2010/75/EU of the European Parliament and of the Council of 24 November 2010 on industrial emissions (integrated pollution prevention and control) [2010] OJ L 334/17. This fact does not detract from the usefulness of the analysis presented here, in particular since the main obligations for member states have remained the same.

${ }^{74}$ Directive 2004/36/EC of the European Parliament and of the Council of 21 April 2004 on the safety of thirdcountry aircraft using Community airports [2004] OJ L 143/76 (consolidated version) Note that this directive
} 
These directives regulate different policy issues that are all relevant for EU citizens, as the following subsections show. Table 4 shows that all compliance instruments at the supranational and transnational level are present in the context of all three directives, save two: inspections carried out by an EU agency, and infringement proceedings started for 'bad application'.

Table 4 The presence of compliance instruments across the selected directives

\begin{tabular}{llccc}
\hline & & GPS & IPPC & SAFA \\
\hline Supranational level & Commission monitoring & + & + & + \\
& EU agency inspections & - & - & + \\
& Naming and shaming & + & + & + \\
Transnational level & Transnational networks & + & + & + \\
\hline
\end{tabular}

While some of these instruments are generally applicable compliance instruments (the infringement procedure is an example of this), others (for instance, particular networks) may only serve to support member states in the application of certain legal provisions. It is for this latter reason that it is only these provisions - which happen to be the core provisions of the directives at stake - that this study focuses on. It is also for this reason that the following subsections focus on these core provisions.

\subsubsection{The GPS Directive}

The Directive on general product safety was adopted with a twofold aim: to improve the functioning of the internal market, and to ensure a high level of consumer health and safety protection. ${ }^{76}$ The specific purpose of the directive is to ensure that products placed on the market are safe. ${ }^{77}$ To this end, it lays down a general safety requirement stipulating that producers must be obliged to place only safe products on the market. ${ }^{78}$ This general safety requirement applies to all products made available in the course of a commercial activity and intended for consumers or likely to be used by them..$^{79}$ It applies

was repealed by Regulation (EC) 216/2008, upon entry into force of the implementing rules adopted by the Commission under this regulation. The relevant rules were adopted by the end of 2012 and became generally applicable at the end of 2014 .

${ }^{75}$ Assessment of actual proceedings started for 'bad application', based on available information. For details, see Chapter 4 on monitoring and sanctions, Section 2.3.

${ }^{76}$ Directive 2001/95/EC, considerations 2 and 4.

${ }^{77}$ Ibid., Art. 1.

${ }^{78}$ Ibid., Art. 3.

${ }^{79}$ Ibid., Arts 1(2), first indent, and 2(a) 
only insofar as there are no specific EU law provisions with the same objective or, where such provisions do exist, only to those aspects that are not covered by those rules. ${ }^{80}$

The GPS Directive requires member states to ensure that producers and distributors place only safe products on the market. ${ }^{81}$ To this end, they must establish or appoint the authorities that are competent to monitor the compliance of products with the general safety requirement and arrange for such authorities to have and use the necessary powers to take, inter alia, the appropriate investigative and corrective measures incumbent upon them under the directive. ${ }^{82}$ Competent authorities must organise inspections to check the safety of products placed on the market, they must demand all of the necessary information from the parties concerned, and they must take samples of products and submit them for safety checks. ${ }^{83}$ For products that do not to comply with the general safety requirement, competent authorities may, depending on the type of risk at issue, impose labelling requirements, require that products are made safe before they are put on the market, temporarily ban the supply of products, and order or organise the immediate withdrawal or recall of products and their destruction. ${ }^{84}$ All measures must be proportional to the seriousness of the risk. ${ }^{85}$ They must be adopted taking due account of the precautionary principle. ${ }^{86}$

As far as the GPS Directive is concerned, the focus of the empirical analysis is on the following question: how useful are the compliance instruments that exist in the context of the GPS Directive for supporting the competent authorities of the member states in carrying out market surveillance for non-food consumer products covered by the directive? Note that the notion of market surveillance covers the implementation of inspections, the assessment and evaluation of the safety of products, and the adoption of corrective measures in relation to noncomplying business operators.

\subsubsection{The IPPC Directive}

Considered "the core of EU pollution control law", 87 the IPPC Directive aims to achieve "a high level of protection for the environment as a whole". ${ }^{88}$ To this end, it purports to achieve integrated pollution prevention and control arising from activities of industrial and agricultural installations. It does this by outlining measures designed to prevent or,

\footnotetext{
${ }^{80}$ Ibid., Art. 1(2).

${ }^{81}$ Ibid., Art. 6(1).

${ }^{82}$ Ibid., Art 6(2) and 8(1).

${ }^{83}$ Ibid., Art. 8(1)(a).

${ }^{84}$ Ibid., Art. 8(1)(b)-(f).

${ }^{85}$ Ibid., Art. 8(2).

${ }^{86}$ Ibid.

${ }^{87}$ Lange, 2008: 11.

${ }^{88}$ Directive 2008/1/EC, consideration 10.
} 
if that is not possible, reduce emissions from industrial activities into air, water, and soil. ${ }^{89}$

Member states must ensure that large industrial installations comply with a range of general principles for the prevention and control of pollution..$^{90}$ These general principles must be complied with in permits issued by the competent authorities to installations. ${ }^{91}$ Such permits must include emission limit values - possibly supplemented or replaced by equivalent parameters or technical measures - that are based on the best available techniques (BAT), ${ }^{92}$ unless environmental quality standards require stricter measures than those achievable by BAT. ${ }^{93}$ BAT are those techniques that are most effective in achieving a high level of protection of the environment as a whole. ${ }^{94}$ They must be developed on a scale that allows implementation in the relevant industrial sector, taking into consideration the costs and the advantages. ${ }^{95}$ Permits must consider the technical characteristics of the installation concerned, its geographical location, the local environmental conditions, ${ }^{96}$ and twelve other specific factors, including the reference documents on BAT adopted by the Commission for types of industrial activities. ${ }^{97}$

As far as the IPPC Directive is concerned, the focus of the empirical analysis is on the following question: how useful are the compliance instruments identified in the context of the IPPC Directive for supporting the competent authorities of the member states in deliberations and decisions about the application of the best available techniques in permits for IPPC installations? ${ }^{98}$

\subsubsection{The SAFA Directive}

The SAFA Directive aims to "establish and maintain a high uniform level of civil aviation safety in Europe" ${ }^{99}$ Its purpose is to outline a common approach to the effective enforcement of international safety standards within the EU, by harmonizing the rules and procedures for ramp inspections of third-country aircrafts landing at airports located in the member states. ${ }^{100}$ The notion of 'third-country aircraft' refers to an aircraft that

\footnotetext{
${ }^{89}$ Ibid., Art. 1.

${ }^{90}$ Ibid., Art. 3.

${ }^{91}$ Ibid., Art. 9(1).

${ }^{92}$ Ibid., Art. 9(3) and (4).

${ }^{93}$ Ibid., Art. 10.

${ }^{94}$ Ibid., Art. 2(12), sub c.

${ }^{95}$ Ibid., Art. 2(12), sub b.

${ }^{96}$ Ibid., Art. 9(4).

${ }^{97}$ Ibid., Annex IV.

${ }^{98}$ Note again that the IPPC Directive has been superseded by the Directive on industrial emissions. The analysis presented in this study will exclusively concern the IPPC Directive, unless indicated otherwise. This is the case, since the IED entered into force in January 2013 only, and the bulk of the empirical research was carried out before this date.

${ }^{99}$ Directive 2004/36/EC, consideration 4.

${ }^{100}$ Ibid., Art. 1(1).
} 
is not used or operated under the control of a competent authority of a member state. ${ }^{101}$ The term 'international safety standards' refers to the minimum standards and recommended practices for international civil aviation set under the 1944 Convention on International Civil Aviation ('the Chicago Convention').

The basic obligation for member states under this directive is to establish the appropriate means of ensuring that third-country aircrafts suspected of noncompliance with international safety standards are subject to ramp inspections. ${ }^{102}$ When particular suspicions are absent, member states may outline rules for conducting ramp inspections in accordance with a spot-check procedure complying with international and European law. ${ }^{103}$ In both cases, they need to comply with the ramp inspection procedures outlined in the directive, and they must use a ramp inspection report containing at least the items described therein. ${ }^{104}$ The directive also contains provisions for the qualification of inspectors, and instructions on the items to be checked and the follow-up actions. ${ }^{105}$ Checks include the presence of aircraft documents and manuals that should be carried in the cockpit, the presence and condition of mandatory cabin safety equipment, flight crew licenses, cargo carried in the aircraft, and the apparent condition of the aircraft. ${ }^{106}$ Follow-up actions may range from a verbal debriefing to the aircraft crew, to grounding of the aircraft. ${ }^{107}$ Inspection reports must be filed into the centralised database managed by the European Aviation Safety Agency (EASA), ${ }^{108}$ which is accessible to all national competent authorities.

As far as the SAFA Directive is concerned, the focus of the empirical analysis is on the following question: how useful are the compliance instruments identified in the context of the SAFA Directive for supporting the competent authorities of the member states in carrying out SAFA ramp inspections? ${ }^{109}$

\footnotetext{
${ }^{101}$ Ibid., Article 2(d). Strictly speaking, the directive thus requires that the national aviation authorities carry out ramp inspections regarding operators from non-EU states. However, NAAs do not only inspect thirdcountry aircrafts; about $50 \%$ of the inspections are done on aircrafts operated by EU (i.e. not 'foreign') operators. This means that the name 'SAFA' does not reflect the reality of inspections on the ground. To better reflect the nature of inspections conducted, the new implementing rules introduce the term 'SACA', which stands for Safety Assessment of Community Aircraft.

${ }^{102}$ Ibid., Article 4 (emphasis added).

${ }^{103}$ Ibid., Article 4(2).

${ }^{104}$ Ibid., Article 4(4), in conjunction with Annex II of the Directive.

${ }^{105}$ Ibid., Annex II.

${ }^{106}$ See the template SAFA Ramp Inspection Report, outlined in Appendix I of the Directive.

${ }^{107}$ Directive 2004/36/EC, Annex II.

${ }^{108}$ Commission Regulation (EC) No 768/2006 of 19 May 2006 implementing Directive 2004/36/EC of the European Parliament and of the Council as regards the collection and exchange of information on the safety of aircraft using Community airports and the management of the information system [2006] OJ L 134/16, Art. 3.

${ }^{109}$ Note again that the SAFA Directive has been superseded by the implementing rules. The analysis presented in this study will exclusively concern the SAFA Directive. This is the case, since application of the implementing rules became a matter of obligation for member states in autumn 2014 only, and the empirical research was carried out before this date.
} 


\subsubsection{The selection of member states}

The selection of member states included in this study has been guided by the idea, common in EU implementation studies, that member states face different problems in the application of EU law. If this is true, then the solutions that are needed to solve compliance problems throughout the Union must be diverse as well - if they are to constitute appropriate responses to such problems. In line with the concomitant notion that a one-size-fits-all approach to compliance problems is unlikely to work to make EU law work, one may expect perceptions of the usefulness of existing compliance instruments to vary across member states. Thus, if one wants to gain insight into what works to improve the application of EU law across member states, one must select countries that are known to face different problems in the application of EU law.

The worlds of compliance typology proposed by Falkner et al. seems an appropriate guideline for selecting member states in the context of the current study. ${ }^{110}$ Although this typology has been criticised in several ways, it has simultaneously been referred to by the relevant critics - as having made great advances in the domain of EU implementation studies. ${ }^{111}$ It has done this by integrating previously detected variables into a single model and including 'old' and 'new' member states. Since this model is the most likely to explain variation in implementation patterns across a great number of member states, the choice was made to select the countries included in this study on the basis of their categorisation into different worlds of compliance.

As referred to previously, the worlds of compliance typology categorises member states based on dominant implementation patterns and outlines the main problems faced by countries in the different worlds of compliance. One may recall that countries categorised as belonging to the world of law observance or the world of domestic politics are thought to have few problems in the application of EU law; both have effective administrative and court systems that ensure smooth application. Countries that are thought to belong to the world of transposition neglect are evaluated as scoring mixed in this regard; whether such countries encounter problems at the application stage depends on whether domestic conditions are fit for application. Countries clustered in the world of dead letters are considered the worst performers for process patterns at the application stage, with noncompliance at this stage referred to as rather systematic. ${ }^{112}$

Practical constraints resulted in the selection of three member states out of these four worlds of compliance. Since compliance instruments are thought to prevent or correct problems experienced at the application stage, the choice was made to compare the usefulness of such instruments for two countries that are diagnosed as facing major

\footnotetext{
${ }^{110}$ Treib, 2014: 16. For an elaboration on the worlds of compliance typology, see Chapter 1 on making EU law work: a problem in need of a solution, Section 3.2.2.1. This study makes use of the most recent version, as in Falkner and Treib, 2008.

${ }^{111}$ E.g. Toshkov, 2007a; Thomson, 2007.

${ }^{112}$ Falkner and Treib, 2008.
} 
hurdles in the application process and for one country where such problems are thought to be generally absent. This implies a need to select one country belonging to either the world of law observance - which encompasses Denmark, Finland and Sweden - or the world of domestic politics - which includes Austria, Belgium, Germany, the Netherlands, Spain, and the United Kingdom. This is the case since, as elaborated on above, countries belonging to either world are said to be effective performers when it comes to the application of EU directives in practice. Given the necessity to conduct a thorough preliminary assessment of the directives and the compliance instruments included in this study - an assessment that is done more effectively in a context in which relatively easy access is gained to national officials involved in the issue at stake - the choice was made to select the country in which the research was conducted. This country is the Netherlands.

From the world of transposition neglect - which comprises France, Greece, Luxembourg, and Portugal - Portugal was selected for study for the following reasons. In contrast to France and Luxembourg, Portugal and Greece have faced many problems in the process of applying EU law. ${ }^{113}$ This makes both of them interesting cases to study regarding the extent that existing compliance instruments are experienced as helpful for improving application. Greece, however, would have been difficult to research given the specific circumstances that the country is involved in. This appeared to be less the case for Portugal. It is for this reason - the feasibility for the researcher to carry out empirical research - that Portugal was the optimal choice in the context of this research. Another reason that Portugal was included in our study is that in comparison with France and Greece, Portugal has been studied relatively little by EU implementation scholars who have conducted qualitative studies. Only Luxembourg accounts for the same number of studies as Portugal ${ }^{114}$ - but Luxembourg was not, as stated above, considered eligible for selection because of its alleged relatively good performance during the application phase of the implementation process. ${ }^{115}$

The final country selected for study is Poland. Those who are familiar with the details of the worlds of compliance typology will note that Poland is not included in any of the worlds of compliance. Indeed, the final world - the world of dead letters - is made up of Ireland, Italy, the Czech Republic, Hungary, Slovakia and Slovenia. However, Poland shares many characteristics with the other post-communist states included in this fourth world. These include the prevailing weakness of civil society, ${ }^{116}$ the questionable capacity of the state to ensure compliance, ${ }^{117}$ and shortcomings in the court system.

\footnotetext{
${ }^{113}$ Leiber, 2007: 352. On capacity limitations of Portugal in the environmental domain, see e.g. Börzel, 2002.

${ }^{114}$ At least at the time of the case selection; see Toshkov et al., 2010: 13.

${ }^{115}$ Data show that out of the countries against which the European Commission started formal infringement proceedings, Portugal does, in contrast to Luxembourg, stand out with a rather high share of bad application cases. See Angelova et al., 2012: 1282.

${ }^{116}$ Sissenich, 2007.

117 Goetz, 2005: 276.
} 
Shortcomings of the latter type are visible from the low level of litigation in administrative cases, the relatively little training for judges, the limited budgetary resources allocated to courts, and the comparatively negative perceptions of judicial independence. ${ }^{118}$ Given these shared characteristics, Poland is assumed to be a good representative of the relevant world of compliance. The relatively large size of the country and the weight that it has in the EU make it an interesting case, compared to smaller states such as the Netherlands and Portugal. Assured that access to relevant Polish officials could be gained, the choice was made to include Poland as the third country in our study.

\subsection{Sources}

The previous paragraph explains the choice for case studies as motivated by the aim of this study to acquire in-depth insight into the usefulness of compliance instruments. In view of the fact that the cases could not be researched without reference to existing theoretical and conceptual frameworks, the relevant academic literature on implementation and compliance constitutes an important secondary source of information in the context of this study. Primary sources consulted in this study concern EU measures, including the three relevant directives and the relevant amending or tertiary measures, and (transposing) measures adopted in the three countries included in this study. EU and national policy documents and research reports on the implementation of the three directives were consulted as well. This also applies to European and national case law. Regarding the former, case law issued by the CJEU in the course of infringement proceedings started by the European Commission, preliminary rulings on the three directives included in this study, and rulings that must be studied to understand the legal framework that applies to the implementation of directives were consulted. Where relevant, case law issued by administrative courts in the Netherlands, Poland, and Portugal was examined as well. Chapter 4 on monitoring and sanctions elaborates on the selection of case law issued in the course of infringement proceedings. Chapter 8 on case law explains the selection of national case law and of preliminary rulings issued by the CJEU.

The sources referred to above are complemented by a survey (77 completed surveys) and elite interviews (91 interviewed persons). The survey was conducted primarily to triangulate the views of national officials expressed through the interviews conducted for this study. Elite interviewing is an indispensable research technique, in view of the interest of this research, for acquiring insight into the preferences and beliefs of actors. This interest is derived from awareness that it is impossible to measure the effect of compliance instruments objectively, by establishing causal relationships between individual compliance instruments and (improved) application practices. ${ }^{119}$ While research-

\footnotetext{
${ }^{118}$ Commission, 'The EU Justice Scoreboard. A tool to promote effective justice and growth' (Communication) COM (2013) 160 final, pp. 11, 18, 19, 21.

${ }^{119}$ See Chapter 1 on making EU law work: a problem in need of a solution, Section 3, and Chapter 2 on im-
} 
ers who use preferences and beliefs as tools to assess phenomena face challenges, preferences and beliefs are simultaneously recognised as valuable for understanding phenomena - at least if they are studied empirically and on the basis of elite interviews. ${ }^{120}$ Since the way in which the method of elite interviewing is put into practice requires some explanation, the remainder of this chapter centres on clarifying the choices that were made in this regard. It does so after elucidating how the survey was developed and conducted, and after explaining how the survey results are incorporated into the empirical chapters.

\subsubsection{Survey}

The purpose of the survey was, as stated in the previous subsection, to triangulate the views expressed by the national officials interviewed for this study. With this aim in mind, the survey questions focused on determining whether officials are familiar with the compliance instruments pre-selected for this study, whether they use these instruments regularly, and how helpful officials think these instruments are for supporting them in the application of the core provisions of the directives. The first question was to be answered by ticking 'yes' or 'no'. The second question was to be answered on a gradient scale including five options, from 'strongly disagree' to 'strongly agree'. The frequency of the use of certain instruments was measured specifically by asking respondents to indicate pre-set time intervals for their use (for example, 'every day', 'several times a week', or 'several times a year'). The third question was to be answered on the same gradient scale. Respondents were also asked, through an open question, why the relevant compliance instruments are useful. Finally, they were given the opportunity to comment on what they think is needed to further support the application of the relevant legal provisions in their country and in other member states. ${ }^{121}$

The survey was circulated amongst national authorities from all member states involved in the administration of the three directives subject to this study. The authorities that were targeted were, when possible, the relevant national ministries and authorities responsible for the administration of the rules on the ground. Contacts were established through email, on the basis of contact information obtained from the website of the European Commission (in particular, from public documents indicating the participation of national authorities in committee meetings or implementation networks) and through information requests to the European Commission. ${ }^{122}$ Seventy-seven complete

\footnotetext{
plementation in the EU: same rules, divergent practices, Section 1.1.

${ }^{120}$ For an elaboration on the use of preferences and beliefs as tools to assess phenomena, see Chapter 1 on making EU law work: a problem in need of a solution, Section 3.

${ }^{121}$ In view of the length of the questionnaires, they are not included in this study. The questionnaires are available from the author upon request.

${ }^{122}$ For the numbers of surveys sent out, see Table 5.
} 
responses were received; 40 for the GPS Directive, 30 for the IPPC Directive, and 7 for the SAFA Directive. ${ }^{123}$

All complete survey responses were analysed on an aggregated level, taking into account all survey responses for a particular directive; where possible, the analysis differentiated respondents based on the position that they occupy. Two groups were deemed relevant in this regard: policy officials and officials involved in the administration of the relevant rules on the ground ('street-level actors'). This differentiation was motivated by the assumption that the views of these two groups on the usefulness of compliance instruments differ, and by our interest in finding out if this is the case. ${ }^{124}$ Note that officials could occupy more than one position, meaning that they may be involved both in policy-making or policy management tasks, ${ }^{125}$ and in street-level implementation practices. When this was the case, respondents were categorised as streetlevel actors. Table 5 shows the numbers yielded by this way of differentiation.

The survey results are incorporated in this study as text boxes, which are inserted in the third sections of the empirical chapters. They are compared with the results obtained through the interviews conducted for this study in the main text of the same sections, and briefly reflected on in the concluding section of each chapter.

Table $5 N$. surveys sent out, responded to, and completed

\begin{tabular}{|c|c|c|c|}
\hline & $N$. surveys sent out ${ }^{126}$ & $N$. responses ${ }^{127}$ & $N$. complete responses \\
\hline \multicolumn{4}{|l|}{ GPS } \\
\hline total & 130 & 50 & 40 \\
\hline of which market surveillance inspectors & N.A. & N.A. & 22 \\
\hline \multicolumn{4}{|l|}{ IPPC } \\
\hline total & 83 & 46 & 30 \\
\hline of which permit writers & N.A. & N.A. & 15 \\
\hline \multicolumn{4}{|l|}{ SAFA } \\
\hline total & 27 & 13 & 7 \\
\hline of which SAFA inspectors & N.A. & N.A. & 5 \\
\hline
\end{tabular}

\footnotetext{
${ }^{123}$ The number for the SAFA Directive could be explained in part by the fact that the SAFA national coordinators, of which there is one per member state, were targeted.

${ }^{124}$ See also Section 4.2.2.1 below on the definition of the target population for elite interviewing.

${ }^{125}$ Or in other tasks that are not street-level implementation tasks.

${ }^{126}$ Note that the position of survey recipients was not always clear from the contact details obtained; this is why officials were asked to clarify their position at the end of the survey.

${ }^{127}$ Note that since survey respondents were to indicate their position at the end of the survey, the proportion street-level actors/others cannot be ascertained at this point.
} 


\subsubsection{Elite interviews}

The last section of this chapter turns to the approach to elite interviewing as a research technique. The focus is, subsequently, on the definition of the target group; the selection of interviewees; and the completion, processing, analysis, and validation of interviews.

\subsubsection{The definition of the target population}

Conducting elite interviews involves, as described in Chapter $1,{ }^{128}$ conducting interviews with actors who are experts on the topic at hand. Experts were sampled based on an initial idea of the target population. ${ }^{129}$ In view of the research question, this target population was comprised of national officials involved in the application of the three directives in this study. Officials from the European Commission and from EU agencies were targeted as well, since some of the compliance instruments included in this study are managed by the Commission or an agency. Moreover, regardless of whether or not compliance instruments are 'owned' by the Commission, the Commission has a stake in the implementation of EU law and may be expected to have a view on the usefulness of compliance instruments other than those under its control. While civil society is considered an instrument that may support the application of EU law, civil society is - in contrast to other compliance instruments - not mute. Since the views held by representatives of non-governmental organisations complement the views of national and EU officials, regarding the functioning of civil society and the application performances of member states, the former were considered to belong to the target group as well.

The target population provided the basis on which the relevant sampling frame was developed. ${ }^{130}$ Decisions on the selection of national officials were based on the assumption that 'position matters'; that is, on the idea that the position that officials occupy in the application context greatly determines their perspective on the usefulness of compliance instruments. For example, it was assumed that perceptions on the usefulness of instruments held by policy officials may differ from views held by street-level actors, that is, those officials that are responsible for conducting market surveillance, inspecting airplanes, and deciding on permit conditions on the ground. Therefore, this study sought to include officials from both the relevant national ministries and from the agencies that are competent to apply the relevant EU law provisions to concrete situations on the ground. The particular interest of this study in the preferences of street-level actors it is these actors who are tasked with the daily administration of the law in practice implies that the emphasis was on those same actors.

Where the responsibility for the application of a directive pertains to subnational agencies or where it is shared between a central agency and regional agencies, a number

\footnotetext{
${ }^{128}$ See Chapter 1 on making EU law work: a problem in need of a solution, Section 3.

${ }^{129}$ Goldstein, 2002: 671 .

${ }^{130}$ Ibid.
} 
of regions were selected for study. Attempts were made to select regions that are expected to have different experiences in the application of the three directives included in this study, for example because of their geographical location and/or the distribution of the regulated entities within that particular region. The selection of regions in the Netherlands was based on the assessment of the researcher. For Poland, suggestions received during preliminary interviews were helpful in this regard. Given the absence of administrative regions in Portugal, ${ }^{131}$ this issue does not play a role in this country.

\subsubsection{The selection of interviewees}

Dutch national officials were primarily sampled by direct contact with the relevant persons. Relatively few officials were contacted on the basis of suggestions by other interviewees ('snowball sampling'). ${ }^{132}$ Snowball sampling was, however, the primary method for approaching officials in Poland and Portugal. In the case of Poland, an initial contact in the European Commission was of great help in establishing contacts with the Foreign Ministry and the Office of Competition and Consumer Protection. Most interviewees were sampled on the basis of suggestions of the relevant officials in these institutions. In the case of Portugal, contacts in the Portuguese Permanent Representation were valuable for forging links with the relevant authorities in all three policy areas included in this study. The relevant EU officials were contacted directly or by suggestion from national and other EU civil servants. In order to prevent biased samples, representatives from national non-governmental organisations were not, when possible, sampled based on suggestions of civil servants; rather they were sampled on the basis of research and suggestions of representatives from other NGOs.

In order to reduce the idiosyncrasies that interviews may display, triangulation between respondents was attempted. In the context of this study, a condition for triangulation was the inclusion of several interviewees from individual organisations, where relevant. ${ }^{133}$ As scheduling and completing interviews always involves "a fair bit of luck", ${ }^{134}$ it was not feasible to interview all of the respondents targeted. An interview with an official from the Polish Ministry of Transport was cancelled due to personal circumstances on the part of the official. An official from the Polish Office of Competition and Consumer Protection refused to support this research because of resource limitations in the authority. Officials from the Portuguese Ministry of Transport stated that for reasons of administrative restructuring, the relevant knowledge was not available at the ministry. While the refusal of the official from the Polish Office of Competi-

\footnotetext{
${ }^{131}$ While administrative regions are foreseen in the Portuguese Constitution, they have never been established. 132 Goldstein, 2002: 671.

${ }^{133}$ As far as the interviews are concerned. Triangulation was also attempted through the survey carried out for this study and by counter-checking facts with other sources (namely, national and EU case law, policy documents, and literature) where possible.

${ }^{134}$ Goldstein, 2002: 671.
} 
tion and Consumer Protection was compensated for by interviewing a colleague with considerable experience in the product safety domain in the recent past, such compensation did not work in the other two cases mentioned.

Table 6 lists the authorities and other entities that were interviewed for this study. In total, 91 persons were interviewed. The complete list of interviewees and the names of the authorities in the original language versions are included in Annex II. Interviewees were guaranteed anonymity; their identities are available upon request.

Table 6 Interviewed entities

Interviewed authorities (number of interviewees)

\section{Netherlands}

GPS

Ministry of Health, Welfare and Sport (1)

Netherlands Food and Consumer Product Safety Authority (6)

Consumer association (1)

Business association (1)

IPPC

Ministry of Infrastructure and the Environment (2)

Inspectorate of the Ministry of Housing, Spatial Planning, and the Environment (1)

Environmental knowledge centre InfoMil (4)

Three provincial administrations (5)

One Environmental Protection Agency (1)

Environmental NGO (2)

Business association (1)

SAFA

Ministry of Transport (1)

Human Environment and Transport Inspectorate (2)

Poland

GPS

Office of Competition and Consumer Protection (1)

Trade inspectorates of three regions (11)

Consumer NGO (1)

Law firm (2)

IPPC Ministry of the Environment (2)

Two provincial administrations (3)

Regional Environmental Protection Inspectorate (1)

Environmental NGO (1)

University/environmental NGO (1)

SAFA Civil Aviation Authority (4)

Others Ministry of Foreign Affairs (2)

Portugal

GPS

Ministry of Economy and Labour, Directorate-General for Consumers (5) 


\begin{tabular}{ll}
\hline & Interviewed authorities (number of interviewees) \\
& Food and Economic Safety Authority (2) \\
& Regional inspectorate of the Food and Economic Safety Authority (1) \\
& Consumer NGO (1) \\
& Portuguese Environmental Agency (2) \\
IPPC & General Inspectorate of Agriculture, Sea, the Environment, and Spatial Planning (1) \\
& Two environmental NGOs (2) \\
& Ministry of Agriculture, Sea, the Environment, and Spatial Planning (1) \\
SAFA & National Civil Aviation Authority (5) \\
Others & Ministry of Foreign Affairs (1) \\
EU institutions/agencies \\
GPS & European Commission, DG Sanco (3) \\
IPPC & European Commission, DG Environment (3) \\
SAFA & European Commission, DG Transport and Energy (2) \\
Ethers & European Aviation Safety Agency (2) \\
European Commission, Secretariat General (1) & \\
\hline
\end{tabular}

\subsubsection{The completion, processing, analysis, and validation of interviews}

Depending on their purpose, the interviews conducted for this research were unstructured or semi-structured. The first interviews for each directive were unstructured. This allowed the researcher to explore and acquire insights into the details of the directives, about which little was known at the beginning of the research project. ${ }^{135}$ All subsequent interviews were semi-structured interviews containing open-ended questions; this type of interviewing enables the fullest answers to be obtained while facilitating comparison between interview results. ${ }^{136}$ In order enable information to be obtained beyond that provided in the context of the questions asked interviewees were, at the end of every interview, given the opportunity to add any information that they thought ought to be added.

The majority of interviews were face-to-face interviews; in a limited number of cases, telephone interviews were conducted. ${ }^{137}$ Apart from most interviews conducted in the Netherlands, all interviews were audio-recorded. Two interviewees in Portugal preferred not to be recorded on tape and this wish was respected. In cases in which audio recordings are absent, extensive notes were taken during the relevant interviews. Given the interest of this study in the informational content of the interviews - rather than the

\footnotetext{
${ }^{135}$ Leech, 2002b: 665 .

${ }^{136}$ Ibid.

${ }^{137}$ For details, see Annex I.
} 
intricacies of spoken language - taped interviews were transcribed in a denaturalised style. A characteristic of this transcription style is the accurate and faithful depiction of the perceptions created and shared during the interview. ${ }^{138}$

Notes and transcripts were coded and used as tools for interview analysis. Coding "the process of breaking down, examining, comparing conceptualizing and categorizing data" 139 - is usually associated with a grounded theory approach to qualitative research. However, even though the purpose of the current research is not to develop theory inductively, coding is considered a convenient tool to facilitate interview interpretation and comparison. Coding was both concept-driven, following codes set in advance of the interviews and data-driven, following the introduction of concepts by interviewees that were not initially considered by the interviewer. Regarding the former method, concepts advanced by relevant theoretical perspectives on implementation were used, thus enabling a theoretically informed reading of the interviews as well. ${ }^{140}$

Finally, in order to ensure the reliability and validity of knowledge generated by the interviews, the validity of quotes taken from unrecorded interviews was checked and all interviewees were asked for permission to use quotes taken from their interviews. In case of doubt about interpretations of concepts or events, interviewees were asked to confirm the interpretations advanced by the researcher. ${ }^{141}$ The National Civil Aviation Authority of Portugal requested the verification of the entire thesis before publication, as a precondition for the participation of officials in interviews.

\section{Synthesis}

The first three chapters of this study outline the purpose, relevance, and methodology of this study, and shed light on the conceptual and theoretical perspectives that are relevant to its context. The first two chapters suggest that notwithstanding the information deficit regarding the extent to which EU measures are implemented effectively by the member states, there is little doubt - amongst the EU institutions and scholars - that EU law often does not work as well as it should. The results are that policy objectives are not always achieved and the beneficiaries of EU measures do not by definition enjoy the rights granted to them by these measures. These results are problematic because they create legal uncertainty and hamper the effective functioning of the single market, and because they question the legitimacy of the EU as a problem-solving system.

In view of their adverse consequences, compliance problems are serious enough to merit political and scholarly attention. Chapter 1 on making EU law work: a problem in

\footnotetext{
${ }^{138}$ Oliver et al., 2005: 1276.

${ }^{139}$ Strauss and Corbin, 1990: 61, in Kvale and Brinkmann, 2009: 202.

${ }^{140}$ Kvale and Brinkmann, 2009: 202.

${ }^{141}$ Ibid.: 255, who label the act of asking interviewees for feedback as "member validation".
} 
need of a solution, has suggested that the past two decades have seen the appearance of numerous EU documents outlining the need to improve the implementation of EU law. Focusing mainly on the transposition phase of the implementation process, the increasing body of scholarly literature has shown that compliance problems exist, and it has identified a variety of structural and circumstantial factors underlying such problems. In contrast, the application of EU law has remained understudied. The explanations that studies indicate explain implementation, particularly application, patterns in the EU are discussed in detail in Chapter 2 on implementation in the EU: same rules, divergent practices.

While EU implementation research has delivered valuable insight into the problems encountered by member states in the implementation of EU measures, comprehensive research on the usefulness of instruments that may support member states in the application of EU law - 'compliance instruments' - does not seem to exist. The foregoing chapters suggest that there is limited knowledge of the patchwork of existing compliance instruments and little insight into the functioning of these instruments individually and in relation to one another. They also suggest that it may, therefore, be promising to reverse our perspective on implementation and compliance in the EU, from studying problems experienced by member states in the transposition of EU directives towards examining the usefulness of instruments that may support the correct application of EU measures on the ground. The research question that guides this study places at its centre the usefulness of compliance instruments for supporting the competent authorities of the member states in the application of EU law.

The compliance instruments that are deemed relevant in the context of this study are categorised based on an appreciation of the institutional context embedding the main actors involved in making these instruments work. On the supranational governance level we find the monitoring and sanctioning powers that the European Commission is endowed with as guardian of the treaties, and inspection powers accruing to EU agencies. This governance level also harbours post-legislative guidance as a compliance instrument. Governance networks involving cooperation amongst the competent authorities of the member states are found on the transnational level. Civil society, national case law, and preliminary rulings are situated on the national governance level.

Note that this chapter outlines that an evaluation of the usefulness of compliance instruments requires an interdisciplinary perspective combining methods and perspectives from political science (in particular public administration) and legal science. Thus, case law analysis is complemented with literature and policy document analysis, and with qualitative interviews and survey analysis. In order to arrive at in-depth insight into the subject of research, a case-study method was preferred to large- $N$ (statistical) analysis. To increase the validity of the research results across policy domains, three EU directives from different policy domains were selected for study: the Directive on general product safety, the Directive on integrated pollution prevention and control, and the 
Directive on safety assessment of third-country aircraft using Community airports. To arrive at more sound conclusions regarding the usefulness of compliance instruments across member states, three member states that are thought to face different obstacles in the implementation of EU law were chosen; these member states are the Netherlands, Poland, and Portugal.

The empirical findings of this study are presented in Parts II, III, and IV, which cover the three jurisdictional levels that serve to categorise the compliance instruments examined in this study. Having outlined what this study sets out to do - and how and why it does so - this book now turns to these empirical parts. 



\section{PART II}

\section{SUPRANATIONAL COMPLIANCE INSTRUMENTS}

Supranational compliance instruments may roughly be divided into two types: mechanisms that primarily aim to coerce member states into compliance and instruments that are intended primarily to support national competent authorities in the application of EU measures. Chapter 4 on monitoring and sanctions studies the former type of instruments; Chapter 5 on post-legislative guidance examines a prime mechanism that belongs to the latter category of instruments. 



\section{Chapter 4}

\section{Monitoring and sanctions}




\section{Introduction}

The first empirical chapter of this study focuses on the monitoring and sanctioning powers that the European Commission has at its disposal as guardian of the treaties. Both of these competencies are closely intertwined, since effective sanctions, which are intended to enforce the observance of EU measures, stand or fall with effective oversight of the implementation performance of member states in the first place. To be blunt, where instances of defection are not detected, there is little sanctioning required. Note that monitoring may not only result in the imposition of sanctions; it may also lead to the adoption of guidelines that are meant to facilitate street-level actors - and other actors involved in the implementation of EU measures - in their daily work. ${ }^{1}$ The usefulness of such guidelines is the subject of Chapter 5 on post-legislative guidance. To enhance readability, and since monitoring is often associated with enforcement in particular, the usefulness of monitoring is studied in the current chapter in conjunction with the usefulness of sanctions.

The extent to which the Commission can be apprised of what happens at the member state level is largely determined by the enforcement competencies that are provided. These competencies may be direct - as in the case of fraud prevention, where the Commission is responsible for implementation - or indirect. ${ }^{2}$ In view of the decentralised implementation of EU directives, the interest of this study lies in the indirect enforcement competencies of the Commission. These competencies are schematically depicted in Figure 3.

At this point, a distinction should be made between police-patrol oversight and fire-alarm oversight. Police-patrol oversight is relatively centralised, active, and direct; it involves examination of member states' implementation performances on the initiative of the supervising body, "by any number of means". ${ }^{3}$ The Commission exercises policepatrol oversight when it conducts spot checks in member states, commissions studies on the implementation performance of national competent authorities, asks member states to report their implementation performance, or instructs $\mathrm{EU}$ agencies to inspect national competent authorities. Fire-alarm oversight is less centralised, less active, and less direct; it comprises the establishment of "a system of rules, procedures, and informal practices that enable individual citizens and organized interest groups to examine administrative decisions", ${ }^{4}$ and to seek remedies from national courts and action on the part of the European Commission as guardian of the treaties. ${ }^{5}$ The role that national

\footnotetext{
${ }^{1}$ For the idea that supervisory oversight could lead to both enforcement and interpretative rules, see e.g. Hofmann et al., 2011: 756.

${ }^{2}$ Adriaanse et al., 2008: 30.

${ }^{3}$ McCubbins and Schwartz, 1984: 166, on congressional oversight in the USA.

${ }^{4}$ Ibid.

${ }^{5}$ McCubbins and Schwartz refer to the idea that citizens and organised interests may seek remedies from agencies, courts, and Congress; see McCubbins and Schwartz, 1984: 166.
} 
courts may play in this regard is elaborated on in Chapter 7 on case law. The function of complaints submitted to the Commission by societal actors, and the usefulness of such complaints to the Commission in monitoring the application of EU law, are the subject of this chapter.

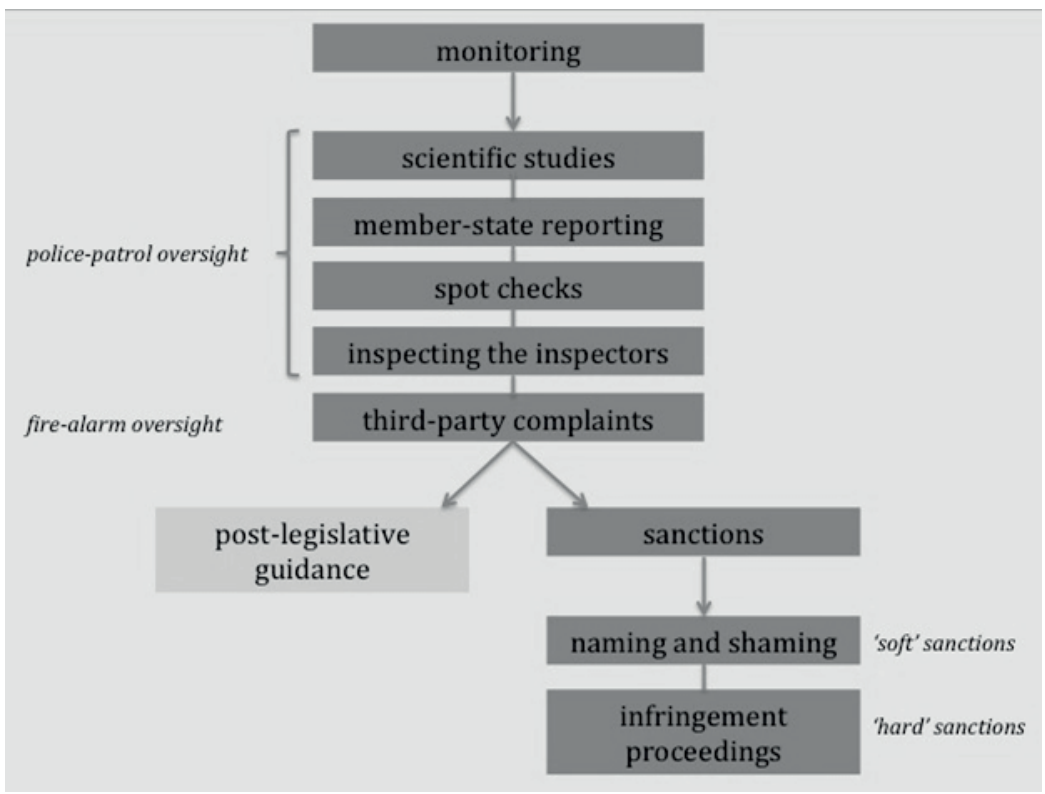

Figure 3 Monitoring and sanctions

Monitoring exercises may result in sanctions, which may come in 'soft' and 'hard' forms. The 'soft' forms include naming and shaming strategies; ${ }^{6}$ these forms highlight 'winners' and 'losers' amongst member states by publicly benchmarking their performance. While naming and shaming was initially used as a compliance instrument in the $1990 \mathrm{~s},{ }^{7}$ the infringement procedure was already enshrined in the 1957 Treaty establishing the European Economic Community (EEC Treaty). ${ }^{8}$ The infringement procedure, now outlined in Articles 258 through 260 TFEU, must be understood as "the ultima ratio enabling the [Union] interests enshrined in the Treaty to prevail over the inertia and resistance of Member States". ${ }^{9}$ This is the case, since the infringement procedure is the only instrument in which the Court of Justice of the European Union may be direct-

\footnotetext{
${ }^{6}$ The term 'naming and shaming' is used interchangeably with 'soft sanctions', 'reputational sanctions', and 'social sanctions', to name a few (Koliev, 2015: 5). I use the term 'soft' sanctions, since it is this term that most clearly distinguishes 'naming and shaming' from the infringement procedure, the 'hardest', most coercive instrument that the Commission has at its disposal to enforce compliance (see below, Section 1.1.2).

7 Tallberg, 2002: 620.

${ }^{8}$ Treaty establishing the European Economic Community [1957] OJ 25.03.1957 [EEC Treaty], Art. 169.

${ }^{9}$ Case 29/59 Netherlands v. High Authority [1960] ECR 355; quoted in Prete and Smulders, 2010: 9.
} 
ly called upon to decide whether a member state complies with the requirements of EU measures. ${ }^{10}$ Moreover, an adverse ruling from the CJEU requires the infringing state to "take the necessary measures to comply with the judgement", ${ }^{11}$ and noncompliance with a Court judgement is punishable by financial sanctions. ${ }^{12}$ Note that this judicial stage is reached only after informal and formal administrative problem-solving mechanisms are exhausted. Note also that infringement proceedings could, in principle, be initiated by both the European Commission and member states. ${ }^{13}$ Since member states rarely start infringement proceedings, ${ }^{14}$ the analysis presented in this study is limited to the Commission's competence to start such proceedings.

Since much has been written about the design of monitoring and sanctioning instruments - and about the infringement procedure in particular - a more detailed review is provided in the following sections of this chapter. Alternatively, little has been written about the usefulness of these mechanisms in the eyes of implementation actors. In view of the idea that monitoring and sanctioning instruments are there, first and foremost, to support the Commission in exercising its function as guardian of the treaties, an examination of the usefulness of such instruments for national implementation actors may, at first sight, seem somewhat remarkable. However, it seems incorrect to assume that these instruments cannot be useful for implementation actors in their work; permit writers and inspectors may benefit from supervision as well. Beginning with this assumption, the empirical analysis presented in this chapter aims to understand whether or not, and if so how, such instruments may be useful for implementation actors.

\footnotetext{
${ }^{10}$ Prete and Smulders, 2010: 10-11, 49ff.

${ }^{11}$ Art. 260(1) TFEU.

${ }^{12}$ Art. 260(2) TFEU.

${ }^{13}$ For the Commission's competences to launch infringement proceedings, see Art. 258 TFEU; the member states' competences in this regard are laid down in Art. 259 TFEU.

${ }^{14}$ Craig and De Búrca, 2011: 433.
} 


\section{Monitoring and sanctions as compliance instruments}

This section aims to identify why monitoring and sanctions may be useful for competent authorities in the application of EU measures (Section 1.1), and which factors may hinder their usefulness as compliance instruments (Section 1.2). As such, it sets the scene for the analysis presented in the subsequent sections of this chapter.

\subsection{Why monitoring and sanctions?}

From a political-theoretical perspective, monitoring and sanctioning instruments fit rationalist thinking about implementation and compliance in particular. Rationalist thinking postulates that states are utility-maximising actors that will choose to comply only when the benefits of compliance outweigh the benefits of defection. States are 'drawn' into compliance, where the probability of noncompliance being detected and the costs of noncompliance are high. From this perspective, monitoring and sanctions are critical tools for making unwilling member states comply with EU measures. ${ }^{15}$ That the effects of monitoring and sanctioning instruments may go beyond forcing member states into compliance is an issue that is not particularly pertinent to scholarly discussions. However, an analysis of the benefits of these instruments that national officials involved in the implementation of EU measures experience, does suggest that these effects may be present. The following subsections elaborate on these benefits and on the particularities of the design and functioning of monitoring and sanctioning instruments. The focus is first on monitoring instruments (Section 1.1.1) and then shifts towards sanctioning instruments, including naming and shaming strategies (Section 1.1.2.1) and the infringement procedure (Section 1.1.2.2).

\subsubsection{Monitoring}

The introduction to this chapter suggests that an important precondition for a successful enforcement strategy is that supervising institutions must be able to detect instances of noncompliance. It also suggests that the European Commission relies on several instruments to acquire information regarding the implementation of $\mathrm{EU}$ measures on the ground, and that these instruments may be thought of either as exemplifying policepatrol oversight mechanisms or as representing fire-alarm oversight tools. The following two subsections discuss the concrete monitoring instruments that the Commission has at its disposal in both of these categories.

\footnotetext{
${ }^{15}$ For a more elaborate discussion on rationalist thinking about implementation and compliance, see Chapter 3 on the approach and methodology of this study, Section 2.1.
} 


\subsubsection{Police-patrol oversight}

Police-patrol oversight involves the implementation of monitoring activities on the initiative of a supervising body. In its exercise of police-patrol competencies, the Commission may, for example, order and examine scientific studies and read other documents on the implementation of EU measures in member states. Reports submitted by member states on their own performance in relation to the implementation of specific EU measures may be amongst those documents. Member states may be obliged to inform the Commission of their implementation performance by virtue of Article 4(3) TEU, which requires them to facilitate the achievement of the Commission's tasks, including that of monitoring compliance with the treaties. Individual EU measures may impose reporting obligations on member states as well. ${ }^{16}$

In a limited number of policy fields, EU regulatory agencies may function as the eyes and ears of the European Commission. Regulatory agencies, of which there are currently thirty-six, ${ }^{17}$ are decentralised, independent bodies with their own legal personality that are created on a case-by-case basis by secondary legislation. ${ }^{18}$ Unlike executive agencies, which support the Commission in the execution of programmes, regulatory agencies contribute to the implementation of EU law by carrying out technical, scientific, or managerial tasks in relevant policy areas. ${ }^{19}$ Two of these agencies have been assigned regular inspection tasks. ${ }^{20}$ While supranational in nature, much of the work in regulatory agencies is done by experts designated by national authorities; this is one of the strategies used to reduce member state resistance against the establishment of EU agencies that may be perceived as a threat to national sovereignty in policy areas. ${ }^{21}$

The surge of agencies as actors in implementation processes is explained by a variety of factors. ${ }^{22}$ These factors include concerns that the enforcement of EU law must be improved if the single market is to deliver ${ }^{23}$ and awareness on the part of the Commis-

\footnotetext{
${ }^{16}$ For examples, see Section 2.1 of the current chapter.

${ }^{17}$ European Union, 'Agencies and other EU bodies', <http://europa.eu/about-eu/agencies>.

${ }^{18}$ Commission, 'European Agencies: The way forward' (Communication) COM (2008) 135 final, p. 4.

${ }^{19}$ European Union, 'Agencies and other EU bodies', <http://europa.eu/about-eu/agencies >. For a discussion, see e.g. Groenleer et al., 2010.

${ }^{20}$ Namely, the European Aviation Safety Agency and the European Maritime Safety Agency. For a review of the inspection tasks of these agencies, see Groenleer et al., (2010). Other agencies have ad hoc investigative powers. For example, the European Securities and Markets Authority (ESMA) can be requested (e.g. by the Commission or by a national authority) to launch 'enquiries' of national authorities and issue recommendations to these same authorities. According to ESMA's website, ESMA will also be able to launch investigations on its own initiative. See European Securities and Markets Authority, 'ESMA in short', $<$ www.esma.europa.eu/page/esma-short $>$. The European Banking Authority (EBA) has an investigative function as well; it can investigate "alleged incorrect or insufficient application of EU law by national authorities". See European Banking Authority, 'Missions and tasks', <http://www.eba.europa.eu/about-us/missions-andtasks $>$.

${ }^{21}$ Kelemen, 2002.

${ }^{22}$ For an overview of the "waves of agencification" in the EU, see e.g. Geradin and Petit, 2004: 36-37.

${ }^{23}$ COM (2001) 428 final, pp. 5, 24. And to restore the perceived loss of credibly of the Commission, one might
} 
sion of the limited resources available to take the necessary action to ensure better administration of EU measures. ${ }^{24}$ It is apparent that the Commission attaches great significance to agencies as governance mechanisms for ensuring compliance, from its 2001 White Paper on European Governance. This white paper outlines the Commission's intention to create further regulatory agencies on top of the twelve then-existing ones, and it states that regulatory agencies "will improve the way rules are applied and enforced across the Union". ${ }^{25}$

The ways in which agencies are supposed to contribute to compliance are as manifold as the reasons for their adoption. Note that not all of the tasks assigned to agencies are enforcement related; some of them may be categorised as matching management rather than rationalist thinking about compliance, or as a combination of both enforcement and management. ${ }^{26}$ Training provided by agencies to support member states in the application of EU rules has more of a capacity-building dimension than an enforcement dimension. Research conducted by agencies may serve both as a capacity-building tool for national authorities - where the agency develops best practices for implementation - and as a basis for the Commission to take enforcement action against member states. Monitoring activities, concerning the implementation of EU legislation on the ground may have similar effects, but they arguably fit rationalist thinking best. Inspections of national inspectors, which EU agencies conduct in cooperation with national authorities - and which therefore follow a mode of "cooperative supervision" 27 - are generally seen as providing potentially useful information for the Commission as guardian of the treaties. ${ }^{28}$

In line with the focus of this chapter, the discussions in the empirical sections of this chapter concentrate on the usefulness of agency tasks that are identified as primarily fitting rationalist thinking about compliance. The latter is particularly true for EU agency inspections of national regulatory authorities. This does not mean that the capacitybuilding effects of tasks that primarily have an enforcement dimension are ignored; they are referred to where relevant. For the usefulness of capacity-building functions of EU agencies in particular, see Chapter 5 on post-legislative guidance and Chapter 6 on transnational networks.

\footnotetext{
add; see e.g. Vos, 2000.

${ }^{24}$ Groenleer et al., 2010: 1215; Schout, 2008: 263.

${ }^{25}$ COM (2001) 428 final, p. 24; emphasis added.

${ }^{26}$ And some tasks are not related to ensuring compliance on the part of national regulatory authorities at all, e.g. individual decisions taken by agencies in the application of EU law. For an elaboration on rationalist and managerialist thinking about implementation and compliance, see Chapter 3 on the approach and methodology of this study, Section 2.

${ }^{27}$ See Hofmann et al., 2011: 755.

${ }^{28}$ These different tasks are derived from Groenleer et al., 2010: 1215-1216.
} 


\subsubsection{Fire-alarm oversight}

While police-patrol oversight involves monitoring activities that the European Commission conducts on its own initiative, the hallmark of fire-alarm oversight is that the Commission acts as a rather 'passive' recipient of information about the implementation performance of member states. As far as this type of oversight is concerned, reference must be made to complaints about the implementation of EU measures by member states submitted to the Commission by third parties, such as national administration, ${ }^{29}$ citizens, businesses, and organised interests. ${ }^{30}$ Note that member states have been rather reluctant to complain about other member states, in view of the adverse political and other consequences that may accompany such an action. ${ }^{31}$

Compared to mechanisms such as self-reporting by member states, fire-alarm oversight has the advantage of providing access to information that is otherwise unattainable, and of directing the Commission to areas that are "particularly ambiguous" and require enforcement action or clarification. ${ }^{32}$ In fact, the Commission has acknowledged "the vital role played by [complainants] in helping [it] to detect infringements of Union law" ${ }^{33}$ Section 2.1 of this chapter, which sheds light on the role of fire-alarm oversight in the context of the directives examined in this study, supports the idea that complaints may play an important role in providing the Commission with information about possible infringements.

\footnotetext{
${ }^{29} \mathrm{~A}$ member state that considers another member state to have failed to fulfil an obligation under the treaties may also bring the matter before the Court by itself. Before it does so, it must bring the matter before the Commission, which must deliver a reasoned opinion after each of the states concerned has been given the opportunity to submit its own case and its observations about the other party's case. The absence of a Commission's opinion does not prevent the matter from being brought before the Court. See Art. 259 TFEU. Member states prefer to complain informally to the Commission though, leaving it up to this institution to formally act. Prete and Smulders, 2010: 27; Tallberg, 2002: 615-616; Van den Bossche, 1996: 390.

${ }^{30}$ These varieties are referred to in the Commission's annual reports that monitor the application of EU law; see e.g. Commission, '30th Annual Report on Monitoring the Application of EU Law' (Report) COM (2013) 726 final, p. 5.

${ }^{31}$ Van den Bossche, 1996: 390. The notion that text books and EU reports generally refer to complaints coming from other actors than member states underlines the idea that member states do not have a big role to play as complainants. For text books, see e.g. Craig and De Búrca, 2011: 410-411; for EU reports, see e.g. Commission, '31st Annual Report on Monitoring the Application of EU Law' (Report) COM (2014) 612 final.

p. 6-7. Note that there seems to be only one court case that followed from a complaint issued by a member state about infringements committed by another member state; see case C-1/00 France v. European Commission [2001] ECR I-09989.

${ }^{32}$ Tallberg, 2002: 616. As such, monitoring may give rise not just to the initiation of infringement proceedings, but also to the publication of interpretative rules. For more information about this issue, see Chapter 5 on post-legislative guidance.

${ }^{33}$ Commission, 'Updating the handling of relations with the complainant in respect of the application of Union law' (Communication) COM (2012) 154 final, p. 2.
} 


\subsubsection{Sanctions}

When monitoring exercises point out instances of noncompliance on the part of member states, the European Commission has several options for subsequently forcing member states into compliance. The Commission may choose to make member states comply by employing 'soft' enforcement tools such as naming and shaming strategies. On the 'hard' side of the enforcement scale, we find that the infringement procedure is the ultimate instrument used to force member states into compliance. Note that soft and hard sanctions may, in theory, be used simultaneously; for example, when the Commission decides to publish information about ongoing infringement cases. ${ }^{34}$ Soft and hard sanctions must therefore not be perceived as mutually exclusive. Since they embody distinct conceptual ideas, they will be discussed separately below.

\subsubsection{Naming and shaming}

Naming and shaming strategies basically consist of publicly benchmarking the implementation performance of member states on the basis of quantitative or qualitative indicators and contrasting strongly performing member states with states that perform relatively weakly. Naming and shaming is considered an important instrument for solving infringement cases ${ }^{35}$ because of the reputational costs that it may create for member states. While these strategies are a great public-relations tool for the best implementers, naming and shaming strategies impose reputational costs on laggards - costs that are thought to increase the consequences of defection and the willingness of member states to comply with EU measures. ${ }^{36}$ Note that transparency of the member states' implementation performances also has a capacity-building effect; it may reassure countries that others are meeting their obligations. In addition, it allows good performers to mandate that defections are accounted for and justified. ${ }^{37}$

Transparency of the member states' implementation performances may come in different forms, and therefore to different degrees. The Commission may choose to share the relevant information only with national representatives during meetings of Council working groups, comitology committees, or implementation networks. Since information provided in such settings is not publicly available, and the information received in the context of this study cannot be quoted, examples cannot be given in this regard. Conventional wisdom seems to tell us that the effectiveness of naming and shaming must be relatively low when information is kept to a group of insiders; the notion of naming and shaming seems, in fact, generally associated with the provision of information to a wider public instead.

\footnotetext{
${ }^{34}$ This, however, rarely occurs in practice, as is clarified in Section 1.2.2 below.

${ }^{35}$ Ciavarini Azzi, 2000: 64; Tallberg, 2002: 618.

${ }^{36}$ See Chapter 3 on the approach and methodology of this study, Section 2.1.

${ }^{37}$ Chayes et al., 1998: 43-44.
} 
There are numerous ways in which the Commission provides the wider public with information about the implementation performances of member states. The Commission's annual reports on monitoring the application of EU law, for example, provide insight into the number of infringement proceedings initiated against individual member states in specific policy domains and in relation to specific EU measures. ${ }^{38}$ The Commission also publishes a biannual internal market scoreboard, which makes it possible for the public to compare the performance of member states regarding the transposition and application of single market legislation. ${ }^{39}$ The annual governance check-ups that the Commission recently began publishing also allow for such comparison. ${ }^{40} \mathrm{Im}$ plementation reports and research reports commissioned by the Commission or by the European Parliament in relation to specific legislative acts and online databases may provide member state specific information as well. ${ }^{41}$

Recent internal market scoreboards do not solely outline the relative implementation performance of member states; they also focus on 'good practices' of member states that have managed to reduce their transposition deficit or that improve the settlement of infringement cases. ${ }^{42}$ As such, scoreboards not only aim to increase the social costs of noncompliance; they may also function as tools to strengthen the capacity of member states in the implementation of EU law by allowing member states to draw lessons from good performers. Capacity-building effects may ensue from infringement proceedings as well, as the following subsection suggests.

\subsubsection{Infringement proceedings}

The introduction to this chapter suggests that infringement proceedings are the ultimate way to force member states into compliance. Infringement proceedings are, however, not altogether contentious; they commence with an administrative stage that aims to settle the matter amicably and informally, before they acquire a more formal and sanctioning style. The following subsections discuss the characteristics of the relevant phases of the infringement procedure.

\footnotetext{
${ }^{38}$ For all Annual Reports, see European Commission, 'Annual reports on monitoring the application of EU law', <http://ec.europa.eu/atwork/applying-eu-law/infringements-proceedings/annual-reports>.

39 These scoreboards may be found on European Commission, 'The Internal Market Scoreboard', $<$ http://ec.europa.eu/internal_market/score>.

${ }^{40}$ Annual governance check-ups may be found at the European Commission, 'The Internal Market Scoreboard', <http://ec.europa.eu/internal_market/score>.

${ }^{41}$ For examples, see Section 2.2 of the current chapter.

${ }^{42}$ E.g. Commission (2013), 'Internal Market Scoreboard 26',

$<$ http://ec.europa.eu/internal_market/score>, p. 29ff.
} 


\subsection{Article 258 TFEU proceedings}

\section{A. Commencement}

Infringement proceedings may be launched either on the Commission's own initiative or in response to a complaint. In relation to the latter, it should be noted that while complaints are "often key in detecting and pursuing infringements", ${ }^{43}$ the infringement procedure is not meant to provide complainants with redress. The Commission and the CJEU have underlined that the procedure is first and foremost an objective mechanism ensuring member state compliance with EU law. ${ }^{44}$ This means, for example, that the Commission does not need to show that any damage to individuals was caused by the failure to implement a measure. ${ }^{45}$ It also means that individuals must demand redress before national courts, which serve as allies of the CJEU (and of the European Commission, one may argue) in the implementation of EU law, particularly by virtue of the doctrines of supremacy, direct and indirect effect, state liability, and effective remedies. ${ }^{46}$ The role of national courts as allies of the CJEU and of the Commission in the implementation of EU measures is further explored in Chapter 8 on case law.

The compliance-inducing - rather than interest-satisfying - goal of the infringement procedure is further underlined by the Commission's claim to discretion when deciding whether or not to initiate infringement proceedings. ${ }^{47}$ This discretionary power - or the principle of selective enforcement ${ }^{48}$ - has been confirmed in CJEU case law, which grants the Commission permission to decide whether or not to start infringement proceedings, ${ }^{49}$ when to start them,${ }^{50}$ and whether or not and when to refer a case to the Court. ${ }^{51}$ The Court has also maintained that this discretionary power applies regardless

\footnotetext{
${ }^{43}$ Craig and De Búrca, 2011: 410.

${ }^{44}$ E.g. case 416/85 Commission v. UK [1988] ECR 3127, para. 9; case 5/68 Commission v. Italy [1968] ECR 423; case 28/67 Mölkerei-Zentrale Westfalen v. Hauptzollamt Paderborn [1968] ECR 00211, p. 153.

${ }^{45}$ Peers, 2012: 47.

${ }^{46}$ Peers, 2012: 34.

${ }^{47}$ See e.g. Commission, 'Application of Article 228 of the EC Treaty' (Communication) SEC (2005) 1658; Commission, 'Information from the Commission - Memorandum on applying Article 171 of the EC treaty' [1996] OJ C 242/6.

${ }^{48}$ Hofmann et al., 2011: 748; Ibáñez, 1999: $203 \mathrm{ff}$.

${ }^{49}$ Case 247/87 Starfruit v. Commission [1989] ECR 291, para 11. It is argued that this is true even though Art. 258 mandates the Commission to issue a reasoned opinion, if it finds that a member state has failed to fulfil an obligation under the Treaties. Such mandatory language is not used regarding the Commission's decision to bring a case before the CJEU. See Craig and De Búrca, 2011: 415.

${ }^{50}$ Case 7/68 Commission v. Italy [1968] ECR 00617, p. 428. The Court has, however, stated that there are certain constraints on the Commission as far as the length of time taken by the Commission to bring proceedings regarding a particular infringement. See Case C-96/89 Commission v. Netherlands [1991] ECR 2461, para 16.

${ }^{51}$ As to whether, see e.g. case 247/87 Starfruit v. Commission [1989] ECR 291, para 12, and case C-562/07 Commission v. Spain [2009] ECR I-9553, para 20. Although time constraints apply here as well, see e.g. case 74/82 Commission v. Ireland [1984] ECR 317, para 12; case 293/85 Commission v. Belgium [1988] ECR 305, para 14. In the latter case, the Court said that a reasonable period must be allowed, although short periods
} 
of pending national judicial proceedings. ${ }^{52}$ Finally, the CJEU's case law underlines the idea that the Commission is formally immune to the wants of others, which may have a stake in the initiation of infringement proceedings against member states. ${ }^{53}$

\section{B. Pre-contentious and administrative stages}

Before formal infringement proceedings are started, member states are typically notified informally by the Commission of a presumed breach, ${ }^{54}$ and given the opportunity to explain their position and reach an agreement with the Commission. This precontentious stage allows the Commission and the member state involved to identify and encourage practices of good administration, and it enables the resolution of problems that are of a political rather than legal nature. ${ }^{55}$ It may be noted that the Commission's preference for pre-contentious problem solving ${ }^{56}$ is visible not only in its efforts to solve infringement cases informally - efforts that have received more emphasis by the relatively recent introduction of EU Pilot ${ }^{57}$ - but also in the Commission's emphasis on the importance of instruments such as SOLVIT. ${ }^{58}$ In addition, the Commission's promotion of other mechanisms of interstate cooperation must be considered to follow from its preference for prevention and early problem solving over correction of infringements. ${ }^{59}$

Where informal negotiations are not effective at solving the problem at hand, the Commission may choose to initiate formal infringement proceedings against the allegedly defecting member state. These proceedings are comprised of an obligatory administrative stage, and eventually a litigation phase. ${ }^{60}$ The first step of the administrative stage is for the Commission to formally notify the member state of the presumed infringement by sending it a letter specifying the facts and legal norms upon which the Commission has based its decision to initiate formal proceedings. The relevant state needs to reply to this letter of formal notice. If the matter is not resolved, the Commission may proceed by sending the state a reasoned opinion setting out the substance of

could be justified in cases of urgency or where member states were fully aware of the Commission's views long before the procedure started.

${ }^{52}$ E.g. case C-508/03 Commission v. UK [2006] ECR I-3969, para 71. According to Peers, this should apply also when procedures under Article 260 TFEU have been started. On the relation between state liability and Article 260 procedures, see Peers, 2012: $49 \mathrm{ff}$.

${ }^{53}$ Case 247/87 Starfruit v. Commission [1989] ECR 291, para 11.

${ }^{54}$ Hofmann et al., 2011: 749.

${ }^{55}$ Prete and Smulders, 2010: 10-11.

${ }^{56}$ E.g. Snyder, 1993; Craig and De Búrca, 2011: 413.

${ }^{57}$ On EU Pilot, see further Section 1.1.2.2.3 below.

${ }^{58}$ SOLVIT, which was created by the Commission in 2002, is an online tool for the resolution of cross-border problems caused by breaches of EU law by public administrations in EU member states and European Economic Area countries. Informal and relatively light by nature, SOLVIT is designed as an alternative to formal, more heavy problem-solving tools, such as national court procedures or complaints to the Commission. European Commission, 'Solvit', <http://ec.europa.eu/solvit/>. For a review, see Kaeding and Voskamp, 2011.

${ }^{59}$ Craig and De Búrca, 2011: 413. For an analysis of the usefulness of transnational networks, see Chapter 6.

${ }^{60}$ For exceptions to the obligatory nature of the administrative stage and concerning supranational supervision outside of Articles 258 and 260, see Hofmann et al., 2011: 751-752. 
the complaint and the grounds on which the Commission's suspicion rests. The reasoned opinion also specifies a time period within which the violation must be remedied. ${ }^{61}$

\section{Litigation stage}

If the state fails to remedy the infringement within the time period specified in the Commission's reasoned opinion, the Commission may bring the case before the Court, and thereby initiate the litigation stage. Member states cannot escape from a judgement by stating that the breach has been remedied in the meantime; what matters to the Court is whether the member state was in breach at the end of the period outlined in the Commission's reasoned opinion. ${ }^{62}$ This rule exists, amongst others, to prevent states from undermining infringement proceedings by ending the violation immediately before a judgement is issued, and in view of the fact that Court judgements provide support for actions of state liability that are brought before national courts by individuals. ${ }^{63}$

The Court's assessment of whether or not the Commission was correct to bring proceedings varies according to the alleged breach. In relation to EU directives, which are the subject of this study, the following information is provided. Regarding transposition, the Court has maintained that member states are under an obligation to give effect to the provisions of a directive, by means of national provisions of a binding nature ${ }^{64} \mathrm{It}$ is up to the Commission to show that the implementation of legislation - or general principles of constitutional and administrative law that should guarantee national authorities will apply the law fully ${ }^{65}$ - does not comply with the provisions outlined in the directive, that transposition has been untimely, or that notification has not taken place. ${ }^{66}$

Proof of one single breach is sufficient for the Commission to support a claim that a member state has infringed an EU measure in the application phase of the implementation process, as court cases concerning Commission actions taken in response to single breaches show. ${ }^{67}$ Such breaches must be evidenced "by means of sufficiently documented and detailed proof of the alleged practice of the national administration and/or courts". ${ }^{68}$ The downside of suing member states for single breaches for the Commission is, however, that member states may seek to correct the infringement right before the

\footnotetext{
${ }^{61}$ For more information on the reasoned opinion, see e.g. Craig and De Búrca, 2011: 418-422.

${ }^{62}$ E.g. case C-173/01 Commission v. Greece [2002] ECR I-6129, para 7; case C-519/03 Commission v. Luxembourg [2005] ECR I-3067, para 18; case C-562/07 Commission v. Spain [2009] ECR I-9553, para 23.

${ }^{63}$ E.g. case 7/61 Commission v. Italy [1961] ECR 317, 334, opinion of AG Langrange (on the first reason); case 240/86 Commission v. Greece [1988] ECR 1835, 1844, opinion of AG Lenz (on the second element). For the link between state liability and Article 258 and Article 260 procedures, see further Peers, 2012: $49 \mathrm{ff}$.

${ }^{64}$ E.g. case 96/81 Commission v. Netherlands [1982] ECR 1791, para 12.

${ }^{65}$ Where this is the case, the adoption of specific legislation may be superfluous; see case 29/84 Commission $v$. Germany [1985] ECR 1661.

${ }^{66} \mathrm{On}$ the idea that the burden of proof in infringement proceedings is on the Commission, see e.g. case C369/11 Commission v. Italy [2013] (not yet published), para. 68.

${ }^{67}$ Wennerås, 2006: 32.

${ }^{68}$ E.g. case C-441/02 Commission v. Germany [2006] ECR I-3449, para 49.
} 
Commission brings the case to the CJEU. Such situations are suboptimal from an efficiency point of view, not only since the Commission must continue running after individual breaches (which requires the dedication of considerable resources), but also because member states have a long period of time to repair each of these breaches (which prevents EU citizens from fully enjoying their rights in the meantime).

In order to prevent such situations, the Court has developed the principle of general and persistent breaches. ${ }^{69}$ Under this principle, which is of particular use in the operationalisation and application phases of the implementation process, the Court may extrapolate a general failure to comply with a measure on the basis of infringements that may seem isolated initially. ${ }^{70}$ The Commission has a case if it can prove that an administrative practice (which is indicative of breaches of a more general nature) can be deduced from individual infringements. ${ }^{71}$ Relevant to this is the number of infringements, the extent to which they are spread across the territory of the member state, and their duration. ${ }^{72}$ Furthermore, infringements that are terminated before the deadline specified in the reasoned opinion and evidence not mentioned in the reasoned opinion may be used by the Commission to support its claim. ${ }^{73}$ It is the member state's responsibility to show that these cases are isolated incidents rather than indicative of a general and persistent practice. ${ }^{74}$

Ruling against accused member states in $95 \%$ of the cases, ${ }^{75}$ the Court has rarely been receptive to member state arguments that excuse their violation of the treaties. Arguments that are certainly not accepted by the Court in this regard are those claiming a lack of deliberate infringement on the part of the state ${ }^{76}$ and those pointing out difficulties in the internal system of the state. ${ }^{77}$ The same applies to arguments alleging the existence of similar breaches in other member states. ${ }^{78}$ Only force majeure seems to be a possible exception. ${ }^{79}$ Note that the general resistance of the Court towards accepting member states arguments that excuse infringements applies to all phases of the implementation process. ${ }^{80}$

If the Court finds that a member state has failed to fulfil an obligation under the treaties, it will require the state to take "the necessary measures" to comply with the

\footnotetext{
${ }^{69}$ Case C-394/01 Commission v. Ireland [2005] ECR I-3331; for a reflection, see Wennerås, 2006.

${ }^{70}$ Ibid. For a reflection, see ibid: $34,47-48$.

${ }^{71}$ Ibid. For a reflection, see ibid: 35 .

${ }^{72}$ Ibid. For a reflection, see ibid: $36-39$.

${ }^{73}$ Ibid. For a reflection, see ibid: 40.

${ }^{74}$ Ibid. For a reflection, see ibid: 41 . Whether or not cases exemplify general and persistent practices determines the type of corrective action to be taken by member states; see further below.

${ }^{75}$ Percentage derived from the data presented by Börzel and Hofmann, 2012: 456.

${ }^{76}$ E.g. case C-43/97 Commission v. Italy [1997] ECR I-4671.

${ }^{77}$ E.g. case 280/83 Commission v. Italy [1984] ECR 2361, para. 4.

${ }^{78}$ E.g. case C-146/89 Commission v. UK [1991] ECR I-3533.

${ }^{79}$ E.g. case C-121/07 Commission v. France [2008] ECR I-9159.

${ }^{80}$ Case C-304/02 Commission v. France [2005] ECR I-6263.
} 
judgement. ${ }^{81}$ An important advantage of cases launched under the principle of general and persistent breaches is that member states must repair not only the individual infringements brought up by the Commission in the court case, but also ex officio the general breaches that these infringements indicate. ${ }^{82}$ Moreover, where new infringements that are indicative of a general and persistent breach emerge after the completion of Article 258 TFEU proceedings, the Commission may bypass new proceedings of this type and immediately launch Article 260(2) TFEU proceedings that aim to penalise member states. ${ }^{83}$ The legal framework that is applied to such proceedings is elaborated on below.

\subsection{Article 260 TFEU proceedings}

The principle of sincere cooperation requires that compliance with a Court judgement must be "initiated at once and completed as soon as possible". ${ }^{84}$ This requirement does not detract from the fact that the Commission must give the member state sufficient time to remedy the relevant shortcoming, accounting for the complexity and duration of the actions required to comply with the judgement. ${ }^{85}$ When the Commission considers that a member state has nonetheless failed to comply with the judgement, it may initiate Article 260(2) TFEU proceedings ${ }^{86}$ and ask the Court to impose a lump sum and/or penalty payment on the member state at fault, ${ }^{87}$ to be paid to the account of the Union's own resources ${ }^{88}$ A lump sum is a dissuasive measure intended to sanction an infringement that has ensued and to prevent similar infringements from occurring; it may be imposed when the member state has failed to comply with the judgement within the time limit outlined in the Commission's reasoned opinion, regardless of whether the infringement has ended by the time the case reaches the Court again. ${ }^{89}$ A penalty payment, on the other hand, is a coercive instrument designed to persuade - rather than

\footnotetext{
${ }^{81}$ TFEU, Art. 260(1). Which measures the member state is supposed to take to comply with the judgement is not specified; since the member state enjoys complete organisational autonomy and is fundamentally responsible for correcting the respective breach, there is no EU competence for directive supervision of member state organs. Secondary EU law can, however, lay down instructions as to the organisation of the administration. Hofmann et al., 2011: 759-760.

${ }^{82}$ Wennerås, 2006: 42-43.

${ }^{83}$ Ibid.: 62 .

${ }^{84}$ Wennerås, 2012: 150. For the principle of sincere cooperation, see Art. 4(3) TEU. Quotation from case C278/01 Commission v. Spain [2003] ECR I-14141, para. 27.

${ }^{85}$ E.g. case C-278/01 Commission v. Spain [2003] ECR I-14141.

${ }^{86}$ Unless the case concerns a notification case; see Section 1.1.3.3 below.

${ }^{87}$ Whereas the Treaty seems to exclude the imposition of both simultaneously, the Court has held that recourse to both types of penalty is not precluded. See e.g. case C-304/02 Commission v. France [2005] ECR I6263.

${ }^{88}$ Wennerås, 2012: 170.

${ }^{89}$ See e.g. case C-304/02 Commission v. France [2005] ECR I-6263; case C-121/07 Commission v. France [2008] ECR I-9159; case C-109/08 Commission v. Greece [2009] ECR I-4657. For an elaboration, see Wennerås, 2012: $156 \mathrm{ff}$.
} 
penalise - member states to end the infringement as soon as possible. It may be imposed when the failure to fulfil obligations continues at the time of the Court's assessment. ${ }^{90}$

It is up to the Commission to specify - but up to the Court to decide on - the amount of lump sum and/or penalty payment that it finds appropriate in the circumstances of the case. ${ }^{91}$ The Commission has adopted a number of communications that set guidelines regarding the exact calculation of financial sanctions. ${ }^{92}$ Penalty payments are fixed using a method that respects both the principle of proportionality and the principle of equal treatment of member states. ${ }^{93}$ Three criteria are fundamental in this regard: the seriousness of the infringement, its duration, and the need to ensure that the sanction is a deterrent to further infringements. ${ }^{94}$ Lump sums should, the Court has argued after disapproving of several methods proposed by the Commission, be based on the seriousness of the infringement and its duration, and on an assessment of the conduct of the member state during the pre-litigation stage of the infringement procedure; for example, in relation to whether it has cooperated sincerely with the Commission and made tangible moves to ensure compliance. ${ }^{95}$

\subsection{Recent developments}

The effectiveness of the infringement procedure for ending instances of noncompliance has been subject to severe criticism. ${ }^{96}$ The Commission itself has referred to improvement of the infringement procedure as one of its priorities in its efforts to make EU law more effective. ${ }^{97}$ While the basic provisions that regulate the infringement procedure have remained the same since the inception of the procedure by the 1957 Treaty of Rome, ${ }^{98}$ several attempts to enhance the efficiency and effectiveness of solving noncompliance cases have occurred over time.

\footnotetext{
${ }^{90}$ See e.g. case C-304/02 Commission v. France [2005] ECR I-6263; case C-121/07 Commission v. France [2008] ECR I-9159; case C-109/08 Commission v. Greece [2009] ECR I-4657. For an elaboration, see Wennerås, 2012: $156 \mathrm{ff}$.

${ }^{91}$ Art. 260(2) TFEU. The notion that the Court is not bound to the Commission's proposal appears in the wording of Article 260(2). See also the Memorandum on applying Article 171 of the EC Treaty, OJ 1996/C 242/07. See also case C-387/97 Commission v. Greece [2000] ECR I-5047; and case C-278/01 Commission v. Spain [2003] ECR I-14141 (on the size of a penalty payment). The fact that the Court may impose both a lump sum and a penalty payment appears in case C-304/02 Commission v. France [2005] ECR I-6263.

${ }^{92}$ The latest communication was published in 2010; see Commission, 'Implementation of Article 260(3) of the Treaty' (Communication) SEC (2010) 1371 final. For an overview, see Peers, 2012: 34-39.

${ }^{93}$ SEC (2010) 1371 final, p. 3.

${ }^{94}$ SEC (2010) 1371 final p. 3. For an elaboration, see e.g. Wennerås, 2012: 156-162; Peers, 2012: 46 (for relevant cases); Craig and De Búrca, 2011: 433-438.

${ }^{95}$ Other methods proposed by the Commission were turned down by the Court. For an overview, see Wennerås, 2012: 163ff; Peers, 2012: 46 (for relevant cases).

${ }^{96}$ For an elaboration, see Section 1.2.2 below.

${ }^{97} \mathrm{COM}$ (2007) 502 final.

${ }^{98}$ Peers, 2012: 33.
} 
The introduction of the possibility of penalising member states for past or continued instances of noncompliance through the imposition of financial sanctions, by the Treaty of Maastricht, is one example of such attempts; this example is discussed above. The Treaty of Lisbon introduced two other novelties. The first concerns the removal of the reasoned opinion stage from Article 260 TFEU procedures. The Commission does not, as was previously the case, have to submit a reasoned opinion before bringing a member state before the Court for noncompliance with an Article 258 TFEU judgement; it only needs to formally notify the member state concerned of its infringement. ${ }^{99}$ This fasttrack administrative procedure should, according to the Commission, reduce the duration of the process from between twelve and twenty-four months, to between eight and eighteen months. ${ }^{100}$ Unless member states react faster to the Court's Article 258 TFEU judgements, this shortened procedure is expected to result in more Article 260(2) TFEU cases. $^{101}$

Secondly, when a member state has failed to notify measures to transpose a directive adopted under a legislative procedure, the Commission may, following Article 260(3) TFEU, seek financial sanctions against that member state, at the stage of infringement proceedings that are initiated pursuant to Article 258 TFEU. The purpose of introducing this article is to provide member states with a stronger incentive to transpose directives in due time, ${ }^{102}$ which should - given the great number of cases brought before the Court for issues of non-notification - considerably reduce the burden on the Commission's enforcement resources. ${ }^{103}$ In view of its applicability to transposition rather than application cases, this reform measure is not relevant to, and therefore not subject to, discussion in the remainder of this chapter.

Against the tightening of the infringement procedure stands a reinforced emphasis on early problem solving, notably by means of the introduction of EU Pilot. EU Pilot, which was introduced in 2008, is a confidential online platform that aims to improve communication and cooperation between the Commission and member states, concerning possible implementation problems at an early stage. The purpose is to clarify and remedy existing problems without beginning formal infringement proceedings. Member state participation is not legally required, but all member states do participate in the system. EU Pilot covers the entire acquis, apart from those areas in which similar mechanisms for clarifying and solving implementation problems already existed prior to the introduction of this tool. ${ }^{104}$ The aim of EU Pilot seems to come close to the aim of

\footnotetext{
${ }^{99}$ Compare Article 260(2) TFEU with Article 228(2) TEC.

${ }^{100}$ SEC (2010) 1371 final, p. 2; COM (2007) 502 final, section 3.

${ }^{101}$ Peers, 2012: 38.

${ }^{102}$ SEC (2010) 1371 final, p. 3.

${ }^{103}$ Wennerås, 2012: 165. For an elaboration on the scope of the Article 260(3) procedure, see Peers, 2012: 3944.

${ }^{104}$ See on European Commission, 'EU Pilot',

<http://ec.europa.eu/internal_market/scoreboard/performance_by_governance_tool/eu_pilot>.
} 
'traditional' pre-infringement proceedings. The difference between the two is, however, that EU Pilot provides a more systematic framework in which communication between the Commission and member states is shaped by the institution of a common online platform, and the establishment of formal deadlines for member states to respond to the Commission's requests for information. If and where the responses of member states are not satisfactory, the Commission will usually begin formal infringement proceedings. ${ }^{105}$

Finally, following earlier announcements regarding the prioritisation of complaints in certain areas, ${ }^{106}$ the Commission has recently indicated that it will focus its enforcement efforts on infringements that "present the greatest risks, widespread impact for citizens and businesses and the most persistent infringements confirmed by the Court". ${ }^{107}$ Such infringements include those related to notification obligations, EU laws that raise issues of principle, those that have far-reaching negative impacts on citizens, and compliance with Court judgements issued under Article 258 TFEU. ${ }^{108} \mathrm{~A}$ further reduction was announced in a subsequent Commission communication, which indicates that the Commission will "focus [its] scarce resources on what matters most", that is, on legislative acts that have the greatest potential to make the single market work better. ${ }^{109}$ In these areas, ${ }^{110}$ the Commission pledges to use its enforcement powers with the "utmost vigour". ${ }^{111}$ It also calls on member states to cooperate with it to end infringements swiftly. ${ }^{112}$

\subsection{Beyond correction: the preventive effect of infringement proceedings}

The measures implemented by member states in response to a finding by the Commission (or by the Court) of a breach of EU law are, by nature, ex post. The effect of infringement proceedings may, however, be expected to go beyond that of the forced correction of EU measure violations; infringement proceedings may have a preventive effect as well.

Two points seem particularly relevant to this topic. The first is that the threat of sanctions may deter member states from infringing EU law in the first place, or from prolonging instances of noncompliance by repairing infringements early on in the

\footnotetext{
${ }^{105}$ Ibid. For an overview, see also Ballesteros, 2013: 63ff. The Commission has published two reports evaluating the effectiveness of EU Pilot for dealing with (presumed) infringement cases; see Commission, 'EU Pilot Evaluation Report' (Report) COM (2010) 70 final and 'Second Evaluation Report on EU Pilot' (Report) COM (2011) 930 final.

${ }^{106}$ For an overview, see Ibáñez, 1999: 232-233.

${ }^{107}$ COM (2007) 502 final, section 3.

108 Ibid.

${ }^{109}$ Commission, 'Better governance for the single market' (Communication) COM (2012) 259 final, p. 2.

${ }^{110}$ For 2012-2013, these areas were transport, energy, services, financial services, and digital economy. COM (2012) 259 final, p. 11-21.

111 Ibid., p. 4.

112 Ibid.
} 
course of infringement proceedings. In fact, figures suggest that the majority of infringement cases are solved early in the process. Commission reports suggest that most cases are solved after member states are formally notified of a breach under EU law. ${ }^{113} \mathrm{~A}$ study focusing on the nature of infringement proceedings between 1978 and 1999 shows that of the more than 5,000 cases, in which a minimum of a reasoned opinion was sent, less than one third were referred to the CJEU under (what is now) the Article 258 TFEU procedure. The Court delivered a judgement in nearly half of the cases that were referred to the CJEU. In almost $10 \%$ of these cases, the Commission launched Article 260 TFEU proceedings against member states for noncompliance with the first Court judgement. Financial penalties were imposed in fewer than a dozen cases. ${ }^{114}$ In other words, member states generally tend to correct infringements rather early in the process, ${ }^{115}$ and escalation in the form of the issuance of an Article 260 TFEU judgement is rare.

A second reason for the preventive effect of infringement proceedings relates to the idea that, since they clarify EU rules and provide precedents for future legal disputes, Court judgements provide legal certainty that enhances the capacity of member states to comply. ${ }^{116}$ The notion of capacity reminds us of management thinking on implementation and compliance, which, as demonstrated earlier, ${ }^{117}$ attaches great value to capacitybuilding instruments for ensuring compliance. This occurs since implementation problems are thought to arise from capacity limitations, rather than from a lack of willingness to comply (rationalism) or a lack of internalisation of applicable norms (constructivism). Management scholars would argue that if states are offered the tools to comply - clarity on the interpretation of norms is one of them - implementation problems may be avoided, or where they exist they may solve themselves. The latter also applies to problems that escape the Commission's attention, since correction does not depend on detection and on the threat of sanctions, but on facilitation.

\subsection{Limitations of monitoring and sanctions as compliance instruments}

While the previous section suggests that monitoring and sanctions are deemed as helpful for compelling or enforcing member state compliance with EU law, this suggestion must be counterbalanced by an acknowledgement of the obstacles faced by the Commission as guardian of the treaties. These obstacles come in the form of financial, political,

\footnotetext{
${ }^{113}$ Commission, '30th Annual Report on Monitoring the Application of EU Law' (Report) COM (2013) 726 final, p. 9.

${ }^{114}$ See Börzel and Hofmann, 2012: 456.

${ }^{115}$ Or at least that is what these figures, taken at face value, seem to suggest. See Section 1.2 .2 for a critical reflection on the role that the Commission may play in the course of infringement proceedings.

${ }^{116}$ Tallberg, 2002: 618. On the notion that international organisations may use enforcement instruments in a non-coercive manner and may e.g. rely on monitoring as a tool for capacity building, see Joachim et al., 2008: 188.

${ }^{117}$ See Chapter 3 on the approach and methodology of this study, Section 2.2.
} 
and other constraints that limit the extent to which the Commission can see what is happening 'on the ground' and effectively act on detected infringements. The following subsections discuss the obstacles that the literature considers the most pressing in this regard.

\subsubsection{Monitoring}

Instances of noncompliance must be identified in order for violating member states to be sanctioned; when infringements do not come to the attention of the Commission, they are bound to escape Article 258 TFEU proceedings. Moreover, when detection mechanisms fail to work effectively, member states are unlikely to attach credibility to the Commission as a supervising agency. While the result of the former aspect is that existing infringements are prolonged, the second aspect increases the temptation for member state to defect in the first place. ${ }^{118}$ Effective monitoring is, however, as unlikely as it is essential, as the following subsections suggest. ${ }^{119}$

\subsubsection{Incomplete information}

The first limitation for the European Commission when monitoring compliance lies in the limited nature of its monitoring competencies. Whereas the Commission has "very precise information" regarding the measures adopted by member states to transpose EU directives, ${ }^{120}$ the application of directives - and other EU measures for that matter - on the ground is "exceedingly difficult to monitor and to evaluate". ${ }^{121}$ Indeed, despite the hierarchical relationship between the Union and the member states and an emphasis on efforts to monitor the application of EU measures, ${ }^{122}$ the Commission is incapable of detecting all instances of noncompliance with EU legislation, leaving an unknown extent of noncompliance undetected. ${ }^{123}$ Concretely speaking, this incapacity is due to insufficiencies regarding the presence and functioning of the police-patrol and fire-alarm oversight powers that are available to the Commission. ${ }^{124}$

\footnotetext{
${ }^{118}$ Van den Bossche, 1996: 389ff.

${ }^{119}$ Note that this section starts from the assumption that the Commission actually wants to know what is happening on the ground. This, however, is not self-evident. Voermans argues that the EU institutions "do not always seem to be very keen to know" what is happening in this regard; "the overall sentiment [amongst the EU institutions] seems to be that after enactment, implementation is the [m]ember [s]tates business". See Voermans, 2014: 349. Given that the Commission has reinforced its efforts to improve the decentralised implementation of EU law, it seems that it will require an interest in attaining adequate information regarding the implementation performance of member states.

${ }^{120}$ Ciavarini Azzi, 2000: 53-54.

${ }^{121}$ Tallberg, 2002: 624; on the idea that it is more difficult for the Commission to monitor application and enforcement than transposition, see also Voermans, 2014: 348-49.

${ }^{122}$ For the latter element, see e.g. COM (2007) 502 final, p. 5. See Voermans, 2014, for an analysis of the efforts undertaken by the Commission in this regard.

${ }^{123}$ See e.g. Börzel, 2001; Voermans, 2014: 345.

124 The difference between police-patrol and fire-alarm oversight is discussed in Section 1.1.1.
} 
As for the Commission's police-patrol powers, it appears that the Commission has relatively few competencies that allow it to exercise direct oversight over ("first-line monitoring" of ${ }^{125}$ ) the implementation of EU measures on the ground, and that the tools that the Commission has at its disposal do not always produce reliable information. Following Article 4(3) TEU, and based on provisions in secondary legislative acts, there are numerous occasions in which the Commission has relied on the member states to provide it with reports on their implementation performances. The problem with this "paper implementation culture"126 is, however, that it relies on the will and capacity of member states to monitor and report on their implementation performance; two aspects that, for various reasons, are not to be taken for granted. ${ }^{127}$ The result is that reporting obligations are unlikely to be prioritised, ${ }^{128}$ and that when member states do report, such reports are "often and almost inevitably self-serving". ${ }^{129}$ While the accuracy of information provided by member states on the transposition of EU directives is capable of being verified by the Commission, this often does not apply to information on application practices.

Certainly, the Commission does order empirical studies on the administration of EU measures, and EU regulatory agencies may function as the eyes and ears of the Commission in the member states. Neither of these mechanisms can, however, compensate for the information gaps left by the self-reporting exercises of member states. Empirical studies are limited in scope and number, which means that they provide an incomplete picture of the practices of national regulatory authorities. And since they have largely remained information provision bodies without monitoring and inspection powers, ${ }^{130}$ the great majority of EU agencies do not provide the Commission with intelligence on the application of EU measures on the ground. Moreover, when agencies are granted inspection powers, their competencies may be compromised because of their dependence on the member states, which are wary about providing far-reaching inspection powers to agencies. ${ }^{131}$ The complicated relationship between the powers granted to regulatory agencies and the Commission's function as guardian of the treaties - which it is eager to protect - is a compromising factor as well. ${ }^{132}$

Fire-alarm mechanisms may complement police-patrol instruments; for example, they permit more truthful monitoring of member states than self-reporting. The problem with complaints, however, is that they are bound to provide selective insight into compliance problems, since civil society is not equally strong across member states and

\footnotetext{
${ }^{125}$ Voermans, 2014: 347.

${ }^{126}$ Ibid.: 345 .

${ }^{127}$ Ibid.: 347-48.

${ }^{128}$ Ibid.: 348 .

${ }^{129}$ Van den Bossche, 1996: 389.

${ }^{130}$ Geradin and Petit, 2004: 40.

${ }^{131}$ E.g. Groenleer et al. (2010) on the European Maritime Safety Agency (EMSA) and EASA.

${ }^{132}$ Ibid.: 1227-1228.
} 
across policy areas. Chapter 7 on civil society demonstrates that non-governmental organisations are more capable of acting as watchdogs of the state and of putting pressure on national authorities through supranational channels, such as the European Commission, in some countries than in others. ${ }^{133}$ It also elucidates that civil society is more active and vocal in some policy areas than in others, and that societal salience plays an explanatory role in this regard. ${ }^{134}$

Therefore, the distribution of complaints across countries and across policy areas does not necessarily indicate the relative compliance performance of member states or the comparative state of compliance in policy domains. Thus, while the United Kingdom, Italy, Germany, and Spain annually appear in the top three countries about which complaints are submitted most frequently, ${ }^{135}$ this does not mean that these countries are amongst the worst implementers. And while complainants report irregularities in particular in the environment, justice, and the internal market and services domains, ${ }^{136}$ this does not mean that EU law is violated most often in these domains. In other words, complaints may be helpful, but they ultimately provide selective and incomplete information about implementation practices across the board, just as police-patrol mechanisms do.

\subsubsection{Insufficient resources for verifying information}

A second reason for the Commission's incapacity to adequately monitor compliance relates to the lack of resources for it to use the information that is acquired through police-patrol instruments or fire-alarm mechanisms. Fire-alarm mechanisms, for example, seem useful when they work, but verifying the veracity of complaints that are submitted to the Commission takes resources - time and salaries - that the Commission, a small organisation, does not always have at its disposal. ${ }^{137}$ The same limitations apply to research reports commissioned by the Commission or by the Parliament, and to the

\footnotetext{
${ }^{133}$ See Chapter 7 on civil society, in particular Section 1.1.2. Börzel argues that societal activism does not explain the distribution of complaints across member states; she suggests that more factors play a role here (see Börzel, 2001: 809-810). However, it is clear that in order for complaints to be submitted, something like a functioning civil society should exist in the first place. A link between civil society activism and the number of complaints submitted to the Commission should, thus, exist. It may be that more civil society activism does not go hand in hand with more complaints. This is logical, since countries with stronger civil societies may be better compliers in the first place or be moved into compliance by the watchdog function of NGOs at the national level. Other factors (e.g. population size) may play a role as well. For the idea that civil society activism varies across policy areas, see e.g. Börzel, 2000: 150-158.

${ }^{134}$ See Chapter 7 on civil society, Section 3.

${ }^{135}$ Analysis of the latest five Annual reports on monitoring the application of EU law; see the first Statistical Annex of the $26^{\text {th }}, 27^{\text {th }}$, and $28^{\text {th }}$ reports and the main document regarding the $29^{\text {th }}$ and $30^{\text {th }}$ reports, on $<$ http://ec.europa.eu/atwork/applying-eu-law/infringements-proceedings/annual-reports>.

${ }^{136}$ Figures for 2011; see Commission, '29 $9^{\text {th }}$ Annual report on monitoring the application of EU law' (Report) COM (2012) 714 final, p. 6.

${ }^{137}$ Peters, 1997: 193. In 2012, the number of complaints submitted to the EU reached over 3,100, against nearly 800 own-initiative cases. See COM (2013) 726 final, pp. 6-7.
} 
reports that member states submit about their own performance. When such reports raise questions, the Commission must verify the relevant information in order to confirm an assumption of noncompliance. However, even if reports do not signal wrongful application practices, the Commission may still want to check if the information provided (by member states in particular) is truthful, by conducting spot checks for example. Such checks are, however, time consuming, and insufficient material resources may prevent them from being implemented. Moreover, spot checks are a matter of political tension and can be blocked by member states. ${ }^{138}$ When they are conducted, they are similar to fact-finding missions, rather than investigations of suspected instances of noncompliance. ${ }^{139}$

Next to resources of a financial and political nature, the Commission also needs knowledge and expertise to appreciate the complexity of national administrative systems and the different ways in which EU measures may be implemented. ${ }^{140}$ Insufficiency is an issue of concern here as well, since the skills of Commission personnel traditionally fall in the area of policy formulation, rather than in the domain of implementation. ${ }^{141}$ Even though implementation has become "a key part of the EU agenda", the processes of learning how to ensure effective implementation and applying relevant lessons are bound to be lengthy and difficult. ${ }^{142}$

Moreover, the move of the EU into an increasingly diverse set of policy areas, which are sometimes less tractable than the original fields of EU activity, demands expertise from Commission officials that these officials may not (yet) command. ${ }^{143}$ The results of these shortages must be selectivity and prioritisation on the part of the Commission when handling information about breaches of EU law. ${ }^{144}$ Selective monitoring may be essential when resources are scarce, and it is adequate when instances of noncompliance that create no serious risks under given circumstances are overlooked. ${ }^{145}$ The problem, however, is that it is hard to believe that the Commission is capable to identify and examine all major infringements.

\footnotetext{
${ }^{138}$ Börzel, 2001: 809.

${ }^{139}$ Ibid.

${ }^{140}$ The notion that time is a scarce good appears in the deadline set by the Commission to respond to complaints. The general rule is that the Commission may take up to one year after the date of registry of the complaint, but exceeding this deadline is possible. See COM (2012) 154 final; 8: Time limits. In a 2007 Communication, the Commission still mentioned that the average period between the reception of a complaint by the Commission and the sending of a formal notice to the relevant member state is 19 months. See COM (2007) 502 final, p. 5.

${ }^{141}$ Ludlow, 1991: 107.

${ }^{142}$ Dimitrakopoulos and Richardson, 2001: 356.

${ }^{143}$ Peters, 1997: 194.

${ }^{144}$ Prete and Smulders, 2010: 17; Börzel and Hofmann, 2012: 456.

${ }^{145}$ Ibáñez, 1999: 203-204.
} 


\subsubsection{Sanctions}

The effectiveness of sanctions is determined by the extent to which they solve infringements and deter member states from infringing EU law in the first place. While sanctions at the EU level are said to work quite effectively, as all instances of noncompliance do get solved eventually, ${ }^{146}$ this statement must be counterbalanced by awareness of the problems faced by the Commission in relation to the implementation of sanctions. Given the limited literature about how the Commission applies naming and shaming strategies, ${ }^{147}$ the following sections focus on the downsides of infringement proceedings that may be initiated by the Commission under Articles 258 and 260 TFEU.

\subsubsection{Restraint with the imposition of sanctions}

Sanctions are credible instruments only when defection is sanctioned consistently. The manner in which the Commission resorts to infringement proceedings does, however, suggest that this consistency is not a matter of course. The Commission exercises restraint when it comes to initiating infringement proceedings under Article 258 TFEU and requests for the Court to impose financial sanctions on member states under Article 260 TFEU. This restraint is particularly clear with regard to the latter type of proceedings. ${ }^{148}$ Practice shows that the Commission has rarely started Article 260 TFEU proceedings when it has had the power to do so, and that it has in such cases resorted to a new set of Article 258 TFEU proceedings instead. This practice undermines the objective of Article 260 TFEU proceedings. ${ }^{149}$ The objective of these proceedings was also undermined when the Commission did initiate Article 260 TFEU proceedings but refrained from asking for a penalty, ${ }^{150}$ and for cases in which the Court abstained from imposing a lump sum without providing adequate reasoning. ${ }^{151}$

The limited extent to which the Commission exercises its competencies under Article 260 TFEU is paired by the fact that when sanctions were requested and imposed, the Commission waived the obligation for a member state to pay its fine in at least one case. In three other cases, information about the execution of Article 260 TFEU judgements is

\footnotetext{
${ }^{146}$ Panke, 2010.

${ }^{147}$ Outside of the area of the open method of coordination (OMC), one may argue. Note, however, that although naming and shaming was, in political documents, foreseen as an important instrument in the OMC, other mechanisms - in particular those of learning - dominate the scholarly literature. See Kröger, 2009: 4, 6. In other words, even in an area that one would - given the importance that naming and shaming is (at least in theory) endowed with - expect quite some literature on naming and shaming to exist, this expectation is incorrect.

${ }^{148}$ Since information about the degree to which the Commission starts Article 260 TFEU proceedings is more readily available than information about the rate of noncompliance cases sued by the Commission in the first place.

${ }^{149}$ Wennerås, 2012: 153.

${ }^{150}$ Peers, 2012: 58.

${ }^{151}$ Wennerås, 2012: 163.
} 
absent. ${ }^{152}$ Given the limited number of cases in which the Court did impose a penalty on member states - twelve between 2000 and $2010^{153}$ - these numbers are significant. The result of the Commission's inconsistent stance on sanctions is that "member states may not perceive the sanctions as a serious threat" until the Commission actually starts a procedure requesting fines ${ }^{154}$, or until the Court actually imposes them. The wider consequence is a reduced probability of member states being dissuaded from continuing their infringements, and an expectation that the "number of unimplemented judgements will only start to decrease permanently if fines are recommended as a matter of course by the Commission and imposed regularly by the Court" ${ }^{155}$ Note that a more systematic stance from the Commission on this topic is not an issue that the Commission proposes in its latest communication about the implementation of Article 260 TFEU.

The Commission shows restraint in the initiation of infringement proceedings because such restraint is legitimate and, in view of the capacity limitations of the Commission, it is necessary. As for the legitimacy element, reference must be made to Section 1.1.2.2.1, which shows that CJEU case law grants the Commission discretionary power to decide whether or not to start infringement proceedings, and whether or not to refer a case to the Court. In relation to the necessity element, reference should be made to the idea that selective sanctioning is in fact an important element of a good enforcement policy. Adequately acting supervisory institutions do not impose sanctions if this would be especially disruptive or costly in relation to the benefits that it would provide. Besides, 'good' supervisors grant a reasonable period of time in which to comply, and accept measures that provide substantial - rather than full - compliance, taking into account good faith efforts on the part of regulatory authorities. ${ }^{156}$

If we accept the propositions outlined above, selective sanctioning may be justified, particularly when supervisory bodies are confronted with capacity limitations. Regarding the European Commission, one of the reasons for the Commission's reluctance to make full use of its power to start infringement proceedings relates to the fact that these proceedings are tedious, time consuming, and - given the complexity of national implementation styles and administrative structures - demanding for Commission personnel. ${ }^{157}$ In view of this burden, coupled with the capacity limitations suffered by the

\footnotetext{
${ }^{152}$ Peers, 2012: 52.

${ }^{153}$ Numbers retrieved from Peers, 2012: 61.

154 Theodossiou, 2002: 42 and 45, in Peers, 2012: 58.

${ }^{155}$ Ibid.

${ }^{156}$ Ibáñez, 1999: 203-204; on the Commission's discretion regarding the initiation of infringement proceedings, see $231 \mathrm{ff}$. The idea that compliance does not have to be full for it to be 'good enough' is, however, not accepted by the Commission and by the Court; neither institution has accepted member state arguments justifying EU law violations. See Section 1.1.2.2.1, sub C, above.

${ }^{157}$ E.g. Joachim et al., 2008: 182; Tallberg, 2002: 626; Munoz, 2006: 16.
} 
Commission as outlined in Section 1.2.1.2, the selective stance on the part of the Commission is logical.

The Commission's sanctioning policy is, however, not fully explained by these factors. The Commission's reluctance to start infringement proceedings is also motivated by concerns about the potential political costs associated with sanctioning. These political costs result from the Commission's dual role as an agenda-setter and a broker in the EU decision-making process, and as guardian of the treaties. As a guardian, the Commission has the power to punish defecting member states - but using this power may compromise its position when it initiates policy and mediates between member states in the Council. In order to secure member state support in the agenda-setting and decision-making stages of the policy cycle, the Commission may want to exercise selfrestraint and compromise its role as a guardian. ${ }^{158}$ This may result in the Commission treating large member states more carefully than small member states, because the former are more powerful and indispensable than the latter when adding issues to the agenda or adopting legislative acts. ${ }^{159}$

Self-restraint may also follow from an appreciation of the possible reputational costs associated with a determined stance on the part of the Commission as guardian of the treaties. Certainly, given the relative brevity of the European integration project and of the EU as a political system, a failure to enforce laws may be a threat to the sovereignty of the EU. ${ }^{160}$ The Commission, however, faces the challenge of "balancing the need for uniformity and legality with the need to utilise some 'rule of reason' to prevent offending the less committed Europeans". ${ }^{161}$ The "politics-of-reputation game" that follows from this challenge may lead the Commission to act as a strong guardian in certain cases and to tolerate noncompliance in others, ${ }^{162}$ while at the same time attempting to balance the need to maintain its credibility as an impartial and unbiased guardian. ${ }^{163}$

Next to capacity limitations and the reputational and political costs that may withhold the Commission from starting infringement proceedings, is the lack of enforceability of some EU rules. In order to be suitable for implementation, EU legislation must be clear and unambiguous, while at the same time accounting for the different characteristics of member states, including the different legal and administrative cultures. ${ }^{164}$ This is

\footnotetext{
${ }^{158}$ Lampinen and Uusikylä, 1998: 233. For the argument that the Commission may also use its rights in the infringement procedure to influence Council negotiations beyond the agenda-setting phase, see Schmidt, 2000.

${ }^{159}$ It is argued that implementation deficits serve to balance national and supranational elements in the EU, and that they are therefore hard to eradicate; see Jordan, 1999.

${ }^{160}$ See Chapter 1 on making EU law work: a problem in need of a solution, Section 1.

${ }^{161}$ Peters, 1997: 194.

${ }^{162}$ Joachim et al., 2008: 189.

${ }^{163}$ Börzel and Knoll, 2012: 8. Systematic biases towards member states are therefore undesired and unlikely; see Börzel and Knoll, 2012: 8-9. See Börzel, 2001: 812, for the idea that statistics do, in fact, not show such biases.

${ }^{164}$ Ibáñez, 1999: 27-34, on enforcement. These conditions clearly apply to the other phases of the implementa-
} 
difficult to achieve, evidenced by the fact that the quality of EU legislation has been subject to considerable criticism, ${ }^{165}$ and by the notion that 'better' or 'smart' regulation is deemed indispensable to improving the implementability of EU measures on the part of member states. ${ }^{166}$ Better legislation is also indispensable to the enforceability of legislation and the legitimacy of enforcement action taken by the Commission, since, one may argue, member states should not be punished for noncompliance with norms that cannot realistically be applied. This notion may withhold the Commission from taking enforcement action in many cases.

\subsubsection{Variable impact of sanctions}

Consistency in the imposition of sanctions does not suffice for such sanctions to be effective; sanctions must also be a sufficient deterrent in order for member states to be compelled to comply. The extent to which sanctions have a deterrent effect is determined by factors that are inherent in the use of sanctions and by factors that are external to it. Both types of factors are discussed in the following subsections.

\subsection{Internal factors}

An example of internal factors - factors that the Commission and/or the Court can, in theory, control - is the extent to which implementation records are publicly available. In relation to this issue, reference should be made to the idea that the Commission seems rather careful when it comes to imposing social costs on member states. Section 1.1.1 suggests that transparency of member states' implementation performances may be contained to a closed group of national officials that gather at the EU level. If we assume, as conventional wisdom states, that the effectiveness of naming and shaming increases with a wide availability of information about the performances of member states, then naming and shaming 'amongst intimae' may not be a particularly effective method of sanctioning poorly performing states. Note also, that inspection reports prepared by EU regulatory agencies are not available to the public; they are addressed to the Commission for follow-up action and sometimes distributed to other national authorities. ${ }^{167}$ While inspection reports may trigger action under Article 258 TFEU, the public naming and shaming effect of such reports is clearly null. In view of the Commission's choice to

\footnotetext{
tion process as well.

165 The Commission itself has at several occasions reiterated the notion that EU law "may be vague or difficult to implement" indeed. Quote taken from COM (2007) 502 final, section II. See also e.g. COM (2001) 428 final; Commission, 'A strategic review of better regulation in the European Union' (Communication) COM (2006) 689 final; Commission, 'EU regulatory fitness' (Communication) COM (2012) 746 final.

${ }^{166}$ Radaelli and De Francesco, 2007: 5. For a critical account of the challenges related to the transposition of EU norms after the introduction of the Commission's Smart Regulation agenda, see Xanthaki, 2014.

${ }^{167}$ Schout, 2008: 282, 284, on EASA inspection reports; Groenleer et al., 2010, on EMSA and EASA inspection reports.
} 
restrict publicity regarding ongoing infringement proceedings, ${ }^{168}$ similar remarks apply in relation to such proceedings.

Internal to financial sanctions is their size; one may point out that low sanctions are unlikely to provide a meaningful impetus for member states to comply. ${ }^{169}$ In this context, the sanctions imposed by the Court are, in some cases, referred to as "hardly sufficient to prevent similar infringements from recurring". ${ }^{170}$ For example, practice shows that the Court typically adds some mitigating circumstances for member states when deciding on the size of lump sums. The Court has usually decided on considerably lower lump sums than those proposed by the Commission, and has imposed lump sums that broadly correspond to or fall below the level of the minimum lump sums indicated for the member state in question in the Commission's guidelines. Penalty payments handed down by the Court were, in all but one case, below the penalty payments proposed by the Commission, and in some cases considerably so. ${ }^{171}$ It is argued that in order for penalty payments to maintain their deterrent effect, the Court must not outline conditions that "in practice allow the $[\mathrm{m}]$ ember $[\mathrm{s}]$ tates to escape penalty payments altogether", ${ }^{172}$ regarding - for example - the suspension and the frequency of payments.

It is not only the size of the sanctions, but also the time that it takes to impose them that does not seem to qualify as particularly dissuasive. Infringement proceedings may take several years, ${ }^{173}$ and member states may - materially speaking - have much to gain by continuing to defect in the meantime, particularly in view of the relatively low penalties that member states may eventually incur. The recent introduction of the opportunity for the Commission to ask the Court to impose penalties on member states during the Article 258 TFEU proceedings that are started for non-notification, does little to improve the situation for cases revolving around the application of EU measures. ${ }^{174}$ The removal of the reasoned opinion stage from Article 260(2) TFEU proceedings is intended to significantly speed up the resolution of infringement cases in general, ${ }^{175}$ but the outcome of the resulting fast-track administrative procedure remains to be seen. The notion that the Commission remains obliged to start separate proceedings against

\footnotetext{
${ }^{168}$ Munoz, 2006: 33.

${ }^{169}$ See e.g. Jans et al., 2007: 199, on financial sanctions.

${ }^{170}$ Wennerås, 2012: 145.

${ }^{171}$ Ibid.: 160 (penalty payments), 164-165 (lump sums).

${ }^{172}$ Ibid.: 162 .

${ }^{173}$ The Commission states that it takes an average of 19 months to close a complaint before a letter of formal notice is sent; 38 months when a case is closed between the letter of formal notice and reasoned opinion; and 50 months when the case is closed after the reasoned opinion and before the case is sent to the Court, producing an average time for all cases of 26 months. See COM (2007) 502 final, section II. For figures across member states and policy domains, see Börzel and Knoll, 2012: 19-20.

${ }^{174}$ For an elaboration, see Section 1.1.2.2.3 above. Prospects regarding the effectiveness of Article 260(3) do not seem to be positive. For critical remarks on the expected functioning of Article 260(3), see e.g. Wennerås, 2012; and Peers, 2012.

${ }^{175}$ For an elaboration, see Section 1.1.2.2.3 above.
} 
member states for the imposition of sanctions has been referred to as "unnecessarily onerous" for the Commission and for the Court, since member states do not usually dispute the Commission's action taken pursuant to Article 258 TFEU, rather they dispute the imposition of sanctions under Article 260 TFEU. ${ }^{176}$

\subsection{External factors}

While the previous section suggests that there are inherent faults in the use of sanctions that may prevent them from effectively compelling member states into compliance, factors external to the use of sanctions are also to blame for this suboptimal effect. This is the case since, while sanctions are designed to affect member states equally and proportionally, member state governments appear to react unequally to them, with some member states complying swiftly once infringement proceedings are initiated and others dragging their feet. Generally speaking, Italy, France, and Germany take the longest time to end infringement proceedings. ${ }^{177}$ Austria, Sweden, and Luxembourg take the shortest amount of time. ${ }^{178}$ Differences do not solely exist across member states; they also exist across policy domains. Statistics show, for example, that infringements in the domains of taxation and employment generally take the longest time to resolve, while cases in the domain of enterprise policy generally end quickly. ${ }^{179}$ These cross-country and crossissue differences imply that the effectiveness of sanctions that should be the same for everyone and in every domain is in fact unequal across the board.

It is clear that factors, which are external to the design of sanctions, play an explanatory role here. Comprehensive explanations for the differences in 'reaction time' across policy domains do not seem to exist, although cases in positive policy sectors that is, sectors with a market correcting dimension - seem to take longer to settle. ${ }^{180}$ As far as inter-country differences are concerned, the political and economic power of member states seems to play an important determinative role. It has been suggested that the more power a member state has, the less sensitive it is to the material and reputational costs that come with the prosecution of noncompliance cases. This means that powerful states are likely to undergo more stages before settling infringement cases. ${ }^{181}$

Moreover, a lack of government autonomy from domestic veto players is said to increase the probability of cases moving to the later stages of the infringement procedure, since veto players may want to oppose change and keep the government in a vice-

\footnotetext{
${ }^{176}$ Wennerås, 2012: 174.

${ }^{177}$ Börzel and Knoll, 2012: 19. Countries with the most outspoken outliers (that is, with cases that take much longer than average for that particular country) are France, Italy, Belgium, the UK, the Netherlands, Denmark, and Luxembourg.

${ }^{178}$ Ibid.: 19.

${ }^{179}$ Ibid.: 20.

${ }^{180}$ Börzel et al., 2011: 18.

${ }^{181}$ Börzel and Hofmann, 2012 458, 464.
} 
like grip. ${ }^{182}$ High levels of bureaucratic efficiency, in contrast, are said to have a positive effect on the speediness of conflict resolution; if a country's bureaucracy is efficient, then fewer cases will make it to the later stages of infringement proceedings. ${ }^{183}$ While these are all issues that the Commission can do little about - let alone control - member state characteristics do mediate the overall effectiveness of the infringement procedure as an instrument for solving EU law breaches smoothly and swiftly across the board.

\section{Monitoring and sanctioning instruments relevant to this study}

This section outlines the monitoring and sanctioning tools relevant to this study. Specifically, the focus is on monitoring instruments (Section 2.1), naming and shaming strategies (Section 2.2), and infringement proceedings (Section 2.3).

\subsection{Monitoring instruments}

Analysis of the implementation context of the three directives included in this study suggests that the Commission has several tools at its disposal that allow it to gain insight into the application performance of member states. Table 7 lists these mechanisms; the following subsections further elaborate on them.

Table 7 Monitoring mechanisms

\begin{tabular}{|c|c|c|c|}
\hline & GPS & IPPC & SAFA \\
\hline \multicolumn{4}{|l|}{ Police-patrol oversight } \\
\hline Self-reporting & Yes & Yes & Yes \\
\hline External research & Yes & Yes & No \\
\hline Inspections of inspectors & No & No & Yes \\
\hline Fire-alarm oversight ${ }^{184}$ & 3 complaints & 60 complaints & No complaints \\
\hline
\end{tabular}

\subsubsection{The GPS Directive}

The GPS Directive includes a general obligation for member states to "provide the Commission with all the necessary assistance and information", when the Commission

\footnotetext{
${ }^{182}$ Ibid.: 460, 464. See also e.g. Jensen, 2007.

${ }^{183}$ Ibid.: 463. The authors found that capacity did not have a significant effect on the speed compared to the number of stages in the infringement procedure through which states settle noncompliance cases.

${ }^{184}$ Complaints submitted to the European Commission on the application of the Directives that were not rejected as "completely out-of-scope" (interview EC8) and that were not solved during pre-infringement proceedings. Note that these complaints were not necessarily acted upon. Rather, they were regarded as eligible to move forward in formal infringement proceedings. Data from the Commission's internal database was received by email from an anonymous Commission official in February 2014.
} 
conducts assessments of implementation practices and prepares reports. ${ }^{185}$ Interviews suggest that the Commission has, on several occasions, requested that the member states fill in questionnaires about market surveillance of products falling under the GPS Directive. External research reports exist as well. These reports address the approaches used by competent authorities for risk assessments, ${ }^{186}$ and the organisation of market surveillance in the member states more generally. ${ }^{187}$ Complaints do not seem to play a large role in the context of the GPS Directive; figures show that the Commission received only three complaints that were capable of moving forward to formal infringement proceedings. The available data does not provide insight into the sources of these complaints.

\subsubsection{The IPPC Directive}

Unlike the GPS Directive, the IPPC Directive includes a concrete reporting requirement for member states. This requirement states that once every three years, member states must report information about their permitting status to the Commission through a Commission questionnaire; for example, information must be reported on the number of new and existing IPPC installations, and on the number of installations that have been granted a permit. ${ }^{188}$ Consultancies were asked to conduct studies on the quality of permits issued for IPPC installations. ${ }^{189}$ Of the sixty complaints that were eligible for the initiation of formal infringement proceedings, fire-alarm oversight was a relatively important monitoring mechanism in the area of integrated pollution prevention and control. The sources of these complaints could not be derived from the available information.

\subsubsection{The SAFA Directive}

In the context of the SAFA Directive, the Commission relies on intelligence gathered by the European Aviation Safety Agency. Information about the implementation performance of member states is gained, first, through the ramp inspection reports that national civil aviation authorities feed into the centralised SAFA database maintained by EASA. ${ }^{190}$ Inspections carried out by EASA of the national civil aviation authorities are a potentially rich source of such information as well. These inspections may include ad hoc visits to national authorities ${ }^{191}$ and standardisation inspections ${ }^{192}$ that member states

\footnotetext{
${ }^{185}$ Directive 2001/95/EC, Art. 19(2).

${ }^{186}$ Risk \& Policy Analysts, 2006 (commissioned by the Commission).

${ }^{187}$ Ramboll Management Consulting, 2009 (commissioned by the European Parliament).

${ }^{188}$ Directive 2008/1/EC, Art. 17(3).

${ }^{189}$ E.g. Entec, 2007, 2010.

${ }^{190}$ Directive 2004/36/EC, Art. 5(2), in conjunction with Commission Regulation 768/2006, Art. 3.

${ }^{191}$ Commission Regulation (EC) No 736/2006, Art. 16; see further below.

${ }^{192}$ Regulation (EC) No 1592/2002 of the European Parliament and of the Council of 15 July 2002 on common
} 
are subject to on a regular basis. Standardisation inspections are conducted by the EASA standardisation team, which is headed by an official from EASA, and includes at least two other members who may be EASA officials and/or staff seconded by the national aviation authorities. ${ }^{193}$ Standardisation inspections are carried out in cooperation with the national authorities; as such, they are an example of "cooperative supervision". ${ }^{194}$ The steps that are involved in the inspection process are shown in Figure 4 and discussed in detail below.

The authority that is to be inspected is notified of inspections in advance and asked to fill out a questionnaire before the visit of the EASA standardisation team. ${ }^{195}$ The team subsequently conducts on-site visits of the relevant offices of the national aviation authority. ${ }^{196}$ It carries out interviews with relevant staff members and with any other desirable person, for the purpose of collecting information that is relevant to the subject matter of the inspection. Relevant documents are examined as well. ${ }^{197}$ This on-site inspection ends with the presentation of a preliminary report to the authority that includes possible comments provided by the authority itself and, if necessary, requests that the authority take immediate effective remedial action to eliminate a direct safety hazard. ${ }^{198}$ The team must request evidence of such remedial action during the closing meeting with the SAFA national coordinator, after which the final report is drawn up. ${ }^{199}$ This report is communicated to the aviation authority, to the member state, and to the Commission. The latter may decide to transmit the report to all national aviation authorities. ${ }^{200}$

rules in the field of civil aviation and establishing a European Aviation Safety Agency, OJ [2002] L 240/1, Arts 16(1) and 45(1). In fact, all SAFA participating states - and not only EU member states - are subject to such inspections.

${ }^{193}$ Commission Regulation (EC) No 736/2006, Art. 6(1) and (2).

${ }^{194}$ Hofmann et al., 2011: 755.

${ }^{195}$ Commission Regulation (EC) No 736/2006, Art. 8.

${ }^{196}$ Ibid., Art. 9(1), sub b.

${ }^{197}$ bid., Art. 9(1), sub c and 9(2).

${ }^{198}$ bid., Art. 9(1), sub d.

${ }^{199}$ bid., Art. 9(1), sub e.

${ }^{200}$ bid., Art. 10. 


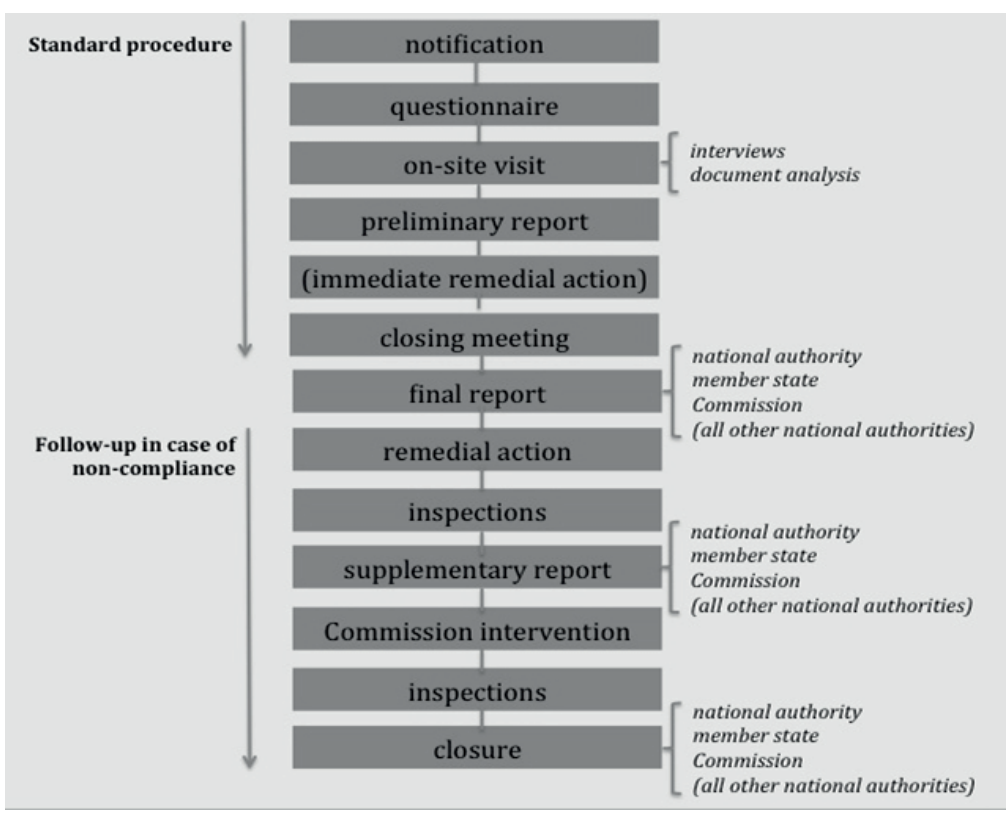

Figure 4 EASA standardisation inspections

When the standardisation team detects instances of noncompliance, it must agree with the authority on an action plan. This plan may request clarifications or remedial action and define the relevant time frame within which such action must be taken. ${ }^{201}$ EASA must monitor progress on the part of the inspected authority in this regard, for example by conducting additional inspections. ${ }^{202}$ When EASA is not satisfied with the action taken, it must address a supplementary report to the authority, to the member state concerned, and to the Commission. The latter may transmit the report to all national aviation authorities. ${ }^{203}$ The Commission may intervene by addressing questions or comments to the member state concerned, or require the Agency to carry out the necessary inspections to check the implementation of remedial actions. ${ }^{204}$ Once satisfied with the progress achieved by the authority, EASA must issue a statement of closure of the findings to the authority, the member state, and the Commission. ${ }^{205}$

While each member state is subject to regular EASA standardisation inspections, this is not true of ad hoc inspections conducted by the Agency. Such inspections are conducted when the Commission deems them necessary for safety reasons. ${ }^{206}$ Whereas

\footnotetext{
${ }^{201}$ Ibid., Art. 11(a) and 15(2).

${ }^{202}$ Ibid., Art. 11(b) and 15(1).

${ }^{203}$ Ibid., Art. 15(3).

${ }^{204}$ Ibid., Art. 15(4).

${ }^{205}$ Commission Regulation (EC) No 736/2006, Art. 12.

${ }^{206}$ Ibid., Art. 16.
} 
all EU member states have been subject to standardisation inspections, which have been carried out since 2009, ad hoc inspections have not yet been conducted. ${ }^{207}$

\subsection{Naming and shaming}

Section 1 of this chapter clarifies that naming and shaming strategies involve the use of quantitative or qualitative indicators that publicly benchmark the implementation performance of member states. The extent to which transparency is provided varies; the relevant information may be restricted to a select group of national officials or available to the public at large. Table 8 provides an overview of possible naming and shaming instruments for each of the directives included in this study. The following subsections discuss reports with a general scope (that is, reports that are not drawn up to discuss the implementation of specific EU measures), and transparency mechanisms for each of the three directives individually.

Table 8 Naming and shaming mechanisms

\begin{tabular}{lccc}
\hline & GPS & IPPC & SAFA \\
\hline General EC reports & Yes & Yes & Yes \\
Implementation reports & Yes & Yes & Yes \\
Public online databases & Yes & Yes & No \\
Research reports & Yes & Yes & No \\
Information for authorities only & Yes & Yes & Yes \\
\hline
\end{tabular}

\subsubsection{General Commission reports}

The Commission publishes a number of general reports showcasing, at least to some extent, the implementation performance of member states. The Commission's annual reports on monitoring the application of EU law are an example of such general reports. ${ }^{208}$ These reports were previously 500-page long documents, providing detailed information about (the stages reached of) infringement proceedings launched against individual member states for particular legislative acts. This level of detail has been compromised since 2011; the latest annual reports are much shorter, include less text and more graphical illustrations, and present more global and selective information for each member state. ${ }^{209}$ The Commission believes that the design of the recent reports is

\footnotetext{
${ }^{207}$ Email from interviewee EASA1 to author.

${ }^{208}$ These reports can be found on the Commission's website; see European Commission, 'Annual reports on monitoring the application of EU law',

<http://ec.europa.eu/atwork/applying-eu-law/infringements-proceedings/annual-reports >

${ }^{209}$ One presumably must resort to the Commission's website and use the search tool to check for regular updates on Commission decisions against allegedly noncomplying member states; European Commission, 'Infringement decisions', <http://ec.europa.eu/atwork/applying-eu-law/infringements-
} 
"more attractive" than that of the earlier reports. It also believes that this new design triggers more interest from actors such as the European Parliament, member states, and civil society organisations, and that the latest reports have created more of a naming and shaming effect than previous editions. ${ }^{210}$

Since 1997, the Commission has published internal market scoreboards on a regular, generally biannual, basis. ${ }^{211}$ These reports benchmark the performance of member states regarding the transposition of single market measures, and compare the number of infringement proceedings started against individual member states. Since the reports do not permit cross-policy comparisons to be made, they provide global insight into the performance of member states. The internal market scoreboard should not be confused with the single market scoreboard. ${ }^{212}$ The single market scoreboard, which is found online, presents a comparative 'performance overview' of all member states regarding the implementation of single market governance tools, and member state specific information regarding the evolution of transposition deficits and infringement proceedings. As is the case for the latest editions of the internal market scoreboard, the single market scoreboard presents examples of best practices regarding member state initiatives that are implemented to reduce the transposition deficit or improve the settlement of infringement proceedings.

\subsubsection{The GPS Directive}

Commission reporting on the implementation of the GPS Directive has been rather irregular. In fact, only a single implementation report has been published to date. ${ }^{213}$ The report is not specific concerning the application of the GPS Directive. It states that market surveillance has been "successful" - but it simultaneously refers to the adoption of a legislative package that should make key provisions of the GPS Directive more stringent for member states. ${ }^{214}$ Differences regarding the implementation performance of member states are not expressly stated. Overall, it seems that this report is not aimed at naming and shaming poorly complying member states, rather it is aims to propagate the idea of how "powerful [a] tool for ensuring a high level of consumer protection" the GPS Directive "has proven to be". ${ }^{215}$

\footnotetext{
proceedings/infringement_decisions $>$.

${ }^{210}$ Interview EC8.

211 These reports can be found on European Commission, 'The Internal Market Scoreboard', $<$ http://ec.europa.eu/internal_market/score $>$.

212 These reports can be found on European Commission, 'Single Market Scoreboard', $<$ http://ec.europa.eu/internal_market/scoreboard/>. Note that the name of this link is deceptive; while the name suggests a link to the Commission's internal market scoreboard - which is different from the Commission's single market scoreboard - it does in fact lead to the the latter type of scoreboard.

${ }^{213}$ Commission, 'Report on the Implementation of Directive 2001/95/EC of the European Parliament and of the Council of 3 December 2001 on General Product Safety' (Report) COM (2008) 905 final.

${ }^{214}$ Ibid., pp. 13, 6. The Commission's proposal for a Regulation on general product safety is now, at the time of writing, being negotiated in Council and Parliament.

${ }^{215}$ Ibid., p. 12.
} 
In contrast to the silence on the performance of member states in the Commission's implementation report, are the more explicit references to this subject in the annual reports on the functioning of RAPEX. ${ }^{216}$ These reports publish statistics for notifications of dangerous consumer products submitted by the national authorities to the Commission during previous years; they expressly list the five most frequently notifying countries. ${ }^{217}$ The relevance of this ranking is nuanced by the Commission, which states that the participation rate of countries is a result of various factors, such as the size of these countries and the production and market structures that characterise them. ${ }^{218}$ In other words, it is difficult to compare the implementation performance of countries, based only on an assessment of the numbers of products reported through RAPEX (or on reactions by market surveillance authorities to RAPEX notifications). ${ }^{219}$ Similar remarks apply to the Commission's monthly updates on the number of RAPEX notifications and member state reactions to such notifications, ${ }^{220}$ and to its weekly reports specifying product risks. $^{221}$

Similar remarks apply to external research reports as well. Some of these reports provide precise descriptions of national performances regarding the transposition of the GPS Directive and merely offer general descriptions of how aspects of the GPS Directive are put into effect by the market surveillance authorities. ${ }^{222}$ Others do focus on the practical sides of market surveillance. ${ }^{223}$ These reports may, for example, say something about the resources available for market surveillance, provide numbers in relation to specific market surveillance indicators, and outline the strengths and weaknesses of market surveillance throughout the EU. ${ }^{224}$ None of these reports, however, explicitly aim to benchmark member state performances. In fact, they seem incapable of doing so since raw numbers are hard to compare and they rely on self-reporting by - sometimes only a selection of - member states:

\footnotetext{
${ }^{216}$ RAPEX is the EU's Rapid Alert System for dangerous non-food products; see further Chapter 6 on transnational networks, Section 2.1. For all reports, see European Commission, 'RAPEX: Statistics and Reports', $<$ http://ec.europa.eu/consumers/archive/safety/rapex/stats_reports_en.htm $>$. Since the nature of the information provided in these reports has basically remained the same, the latest report will, for the purpose of simplicity, serve as a reference.

${ }^{217}$ Commission (2013), 'Keeping European Consumers Safe. 2012 Annual Report on the operation of the Rapid Alert System for non-food dangerous products RAPEX', Luxembourg: Publications Office of the European Union, pp. 15-18.

${ }^{218}$ Ibid.: 18.

${ }^{219}$ Ibid.: $30-32$.

${ }^{220}$ See on European Commission, 'RAPEX: Statistics and Reports', $<$ http://ec.europa.eu/consumers/archive/safety/rapex/stats_reports_en.htm>.

${ }^{221}$ See on European Commission, 'Rapid Alert System for non-food products posing a serious risk (RAPEX)', $<\mathrm{http}: / /$ ec.europa.eu/consumers/safety/rapex/index_en.htm>.

${ }^{222}$ E.g. Baker\&McKenzie, 2006.

${ }^{223}$ E.g. BSI Development Solutions, 2011; Risk \& Policy Analysts, 2006.

${ }^{224}$ E.g. BSI Development Solutions, 2011.
} 
Not all member states collect the detailed information that is required to complete the questionnaire accurately [and] there appear to be very few correlations between the outcome data provided by the Eurobarometers and the input and output indicators provided by member states [market surveillance authorities]. ${ }^{225}$

The limited availability and comparability of data across member states was also problematic for the first consumer scoreboards, ${ }^{226}$ which the Commission has published since 2008. ${ }^{227}$ These problems seem to be less urgent for subsequent scoreboards; these scoreboards do not compare the performances of member states, rather they compare consumer and retailer perceptions of product safety across these same member states, ${ }^{228}$ and retailer perceptions of compliance monitoring by market surveillance authorities. ${ }^{229}$ A number of Eurobarometers present country-specific figures on similar issues. ${ }^{230}$

\subsubsection{The IPPC Directive}

The Commission has published three communications on the implementation of the IPPC Directive. These reports, which are based on self-reporting by member states, are specific concerning the member states that have failed to meet the transposition deadline. In relation to the application of the directive, the Commission's first implementation report refers to an earlier report that evaluated the performance of member states as "largely satisfactory". It does not refer to individual member states that are not considered to perform adequately. ${ }^{231}$ The Commission does name member states in its second implementation report. Here it not only points out that there is cross-country variation in the numbers of IPPC permits issued, it also refers to individual member states that

\footnotetext{
${ }^{225}$ Ibid.: 5 .

${ }^{226}$ Commission, 'Monitoring Consumer Outcomes in the Single Market: the Consumer Markets Scoreboard' (Communication) COM (2008) 31 final, p. 9.

${ }^{227}$ For these scoreboards, European Commission, 'Consumer Scoreboard',

$<$ http://ec.europa.eu/consumers/archive/consumer_research/cms_en.htm>. For the purpose of simplification, in this paragraph, reference will solely be made to the latest scoreboard.

${ }^{228}$ Commission, 'The Consumer Conditions Scoreboard - Consumers at home in the single market' (Working Document) SWD (2013) 291, pp. 37-42.

${ }^{229}$ SWD (2013) 291: 37.

${ }^{230}$ E.g. Commission (2006), 'Special Eurobarometer 252. Consumers protection in the internal market'; Commission (2008), 'Special Eurobarometer 298. Consumer protection in the internal market'; 'Eurobarometer 299. Consumers' attitudes towards cross-border sales and consumer protection'; (2010), 'Flash Eurobarometer 282. Consumers attitudes towards cross-border sales and consumer protection'; (2012), 'Flash Eurobarometer 332. Consumers' attitudes towards cross-border trade and consumer protection'; (2013), 'Flash Eurobarometer 358. Consumer attitudes towards cross-border trade and consumer protection', all available on $<$ http://ec.europa.eu/public_opinion>.

${ }^{231}$ Commission, 'On the road to sustainable production. Progress in implementing Council Directive 96/61/EC concerning integrated pollution prevention and control' (Communication) COM (2003) 354 final, p. 9.
} 
have reported low numbers of permits granted to IPPC installations. ${ }^{232}$ Moreover, it explicitly refers to a Court ruling against a particular member state that may be of relevance for other member states as well. ${ }^{233}$

In its third and final report on the implementation of the IPPC Directive, the Commission names all countries against which infringement proceedings were started. It states that four of these cases have been referred to the CJEU, and it names one country that the Court has already judged to have infringed the directive. ${ }^{234}$ This report also features examples of the application of particular provisions of the directive, for example the extent to which member states have resorted to cross-border cooperation while issuing permits, and the inclusion of measures stricter than BAT in permits to meet environmental quality standards. In these cases, member states are seemingly referred to only when their performance is judged as positive or neutral. ${ }^{235}$ The report concludes on a rather general note, that self-reporting by member states has "revealed a need for some countries to finalise the issuing of permits in order to ensure compliance with the Directive", and that "case studies undertaken by the Commission have shown that permits are not based sufficiently on BAT" ${ }^{236}$ Culprits are not mentioned in this regard.

Case studies are found in the three research reports on the implementation of the IPPC Directive that were commissioned by the European Commission. ${ }^{237}$ These reports assess, for example, the permitting status in member states; specifically, whether permits are issued in accordance with the requirements outlined in the Directive, and whether permit conditions are based on BAT, outlined in the best reference guidance documents (BREFs). ${ }^{238}$ It is with regard to the permitting status of member states that these reports permit benchmarking. Exact numbers of granted and outstanding permits are provided per member state, and member states are compared and then ranked on the basis of this comparison; the five best performers are referred to explicitly. ${ }^{239}$

Public access to information reported by member states to the Commission is available on the Industrial Emissions Reporting Information System (IRIS) website, ${ }^{240}$ and on the website of the European Pollutant Release and Transfer Register (E-PRTR). ${ }^{241}$ IRIS

\footnotetext{
${ }^{232}$ Commission 'Report of the Commission on the implementation of Council Directive 96/61/EC' (Communication) COM (2005) 540 final, pp. 3-4.

${ }^{233}$ Ibid., p. 9.

${ }^{234}$ Commission, 'The implementation of Directive 2008/1/EC concerning integrated pollution prevention and control and Directive 1999/13/EC on the limitation of emissions of volatile organic compounds due to the use of organic solvents in certain activities and installations' (Report) COM (2010) 593 final, p. 3.

${ }^{235}$ Ibid., p. 6.

${ }^{236}$ Ibid., p. 9.

${ }^{237}$ Entec 2007, 2010, 2011.

${ }^{238}$ For an elaboration on the BREFs, see Chapter 5 on post-legislative guidance, in particular Section 2.2.

${ }^{239}$ Entec, 2007: 11ff.

${ }^{240}$ See European Environment Agency, 'Eionet: Industrial Emissions Reporting Information System (IRIS)', $<$ http://iris.eionet.europa.eu>.

${ }^{241}$ See European Environment Agency, 'The European Pollutant Release and Transfer Register (E-PRTR)',
} 
makes it possible to verify the permitting status in individual member states and the precise, translated, implementation reports submitted by member states to the European Commission. ${ }^{242}$ The website also has a tool that allows one to compare member state answers to Commission questionnaires and to search national reports for key terms. EPRTR provides environmental data on pollutant releases and transfers for 25,000 industrial installations throughout the EU. The website presents precise figures for all EU member states and for all industrial activities registered in these member states.

\subsubsection{The SAFA Directive}

Compared to the GPS and IPPC Directives, the SAFA Directive appears to be subject to the most frequent reporting cycle. This may be explained by the continuous flow of inspection reports to the SAFA centralised database, which is maintained by EASA. ${ }^{243}$ The flow of reports provides EASA with precise information about how many aircraft inspections authorities undertake, how many safety risks they find, and which corrective measures they impose on airline operators. Annual reports on the implementation of the directive have not been based on subjective self-reporting by member states or on questionnaires submitted by them, but on the data that EASA has retrieved from 'realtime' SAFA inspection reports.

The Commission's report "on the application of the SAFA Directive" 244 seems rather misguiding, since it specifically addresses the performance of member states regarding the transposition of the directive, rather than its application in practice. Whereas the report includes a table specifying which member states the Commission has started infringement proceedings against for transposition issues, it does not provide telling information about the way in which SAFA inspections are carried out in practice. Certainly, it presents the numbers of SAFA inspections conducted annually by the member states for a number of years. However, these numbers do not provide information about the quality of inspections or the relative performance of member states. The notion that the United Kingdom carried out 233 inspections in 2007, Greece implemented 182 inspections, and Malta conducted 9 inspections is not relevant, unless one knows the traffic volume to and from those member states. ${ }^{245}$ The Commission states that the output

\footnotetext{
$<$ http://prtr.ec.europa.eu>. PRTR, the predecessor of E-PRTR, was established by Regulation (EC) No 166/2006 of the European Parliament and of the Council of 18 January 2006 concerning the establishment of the European Pollutant Release and Transfer Register and amending Council Directives 91/689/EEC and 96/61/EC [2006] OJ L 33/1.

${ }^{242}$ Original reports, which may be submitted in a language other than English, are available on European Environment Agency, 'Eionet: Central Data Repository', <http://cdr.eionet.europa.eu>.

${ }^{243}$ Directive 2004/36/EC, Art. 5(2), in conjunction with Commission Regulation 768/2006, Art. 3.

${ }^{244}$ Commission, 'Safety of third-country aircraft using Community airports (Report on the application of Directive 2004/36/EC of the European Parliament and of the Council)' (Report) [2008] OJ C244/4.

${ }^{245}$ Apart from the idea that it must be greatly different.
} 
registered by many member states is "unacceptable", ${ }^{246}$ but it fails to point out which member states allegedly do not do enough.

Similar remarks apply to the Commission's first report on the SAFA Programme. ${ }^{247}$ This report presents both the number of inspections conducted by individual member states and the number of findings detected by the aviation authorities, but what the reader should infer from this information remains unclear. The Commission's second report on the SAFA Programme ${ }^{248}$ also contains a list of average numbers of items checked per inspection by the national authorities. At first glance, this report appears to provide more insight into how member states perform, as it indicates the relative rate of activity displayed by member states when they inspect a plane. However, once again it does not indicate the quality of the inspections; for example, inspecting forty items in an hour may deliver different findings than inspecting the same forty items in twenty minutes.

After the second Commission report, ${ }^{249}$ member state specific information has been provided exclusively in the staff working documents annexed to the Commission report $^{250}$ or, since 2013, in the EASA report on the functioning of the SAFA Programme. ${ }^{251}$ The nature of the information and the method of reporting have remained the same; the only relevant change is the insertion of the number of airports inspected by EASA in each individual member state. ${ }^{252}$ While SAFA reports may, in theory, be thought of as capable of naming and shaming poor compliers, in reality, they do not accomplish this.

Finally, the Commission may decide to circulate reports created by the EASA standardisation team to all national aviation authorities. ${ }^{253}$ This applies to both the final reports on standardisation inspections, and supplementary reports issued after EASA's assessment that the inspected authority has not taken the required action to correct

\footnotetext{
${ }^{246}$ Ibid., p. 10.

${ }^{247}$ Commission, 'Report on the European Community SAFA Programme (Safety Assessment of Foreign Aircraft)' (Report) [2008] OJ C 42/1.

${ }^{248}$ Commission, 'Report on the European Community SAFA Programme (Safety Assessment of Foreign Aircraft)' (Report) [2008] OJ C231/1.

${ }^{249}$ Commission, 'European Union SAFA Programme (Safety Assessment of Foreign Aircraft)' (Report) COM (2011) 159 final; COM (2012) 91 final.

${ }^{250}$ The staff working document annexed to the second report contains the same member-state specific information as the Commission's report. See Commission, 'Staff working paper accompanying the report from the Commission to the European Parliament and the Council: European Community SAFA Programme (Safety Assessment of Foreign Aircraft) Aggregated information report (01 January 2007 to 31 December 2007)' (Staff Working Paper), SEC (2008) 2484 final; SEC (2009) 1576 final; SEC (2011) 301 final; SWD (2012) 38 final.

${ }^{251}$ European Aviation Safety Agency, 'The EU SAFA Programme (Safety Assessment of Foreign Aircraft). Aggregated information report 2011-2012) Aggregated information report (01 January 2011 to 31 December 2012)' [2013], available on <www.easa.europa.eu>.

${ }^{252}$ The introduction of this information seems to be linked to the introduction of a quota system for inspections, according to which authorities receive more points for inspections that are conducted on remote airports.

${ }^{253}$ See Section 2.2.3 above, on standardisation inspections.
} 
instances of noncompliance. In fact, both types of reports are made available to SAFA national coordinators through a restricted online database. ${ }^{254}$

\subsection{Infringement proceedings}

\subsubsection{Preliminary remarks}

While it seems feasible to gain insight into the naming and shaming strategies employed by the Commission, ${ }^{255}$ determining how the Commission makes use of its power to initiate infringement proceedings against member states proves rather difficult. Certainly, the website of the Commission's Secretariat General provides an option to check for the Commission's decisions against noncomplying member states, from the stage of the letter of formal notice onwards. ${ }^{256}$ However, even if one checks the updates on Commission decisions posted annually - which is a laborious exercise - one cannot be sure that a complete picture will be attained since the Commission reports on the progress of files "unless it decides otherwise". ${ }^{257}$ In other words, there may well be instances of infringements that are not included in the system. ${ }^{258}$

The system is not only time consuming to consult and incomplete, in many cases it also fails to clarify whether the infringements concern transposition or application issues. Unfortunately, the Commission's annual reports on monitoring the application of EU law are not helpful in this regard. First, these reports usually distinguish between non-notification of transposition measures, and non-conformity of transposition measures and incorrect application. There is no way to determine whether an infringement that falls into the second category concerns the transposition stage or the application phase of the implementation process, unless the case has been brought to the Court and the Commission has not withdrawn it. Where the Commission has chosen withdrawal, information about the nature of the case may be unavailable.

Second, reports rarely refer to instances in which the Commission has sent member states a letter of formal notice and has decided not to take the case beyond this first stage of the infringement procedure. Since most reports only provide information regarding cases that have reached the reasoned opinion stage - and beyond - they do not allow the

\footnotetext{
${ }^{254}$ Email from interviewee EASA1 to author.

${ }^{255}$ Especially where naming and shaming takes place in public (rather than 'amongst intimae', that is, in Council working groups and similar).

${ }^{256}$ See European Commission, 'Infringement decisions', <http://ec.europa.eu/atwork/applying-eu-law/ infringements-proceedings/infringement_decisions $>$.

${ }^{257}$ European Commission, 'Infringement decisions', <http://ec.europa.eu/atwork/applying-eu-law/ infringements-proceedings/infringement_decisions $>$.

${ }^{258}$ Note that the system changed in the course of 2014. The Commission's website seems more user-friendly, for example because it allows the user to search for individual member states and policy areas. However, the information available will likely still be incomplete.
} 
reader to acquire complete insight into infringement proceedings launched against member states.

Third, whereas earlier annual reports specify the precise legislative acts at issue in infringement proceedings, the member state(s) at fault, and the respective stage of the infringement procedure reached, the latest reports provide more global and selective information for each member state. ${ }^{259}$ While this new presentation may make it easier to compare the implementation performance of member states on a global level, it fails to provide specific insight into how member states implement EU law. From this perspective, the latest reports seem to be intended for use as public-relations tools - to serve a broader public that may want to obtain a convenient overview of how member states are doing - than as a source of information for those who want to understand the details of the performance of member states. ${ }^{260}$ A Commission official does, as previously stated, confirm that the changed presentation is meant to make the reports "more digestible, more transparent, and more attractive" to the main target group of the reports - namely, the European Parliament - and to other interested parties, such as the legal advisors of permanent representations, European Affairs coordinators of the national ministries, and NGOs and law firms that complain to the European Commission. ${ }^{261}$

The Commission has a set of databases that gather information about (potential) instances of noncompliance, which are not publicly accessible. The secrecy of these databases is said to have a trust-related function:

It is believed that this secrecy makes member states comply, and before the case goes to the Court or at least before the reasoned opinion, people should not know about it. So we are secretive for the purpose of keeping the trust between the Commission and member states. ${ }^{262}$

According to a Commission official, it is the principle of loyal cooperation, outlined in Article 4(3) TEU, that member states rely on as an argument for keeping transparency at bay in the resolution of infringement cases. ${ }^{263}$ The Commission's right to secrecy during the pre-litigation stage of infringement proceedings has been confirmed by the CJEU. In relation to the disclosure of documents at this stage, the Commission has stated that such disclosure would:

\footnotetext{
${ }^{259}$ All reports are available on European Commission, 'Annual reports on monitoring the application of EU law', <http://ec.europa.eu/atwork/applying-eu-law/infringements-proceedings/annual-reports>.

${ }^{260}$ Note that the above ideas are by no means novel; the notion that the Commission's infringement data are neither complete nor consistent has been highlighted by others; see e.g. Börzel, 2001. My own search merely confirms, and in some instances adds to, the arguments advanced by others.

${ }^{261}$ Interview EC8.

${ }^{262}$ Email 2 from a Commission official; similar interview EC8.

${ }^{263}$ Interview EC8.
} 
be likely to change the nature and progress of that procedure, given that, in those circumstances, it could prove even more difficult to begin a process of negotiation and to reach an agreement between the Commission and the $[\mathrm{m}]$ ember [s] tate concerned putting an end to the infringement alleged, in order to enable European Union law to be respected and to avoid legal proceedings. ${ }^{264}$

In other words, the lack of transparency of infringement proceedings is as explicable in terms of the compliance-seeking goal of the system as it is unpractical for scholars and others who would like to understand the implementation performances of member states.

\subsubsection{Findings}

This study relied on publicly accessible records and on information from one of the Commission's internal databases. ${ }^{265}$ The relevant database includes all cases that are eligible for infringement proceedings; that is, cases that were not solved during preinfringement proceedings and that were not initially rejected as irrelevant ('serious infringements'). Drawing on this database, Table 9 below demonstrates the numbers of serious infringements for the three directives examined in this study for the different stages of the implementation process, and the sources of information for these infringements. The figures show that serious infringements in the application phase of the implementation process exist, particularly for the IPPC Directive. They also suggest that complaints have constituted a major source of information for the Commission in this regard. While the Commission had identified serious infringements of the IPPC Directive in a total of 35 cases, complaints pointing out such infringements were submitted in 60 instances.

\footnotetext{
${ }^{264}$ Joined cases C-514/11 P and C-605/11 P Liga para a Protecção da Natureza (LPN) and Republic of Finland v. European Commission, not yet published, para. 63 .

${ }^{265}$ The relevant information was received by email 1 from a Commission official to author.
} 
Table 9 Numbers and sources of infringements ${ }^{266}$

\begin{tabular}{lllll}
\hline & Source & \multicolumn{2}{l}{ Transposition } & Application \\
\cline { 3 - 5 } & & Notification & Correctness & \\
\hline GPS & Total & $\mathbf{1 0}$ & $\mathbf{1}$ & $\mathbf{3}$ \\
& Identified & 10 & 1 & 0 \\
& Complaints & 0 & 0 & 3 \\
& Otherwise presumed & 0 & 0 & 0 \\
IPPC & Total & $\mathbf{9}$ & $\mathbf{2 0}$ & $\mathbf{7 9}$ \\
96/69/EC & Identified & 9 & 17 & 16 \\
& Complaints & 0 & 0 & 51 \\
& Otherwise presumed & 0 & 3 & 12 \\
\multirow{2}{*}{ 2008/1/EC } & Total & $\mathbf{1}$ & $\mathbf{3}$ & $\mathbf{2 9}$ \\
& Identified & 1 & 3 & 19 \\
& Complaints & 0 & 0 & 9 \\
& Otherwise presumed & 0 & 0 & 1 \\
\multirow{2}{*}{ SAFA } & Total & $\mathbf{1 7}$ & $\mathbf{0}$ & $\mathbf{0}$ \\
& Identified & 17 & 0 & 0 \\
& Complaints & 0 & 0 & 0 \\
& Otherwise presumed & 0 & 0 & 0 \\
\hline
\end{tabular}

Table 10 aims to show what happened to the infringements listed in Table 9 above. Table 10 shows the alleged numbers of infringements for each directive and for each stage in the implementation process, regardless of the source of these infringements $(N$. infringements). The numbers for reasoned opinions and CJEU cases were determined by combining the information included in the Commission's internal database with the data available in the Commission's annual reports and on the website of the CJEU. ${ }^{268}$

\footnotetext{
${ }^{266}$ Data from the Commission's internal database; received by email from an anonymous Commission official in February 2014. Numbers for 'serious infringements' (for this term, see the in-text explanation above) present in the Commission's database by the said date.

${ }^{267}$ 'Identified' and 'presumed' infringements are basically those (alleged) infringements detected by the Commission through its police-patrol oversight powers (i.e. member state reports on implementation, studies, etc.). The notion of 'complaints' refers to (suspected) infringements brought to the Commission's attention through its fire-alarm oversight powers. For a distinction between both types of oversight, see Section 1.1.1 of this chapter.

${ }^{268}$ This combination is needed, since the internal database does not provide information about the stage of infringement proceedings reached for every infringement. For the Commission's annual reports, see European Commission, 'Annual reports on monitoring the application of EU law', <http://ec.europa.eu/atwork/applyingeu-law/infringements-proceedings/annual-reports $>$. For the website of the Court, see Court of Justice of the European Union, $<\mathrm{http}: / /$ curia.europa.eu $>$.
} 
The number of formal letters could not usually be derived from these sources. ${ }^{269}$ They were calculated by combining the number of infringements for each stage in the implementation process (which equals the number of opportunities for the Commission to send a formal letter) with the number of reasoned opinions sent (which represent the minimum number of formal letters sent for each stage). For example, in the case of the IPPC Directive, the Commission sent thirteen reasoned opinions to member states for alleged infringements in the application phase of the implementation process. Since information about the number of formal letters sent is lacking, it can only be determined that the Commission sent at least thirteen formal letters. As there are 29 alleged infringements regarding the application of the IPPC Directive and thirteen cases in which the Commission certainly acted, what happened in the remaining sixteen cases is unknown.

A glance at the numbers listed in Table 10 suggests that of the total of 172 alleged infringements in the implementation process as a whole, only 48 made it to the reasoned opinion stage, and 26 made it to the litigation stage. The numbers for the application stage of the implementation process are (naturally) considerably lower; of all 111 alleged instances of noncompliance present at this stage, seventeen cases made it to the reasoned opinion stage, and eleven cases made it to the Court. All of the cases initiated for 'bad application' were started under the IPPC Directive; infringement proceedings for the incorrect application of the GPS and SAFA Directives appear to be absent, at least as far as the reasoned opinion and litigation stages are concerned. The relatively small share of cases that made it to the later stages of the infringement procedure may suggest that many cases were either solved early on in the process, or not acted upon in the first place. In view of the incomplete information regarding action taken at the early stages of the infringement procedure, neither suggestion can be confirmed.

The number of proceedings that were initiated against the three countries included in this study can also not be determined. EU reports suggest that as far as 'bad application' is concerned, action going beyond sending a letter of formal notice was only taken against the Netherlands and Portugal. Both cases concerned the application of the IPPC Directive, as can be derived from the previous paragraph and from Table 10. Whether any of the three countries received letters of formal notice for cases that did not proceed further is unknown, based on the information that is available.

${ }^{269}$ The SAFA Directive is an exception, as is clear from the table. 
Table 10 Infringement proceedings $\mathrm{s}^{270}$

\begin{tabular}{lcclccc}
\hline & & N. infr. & Formal notice & Reasoned opinion & CJEU & Unknown \\
\hline GPS & & & & & $3^{271}$ & 4 \\
& Notification & 10 & $\geq 6$ & 0 & 0 & 1 \\
& Correctness & 1 & $\leq 1$ & 0 & 0 & 3 \\
& Application & 3 & $\leq 3$ & & & \\
IPPC & & & & 5 & 0 & 4 \\
96/69/EC & Notification & 9 & $\geq 5$ & $14^{273}$ & $8^{274}$ & 6 \\
& Correctness & 20 & $\geq 14$ & 4 & $1^{275}$ & 75 \\
& Application & 79 & $\geq 4$ & 0 & 0 & 1 \\
2008/1/EC & Notification & 1 & $\leq 1$ & 1 & 0 & 2 \\
& Correctness & 3 & $\geq 1$ & $13^{276}$ & $10^{277}$ & 16 \\
& Application & 29 & $\geq 13$ & & & \\
SAFA & & & $17^{278}$ & $5^{279}$ & $4^{280}$ & 0 \\
& Notification & 17 & 0 & 0 & 0 & 0 \\
& Correctness & 0 & 0 & 0 & 0 & 0 \\
\hline
\end{tabular}

${ }^{270}$ Data from the Commission's internal database, received by email from an anonymous Commission official in February 2014. Numbers for infringement proceedings initiated by the Commission until the said date.

${ }^{271}$ Amongst which are Portugal and the Netherlands.

${ }^{272}$ Case C-308/05 Commission v. Netherlands [2006] ECLI:EU:C:2006:343 (withdrawn) and case C-323/05 Commission v. United Kingdom [2006] ECLI:EU:C:2006:157 (withdrawn); case C-310/05 Commission v. Luxembourg [2006] ECR I-00039.

${ }^{273}$ Amongst which is the Netherlands.

${ }^{274}$ Case C-263/07 Commission v. Luxembourg [2007] ECR I-00180, case C-64/01 Commission v. Greece [2002] I-02523, case C-39/01 Commission v. United Kingdom [2002] ECR I-02513. case C-29/01 Commission v. Spain [2002] ECR I-02503, case C-271/07 Commission v. Belgium [2008] ECR I-00078, case C-84/05 Commission v. Italy [2005] ECLI:EU:C:2005:505 (withdrawn), case C-78/04 Commission v. Austria [2004] ECLI:EU:C:2004:735, case C-247/05 Commission v. Netherlands [2006] ECLI:EU:C:2006:84. (withdrawn).

${ }^{275}$ Case C-84/05 Commission v. Italy [2005] ECLI:EU:C:2005:505 (withdrawn).

${ }^{276}$ Amongst which Portugal and the Netherlands.

${ }^{277}$ Case C-258/09 Commission v. Belgium [2010] ECR I-00029, case C-49/10 Commission v. Slovenia [2010] ECR I-00128, case C-534/09 Commission v. Greece [2010] ECR I-00160, case C-50/10 Commission v. Italy [2011] ECR I-00045, case C-48/10 Commission v. Spain [2010] ECR I-00151, case C-352/11 Commission v. Austria [2012] ECLI:EU:C:2012:315, case C-158/12 Commission v. Ireland [2013] ECLI:EU:C:2013:234, case C-607/10 Commission v. Sweden [2012] ECLI:EU:C:2012:192, case C-44/10 Commission v. Portugal [2010] ECLI:EU:C:2010:657 (withdrawn), case C-33/10 Commission v. Denmark [2010] ECLI:EU:C:2010:750 (withdrawal).

${ }^{278}$ Amongst which is the Netherlands.

${ }^{279}$ Amongst which is Poland.

${ }^{280}$ Case C-412/07 Commission v. Ireland [2008] ECLI:EU:C:2008:72 case C-72/08 Commission v. Poland [2009] ECLI:EU:C:2009:412 (withdrawn), and case C-449/07 Commission v. Italy [2008] ECLI:EU:C:2008:199 (withdrawn), case C-417/07 Commission v. Luxembourg [2008] ECR I-00051. 


\section{The usefulness of monitoring and sanctions as compliance instruments}

This section aims to examine the usefulness of supranational monitoring and sanctioning mechanisms as compliance instruments. The intertwinement of the Commission's monitoring activities, and naming and shaming strategies and infringement proceedings makes it imperative to discuss the usefulness of monitoring activities in conjunction with the usefulness of sanctioning instruments. Thus, the following sections do not discuss the usefulness of monitoring as a separate compliance instrument; instead this instrument is included in the sections on naming and shaming (Section 3.2) and infringement proceedings (Section 3.3). This does not apply to standardisation inspections carried out by EASA in the context of the SAFA Directive, which are discussed separately in Section 3.1 below.

These inspections are discussed separately for the following reasons. First, agency inspections are considered a great asset to the Commission in the exercise of its monitoring tasks, since inspections allow the agency to attain an immediate (rather than mediated) picture of implementation practices in the member states. This makes inspections the hallmark of police-patrol oversight, since in contrast to external research and self-reporting by member states, such inspections seem - at least in theory - capable of yielding the most precise insight into the implementation performance of national competent authorities. This theoretical edge of inspections over other monitoring mechanisms makes it interesting to study such inspections. Second, little research has been conducted on the nature of EASA inspections and their significance in practice. Therefore, this section now examines the usefulness of such inspections as compliance instruments, before it proceeds to a discussion of naming and shaming and infringement proceedings.

\subsection{Inspections carried out by EASA}

The way in which standardisation inspections ought to be carried out has been discussed in Section 2.1.3 above. Before moving on to an analysis of the usefulness of such inspections in the eyes of implementation actors, it may be relevant to briefly reflect on the meaning that Commission and EASA officials attach to such inspections. Commission officials seem to consider standardisation inspections exclusively as practical tools to acquire "a full picture of application". ${ }^{281}$ EASA officials agree that the main purpose of inspections is to monitor compliance, but they add that EASA does not want to be "just a policeman". The following quotation illustrates this latter perspective:

\footnotetext{
${ }^{281}$ Interview EC6.
} 
Standardisation inspections are mostly about compliance monitoring. We look at the implementation of the principles laid down in the Directive, at the working procedures, and at the number, and especially the quality, of resources. The EASA team comprises of a team leader and two inspectors from the member states. This is a win-win situation. These inspectors are persons with hands-on expertise, and it allows them to see what is happening in other member states. We also explain what we want to see, so there is an educational function, although this is more ad hoc than institutionalised. We inspect the inspectors. This is stressful for them; nobody likes to be looked at. We try to create a classroom situation. Acting just as a policeman would be failing. We also have a follow-up part, which is educational. ${ }^{282}$

In other words, standardisation inspections not only have a monitoring function, they

All SAFA survey respondents agree or strongly agree that standardisation inspections regularly take place in their country; in fact, all SAFA states are subject to biannual inspections. $83 \%$ agree or strongly agree that such inspections are useful. This percentage is slightly lower for SAFA inspectors. also create learning opportunities for national SAFA inspectors that are part of the inspection team, and for inspectors that are inspected; at least, this is what EASA officials consider to be the case. Interviews with national officials suggest that

perceptions of the nature and benefits of such inspections vary greatly across the board, as the following subsections show. Since important fault lines seem to exist across member states, these sections discuss the perceptions of the three countries included in this study separately.

\subsubsection{Poland: EASA as a policeman ${ }^{283}$}

Of all the SAFA inspectors interviewed for this study, Polish inspectors seem to have the most 'narrow' view of standardisation inspections. Polish inspectors indicate that they perceive such inspections exclusively as compliance monitoring tools, and EASA as a monitoring body only; EASA is "just there to monitor", inspectors argue, simply because "that is its function". ${ }^{284}$ Thus, in contrast to what Dutch and Portuguese officials have to say on the subject, as we see further below, Polish inspectors do not seem to appreciate standardisation inspections for the educational function that EASA imbues these inspections with. It is the guidance materials that are for learning, inspectors say;

\footnotetext{
${ }^{282}$ Interview EASA3.

${ }^{283}$ The terminology of EASA as a policeman versus facilitator (see below) is derived from Versluis and Tarr, 2013.

${ }^{284}$ Interview PL15.
} 
standardisation inspections are less important in this regard. ${ }^{285}$ Note that this does not mean that Polish inspectors do not attach importance to standardisation inspections. According to interviewees:

Standardisation inspections show us we are not perfect. Sometimes you need an outside party to see what you can do better. They show us our weak points of the organisation, procedures, performance, et cetera. Sometimes you need someone from the outside to correct you, to make you aware. ${ }^{286}$

To support this perception, inspectors refer to the fact that standardisation inspections resulted in organisational overhauls that made it easier for them to do their work and that greatly reduced the number of findings detected by EASA during a second inspection round. ${ }^{287}$

While inspections have had a positive effect on the implementation practice, learning does not seem to be a notion that inspectors connect to standardisation inspections, as suggested above. This seems to be explained by the one-sided perception that officials have of EASA and the inspections carried out by it, as outlined at the beginning of this subsection. The idea that Polish inspectors view EASA as a monitoring body - or in other words, as a police authority - implies a perception of EASA as merely there to test the performance of the inspectors and to correct them when it is justified. This situation makes it difficult to develop a fruitful learning environment - no matter how much the EASA team may try to establish a 'classroom situation'.

The rejection of standardisation inspections as providing useful learning opportunities is not a matter of unwillingness on the part of inspectors to learn. In contrast, interviewees point out that the SAFA guidance materials - which are covered in Chapter 5 on post-legislative guidance - and meetings of the European SAFA Steering Group (ESSG) - which are studied in Chapter 6 on transnational networks - present learning opportunities that make it possible for them to see how they could perform better. Inspectors also refer to the inspector exchange programme as useful in this regard; this programme is financed by EASA and enables national SAFA inspectors to visit their colleagues in other member states to see how SAFA inspections are dealt with there. It should be noted that these instruments are first and foremost aimed at strengthening the capacity of organisations to comply, rather than at coercing authorities into compliance. Moreover, rather than being scrutinised by a supervisory body that must be reported to for any shortcomings that might surface, national officials that partake in the ESSG and in the inspector exchange programme find themselves amongst equals. ${ }^{288}$ Overall, it

\footnotetext{
${ }^{285}$ Ibid.

${ }^{286}$ Interview PL15 and email from interviewee PL15 to author.

${ }^{287}$ Interview PL15.

${ }^{288}$ For how this could occur in view of the (formal) centrality of the Commission in ESSG meetings, see Chapter 6 on transnational networks.
} 
seems that the vertical relationship between EASA and the aviation authority, and the fact-finding purpose of standardisation inspections make it difficult for Polish inspectors to consider such inspections as learning opportunities.

\subsubsection{The Netherlands: EASA as a policeman and as a facilitator}

Perceptions amongst Dutch officials greatly diverge from those held by Polish inspectors. While Dutch SAFA inspectors do regard EASA as a "super authority" - as it does have a powerful position - they are also quick to state that the Agency "is not the almighty" that can act as it pleases. ${ }^{289}$ Interviewees indicate that "one has to be aware that audits are never an almighty judgement", since inspections only provide a snapshot of the way in which ramp inspections are carried out. ${ }^{290}$ The following quotation illustrates such perceptions:

I myself do not fear inspections so much. I consider the findings that EASA may or may not have to be irrelevant. Irrelevant in this sense: of course they are relevant, but they are not relevant in the sense that I would want to pretend to be better than we are. In every organisation there are mistakes and there will always be matters that can be improved. Quality is an ongoing process. An EASA audit is, of course, just a thermometer. ${ }^{291}$

In other words, Dutch inspectors do not seem impressed with the policing aspect that inspections provide. This rather laconic attitude may also be explained by the fact that officials are convinced that inspections carried out by the Dutch inspectorate are of "high quality". ${ }^{292}$

Leaving little room for apprehension of EASA as a policeman, perceptions of standardisation inspections amongst Dutch officials are generally appreciative. Dutch officials perceive such inspections as useful for improving implementation practices, and they claim to be quite open to EASA in order for matters to be improved and for lessons to be learned:

The fact that we are very open during audits carried out here, in the Netherlands, also makes that we can learn something. Also when I contribute to standardisation inspections I get new ideas about how things can be done. There is always some cross-pollination of ideas. ${ }^{293}$

\footnotetext{
${ }^{289}$ Interview NL28.

${ }^{290}$ Interview NL30.

${ }^{291}$ Interview NL30.

${ }^{292}$ Interview NL29.

${ }^{293}$ Interview NL28.
} 
But also strategically, if you know that certain things are difficult - and here is maybe a cultural difference with other countries - I think that we, in the Netherlands, would prefer to have a finding being detected. Management would prefer to hide such things, but inspectors sometimes prefer these things to be found out, so that the organisation may be forced to actually correct things where necessary. ${ }^{294}$

In other words, the results of inspections may be used as a 'safeguard' in relation to managers; managers who, inspectors say, are eager to cut resources where possible. The irony of this is that in order to secure resources, implementation cannot be perfect (or close to it), since if EASA were to establish perfect compliance, resource cuts would be certain to follow. This paradox is expressed in the following interview excerpt:

I certainly do not think that we want to be the blue-eyed boy of the SAFA community. At the moment that I were to try to be exactly that, I would be punished, since in the Netherlands we may want to be good, but what also applies is that when you stand out from the crowd, you're done with, meaning that management may want to cut your resources. We need the supervision by EASA and by the Commission to be able to keep on doing our work properly. $^{295}$

The idea that Dutch officials use EASA as a patron in their quest to secure sufficient resources for the implementation of SAFA rules is elaborated on in Section 3.2 below, which deals with the usefulness of scoreboards that may name and shame badly complying member states. Perceptions expressing contentment with the role of EASA as a teacher are absent amongst Polish inspectors and, as described below, not particularly present amongst their Portuguese colleagues either.

\subsubsection{Portugal: EASA as a (bad) teacher vs. a reassuring agent}

In contrast to the relative homogeneity of perceptions within the Dutch inspectorate and the Polish aviation authority, are the diverging perceptions amongst Portuguese SAFA officials. SAFA inspectors emphasise that they would like to learn from the EASA inspection team, but that learning opportunities from standardisation inspections fail to materialise. Limited openness on the part of inspectors seems to be an important explanatory factor in this regard. Indeed, while Dutch inspectors claim to be rather open during meetings with the EASA standardisation team, Portuguese inspectors argue that openness is not possible for them. This is not because they do not want to share their

\footnotetext{
${ }^{294}$ Interview NL30.

${ }^{295}$ Interview NL30.
} 
questions and doubts, but because higher management echelons within the aviation authority prevent them from doing so, inspectors say:

EASA does not just want to check, it also tries to help. The problem is that standardisation inspections are never done with the inspectors alone; there is always someone else from management. I personally like to give a direct answer to the team. But bosses are always intervening; they can manage the information. We have an internal meeting before EASA comes to audit us, where we are told not to say this and that. ${ }^{296}$

Such arrangements are likely to take place in other member states as well; complete openness about the difficulties faced by officials in the implementation process may be an illusion. ${ }^{297}$ However, the fact that Portuguese inspectors explicitly mention their discontent with such procedures and refer to these procedures as hindrances to learning seems to make it relevant to discuss these issues here.

Next to a lack of openness on the part of those who may want to learn, stands a lack of knowledge and expertise on the part of those who should be in the position to act as teachers - or this is at least what Portuguese officials consider to be the case for members of the EASA standardisation team. In fact, Portuguese inspectors are outspokenly critical about the knowledge and the expertise that the EASA team has brought to bear:

I think what we usually feel is that they don't have enough experience to audit us. That's what we normally feel, not just in this area. It's in all areas, generally. They just come with a sheet of paper, and they just tick the boxes - this is ok, this is not ok. You know, this is only half of the job, because just by ticking boxes you cannot have a proper idea of the reality of things. Of course they have their own problems as well; perhaps they don't have the possibility to have such knowledgeable and experienced staff to come here and observe things as profoundly as it should be to assess the real characteristics of the team in Portugal or wherever else. And as to learning, only sometimes we may find, 'oh, this guy is really good', and we can ask him something on top of the job he is doing, or we can rely on him for advice, or what he thinks personally about our job, what he thinks we can improve in our performance. ${ }^{298}$

These views clearly diverge from the perceptions held by Dutch officials outlined above; these officials indicate not only that standardisation inspections have made them learn,

\footnotetext{
${ }^{296}$ Interview PT16.

${ }^{297}$ At least in vertical relationships, between a supervisory body and member states. For how this may be different in the context of horizontal cooperation, see Chapter 6 on transnational networks.

${ }^{298}$ Interview PT14; similar PT16.
} 
but also that "in our case, EASA has done a good job". ${ }^{299}$ These divergent perceptions may be explained by, first, the fact that EASA examines national implementation practices from a natural distance. This means that it needs national officials to be open about the details of the daily practice of implementation, in order for it to acquire meaningful insight into the implementation performance of national authorities. With such openness being variable, the quality of the assessment process, including the role that EASA can play as a teacher, is bound to diverge as well. In this sense, the rather negative evaluation of Portuguese inspectors on the benefits that they derive from inspections is not surprising. Second, since the composition of the EASA team varies because of the rotation of national senior inspectors in the team, variations in the technical knowledge and expertise of auditors are likely to surface as well. This may explain why inspectors from one country seem disappointed, whereas inspectors from another state seem happy, with the work done by the standardisation team.

Unlike the sections on Poland and the Netherlands, this section has, until now, focused exclusively on the views of SAFA inspectors, rather than on the views of the SAFA national coordinator as well. This is the case since in contrast to the situation in Poland and the Netherlands - where the SAFA national coordinator conducts ramp inspections similar to regular SAFA inspectors - the Portuguese SAFA national coordinator is a manager who is not part of the inspection team. The resulting inspectormanagement gap' produces fundamentally different perspectives on what standardisation inspections are, and what they should ideally be, on the part of SAFA inspectors and the SAFA national coordinator.

These differences seem to boil down to the fact that, while Portuguese inspectors would like to learn something from the EASA standardisation team, what counts for the Portuguese SAFA national coordinator seems to be the reassurance function that standardisation inspections have. The following quotation from an interview with this coordinator, serves to illustrate this point:

I have nothing against EASA. On the contrary, the standardisation inspections help us a lot in becoming confident that we are interpreting the guidance materials in the correct way and that there are no big issues regarding the way we are carrying out the programme in Portugal. Yes, they help us a lot in showing us that we are doing this in the correct way. Since the Commission is the owner of the programme, I have the reassurance that I am performing this in an acceptable way. ${ }^{300}$

\footnotetext{
${ }^{299}$ Interview NL30. For a similar idea regarding the knowledge and expertise of the EASA team, see email from interviewee PL15 to author.

${ }^{300}$ Interview PT17.
} 
The importance that the SAFA national coordinator attaches to the reassurance function of standardisation inspections seems logical in view of the authority's performance in the past. This performance suggests that Portugal still needs to prove itself as a good implementer. ${ }^{301}$ This is different for the Dutch SAFA national coordinator, who as we have seen above, is careful not to perform too well in view of the adverse consequences that this may have on the resources allocated to the SAFA inspection team by higher management echelons.

\subsubsection{Synthesis}

The above sections suggest that inspections may be useful for national implementation actors in two ways. First, inspection results may be used as an instrument to ensure the flow of resources to authorities, as the Dutch case shows. Second, inspection results may "make officials do their job better", either because they correct wrongs or because they provide learning opportunities for officials. The extent to which opportunities of the latter kind are exploited partly depends on the degree to which national officials are open about difficulties that they are confronted with in the implementation process, partly on the knowledge and expertise of the SAFA inspection team, and partly on whether officials consider inspections the proper framework for learning in the first place. While the Portuguese case shows that the first and second aspects may be problematic, the Polish case suggests that the latter element is not self-evident. Overall, the cases studied here suggest that the usefulness of inspections for national officials varies across the board and that limitations on the usefulness of inspections as policing instruments and as learning instruments are at least partly a matter of (organisational) culture. In view of the stickiness of cultures, these variations in perceptions are, one may hypothesise, likely to persist, at least in the near future.

\subsection{Naming and shaming}

Section 2.2 of this chapter shows that naming and shaming may take place in different forms. While public EU reports may constitute one extreme of the availability of information on the implementation performance of member states, information shared in Council working groups or implementation networks constitutes the other extreme. The following subsections elaborate on the usefulness of both forms of naming and shaming. They first elaborate on the usefulness of publicly available EU reports (Section 3.2.1), and then on the usefulness of naming and shaming exercises 'amongst intimae' (Section 3.2.2).

\footnotetext{
${ }^{301}$ This conclusion is drawn from an interview with an official involved in the implementation of the SAFA Directive and from confidential documents about the implementation performance of the country.
} 


\subsubsection{Naming and shaming: EU reports}

In order to analyse the naming and shaming effect of EU reports, two points seem relevant: first, whether officials are familiar with reports that may be thought of as naming and shaming badly performing member states, and second, whether officials consider these reports useful compliance instruments. While the first question is examined in Section 3.2.1.1, the second question is elaborated on in Section 3.2.1.2.

\subsubsection{Variable familiarity with EU reports}

While perceptional differences across member states regarding the usefulness of the same compliance instrument in the same policy area dominate the previous section, commonalities across member states and across policy domains seem to prevail in the this section. Unfamiliarity with Commission reports benchmarking the performance of member states seems to be common for street-level actors in all countries and in all policy domains included in this study. This is particularly true for street-level actors that have little affinity with policy-making aspects in the respective policy domains; in other words, for civil servants who are exclusively in charge of inspecting products or airplanes and for officials who are responsible 'only' for permitting IPPC installations. This picture comes to the fore in the interviews carried out for this study and in the survey, as the boxes show elsewhere in this section. Note that the finding that a rather large part of the SAFA survey respondents claim to have consulted EU reports is explained by the fact that nearly all respondents are SAFA national coordinators

$72 \%$ of the SAFA survey respondents have consulted SAFA application reports, the SAFA aggregate information report, and/or the Commission's general annual application report.

with a policy management function at the domestic level and involvement in regulatory policy-making at the EU level.

$59 \%$ of the GPS survey respondents have consulted GPS implementation reports, the consumer scoreboards, and/or the Commission's general annual application reports. These numbers are, apart from that for the consumer scoreboards, lower for inspectors.
The unfamiliarity with EU reports amongst lower-level officials seems to derive from several factors. Generally speaking, lower-level officials are unlikely to proactively look for EU documents and supervisory authorities do not, as a rule, inform implementing authorities of the existence of such reports. Moreover, it is by no means self-evident that reports forwarded to implementing agencies reach street-level implementation actors; in fact, it seems that familiarity with such reports is likely to be contained to top-officials within the relevant implementing agencies. The notion that Dutch permit writers at subnational levels are famil- 
iar with EU reports on the implementation of the IPPC Directive ${ }^{302}$ seems rather exceptional; at least, this is what the interviews carried out for this study suggest.

Familiarity does not equal interest or appreciation, though, as interviews with Dutch IPPC permit writers suggest. These permit writers do not see why the information contained in implementation reports should be useful for them. According to officials, reports may provide a basis for policy work; through the impact that they have on policy-making processes, they may have an indirect effect on their work too. ${ }^{303}$ However, to say that reports showcasing the implementation performance of member states are interesting for permit writers in any other way seems to miss the point.

The lack of interest in EU reports amongst Dutch streetlevel actors may be explained, in part, by the idea that subnational officials are not overly concerned with the implementation performance of the Netherlands. In the words of an official from the Dutch knowledge centre on environmental policy matters (InfoMil):

$55 \%$ of the IPPC survey respondents have consulted IPPC implementation reports, research reports, and/or the Commission's general annual application report. These numbers are, apart from that for the Commission's general reports, considerably lower for permit writers.

$54 \%$ of all respondents have consulted EU websites; $69 \%$ have consulted the E-PRTR website and $38 \%$ the IRIS website. These numbers are considerably lower for permit writers.

Implementation reports and monitoring don't do so much for the municipalities and for the provinces. They are quick to say that implementation issues are on the state's shoulders. If the Netherlands gets a fine, they do not feel that as their responsibility. ${ }^{304}$

With street-level actors unaware of, or uninterested in, EU reports, the usefulness of such reports for higher-level civil servants must be considered. These civil servants could be part of the relevant national ministries or of central agencies tasked with the implementation of the relevant legislation. Such agencies may be involved in regulatory policy-making at the EU level as well, as is the case for the Netherlands Food and Consumer Product Safety Authority (NVWA), the Polish Office of Competition, and Consumer Protection (UOKiK) in the area of general product safety; the Portuguese Environment Agency (APA) in the area of integrated pollution prevention and control; and the civil aviation or inspection authorities of the three member states in the area of SAFA. In view of the involvement of these agencies in policy work at the EU level, it is

\footnotetext{
${ }^{302}$ See further below.

${ }^{303}$ Interview NL25.

${ }^{304}$ Interview NL16.
} 
likely that the relevant officials are familiar with reports published by the Commission on the implementation performance of member states. A similar concept applies to national ministries; since these ministries act as the main national-level points of communication for the Commission, ministerial officials involved in certain policy areas will likely be familiar with reports showcasing the implementation performance of their country compared to the performances of others. Interviews do in fact suggest that this is the case.

The following subsections discuss the perceptions of higher-level civil servants of reports benchmarking the implementation performance of member states. They suggest that if EU reports aim to name and shame member states, their usefulness is limited, and the limited meaningfulness of the information presented in such reports is a crucial explanatory factor in this regard.

\subsubsection{The meaningfulness of information}

The reasons for the limited meaningfulness of information that, as suggested in the previous section, reduce the usefulness of reports seem to lie in the questionable objectivity of information included in the reports, the lack of understandability of information and its weak capacity to 'bite', and the quantitative nature of implementation performance evaluations of member states. These three aspects are discussed in the following subsections.

\subsection{Objectivity of information}

The meaningfulness of information presented in EU reports is limited, first of all, by the questionable objectivity of the data that they are based on. Sections 2.1 and 2.2 of this

$44 \%$ of the IPPC survey respondents agree or strongly agree that information provided in IPPC implementation reports, the Commission's general annual report, or research reports is useful. These numbers are roughly the same for permit writers. chapter suggest that most reports that are relevant to the context of this study are based on self-reporting by member states. Section 1.2.1 suggests that self-reporting exercises are accompanied by self-incrimination problems, which result from the idea that there are incentives for member states to 'look good', and which are thus likely to produce 'polished' images of member state performances. These sections also suggest that it is difficult, if not impossible, for the Commission to verify the correctness of reported information regarding the application of EU law on the ground. It is unlikely that the Commission is able to check whether the numbers of permits that are reportedly granted to IPPC installations reflect the actual numbers of permits issued. It is impossible for the Commission to verify whether all of these permits are granted in accordance with the requirements set out in the IPPC Directive. A similar concept applies to the number of 
consumer products inspected by the market surveillance authorities and the correctness of risk assessments and evaluations implemented by these authorities in particular.

Without suggesting that member states generally manipulate information as they please, there are indications that honesty is not attempted at all times. This is not a bold statement due to the fact that even in the case of on-site supervision, information may be managed in such a way as to present member states in a better light, as seen in Section 3.1 on EASA inspections above. Interviews suggest that, for reports submitted to the Commission by member states, it is Dutch officials specifically who doubt the reliability of information submitted by their colleagues. Officials indicate that there have been informal moments with colleagues from other member states when the veracity of formally submitted information was nuanced. ${ }^{305}$ Dutch officials seem to consider their own country the 'blue-eyed boy' of the EU when it comes to compliance with the Commission's information requests. The idea that the desirability of the asserted honest reporting practices of the Netherlands is doubted in view of the supposed practices of other member states is illustrated by the following quotations:

Reports from other member states often say: we comply with everything. Yeah right. The Netherlands is not very clever in reporting so precisely. Of course the Commission has to do something with the information, because we reported officially. But if you compare with other countries, it really can't be true that we are doing badly. In fact, the Commission sees us as an example for other countries. $^{306}$

There were some discussions at the ministry about this. Should you report in this way? You don't want to cheat, but couldn't it be more general rather than so detailed? Other member states don't report in such a detailed way either. It is ambiguous: we want to be precise, but how precise should we want to be? Spain reports $100 \%$ compliance although we know this is not true to the facts. This is frustrating. ${ }^{307}$

In fact, the Commission seems to have the same concerns regarding the reliability of information submitted by member states, as the following excerpt from an interview with a representative from a Portuguese environmental NGO suggests:

One of the things that the Commission should have is the resources to do its own inspections and monitoring of implementation. They rely too much on

\footnotetext{
${ }^{305}$ Interview NL16.

${ }^{306}$ Interview NL15. Regarding the notion that other member states are not always trusted, see also NL16; NL23; NL24; NL25; NL30.

${ }^{307}$ Interview NL21.
} 
reports submitted by the member states. Nobody trusts these reports, not even the Commission. If you talk to people at the Commission, they know that the reports are filled with information that was not independently assessed. But what they tell us is that they don't have the resources - not yet, at least. ${ }^{308}$

A Commission official indicates that, while the Commission should spend resources on finding evidence that proves member state reports are incorrect, this is not a straightforward exercise since the Commission may not want to spend resources on such an exercise. Indeed, due to the Commission's limited resources and its limited powers to check implementation on the ground, it is only when NGOs indicate that "things are not right" that the Commission "should do something with that [with the idea that member state reports may not always provide correct information about implementation performances]" ${ }^{309}$ This statement underlines both the importance of civil society organisations as watchdogs of national competent authorities in the implementation of EU law, and the differentiated effect that variations in civil society activism across member states and across policy areas may have on the extent to which the Commission can see what is happening in the application of EU law on the ground. These issues are further elaborated on in Chapter 7 on civil society.

The fact that the Commission attaches great importance to inspections carried out by EU regulatory agencies, such as standardisation inspections carried out by EASA, and that it contracts external consultants to research the implementation performance of member states, may confirm the Commission's scepticism about the reliability of member state reports. The notion that inspections may, however, yield distorted pictures of reality is hinted at in Section 3.1 above. The notion that this may be true for consultancy reports as well is illustrated by the following quotation, which is taken from a consultancy report on the implementation of the GPS Directive (and which has been quoted earlier):

Not all member states collect the detailed information as required to complete the questionnaire accurately [and] there appear to be very few correlations between the outcome data provided by the Eurobarometers and the input and output indicators provided by member states' [market surveillance authorities]. ${ }^{310}$

The mismatch between information delivered by member states and results published in Eurobarometers is remarkable, since it remains unclear how this mismatch could be accounted for. What this section suggests most of all, is that it seems quite impossible

\footnotetext{
${ }^{308}$ Interview PT12.

${ }^{309}$ Interview EC8.

${ }^{310}$ BSI Development Solutions, 2011: 5.
} 
for the Commission to acquire sufficiently precise insight into the application performance of member states that may serve as a basis for adequately benchmarking national performances in the first place.

In addition, the unreliability of information submitted to the Commission by the member states may result from more than purposeful manipulation on the part of national authorities. Member states may be

$60 \%$ of the GPS survey respondents agree, or strongly agree, that information provided in the GPS implementation report, the Commission's annual reports, and/or the consumer scoreboards is useful. These numbers are (considerably) lower for inspectors. eager to comply with the Commission's information requests, but compliance may be difficult to achieve due to practical difficulties in the reporting process. Such difficulties may, first of all, relate to the manner in which questionnaires sent by the Commission to the national authorities are set up. Interviewees indicate that they have struggled with a lack of clarity on the interpretation of key terms, with seemingly simple notions - for example, the terms 'inspectors' and 'market surveillance inspections' - posing questions of interpretation. ${ }^{311}$ Where national authorities interpret such terms differently, the information that they deliver to the Commission is bound to be unintentionally unreliable in view of the Commission's wants. ${ }^{312}$

Second, member states may face difficulties in the reporting process when the data collected by national authorities do not match the informational needs of the Commission, or when reality does not fit the conceptual framework used by the Commission. The Commission may want to obtain information on the number of inspectors conducting SAFA inspections, but these inspectors may dedicate a variable amount of time to this task next to other prime tasks that they have. How to estimate the available budget for product safety inspections if budget figures are readily available only for market surveillance on food and non-food products as a whole is unclear. Moreover, it is unclear how to guarantee that regional authorities report honestly to the national ministry about the quality of IPPC permits.

Such reporting difficulties raise concerns about the reliability of the information presented in Commission reports, and about the comparability of this information across member states. If one is not aware of how other member states have interpreted questions that are included in Commission questionnaires, it is difficult to conduct a meaningful comparative evaluation on the performance of member states and to draw usable conclusions from such an evaluation. This lack of comparability is what national officials perceive as limiting the usefulness of the information represented by the Commission, as we see below.

\footnotetext{
${ }^{311}$ Interview NL7.

${ }^{312}$ In view of the idea that vagueness opens the door for purposeful manipulation on the part of member states, the possibility of such manipulation occurring cannot be excluded.
} 


\subsection{Understandability of information that 'bites'}

While the reliability of information contained in EU reports is an important precondition for such reports to be useful, it is not a sufficient variable; in order for reports to effectively name and shame member states, information needs to be understandable to a wider public and it must sufficiently 'bite' badly performing member states. It is the Commission and EASA reports on the implementation of the SAFA Directive that demonstrate the notion that information may be reliable, but not understandable and therefore fail to bite. In contrast to the GPS and IPPC Directives, attaining objective information on member state performances is not such a problematic issue, since figures on numbers of SAFA inspections carried out, items inspected per inspection, and findings detected per inspection are retrieved from ramp inspection reports. These ramp inspection reports, which are forwarded to the inspected airline operators, are submitted to the SAFA database that is managed by EASA. Since the information contained in SAFA reports is not mediated - that is, made to look better - there is no way for member states to cheat on either indicator mentioned above. In this sense, the image arising from ramp inspection reports does, in principle, speak to the objective about the implementation performance of member states.

The question of whether such information is useful for effectively benchmarking member state performances is, however, of a completely different nature. One must agree with an EASA official that this information being published in staff working documents attached to SAFA implementation reports - instead of in implementation reports themselves - is not conducive to such information becoming known to the interested public. ${ }^{313}$ Even if one were to find this information, it is likely that a subsequent examination would yield more questions than answers - at least as far as relative outsiders are concerned. In fact, it may be the case that only SAFA national coordinators are capable of making sense of this information:

The figures presented by EASA in its annual reports, well, these may all be jolly, but what I have already noticed is that in some cases, people draw completely idiosyncratic conclusions from these figures. (...) You can't conclude anything from these reports. If you really want to have a picture of the quality of implementation you need to have more than the simple statistical information that is being published, because you can of course explain this in whatever way you want. It's like comparing apples and oranges. (...) As for me, this information does certainly tell me something, since I know the programme through and through as we implement it, and as an auditor I've also had the opportunity to check practices in other countries. So, since I have the knowledge and the expertise of how the programme works and should work, I am able to translate

${ }^{313}$ Interview EASA1. 
this information to what really matters. But of course it doesn't tell a layperson anything. ${ }^{314}$

If the perceptions implied in this quotation are true, a number of questions seem to arise. The first is about why the Commission (or EASA) publishes information that only those who have already seen this information ${ }^{315}$ - namely, SAFA national coordinators are able to understand. There are several arguments supporting the hypothesis that this choice results from the difficult balance that the Commission must strike between its commitment to providing transparency of member states performances and the need to ensure proper 'anger management' regarding member states' authorities. One of these arguments is that the Commission could choose to publish information on member state performance in its main implementation report, but that it has not done so. In fact, the current situation constitutes a step back from earlier reporting practices, since the first Commission report did include performance indicators. These indicators have been relegated to staff working documents only in the second and subsequent reports.

A second reason for the seeming lack of willingness of the Commission to effectively exploit its naming and shaming strategy is that the Commission disposes of information that may significantly increase the extent to which reports may bite. The Commission could, for example, publish exact numbers regarding the minimum inspection quota to be attained by member states each year. This would put the actual numbers of $48 \%$ of the SAFA survey respondents agree, or strongly agree, that information provided in the SAFA aggregate reports, the SAFA application report, and/or the Commission's general annual report is useful. annual inspections carried out by member states into perspective. One step further would be for the Commission to make final reports of standardisation inspections carried out by EASA available to a broader public. These reports, which provide more insight into the quality of implementation than the currently published objective numbers could, are currently shared through an internal Commission database, which means that they are available to SAFA national coordinators only. ${ }^{316}$

Note that information that has the potential to bite member states at first glance may yield concerns because of the reduced comprehensibility of this information for members of the general public. The European Pollution Release and Transfer Register provides an example this. The E-PRTR website is widely accessible and easy to search, and it provides a wealth of information about pollutants emitted for industrial sectors and individual member states. The notion that the presented information is not contex-

\footnotetext{
${ }^{314}$ Interview NL30.

${ }^{315}$ This information is also shared in meetings of the European SAFA Steering Group, as we see in more detail below.

${ }^{316}$ Interview NL30; EASA1.
} 
tualised does, however, make it difficult for a layperson to draw comparative conclusions as to the implementation performance of member states, as the following quotation suggests:

The Commission thinks a lot of things are very helpful, even E-PRTR. But it's a total waste of time, because what conclusion can you attach to an E-PRTR report if what you've got is only general information about emission levels? It is meaningless in fact, for me at least. This is a Commission opening up to general society. Someone from the Netherlands can enter E-PRTR and can see that a power plant in Poland produces so and so much. But it doesn't tell you anything. If it is the biggest power plant in Europe, it must emit also more, so it is very misleading. ${ }^{317}$

In other words - and put bluntly - since information may mislead interested members of the public, member states that ought to be famed may be shamed and the other way around. This may anger member states, as the above quotation suggests is the case. A Commission official indicates that it is this potential adverse effect of naming and shaming that has limited the extent to which the Commission makes use of scoreboards and that

$37 \%$ of the IPPC survey respondents agree or strongly agree that information presented on IRIS is useful. Over $46 \%$ think the same about information provided on E-PRTR. Permit writers find IRIS less useful, and E-PRTR more useful. explains why the Commission is "not famous for strong words" in its implementation reports. ${ }^{318}$ This official suggests that there is a fear that "simplistic naming and shaming" may trigger opposition from member states because they might feel offended, damaged, or treated unjustly; opposition that is not desirable in view of the dependency of the Commission on member states in the area of law making. The varying role that NGOs play as whistle-blowers across member states is another important factor that is considered by the Commission in this context. Since the nature of 'bottom-up' information about the implementation performance of member states varies, it is difficult for the Commission to provide information that compares the performance of member states in a manner that prevents member states from being upset. ${ }^{319}$

Two other considerations seem to account for the limited way that the Commission makes use of naming and shaming as an instrument to pressurise member states into compliance. The first consideration relates to the idea that the Commission wants to be seen as a neutral and professional actor instead of a political body. Using strong words to reproach member states is not seen as appropriate to sustain such an image. Second,

\footnotetext{
${ }^{317}$ Interview PL12.

${ }^{318}$ Interview EC8.

${ }^{319}$ Ibid.
} 
the Commission does not like to talk about "bad things"; it wants to send positive messages, "think big", and look forward. ${ }^{320}$ While the Commission is an engine and a guardian at the same time, it wants to be more of an engine, and aggressive naming and shaming strategies do not fit this role. ${ }^{321}$

\subsection{Relevance of information}

Reports should not only present objective and comprehensible information that bites in order for them to be credible naming and shaming instruments, interviews suggest that the information included in EU reports must also be relevant in view of the subject of these reports; namely, the implementation performance of member states. Interviews also suggest that, as is the case for the former conditions, this latter condition is not always met.

The predominantly quantitative nature of the information presented in EU reports must be understood to account for the observed lack of relevance, at least in part. Both Section 2 and the above subsection suggest that information on the quality of SAFA ramp inspections that are carried out by national aviation authorities is absent from reports. In the area of product safety, only consumer scoreboards and Eurobarometers measuring the perceptions of citizens and economic operators on product safety across member states seem to provide insight into the quality of market surveillance throughout the EU. These reports are based on subjective perceptions from stakeholders who are not directly involved in market surveillance activities; this data may be useful as such, but not for acquiring objective insights into how member states carry out inspections and risk assessments, and how they decide on the adoption of corrective measures.

In the area of IPPC, attempts to assess the implementation performance of member states in qualitative terms have been made. Section 2.1.2 describes that the Commission contracted external experts to verify the extent to which IPPC permits that are granted to selected installations in various member states meet the requirements that are outlined in the IPPC Directive. Such assessments are undeniably of a qualitative nature. The problem with such studies, however, is that they examine few IPPC permits and explicitly claim to provide no information about the compliance of these permits with the relevant legislative requirements (giving the term 'compliance assessment', which is explicitly used in such reports, a completely new meaning). The impact of these reports seems to be limited to highlighting implementation problems that may have arisen more generally. As such, they may feed into policy-making processes, provide the Commission with clues about where interpretative guidance is needed, and offer a general justification for Commission action taken to improve implementation. However, they do not permit hard conclusions on the performance of member states to be drawn.

\footnotetext{
${ }^{320}$ Ibid.

${ }^{321}$ Ibid.
} 
The resulting negative perceptions of the usefulness of implementation reports are exemplified by a Dutch official's perception of reports on the implementation of the IPPC Directive:

Implementation reports are far removed from reality. They are very theoretical and very formal. Authorities are not judged by the quality of the permits issued by them; it all remains very quantitative. This does not bring anything. These are endless reports, and they are an administrative burden for us. It is very difficult to convey this message to the European Commission. The Commission looks for measurable indicators, but such indicators contribute hardly visibly to the effectiveness of application. ${ }^{322}$

A Polish ministerial official from the same policy area shares this view, and seems to doubt whether the Commission's monitoring activities regarding the application of legislation are in line with the principle of subsidiarity:

Whether it is useful what the Commission does? For me as a worker of the ministry not, and for the competent authorities neither. It's a waste of time. I don't know for whom it might be useful. Probably the Commission has its own reasons for this. The Commission really watches what we do. It is a good guardian for the member states when it monitors if directives were transposed in time and correctly. But when the Commission is trying to have an effect on application I think it's different; this kind of documents, I think it's against the rules. There are some responsibilities for member states; member states have to check that directives are applied correctly. It's not the work of the Commission to do so. ${ }^{323}$

Generally speaking, the perceptions of national officials on the usefulness of EU reports as naming and shaming instruments seem to be rather negative; ${ }^{324}$ an idea that seems understandable, given the manifold factors that limit the meaningfulness of the information presented therein. The idea that representatives from NGOs may consider research reports useful for supporting them in their watchdog function may, in view of the factors outlined above, seem odd at first. Such a stance is understandable if one considers that the usefulness of EU reports for NGOs does not require truly meaningful information about the performance of member states in the terms set out above. For NGOs, reports are useful for increasing the visibility of a policy issue (and of associated

\footnotetext{
${ }^{322}$ Interview NL26.

${ }^{323}$ Interview PL8.

${ }^{324}$ As a matter of fact, such reports are not referred to as important instruments by any of the officials, for aiding them in the daily application of the directives included in this study.
} 
implementation problems), and for providing them with grounds for litigation before a national court. ${ }^{325}$ Whether the information presented in reports is of a quantitative or of a qualitative nature, and whether the performance of member states is truly comparable or not, is not necessarily important in this regard.

\subsubsection{Capacity-building effects of EU reports}

The above paragraphs depict a negative image of the usefulness of EU reports for benchmarking the implementation performance of member states and for naming and shaming the poorly performing states amongst them. Note, however, that reports may be considered to have effects other than naming and shaming; these effects do (or may) explain why some interviewees (and some survey respondents) refer to such reports as useful for the implementation of EU law. These effects could be understood as capacitybuilding effects. Portuguese officials in the area of market surveillance, for example, point out that EU reports may provide them with learning opportunities, as the following interview excerpt suggests:

Such reports are useful to see how other countries carry out market surveillance, since they give ideas; we can take lessons from such studies. If one member state dedicates its efforts to a product or a category of products, this knowhow will certainly be helpful for all member states. ${ }^{326}$

Practical benefits are also associated with E-PRTR. This register is not generally thought of as an appropriate instrument for benchmarking the performances of member states, as we have seen. Some interviewees also refer to it as "not very useful" from the perspective that it does (or should) not provide writers with any new information, since "if that were true, we would be doing something wrong" ${ }^{327}$ Other officials, however, do refer to E-PRTR as a useful tool for verifying how companies perform; they argue that it is practical to have more information on the performance of regulated sectors in their own country regardless of the performance of IPPC installations in other member states. ${ }^{328}$ This may explain why at least some permit writers who took part in the IPPC survey consider E-PRTR a useful compliance instrument.

These perceptions suggest that reports might not only (or not even) be seen as naming and shaming member states; this is not surprising due to the cautious way in which the Commission makes use of naming and shaming strategies. These perceptions also suggest that it is awareness of the capacity-building effects of EU reports that allows us to understand why a number of officials consider such reports useful. Note that the

\footnotetext{
${ }^{325}$ Interview NL19.

${ }^{326}$ Interview PT6.

${ }^{327}$ Interview NL25.

${ }^{328}$ Interview NL22; NL24; NL26; PT9.
} 
idea that the interviews conducted for this study were essential to unravel this effect underlines the importance of interviews as a research method in the context of this study. Also note that the idea that reports may both have an enforcement and capacityrelated function provides further ammunition to those advocating the abolishment of the fine line between rationalist and management perspectives on implementation and compliance.

\subsubsection{Naming and shaming 'amongst intimae'}

While EU reports that are open for consultation by the general public are the subject of discussion in Sections 3.2.1 and 3.2.2 above, this section focuses on the usefulness of information available to a smaller circle of stakeholders. The SAFA Directive seems to provide a good example of how information presented to a limited number of persons may be experienced as useful, and how this information may generate a naming and shaming effect that publicly available information may not be able to produce.

Information about the performance of member states in view of the objectives set by the SAFA Directive is provided by EASA during meetings of the European SAFA Steering Group, which gathers the SAFA national coordinators of all SAFA participating states, and representatives from the European Commission and EASA. ${ }^{329}$ This information covers more than the number of inspections conducted by member states and the number of items inspected per inspection. It also benchmarks member state performance regarding, for example, the achievement of the annual inspection quota established for each member state individually, and the timeliness of the submission of reports to the centralised SAFA database by the national authorities. This information covers many more variables than those presented in publicly available implementation reports, providing a more complete picture of the implementation performance of member states.

One may be inclined to think that the impact of such information must be limited given the restricted audience that it is made available to. Interviews do, however, suggest that meaningful information shared amongst a limited number of people may be a powerful tool for supporting the implementation performance of member states. The latter is certainly true for the Portuguese SAFA national coordinator, as the following quotation suggests:

How I know how other member states do? Yes, that's the role for EASA to play. The agenda of ESSG meetings always has a fixed bullet for EASA to present a general overview of the way in which member states are implementing the programme. And it works very well, because we are all extra attentive to the performance, to the benchmarks. There are several of them, and we all check

\footnotetext{
${ }^{329}$ For a description of the ESSG, see Chapter 6 on transnational networks, Section 2.3.
} 
these benchmarks to see if our country is behaving correctly or not. And I think it's a good thing. It's of human nature to have this. Of course, some states feel the obligation to ask for the floor and to give an explanation for something. I don't know, but it's better not to have a bad performance there that makes you feel you need to give that explanation. Nobody is wiling to have his country, him being the national official responsible, to have this benchmark, not behave correctly. Interestingly enough, the guy from EASA knows exactly the correct way of presenting it. So he does it in a very quick way - 'oh there's my country, oh very good' - but he knows that everybody is waiting for it. And after that, of course the presentations are uploaded on the restrictive website, so we know we have the opportunity to look back. ${ }^{330}$

For the Portuguese SAFA national coordinator, then, the prospect of reputational damage following a negative ranking seems to be a performance driver. This is completely different from the Dutch SAFA national coordinator, who seems to be reluctant to the naming and shaming effect that a negative ranking may have. While one official from the EASA SAFA standardisation team does confirm that naming and shaming is used as a mechanism to compel positive domestic change, ${ }^{331}$ the Dutch SAFA national coordinator actually denies the existence of any relationship between benchmarking and naming and shaming. ${ }^{332}$

One explanation for this stance is that the Dutch SAFA national coordinator simply does not feel shamed. This is logical in view of the positive perception held by this same national coordinator regarding the implementation performance of the Dutch SAFA team; ${ }^{333}$ such a self-perception leaves little room for apprehension about the reputational damage that EASA reports might cause - because the likelihood of such damage occurring is absent. A second factor that explains the reluctance of the Dutch SAFA national coordinator relates to the positive perception of benchmarking as necessary for reporting to management and as practical for identifying weak spots in the implementation performance of the Dutch SAFA team. ${ }^{334}$ Note that the Dutch SAFA national coordinator appears to be content with scoreboards, as long as they show that the Netherlands does not stand out from the crowd; an issue that has previously been referred to in the context of standardisation inspections, and in view of the consequences that an overly positive evaluation may have for the resources allocated to the SAFA team. The following quotation underlines this point:

\footnotetext{
${ }^{330}$ Interview PT17.

${ }^{331}$ Email from interviewee EASA1 to author.

${ }^{332}$ Email from interviewee NL30 to author.

${ }^{333}$ See Section 3.1.2 of the current chapter.

${ }^{334}$ Email from interviewee NL30 to author.
} 
If I see the areas in which the Netherlands scores significantly worse, I can tell management, 'listen, these are the points for improvement, this is where we want to improve, because otherwise we'll get problems.' So I can use the fact that EASA is aware of something, that EASA indicates that we need to improve, as a 'stick in the cupboard' in relation to management. The fact that I can use instances of underperformance to establish improvements, yes, that makes me happy. Because if we're doing well, management will say that we can do our work with fewer inspectors. If I say that management is - and I make a comparison here - a bully, then to beat that bully you need a bigger bully. Well, who's more powerful than our management? Formally, EASA and the Commission. Yes, I use EASA and the Commission as patrons. ${ }^{335}$

The notion that the Dutch SAFA national coordinator may use EASA and the Commission as patrons may be enhanced by the fact that for Dutch officials, EASA reports have a binding effect:

We basically sell the EASA story as being more or less binding. So yes, you can stone-facedly say that it legally unbinding and thus voluntary, but we say, 'no, it is not voluntary' ${ }^{336}$

Whether or not "the EASA story" is binding seems to be less of an issue in Portugal, where the threat of reputational costs suffices for the authority to feel compelled to comply. Given the absence of this scenario in the Netherlands, the Dutch perception of EASA reports as binding to the authority may constitute an important substitute for the fear of social costs as a motivating factor to perform better. What all of this seems to suggest is that it is not necessary for social costs to follow from EU reports in order for such reports to have a potentially positive effect on the implementation performance of member states - at least not where officials consider such reports to be binding.

The foregoing remarks suggest two things. The first is that in contrast to what one may be inclined to think, information on the implementation performance of member states does not need to be widely available in order for it to have an effective naming and shaming effect. Indeed, the case of the SAFA Directive suggests that the most important prerequisite for naming and shaming is not widespread transparency on the implementation performance of member states, but the provision of information that provides meaningful insight into this issue in the first place. This is not to say that the provision of truly meaningful information to the wider public would not increase the naming and shaming effect of such information, as this might well be the case. Since empirical ex-

\footnotetext{
${ }^{335}$ Interview NL30.

${ }^{336}$ Interview NL30.
} 
amples in the context of the three directives under examination are lacking, this study can, unfortunately, not say anything about this topic.

What can be said, however, is that superficial information available to society at large may not serve to support the application of EU law in any way. Moreover, member states may feel damaged by the publication of information that the public does not know how to interpret correctly, as Section 3.2.2.2.2 suggests. Thus it is unclear why the Commission publishes such information at all. It is difficult to identify any reason other than the Commission's commitment to providing transparency to the public on compliance issues - however formalistic the implementation of such a commitment may be while at the same time honouring the need to maintain good relations with member states in the Council.

The second suggestion that may be inferred from this section is that naming and shaming does not always function in a way that one would expect. In some instances, the prospect of reputational costs from a low ranking in EU scoreboards may compel member states into compliance; an outcome that must be considered in line with intentions underlying the implementation of a naming and shaming strategy. In other instances, naming and shaming exercises may deter national authorities from performing 'too well' given domestic (resource related) repercussions that officials fear may accompany a flawless performance. It is in these latter instances, that naming and shaming strategies initially seem to have the opposite effect of what they are intended to produce. At second glance, however, it seems that when national officials exploit rankings to maintain a certain level of resources, such rankings may act as effective guardians of an already adequate status quo in terms of compliance. ${ }^{337}$ The latter is likely to happen when EU reports are considered to have binding effect.

\subsubsection{Issue salience}

While the above sections suggest that scoreboards may have the potential to name and shame laggard states or be useful as defence mechanisms at home - namely when meaningful information is shared amongst national representatives - this does not necessarily mean that such reports positively impact the work of street-level actors in the daily administration of EU law. While the commitment of such actors may be sufficient for some implementation practices to improve, there are cases in which implementation may be supported only if the authority is granted additional resources, which may have to come from higher management echelons or from the government budget. Relevant to the question of whether such resources are provided is not whether street-level actors feel 'shamed into compliance', but whether those responsible for resource distribution are persuaded that implementation practices must improve. Whether such officials are

\footnotetext{
${ }^{337}$ Of course, to determine what an 'adequate status quo' is, one would need to answer the question of what the 'acceptable' or 'adequate' compliance level is in a certain case. On the difficulties related to answering this question, see Chapter 2 on implementation in the EU: same rules, divergent practices, Section 1.1.
} 
persuaded seems to depend on the salience of the policy issue amongst the relevant actors. $^{338}$

Interviews suggest that issue salience mediates officials' sensitivity to negative publicity on the implementation performance of implementing agencies. The environment seems to constitute a notorious policy example in this regard, as interviews with officials from all three countries included in this study suggest. ${ }^{339}$ Dutch officials suggest a direct link between the low salience of environmental issues and the appreciation by the government of negative rankings:

Nowadays, member states do not mind receiving a bad score from the Commission. See what is happening in politics nowadays. Our current government is probably even happy if they can show that we are not on top of the list. ${ }^{340}$

Similarly, Portuguese officials in the area of market surveillance indicate that they are not sure whether politicians would be sensitive to negative publicity in the current context of general economic constraints. ${ }^{341}$ Likewise, in Poland resource limitations are considered a general indication of the relatively low priority accorded to product safety. ${ }^{342}$ Finally, Dutch officials argue that product safety is not a priority for the government, as evidenced by the budget cuts that were implemented in previous years. ${ }^{343} \mathrm{In}$ fact, the only positive exception that appears in the context of this study is the perception held by Dutch SAFA inspectors of the salience of the issue of air safety and the resulting management and ministerial support for the SAFA Programme:

If EASA really finds something that I cannot solve myself, then it is something that the ministry or even the minister has to solve. And then the question is whether the ministry is prepared to do that. But I think SAFA enjoys considerable support because of the high level of societal and political commitment to aviation safety, which has been triggered by for example the Bijlmer crash. ${ }^{344}$ SAFA does not only enjoy great societal and political support, but it also has an important status in our organisation. We feel that our organisation supports us

\footnotetext{
${ }^{338}$ For the notion of issue salience, see Chapter 2 on implementation in the EU: same rules, divergent practices, Section 3.2.2.2.2.

${ }^{339}$ E.g. interview NL16; PL12; PL13; PL14; PT9; PT13.

${ }^{340}$ Interview NL16.

${ }^{341}$ Interview PT6.

${ }^{342}$ Interviews PL3; PL4; PL5.

${ }^{343}$ E.g. interview NL12.

${ }^{344}$ The Bijlmer crash was an accident that caused hundreds of deaths in the Amsterdam Bijlmer district, in 1992.
} 
so that we can do our work optimally, which is certainly not the same for other countries. $^{345}$

Note that a Dutch ministerial official suggests the opposite; according to this official, attention to air safety amongst politicians and ministerial managers is decreasing, since there have been few airplane crashes that might focus attention on the issue of air safety:

The level of safety in aviation is very high, which makes that attention for this issue within politics and at management layers at ministries tends to fade away. There will always be competition between different modes of transportation on where to spend money to improve safety. For example, there are much more accidents with road traffic and specifically touring cars than aviation accidents, and accidents trigger thinking about priorities. ${ }^{346}$

The apparent differences of opinion are relevant in practice, but they all support the idea that an issue needs to be salient amongst those who are in the position to support streetlevel actors if support 'from above' is to materialise.

This section suggests that civil servants may be shamed into compliance and motivated to perform as well as possible, but that this does not necessarily speak to the materialisation of progress - at least not in cases when civil servants are not in control of the resources needed for such progress to take place. When this is the case and higher-level officials do not attach importance to the policy issue at stake, naming and shaming strategies may be ineffective for bringing about positive domestic change.

\subsubsection{Synthesis}

The foregoing sections suggest, first, that EU reports are generally not known amongst street-level implementing actors. Second, national officials that are familiar with EU reports see them in rather negative terms, as far as the naming and shaming effect that they are thought to produce is concerned. This negative view is due to the fact that information presented in EU reports is not always objective, is often incomprehensible to laypersons, and is too superficial to bite bad performers. Moreover, the indicators used often provide little information about the quality of the implementation process. Note that this does not necessarily indicate the usefulness of reports as such; it seems that reports may be useful for implementation actors when they present meaningful information that meets the conditions of objectivity, comprehensibility, and relevance. Moreover, reports may be useful for strengthening the capacity of authorities in the

\footnotetext{
${ }^{345}$ Interview NL30. See interview PT15 for the view that reports may only have the power to change things if management finds SAFA sufficiently important.

${ }^{346}$ Interview NL27. Note that these interviews were carried out before the crash of flight MH17 in Ukraine. The influence of this crash on the salience accorded to the SAFA Programme is therefore unclear.
} 
implementation process. Third, what seems more useful than publicly available reports that say little about the implementation performance of member states is the meaningful information shared amongst national representatives. This information may effectively shame officials into compliance or function as a safeguard for these same officials at home. Finally, whether either of these effects brings about positive changes for streetlevel actors on the ground greatly depends on whether those that are in the position to affect such changes are persuaded into change. When actors other than street-level actors can affect change, the salience of the issue is an important variable in these types of decision-making processes.

\subsection{Infringement proceedings}

While naming and shaming strategies are equated with 'soft sanctions', the infringement procedure is the ultimate instrument that the Commission may resort to in order to coerce compliance (as outlined in Section 1.1.2.2 above). While the procedure has been deemed successful due to the eventual resolution of noncompliance cases, this section questions how useful the different functions of the infringement procedure are for national civil servants involved in the application of EU measures. From Section 1.1.2.2.4, one may recall that the infringement procedure is thought to have not only a corrective function, but a preventive effect as well, by deterring member states from defecting in the first place or by clarifying EU law provisions. Moreover, since it combines enforcement and capacity-building functions, the procedure mixes solutions that fit rationalist and management perspectives on implementation and compliance. ${ }^{347}$

This section examines the extent to which the Commission has taken action against member states under Article 258 TFEU in the three domains of this study (Section 3.3.1). It subsequently considers national officials' perceptions of two issues that surfaced in interviews: the way in which the Commission has made use of its discretion to begin infringement proceedings (Section 3.3.2), and the threat of infringement proceedings being started against member states (Section 3.3.3).

\subsubsection{Intensity of enforcement activity}

Section 1.2 of this chapter suggests that infringement proceedings that are started in connection to 'bad application' are greatly outnumbered by cases launched in relation to notification or transposition

$20 \%$ of all GPS survey respondents agree, or strongly agree, that the Commission is active in pursuing member states for 'bad application'. issues. Section 2.3 shows that this is similar to the cases included in this study, with respect to the GPS and SAFA Directives. While notification or transposition issues mo-

\footnotetext{
${ }^{347}$ For a discussion of rationalist, management, and constructivist perspectives of implementation and compliance, see Chapter 3 on the approach and methodology, Section 2.
} 
tivated the Commission to take action against member states in six and seventeen cases respectively, no action has been initiated regarding the application of either directive in

$43 \%$ of the SAFA survey respondents agree, or strongly agree, that the Commission is active in pursuing member states for 'bad application'. practice. This makes the relatively high percentage of SAFA survey respondents who agree that the Commission is active in

pursuing member states for 'bad application' difficult to explain. This is also difficult to explain because figures show that the Commission refrains from taking action against member states and because interviews with Commission and EASA officials suggest that the Commission leaves the resolution of problems regarding the implementation of the SAFA Directive to EASA. ${ }^{348}$

In stark contrast to the numbers for the GPS and SAFA Directives, are the seventeen procedures for inadequate application of the IPPC Directive, making this directive a notable exception in the context of this study. Note, however, that only one-fifth of the survey respondents agree that the Commission is active in pursuing member states for 'bad application'; this might be

$21 \%$ of the IPPC survey respondents agree or strongly agree that the Commission is active in pursuing member states for 'bad application'.

explained by the idea that the implementation of the IPPC Directive is widely known to encounter formidable and persistent obstacles across member states. From this perspective, while the number of infringement procedures started by the Commission is certainly high compared to the number of proceedings started for the other two directives included in this study, the fact that Commission action is still seen as an ineffective response to the seriousness of the problem of incorrect application is not surprising.

Note, in relation to this, that concerns expressed by EU officials regarding the application of the GPS Directive and the SAFA Directive make it unlikely that the Commission had no reason to start infringement proceedings in these areas. ${ }^{349}$ If this is true, then there must be other reasons for the Commission to abstain from initiating such proceedings. Possible reasons for such abstention are outlined in Section 1.2 of this chapter; the following subsections suggest that they mediate the enforcement activity in the policy areas examined in this study as well.

\subsubsection{Availability of information}

One of the factors mediating the enforcement activity of the European Commission is the amount of information about instances of noncompliance that reaches it. Previous sections discuss in detail that there is much about the application of EU measures that escapes the Commission's attention, and why this is the case. It is currently sufficient to remind ourselves of the fact that the police-patrol and fire-alarm oversight mechanisms

\footnotetext{
${ }^{348}$ See Section 3.3.1.3 below.

${ }^{349}$ For GPS, see interview EC2; for SAFA, see interview EASA3.
} 
that the Commission relies on provide partial insights at best, and incorrect insights at worst, into the implementation performance of member states. ${ }^{350}$ The following quotations from interviews with Commission officials involved in the area of IPPC and the domain of GPS, respectively, underline the weakness of such instruments and the veracity of the idea that application has remained much of a black box:

You're asking us about application problems...? You'll have to check the Entec reports. They are the primary source of information also for the Commission. ${ }^{351}$

The problem is that we don't know exactly what is happening. The only things that we see are market surveillance plans and RAPEX notifications. These are not sufficient to say, 'you are doing enough or you are not doing enough'. We do not see what member states do. Reports by member states are also partly a public-relations exercise, so that doesn't quite help either. ${ }^{352}$

In contrast to the perceptions of officials in the areas of IPPC and GPS, are the views of Commission officials involved in the domain of SAFA; views that standardisation inspections carried out by EASA allow the Commission to obtain a full picture of application, as Section 3.1 describes. That same section suggests that this view is in need of some qualification; one may recall that some national SAFA inspectors claim not to be entirely transparent about the difficulties that they encounter in their work. ${ }^{353}$

Section 1.1.1.2 of this chapter suggests that in order to make up for the limitations associated with police-patrol oversight mechanisms, such as those outlined above, the Commission relies on complaints to provide it with 'close-up information' about the application of EU measures by the member states. ${ }^{354}$ Section 1.2.1.1 suggests that the problem with fire-alarm oversight is that the extent to which non-governmental organisations act as whistle-blowers to the Commission varies across countries and across issue areas. Note that such variation was found for the cases examined in this study as well. While civil society activism seems absent in the domain of air safety, it varies greatly across member states in the domain of integrated pollution prevention and control in particular. While environmental NGOs in all countries primarily act in opposition to the state, the extent to which they are capable of acting as credible watchdogs varies across countries. This issue is elaborated on in Chapter 7 on civil society. It is sufficient to say here that these divergent activity levels of NGOs across the board lead us to expect variations in the numbers of complaints submitted to the Commission across countries and across policy areas.

\footnotetext{
${ }^{350}$ The limitations of police-patrol mechanisms are discussed in Section 1.2.1.1, Section 3.1 (inspections) and Section 3.2 (naming and shaming) above; for fire-alarm mechanisms, see Section 1.2.1.1 and further below.

${ }^{351}$ Interview EC5.

${ }^{352}$ Interview EC2.

${ }^{353}$ See Section 3.1.3.

${ }^{354}$ See Section 1.1.1.2.
} 
Unfortunately, detailed statistics on the numbers of complaints submitted to the Commission are not publicly available, ${ }^{355}$ which means that the expectation outlined in the previous paragraph cannot be confirmed. The data used for this study suggest that, out of the total number of complaints received by the Commission on the application of the three directives, eighty were deemed eligible for infringement proceedings against member states in the area of IPPC. The numbers for the areas of general product safety and SAFA are three and zero, respectively. While the discrepancy in these numbers does not necessarily mirror the discrepancy in numbers of complaints submitted to the Commission in the first place, the diverse patterns of civil society activism across policy areas make it likely that these numbers speak to the activity level of NGOs across policy domains. They suggest that complaints play more of a supporting role for the Commission in the area of IPPC than in the other two areas of this study.

\subsubsection{Clarity and binding effect of rules}

A second explanation for the varying intensity of infringement action from the Commission is the variable extent to which legislative provisions provide clarity on the requirements for member states. The majority of infringement proceedings in the area of integrated pollution prevention and control involve actions launched by the Commission against member states for violations of the requirement that existing IPPC installations be granted an IPPC permit by a certain date. ${ }^{356}$ This requirement is so clear as to leave no room for divergent interpretations; ${ }^{357}$ an issue that must be deemed essential for the Commission to successfully start infringement action against member states. This latter notion is supported by the idea that there are instances in which legislative vagueness has prevented the Commission from pursuing alleged breaches. For example, when asked why the Commission has started few proceedings for 'bad application' of the best available techniques in IPPC permits in a situation where the performance of member states is widely known to be substandard, a Commission official states that the IPPC Directive is "too vague" in this regard; that it "does therefore not provide strong grounds for the Commission in taking enforcement action". ${ }^{358}$ The Directive on industrial emissions, which has succeeded the IPPC Directive, is supposed to offer more enforcement possibilities. ${ }^{359}$

\footnotetext{
${ }^{355}$ See Section 2.3.1. Note that the Annual reports on monitoring the application of EU law give numbers for some member states and for some policy domains only; see e.g. Commission, '31st Annual Report on Monitoring the Application of EU Law' (Report) COM (2014) 612 final, pp. 6-8.

${ }^{356}$ Directive 2008/1/EC, Art. 5(1).

${ }^{357}$ Note that this clarity refers to the fact that installations should be granted a permit by the deadline specified in the Directive; it does not refer to the conditions that must be met. Chapter 5 on post-legislative guidance will show that these conditions are surrounded by a considerable lack of clarity.

${ }^{358}$ Interview EC7.

${ }^{359}$ Ibid.
} 
What applies to the IPPC Directive seems to apply to the GPS Directive as well. Analysis suggests the latter to be rather open and vague where obligations for the market surveillance authorities of the member states are concerned; a suggestion that is confirmed by interviewees ${ }^{360}$ and, one may argue, by the fact that post-legislative guidance has been adopted in order to clarify the relevant provisions. In fact, interviews suggest that what really matters for officials in the daily application of general product safety rules are the RAPEX guidelines, which clarify the obligations for member states under the RAPEX information exchange system and outline risk assessment guidelines for authorities to follow in product safety assessments. ${ }^{361}$ The problem for the Commission is that since guidelines lack inherent legally binding force, ${ }^{362}$ the RAPEX guidelines are difficult to enforce.

The latter remarks apply to the SAFA guidance materials, which play a pivotal role in the practical implementation of the SAFA Directive, ${ }^{363}$ and to the BREFs, which authorities must take into consideration in the determination of BAT for IPPC installations as well. ${ }^{364}$ These examples underline that, while the elaboration of key obligations for authorities in guidance documents might be desirable from a political and/or practical point of view, the downside of such practices is that the Commission seems deprived of the opportunity to subsequently enforce compliance with these rules by starting infringement proceedings.

\subsubsection{Political and pragmatic considerations}

Finally, mention should be made of the factors that interviews suggested may prevent the Commission from starting infringement proceedings even where it does, in principle, have sufficient grounds start a case. ${ }^{365}$ Note that some of these factors are discussed in previous sections, ${ }^{366}$ in which case the interviews carried out for this study confirm them.

The potentiality of political costs accompanying the initiation of infringement proceedings is one of these factors. Indeed, while the dependency on member states in the Council is said not to affect the Commission's publication of reports that may name and shame member states - the damage of such reports is limited since strong words are

\footnotetext{
${ }^{360}$ E.g. interview NL2; NL12; PT4.

${ }^{361}$ See Chapter 5 on post-legislative guidance, Section 2.1.1.

${ }^{362}$ For a theoretical reflection on the unclear (legal) effects of guidance, see Chapter 5 on post-legislative guidance, Section 1.2.2.

${ }^{363}$ See Chapter 5 on post-legislative guidance, Section 2.3.1.

${ }^{364}$ Ibid., Section 2.2.1.

${ }^{365}$ Section 1.1.2.2.1, sub C, has shown that the Commission's finding of a single infringement suffices in this regard (although it may, from an efficiency point of view, be preferable for the Commission to group a number of individual infringements in order to sustain a claim of general and persistent noncompliance).

${ }^{366}$ See Section 1.2.2.1.
} 
avoided $-{ }^{367}$ the potentiality of member states "making problems" in the Council "is normally an explanation for the Commission's inaction in starting infringement proceedings in some cases" ${ }^{368}$ The latter occurs only when the member state in question can offer the Commission something in return, such as supporting a particular Commission initiative. ${ }^{369}$ When asked how the Commission ensures impartiality in view of the tacit agreements between the Commission and member states, a Commission official provided the following explanation:

All that I can say is that it is politics and I cannot guarantee that sometimes sacrifices are not made. It might be the case. That's why we [the Commission's Secretariat General] are here; that's why there is a need for the political coordination of infringement cases. ${ }^{370}$

Interviews suggest that political considerations are not alone in explaining the Commission's behaviour towards starting infringement proceedings; an interview with a Commission official involved in the area of general product safety suggests that the Commission's approach is also characterised by a degree of pragmatism, which may withhold it from suing member states when it knows that instances of noncompliance are caused by capacity limitations, rather than by a lack of willingness from member states to meet their commitments. ${ }^{371}$ Such considerations seem wise in view of the theoretical perspectives on the effectiveness of compliance instruments outlined in Chapter 3 on the approach and methodology of this study; according to these perspectives, capacity problems must be addressed by capacity building, rather than sanctioning, instruments. In addition, from a practical perspective of cost-benefit considerations, the pragmatism on the part of the Commission seems logical, as it is not useful to dedicate considerable resources to a cause that is unlikely to improve. Of greater concern is that the above quotation seems to raise the question of whether or not the Commission uses its discretion to start infringement proceedings in an acceptable manner. The idea that the Commission is free in its decision of whether and when to initiate proceedings against member states seems undisputed, ${ }^{372}$ but the principle of non-discrimination may be perceived as limiting this discretion.

The idea that the Commission's pragmatism is not idiosyncratic to the area of product safety is supported by the following quotation about the Commission's role in relation to SAFA, which is from an interview with an official from EASA:

\footnotetext{
${ }^{367}$ See Section 3.2 on naming and shaming above.

${ }^{368}$ Interview EC8.

${ }^{369}$ Ibid.

${ }^{370}$ Ibid.

${ }^{371}$ Interview EC2.

${ }^{372}$ See Section 1.1.2.2.1, sub A.
} 
The question is what the Commission actually does with our information. The Commission often says: 'why don't you go after it?' EASA does have a better overview in the end. But as to enforcement action, the Commission doesn't do anything with it; it's just like a traffic offense. Often, is it also not necessary for the Commission to do something. The member state often has a reason. Sometimes the safety aspect is null. Sometimes it is not useful to magnify problems. ${ }^{373}$

The Commission's reliance on EASA is confirmed by an interview with Commission officials, who indicate that EASA has "an excellent team", that the Commission "acts in a positive way", and that "no stick is needed". ${ }^{374}$ The reason for this hands-off approach, in terms of infringement action, is that member states are considered willing to comply: "if member states refuse to do something, we would have no choice. But we have never got to that" ${ }^{375}$ These officials also indicate that in view of the financial difficulties that member states are confronted with, "it is hard to justify asking more input from member states" ${ }^{376}$ In other words, it seems to be both pragmatism on the part of the Commission about what may be asked from member states as well as a reliance on the problem-solving capacities of EASA that explain the Commission's reluctance to engage in infringement action against member states. The possibility of political motivation playing a role in the Commission's 'shifting of the burden' on EASA must also be considered.

\subsubsection{Between (much) frustration and (little) appreciation}

While the previous section suggests - and partly confirms - various factors that influence how the Commission makes use of its power to initiate infringement proceedings, this section turns towards member state perceptions of the Commission's use of discretion, and the usefulness of infringement proceedings for the daily application of EU measures. Note that similar to EU reports that may name and shame 'bad compliers', awareness of the Commission's power to sue member states for infringements is not always present amongst officials that exclusively carry out street-level implementation tasks. It is in particular Dutch IPPC permit writers who seem to be familiar with the Commission's competencies in this regard. This familiarity is explicable by the fact that the Commission started proceedings against the Netherlands for failing to meet the deadline to permit existing IPPC installations; proceedings that were closed after the Commission had sent the Netherlands a reasoned opinion setting out its concerns and requiring that action be taken to remedy the violation. ${ }^{377}$ Since most street-level actors do not seem to be familiar or experienced with Article 258 TFEU proceedings, the fol-

\footnotetext{
${ }^{373}$ Interview EASA2.

${ }^{374}$ Interview EC6.

375 Ibid.

376 Ibid.

${ }^{377}$ See Section 2.3, Table 10.
} 
lowing sections present the perceptions of Dutch IPPC permit writers and the higherlevel officials interviewed for this study relating to whether or not they think infringement proceedings are useful for supporting them in their work.

\subsubsection{The Commission's use of discretion}

Lower-level officials' perceptions of the potential usefulness of infringement proceedings for the daily application of EU measures seem rather negative, similar to the case for scoreboards published in publicly available EU reports. Interviewees indicate that these instruments are not intended to influence the implementation practice, ${ }^{378}$ that they do (therefore) not really look at these instruments, ${ }^{379}$ and that these instruments do not worry them. ${ }^{380}$ Such perceptions are reflected in the following quotation, which is incorporated in this chapter above:

[Regional and local authorities] are quick to say that implementation issues are on the state's shoulders. If the Netherlands gets a fine, they do not feel that as their responsibility. ${ }^{381}$

The apparent limited relevance of infringement proceedings for permit writers does not mean that permit writers do not have an opinion about the way in which the Commission has made use of its competencies in this regard. Officials claim to be rather uncomfortable with the fact that infringement proceedings were started against the Netherlands but not against other member states. They argue that these other member states escaped the Commission's attention only because they made themselves look better than they are:

Action undertaken by the Commission is fine. Ministries argue that fines may be imposed if we appear not to have fulfilled our obligations. But this is something that we ourselves are causing, by our way of reporting. Other countries do not report anything, or the honesty of such reports is questionable, and nothing is happening there as far as infringement proceedings are concerned. This gives me a very uncomfortable feeling. ${ }^{382}$

The questionable reliability of information submitted by member states about their own performance - an issue that was previously described as limiting the meaningfulness of scoreboards - is thus problematic in relation to the acceptability of infringement pro-

\footnotetext{
${ }^{378}$ Interview NL22; NL25.

${ }^{379}$ Interview NL21.

${ }^{380}$ Interview NL22.

${ }^{381}$ Interview NL16.

${ }^{382}$ Interview NL23. Note that action has been taken against other member states too, and that this official may not be aware of this. Regardless of whether or not this is the case, action has not been taken against member states that have 'even worse' compliance; for this point, see below.
} 
ceedings as well. The above quotation clearly suggests that, while the function of the Commission as guardian of the treaties is supported, the questionable role of member states in the provision of information and the fact that Commission action is based on such information limits national support for the Commission's methods for exercising discretion in specific cases.

The officials quoted above are not alone in their criticism of the Commission's use of its discretion, and the discussed unreliability of information about the implementation performance of member states is not the only reason for scepticism. An official from the former Dutch Public Health, Spatial Planning and Environment Inspectorate (VROM Inspectie) said that it was difficult to explain to the government why the Commission initiated enforcement action against the Netherlands in a situation of nearcomplete compliance:

The Commission has the right to pursue infringements. That was not a point of discussion. The discussion was more about standards. We are content with a compliance rate of $95 \%$. Then we start thinking about how to ensure even more compliance. But in Brussels they said, 'we are not satisfied, we want $100 \%$ compliance'. Back here it was difficult to clarify why we needed resources for more inspections. The reaction was, 'but aren't we already doing well?'383

A representative from a Dutch environmental NGO depicts a slightly different picture of the Netherlands' implementation performance in the area of integrated pollution prevention and control, as the below quotation demonstrates. This, however, is not the main point here; the main point is that there is some criticism of the appropriateness of the indicators used by the Commission to evaluate implementation:

It is astonishing how the Commission carries out infringement procedures. The quality of permits in the Netherlands is very bad, and Europe has said that the Netherlands does not execute the IPPC Directive. In the United Kingdom [UK], the situation is even worse: there, permits are super bad when it comes to the incorporation of BAT. But the Netherlands got punished, whereas it performs better than the UK when it comes to the revision of permits. But the problem is that procedures are being started based on quantitative data - and quantitatively, the Netherlands has revised fewer permits than the UK, while qualitatively, it does better. The Netherlands has submitted a complaint to the Commission about this; the Commission has examined the issue and said that

${ }^{383}$ Interview NL18. 
quality is also an issue of consideration. But of course it is much easier to evaluate quantity, because this boils down to nothing more than ticking boxes. ${ }^{384}$

Implied in the above views, is a desire for the Commission to be a guardian that coerces compliance on the basis of accurate information about relevant compliance indicators, and a guardian that is guided by the principles of fairness and reasonableness. Moreover, the above views express frustration about the application of these ideas in practice. In relation to this frustration, the following information must be noted.

First, while member states that are indicted by the Commission may suffer from competitive disadvantages compared to defecting member states that are not sued, the Commission has the right to act whenever information submitted to it by member states indicates that certain standards are not met. In relation to this issue, one may recall that the idea that other member states are also in breach of EU law is not accepted as a justification for infringements or as a mitigating circumstance. ${ }^{385}$ In other words, while member states may feel that they are treated unfairly in comparison to others, legally there is nothing to withhold the Commission from initiating infringement proceedings against member states that it deems to have infringed EU measures.

Second, it might be useful to restate that the need for member states to comply with EU measures means that that they should obey the requirements outlined therein, and that they should do so fully and not partially. This necessity does not permit a margin of $5 \%$ - or less for that matter - of noncompliance to be tolerated by the Commission. Note that this stance has been confirmed by the Court, which has been rather radical in declaring that member states should fully comply with EU law. Put briefly, while member states may feel that they are doing a good job when they 'largely' comply with EU law, such performance is clearly not enough to escape infringement proceedings.

Third and finally, while it will in many cases be correct to argue that the use of certain indicators cannot provide a full picture of application, the fact that member states might score better on other indicators than those about which information is available should not withhold the Commission from suing member states for failing to meet their obligations if evidence of such failure is available. This might be frustrating for member states, but is seems difficult to argue why this should be different. Overall, while the concerns expressed by national officials are understandable from a practical point of view, there seems to be little that pleads in favour of them from a legal point of view. This does not mean that such concerns should - since they are legally irrelevant - be ignored; one may submit that if the Commission is to maintain support for the way in which it carries out its tasks as guardian of the treaties, it should be transparent about how these tasks are exercised in sectoral areas and which limitations it faces in this regard. ${ }^{386}$

\footnotetext{
${ }^{384}$ Interview NL19.

${ }^{385}$ See further Section 1.1.2.2.1, sub C.

${ }^{386}$ That such an exercise should boil down to something more than outlining priority areas for infringement
} 


\subsubsection{A useful 'stick in the cupboard'?}

While the above section has suggested that perceptions of the Commission's exercise of its discretion to start infringement proceedings are rather negative, perceptions on the usefulness of the infringement procedure - as a 'stick in the cupboard', or as a facilitating instrument - seem not much different. The above section already suggests that many lower-level officials are not aware of the Commission's powers under Article 258 TFEU to begin with, and that those who are familiar with the infringement procedure

$31 \%$ of the IPPC survey respondents agree or strongly agree that (the threat of) infringement proceedings started against their country are (is) useful. This is the same for a slightly lower share of the permit writers. indicate that they do not attach much importance to it. Infringement proceedings are typically considered more relevant for higher-level (ministerial) civil servants than for streetlevel actors. When asked which instruments they find most useful for supporting the daily application of EU measures, these higher-level civil servants do not, however, refer to the infringement procedure as a favourite. Most outspoken in their rejection of infringement proceedings as useful are Polish ministerial officials, who indicate that Commission action in this regard may yield quick fixes that do not solve implementation problems sustainably in the end. ${ }^{387}$ Many problems are caused by interpretational questions, they say, and consultation with the Commission is deemed to be more useful for correcting problems than pressure. ${ }^{388}$

Note that the idea of the infringement procedure as rarely useful is broadly reflected by the results of the surveys carried out for this study, as shown in the boxes elsewhere in this section. It is only in the area of IPPC that a substantial minority of the respondents agree that the (threat) of infringement proceedings started against their country is useful; something that might be explained by the fact that more proceedings have been started in the area of IPPC than in the other two areas included in this study.

This does not mean that views acknowledging the usefulness of the infringement procedure are absent. Positive views are expressed exclusively by Dutch officials who, it must be noted, do not necessarily refer to infringement proceedings as useful for the Dutch implementation practice. A Dutch official in the area of product safety indicates that the threat of infringement proceedings is useful "as it provides clarity and puts an end to matters that have been going on for years or that have returned"

$5 \%$ of the GPS survey respondents agree or strongly agree that the threat of infringement proceedings started against their country is useful. None of the inspectors agree this is the case.

\footnotetext{
action, as it has done in several communications (see Section 1.1.2.2.3 above), speaks for itself.

${ }^{387}$ Interview PL1.

${ }^{388}$ Interview PL1. Note that EU Pilot provides a tool for negotiation between member states and the Commission; on this issue, see Section 1.1.2.2.3 above.
} 
- adding that, "this we dare say since we think this procedure will be applied to us only rarely. It applies to other member states that could actually use a 'stick in the cupboard"' ${ }^{389}$ The idea that Commission action is seen as useful in particular for other member states may be explained by the idea that - as we see in Chapter 6 on transnational networks - Dutch officials are quite confident regarding their own implementation performance in the field of general product safety.

Confirming the idea that the infringement procedure is perceived as rarely useful for the Dutch authorities is the suggestion, by the same official that is quoted above, that the administration tries to avoid such proceedings from being started or taken further not because of reputational costs or "political hustle and bustle", but since such proceedings take up "enormous amounts of time and energy" and because once a case is submitted to the CJEU, "anything can happen, including the undermining, by the Court, of the entire implementation strategy" ${ }^{390}$ Since the latter is to be avoided, preventing infringement proceedings from being started or moving further is "a way to keep control in our own hands in order to prevent damage from being done". ${ }^{391}$ Rather than being regarded as a potentially helpful tool for solving outstanding issues or for ensuring that compliance with applicable measures is attained, the infringement procedure is, thus, seen as an unwelcome guest endangering well-established and not-to-be changed ways of doing things.

As the only real positive exception in this context seems to qualify the view of the Dutch SAFA national coordinator who, in line with findings on naming and shaming discussed in Section 3.2 above, indicates to use the threat of infringement proceedings being started as the ultimate safeguard in relation to superiors that are in charge of de-

$14 \%$ of the SAFA survey respondents agree or strongly agree that the threat of infringement proceedings started against their country is useful. ciding on the allocation of resources to the SAFA inspection team. ${ }^{392}$ This official does, however, also indicate that the amount of time between the finding of an infringement by EASA and the pursuance of the case by the Commission, reduces the urgency and relevance of the procedure as a compliance instrument. It seems that in the short term, naming and shaming by EASA is more of a useful instrument to secure resources than the possibility of infringement proceedings being started.

\subsubsection{Synthesis}

While often hailed as the ultimate - and eventually effective - instrument for forcing member states into compliance, infringement proceedings are looked at with little ap-

\footnotetext{
${ }^{389}$ Email from interviewee NL12 to author. Similar NL7.

${ }^{390}$ Email from interviewee NL12 to author.

${ }^{391}$ Ibid.

${ }^{392}$ Interview NL30.
} 
preciation by the national officials interviewed for this study. When asked which of the instruments discussed in this study they consider useful for supporting the daily application of EU measures, none of these officials refers to the infringement procedure. The instrument had low popularity amongst survey respondents too. Four factors seem to account for the rather negative evaluations of the procedure as a compliance instrument.

First, lower-level officials do not see how the procedure should have a direct effect on their work. Second, officials do not seem to comprehend how the Commission makes use of its discretion in the initiation of infringement proceedings. National officials seem sceptical about the reasonableness of infringement proceedings in situations of near-complete compliance, and about the Commission's reliance on certain indicators and member state reports for deciding on infringement action. Commission officials suggest that enforcement action is not only circumscribed by the variable availability of information about the implementation performance of member states, but also determined by a great deal of pragmatism about whether or not infringement proceedings are helpful for making directives work in specific situations. Often, this answer seems to be a clear 'no'. Political considerations are confirmed to play a role in this regard as well.

Third, the infringement procedure does not always seem to be the appropriate tool to bring about real, lasting changes in implementation practices. The notion that the infringement procedure is the hardest enforcement tool that the Commission has at its disposal may be problematic in this regard. Because member states may want to avoid the political or practical costs associated with the initiation or continuation of proceedings, the threat of such proceedings being started or taken further may lead to quick fixes that do not fix anything.

Fourth and finally, even when the procedure is regarded as theoretically useful for ensuring political commitment to implementation, the time between the finding of an infringement and the initiation of proceedings greatly reduces the credibility of the procedure as a compliance instrument. Thus, considerations regarding the usefulness of recently introduced reforms for the functioning of the procedure - in particular those in relation to Article 260 TFEU, which may lead to the imposition of financial sanctions do not even appear in interviews with officials.

Note that this rather negative evaluation of the usefulness of the infringement procedure does not mean that the procedure is intrinsically wrong. What it does mean, is that there is much to gain if and when the procedure is used more consistently, vigorously, and wisely. These are all elements that the Commission (and the Court) can - at least in theory - control, which means that increasing the usefulness of the infringement procedure for national implementation practices is possible. Specific recommendations to this effect are provided in the chapter that concludes this thesis. 


\section{Concluding remarks: how and when do monitoring and sanctions work?}

This chapter suggests that the functioning of monitoring and sanctions as compliance instruments generally leaves much to be desired. While the picture is negative when it comes to the infringement procedure, it is mixed when it comes to inspections carried out by EU regulatory agencies and to naming and shaming strategies implemented by the European Commission. Note that negative perceptions do not necessarily speak to the inherent design of compliance instruments; they may say more about how instruments are used by the Commission, the Court, or a regulatory agency - ways that can, at least in theory, be controlled and manipulated for the better. The current section aims not only to summarise the findings of this chapter regarding the usefulness of each individual compliance instrument, but also to outline the conditions that these instruments need to meet in order for them to work well (or better).

\subsection{Inspections by EU regulatory agencies}

Table 11 Conditions for EU inspections to be useful compliance instruments

Inspections are perceived as most useful when:

- they not only aim at correcting existing instances of compliance, but allow for learning opportunities as well

- the (organisational) culture of member states allows for learning to occur

- the inspection team brings sufficient knowledge and expertise to bear

Standardisation inspections carried out by EASA, which are the subject of this chapter, have two objectives. While the prime purpose of such inspections is to detect existing instances of noncompliance and to enforce their correction, such inspections also have an educational function. The survey carried out for this study suggests that standardisation inspections are generally considered useful for supporting SAFA officials in their work. Interviews with Dutch, Polish, and Portuguese officials broadly confirm this idea, but they simultaneously demonstrate cross-country differences in perceptions of what makes such inspections useful. The Polish case shows that inspections may be considered to have a monitoring and correction function only; in such a situation, a fruitful learning environment is unlikely to develop. That experiences with inspections may be completely different is suggested by the Dutch case, which shows a degree of laconicism on the part of inspectors as to the authority of EASA as a monitoring agency. An explanation for this laconicism may be the Dutch self-perception that implementation is more than adequate, and the idea that EASA inspection results may come in useful as a safeguard in relation to superiors who may be keen on cutting resources. Dutch officials also indicate that EASA inspections have had a positive learning effect. 
The notion that learning opportunities may fail to materialise even when learning is appreciated, is demonstrated by the Portuguese case; here, insufficient knowledge and expertise on the part of the agency's inspection team, and a lack of openness on the part of inspectors regarding difficulties encountered in the implementation process, pose as obstacles to learning. The Portuguese case also shows that position matters. The wish to learn from the EASA team is held by inspectors in particular; what seems to count for the SAFA national coordinator - who is not involved in SAFA inspections on the ground - is the reassurance effect that standardisation inspections have produced.

The above paragraph suggests that the usefulness of inspections carried out by EU regulatory agencies is greatly determined by domestic idiosyncrasies and the characteristics of the agency's inspection team. Cultural predispositions about 'authority' and organisational behaviour play a role in relation to the former element; both of these factors mediate the extent to which inspectors 'get something out of inspections' apart from the benefits that may follow from the forced correction of infringements. Note that since cultural predispositions are 'sticky', the views and behavioural dynamics that flow from it are unlikely to change overnight. Variation in the knowledge and expertise of inspectors on the agency's inspection team seems to be a factor in determining the beneficial effect of inspections for national authorities as well. These variations are partly explained by the rotation of national inspectors in the inspection team. If this rotational system is to be maintained, such variations are likely to persist - at least as long as qualitative differences across member state authorities are present.

From a theoretical point of view, since the findings from this chapter indicate that inspections which are primarily aimed at correcting compliance problems may have a capacity-building effect as well, they provide further ammunition for those advocating for the abolishment of the borders between rationalist and management perspectives on compliance. Note that these findings may also suggest that a combination of these functions may be required to increase the effectiveness of compliance instruments. In the case examined in this chapter, the combination of management and enforcement functions is considered indispensable for standardisation inspections to be truly effective compliance mechanisms; when attempts to create a classroom situation fail, such inspections are thought to be suboptimal mechanisms for compelling compliance. 


\subsection{Naming and shaming}

Table 12 Conditions for naming and shaming to be a useful compliance instrument

Information shared must be meaningful. Information should:

- be objective

- allow for truly comparative and comprehensible insights to be gained

- say something about the quality of implementation

Information must bite. This means that:

- member states may fear the associated reputational costs, which motivates them to perform as well as possible

- member states may use scoreboards as a stick in relation to management, which ensures resource flow - at least where an issue is salient

The literature suggests that naming and shaming may be expected to pressure authorities into compliance by virtue of the reputational costs that accompany negative evaluations of implementation performances (and that member states may want to avoid or compensate for). This chapter examines the usefulness of publicly available EU reports that are thought to have the potential to name and shame badly performing member states, and naming and shaming exercises 'amongst intimae', for example in the context of EU implementation networks. It suggests that EU reports are not considered useful instruments for supporting the application of EU law, at least not when they aim to name and shame member states. Street-level actors are not familiar with such reports, or they do not see how such reports should benefit their daily work. Higher-level civil servants mainly express frustration regarding the meaningfulness of information presented in such reports. Complaints concern the objectivity of the information that reports are based on (the extent of which is doubted, given that most reports are based on selfreporting by member state), the comparability and comprehensibility of member state performances for members of the public in particular (the lack of which may lead to a situation in which member states that are famed should be shamed, and vice versa), and the indicators used to measure compliance (the nature of which is often quantitative rather than qualitative). An examination of these reports also demonstrates that they rarely include information that may actually bite member states; this greatly reduces the extent to which such reports may put pressure on laggards. The concerns outlined above seem to follow, in part, from resource limitations on the part of the European Commission, and in part from the wish of the Commission to maintain good relations with member states in the Council.

Note that approximately half of the survey respondents indicate that EU reports are useful; this seems odd in view of the considerations outlined above. Interviews do, however, suggest that such positive perceptions may be explained by the capacity-building effects that reports may have. Such reports may, for example, allow officials to learn from best practices in other member states or otherwise contain information that is not 
readily available to officials. Thus, reports are not only (or not even) seen as naming and shaming member states; a matter that should not come as a surprise in view of the Commission's cautious behaviour when it comes to naming and shaming member states. Similar to agency inspections, the idea that reports that may be intended to name and shame member states may have a learning effect at the same time, contributes to the erosion of the border between rationalist and management perspectives on implementation and compliance.

Naming and shaming exercises 'amongst intimae' seem to be more useful as naming and shaming mechanisms than EU reports, at least that is what interviews with national officials involved in the implementation of the SAFA Directive suggest. The reason for this is that information on the implementation performance of member states presented in closed meetings is more telling than the rather superficial information that is presented in EU reports. The effect of naming and shaming implemented in this fashion varies, though. In the Portuguese case, the threat of reputational damage following from having to account, en plein public, for a bad ranking acts as a driver for the authority to perform as well as possible. This case broadly matches expectations regarding the effect of naming and shaming outlined in the literature.

The idea that officials might be reluctant to possible negative rankings is demonstrated by the Dutch case. Such reluctance may be explained, in part, by the Dutch selfperception of implementation as more than adequate; a self-perception that leaves little room for fear of reputational damage. The noted reluctance also follows from the fact that officials might actually want to prevent standing out from the crowd, since overly positive evaluations might lead to adverse consequences in terms of the allocation of resources to authorities. In view of the potentiality of such adverse consequences materialising, it is better to be criticised in some way than to exclusively receive praise. The use of scoreboards as sticks in relation to superiors might be particularly effective if such scoreboards are seen as binding by the authority and the relevant superiors.

Note that naming and shaming does not always lead to positive domestic change for street-level actors involved in the application of EU measures on the ground. Whether such change materialises depends on whether those who are in the position to effectuate change are persuaded about the desirability or necessity of this change. Where actors other than street-level actors are essential in this regard, the salience of the issue in the eyes of these actors is a relevant variable. Thus, naming and shaming may be a powerful instrument for supporting the application of EU law, but even if information is meaningful enough to bite, its effect may be rather erratic in the end. 


\subsection{Infringement proceedings}

Table 13 Conditions for infringement proceedings to be useful compliance instruments

Infringement proceedings are amongst the least useful compliance instruments. Drawing on why they do not work as well as they could, what may make them work better is:

- a more consistent and more vigorous use of infringement proceedings

Moreover, the Commission should:

- have access to more objective and relevant information about the quality of compliance

- clarify the choices made by it as guardian of the treaties

- reconsider the reasonableness of the $100 \%$-compliance standard

National officials agree that the infringement procedure is amongst the least useful instruments for supporting the application of EU law. Note that the reasons for this evaluation do not necessarily relate to the intrinsic design of the procedure. In fact, they seem to focus on how the procedure is used by the Commission (and by the Court) - on methods that these institutions can, in theory, do something about. Specifically, the analysis suggests that the usefulness of the procedure could be enhanced if the Commission and the Court were to use in a more consistent, vigorous, and wise manner.

Note that street-level officials are not always aware of the competencies of the European Commission in relation to the initiation of infringement proceedings, and that when they are aware they consider the potentiality of such proceedings as the central government's responsibility. Some officials indicate that the procedure might be used as a safeguard in relation to superiors, similar to naming and shaming exercises 'amongst intimae', were it not for the considerable time lapse between the finding of an infringement and the sanctions being imposed. This makes the procedure a rather incredible safeguard indeed. The idea that the procedure might be useful if only it were to work better, suggests that officials are not in principle hostile towards the use of the infringement procedure; in fact, they may well embrace a more vigorous use of the procedure by the Commission and by the Court.

It is self-evident that infringement proceedings can only be initiated if violations of EU law are detected in the first place, and such detection is not simple. This study is not the first to suggest that verifying the compliance behaviour of member states in the application of EU measures is difficult in view of the limited police-patrol oversight powers that the Commission has at its disposal, the suboptimal functioning of policepatrol instruments, and the varied role that civil society plays as a whistle-blower to the Commission across countries and policy areas. In addition EU law provisions may be too vague to be successfully enforced, and there may be political and pragmatic considerations for the Commission to choose not to start proceedings when it does in fact have sufficient grounds to do so. Thus, the picture that arises is one of a greatly erratic implementation of the infringement procedure. 
The idea that the erratic use of the infringement procedure may cause a degree of frustration on the part of member states is suggested by the Dutch case in the area of IPPC in particular. While they claim to respect the Commission's enforcement competencies, Dutch officials also indicate feeling frustrated about the incomprehensible way in which the Commission makes use of its competencies in this regard. The notion that the Commission bases its decisions on information that is reported by member states about their own performances - information that is not necessarily accurate - is one reason for this frustration. Another reason relates to the use of indicators by the Commission that may not indicate the quality of implementation but, instead, progress towards certain quantitative goals. National officials also express a degree of frustration with the idea that the Commission sues member states in cases where compliance is (allegedly) close to complete.

While these frustrations are easily ignored from a legal point of view, they might be considered when questioning the acceptance rate amongst national authorities of the Commission's use of its enforcement powers. The good news is that since these factors are external to the design of the procedure, the Commission is theoretically able to control and to manipulate them for improvement. Note, however, that the Commission is not in the position to repair all of the flaws indicated by national implementation actors. First, it seems difficult for the Commission to solve the informational deficit that it is confronted with; the limited resources on the part of the Commission alone suffice to support this view. Moreover, the requirement to comply fully - and not partially - with EU law is more than a soft standard; it is a standard that is laid down in CJEU case law and, thus, a standard that the Commission must comply with.

While it seems that the Court should be more drastic in sanctioning member states, one may wonder if the rather radical stance of the Court - and thus, of the Commission - requiring $100 \%$ compliance from member states is reasonable. In an ideal world, full compliance may be desirable, but we are far removed from such a world. It may be argued that in situations of insufficient resources, member states should direct their resources to agreed on areas of priority, and that a good enforcement policy should overlook instances of noncompliance with a merely small or negligible impact on those who are set to benefit from the implementation of legal rules. Of course, the path from 'full compliance' to 'acceptable compliance levels' is a slippery one, as it is not easy to draw the line between what is 'good enough' and what borders on unacceptable. ${ }^{393}$ However, the findings of this chapter suggest that a discussion about this issue may be an important endeavour, not only for the European Commission, but also for other actors involved in making EU law work.

Finally, the use of the infringement procedure may trigger frustration or misunderstanding as well, because member states do not necessarily act in bad faith when they

\footnotetext{
${ }^{393}$ On the difficulties of establishing what 'effective implementation' is, see Chapter 2 on implementation in the EU: between rules and practices, Section 1.1.
} 
infringe EU law. Infringements may be caused, not by a lack of willingness to comply, but by a lack of capacity to implement EU measures or by a lack of awareness of applicable norms. ${ }^{394}$ In both these cases, coercion does not seem to be the most effective way to make member states comply; interviews suggest that it is certainly not perceived as such by member states. What member states may need in many situations are capacitybuilding measures instead of punishment. This may explain officials' appreciation of post-legislative guidance, the usefulness of which is discussed in the following chapter.

${ }^{394}$ For an elaboration on these different ideas on how compliance problems may be caused, see Chapter 3 on the approach and methodology of this study, Section 2. 


\section{Chapter 5}

Post-legislative guidance 



\section{Introduction}

While the previous chapter focuses on supranational instruments that are primarily associated with enforcement, the focus of this chapter is on post-legislative guidance, an instrument that aims to facilitate the administration of EU measures by the competent authorities of the member states. It is meant to accomplish this through clarifying "how the body of primary and secondary [EU] law must or will be applied". ${ }^{1}$ Post-legislative guidance is a regular feature of EU law ${ }^{2}$ that has been increasingly used over time ${ }^{3}$ because of the complexity of legislative provisions ${ }^{4}$ and the increasing amount of CJEU jurisprudence on the interpretation of EU measures, ${ }^{5}$ which is not always accessible to national competent authorities. ${ }^{6}$

Post-legislative guidance has also become a regular feature because the judicial interpretation powers granted to the CJEU are unsatisfactory for the daily practice of administering EU law. They are unsatisfactory, first, because court cases are time consuming. Second, their occurrence depends on the willingness of the Commission to take infringement cases to the Court, or on the existence of a national dispute with an EU law dimension and a judge willing to refer preliminary questions to the Court. ${ }^{7}$ While Chapter 4 on monitoring and sanctions suggests that few infringement cases make it to the Court, Chapter 8 on case law shows that there may be many obstacles preventing that questions about the interpretation of EU law are sent to the CJEU for consideration. It is in view of these drawbacks that post-legislative guidance, designed as a flexible tool to address questions of EU law, may be a useful compliance instrument.

Post-legislative guidance may come in three forms, as shown in Figure 5.

\footnotetext{
${ }^{1}$ Senden, 2004: 140 .

${ }^{2}$ Scott, 2011: 329 .

${ }^{3}$ Senden, 2004: 138 .

${ }^{4}$ Ibid.: $363,407$.

${ }^{5}$ Lefevre, 2004: 809 .

${ }^{6}$ Ibid.

${ }^{7}$ Adam and Winter, 1996: 630; in Lefevre, 2004: 811.

${ }^{8}$ This differentiation is based on Scott, 2011: 334. Senden only distinguishes between interpretative rules and decisional acts; see Senden, 2004: 140ff.
} 


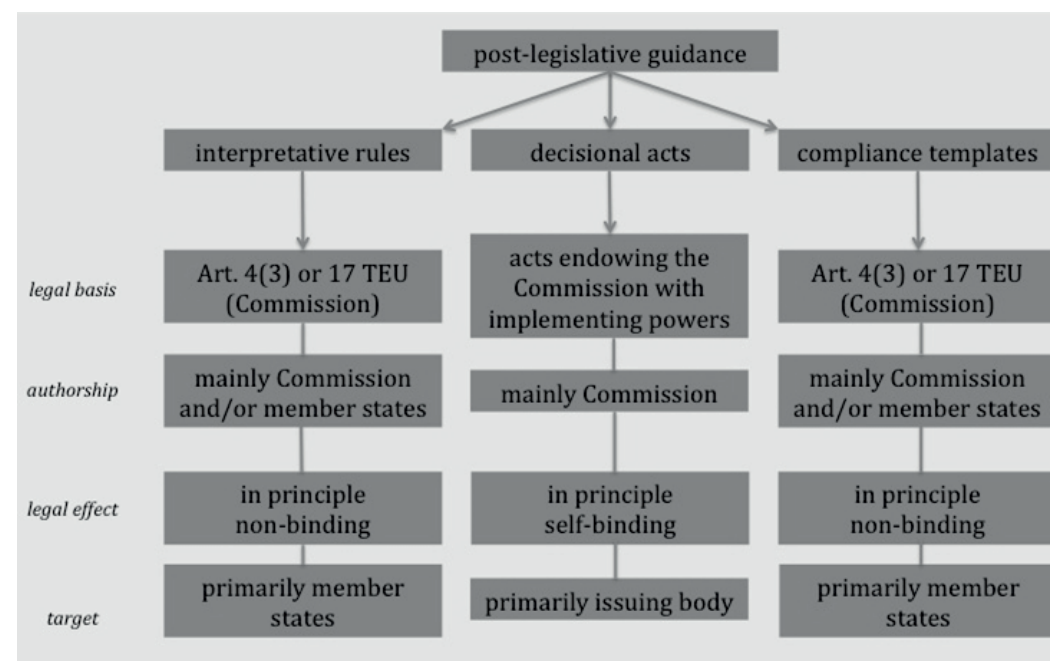

Figure 5 Types and features of post-legislative guidance

Interpretative rules serve to clarify certain legal provisions in order to prevent different interpretations from occurring ('active interpretation'), or to codify the existing legal framework and CJEU case law in order to increase accessibility of a certain domain ('passive interpretation'). ${ }^{9}$ Such rules are primarily targeted at member states. While they may be adopted by institutions other than the European Commission, ${ }^{10}$ such as EU agencies, the Commission remains the primary body for the issuance of interpretative rules. ${ }^{11}$ The Commission may take the initiative to adopt such rules whenever it deems this is necessary to clarify the rights and obligations inherent in certain legal provisions; this is a competence that is implied in the general power for the Commission to ensure the application of EU law, as outlined in Article 17 TEU. ${ }^{12}$ Indeed, it is argued that if the Commission is to properly fulfil its task as guardian of the treaties, it must be empowered not only to react to infringements that have already occurred, but also to act proactively and prevent such infringements from occurring in the first place. ${ }^{13}$ Note that the development of interpretative rules may also follow from a request on the part of member states for assistance or advice, in which case the principle of loyal cooperation outlined in Article 4(3) TEU can oblige the Commission to support the member states. Since they lack comparable powers, bodies other than the Commission must explicitly be granted the competence to adopt interpretative rules.

\footnotetext{
${ }^{9}$ Senden, 2004: 146; Senden, 2013: 60; Reale in Lefevre, 2004: 809-810. For the distinction between passive and active interpretation efforts, see Lefevre, 2004: 813. For the remainder of this chapter, the term interpretative rules' will be used to refer to both passive and active interpretation efforts.

${ }^{10}$ Senden, 2004: 141.

${ }^{11}$ Case C-2/88 Criminal proceedings against JJ Zwartveld and Others [1990] ECR I-3365, 17-33.

${ }^{12}$ Senden, 2004: 141, 146-147, $312 \mathrm{ff}$.

${ }^{13}$ Ibid.: 317-318.
} 
The Commission may opt to involve the member states in the development of interpretative rules. Working in partnership with the member states may be beneficial for the Commission, since it allows it to make use of the expertise of the national authorities, and since cooperation may enlarge the support base for interpretative rules once adopted. ${ }^{14}$ Explicit consultation requirements may exist, particularly when tasks regarding the development of guidance are assigned to bodies other than the Commission. ${ }^{15}$ Note that the Commission has also promoted the development of guidance materials by member states, for instance through online forums such as CIRCABC (Communication and Information Resource Centre for Administrations, Businesses, and Citizens). ${ }^{16}$ Also note that while this forum was first comprised exclusively of member states, it now includes the Commission as well. When member states arrive at a solution to implementation problems, this solution may be included in online guidance documents, which are seen as a Commission service opinion. ${ }^{17}$ Interpretative rules are nonbinding in principle, although exceptions do apply. ${ }^{18}$

Decisional acts are also intended to support the administration of EU measures, though in a different manner. ${ }^{19}$ Decisional acts are adopted mainly by the Commission, and only in areas where the treaties or secondary acts assign implementing and discretionary powers to the Commission..$^{20}$ More recently, committees, networks, and agencies have been gaining the power to establish decisional rules that ensure the implementation of EU measures as well. ${ }^{21}$ Decisional acts go beyond a mere interpretation of legislative provisions by indicating how the issuing body intends to apply EU law in individual cases and how it will make use of the discretionary powers assigned to it. ${ }^{22}$ While interpretative acts cannot be decisional - because the assignment of implementing powers is a precondition for the adoption of decisional acts - decisional acts may have an interpretative element. ${ }^{23}$ Decisional acts are primarily meant as internal guidelines for the relevant issuing bodies, but they may have external effects as well; they may be beneficial for member states, since they contribute to equal treatment and increase the transparen-

\footnotetext{
${ }^{14}$ See Scott, 2011: 331, for the notion that guidance may be elaborated on through a 'partnership working method' between the Commission and the member states.

${ }^{15}$ See e.g. the cases discussed in Section 2 of this chapter.

${ }^{16}$ Korkea-Aho, 2014: 654 .

${ }^{17}$ Ibid.

${ }^{18}$ See Section 1.2 .3 of the current chapter.

${ }^{19}$ Decisional acts shall not be confused with Commission decisions. While the latter lay down rules that bind the addressees of these acts, the former specify how the Commission (or other issuing body) uses the discretionary powers that are assigned to it. These acts do, in principle, exercise a self-binding effect; for this idea and for the effect of decisional rules more generally, see below.

${ }^{20}$ See, initially, case 146/84 De Santis v. Court of Auditors [1985] ECR 1723 (staff cases), and further e.g. case C-311/94 IJssel-Vliet [1996] ECR I-502; C-169/95 Spain v. Commission [1997] ECR I-315. For a discussion, see Senden, 2004: 312ff, and Senden, 2013: 63-64.

${ }^{21}$ Senden, 2013: 61.

${ }^{22}$ Senden, 2004: 148.

${ }^{23}$ Ibid.
} 
cy of individual decisions, ${ }^{24}$ and since they allow member states to anticipate the way in which EU measures will be applied. ${ }^{25}$ Decisional acts are, in principle, binding to the issuing body and they may bind member states alike. ${ }^{26}$

Finally, compliance templates serve to steer the national competent authorities to the registration of data by fleshing out legislative requirements. ${ }^{27} \mathrm{~A}$ uniform registration of data through the use of compliance templates is important when information gathered by national competent authorities is submitted to the Commission or to another EU body, in order for this information to be analysed or exchanged amongst member states. It seems that, similar to the case for interpretative rules, compliance templates may be adopted by the Commission or by other EU bodies, sometimes in partnership with the member states. ${ }^{28}$ The latter may have given rise to the development of compliance templates in the first place. Member states may also choose to develop compliance templates on their own. When adopted by the Commission, no specific legal basis seems to be required; as is the case for interpretative rules, the Commission may act on the basis of Articles 4(3) and 17 TEU. Compliance templates are, in principle, not binding to member states, but exceptions apply. ${ }^{29}$

In view of the idea that all three types of guidance may be useful for directing national competent authorities in the law administration process, this chapter focuses on all of them, where relevant. The analysis in this chapter adds to the academic literature on post-legislative guidance, since it provides an empirical rather than (normative) legal perspective on the use of guidance by, and the usefulness of guidance to, national authorities. Such an empirical perspective seems to be lacking and little insight has been gained into the practical effect of post-legislative guidance in the law administration context.

\footnotetext{
${ }^{24}$ Case C-442/97 Spain v. Commission [1999] I-08093, para. 32.

${ }^{25}$ Senden, 2004: 141, 148.

${ }^{26}$ See further Section 1.2.3 of this chapter.

${ }^{27}$ Scott, 2011: 334 .

${ }^{28}$ See e.g. Scott, 2011, for an example of templates developed by the Commission and member states acting in concert.

${ }^{29}$ On the binding effect of guidelines, see further Section 1.2.3.
} 


\section{Post-legislative guidance as a compliance instrument}

This section aims to identify why post-legislative guidance may be useful for competent authorities in the application of EU measures (Section 1.1), and which factors may hinder its usefulness as a compliance instrument (Section 1.2). As such, it sets the scene for the analysis presented in the subsequent sections of this chapter.

\subsection{Why post-legislative guidance?}

The introduction to this chapter states that post-legislative guidance is adopted in order to clarify the meaning of EU law provisions. On a meta level, such clarifications may be helpful for ensuring the effective and coherent implementation of EU measures. ${ }^{30}$ The virtues of post-legislative guidance at the micro level vary with the type of guidance at stake. As previously suggested, decisional rules may be useful for implementing actors, since they stipulate how the Commission will make use of its implementing powers. Familiarity with these rules then allows member states to anticipate the behaviour of the Commission and to adapt to it where necessary. Interpretative rules and compliance templates, on the other hand, inform member states of how EU measures are to be applied by the national competent authorities. Interpretative rules do this, either by making a legislative framework more accessible through consolidation of the relevant rules, or by clarifying legislative provisions through interpreting them. Compliance templates concretise legislative provisions. All three types of guidance may therefore offer concrete support to authorities, regarding the interpretation of legislative provisions and, as such, support these authorities in the law application process.

The idea that guidance supports implementing agencies in the application of EU law by clarifying EU law provisions fits managerialist thinking on implementation and compliance, which has been elaborated on in Chapter 3 that outlines the approach and methodology of this study. ${ }^{31}$ As a rule interpretation instrument, guidance addresses normative ambiguities that managerialists blame for causing implementation failure. In view of the often-vague nature of EU measures, ambiguity is not rare; as a matter of fact, criticism on the quality of EU legislation is abundant. The need for better-quality legislation was first acknowledged by the 1992 Edinburgh European Council, after which several efforts to address the relevant concerns have been implemented. ${ }^{32}$ Legislative

\footnotetext{
${ }^{30}$ Senden, 2004: 146-148, 151-152.

${ }^{31}$ See Chapter 3 on the approach and methodology, Section 2.2.

${ }^{32}$ See e.g. Declaration No 39 on the quality of the drafting of Community legislation, annexed to the Treaty of Amsterdam (referred to earlier), which tasks the Parliament, the Commission, and the Council to adopt guidelines for improving the quality of the drafting of legislative texts and to accelerate the codification of existing legislation. These guidelines are outlined in the Interinstitutional Agreement of 22 December 1998 on common guidelines for the quality of drafting of Community legislation [1999] OJ C 73/1. The Legal Services of all three institutions published a Joint Practical Guide aimed at clarifying the guidelines outlined in this Agreement. For the latest version of this Guide, see European Parliament, Council, and Commission, 2013.
} 
improvements are, however, cumbersome and slow; guidance is regarded as a relatively fast and flexible tool to address the needs for clarification that emerge in the system of shared administration in the EU. ${ }^{33}$

The following subsections address three concrete benefits that may accompany law clarifications for national competent authorities. These benefits concern the prevention and smoothing of infringement proceedings (Section 1.1.1), the reassurance of national authorities that act in compliance with guidelines (Section 1.1.2.), and information exchange opportunities that may ensue in the context of guidance development processes (Section 1.1.3). ${ }^{34}$

\subsubsection{Smoothing and prevention of infringement proceedings}

The clarity created by guidance may, first of all, smooth infringement proceedings or prevent such proceedings from beginning in the first place. It may smooth these proceedings, since guidance may help the Commission and member states agree on a breach of an underlying norm. Guidance may prove particularly useful when legislative provisions are complex or open, since this often leads to conflicting interpretations about whether an alleged violation exists or is likely to occur. ${ }^{35}$ Note that it is specifically interpretative rules that are developed by the Commission and member states together, that may be useful in this regard. In this case, understandings of contentious terms are harmonised across the board and member states are likely to agree on understandings advanced by the Commission in infringement proceedings - unless a member state has objected to the relevant interpretation in the first place, in which case infringement proceedings may constitute high-profile options for member states to challenge interpretative choices made in the relevant guidance documents. ${ }^{36}$ In the latter case, guidance may not be helpful for smoothing infringement proceedings.

Post-legislative guidance may be useful, not only once infringement proceedings are started, but also as a tool to prevent infringement proceedings from being launched in the first place. This is the case, since guidance makes it possible for national authorities to correct existing instances of noncompliance on their own motion. Moreover, guidance has the power to prevent infringements from occurring in the first place, at

\footnotetext{
See also e.g. COM (2001) 428; COM (2007) 502, both of which refer to improved law making practices as a specific area of action.

${ }^{33}$ Senden, 2013: 61-62.

${ }^{34}$ Note that the benefits of guidance do not only apply to implementing actors but to the issuing body as well,which is the European Commission in the majority of cases. Since the focus of this study is on the usefulness of compliance instruments for implementing actors, this chapter does not pay particular attention to the usefulness of post-legislative guidance for such issuing actors. Possible benefits for issuing actors are, however, referred to briefly when relevant.

${ }^{35}$ Korkea-Aho, 2014: 655. Something similar can be said to apply to EU agencies; where invested with inspection powers, agencies may use guidance materials as benchmarks against which to check compliance.

${ }^{36}$ Ibid.: 665 .
} 
least when it is adopted early in the implementation process. Guidance may have a positive affect specifically, when (existing) infringements are inadvertent and when member states are in principle willing to comply. If guidance produces such an effect, it may prevent the Commission from having to sue member states for infringing EU law, thus freeing resources for it to act on other infringements instead. The benefit for member states lies in the fact that they do not need to endure slow and administratively heavy proceedings that may not help them apply the law correctly in a speedy and efficient manner.

\subsubsection{Reassurance}

In addition to being capable of smoothing infringement proceedings or preventing such proceedings, post-legislative guidance has a reassurance function for authorities that act in accordance with it. ${ }^{37}$ This is the case, since compliance with guidance documents assures authorities' compliance with the underlying norms. ${ }^{38}$ The practical benefit for member states and competent authorities is that they are assured that the Commission is unlikely to initiate infringement proceedings against member states for violation of the relevant norms, ${ }^{39}$ at least when the Commission has drafted the guidance alone or in concert with the member states.

\subsubsection{Information exchange}

Finally, when the development of post-legislative guidance involves member states working in partnership with the European Commission or another issuing body, national authorities may benefit from the information exchange opportunities that present themselves in the context of this development process. ${ }^{40}$ The virtues of information exchange processes are manifold: exchanging information may reduce transaction costs for authorities in the administration of EU measures and increase mutual trust amongst authorities, it may allow authorities to learn from one another, and it may socialise authorities to appropriate 'ways of doing things'. The mechanisms underlying these benefits are further elaborated on in Chapter 6 on transnational networks.

\subsection{Limitations of post-legislative guidance as a compliance instrument}

While the benefits of guidance for both issuing and receiving actors are plentiful, this is also the case for the drawbacks that guidance is associated with. This section discusses three drawbacks that seem most relevant to discussions on post-legislative guidance.

\footnotetext{
${ }^{37}$ See Scott, 2011: 330, who addresses guidance in the area of environmental law. The reassurance function of guidelines is not limited to this policy domain.

${ }^{38}$ Ibid.

${ }^{39}$ Senden, 2004: 226; 345; Scott, 2011: 344.

${ }^{40}$ See Von Homeyer, 2010.
} 
These drawbacks relate to the accessibility of guidance in general, the legitimacy of interpretative rules in particular, and the legal effects of guidance.

\subsubsection{Accessibility}

The first downside to post-legislative guidance is that those who are affected by it may not always be aware of its existence, since rules on the publication of guidance do not exist. ${ }^{41}$ This lack of rules has led to an inconsistent approach towards the publication of guidance in practice, with post-legislative guidance offered in many forms. Interpretative rules may, as decisional acts, be found in the C-series of the Official Journal of the European Union, but decisional acts may also be published as COM documents only. ${ }^{42}$ Interpretative rules may also exist as freestanding guidelines. Such guidelines may be found only online, ${ }^{43}$ on specific webpages of the European Commission or of other EU bodies that may be difficult to find, particularly for parties that have not participated in the development of the guidelines. Both the lack of consistency in the publication of guidance, and the notion that guidance is sometimes difficult to retrieve, makes one wonder about the extent to which external parties that are affected by the relevant rules are aware of their existence. ${ }^{44}$ If national authorities are not (made) aware of the existence of guidance, guidance cannot be helpful as a compliance instrument.

\subsubsection{Consultation and legitimacy}

A second factor that may limit the usefulness of guidance as a compliance instrument relates to the notion of legitimacy. Governance can only be legitimate if both substantive (output) and procedural (input) legitimacy requirements are met. ${ }^{45}$ The inclusion of affected actors in deliberation processes is an important prerequisite in this regard, since it responds to the functional need to tap into the resources of these actors for effective policy solutions, ${ }^{46}$ and to the normative belief that those who are affected should have the right to participate for a democratically legitimate outcome of the deliberation process. $^{47}$

The current section elaborates on the rules of consultation that apply to three categories of actors that are important to consult for the development of post-legislative guidance. These actors concern the national competent authorities in the policy domain at issue, the European Parliament, and societal actors. The upside to this is that in certain areas, consultation standards that ensue from secondary law acts or other EU doc-

\footnotetext{
${ }^{41}$ Senden, 2004: 495-496; Senden, 2013: 68.

${ }^{42}$ Senden, 2004: 496.

${ }^{43}$ Ibid.: 143-147; Senden, 2013: 68; Scott, 2011: 330.

${ }^{44}$ Senden, 2004: 496.

${ }^{45}$ For the notions of input and output legitimacy, see e.g. Scharpf, 1999.

${ }^{46}$ For this point, see e.g. COM (2001) 428 final, p. 7; Kohler-Koch, 2009: 51.

${ }^{47}$ Kohler-Koch, 2009: 51.
} 
uments oblige or encourage the Commission to actively consult (some of) those actors. ${ }^{48}$ The downside is that, since the development of post-legislative guidance is geared mainly towards enhancing the effectiveness of EU law, concerns regarding the participation of interested parties usually take a backseat. ${ }^{49}$ Regarding this latter notion, it is useful to shed light on the adverse consequences of a lack of inclusive deliberation for the usefulness of guidance as a compliance instrument. The relevant reflections follow our discussion about the rules of the stakeholders' consultation in the guidance development process, which is presented in the three subsections below.

\subsubsection{National competent authorities}

One may argue that particularly those who are to use the guidelines in practice, the relevant national competent authorities, should be consulted in the development of guidance documents. Whether such consultation is obligatory depends on whether the guidelines are adopted as implementing acts under Article 291 TFEU or as freestanding guidelines.

When guidelines are adopted as implementing acts, draft guidelines are tabled for discussion in 'comitology' committees, ${ }^{50}$ and fixed rules on the consultation of member states in such committees and in the Council apply. In relation to these consultation rules, two problems seem to arise. First, the consultation of committees is generally inadequate. This consultation could be organised under one of two procedures: the advisory procedure or the examination procedure. The latter specifically applies to the adoption of implementing acts with a general scope and to other implementing acts "with a potentially important impact"; ${ }^{51}$ the former applies to all other cases "or where it is considered more appropriate". ${ }^{52}$ The views of member states are given more weight in the examination procedure than in the advisory procedure; whereas the Commission must "take utmost account" of the opinion delivered by the committee when the advisory procedure applies, ${ }^{53}$ in principle, implementing acts cannot be adopted by the Commission if they are not in accordance with the opinion of an examination committee. ${ }^{54}$ Irrespective of the fact that these procedures do not necessarily provide (a qualified majority of) member states with a definite opinion on proposed acts, ${ }^{55}$ one may argue

\footnotetext{
${ }^{48}$ Senden, 2013: 69.

${ }^{49}$ Ibid.: 59 and 69. Note that Senden comments generally about soft governance modes.

${ }^{50}$ Following Art. 291(3), member states have laid down the rules and general principles concerning the mechanisms for control by member states of the Commission's exercise of implementing powers. These rules are laid down in Regulation (EU) No 182/2011 of the European Parliament and of the Council of 16 February 2011 laying down the rules and general principles concerning mechanisms for control by Member States of the Commission's exercise of implementing powers [2011] OJ L 55/13,

${ }^{51}$ Ibid., Art. 2 and consideration 11.

${ }^{52}$ Ibid., Art. 2 and consideration 15.

${ }^{53}$ Ibid., Art. 4(2).

${ }^{54}$ Except in exceptional circumstances. Ibid., Art. 5(3) and consideration 11, in conjunction with Art. 7.

${ }^{55}$ The Commission is not legally obliged to follow the opinion of an advisory committee. Where the examina-
} 
that true consultation should involve more than the arrangement of discussions with member states on a fait accompli. Indeed, it seems defendable to say that parties with the right to control the Commission's implementing powers should have the right to actively participate in the rule-making process as well. ${ }^{66}$ This is not something that the comitology system permits, at least not explicitly.

The second problem with member state control of the Commission's exercise of its implementing powers through comitology relates to the right of scrutiny that the rules on comitology endow the Council with. According to these rules, the Council may indicate its objection to a draft implementing act if this act exceeds the implementing powers provided in the basic act. In this case, the Commission must review the act and inform the Council of its intended follow-up. ${ }^{57}$ The problem with these provisions is that they only allow for 'procedural' review and they only apply to acts that are meant to implement a basic act adopted under the ordinary legislative procedure. ${ }^{58}$ While the Lisbon Treaty has made the co-decision procedure the primary procedure for the adoption of secondary legislative acts, there are still acts (adopted both prior to and after the entry into force of the Lisbon Treaty) that escape this procedure. In such cases, member state control over implementing rules is greatly diminished.

Note that guidance documents do not, as a rule, pass through a committee before being adopted by the Commission; only when a secondary act prescribes that the Commission 'shall be assisted by a committee' in the adoption of guidance documents does a committee procedure apply. If such an obligation does not exist, and a secondary law act does not impose a duty to consult the member states on the Commission, ${ }^{59}$ the Commission escapes any obligation to consult the member states on draft guidelines. Thus, whether consultation opportunities are organised in these cases depends on the willingness of the Commission to organise them. Since most guidelines are not adopted as implementing acts and explicit consultation requirements may particularly exist when tasks regarding the development of guidance are assigned to bodies other than the Commission, ${ }^{60}$ much of the guidance adopted as Commission documents seems capable of escaping formal consultation of the member states.

tion procedure applies, the Commission needs a qualified majority in favor of adoption of the implementing act. See ibid., Arts 4(2) and 5(1). Different rules apply to immediately applicable implementing acts and to the adoption of implementing acts in exceptional cases; see ibid., Arts 7 and 8.

${ }^{56}$ Scott, 2011: 352-352; see also Tshuma, 2000: 135, on networks.

${ }^{57}$ Regulation (EU) No 182/2011, Art. 11.

${ }^{58}$ Ibid., Art. 11.

${ }^{59}$ For an example of guidelines adopted as a Commission decision, see Section 2.1.1 of the current chapter. For an example of the idea that secondary acts may well impose consultation requirements on the Commission, see Section 2.2.1 of the current chapter.

${ }^{60}$ See e.g. the cases discussed in Section 2 of this chapter. 


\subsubsection{The European Parliament}

If the picture for member state consultation in guidance development processes does not look bright, it seems even less bright for the European Parliament. Similar to the Council, the Parliament is endowed with the right of scrutiny for rules implementing a basic act that is adopted under the ordinary legislative procedure. Refer to the previous subsection for the idea that draft guidelines are not generally tabled in committees and that when they are, they are not always proposed to implement a basic act adopted under the ordinary procedure. Next to these procedural limitations, are two - possibly interrelated - material factors that limit the Parliament's involvement in guidance development processes. First, the Parliament has rarely used its right of scrutiny in the previous years, ${ }^{61}$ and second, doubts exist as to the extent to which the Parliament has the resources needed to engage in discussions of Commission drafts. ${ }^{62}$ Together, these factors do not seem to make (effective) parliamentary review of Commission guidance a realistic scenario.

\subsubsection{Societal actors}

While rules for the consultation of member states and the European Parliament do not make for truly effective consultation opportunities, such rules are absent for societal actors to begin with. Granted, in its White Paper on European Governance, the Commission pledged to commit to the creation of "a coherent framework for the consultation of interested parties". ${ }^{63}$ The Commission's Communication Towards a Reinforced Culture of Dialogue and Consultation, which results from this commitment, ${ }^{64}$ outlines minimum consultation standards related to the content of the consultation process, the definition of the target group consulted, the publication of consultation opportunities, time limits for participation, and acknowledgement of, and feedback about, comments submitted to the Commission. ${ }^{65}$ However, there are several problems with these standards; ${ }^{66}$ one of them is particularly relevant to the context of this study: the fact that they only apply to a limited range of EU acts.

The limited applicability of the consultation standards is apparent from the fact that they only pertain to "major policy initiatives" that are subject to an extended impact assessment (IA). To be covered by an extended IA, the initiative must, amongst other requirements, result in "substantial economic, environmental, and/or social impacts on

\footnotetext{
${ }^{61}$ Kaeding and Hardacre, 2013: 394-396.

${ }^{62}$ Ibid.: 384, 391-394.

${ }^{63}$ Commission, 'Towards a reinforced culture of dialogue and consultation - General principles and minimum standards for consultation of interested parties by the Commission' (Communication) COM (2002) 704 final, p. 10.

${ }^{64}$ Ibid.

${ }^{65}$ COM (2002) 704, p. $19 f f$.

${ }^{66}$ See Senden, 2013.
} 
a specific sector", have a "significant impact on major interested parties", and represent "a major policy reform in one or several sectors". ${ }^{67}$ The problem with these requirements is that, since guidelines clarify existing norms and do not have the power to outline new norms, guidance development processes are bound to escape the consultation requirements outlined in the Commission's communication.

This does not necessarily mean that stakeholders are not provided with consultation opportunities; the Commission's DGs are "encouraged to apply the general principles and minimum standards to any other consultation exercises [that they intend to launch" ${ }^{68}$. However, the voluntary nature of this application raises questions about the use of the Commission's standards in practice; there is no guarantee that relevant societal actors are consulted in guidance development processes, or made aware of any such consultation opportunities to begin with. ${ }^{69}$ Moreover, since decisions on the consultation of stakeholders are ad hoc and likely to be erratic, ${ }^{70}$ the likelihood that societal actors are directly involved in guidance development processes seems low.

\subsubsection{Adverse effects of a lack of consultation}

The previous subsections present a negative image of the consultation of stakeholders in the guidance development process. This is problematic, since the lack of inclusiveness in guidance development processes threatens the legitimacy of the resulting guidelines and their implementation in practice. While the outcome-oriented focus on flexible governance instruments such as guidance may have led the focus shifting from procedural concerns, such as the inclusion of stakeholders in rule-making processes, such attention is indispensable for these instruments to effectively solve the policy issues that they are meant to solve, as we see below.

From a democratic legitimacy point of view, concerns about the lack of inclusion seem to specifically apply to interpretative rules. This is the case, since unlike compliance templates, interpretative rules aim to interpret rather than 'make practical' EU law provisions. And unlike decisional rules, interpretative rules are usually not adopted on a specific legal basis, legitimising the Commission's action in this regard. In view of these aspects, the consultation of affected actors in the development of interpretative rules seems particularly imperative.

Inclusion, as suggested above, accomplishes two goals; it addresses not only democratic legitimacy concerns, but effectiveness concerns as well. This is the case, since a

\footnotetext{
${ }^{67}$ COM (2002) 704, p. 15.

${ }^{68}$ Ibid.

${ }^{69}$ The communication stipulates that the Commission should ensure clarity as to the content of the consultation, "establish awareness-raising publicity", "ensure that relevant parties have an opportunity to express their opinions", and strive to permit a consultation period of at least eight weeks. Moreover, the Commission should provide feedback to those who commented and to the public at large. See COM (2002) 704 final, pp. $19-22$.

${ }^{70}$ For an example, see Ehnert, 2015: 60-61.
} 
lack of inclusiveness is bound to have an adverse effect on the quality of post-legislative guidance by leaving legal and substantive inadequacies in the proposed guidance undetected. ${ }^{71}$ A lack of inclusion is also problematic because it may threaten the acceptability of guidelines amongst national authorities. For example, it may be argued that national authorities should not have to comply with guidelines - guidelines that may significantly encroach on their implementation powers - if they have not been consulted about these guidelines. ${ }^{72}$ Finally, a lack of consultation may postpone the implementation of guidance, since it makes it impossible for national authorities to anticipate the Commission's view on the correct application of the relevant hard law provisions. ${ }^{73}$

The latter two aspects suggest that even when guidelines are drafted adequately and when they are, in principle, capable of increasing consistency in the application of EU law - a lack of participation in the development of guidance may eventually delay the materialisation of more consistent administration practices across the board, or prevent that consistency in the first place. From the perspective of national authorities, a lack of consistency seems particularly problematic when authorities are interdependent in the implementation process; an issue that is discussed in detail in Chapter 6 on transnational networks. ${ }^{74}$

\subsubsection{Effects of guidance}

A final factor compromising the usefulness of guidance as a compliance instrument relates to its unclear legal effect. Guidance unmistakably qualifies as soft law; ${ }^{75}$ rather than creating new legal effects, it is comprised of rules of conduct that are outlined in instruments that have not been attributed with legally binding force. Given the lack of inherent legally binding force, there is no general duty of implementation and compliance for the EU institutions and member state authorities. Exceptions do, however, seem to exist. ${ }^{76}$ This subsection elaborates on the implications of guidance for national competent authorities and for the European Commission (the latter being the main supranational guidance-issuing body), and then discusses the effects of guidance for the CJEU and for national courts. This section concludes by describing the conditions under which guidance may be thought to have an indirect legal effect instead of a de facto effect only.

\footnotetext{
${ }^{71}$ Senden, 2013: 72. See Chiti, 2013: 106-107, on guidance issued by agencies. The link between consultation and quality has been established by the Commission, too. See e.g. COM (2002) 704 final, p. 5.

${ }^{72}$ On the idea that guidelines encroach on the implementation powers of authorities, see Lefevre, 2004: 815; 819-821; Scott, 2011: 352-353.

${ }^{73}$ Senden, 2013: 72.

${ }^{74}$ See Sections 1.2.1 and 3.1 of the stated chapter.

${ }^{75} \mathrm{I}$ follow the understanding of the notion of soft law as proposed in Senden, 2004: 112-113.

${ }^{76}$ Ibid.: 346.
} 


\subsubsection{The European Commission and national competent authorities}

In principle, the European Commission is not obliged to comply with the interpretative rules that it has adopted. Declarations in interpretative guidance documents vary with respect to the meaning that the Commission attaches to the rules outlined therein. Such documents may state that the Commission should use these rules as a reference for conducting the tasks assigned to it in the respective legislative act, ${ }^{77}$ or they may highlight the idea that the relevant rules do not represent the official position of the European Commission and that they cannot be invoked as such in legal proceedings. ${ }^{78}$ The meaning of such guidance for the Commission is, thus, rather unclear and the influence that it exerts on the Commission's behaviour is often uncertain.

This does not apply to decisional acts that are issued in domains in which the Commission has been given the competence to implement EU measures, notably - but not only - in areas where the Commission has the power to apply EU law in individual cases. ${ }^{79}$ As mentioned above, lawful decisional acts are recognised as exercising a selfbinding effect on the Commission. This does not mean that deviation is not allowed; deviation is thought to be possible when it is sufficiently reasoned, when the degree of clarity of the rules permits it, and when the Commission does not overstep the limits of its discretion. ${ }^{80}$ Arguably, the foregoing remarks apply to decisional rules issued by other bodies in addition to the Commission.

Decisional rules that bind the Commission may exercise a binding effect on member state authorities as well. Particularly, when there is a specific duty of cooperation for member states - which is the case in the area of state aid - and when member states have accepted or approved the Commission's guidance rules. ${ }^{81}$ Furthermore, decisional rules arguably also bind member states when a secondary law act empowers the Commission to adopt decisional rules - or even provides an obligation to this effect - and when it provides a certain level of compliance with such rules by the member states. ${ }^{82}$ It seems that since decisional rules are intended to produce legal effects vis-à-vis third parties, national authorities may rely on them before national courts, not only as an interpretation aid, but also as standards for judicial review. ${ }^{83}$ Moreover, and for the same

\footnotetext{
${ }^{77}$ See e.g. Commission Decision of 16 December 2009 laying down guidelines for the management of the Community Rapid Information System 'RAPEX' established under Article 12 and of the notification procedure established under Article 11 of Directive 2001/95/EC (the General Product Safety Directive) [2010] OJ L22/1, Part I, point 2, second indent.

${ }^{78}$ See e.g. Commission, "Guidance on Interpretation of "Installation" and "Operator" for the Purposes of the IPPC Directive' [2007] available on <http://ec.europa.eu/clima/policies $>$. Note that decisional acts can be relied on in legal proceedings. See case T-374/04 Germany v. Commission [2007] ECR-II 4441.

${ }^{79}$ Competition law and state aid are notable examples; see Stefan, 2013.

${ }^{80}$ See e.g. case T-374/04 Germany v. Commission [2007] ECR-II 4441 (on environmental law).

${ }^{81}$ See case C-311/94 IJssel-Vliet [1996] ECR I-5023; case C-88/96 Germany v. Commission [2000] ECR I-823.

${ }^{82}$ Senden, 2013: 63.

${ }^{83}$ Ibid.
} 
reason, authorities may ask the national court to submit preliminary questions about their validity to the European Court. ${ }^{84}$

One may argue that interpretative rules should play an important role for national competent authorities; interpretative rules are meant to support authorities in the administration of EU measures, and when they are used they can make a significant contribution to the coherence, consistency, and effectiveness of EU law. Guidance may accomplish this by 'merely' suggesting an approach to some interpretation questions ${ }^{85}$ or by putting the interpretative rules that it comprises on the same level as the underlying legislation. ${ }^{86}$ However, there is little clarity regarding the precise obligations of national authorities in relation to interpretative guidance; ${ }^{87}$ it seems it is "a matter of debate whether the guidelines reflect the obligations of [the member states] or what the Commission wishes those obligations to be" ${ }^{88}$

\subsubsection{The CJEU and national courts}

The CJEU is neither required nor willing to follow interpretative rules drawn up by the Commission. ${ }^{89}$ This is explained by the fact that Articles 19(3) TEU and 267 TFEU invest the Court with the sole power to interpret EU law. If the Court were bound by interpretative rules issued by the Commission, this monopoly would surely be compromised..$^{90}$ Disclaimers in guidance documents may refer to the notion that the ultimate interpretation of the underlying hard law provisions is the responsibility of the CJEU. ${ }^{91}$ The role of the Court is different for decisional guidance, indicating how the Commission intends to use administrative discretion. In this case, the CJEU will consider these documents as having a self-binding effect, limiting the Commission's discretion in such a way that it can, in principle, not depart from such guidance. ${ }^{92}$

EU case law indicates that, in areas where judges lack the necessary expertise to evaluate the correctness of guidance - which is likely the case in particular in areas that require considerable technical or other expertise that courts may not naturally possess the Court usually considers such guidance authoritative, unless third parties challenge

\footnotetext{
${ }^{84}$ This follows from Art. 263 TFEU in conjunction with Art. 267 TFEU.

${ }^{85}$ E.g. Commission, 'Guidance on Interpretation of "Installation" and "Operator" for the Purposes of the IPPC Directive' [2007] available on <http://ec.europa.eu/clima/policies $>$.

${ }^{86}$ See e.g. Commission Decision 2010/15/EC, Part I, point 1.1, fourth indent.

${ }^{87}$ Senden, 2004: 436-442.

${ }^{88}$ Lefevre, 2004: 814-815.

${ }^{89}$ Senden, 2004: 373-374. Using interpretative guidance as a voluntary interpretation aid, the former Court of First Instance has been more open.

${ }^{90}$ See Senden, 2004: 373.

${ }^{91}$ See e.g. Commission, 'Guidance on Interpretation of "Installation" and "Operator" for the Purposes of the IPPC Directive' [2007] available on <http://ec.europa.eu/clima/policies>.

${ }^{92}$ See e.g. case T-374/04 Germany v. Commission [2007] ECR-II 4441.
} 
such guidance in litigation. This is the case even when such guidance is developed by organisations other than the Commission or member states. ${ }^{93}$

Courts at the national level are obliged to take interpretative rules into account in the interpretation and application of national and EU law, at least when such rules are outlined in Commission recommendations. ${ }^{94}$ In such (rare) cases, interpretative rules are a mandatory interpretation aid; there is no duty of consistent interpretation, but national courts are obliged to take these recommendations into account when they can help clarify the meaning of EU or national law. ${ }^{95}$ When national courts choose to voluntarily consider interpretative rules, these rules could provide a standard in the evaluation of whether national authorities comply with the provisions established in the underlying legislative act. ${ }^{96}$ When they are acknowledged as creating legal effects vis-à-vis third parties, decisional acts may be used as standards for judicial review. ${ }^{97}$

Since the preliminary ruling system depends on the existence of an act in the sense of Article 263 TFEU - meaning that the CJEU will only review the legality of acts that are intended to produce legal effects vis-à-vis third parties - national courts cannot refer a question concerning the validity of interpretative rules to the Court. ${ }^{98}$ This may be different for decisional rules, at least when they are acknowledged to produce legal effects in relation to third parties; in this case, national courts may, as stated above, submit preliminary questions about the validity of such acts to the Court. ${ }^{99}$

\subsubsection{Incidental effects of interpretative rules}

The above paragraphs assert that while lawful decisional acts do, in principle, bind the issuing body and the member states when certain conditions are fulfilled, interpretative rules do, in principle, not bind anyone. The impact of interpretative rules on the national and EU level ultimately depends on the indirect legal effect that these rules may incidentally be associated with, or in the absence of this indirect legal effect, on the purely de facto effect that these rules may have. ${ }^{100}$ The distinction between indirect legal effect and de facto effect is important, since next to hard law acts that have been attributed with legally binding force, only soft law acts with indirect legal effect may be susceptible

\footnotetext{
${ }^{93}$ See e.g. European Commission, 'Assessment of Plans and Projects significantly affecting Natura 2000 sites, regarding the implementation of Article 6(3) and (4) of the 'Habitats' Directive 92/43/EEC' [2001] available on <http://ec.europa.eu/environment/nature/natura2000/management/guidance/en. htm>. See also Senden, 2013: 62 .

${ }^{94}$ Case C-322/88 Grimaldi [1989] ECR I-4407, para. 18.

${ }^{95}$ Case C-322/88 Grimaldi [1989] ECR I-4407; for a discussion, see Senden, 2004: 387-393.

${ }^{96}$ Senden, 2004: 397.

${ }^{97}$ Senden, 2013: 63.

${ }^{98}$ Scott, 2011: 345-346.

${ }^{99}$ This follows from Art. 263 TFEU in conjunction with Art. 267 TFEU.

${ }^{100}$ Senden, 2004: 239-242; also Snyder, 1994: 198; and Scott, 2011: 331.
} 
to EU-level judicial review - at least when they are authored by an EU institution or another body, office, or agency of the Union. ${ }^{101}$

A liberal view on the question of when purely interpretative soft law acts produce an indirect legal effect, would argue that if interpretative rules are to have an indirect legal effect, this effect must follow from the operation of general principles of law; notably, from the principles of effectiveness and legal certainty. The avenues that are relevant to determining whether or not this condition is met are shown in Figure 6.

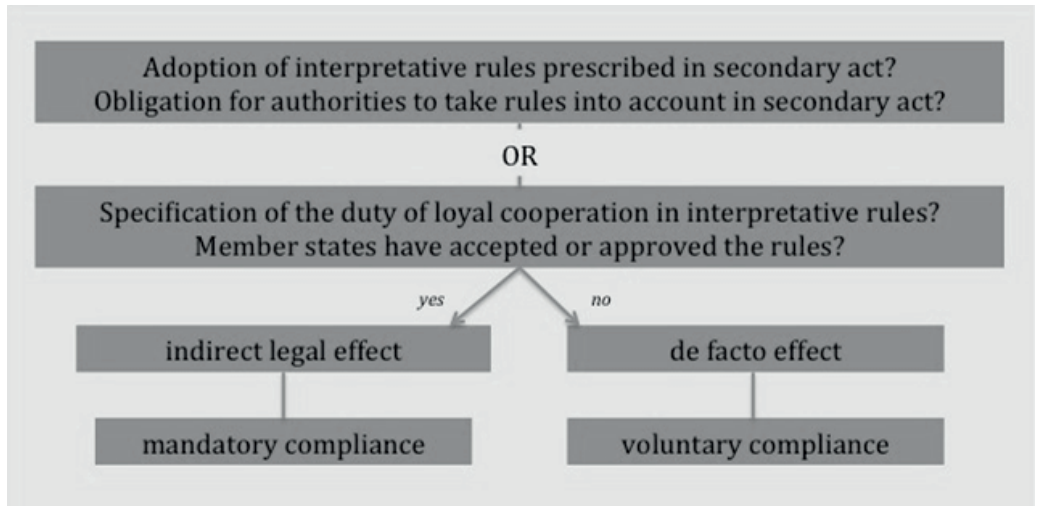

Figure 6 Possible effects of interpretative rules

A duty of compliance may exist, first, when an act entails a specific expression of the obligation of loyal cooperation outlined in Article 4(3) TEU - that is, when it defines what the duty of loyal cooperation entails in the specific matter at hand - and when member states have accepted or approved the rules. ${ }^{102}$ Second, member states may be under a duty of compliance where a binding legislative act provides the adoption of interpretative rules and calls upon the national authorities to take these rules into account in the implementation of law, or to comply with them to a certain extent. ${ }^{103}$ One may argue that in both these cases, national competent authorities can - as in the case of binding decisional rules - rely on guidance in national courts, not just as an interpretation aid, but as standards for judicial review as well. ${ }^{104}$

If one accepts that a binding effect may be acquired by the operation of either of the sets of requirements discussed above, interpretative rules that fail to meet both of these

\footnotetext{
${ }^{101}$ See Article 263 TFEU.

102 These requirements follow from case C-311/94 Ijssel-Vliet [1996] ECR I-5023. They are particularly relevant to areas that presuppose close cooperation between the European Commission and the national authorities, and when there is a legal basis explicitly granting the Commission the power to bind the member states. This is the case in the areas of state aid and competition law.

${ }^{103}$ On decisional rules, see Senden, 2004: 439; Senden, 2013: 63; similar Scott, 2011: 341.

${ }^{104}$ Senden, 2013: 63.
} 
sets must be nonbinding and have de facto effects. ${ }^{105}$ In this case, compliance is voluntary and the decisive power on the use of guidance in the law administration practice remains with the member states. Although one may be inclined to think that the meaning of such unbinding soft law acts must be minimal, it is argued that such acts may in fact have a high degree of persuasiveness for, and be influential in, national administrative practices. ${ }^{106}$ The use of guidance with a de facto effect is, however, likely to be erratic. This erraticness - which is not only present when guidance has a mere de facto effect, but which also exists because of the initial lack of clarity regarding the legal effects of guidance - compromises the usefulness of guidance as a compliance instrument for two reasons.

First, the usefulness of guidance lies in its application to all member states. This is true not only on a meta level - where inconsistent application has detrimental effects on the extent to which guidance may contribute to the achievement of EU policy objectives - but also on a micro level. In relation to the latter, consistency is important particularly when authorities are interdependent in the administration of EU measures and need one another for each of them individually to perform well. ${ }^{107}$ When guidance is not applied consistently and faithfully across the board, the effects may be that authorities are hindered in their attempts to implement their work efficiently. Second, a lack of consistency may also result in uncertainty of authorities as to the implementation performance of other member states. Uncertainty may create a vicious circle of mis- and distrust and defection on the part of national authorities. Rather than collegiality, it is utility-related considerations that may be prevalent in such a context. ${ }^{108} \mathrm{~A}$ related problematic factor is that this vicious circle may not only endanger the usefulness of guidance, but also that of other mechanisms - notably, transnational cooperation, as mutual trust is essential for its operation - as a compliance instrument. ${ }^{109}$ The cross-instrument nature of the problems related to the lack of clarity of post-legislative guidance makes this issue particularly pertinent.

\section{Post-legislative guidance relevant to this study}

This section elaborates on the guidance documents that are relevant to the three directives included in this study. It does this by describing the contents of the guidelines, the

\footnotetext{
${ }^{105}$ Senden, 2004: 242.

${ }^{106}$ Scott, 2011: 336.

${ }^{107}$ For the notion of interdependence, see Section 3.1 of this chapter, and Chapter 6 on transnational networks, Sections 1.2.1 and 3.1.

${ }^{108}$ On the theoretical perspectives that are particularly relevant in this regard, see Chapter 3 on the approach and methodology of this study, Section 2.1 (on rationalism) and 2.2 (on management perspectives).

${ }^{109}$ See Chapter 6 on transnational networks.
} 
adopting actor(s), and the legal or de facto effect that the documents are presumed to have. ${ }^{110}$ The key features of the guidance documents are outlined in Table 14 below.

Table 14 Post-legislative guidance relevant to the context of this study

\begin{tabular}{|c|c|c|c|c|}
\hline & Interpretative & Decisional & Template & Effect \\
\hline \multicolumn{5}{|l|}{ GPS } \\
\hline RAPEX Guidelines & $\mathrm{X}$ & $\mathrm{X}$ & $\mathrm{X}$ & Indirect legal effect ${ }^{111}$ \\
\hline Other guidance & $\mathrm{X}$ & & & Possible de facto effect \\
\hline \multicolumn{5}{|l|}{ IPPC } \\
\hline BREFs & $\mathrm{X}$ & & & Indirect legal effect \\
\hline Other guidance & $\mathrm{X}$ & & & Possible de facto effect \\
\hline \multicolumn{5}{|l|}{ SAFA } \\
\hline Guidance Materials & $\mathrm{X}$ & & $\mathrm{X}$ & Possible de facto effect \\
\hline Training Bulletin & $\mathrm{X}$ & & & Possible de facto effect \\
\hline
\end{tabular}

\subsection{The GPS Directive}

\subsubsection{The RAPEX Guidelines}

In the context of the GPS Directive, the RAPEX guidelines are the most prominent example of post-legislative guidance. The preamble to the Directive provides the establishment of nonbinding guidelines regarding the management of the RAPEX system, ${ }^{112}$ the Rapid Alert System for dangerous consumer products used by the Commission and the member states for the exchange of information about dangerous non-food products. ${ }^{113}$ The RAPEX guidelines, a first version of which was adopted in 2004 and a revised version was created in $2010,{ }^{114}$ focus on this issue. In 64 pages, the guidelines that are currently in force clarify the obligations for member states under the information exchange system and provide reporting templates for member states when they use RAPEX. The guidelines also outline risk assessment guidelines, which steer market surveillance authorities in product safety assessments. Finally, the guidelines stipulate the responsibilities of the Commission in the RAPEX notification system.

\footnotetext{
${ }^{110}$ The criteria that are relevant in relation to the latter element are those set out in Section 1.2.3.3 above.

${ }^{111}$ For a nuanced picture, see Section 2.1.1.

${ }^{112}$ Directive 2001/95/EC, consideration 28.

${ }^{113}$ For an elaboration on RAPEX, see Chapter 6 on transnational networks, Section 2.1.

${ }^{114}$ See Commission Decision 2004/418/EC laying down guidelines for the management of the Community Rapid Information System (RAPEX) and for notifications presented in accordance with Article 11 of Directive 2001/95/EC [2004] OJ L 151/83; Commission Decision 2010/15/EC, respectively.
} 
As they specify the duties of both the Commission and the member states, ${ }^{115}$ the RAPEX guidelines seem to exhibit a combination of decisional and interpretative rules. They also include compliance templates. The revised version of the guidelines has been drawn up jointly by the Commission and the member states, at least to the extent that the interpretative rules outlined therein are concerned. The Commission established a risk assessment working group of member state experts for this purpose. ${ }^{116}$ Both versions of the guidelines were eventually adopted as Commission decisions, after consultation of the General Product Safety Directive (GPSD) committee.

Establishing the (legal) effects of the RAPEX guidelines seems at first like a curious undertaking in light of the friction between the form of the document and its substance. This friction exists since, while Commission decisions are inherently legally binding, ${ }^{117}$ the hallmark of guidelines is that they are soft-law elaborations of binding hard law norms. ${ }^{118}$ The idea of unbinding guidelines wrapped up in a hard law cover seems to be a contradictio in terminis. However, this contradiction does seem solvable, since the Court has taken a substantive rather than formalistic approach to determining whether or not EU acts have legal effects. ${ }^{119}$ Thus, norms can only have inherent legally binding force if the document in which they are outlined is formally legally binding and the contents of the document bind the addressee(s). The latter is clearly not the case for the RAPEX guidelines; while the norms are outlined in a document that has the formal status of law, the nature of these norms makes it impossible for them to be conceived of as having inherent legally binding force. ${ }^{120} \mathrm{With}$ inherent legally binding force ruled out, indirect legal effect is 'as far as one can get'.

In view of this conclusion and following Section 1.2.3.3 above, the following conclusions can be drawn. First, decisional rules circumscribing the discretionary competencies of the European Commission in the RAPEX system must be understood to exercise a self-binding effect on the Commission. Second, it seems that both decisional and interpretative rules included in the guidelines have an indirect legal effect for national competent authorities. This effect is due to the fact that the GPS Directive requires the European Commission to adopt and regularly update guidelines concerning the management of RAPEX by the Commission and the member states, ${ }^{121}$ and because it obliges member states to consider these guidelines in risk assessment and risk management

\footnotetext{
${ }^{115}$ Commission Decision 2010/15/EC, Part I, point 2.

${ }^{116}$ See European Commission, 'Consumers, Committees, networks, and working groups', <http://ec.europa. $\mathrm{eu} /$ consumers/archive/safety/committees $>$.

${ }^{117}$ See Art. 288 TFEU, fourth indent.

${ }^{118}$ See Scott, 2011: 334.

${ }^{119}$ See e.g. case C-57/95 France v. Commission [1997] ECR I-1627, para 7; case C-22/70 Commission v. Council (ERTA) [1971] ECR 263, para 42.

${ }^{120}$ As is the case for many national norms. The Dutch bestemmingsplan (zoning plan) is an example. While Dutch law endows them with legally binding effect, the norms included in zoning plans are, judged by their contents, only partially binding.

${ }^{121}$ Directive 2001/95/EC, Art. 11(1) and 12(3), and Annex II, point 8.
} 
processes $^{122}$ and in the notification of unsafe products to the Commission through RAPEX. ${ }^{123}$ Note that the RAPEX guidelines outline that member states "participate in the system according to the rules provided for in the GPSD and in the Guidelines". ${ }^{124}$ While this sentence cannot necessarily be read as a specification of the duty of loyal cooperation, it does seem to equate the GPS Directive and the guidelines.

Note for the sake of completeness that the above evaluation does not concur with the unbinding effect that the preamble to the GPS Directive associates with the RAPEX guidelines. ${ }^{125}$ Also note that this fact is not relevant to the decision about the binding effect of the guidelines, since preambles to EU measures do not have legally binding force. More relevant is the nature of the substance of the guidelines, as highlighted above. The tension between form and substance raises questions as to why the Commission has chosen to adopt the guidelines in the form of a decision; in view of the basically unbinding nature of post-legislative guidance, it may have chosen to employ a form corresponding to the nature of the substance.

\subsubsection{Other guidance}

Other guidance documents besides the RAPEX guidelines do exist. One of these is the Guidance document on the relationship between the General Product Safety Directive (GPSD) and certain sector directives with provisions on product safety. This document consists of two chapters, which have been adopted separately from one another and which can therefore be found as separate documents on the website of the Commission. ${ }^{126}$ The documents present informal interpretative rules to assist member states in the implementation of product safety measures. The guidelines were adopted by the Commission's DG Health and Consumers and DG Enterprise, after "a wide consultation of [m]ember [s]tates and stakeholders [was] carried out". ${ }^{127}$ The chapters refer to the notion that the rules outlined therein do not commit the Commission, and that the interpretation of EU law is ultimately the responsibility of the CJEU. ${ }^{128}$ In view of the notion that the guidance document does not meet any of the conditions that may imbue it with an indirect legal effect, its effects are of a de facto nature only.

The Commission also published a Working paper on the relationship between the General Product Safety Directive 2001/95/EC and the market surveillance provisions of

\footnotetext{
${ }^{122}$ Ibid., Art. 8(3).

${ }^{123}$ Ibid., Art. 12(1), second indent; Annex II, point 2, 3, 6, and 11.

${ }^{124}$ Commission Decision 2010/15/EC, Part I, point 1.1, fourth indent.

${ }^{125}$ Directive 2001/95/EC, consideration 28.

${ }^{126}$ See European Commission, 'Guidance document on the relationship between the General Product Safety Directive (GPSD) and certain sector directives with provisions on product safety', $<\mathrm{http} / /$ ec.europa.eu/consumers/consumers_safety/product_safety_legislation/general_product_safety_directi ve/index_en.htm>.

${ }^{127}$ Ibid., Chapter 1, p. 4; similar Chapter 2, p. 3.

${ }^{128}$ Ibid., Chapter 1, p. 4.
} 
Regulation (EC) No 765/2008. ${ }^{129}$ The aim of this document is to help member states properly implement EU measures on market surveillance regarding non-food products; thus, it incorporates interpretative rules targeted at member states. These rules are not binding; the Commission notes that they do not prejudge any formal position of the Commission. ${ }^{130}$ It also emphasises that it is the Court's responsibility to provide a binding interpretation. ${ }^{131}$ This working paper has a potential de facto effect.

Finally, the Commission also published a Guidance Document on the relationship between Directive 2001/95/EC and the Mutual Recognition Regulation. ${ }^{132}$ This document aims to provide "user-friendly" guidance on the relationship between the provisions of the acts referred to in its title. ${ }^{133}$ It explicitly states that it is not legally binding, and that it does not necessarily reflect the view or position of the Commission. ${ }^{134}$ It has a de facto effect at best.

\subsection{The IPPC Directive}

\subsubsection{The BREFs}

Most prominent in the context of the IPPC Directive are the best available techniques reference documents (BREFs). ${ }^{135}$ The BREFs provide guidance on the application of the best available techniques for categories of industrial activities listed in Annex I to the IPPC Directive, and on horizontal issues such as economic and cross-media effects and energy efficiency. Each BREF consists of several hundred pages that provide general information regarding, amongst other topics, the sector of concern and the applied processes and techniques in that sector. It then moves on to discuss the best available techniques for the relevant sector. While BREFs may provide clear and specific instructions on the best available techniques for an industrial sector or a particular installation, they may also provide instructions that are less determinative and thus more open. ${ }^{136}$ In total, thirty-three BREFs are available. ${ }^{137}$

\footnotetext{
129 Commission, 'Working paper on the relationship between the General Product Safety Directive 2001/95/EC and the market surveillance provisions of Regulation (EC) No 765/2008' [2010] no longer available online.

${ }^{130}$ Working paper on the relationship between the General Product Safety Directive 2001/95/EC and the market surveillance provisions of Regulation (EC) No 765/2008, p. 1.

${ }^{131}$ Ibid.

${ }^{132}$ See Commission, 'Guidance Document on the relationship between Directive 2001/95/EC and the Mutual Recognition Regulation' [2010], available on <http://ec.europa.eu/enterprise/policies/single-marketgoods/free-movement-non-harmonised-sectors/mutual-recognition>.

${ }^{133}$ Guidance Document on the relationship between Directive 2001/95/EC and the Mutual Recognition Regulation, point 1 .

${ }^{134}$ Ibid., n. 1.

${ }^{135}$ All BREFs are retrievable online; see European IPPC Bureau, 'References', <http://eippcb.jrc.ec.europa.eu/ reference>.

${ }^{136}$ Lange, 2008: 145-149. Lange adds that the distinction between 'open' and 'closed' should not be seen as a
} 
The BREFs are addressed to the member states. ${ }^{138}$ They are published by the European Commission pursuant to the IPPC Directive, which requires the Commission to organise "an exchange of information between [m]ember [s]tates and the industries concerned on best available techniques, associated monitoring and developments in them", and to publish the results of this exchange. ${ }^{139}$ Member states are, thus, actively consulted on the information exchange process leading up to the adoption of the BREFs. Figure 7 shows the mechanisms that shape this information exchange process. ${ }^{140}$

The information exchange process is managed by the European IPPC Bureau (EIPPCB), which is part of the Commission's DG Joint Research Centre (JRC); ${ }^{141}$ hence, the nickname of the process is 'Seville process'. The EIPPCB conducts its work through technical working groups (TWGs). TWGs are set up for the development and review of each BREF; they carry out the detailed work for the exchange of information about the different industrial activities covered by the IPPC Directive. TWGs send progress reports and draft BREFs to the Information Exchange Forum (IEF), which steers the information exchange process and acts as a forum for the discussion of horizontal and general issues relating to the information exchange. Formal responsibility for ensuring that progress is made lies with the Commission. The IEF receives advice from the IPPC Expert Group (IEG), which exchanges information on the IPPC Directive as a whole and primarily deals with the implementation and review of the directive.

\footnotetext{
strict one. Both categories are not mutually exclusive - some elements of a BAT determination may be open while others may be closed. Hence, BAT norms can be envisaged as situated on a sliding scale with various degrees of openness and closure. See Lange, 2008: 149-151.

${ }^{137}$ Number valid for July 2014.

${ }^{138}$ Directive 2008/1/EC, consideration 27.

${ }^{139}$ Ibid., Art. 17(2).

${ }^{140}$ This figure is adapted from Schoenberger, 2009: 1527.

${ }^{141}$ The following summary of the methods of the information exchange process greatly relies on Schoenberger, 2009. Note that the details of the information exchange process under the Industrial Emissions Directive are slightly different. For an overview, see European IPPC Bureau, 'Working procedures to elaborate BREFs', <http://eippcb.jrc.ec.europa.eu/about/working_procedures.html >.
} 


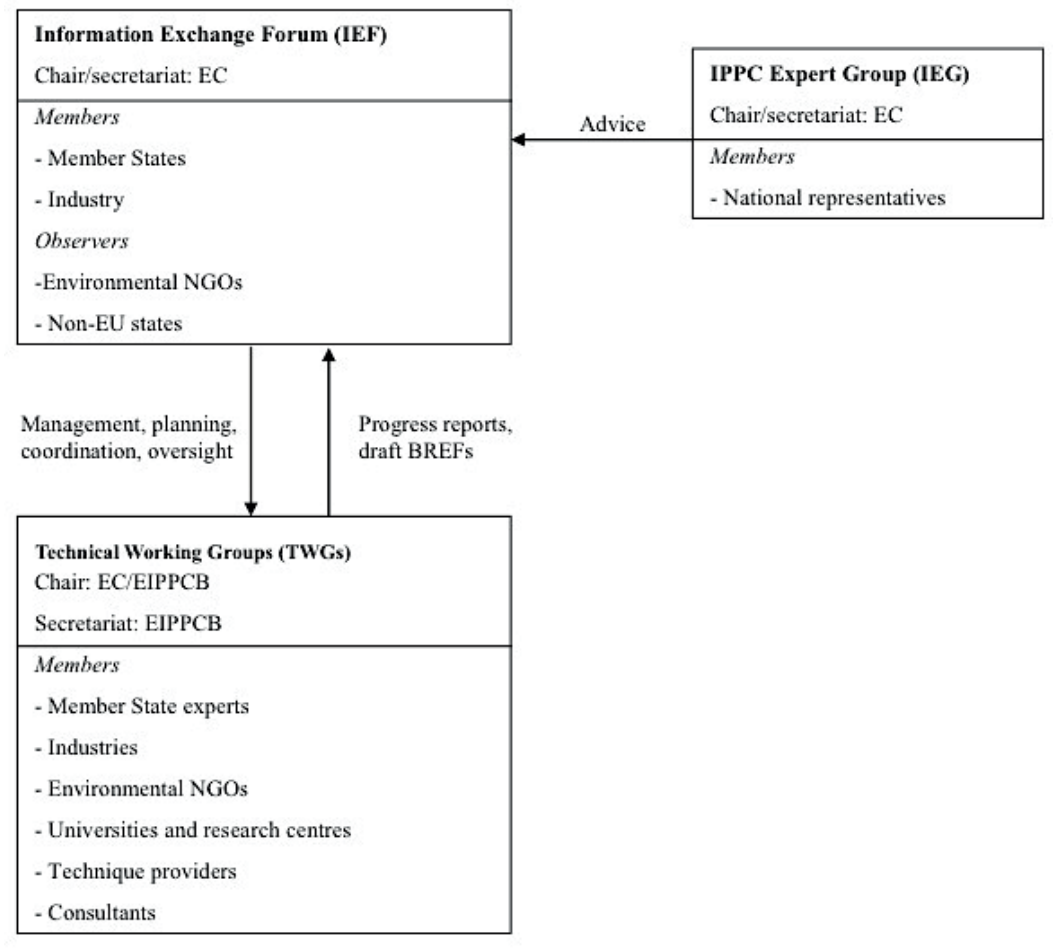

Figure 7 Schematics of the information exchange - 'Seville' - process

Following Section 1.2.3.3 above, the BREFs must be understood to have an indirect legal effect. This is the case, first, since the IPPC Directive requires the Commission to establish guidance on BAT, as suggested above, and second, since the IPPC Directive obliges member states to take the BREFs into account when determining the best available techniques. ${ }^{142}$ Note that the directive does not outline a duty of compliance for member states; its wording suggests that deviation from the BREFs is possible, provided that such deviation is motivated adequately. The possibility of deviation also seems implied in the idea that authorities must not only take into account the BREFs, but also the technical characteristics of the installation, the local environmental conditions, and the geographical characteristics in the determination of BAT. ${ }^{143}$

The nonbinding nature of the BREFs appears in the guidance documents as well, which state that they "do not set legally binding standards" and "are meant to give information for the guidance of industry, [m]ember [s]tates and the public". ${ }^{144}$ This is similar to a statement from the CJEU; in a preliminary ruling, the Court briefly recalled

\footnotetext{
${ }^{142}$ Directive 2008/1/EC, Annex IV(12).

${ }^{143}$ Ibid., Art. 9(4).

${ }^{144} \mathrm{BREF}$ on the intensive rearing of poultry and pigs (version of 2003), p. 274.
} 
that the BREF document relevant to the context of the case at hand "has no binding effect or interpretative value for Directive 96/61, as it is limited to providing an inventory of technical knowledge on the best available techniques". ${ }^{145}$ The CJEU's denial of a binding effect of the BREFs is understandable in view of the interpretative monopoly of the Court, and it must be understood to extend to the other BREFs as well.

\subsubsection{Other guidance}

In addition to the BREFs, the Commission has published several other guidance documents to support member states in the administration of the IPPC Directive. Guidance on the interpretation and implementation of the IPPC Directive, which aims to provide guidance to member states for the implementation of the directive "by suggesting an approach to some questions on how certain provisions of the [d]irective should be understood", can be found on the website of the European Commission. ${ }^{146}$ The relevant guidance documents are much less committal than the BREFs; the notion that the Commission states that they do not present an official position and that they cannot be invoked in the context of legal proceedings is a clear sign of this. ${ }^{147}$ The effect of these guidance documents is potentially de facto only.

\subsection{The SAFA Directive}

\subsubsection{The SAFA Guidance Materials}

In the context of the SAFA Directive, we find the SAFA guidance materials (GMs) potentially useful sources of post-legislative guidance for national competent authorities. Two versions exist: the guidance material for the qualification of SAFA inspectors, ${ }^{148}$ and the guidance material for SAFA ramp inspections. ${ }^{149}$ The first GM, which is 81

\footnotetext{
${ }^{145}$ Case 473/07 Association nationale pour la protection des eaux et rivières - TOS, Association OABA v. Ministère de l'écologie, du développement et de l'aménagement durables [2009] ECR I-00319, para. 30.

${ }^{146}$ See Commission, 'Guidance on Interpretation of "Installation" and "Operator" for the Purposes of the IPPC Directive’ [2007] available on <http://ec.europa.eu/clima/policies>.

${ }^{147}$ Ibid.

${ }^{148}$ European Aviation Safety Agency, ED Decision N ${ }^{\circ} 2008 / 001 / S$ of the Executive Director of the European Aviation Safety Agency of 29 September 2008 on the guidance material for the qualification of SAFA inspectors, available on <www.easa.europa.eu> (not published in the Official Publication of the Agency).

${ }^{149}$ European Aviation Safety Agency, ED Decision N²009/001/S of the Executive Director of the European Aviation Safety Agency of 22 July 2009 on the guidance material for SAFA ramp inspections (first version); European Aviation Safety Agency, ED Decision N 2012/001/S of the Executive Director of the European Aviation Safety Agency on the guidance material for SAFA ramp inspections (second version), both available on <www.easa.europa.eu> (not published in the Official Publication of the Agency). In autumn 2014, these guidance materials were replaced by inspection instructions on the categorisation of ramp inspection (SAFA/SACA) Findings, Doc \# INST.RI.01/001, available on <www.easa.europa.eu $>$ (not published in the Official Publication of the Agency). Since the empirical research was conducted before the entry into force of these inspection instructions, these instructions are not covered in the remainder of this chapter. Note that the
} 
pages long, clarifies the qualification criteria for inspectors, the organisation of training courses for inspectors in accordance with the relevant syllabi established and published by EASA, and the criteria for the assignment of senior inspectors. The second GM, which is most relevant to this study, is 217 pages long and elaborates on the scope and method of inspection for each of the items on the SAFA checklist, on the categorisation of findings, and on the relationship between such categorisation and the corrective actions required. Approximately 180 pages provide detailed inspection instructions, which include standard references to applicable international standards and pre-described findings (PDFs). ${ }^{150}$ This second GM also provides communication and reporting templates that SAFA officials should use in the implementation process. ${ }^{151}$

Encompassing both interpretative rules and compliance templates, the SAFA guidance materials are addressed to the member states. ${ }^{152}$ They are adopted by EASA, as an executive director decision. ${ }^{153}$ Member states were given the right to be consulted in the development process; the SAFA Directive stipulates that in the development of the guidance materials, EASA must establish a "transparent procedure for consulting the $[\mathrm{m}]$ ember [s]tates drawing on available expertise in the aviation regulatory authorities of $[\mathrm{m}]$ ember $[\mathrm{s}]$ tates and by involving, whenever necessary, appropriate experts from relevant interested parties". ${ }^{154}$ It also states that EASA may create a working group to this effect. ${ }^{155}$ The decisions of the GMs indicate that the agency established such a procedure and consulted all member states and interested parties in accordance with it. ${ }^{156}$ For the GM on the qualification of SAFA inspectors, a single consultation round sufficed for EASA to adopt its decision; ${ }^{157}$ in the case of the GM for SAFA ramp inspections, a second round was deemed necessary. ${ }^{158}$

Applications of the conditions outlined in Section 1.2.3.3 suggest that the guidance materials are not legally binding and that they have a de facto effect at best. This is the case since, while the SAFA Directive mandates that EASA develop and publish detailed guidance materials to assist the member states in the implementation of certain provi-

\footnotetext{
form of the document is very similar to that of the SAFA Guidance Materials, and that the main difference lies in its coverage of third-country and EU aircraft (rather than only third-country aircraft).

${ }^{150}$ European Aviation Safety Agency, ED Decision N ${ }^{\circ} 2012 / 001 / S$ of the Executive Director of the European Aviation Safety Agency on the guidance material for SAFA ramp inspections, Appendix I.

${ }^{151}$ Ibid., Appendices 5 and 6.

${ }^{152}$ Commission Directive 2008/49/EC amending Annex II to Directive 2004/36/EC of the European Parliament and of the Council regarding the criteria for the conduct of ramp inspections on aircraft using Community airports [2008] OJ L 109/17, Art. 2. See also European Aviation Safety Agency, Decision N 2008/001/S, p. 2; Decision $\mathrm{N}^{\circ} 2012 / 001 / \mathrm{S}$, p. 5.

${ }^{153}$ Note that these decisions are not published in the Official Publication of EASA; they are only available online.

${ }^{154}$ Commission Directive 2008/49/EC, Art. 2.

155 Ibid.

${ }^{156}$ ED Decision $N^{\circ}$ 2008/001/S, considerations 3 and 4; Decision $\mathrm{N}^{\circ}$ 2012/001/S, considerations 4 and 7.

${ }^{157}$ Ibid., consideration 5.

${ }^{158}$ Decision $N^{\circ}$ 2012/001/S, considerations 8 and 9.
} 
sions, ${ }^{159}$ it does not explicitly impose an obligation on member states to take these guidelines into account or to comply with them. Moreover, the GMs do not include a specification of the duty of loyal cooperation. This means that none of the conditions that help to determine whether guidelines have an indirect legal effect are met. The GM for the qualification of inspectors mentions that "it is important that [m]ember [s]tates adhere as much as possible to the listed references", and that non-adherence should be motivated. ${ }^{160}$ The GM on SAFA ramp inspections is entirely silent about the necessity of any such adherence by the member states, putting the emphasis on the assistance function of the guidelines instead.

For the sake of completeness, it should be added that the SAFA Directive already includes reporting templates. ${ }^{161}$ Since these templates are an integral part of the directive, they do not qualify as post-legislative guidance.

\subsubsection{Other guidance}

Next to the guidance materials, EASA has issued three training bulletins clarifying and underlining certain issues outlined in the GMs, and identifying the issues that training programmes for inspectors should focus on. Annexed with these bulletins are some supporting documents that inspectors may consult. The training bulletins, which were developed following discussions in the European SAFA Steering Group - which involves the SAFA national coordinators, the Commission, and EASA as active participants $^{162}$ - have a de facto effect only.

\section{The usefulness of post-legislative guidance as a compliance instrument}

This section aims to examine the usefulness of post-legislative guidance for national officials involved in the administration of the three directives in this study. The analysis proceeds as follows. Section 3.1 reflects on the motivations that may underlie the use of guidance by national officials. Section 3.2 elaborates on the factors that influence the quality of guidance; this quality must be adequate for guidance to be useful for streetlevel implementation actors. Focusing on officials' perceptions of the legal effect of the guidance materials under examination in this study, Section 3.3 sets the scene for our discussion in Section 3.4, which concludes this part of the chapter by reflecting on the rationales for, and the upsides and downsides of, 'making guidance binding'.

\footnotetext{
${ }^{159}$ Directive 2004/36/EC, Annex II, point 2.3.4, 2.4.7, 2.5.4, 4.3, 5.2, 6.1, 6.4.

${ }^{160}$ Guidance Material on the qualification of SAFA inspectors, Annex to ED Decision N ${ }^{\circ}$ 2008/001/S, p. 2.

${ }^{161}$ Directive 2004/36/EC, Appendices 1 and 2.

${ }^{162}$ For an elaborate description of the ESSG, see Chapter 6 on transnational networks, Section 3.3.1.
} 


\subsection{Motivations for the use of guidance}

The usefulness of post-legislative guidance as a compliance instrument must be evaluated stepwise: first, there is the question of whether or not officials use such guidance in the application of EU law and if so, what motivates them to do so. Answering this question illuminates the benefits that the availability of guidance is initially associated with. Second, where post-legislative guidance is used, the question is about what extent officials find this guidance useful and what they appreciate in this regard. The current section looks into the former element; the latter element is elaborated on in the following sections.

Interviews suggest that all national officials - ministerial civil servants and streetlevel actors alike - are at least familiar with the RAPEX guidelines, the BREFs, and the SAFA guidance materials. This is not surprising, due to the prominence that the European Commission has accorded to these guidance documents in the law administration process; none of these guidelines could have escaped the attention of national officials involved in the administration of the relevant directives. Whereas awareness of the existence of the mentioned guidelines is common amongst officials, officials' motivations to use these guidelines in the implementation practice seem to diverge across policy domains and across member states.

With respect to cross-issue variation regarding motivation to use available guidance documents, it is specifically the notion of interdependence that appears to play an important explanatory role. This notion usually surfaces in discussions about the functioning of inter-organisational networks, which is why Chapter 6 on transnational networks elaborates on this topic. ${ }^{163}$ At this point, it is sufficient to refer to the fact that the notion of interdependence refers to a situation in which organisations affect each other in their work, and as a result the performance of each individual authority depends on that of the others. While Chapter 6 suggests that a shared perception amongst national officials that authorities are interdependent in the implementation of EU law constitutes a strong motivational factor for cooperation, the current chapter suggests that such a perception may be a strong motivation for the use of post-legislative guidance as well.

Interviews suggest that, similar to transnational networks, ${ }^{164}$ the notion of interdependence does not explain the use of guidance in the area of integrated pollution prevention and control. Almost all permit

93\% of the IPPC permit writers use the BREFs: $67 \%$ of them use the BREFs for every permitting process, $13 \%$ use them in most situations, and $13 \%$ use them in some situations.

$80 \%$ of the permit writers agree or strongly agree that the BREFs are useful.

writers who completed the survey that was conducted for this study claim to use the

${ }^{163}$ For a theoretical discussion, see Chapter 6 on transnational networks, Section 1.2.1.

${ }^{164}$ See Chapter 6 on transnational networks, Section 3.1. 
BREFs, with two-thirds of them using the BREFs in every permitting situation. In addition, all permit writers interviewed for this study use the BREFs. The majority of survey respondents who use the BREFs agree or strongly agree that these documents support them in the application of BAT in IPPC permits. These perceptions are also reflected in the interviews conducted for this study; all interviewed officials consider the BREFs the most useful compliance instrument.

However, these positive evaluations do not follow from appreciation of the standardising effect that the BREFs may have on environmental licensing processes across member states; ${ }^{165}$ the idea of the guidelines as helpful for effectuating standardisation is absent because of the weak perception amongst officials that authorities are interdependent in the implementation process. With interdependence not capable of explaining the widespread use of the BREFs across member states, other explanatory factors must be relevant. Interviews suggest that what motivates officials to use the BREFs in environmental licensing processes appears to be a mix of an appreciation of the binding effect of the BREFs, their helpfulness for providing direction about the environmental licensing process, and the awareness of the prominence accorded to the BREFs by the Commission. ${ }^{166}$ The varied perceptions across member states regarding particularly the first factor account for the notable divergences in the use of the BREFs in practice, as the following sections aim to demonstrate in more detail.

Cross-country divergences in the use of guidance documents are also present in the areas of product safety and air safety. What sets both areas apart from the area of integrated pollution prevention and control is an appreciation of the relevant guidance documents as useful for standardising law administration practices in a context where national authorities are interdependent at making EU rules work. When it comes to the area of air safety, this interdependency - and standardisation - argument appears to be a predominant consideration in officials' perceptions of the usefulness of the SAFA guidance materials, ${ }^{167}$ as the following excerpt from an interview with Dutch officials involved in the application of the SAFA Directive illustrates:

How do you transpose a directive into practical tools? By means of guidance! For inspectors, the Guidance Materials are holy. I fail to understand how we have ever been able to cope without them. They are gold. With these you ensure that the person behind the inspector cannot get dominant. 'I' is not a legal reference. You need to stick to the Guidance Materials; they have an enormous validity. Particularly the PDFs are important in this context, as they link the relevant legal provision to the standard description of findings given by

\footnotetext{
${ }^{165}$ See Directive 2008/1/EC, consideration 27, which argues that the BREFs 'should help to address the technological imbalances' in the EU.

${ }^{166}$ Interviews with all national officials involved in IPPC licensing activities.

${ }^{167}$ See e.g. interview PT14; PT17; NL15; PL15.
} 
ICAO. ${ }^{168}$ It is because of these that you get to a standardisation of findings. Whether or not you agree on it personally doesn't matter. ${ }^{169}$

All SAFA inspectors use the SAFA guidance materials: $80 \%$ of the respondents use the guidance materials every week, and $20 \%$ use them several times a year.

All of those who use the SAFA guidance materials agree or strongly agree that they are useful. This is the same for the pre-described findings.
The importance that officials attach to 'getting on the same line' in the implementation of SAFA inspections seems to be an important explanatory factor for the fact that all SAFA inspectors - both those who participated in the survey and those who were interviewed - use the guidance materials and agree, or strongly agree, that they are useful for supporting them in conducting SAFA ramp inspections.

An analogous reasoning applies to the area of product safety, where the interdependency argument plays a similar role, as Chapter 6 on transnational networks discusses in detail. ${ }^{170}$ The survey and interviews conducted for this study suggest that the RAPEX guidelines are used and evaluated as useful, by the majority of product safety inspectors. Interviews suggest that this is the case, not only because the guidelines are useful for directing each individual authority in its work, but also because they contribute to the standardisation of implementation practices across member states in a situation where member states are interdependent. It is specifically the risk assessment guidelines, which are included in the RAPEX guidelines, that are considered valuable in this regard. The following quotation, which is similar to the interview excerpt about the 95\% of the GPS inspectors use the RAPEX guidelines: $14 \%$ use the guidelines every day, $9 \%$ use them every week, $32 \%$ use them every month, $36 \%$ use them several times a year, and $5 \%$ use them once a year.

$86 \%$ of the inspectors agree or strongly agree that the RAPEX guidelines are useful. area of air safety presented above, highlights the considerations that play a role here:

Arriving at common risk management solutions is difficult given the different backgrounds of people and the fact that risk evaluations are not set up in a simple way. The good thing is that because we have the risk assessment guidelines, you talk about a model instead of about emotions. You may have a discussion with companies or other authorities, but at least now you discuss a

\footnotetext{
${ }^{168}$ International Civil Aviation Organisation.

${ }^{169}$ Interview NL29.

${ }^{170}$ See Chapter 6 on transnational networks, Section 3.1.
} 
model instead of emotions. The question, however, is, whether this model is always applied, because if you see the notifications in RAPEX... ${ }^{171}$

The latter sentence hints at the idea that guidance is not the magic bullet for removing divergences in risk assessment processes. While existing divergences may be explained by an erratic application of the guidelines in practice, as the interview excerpt above suggests, other factors seem to play a role as well. It is the interplay of these factors that the following sections discuss.

\subsection{Quality of guidance}

The first factor to consider is the quality of post-legislative guidance. Particularly relevant to discuss in this regard are the consultation of interested parties in guidance development processes (Section 3.2.1), and the nature of the policy domain in the context of which guidance is adopted (Section 3.2.2).

\subsubsection{Consultation}

Flaws in the quality of guidance appear to exist in the context of all three directives included in this study. The following interview excerpt on the first version of the SAFA guidance materials for the qualification of inspectors illustrates how such flaws may drastically reduce the usefulness of guidance:

The first GM has some articles that are misleading. They are by no means clear, they make for a lot of confusion, and it is a total waste of time to implement these articles. The last time we were visited by the EASA standardisation team, ${ }^{172}$ there were a lot of questions about that, and it was clear that they had the same problems as we did. But even before EASA came to Portugal there was this public presentation on the European SAFA Steering Group and EASA showed us the results of the audits conducted in previous years. And that was terrible; there were lots of findings related to this subject. So for me it was very reassuring that it's not only me who has this opinion that it's misleading, confusing, and contradictory. The findings were not related to the size of the country, or to the level of participation in the programme, or to the geographic nature - it's the same findings. So we can say there was a harmonised way of badly interpreting the GMs. They really have to be revoked, because they give us a

\footnotetext{
${ }^{171}$ Interview NL4.

${ }^{172}$ Chapter 4 on monitoring and sanctions explains that EASA conducts biannual inspections in SAFA participating states in order to verify their compliance with the applicable rules; see Sections 2.1.3 and 3.1 of this chapter.
} 
lot of problems. It's a dead document; it's a binding, bureaucratic, administrative thing. ${ }^{173}$

The above quotation clearly demonstrates how post-legislative guidance that is meant to support authorities in the administration of EU rules can have the opposite effect. In the case of the SAFA guidance materials referred to above, the rather hasty and exclusive nature of the process leading up to their adoption is referred to as the culprit for the inadequacies that are present. The Portuguese SAFA national coordinator claims not to have been asked for an opinion on the draft guidelines; a procedural flaw that is blamed on the fact that the Commission directive that requires EASA to publish guidelines permits a short period for the agency to accomplish this. ${ }^{174}$

In its decision to adopt the GM, however, EASA posits that the guidelines were established after consultation with all member states and interested parties. ${ }^{175}$ The relevant comment response document (CRD) indicates that the draft guidance document was sent to all SAFA national coordinators, who were given three weeks to review the draft and to respond to the agency with comments; ${ }^{176}$ a short consultation period in comparison with the period outlined in the minimum consultation standards established by the Commission, which refer to a term of eight weeks. ${ }^{177}$ It seems that the brevity of this consultation period may explain why only seven of these coordinators amongst which are none of the countries included in this study - provided feedback, ${ }^{178}$ and why EASA has not organised a second consultation round. ${ }^{179}$ The comments in the CRD express both astonishment over the absence of a working group and concern about the lack of communication on the part of EASA in the elaboration of the guidance materials. ${ }^{180}$ These comments also link the absence of 'true consultation' to perceptions of the resultant guidelines as overly regulatory and far too complex. ${ }^{181}$

It seems that EASA has seriously considered these comments, and that it has learned that 'big bangs' do not work; this is apparent from the fact that the subsequent

\footnotetext{
${ }^{173}$ Interview PT17.

${ }^{174}$ Interview PT17. Commission Directive 2008/49/EC amending Directive 2004/36/EC was adopted on 19 April 2008 and requires EASA to adopt guidelines by 30 September 2008; see, amongst others, Annex II, point 2.3.4.

175 See Section 2.3.1.

${ }^{176}$ European Aviation Safety Agency, 'Comment Response Document to Guidance Material on Inspectors Qualification, Explanatory Note', in possession of the author (no longer available online), point II(2).

${ }^{177}$ COM (2002) 704 final, p. 21.

${ }^{178}$ Including one non-EU SAFA Participating State. The draft was also sent to three SAFA training organisations, two of which provided feedback. For these numbers, see European Aviation Safety Agency, 'Comment Response Document [CRD] to Guidance Material on Inspectors Qualification, Explanatory Note', point II(2). ${ }^{179}$ See Section 2.3.1.

${ }^{180}$ European Aviation Safety Agency, 'Comment Response Document [CRD] to Guidance Material on Inspectors Qualification, Explanatory Note', comments 11 and 12. Note that these comments were made by a SAFA training organisation.

${ }^{181}$ Ibid.
} 
guidance materials were developed over a longer period of time, following discussion and agreement between EASA and the SAFA participating states. The vehicle for such discussions has been the European SAFA Steering Group, which gathers SAFA national coordinators, is chaired by the Commission and involves EASA as an important participant. $^{182}$

A similar dynamic seems to have occurred in the case of the GPS Directive. The European Commission adopted the first version of the RAPEX guidelines after consulting the GPSD committee in accordance with the advisory procedure. ${ }^{183}$ It seems that this consultation procedure did not allow for any real participation of member states in the process leading up to the adoption of the guidelines. The lack of input from those who needed to work with the guidelines has been referred to as an important explanatory factor for the fact that these guidelines did little to reduce variation in risk assessment outcomes. ${ }^{184}$ Awareness of the downsides of a lack of participation in the guidance development process subsequently led the Commission to establish a risk assessment working group made up of member state experts in the revision process of the guidelines. Participatory opportunities for other stakeholders were created as well. ${ }^{185}$ According to an interviewee, this improved consultation process has made the second version of the RAPEX guidelines more usable than their predecessors. ${ }^{186}$

These cases underline that the quality of post-legislative guidance hinges on the institution of a veritable consultation process and on the participation of interested parties, particularly member state experts, in this process. ${ }^{187}$ The revision process of the RAPEX guidelines appears to score better on the scale of inclusion than the development process of the SAFA guidance materials. This is because, while national risk assessment experts participated in discussions regarding the RAPEX guidelines, EU-level deliberations on the SAFA guidance materials seem to have included only SAFA national coordinators. While these officials may be part of the SAFA inspection team, as is the case for the Dutch and Polish SAFA national coordinators, this is not always the case, as the Portuguese practice exemplifies. Particular in this latter case, the lack of involvement of street-level actors may become problematic; ${ }^{188}$ it creates Chinese Walls that render it difficult for guidelines to match the needs and understanding of those discussing the guidelines 'in Brussels' and those who have to do the job at airports across the EU. The following quotation from an interview with a Portuguese SAFA inspector testifies to the

\footnotetext{
${ }^{182}$ Interview PT17; PL15. On the ESSG, see Chapter 6 on transnational networks, Section 2.3.1.

${ }^{183}$ Commission Decision 2004/418/EC, preamble and Annex, point 1.2.

${ }^{184}$ Interview NL5.

${ }^{185}$ See Section 2.1 .1 of this chapter.

${ }^{186}$ Interview NL5.

${ }^{187}$ The idea that consultation opportunities are indispensable in terms of both input and output legitimacy is discussed in Section 1.2.2.4 above.

${ }^{188}$ At least where street-level actors are not otherwise asked to provide input into the development of the guidelines.
} 
mismatch between paper and reality that may result from a lack of involvement from street-level actors:

One thing is to write and to fabricate rules based on existing texts and alterations, but something very different is to be in the terrain for a lifetime, to know exactly what the problems are, to write about them, and to make rules about them. There is a discrepancy between the two situations. So when people that have to go into the terrain have to adapt to rules written by bureaucrats, sometimes the situation is not the one that is described in the guidelines. ${ }^{189}$

This quotation echoes often-heard complaints regarding the disruptive effect of Chinese Walls on the implementability of EU directives, and other legislative acts for that matter. ${ }^{190}$ What this quotation adds to the above discussion about consultation and participation in the elaboration of guidelines, is that one should be aware that since it is primarily street-level actors that use these guidelines, these actors must initially be content with the guidelines. Guidance development processes may appear inclusive from the outside and participants may be satisfied about the level of discussion that is occurring, but what matters is whether or not those who should have been included are included, and whether they are happy with the nature and the level of deliberation. In view of the absence of specific rules that dictate which national-level actors to include in EU-level consultation exercises, the task of ensuring that street-level actors are involved in such exercises seems to lie with national authorities.

\subsubsection{Nature of the policy issue}

The above section could be interpreted as a strong case for organising ample consultation opportunities for member state officials - including street-level actors - in the elaboration of post-legislative guidance; opportunities that were underdeveloped in the drafting of some of the guidelines discussed above. The following paragraphs show that opportunities for national experts to provide input into the guidance development process, however, do not ensure qualitatively adequate guidance.

This is the case, in part, because member states do not always make use of consultation opportunities. The process leading up to the adoption of the BREFs provides a lucid example of this. In theory, member states' experts may be equally involved in the drafting of the BREF documents through their participation in the Seville information exchange process, particularly through their contribution to the work of the relevant technical working groups. ${ }^{191}$ In practice, however, the participation of member states greatly varies with the importance of the industrial sector of concern, and some member states

\footnotetext{
${ }^{189}$ Interview PT15.

${ }^{190}$ See e.g. Mastenbroek, 2003.

${ }^{191}$ For a description of the Seville information exchange process, see Section 2.2.1 above.
} 
are structurally underrepresented. The latter seems to apply specifically to the southern member states and to some of the latest entrants into the Union. ${ }^{192}$

While some interviewees seem rather contemptuous towards non-participating member states, the absence of these states may be explained by constraints that are not easily solvable and that are beyond the control of the relevant officials. Portuguese interviewees, for example, indicate that they would like to participate in the formulation of the BREFs, but that they are rarely authorised to travel to Seville to take part in TWG meetings:

Our problem now is that in our agency, we don't have the human resources to discuss BREFs. It is difficult to send people to Seville. When we want to attend a committee meeting, at least the travel costs are reimbursed, but this is not the case for the Seville process. Clearly, we have financial problems, and most of the time we are not allowed to go. Seville is not so far from Lisbon. But well... Some of the comments we send by email, but sometimes there is no time to see everything, and it is different to be there. ${ }^{193}$

If some member states are underrepresented in the drafting of the BREFs while others have their preferences heard, industry and equipment sellers seem to be overly dominant. ${ }^{194}$ The magnitude of forces that are pulling in different directions and the incomplete and biased information base that BREF authors may have to rely on inadvertently affect the quality of at least some of the guidance documents. These quality problems are apparent in perceptions that indicate that the requirements outlined in the guidelines may be incompatible, that the BREFs may pose emission limit values that are unattainable or too low for the majority of installations, ${ }^{195}$ or that they may be too general. ${ }^{196}$

The issue of biased, strategic information on the part of member states does not seem to apply to the context of the GPS Directive and the SAFA Directive. In both of these cases, the participation of member states is driven not primarily by a desire to influence the drafting process to ensure that the resulting guidelines reflect national preferences; rather, it is driven by a wish to commonly agree on guidance that is as objective and as workable as possible. A shared perception amongst officials of guidelines as useful for achieving more harmonised implementation practices in these areas may

\footnotetext{
${ }^{192}$ As the BREFs do not provide information about who was involved in the drafting process and in what manner, this assertion is based on interviews. See e.g. interview NL16, PT9.

${ }^{193}$ Interview PT9. On this issue, see Chapter 6 on transnational networks, Section 3.4.1.

${ }^{194}$ E.g. interview PT9; NL16; PL9.

${ }^{195}$ Whereas it may be logical to think of companies as lobbying for environmental requirements that are as low as possible, one could also think of companies with a competitive edge in the implementation of certain technological equipment to lobby for higher requirements. Both dynamics could be present in the BREF writing process.

${ }^{196}$ E.g. interview PT9; PL9. Concerns about the quality of the BREFs are certainly not new. See e.g. Oosterhuis et al., 2007: Chapter 4.
} 
underlie this dynamic; a dynamic that clearly differs from that in the area of integrated pollution prevention and control. ${ }^{197}$

Consensus in the areas of product and air safety on the direction that guidelines should take does not mean that the drafting of guidance in these areas is problem free. If strenuous preference-based tug-of-wars are a major problem in the drafting of the BREFs, the difficulty in the areas of product and air safety seems to relate to the extent that scientific objectivity in the drafting of guidelines can be attained. For officials in these areas, objectification is a majorly important determinant for quality, since in order for risk assessments to yield the same results throughout the EU risk assessment models must remove as much subjectivity on the part of risk assessors as possible.

Attaining full objectification in the drafting of the RAPEX guidelines and the SAFA guidance materials has, thus, been proven impossible. Although interviewees consider the RAPEX guidelines high quality and useful, all of them agree that risk assessment processes have remained a subjective exercise. It is still possible to discuss every step taken in the process; this leaves room not just for inadvertent divergences, but also for purposeful manipulation on the part of those who have an interest in this. ${ }^{198}$ Risk assessment processes are error sensitive; deviations at individual steps in such processes need only be small to create large differences in risk assessment outcomes. The unavoidable room for subjectivity explains not only why risk assessment guidelines are an imperfect means of achieving standardisation; an issue that, in view of the perceived relevance of guidance documents for enhancing consistency in these areas, reduces their usefulness as a compliance instrument. ${ }^{199}$ It also explains why cross-border cooperation amongst market surveillance authorities has focused on achieving consensus in risk assessment processes in certain product categories, as Chapter 6 on transnational networks demonstrates. ${ }^{200}$

Objectification is also difficult in the implementation of SAFA inspections. However, the probability of two inspectors arriving at the same risk assessment seems higher in this area than in the areas of product safety, since the SAFA guidance materials cover a much greater number of scenarios than the RAPEX guidelines. Whereas the latter include exemplary risk assessments for a few consumer products only, the SAFA guidance materials include more than three hundred pre-described findings (PDFs) that cover approximately $80 \%$ of the defects that SAFA inspectors can possibly detect. Of course, the establishment of PDFs in the field of product safety is not possible, due to persistent divergent opinions about what is and is not safe, the ever-changing market in consumer

\footnotetext{
${ }^{197}$ See Section 3.1. above. Note that this does not subtract from the possibility that leaders may - by virtue of their being leaders - impose their own model on other member states; see further Chapter 6 on transnational networks, Section 3.2.1.

${ }^{198}$ E.g. interviews PT4; PT6; PL3; NL5; NL11.

${ }^{199}$ Recall, however, that the SAFA guidance materials and the RAPEX guidelines are perceived as useful for supporting the application of the relevant directives; see Section 3.1 of this chapter.

${ }^{200}$ See Chapter 6 on transnational networks, Section 3.2.4.
} 
products, and the sheer number of products traded in the EU. Guidance may be flexible, but there are limits regarding the extent to which it can respond to quickly changing situations. ${ }^{201}$

The case studies included here suggest that the quality of guidance is assured best in highly technical areas featuring a manageable number of decision-making scenarios. This is the case, since when deliberations take on a political character, the resulting guidelines are bound to be biased and suboptimal for use by street-level actors. Moreover, while provisions in domains that include a limited number of scenarios may be captured in guidelines, this is impossible for rules in areas that encompass uncountable decision-making instances. While guidance in such areas may be useful, a degree of subjectivity and a lack of clarity are bound to linger.

\subsection{The (legal) effect of post-legislative guidance}

While the quality of guidance appears to constitute an important determinant for the usefulness of guidance for national officials across the board, perceptions of the importance of other factors appear to diverge across countries and across policy domains. One of these factors concerns the legal effect of guidance, particularly the extent to which guidance should be 'more binding'. In order to describe the context, the current section discusses officials' perceptions of the guidance materials' status, and the effect of such perceptions on the use and usefulness of such guidance in practice. The subsequent section takes a closer look at the desirability of 'more binding' guidance.

\subsubsection{The BREF guidance documents}

The status of guidance documents seems to be the subject of discussion most explicitly in the area of integrated pollution prevention and control. This is the case because of the prominence accorded to the BREF guidance documents by the European Commission, and the divergence in the use of the BREFs in environmental licensing practices across member states. The three countries included in this study exemplify some of these divergences.

The position of the BREF guidance documents in the national implementation context seems to be strongest in the Netherlands. In line with the provisions outlined in the IPPC Directive, Dutch legislation stipulates that authorities need to take the BREFs into account in the determination of the best available techniques for industrial installations covered by the IPPC Directive. ${ }^{202}$ While legislation provides officials with a margin

\footnotetext{
${ }^{201}$ What may help is the circulation of test reports drawn up by market surveillance authorities across member states. In fact, this is something that ICSMS, the Commission's internet-supported information and communication system for the pan-European market surveillance, is to provide a platform for.

${ }^{202}$ Besluit omgevingsrecht, Besluit van 25 maart 2010, houdende regels ter uitvoering van de Wet algemene bepalingen omgevingsrecht [2010] Stb. 143, Article 5(4), sub 2. This article states that 'rekening gehouden moet worden met' the BREF documents. The BREFs (and the other information documents that must be
} 
of discretion as to the conclusions attached to this exercise, jurisprudence of the Dutch Council of State endows the BREFs with a rather concrete legal meaning. ${ }^{203}$ The Council of State has judged that deviation from the BREFs is possible only if motivated adequately. ${ }^{204}$ The Council has also ruled that when the requirements outlined in the BREFs are met, compliance with BAT is assumed. ${ }^{205}$ Moreover, if techniques are not listed in the BREF documents, only those techniques that facilitate the achievement of a similar or further reduction of emission levels are permitted. ${ }^{206}$ And, where BREFs are clearly out-dated by the time of permitting an installation, a draft BREF should be used as an indication of whether or not techniques are BAT. ${ }^{207}$

Due to the strict judicial interpretation of the status of the BREFs, national authorities attach great importance to the BREFs in the determination of BAT. Dutch officials indicate that, regarding the determination of BAT in specific cases, they first examine the relevant (draft) BREFs in combination with the relevant national BAT documents. ${ }^{208}$ Interviewees tend to denote the Netherlands as the 'blue-eyed boy' of the EU in this regard; a qualification that may be illustrated by the following quote:

In the Netherlands, because of jurisprudence, the BREFs have a much more important status than in other member states. Therefore, the impact of the BREFs is much bigger than elsewhere. We may only deviate from the BREFs if we motivate this adequately. In other countries, people just read the BREFs and they may say: 'this is not so good, I know a better solution than what the BREF says'. ${ }^{209}$

The notion that the BREFs are basically binding and allow for deviation only if adequately motivated is in line with the limited binding effect that the BREFs may be

\footnotetext{
taken into account in the determination of BAT) are listed in Ministeriële Regeling Omgevingsrecht, Annex I, Table 1 and II.

${ }^{203}$ E.g. RvS, 26 April 2006, ECLI:NL:RVS:2006:AW3976; 25 January 2006, ECLI:NL:RVS:2006:AV0295; 22 April 2009, ECLI:NL:RVS:2009:BI1839; 22 July 2009, ECLI:NL:RVS:2009:BJ3426; 16 March 2011, ECLI:NL:RVS:2011:BP7775; 5 October 2011, ECLI:NL:RVS:2011:BT6639. But according to Borgers, the concrete meaning of the BREFs needs to be nuanced: when it comes to deciding on a permit, case-specific conditions also play a role; BREFs provide a degree of discretion as they may offer several potential BATs and a range of emission limit values; and when adequately motivated, deviation from BREFs is possible; see Borgers, 2007: 36-41.

${ }^{204}$ For an overview, see Van den Broek, 2007.

${ }^{205}$ E.g. RvS, 14 November 2006, no. 200608547/1; 4 April 2007, ECLI:NL:RVS:2007:BA2227; 16 May 2007, ECLI:NL:RVS:2007:BA5207; 21 December 2007, ECLI:NL:RVS:2007:BC1397; 21 December 2007, ECLI:NL:RVS:2007:BC1400; 22 July 2009, ECLI:NL:RVS:2009:BJ3426; 7 April 2010, ECLI:NL:RVS:2010:BM0215; 7 July 2010, ECLI:NL:RVS:2010:BN0430.

${ }^{206}$ RvS 23 February 2005, ECLI:NL:RVS:2005:AS7235; 17 February 2010, ECLI:NL:RVS:2010:BL4140.

${ }^{207}$ E.g. RvS, 26 April 2006, ECLI:NL:RVS:2006:AW3976; 5 January 2007, ECLI:NL:RVS:2007:AZ5854.

${ }^{208}$ All interviews with Dutch officials.

${ }^{209}$ Interview NL22. Despite this positive self-evaluation, reports commissioned by the administration show that the concrete status of the BREFs in the Dutch application practice has not always translated into compliance with the requirements outlined therein. See e.g. VROM Inspectie, 2011.
} 
thought to be endowed with. ${ }^{210}$ The idea that Dutch case law makes it excessively difficult for authorities not to comply with the BREFs - deviation is possible only if they can prove that application of a technique that is not mentioned in the relevant BREF is equally effective for achieving the objective prescribed by the IPPC Directive $-{ }^{211}$ however, seems to narrow the margin of discretion for permit writers a lot. Note that this is the case in particular if one considers the wording in the IPPC Directive and in the BREFs, according to which the BREFs constitute a help to member states in the efficient implementation of the directive; ${ }^{212}$ this wording suggests that they are not meant to limit officials in the exercise of their job. ${ }^{213}$

The meaning that the BREFs are endowed with seems to be different in Portugal and Poland. Portuguese implementation legislation refers to the BREFs as one of the information sources that should be taken into account in the determination of BAT. ${ }^{214}$ Legislation also states that the environmental permit must be rejected when an installation's operating conditions do not comply with BAT, particularly when the installation does not attain emission limit values within the range associated with BAT (BAT-ELVs), as outlined in the BREFs. ${ }^{215}$ In its reply to a Commission questionnaire, the Portuguese Environment Agency (APA) confirms that "Portugal considers application of the BREFs formally adopted as at the date of the permit to be mandatory" ${ }^{216}$ Interviewees, however, indicate that the BREFs are viewed as "something that we want to achieve as binding", and that the BREFs are not strictly binding. ${ }^{217}$ Supporting these latter perceptions is the fact that Portuguese officials do have room to accommodate what they call "the really problematic cases". ${ }^{218}$ This approach seems to leave room for a greater degree of leniency on the part of permit writers than the approach taken in the Netherlands. Since

\footnotetext{
${ }^{210}$ See Section 2.2 .1 of the current chapter.

${ }^{211}$ RvS 23 February 2005, ECLI:NL:RVS:2005:AS7235; 17 February 2010, ECLI:NL:RVS:2010:BL4140.

${ }^{212}$ Directive 2008/1/EC, recital 27; Directive 96/69/EC, recital 25; emphasis added. See also the wording in the BREFs (e.g. BREF on the intensive rearing of poultry and pigs (version of 2003), p. 274). See also case 473/07 Association nationale pour la protection des eaux et rivières - TOS, Association OABA v. Ministère de l'écologie, du développement et de l'aménagement durables [2009] ECR I-00319, para. 30.

${ }^{213}$ According to Oosterhuis et al., it is questionable whether Dutch legislation gives sufficient consideration to the other factors - next to BAT, as outlined in the BREFs - that permit writers do, according to the IPPC Directive, need to take into consideration in environmental licensing processes. Also note that the BREFs do not always include a balanced approach to the environmental aspects that need to be considered in licensing processes; the result is that using the BREFs does not guarantee that all aspects are taken into account in a complete and balanced manner. See Oosterhuis et al., 2007: 71, 77.

${ }^{214}$ Decreto-Lei no 173/2008 de 26 de Agosto [2008] DR 1. a série, No 164/5967, Art. 7, 18(1).

${ }^{215}$ Ibid., Art. 16(6)(e).

${ }^{216}$ European Environment Agency, 'Reply to the second questionnaire on the implementation of Directive 96/61/EC concerning integrated pollution prevention and control (IPPC), reference period 2003-2005' $<\mathrm{http} / / /$ forum.eionet.europa.eu/x_reporting-guidelines/library/ippc $>$, p. 15.

${ }^{217}$ Interview PT9.

${ }^{218}$ Ibid. Such deviation is possible where motivated adequately, as stated previously.
} 
national case law on the use of BREFs in Portugal is absent, the validity of these perceptions has not been confirmed in court.

In Poland the interpretation of the BREFs seems to be less committal than in the Netherlands and Portugal. Similar to Dutch and Portuguese legislation, the relevant Polish implementing act stipulates that the BREFs must be considered in the determination of BAT. ${ }^{219}$ And, similar to Dutch and Portuguese permit writers, Polish permit writers also refer to the BREFs - in combination with national regulations and national guidance - as important, and as the basis for the determination of BAT. ${ }^{220}$ However, unlike Dutch and Portuguese legislation, the relevant Polish act does not assign special importance to the BREFs compared to other aspects that must be considered in the determination of BAT. Rather than treating the BREFs as sources that outline unequivocal recommendations of solutions to apply or standards to comply with, Polish legislation seems to consider the BREFs exclusively as points of reference. ${ }^{221}$

In contrast to Portugal, jurisprudence on the status of the BREFs does exist in Poland; although in contrast to the Netherlands, the BREFs do not have a pivotal position in such jurisprudence. An analysis of Polish case law on the application of the IPPC Directive, which is presented in detail in Chapter 8 on case law, suggests that unlike Dutch judges, Polish judges do not examine the contents of individual BREF documents or verify whether permit requirements are set within the scope of the requirements outlined in the BREFs. ${ }^{222}$ When regional courts refer to the guidance documents, these references are usually formalistic; in most cases the court does not go beyond stating that the BREFs need to be taken into account. ${ }^{223}$ The unbinding nature of the BREFs is confirmed by the Polish Supreme Administrative Court (SAC), which has noted that the BREFs "give opinions" on BAT, and that "these studies are not official", and "not binding" to the administration of the member states. ${ }^{224}$ In view of this case law, the relatively loose attitude of Polish officials with regards to the BREFs seems understandable. ${ }^{225}$

\footnotetext{
${ }^{219}$ Ustawa z dnia 27 kwietnia 2001 r. Prawo ochrony środowiska [Environmental Protection Act], Art. 207(1), sub 6.

${ }^{220}$ Interviews PL11, PL12.

${ }^{221}$ Entec, 2010: 391; EU Forum of Judges for the Environment (2009), 'Questionnaire on the IPPC Directive for the annual conference in Stockholm 2009 [country report for Poland]', $<$ http://www.eufje.org/index.php/en/conferences/stockholm-2009>.

${ }^{222}$ Note that CJEU case law on this issue does not exist; see Chapter 8 on case law, Section 3.2.2.A. Had this been the case, this might have been different.

${ }^{223}$ E.g. cases IV SA/Wa 2324/12, judgement of 6 February 2013; IV SA/Wa 1650/11, judgement of 23 January 2012; IV SA/Wa 889/09, judgement of 12 January 2010; II SA/Sz 816/09, judgement of 4 November 2009; IV SA/Wa 1757/11, judgement of 12 January 2012; IV SA/Wa 771/13, judgement of 5 July 2013; IV SA/Wa 231/08, judgement of 9 May 2008.

${ }^{224}$ Case OSK 874/10, judgement of 15 May 2011.

${ }^{225}$ None of the Polish officials interviewed for this study refer to the BREFs as binding; rather, they emphasise the idea that the BREFs are non-binding documents.
} 
In view of the cross-country variations in perceptions of the status of the BREF documents and the desire to limit imbalances in the Union regarding the level of industrial emissions, calls to make guidance on the best available techniques 'more binding' have not come as a surprise. These calls have been answered by the Industrial Emissions Directive, which states that BAT conclusions, which outline the conclusions on the best available techniques and which are to be adopted as Commission implementing decisions, "shall be the reference for setting the permit conditions for installations covered by the [d]irective." ${ }^{226}$ Deviation from the ELVs outlined in these conclusions is allowed in limited circumstances only. ${ }^{27}$ This wording constitutes a great difference with that used in the IPPC Directive, in the BREFs, and in CJEU case law, which, as we have seen above, referred to the BREFs as a 'help' to authorities in the implementation process. ${ }^{228}$ Interviews suggest that the upgrade of the BREFs by the IED has brought about a (more or less) watershed change in officials' perceptions of the legal effect of guidance on BAT; all officials consider the BAT conclusions legally binding. ${ }^{229}$

\subsubsection{The SAFA guidance materials}

If questions regarding the legally binding nature of the BREFs appear to be answered differently across the three countries subject to this study, the question of whether or not the SAFA guidance materials are binding appears to be answered with a clear 'no' across the board. ${ }^{230}$ In all three national aviation authorities included in this study, the GMs are perceived as outlining working procedures only; national legislation does not refer to them as binding. National case law on the status of the GMs is absent. ${ }^{231}$ The

\footnotetext{
${ }^{226}$ Directive 2010/75/EU on industrial emissions, Art. 14(3); emphasis added.

${ }^{227}$ Ibid., Art. 15(4).

${ }^{228}$ Directive 2008/1/EC, recital 27; Directive 96/69/EC, recital 25; emphasis added. See also the wording in the BREFs themselves (e.g. BREF on the intensive rearing of poultry and pigs (version of 2003), p. 274) and case 473/07 Association nationale pour la protection des eaux et rivières - TOS, Association OABA v. Ministère de l'écologie, du développement et de l'aménagement durables [2009] ECR I-00319, para. 30.

${ }^{229}$ More so for Polish officials, and less so for Dutch officials, for the reasons specified above; see all interviews with officials involved in the implementation of the IPPC Directive. Note that if we follow our understanding of the legal effect of the BREFs outlined in Section 2.2.1, this amendment does not seem to represent such a significant change in comparison to the situation that existed before entry into force of the IED. Granted, the BAT conclusions are given more standing than the BREFs by virtue of their adoption as Commission decisions and by virtue of the fact that they "shall" be the reference point in environmental licensing processes. Moreover, the possibilities for deviation from the BAT conclusions are limited and are spelled out specifically. However, if we agree that the BREFs may be considered to have indirect legal effect, the fact that the BAT conclusions are - as the BREFs under the IPPC Directive - in principle to be complied with does not seem to make the BAT conclusions the watershed change that they are sometimes considered to be.

${ }^{230}$ Interviews with all EU and national SAFA officials.

${ }^{231}$ The two Dutch cases on the implementation of the SAFA Directive are irrelevant as far as the status of the guidance materials is concerned. For a discussion of these two cases, see Chapter 8 on case law, Section 3.1.2.3.
} 
perception amongst interviewees that the GMs lack legal effects is consistent with our consideration that the guidance materials have de facto effect at best. ${ }^{232}$

Interviews suggest that this de facto effect is enormous. ${ }^{233}$ Dutch officials indicate that, although deviation from the guidance materials is possible, "you need to stick to the GMs, since they have an enormous validity". ${ }^{234}$ This is the case because the guidelines are seen as greatly important for standardising implementation practices across member states; this has previously been referred to as essential for each and every authority in view of the perceived levels of interdependence amongst authorities in the area of air safety. ${ }^{235}$ It is particularly the pre-described findings that are referred to as important in this regard; because they list the officially applicable legal text, the standard description of findings provided by ICAO, and the categorisation of the findings, the PDFs are thought to constitute an especially powerful tool for the standardisation of findings across the board. ${ }^{236}$ The following quotation from an interview with the Portuguese SAFA national coordinator, not only confirms this idea, it underlines a second benefit of the guidelines; namely, their practical usefulness for supporting SAFA inspectors in their work:

I can spend half an hour arguing against the harmonised and eurocratic way of doing things, but it's a total waste of time. In my opinion, the practical way of doing that and of assuring that the same criteria are applied all over the participating states is by having this approach: using always, if possible, the PDFs. It's so practical, since if there is an issue that can be considered to be a finding, we apply the standard, and the technical requirement and even the categorisation of the finding immediately pop up. And what I really like about this system is that it is not mandatory, there is always room for UDFs [user-defined findings]. ${ }^{237}$

This quotation underlines the great de facto effect that the SAFA guidance materials appear to have; it also suggests that the idea of guidance as 'binding' may cause resistance from officials to duly use such guidance in the implementation practice. Bindingness is associated with rigidity ${ }^{238}$ and an unwanted harmonizing drift on the part of the European bureaucracy. ${ }^{239}$ It seems that the allowance of a certain margin of discre-

\footnotetext{
${ }^{232}$ See Section 2.3.1.

${ }^{233}$ All interviews with national SAFA officials.

${ }^{234}$ Interview NL29.

${ }^{235}$ See Section 3.1 above.

${ }^{236}$ Interview NL29; PT17.

${ }^{237}$ Interview PT17.

${ }^{238}$ Interview NL29; PT17; PT15; PL15.

${ }^{239}$ Interview PT17.
} 
tion to officials may help these officials overcome initial resistance to the use of guidance documents on the ground. ${ }^{240}$

The latter aspect is something that EASA has been aware of as well. An official from EASA indicates that while the guidance materials are "pretty binding" and SAFA inspectors "cannot deviate too much", ${ }^{241}$ guidance should be "guiding rather than complicating", and bindingness is certainly not considered helpful in this regard. ${ }^{242}$ In line with this perception, cooperation with member states rather than top-down imposition is considered the appropriate method; the same EASA official clarifies that the agency wants "to sell the guidance to the member states rather than force it down their throat". ${ }^{243}$ The desire of EASA to be more than a 'policeman' reminds us of the role that EASA aims to play in the context of standardisation inspections, which are examined in Chapter 4 on monitoring and sanctions. ${ }^{244}$ It is also in the latter context that acting as a policeman only has been seen as undesirable, since it is considered counterproductive if standardisation inspections are to be truly effective mechanisms for creating positive domestic change.

National officials do not necessarily describe their relations with EASA in terms of cooperation. For example, Polish officials claim to use the GMs not only because the guidelines are helpful on the ground, but also because EASA insists that they use them. ${ }^{245}$ Moreover, the idea that cooperation with the member states should be sought has not always been popular; Section 3.2.1 demonstrates that the development of the first guidance materials was an ad hoc affair without serious consultation of SAFA states. The result was the adoption of a top-down, non-negotiated document, which has been perceived as a "dead, binding, administrative, bureaucratic thing". ${ }^{246}$ The move of EASA towards more inclusive deliberation on the guidance materials highlights the idea that participation is important to ensure the quality of guidelines and their acceptability as a potentially useful support tool.

Overall, the case of air safety suggests that guidance does not have to be binding in order for it to be used across member states. Moreover, it suggests that a perception of guidance as binding may have the opposite effect of creating an aversion to the use of these guidelines amongst officials. Guidelines should essentially be no-strings-attached mechanisms for officials to accept them as a compliance instrument. This conclusion sets the area of air safety apart from the domain of integrated pollution prevention and control, in which a call for binding guidance was made. It seems that this difference may be explained, in part, by the previously referred to divergent dynamics underlying com-

\footnotetext{
${ }^{240}$ Interviews PT17; PT15; PL15; NL29.

${ }^{241}$ Interview EASA3.

242 Ibid.

${ }^{243}$ Ibid.

${ }^{244}$ See Chapter 4 on monitoring and sanctions, Section 3.1.

${ }^{245}$ Interview PL15.

${ }^{246}$ Interview PT17.
} 
pliance behaviour in both areas. In the area of air safety, voluntary compliance driven by a shared appreciation of the usefulness of guidance materials for achieving standardisation in situations of interdependence seems to be the rule. In contrast, in the area of integrated pollution and control, compliance behaviour seems directed, at least in part, by one's own interests, making compliance with the BREFs quite unpredictable. Thus, the differences between both areas seem explicable.

\subsubsection{The GPS Directive}

Views on the status of the RAPEX guidelines have much in common with perceptions of the nature of the SAFA guidance materials. Similar to the SAFA guidance materials, the RAPEX guidelines are not perceived as binding; ${ }^{247}$ more precisely, they are considered "just one model on how to do risk assessment". ${ }^{248}$ Such perceptions are not surprising in view of the national legislative frameworks of the three countries included in this study, which do not endow the guidelines with a legal effect, and in view of the absence of national case law on the status of the guidelines in these same countries. ${ }^{249}$ These perceptions are not, however, in line with the indirect legal effects that the guidelines seem to have.

At this point one may recall that establishing the legal effect of the RAPEX guidelines is not a clear-cut exercise, since the guidelines are clothed in hard law, which gives them inherent legally binding force when judged by their form. However, since substance takes precedence over form - and since the hallmark of guidelines is their softlaw character - inherent legally binding force is excluded. The prescription in the GPS Directive for the Commission to adopt guidelines and the obligation for member states to take these guidelines into account in the implementation practice, do seem to suggest that the guidelines have an indirect legal effect. If this is true, then the apparent widespread perceptions that the guidelines solely have a practical effect seems misguided. It would be interesting to verify whether or not such perceptions are in line with national court rulings - if only case law on the interpretation of the RAPEX guidelines existed.

If it is not a perception of the RAPEX guidelines as binding that causes officials to use them and perceive them as useful in risk assessment and risk management processes, then there must be other factors that explain these perceptions. Section 3.1 above suggests that the existence of guidelines is seen as useful for harmonizing implementation practices in situations of interdependence. The notions that the guidelines are " $\mathrm{a}$ useful tool to understand what the Commission wants", ${ }^{250}$ and a helpful instrument for

\footnotetext{
${ }^{247}$ Interview PT7; PL3; NL5.

${ }^{248}$ Interview NL5.

${ }^{249}$ For a discussion of national case law on the implementation of the GPS Directive, see Chapter 8 on case law, Section 3.1.2.1.

${ }^{250}$ Interview PT2.
} 
carrying out risk assessment procedures, ${ }^{251}$ appear to add to the usefulness of the RAPEX guidelines as well.

In brief, whether or not the RAPEX guidelines are binding does not seem to be at the forefront of officials' minds; if anything, the guidelines are considered another helpful tool in the market surveillance process. The idea that the guidelines are not exactly watertight may explain this particular stance, at least in part. Unlike the SAFA guidance materials, the RAPEX guidelines allow for subjectivity, which not only makes for inadvertent divergences, but also invites purposeful manipulation on the part of risk assessment officers. This noted leeway also makes compliance difficult to verify. As such, the room to manoeuvre for member states makes it difficult, not only for national officials to consider them binding, but also for the Commission to communicate them as such.

\subsection{Requests for binding guidance: a question of culture?}

The preceding section suggests that perceptions on the (legal) effects of guidance documents may vary greatly across countries, as is the case for the BREFs, and that these perceptions may not correspond to the effect that these documents seem to be endowed with, as is the case for both the RAPEX guidelines and the BREFs. ${ }^{252}$ The preceding paragraphs also suggest that perceptions of guidance as nonbinding may be beneficial in terms of their use by national officials in the implementation practice, as the case of the SAFA guidance materials demonstrates; a suggestion that clearly erodes the veracity of the idea that bindingness necessarily equals compliance. However, a shift towards 'more binding guidance' is what has occurred with guidance on BAT, as outlined above. This section discusses officials' perceptions regarding this shift in the area of IPPC, and it examines (the absence of) calls for binding guidance in the areas of GPS and SAFA.

\subsubsection{Guidance in the area of IPPC}

Although the introduction of 'binding' BAT conclusions is a fait accompli, the debate about the desirability of this development does not seem to have decreased. Interviews suggest that perceptions of this issue have continued to diverge. While all officials see the benefits of binding guidelines on the application of the best available techniques in permits for IPPC installations (described further below), there has also been criticism. This criticism relates to the quality of the BREFs on which the BAT conclusions are based; Section 3.2.2 above suggests that this quality is not always impressive. While unpractical, to put it euphemistically, in the case of 'unbinding' guidance, such quality issues are likely to become a problem if guidance must be complied with. This is the case not only for member states - which are likely to face problems in the dutiful implemen-

\footnotetext{
${ }^{251}$ Interview PL3.

${ }^{252}$ Note that the reference points in this regard are the considerations regarding the effect of these guidelines, which are outlined in Section 2 of this chapter.
} 
tation of guidelines that may confuse rather than clarify - but also for the Commission, which may have trouble with the enforcement of rules that leave room for discussion on what constitutes compliance in specific situations.

Furthermore, concerns also relate to the infrequent updating of the BREFs, which must be explained by the excessive duration of the drafting process. This duration is explained in part, by the manifold tugs of war amongst stakeholders involved in the drafting process. The problem with the duration of the drafting process is that the time period between two consecutive guidance documents may be more than a decade; this questions the extent to which the BREFs provide guidance about the best available techniques. ${ }^{253}$ Another problem is that the number of sectors in which BAT conclusions do not yet exist is considerable; more than three years after the transposition deadline of the Industrial Emissions Directive, only seven out of the over thirty BAT conclusions that need to be adopted have been adopted. ${ }^{254}$ Therefore, divergences in permitting outcomes are likely to persist for some time. It is likely that the drafting process under the IED will incur further delays; in view of the idea that the 'new' BREFs produce guidance that unmistakably qualifies as binding, stakeholders may be more motivated to defend their interests than in the previous situation, in which it was easier to maintain that the BREFs provided helpful tools rather than norms to be complied with.

Finally, officials refer to the binding nature of the BAT conclusions as problematic since it removes the room that authorities used to accommodate for problematic cases. ${ }^{255}$ It should be noted that this complaint was not expressed by Dutch officials who, as stated previously, already had little room to manoeuvre in the previously applicable legal framework.

In contrast to these critical considerations are perspectives on the benefits of binding guidelines for the application of the best available techniques. Some officials claim to be content with the BAT conclusions, since, despite the delays in the adoption of the BAT conclusions that are observed, they are thought to increase the probability of the underlying legislative requirements being applied consistently across member states. This motivation seems to be particularly relevant for officials who perceive themselves as faithful compliers and of others as having a casual attitude towards compliance with the BREFs. In the context of this study, the former are typically Dutch and Portuguese officials. ${ }^{256}$

What matters to Polish officials is the idea that the bindingness of the BAT conclusions is likely to ease discussions on permit requirements with economic operators in the environmental licensing process. More concretely, Polish interviewees indicate that

\footnotetext{
${ }^{253}$ Interview NL25.

${ }^{254}$ Number for February 2015. See on European IPPC Bureau, 'References', <http://eippcb.jrc.ec. europa.eu/reference/>.

${ }^{255}$ Interview PT9; interview PL11.

${ }^{256}$ Interview PT9; NL21.
} 
the nonbinding nature of the BREFs gives them little persuasive power in discussions with economic operators that may seek to exploit loopholes in legislation. ${ }^{257}$ The limited margin of discretion for authorities under the IED makes it easier for officials to justify decisions and to 'stand strong' in relation to operators, as the following quotation illustrates:

Now [prior to application of the BAT conclusions] you've got more flexibility. You must always say: 'of course this is in the BREF, but I took into account regional circumstances', whatever those regional circumstances will be. This will be much more difficult when the BAT conclusions need to be applied. In fact, I would say that it would be easier for permit writers to issue permits, because they don't have a lot of thinking. They just need to use the BAT conclusions. Now you can also prove as a company that maybe it is not in the BREF, but it is in my local BREF. With the BAT conclusions, this will be much more difficult. So it will be easier for authorities, but more difficult for companies. ${ }^{258}$

Dutch and Portuguese interviewees also give the impression that relations with companies are not always easy-going. In fact, interviews suggest that permitting processes are often a negotiation game between authorities and companies. ${ }^{259}$ Most companies are mainly preoccupied with cost implications, ${ }^{260}$ and aim to compel authorities into setting more lenient permit conditions. ${ }^{261}$ Portuguese permit writers indicate that since they had already taken a tough position on the applicability of the BREFs, the BAT conclusions are useful because they justify this tough stance in relation to companies; according to interviewees, "what BAT conclusions give us is saying, towards companies: you see, our interpretation was correct". ${ }^{262}$ Dutch officials indicate that even though the BREFs were rather binding already, the BAT conclusions are "better, since they are more directing" ${ }^{263}$ The BAT conclusions are useful for the permitting authorities, they say, since there is less room for discussion for environmental organisations and economic operators. ${ }^{264}$ The notion that environmental NGOs are explicitly referred to in

\footnotetext{
${ }^{257}$ Interview PL9, PL11, PL12. Reports on the implementation of the IPPC Directive confirm that less stringent requirements than the BAT-ELV ranges are not always justified by authorities; that where operators need to propose ELVs in permit applications, deviations from the BAT-ELVs are usually implemented in the permits; and that factors that are not to be taken into account in the determination of BAT, but that benefit economic operators, may in fact influence permit conditions. See e.g. Entec, 2010: 453, 464-465. Poland is certainly not the only country where these instances are found.

${ }^{258}$ Interview PL12; similar PL11.

${ }^{259}$ Interview NL21, NL23, similar NL25, NL24.

${ }^{260}$ Interview NL18; NL21.

${ }^{261}$ Interview NL23.

${ }^{262}$ Interview PT9.

${ }^{263}$ Interview NL24.

${ }^{264}$ Interview NL24.
} 
this regard relates to the idea that, in contrast to what is the case for Poland and Portugal, Dutch NGOs play an active role as watchdogs of the administration in the permitting process, as Chapter 7 on civil society demonstrates.

To the discussion in the above paragraphs, one may add that officials see benefits not only to binding guidance, but also to more guidance. This is the case for all officials, regardless of the 'fit' of previously existing national legislation with the requirements outlined in the IPPC Directive. ${ }^{265}$ The following quotation from an interview with Dutch officials involved in this area suggests that relations with economic operators surface as an important reference point here as well:

Questions about how to solve issues related to the determination of BAT keep coming up. There should be more guidelines, so that we can refer to what the Commission says. This also makes it easier to justify choices in relation to companies: this is what the Commission says, so that is why we have to prescribe these requirements. ${ }^{266}$

Both Portuguese and Polish officials join Dutch officials in their wish for more guidance. Interviewees from the Portuguese Environment Agency, for their part, underline that the Commission could be of greater help by providing more guidance, and by doing so in a timely manner. ${ }^{267}$ Polish officials reproach the Commissions' perceived reluctance to provide guidance related to the implementation of the IED. According to a ministerial official:

The Commission promised a lot of information connected with the implementation of the IED, and we are still waiting for guidance on, for example, baseline reports. This kind of information is very useful for us, because sometimes the legal requirements are not clear enough. ${ }^{268}$

In some cases, the lack of guidance provided by the Commission and the delays associated with its adoption may, according to some national officials, be explained by a lack

\footnotetext{
${ }^{265}$ Dutch legislation in the spirit of IPPC dates back to 1993 and existed prior to entry into force of the IPPC Directive. See Entec, 2007: 69. In Portugal, the introduction of the IPPC Directive marked an important change to the previously-existing licensing regime, which was based on several permits, non-integrated, and not based on BAT. See Entec, 2007: 71. The concept of IPPC was introduced into Polish law following the adoption of European environmental legislation. A system of permits had been in place since 1980, but this system encompassed a single-medium rather than an integrated approach. Prior to the transposition of the IPPC Directive, the concept of the 'best available techniques' was unknown to the Polish permitting system. See Entec, 2007: 70.

${ }^{266}$ Interview NL16.

${ }^{267}$ Interview PT9.

${ }^{268}$ Interview PL9; also NL 22.
} 
of resources within the relevant Commission department. ${ }^{269}$ Other officials argue that Commission requests for input from the member states are to blame for the duration of the drafting process. ${ }^{270}$ Without making a case for more exclusive or more limited consultation procedures, it should be noted that these remarks open the door to discussion about the extent to which the principles of democratic legitimacy and effectiveness - in terms of speedy problem resolution - may be successfully reconciled.

\subsubsection{Guidance in the area of GPS}

The question of whether guidance should or should not be binding may seem peculiar with respect to the GPS Directive. This is the case for two reasons: formally speaking, the RAPEX guidelines already have the status of law, and materially speaking they do seem to exercise indirect legal effects, ${ }^{271}$ which is 'as far as one can get' when it comes to 'making soft-law guidance binding'. However, since officials' views converge on the idea that the RAPEX guidelines exercise a de facto effect at best, calls for binding guidance are not odd.

The perception that binding guidance may ease relations between authorities and economic operators seems to be, similar to the domain of integrated pollution prevention and control, an important motivation in this regard. In contrast to the area of IPPC, in the area of product safety only Polish officials express these perceptions. The following quotation from an interview with an official from the Polish Office for Competition and Consumer Protection (UOKiK), suggests the importance of cultural determinants shaping state-society relations in this context, and intra-organisational relations within the state bureaucracy:

We need formal guidance in relation to companies. If we don't have this interpretation than we have to rely on our own interpretation, which might be too vague, which might not be enough for convincing the market operator. Whenever there is formal guidance from the Commission, from the author of the law, that will end any discussion. I think the trade inspectorates are quite strict. In the sense that they want interpretation and they want to follow this interpretation very strictly, maybe for precautionary reasons. Maybe in some cases they are not totally safe of their interpretation and they want an additional, superior authority that says: 'yes, you are right'. So I think they want formal guidance for additional proving that they are right, and that goes into two directions. There is whether they are right vis-à-vis the market operator, and there is whether they are right vis-à-vis any audit from the supervisory office that says: 'what the hell are you doing here, this is illegal'. And they would say: 'oh, we

\footnotetext{
${ }^{269}$ Interview PT9.

${ }^{270}$ Interview NL22.

${ }^{271}$ For an elaboration, see Section 2.2.1.
} 
didn't know this, and we are sorry for that, but well we did what we wanted'. It is the fear of being punished. ${ }^{272}$

Polish trade inspectors do indicate that formal guidance is what they need most, and they look to UOKiK to provide them with that guidance. ${ }^{273} \mathrm{UOKiK}$ looks up to the European Commission, seemingly in vain, since the Commission is perceived as "not very eager" to provide formal interpretations of legislative requirements. In the words of one official: "it looks like the Commission serves mostly as a guardian of the treaties, and not as a guide of the treaties". ${ }^{274}$

In view of the indirect legal effect that the RAPEX guidelines may be considered to have, calls for binding guidance seem easily addressed; the Commission could simply make national competent authorities aware of the limited binding effect that the guidelines exercise. The Commission could also choose to emphasise the binding effect of the guidelines by stating more clearly, in the proposed Regulation on general consumer product safety, the obligation of member states to comply with the guidelines. However, while the proposal does refer to Commission guidelines on product safety assessment as one element to consider in assessments on the safety of products, ${ }^{275}$ the guidelines seem to have less weight in the proposal than in the GPS Directive. ${ }^{276}$ Moreover, while the GPS Directive refers to the necessity for member states to consider Commission guidelines on risk assessment in the market surveillance process in several places, ${ }^{277}$ comparable references are absent in the proposed regulation.

The perceived reluctance of the Commission to provide more guidance - and to insist on the RAPEX guidelines as having limited binding effect - might be explained, at least in part, by the impossibility of providing conclusive guidance on a topic as uncertain and complicated as product safety. For products that are not covered by harmonizing legislation, it may be difficult to draw the line between what is 'safe', and what is 'unsafe'. ${ }^{278}$ This explains why the RAPEX guidelines leave room for differences of opinions, why the Commission may not want to enforce compliance with the guidelines, and why it refrains from providing detailed guidance about when a risk is 'serious' and when it is 'acceptable'. Extended discussions in the GPSD committee testify to the difficulty of drawing a line that divides these notions. From a liability perspective, it may be better

\footnotetext{
${ }^{272}$ Interview PL2. For the impression that the trade inspectorates are very strict when it comes to the interpretation of the law, see also PL7.

${ }^{273}$ Interview PL3; PL4.

${ }^{274}$ Interview PL2. Similar NL8.

${ }^{275}$ See Commission, 'Proposal for a Regulation on consumer product safety and repealing Council Directive 87/357/EEC and Directive 2001/95/EC' (Product Safety Regulation), COM (2013) 78 final, Article 6(2), sub e.

${ }^{276}$ Compare Article 6(2) of COM (2013) 78 final, with Article 3(3) of Directive 2001/95/EC.

${ }^{277}$ See Section 2.1 of this chapter.

${ }^{278}$ See interview NL2.
} 
for the Commission not to draw that line, and to refrain from providing detailed guidance on this matter.

\subsubsection{Guidance in the area of SAFA}

The area of air safety seems to be the only domain in which calls for binding guidance are absent across the board. In view of the Polish insistence in the other two areas included in this study on the usefulness of binding guidance, it is particularly the Polish silence that seems surprising. However, Polish inspectors indicate that they use the SAFA guidance materials not only because they are useful in the implementation process, but also because EASA insists they use them. ${ }^{279}$ In other words, Polish inspectors consider the GMs binding despite the (mere) de facto effect that these guidelines are thought to have. The idea that Polish inspectors say that the GMs "are adequate to their needs" 280 seems partially explained by the fact that they are seen as binding.

Motivations for the use of the guidance materials are markedly different for Dutch and Portuguese officials. Section 3.3.2 above suggests that these officials use the GMs for several reasons, but not because they are thought to be binding. Moreover, these officials seem to harbour a degree of aversion to the idea of the GMs as binding. Note that Portuguese inspectors specifically, complain that the GMs provide excessive information and "too much and too rigid guidance". ${ }^{281}$ The observed divergence between Polish inspectors and Portuguese inspectors seems to support the idea that perceptions of the desirability of detailed and binding guidance are, in part, mediated by cultural predispositions.

\subsubsection{Binding guidance: a choice between the devil and the deep blue sea}

Together, the findings outlined in the preceding sections suggest that the introduction of binding guidance may imply a choice between the devil and the deep blue sea. This is the case, first, in view of the importance of cultural determinants as a factor that shapes authorities' perceptions of (the desirability of) binding guidance. The notion of culture, a rather abstract term when used alone, should be understood here to refer most notably to state-society relations and intra-organisational relations within the public administration. In view of the diversity within the EU in this regard, both across member states and across policy domains, it seems difficult for the European Commission to do it right with respect to the adoption of guidance that is intended to be equally useful for all.

This difficulty is also expressed in a second aspect that seems to bear some importance here: the idea that there are great advantages and serious disadvantages to both voluntary and mandatory compliance with guidance. On one hand, binding guidance

\footnotetext{
${ }^{279}$ Interview PL15.

${ }^{280}$ Ibid.

${ }^{281}$ Ibid.
} 
may elicit compliance on the part of authorities that would, without it, take a casual attitude towards the use of guidance in the implementation practice. An important precondition here is that authorities are aware that the relevant guidance documents are binding, which is by no means self-evident. Binding guidance may also help willing authorities to apply the underlying norms, by endowing them with a stronger position in relation to regulated actors who may seek to undermine the validity of guidance by reference to its soft-law nature. On the other hand, 'making guidance binding' may deprive it of one of the key strengths that it is associated with: flexibility and its capacity to adapt to quickly changing realities. If the goal of guidance is to effectively respond to such realities, the worst thing to do may be to make such guidance formally binding.

\section{Concluding remarks: how and when does post-legislative guidance work?}

If this chapter suggests anything, it is that post-legislative guidance constitutes one of the most useful compliance instruments; while almost all survey respondents agree, or strongly agree, that the guidance documents examined in this study are useful for supporting the application of the underlying legal provisions, this seems no different for the officials interviewed in this study. While the usefulness of guidance broadly lies in its ability to clarify legislative provisions, perceptions of how and when guidance is particularly useful for supporting the application of EU law seem to vary across countries and across policy domains. Table 15 shows the factors that this chapter suggests are relevant to determining the usefulness of guidance. These factors are recapped in more detail below.

Table 15 Conditions for post-legislative guidance to be a useful compliance instrument

There must be a point for officials to use guidance in the first place. This may be the case:

- in situations of perceived interdependence

- when the use of guidance is perceived as compulsory

- when guidance is considered helpful in the implementation process

Guidance must be qualitatively adequate. This is most likely when:

- the deliberation process has involved 'the right partners'

- the relevant policy domain is highly technical rather than highly politicised

- the characteristics of the policy issue itself allow for guidelines to be specific

Guidance is binding - or not. It is here where perceptions diverge. Bindingness may:

- create aversion amongst national officials

- be unattainable because of issue-specific characteristics

- be regarded as desirable; this is the case when:

- guidance is not complied with across the board, in particular in situations of interdependence

- state-society relations are strenuous

- strictly hierarchical intra-organisational relations within the state bureaucracy exist 
The current chapter suggests that the usefulness of 'having guidance' may be derived from several factors. Interdependence is one of these factors. Officials in the areas of product safety and air safety indicate that since authorities are interdependent in the implementation of EU law, consistent implementation practices across the board are important in order for each of these authorities to perform well. Guidelines are considered important tools for achieving such consistency, which means that the level playing field that they are intended to create is not only seen as a far-fetched ideal, but also as a necessity for individual authorities to conduct their work effectively. When feelings of interdependence are missing or weak - as is the case in the area of integrated pollution prevention and control - motivations for officials to use guidelines must come from somewhere else. A perception of guidance as binding and an appreciation of the usefulness of guidance in the implementation process seem to be critical in this regard.

This chapter suggests that the usefulness of specific guidance materials is greatly determined by the extent to which they are considered qualitatively adequate. Important in this regard is that the deliberation process leading up to the adoption of the guidance documents has been inclusive. The cases examined in this chapter suggest that such inclusiveness is not self-evident. Even when specific procedural rules for the consultation of interested parties exist - which is the case for all three directives included in this study - and when they are implemented, ensuing consultation processes may not permit sufficiently extensive consultation. This may be the case when consultation takes place in the context of comitology alone, which may not permit 'real' deliberation. Furthermore, when consultation opportunities are organised beyond or instead of discussions taking place in comitology committees - which is the case for all guidance materials discussed in this chapter - consultation opportunities may be organised hastily and interested parties may not receive sufficient time to provide feedback. Moreover, member state officials may, because of situations that are beyond their control, not always be able to participate in consultation rounds organised by the Commission or other bodies responsible for issuing the relevant guidance documents. Finally, the notion of interested parties may be too limited. If interpretative rules are to be useful to those whom they are intended for in the first place - that is, street-level implementation actors - these actors must be consulted in the process. When this does not occur, the implementability of guidelines is bound to have limitations. This latter notion echoes concerns about the existence of Chinese Walls in negotiations of EU legislation, which are known to limit the implementability of EU measures on the ground.

While consultation processes can, at least in part, be shaped to (try to) improve the quality of guidelines, this is not true for the degree of politicisation of a policy issue or the degree of specificity that guidelines may attain. These factors are important determinants for the quality of guidance, since they both affect the extent to which guidance may present detailed and objectified directions to street-level actors in the implementation process. When national interests and policy preferences overrule a shared desire for 
workable solutions, guidelines are bound to present diluted compromises that may not help anyone or eliminate confusion regarding the interpretation of norms. Where policy issues are hard to objectify for reasons of scientific uncertainty, guidelines are bound to permit subjectivity on the part of street-level actors and, thus, leave space for inconsistent implementation outcomes. The latter particularly seems problematic for national competent authorities in situations where achieving consistency is not only a lofty policy objective, but a practical necessity in view of the interdependence of authorities in the implementation of EU measures as well.

As important a determinant for the usefulness of guidance as quality, seems to be the (legal) effect that guidance is perceived to have; 'perceived', since the effect that guidance documents must be considered to have does not always correspond to officials' perceptions. Discrepancies between theory and reality are not problematic, if guidance is used faithfully across the board. This is not always the case, though, as the use of the BREFs in the area of integrated pollution prevention and control demonstrates. The erratic use of the BREFs across member states seems to be caused by the absence of a shared interest in dutiful implementation of the BREFs, and a lack of clarity regarding the status of the BREFs, which opens the door to purposeful defection. It is in view of this erratic implementation, which hinders the policy objectives of the IPPC Directive, that binding BAT conclusions were introduced. Developments in the area of IPPC suggest that endowing guidance with a binding effect may be imperative to ensure compliance in situations that lack a shared incentive to comply.

While it seems imperative for ensuring compliance in domains in which national interests are dominant, 'making guidance binding' may not be needed if a shared incentive to use guidance is present; in the context of this study, this is the case for the areas of product and air safety. It is at this point that the notion of interdependence becomes relevant again; officials perceive guidance as a useful tool, not only because it helps them understand legislative provisions, but also because guidance increases the consistency of application across member states and the effectiveness and efficiency of their own implementation performances. Note that 'making guidance binding' may not only be unnecessary; it may also be impossible, since practical problems may be encountered where conclusive guidance cannot be provided, because of the nature of the policy issue. The area of product safety provides an example of this. Such attempts may also be unwise when aversion to binding guidance exists, which seems to be the case particularly in the area of air safety. Were the Commission to explicitly endow guidance in the latter two domains with binding force, this could be met with a lack of understanding as to the reasonableness of such efforts, and perceived as an act of unnecessary - and unwanted intrusion on the part of the Commission.

Binding guidance could, in theory, be useful in all areas for easing relations between authorities and regulated actors. Whereas nonbinding guidance offers officials a weak reference point in relation to actors that may seek to challenge the authority of guidance 
as outlining norms to be complied with, binding guidance may arm these officials in discussions with such actors. The extent to which this argument appears important for officials seems to depend partly on cultural determinants that shape state-society relations within individual countries. Administrative culture may plead to have binding guidance as well; if this culture is strictly hierarchical, perceptions of binding guidance as desirable in view of possible punishment 'from above' may manifest. Such considerations will likely be different if intra-organisational relations are relatively horizontal.

These considerations further complicate the Commission's mission to do it right in the adoption of guidance: it is not just the aggregated compliance behaviour of member states and the specificities of individual policy domains that should be considered in decisions about whether or not to make guidance binding, but cultural idiosyncrasies as well. The outcomes of evaluations of what works to make guidance work well for individual member states may prove irreconcilable. To these considerations one should add that even when the introduction of binding guidance seems logical and desired, bindingness is likely to have consequences in terms of the capacity of guidance to guide. This is the case, first, since bindingness reduces the capability of guidelines to respond to a quickly changing reality; an important reason for the adoption of soft-law guidance in the first place. Second, if guidance documents are binding, they should be qualitatively adequate. This is not self-evident, as particularly the case of the BREFs demonstrates.

Overall, it seems that it may be difficult for guidance to meet the needs of all member states equally. If the diversity across member states is a valuable asset for the functioning of certain compliance instruments, amongst which are those under examination in the following chapter of this study, it is in relation to post-legislative guidance that it becomes potentially problematic. Note that this does not subtract from the fact that all officials refer to guidance as particularly useful in the implementation process. Moreover, if and when attempts to meet the conditions that this chapter suggests are important for guidance to be particularly helpful are made, guidance may be a very powerful instrument for supporting street-level actors in the implementation of EU law. 



\section{PART III}

\section{TRANSNATIONAL \\ COMPLIANCE INSTRUMENTS}





\section{Chapter 6}

\section{Transnational networks ${ }^{1}$}

${ }^{1}$ A short version of this chapter will be published as a book chapter; see Polak and Versluis, forthcoming. 


\section{Introduction}

Much has been written about transnational networks as governance instruments. This is not surprising; the ubiquitous networked character of public administration in this "new, networky world"2 is something that cannot be disregarded. Governance networks may broadly be conceptualised as structures of interdependence that involve horizontal cooperation of multiple, operationally autonomous actors pursuing common public goals. ${ }^{3}$ They are governed by reciprocal, preferential, and mutually supportive actions. ${ }^{4}$ The adjective 'transnational' implies that these networks constitute a vehicle for officials of national competent authorities to act directly with their counterparts in other member states.

The above conceptualisation sets networks apart from the two other primary modes of governance, states, and markets. ${ }^{5}$ The state mode is characterised by a reliance on hierarchy and legitimate authority as a means to regulate relationships between actors; ${ }^{6}$ the market mode relies on "price signals and formalized, legal contractual relations to bring dispersed suppliers and purchasers together". ${ }^{7}$ Many governments in west European countries have resorted to a mix of state and market-based governance in the provision of public services. ${ }^{8}$ States and markets do, however, have certain weaknesses in this regard. States can fail to solve public policy problems because of a weak centralisation of resources, such as finances, information, knowledge, expertise, and political support, which are required for the effective resolution of public policy problems. ${ }^{9}$ Markets can fail because they are unable to control and compensate for, the production of negative externalities, leading to an inefficient allocation of resources in society and an overall loss of welfare. ${ }^{10}$

Both the problems associated with the two traditional modes of governance, and an increasing realisation of the added value of networks for solving public policy problems, have led governments to shift their focus away from states and markets towards networks as a third mode of steering. ${ }^{11}$ This third mode of steering has various forms; starting from the general conceptualisation of networks provided above, further distinctions

\footnotetext{
${ }^{2}$ Latour, 2010: 1.

${ }^{3}$ E.g. Börzel and Heard-Lauréote, 2009: 137; Sørensen and Torfing, 2007: 9; O’Toole, 2010: 8.

${ }^{4}$ E.g. Powell, 1990: 303; similar Keast et al., 2006; Podolny and Page, 1998: 60.

${ }^{5}$ The distinction between these three modes of governance has been elucidated in a seminal article by Powell. See Powell, 1990.

${ }^{6}$ Keast et al., 2006: 4. For an elaboration on the features of states, see Powell, 1990.

${ }^{7}$ Ibid.

${ }^{8}$ Keast et al., 2006; Sørensen and Torfing, 2005.

${ }^{9}$ Börzel and Heard-Lauréote, 2009: 141.

${ }^{10}$ For a brief overview, see e.g. Tshuma, 2000: 118.

${ }^{11}$ Keast et al., 2006; Sørensen and Torfing, 2005. For an overview of competing explanations for the surge of governance networks, see Sørensen and Torfing, 2007.
} 
could and should be made, as Figure 8 demonstrates. The darkly shaded boxes in this figure indicate the focus of this study.

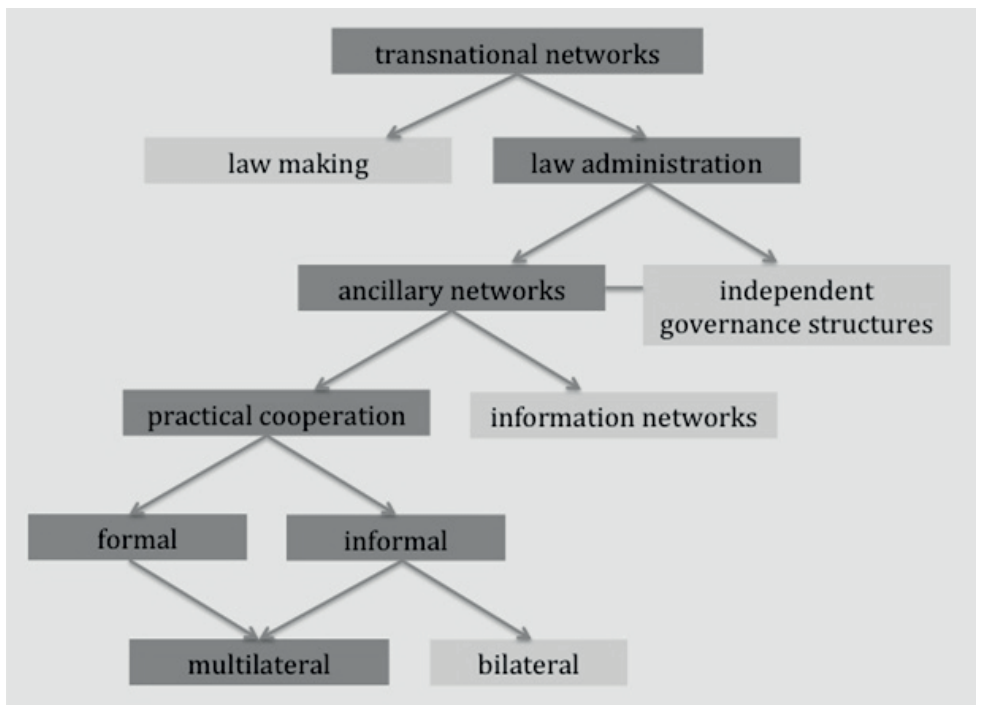

Figure 8 Distinctions between different forms of transnational networks ${ }^{12}$

The focus of this chapter is on transnational governance networks, as noted above. Figure 8 suggests that there is a distinction between law-making networks and law administration networks. Since this study is concerned with the administration of EU rules, attention will be paid to the latter type of networks (these networks are, for reasons of simplicity, hereafter referred to as 'implementation networks'). Thus, cooperation that takes place in the context of comitology committees is not at the centre of our investigation; although such committees may engage themselves in reaching agreements on the interpretation and application of EU directives, they primarily aim to oversee the Commission in the exercise of its implementing powers. ${ }^{13}$ Implementation networks have different forms and different degrees of sophistication. At one end of the scale of sophistication, are networks that are conceived as independent governance structures, fully integrating national authorities as the ultimate responsible bodies for enforcing EU rules. The European Competition Network, which has a firm basis in EU secondary law, is a prominent example of such networks. ${ }^{14}$

\footnotetext{
${ }^{12}$ The distinction between ancillary networks and networks as interdependent governance structures is based on De Visser, 2009: 37-38. Both notions are linked, since they represent two extremes on a continuum, and networks may find themselves in between these two extremes.

${ }^{13}$ For a brief review of the main rules that apply to the comitology system, see Chapter 5 on post-legislative guidance, Section 1.2.2.1.

${ }^{14}$ See e.g. De Visser, 2009; Yesilkagit and Danielsen, 2011.
} 
Since the three directives in this study do not feature networks that function as truly independent governance structures, our focus will be on networks at the other end of the scale of sophistication: ancillary networks. Such networks are merely an element of the decentralised model of law administration, without a particularly meaningful role or competencies to speak of. ${ }^{15}$ Here, another distinction can be made, which features information networks and networks that enable practical cooperation. Information networks, which are aimed at gathering, sharing, and composing information, are established in all areas where administrative cooperation is an important element in the implementation of EU measures. The information managed and circulated within such networks is generally provided by the network participants. Such information does, in many cases, circulate through centralised databases that are administered at the EU level, which are generally managed and maintained by the Commission or EU agencies. The rules governing the functioning of such networks differ across policy areas. ${ }^{16}$

This study does not focus on the functioning of information networks, but on the functioning of networks that facilitate practical cooperation amongst member states. Such networks may be formal or informal. From a legal perspective, formal networks are those networks that are encapsulated in the EU institutional framework by codification in legislation and that are subject to regular, publicly sanctioned exchanges. ${ }^{17}$ If we follow this definition, forms of cooperation that do not meet these conditions must be categorised as informal. From a more material point of view, however, one could conceive of several gradations on the scale of formality. Networks may be legally informal, yet still formal in practice to an extent, for example because they are materially embedded in the EU institutional framework and characterised by a strong presence of the European Commission or an EU agency. This study is interested in networks that are on this scale of formality, as long as they represent multilateral forms of cooperation. Bilateral contacts are not the main interest of this study.

In summary, the analysis presented in the remainder of this chapter must focus on formal and informal multilateral implementation network enabling practical cooperation. The comparative nature of this analysis intends to establish a more comprehensive understanding of how and when networks can be useful compliance instruments, and which possible trade-offs between effectiveness and democracy exist regarding the different forms of networked governance relevant to this study. Little empirical research has been carried out in this regard. ${ }^{18}$

\footnotetext{
${ }^{15}$ De Visser, 2009: 37.

${ }^{16}$ For an overview of such networks, see Hofmann et al., 2011: $419 \mathrm{ff}$.

${ }^{17}$ Christiansen et al., 2003: 7.

${ }^{18}$ Sørensen and Torfing, 2009: 254.
} 


\section{Networks as compliance instruments}

This section aims to identify why networks may be useful for competent authorities in the application of EU measures (Section 1.1), and which factors may hinder their usefulness as compliance instruments (Section 1.2). As such, it sets the scene for the analysis presented in the subsequent sections of this chapter.

\subsection{Why networks?}

The contemporary frenzy regarding transnational networks as governance instruments may persuade one to think that networks are new phenomena. However this is not the case, rather it is their increasing use by policy makers and their reputation as efficient and legitimate mechanisms of governance that make them new. ${ }^{19} \mathrm{With}$ respect to the EU regulatory context, the fact that networks are not new phenomena could be illustrated by the idea that the precursors of Article 4(3) TEU already contained a requirement for member state administrations to engage in cooperation. Article 10 of the Treaty establishing the European Community (EC Treaty) and Article 5 of the EEC Treaty initially implied only a duty of cooperation for member states in relation to the European Commission. The Court, however, expanded the scope of the principle to include "mutual duties of sincere cooperation" for member states in relation to one another. ${ }^{20}$ Because of this expansion, the principle of loyal cooperation may have produced "some of the strongest 'ties that bind' member states within the European Union". ${ }^{21}$

The creation of networks was given impetus by the 1992 Sutherland report, which recommended that the Union develop a cooperative approach to the enforcement of internal market legislation. ${ }^{22}$ In two subsequent communications, the Commission proposed a more coherent and transparent approach to administrative cooperation and, when a sufficient level of implementation could not be achieved, binding forms of cooperation. ${ }^{23}$ In its White Paper on European Governance, the Commission further stressed

\footnotetext{
${ }^{19}$ Sørensen and Torfing, 2005: 198. See also Smismans, 2003: 877, who points out that the 'shift in intensity' in the use of new governance instruments does not imply a 'taking over' of these new modes of governance from the community method.

${ }^{20}$ Case 230/81 Luxembourg v. European Parliament (Seat and Working Place of the Parliament) [1983] ECR 255, para. 37 (on Article 5 TEEC), and case C-511/03 Ten Kate Holding [2005] ECR I-8979, para. 28 (on Article 10 TEC).

${ }^{21}$ Klamert, 2014: 1. Article 5 TEEC was modeled on Article 86 of the Treaty establishing the European Coal and Steel Community. See Ibid.: 10ff.

${ }^{22}$ Commission, 'Reinforcing the effectiveness of the Internal Market. Working Document of the Commission on a Strategic Programme on the Internal Market' (Sutherland Report) COM (93) 256 final, Section IV, Enforcing the rules through partnership.

${ }^{23}$ Commission, 'Communication on the development of administrative cooperation in the implementation and enforcement of Community legislation in the internal market' (Communication) COM (94) 29 final: x; Commission, 'Cooperation between Administrations for Enforcement of Internal Market Law: A Progress Report' (Report) COM (96) 20 final.
} 
the added value of networks for arriving at more effective and inclusive governance of the internal market. ${ }^{24}$ Since the turn of the millennium, the Commission has increasingly relied on "networked governance" 25 as an independent mode of steering rather than a mere element of the traditional governance structure. ${ }^{26}$ As a result networks have become an important sub-part of the model of shared administration in the EU, ${ }^{27}$ in an increasingly "cluttered, fragmented, and complex regulatory space". ${ }^{28}$

The emergence of transnational networks as governance instruments must be viewed as a response to the "governance dilemma" faced by the EU. ${ }^{29}$ This dilemma entails an acknowledgement of the need for more government at the supranational level, and an aversion to greater centralisation and coercive authority. ${ }^{30}$ More centralisation is needed, in view of the desire to ensure greater consistency in the implementation of $\mathrm{EU}$ law. ${ }^{31}$ More centralisation is, however, "politically inconceivable, and probably undesirable". ${ }^{32}$ One reason for this undesirability is the notion that, according to the principle of subsidiarity, it is national authorities that should be the primary responsible bodies for the administration of EU law. "Regulation by networks"33 has been seen as an apt way to meet the need for increased uniformity, while preserving the decentralised nature of the implementation system in the EU. ${ }^{34}$

It has been suggested that the usefulness of networks should be evaluated at three levels: the community level, the network level, and the participant level. ${ }^{35}$ On the community level, the strength of networks is that they lead to consistent law administration practices, since they "softly harmonize member state regulatory activities". ${ }^{36}$ The beneficiaries of more consistent implementation practices are EU citizens and businesses operating in the single market. On a micro level, networks may bring several concrete and direct benefits to the participants involved in cooperation. The participants that are of

\footnotetext{
${ }^{24}$ COM (2001) 428 final.

${ }^{25}$ Schout and Jordan, 2005.

${ }^{26}$ E.g. Coen and Thatcher, 2008; Dehousse, 1997; Eberlein and Newman, 2008; Thatcher and Coen, 2008. For early developments of administrative cooperation for implementation and enforcement of Internal Market legislation in the EU (and a call for the creation of a coherent and administrative approach to administrative cooperation), see COM (94) 29 final.

${ }^{27}$ Craig, 2009: 27.

${ }^{28}$ Thatcher and Coen, 2008: 830 .

${ }^{29}$ Schout and Jordan, 2005: 1-8; Eberlein and Newman, 2008: 26. Term coined by Keohane, 2001.

${ }^{30}$ Slaughter, 2004: 8.

${ }^{31}$ The rationale for greater consistency is outlined in Chapter 1 on making EU law work: a problem in need of a solution.

${ }^{32}$ Dehousse, 1997: 246.

${ }^{33}$ Dehousse, 1997.

${ }^{34}$ Ibid.: 259; similar Eberlein and Newman, 2008: 35; Coen and Thatcher, 2008: 56; Thatcher and Coen, 2008: 808-809. This does not mean that networks do not exist in areas of centralised implementation; the Commission may choose to resort to an executive agency or to a network of national agencies. See Craig, 2009: 29.

${ }^{35}$ Provan and Milward, 2001.

${ }^{36}$ Eberlein and Grande, 2005: 100.
} 
interest in this study are those involved in the practical implementation of EU law on the ground, rather than "metagoverners" (public authorities at higher levels of governance "transcending the concrete forms of governance through which social and economic life is shaped, regulated and transformed"; ${ }^{37}$ for example the European Commission) or other actors (for example business actors or civil society organisations) that may be involved in networks. The network-level benefits shown in Figure 9 are derivatives of the participant-level benefits that networked cooperation is thought to produce. ${ }^{38}$

Given the interest of this study in the usefulness of compliance instruments for national civil servants that do the job of administering EU rules on the ground, the focus of the following subsections is on the benefits that these particular actors may derive from cooperation. While such benefits are interlinked in practice, they are conceptually distinct; thus, the following subsections elaborate on them individually.

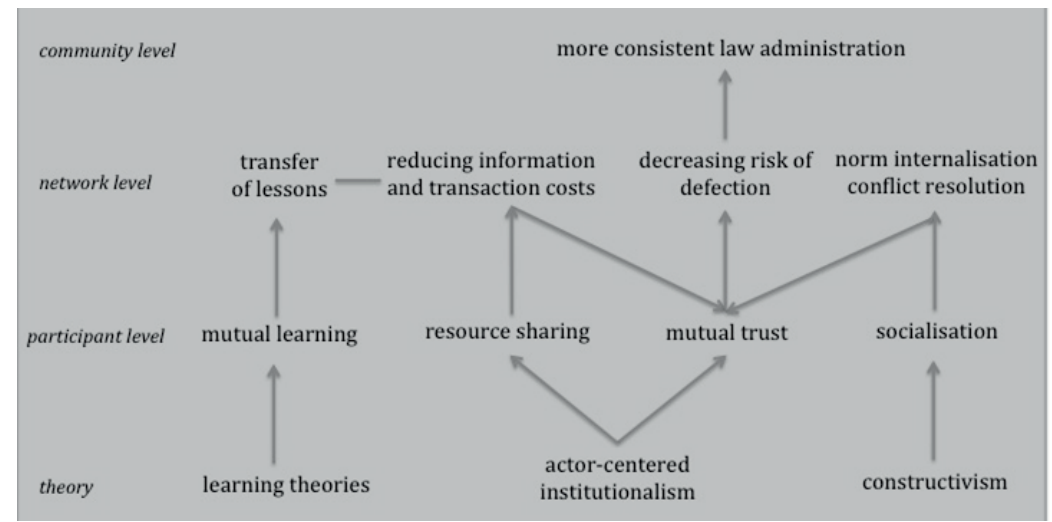

Figure 9 The usefulness of networks

\footnotetext{
${ }^{37}$ Sørensen and Torfing, 2009: 245. Note that the benefits of networks for metagoverners may be substantial. Networks may, for example, reduce the burden on the Commission as guardian of the treaties by making infringement action more targeted and swift (by keeping the Commission informed), while at the same time removing from the legal sphere those issues that may be solved by the network participants. For this argument, see Korkea-aho, 2014. By virtue of the monitoring opportunities that they offer, networks may also allow the Commission to name and shame badly performing network members. For this idea, see Sørensen and Torfing, 2009: 250. The issue of naming and shaming is elaborated on in Chapter 4 on monitoring and sanctions.

${ }^{38}$ This understanding of network-level benefits corresponds to the indicator 'range of actual services provided by the network', which Provan and Milward posit to be one way of measuring network-level effectiveness. Other indicators relate to the entry to and withdrawal from, the network of organisations, the strength of relationships between members, and the administrative structure of the network. See Provan and Milward, 2001: 418-419. It is the first that is most relevant to the context of this study, since it links in with the participant-level benefits encountered in the literature.
} 


\subsubsection{Actor-centred institutionalism: resource sharing and mutual trust}

In actor-centred institutionalism, which combines rational choice and institutionalist tenets, institutions are understood as regulatory structures that provide opportunities and constraints for rational actors striving to maximise their preferences. ${ }^{39} \mathrm{~A}$ main function of institutions is to overcome collective action problems. ${ }^{40}$ Collective action problems arise in situations where cooperation is preferable for everyone involved, but where individuals have an incentive not to cooperate. ${ }^{41}$ In the vein of actor-centred institutionalism, networks are institutions that are capable, first, of lowering information and transaction costs for national authorities by drawing knowledge and expertise that single actors may not possess. ${ }^{42}$ This function is particularly important in view of the complexity of contemporary policy problems, ${ }^{43}$ and in a situation in which the implementation of common policies is decentralised and the availability of resources greatly differs across jurisdictions. ${ }^{44}$ In such a situation, resource sharing can support individual authorities in applying the law more efficiently and effectively.

Second, networks can create mutual trust amongst network participants, reducing the risk of intentional deviation by reassuring actors that they are not being cheated. ${ }^{45}$ In a situation of decentralised governance, cooperation between national authorities "essentially depends on their mutual trust and loyalty" 46 and mutual trust is often lacking. The result may be that member states default on their obligations under EU law, and may be induced to cut down on the regulatory capacities allocated to the administration of EU law, or tend to adopt solutions that are favourable to the national rather than the common interest. With capacities cut or nationally favoured solutions adopted, effective enforcement is likely to be compromised and other member states will have their suspicions of poor implementation confirmed. ${ }^{47}$ Mistrust transforms into distrust, providing states with stronger incentives to cheat.

Cooperation may offer a way out of this situation by restoring mutual trust amongst authorities. It does this by enabling the establishment of relationships between authorities to share information about interests of, and approaches adopted by, other

\footnotetext{
${ }^{39}$ Scharpf, 1997, 2000.

${ }^{40}$ Ibid.

${ }^{41}$ E.g. as in the prisoner's dilemma, which refers to a situation in which individuals would be better of if they could cooperate, but, in the absence of credible commitment of the other(s) and lacking credible sacntions in case of defection, nonetheless choose to defect. See Putnam, 1993: 163-164, for this and other examples of collective action problems.

${ }^{42}$ Sørensen and Torfing, 2005: 198-199; similar Slaughter, 2004. For the idea that states and markets are poor mechanisms for the transfer of knowledge, see Powell, 1990: 303-304. For the idea that the transaction costs in networks themselves may be high, see Scharpf, 1997: 70.

${ }^{43}$ Börzel and Heard-Lauréote, 2009: 141-142.

${ }^{44}$ Majone, 1996: 277.

${ }^{45}$ Scharpf, 1997.

${ }^{46}$ Yataganas, 2001: 32.

${ }^{47}$ De Visser, 2009: 20, 239-240.
} 
authorities. This makes it possible for authorities to monitor the work of others; it also creates a threat of reputational costs for those that choose to defect. Both these aspects create a stronger incentive for authorities to pursue the EU interest, rather than narrowly defined national interests. ${ }^{48}$

The emphasis of actor-centred institutionalism on resource sharing and mutual trust as important mechanisms for ensuring compliance, is somewhat related to the perspectives of the managerialist school on implementation and compliance, the tenets of which are outlined in Chapter 3 on the approach and methodology of this study. ${ }^{49}$ Management perspectives attach great importance to capacity-building measures - for example, technical and educational assistance - and to transparency as a trust-building mechanism, as instruments to address compliance problems. This is why the concrete benefits that actor-centred institutionalism associates networked cooperation with must be accepted by managerialists as important for addressing compliance problems. Note, however, that the wider function that actor-centred institutionalism endows networks with - in the sense that it regards networks as useful tools for constraining egoistic behaviour on the part of rational actors - does not fit the conception of managerialists of actors as willing, but not always capable, to comply.

\subsubsection{Learning theories: mutual learning}

While the previous section elaborates on resource sharing in general terms, the current section elaborates on one particular element that is closely linked to the notion of resource sharing: that of mutual learning. ${ }^{50}$ Theories of policy learning, which focus on learning as a source of policy change, generally hold that "states can learn from their experience and that they can modify their present actions on the basis of their interpretation of how previous actions have fared in the past" ${ }^{51}$ These theories stick to different concepts of learning and to different ideas about the agents and the objects of learning. ${ }^{52}$ Applicable to the context of this study seems to be a conceptualisation of learning as an ongoing process taking place at the individual level, by administrative officials; ${ }^{53}$ a process that is aimed at improving the effectiveness of the implementation of policies by

\footnotetext{
${ }^{48}$ Ibid.: 238-240. Outside the literature of network governance, the notion of trust is known mainly because it takes on a central position in Putnam's pivotal work on civic life and democracy, in which he argues that "networks encourage social trust and cooperation because they reduce incentives to defect, reduce uncertainty, and provide models for future cooperation". See in particular Putnam, 1993: Chapter 6. Quote on p. 177.

${ }^{49}$ See Chapter 3 on the approach and methodology of this study, Section 2.2.

${ }^{50}$ The notion of mutual learning is most famously associated with the open method of coordination, which is employed in the domain of employment, and economic and social policy. For an overview, see e.g. De la Porte and Pochet, 2002, and Zeitlin et al., 2005. For the notion that states and markets are a poor device for learning, see Powell, 1990: 303-304.

${ }^{51}$ Bennett and Howlett, 1992: 276.

${ }^{52}$ For an overview, see Bennettt and Howlett, 1992.

${ }^{53}$ See Etheredge, 1981, who utilises the concept of 'government learning'.
} 
allowing such officials to acquire knowledge about techniques and processes used in the implementation process by others. ${ }^{54}$ While implementation networks are potential vehicles for learning, it is the participants in these networks that are responsible for this learning. ${ }^{55}$

Learning is important in a situation in which unequal expertise on the part of national authorities undermines the efficiency of the system of decentralised implementation in the EU. ${ }^{56}$ In the vein of learning (inspired) theories, the diversity in the EU is a great asset for mutual learning, since it means that many different approaches will be attempted - and many different experiences gained - at the same time for similar policy problems. In such a context, the exchange of experiences and best practices amongst member states may help them find new solutions to problems "often thought to be unsolvable". ${ }^{57}$ Learning is understood as facilitated by mechanisms that:

destabilize existing understandings; bring together people with diverse viewpoints in settings that require sustained deliberation about problem-solving; facilitate erosion of boundaries between both policy domains and stakeholders; reconfigure policy networks; encourage decentralized experimentation; produce information on innovation; require sharing of good practice and experimental results; encourage actors to compare results with those of the best performers in any area; and oblige actors collectively to redefine objectives and policies. $^{58}$

If networks meet these conditions, they may be expected to be effective vehicles for learning. This does not mean that particular solutions are generalisable in a straightforward way. ${ }^{59}$ Lessons that work in one jurisdiction may be copied by another, but only when the cultural, political, and social conditions in the two jurisdictions are identical. If this is not the case, lessons may serve as inspiration. Other effects, such as emulation according to which lessons learned are used as a model and tailored to fit the characteristics of the receiving jurisdiction - find themselves between these two extremes. ${ }^{60}$

\footnotetext{
${ }^{54}$ This closely follows Sabatier's concept of 'policy-oriented learning' (see Sabatier, 1988), which is closely connected to Rose's concept of learning as 'lesson-drawing' (see Rose, 1991). Etheredge and Short focus on learning as involving both a growth in intelligence and an increase in effectiveness (Etheredge and Short, 1983: 43).

${ }^{55}$ Rose, 1991: 3. Hence the conceptualisation of networks as transnational instruments; the main actors in control of the functioning of networks are the participants, who represent national authorities from several member states.

${ }^{56}$ Yataganas, 2001: 32

${ }^{57}$ Trubek and Trubek, 2005: 358; cf. Sabel and Zeitlin, 2008: 276.

58 Trubek and Mosher, 2003: 76-77.

${ }^{59}$ Sabel and Zeitlin, 2008: 276.

${ }^{60}$ Rose, 1991.
} 


\subsubsection{Constructivism: socialisation}

For constructivists, networked cooperation is a primary tool for socialisation. According to constructivists, socialisation - "which directs the individual away from the self to the socialising group" 61 - is the answer to compliance problems, since it has the effect of changing the preferences of individuals by internalising them into the normative belief that a rule ought to be obeyed, that is, that compliance is 'the right thing to do'. More concretely, socialisation can persuade actors into widely shared causal beliefs about the operation of a policy issue and about the necessity of rules that promote valued policy objectives. ${ }^{62}$ Operating through a logic of appropriateness, networked cooperation is expected to facilitate consensus and conflict resolution. ${ }^{63}$ Material interests or coercion are not mediating factors in this regard, as Chapter 3 setting out the approach and methodology of this study outlines; individuals are understood to develop preferences because these preferences are seen as "natural, rightful, expected and legitimate", ${ }^{64}$ not because they are the result of a rational calculation of material interests.

\subsection{Limitations of networks as compliance instruments}

For networks to deliver the benefits outlined in the previous section, several conditions must be met. These conditions may be of an internal (organisational) or of an external (contextual) nature. The literature on networked governance suggests that it is not a matter of course that such conditions are met. The current section elaborates on what seem to be the most pressing factors that play a role in this regard. It addresses, first, the issue of interdependence (Section 1.2.1) and structural contingencies of network models that co-determine the effectiveness of networked cooperation (Section 1.2.2). It then discusses the legitimacy of such cooperation from both an output and input legitimacy point of view (Sections 1.2.3 and 1.2.4, respectively), both of which are strongly intertwined. ${ }^{65}$

\subsubsection{The dependence of networks on interdependence}

From a contextual perspective, we find interdependence an important precondition for (effective) cooperation. ${ }^{66}$ The notion of interdependence refers to "a condition where two (or more) organisations require each other, are dependent each upon the other", meaning that their "behavior is affected by and in turn affects the behaviors of those

\footnotetext{
${ }^{61}$ Hooghe, 2001: 15.

${ }^{62}$ Haas, 1998: 32.

${ }^{63}$ March and Olsen, 1995.

${ }^{64}$ March and Olsen, 2006: 689.

${ }^{65}$ Note that legitimacy issues are discussed in relation to post-legislative guidance too; see Chapter 5 on postlegislative guidance, Section 1.2.2.

${ }^{66}$ Ostrom, 1990: 197-206; Van Boetzelaer and Princen, 2012.
} 
involved in the relationship" ${ }^{67}$ While higher levels of interdependence are associated with greater efforts of coordination, lower levels of interdependence correlate with weaker coordination efforts. This is because when the activities of authorities affect each other, the success of each individual authority in the implementation of legislation is, to a greater or lesser extent, dependent on the implementation performance of the others. It is in this situation that authorities feel motivated to engage in cooperation with each other, since they perceive cooperation as beneficial for them.$^{68}$ When authorities are forced to work together without seeing the benefit of cooperation - notably when differences in implementation practices across member states are of limited relevance to authorities - they may not want to invest in cooperation, in particular in light of the costs (resource investments, adaptation costs) that cooperation brings. ${ }^{69}$ Where this is the case, metagoverners (for example politicians, public managers) can strengthen interdependencies by convincing the network actors that there is an urgent need for coordination. ${ }^{70}$

Practically speaking, the above discussion suggests that the Commission should keep in mind that cooperation may not work well if levels of interdependence are low. This suggestion may be useful in view of the Commission's bold statement in one of its communications, that there is a "high degree of interdependence which characterises the management of the single market". ${ }^{71}$ Reality is not as homogeneous as this assertion conveys; studies suggest that measures of interdependence are policy domain, and issue, specific. ${ }^{72}$ In other words, the Commission should be aware that networked cooperation may be more effective in some instances than in others, and that the potential role that the Commission may (have to) play in cooperation is not pre-set but case specific.

\subsubsection{Output legitimacy: an institutional design and capacity perspective}

In order for networks to succeed from an output legitimacy (performance) perspective, they need to produce outcomes that are effective and coherent. ${ }^{73}$ Section 1.1 of the current chapter suggests that networks may be useful compliance instruments if they enable resource sharing, mutual learning, and problem solving, and allow for mutual trust to develop. The current section suggests that much of what networks may achieve in this regard depends on their governance form and their structural contingencies.

Note that networks can broadly come in three governance forms. Networks can be participant governed (self-organised networks', or 'shared governance networks'); such

\footnotetext{
${ }^{67}$ Chisholm, 1989: 42, in Boetzelaer and Princen, 2012: 824.

${ }^{68}$ Van Boetzelaer and Princen, 2012: 822-824. See also Craig, 2009: 9-10.

${ }^{69}$ Van Boetzelaer and Princen, 2012: 822-824.

${ }^{70}$ Sørensen and Torfing, 2009: 250.

${ }^{71}$ Quote from COM (94) 29 final, p. xi.

${ }^{72}$ See e.g. Van Boetzelaer and Princen, 2012.

${ }^{73}$ COM (2001) 428 final, pp. 7-8.
} 
networks depend on the involvement and commitment of all participant organisations, or of a substantial subset of them. ${ }^{74}$ Networks may also be governed by a lead organisation, meaning that coordination of all major network activities and key decisions lies with a single participating state. ${ }^{75}$ In the network administrative organisation (NAO) model ('centrally-steered networks'), a separate administrative entity is set up to govern the network and its activities. ${ }^{76}$ Whether or not these governance modes create effective networks depends on the characteristics of four structural contingencies: trust, the size of the network, goal consensus, and network competencies. ${ }^{77}$ The following subsections elaborate on each of these contingencies and, where relevant, point out weaknesses that relate to EU governance networks on this topic.

\subsubsection{Trust}

The first factor is trust, an expression of the "spirit of goodwill", ${ }^{78}$ which could be defined as an aspect of a relationship that reflects "the willingness to accept vulnerability based on positive expectations about another's intentions or behaviors". ${ }^{79}$ When network members trust each other, they constitute a moral community insofar as "trustworthy behaviour can be expected, normative standards understood, and opportunism forgone" ${ }^{80}$ It is not 'deep trust', but rather the density of trust that is important in this regard, meaning that what matters is the number of people in a network that trust each other. ${ }^{81}$ Trust is thus premised on personal relations; a notion that is clearly expressed in the idea that "you trust best [information] that comes from someone you know well". ${ }^{82}$

High-density trust is a precondition for self-organised governance to be effective. When such trust is absent and network members "screw each other", ${ }^{83}$ and when a strong basis for cooperation is lacking, networks can still be effective if they involve a lead organisation or $\mathrm{NAO}^{84}$ that attempts to inhibit opportunism and nourish trust. ${ }^{85}$ Also metagoverners that are involved in networks as participants could play a role in building trust through a unilateral display of trust in the network, after which other network participants may follow suit. ${ }^{86}$

\footnotetext{
${ }^{74}$ Provan and Kenis, 2008: 234; also Jordan and Schout, 2005.

${ }^{75}$ Provan and Kenis, 2008: 235.

${ }^{76}$ Ibid.: 236; also Jordan and Schout, 2005.

${ }^{77}$ Provan and Kenis, 2008: 236ff. Note that the notion of effectiveness relates, in this case, to collectively generated network-level outcomes, not to the benefits that individual participants may gain from cooperation.

${ }^{78}$ Dore, 1983, quoted in Podolny and Page, 1998: 60.

${ }^{79}$ McEvily et al., 2003: 92, in Provan and Kenis, 2008: 237.

${ }^{80}$ Granovetter, 1995, quoted in Podolny and Page, 1998: 61.

${ }^{81}$ Provan and Kenis, 2008: 238.

${ }^{82}$ Powell, 1990: 304.

${ }^{83}$ Schrank and Whitford, 2011: 161.

${ }^{84}$ Provan and Kenis, 2008: 238. Similar Ostrom, 1990: 197-206.

${ }^{85}$ Schrank and Whitford, 2011: 165-169.

${ }^{86}$ Sørensen and Torfing, 2009: 251.
} 


\subsubsection{Size of networks}

The complexity of network governance increases with the number of network participants; the more organisations are involved, the more needs must be accommodated and coordinated. ${ }^{87}$ What follows is that self-organised networks can be effective only if the number of participants is low. If this is not the case, some degree of centralised governance is required for networks to be effective. ${ }^{88}$ Note that this second contingency is clearly relevant to the first; low numbers of network nodes not only make coordination between these nodes easier, they facilitate getting to know and trusting one another.

\subsubsection{Goal consensus}

The notion of goal consensus comprises agreement on the content of network goals and on the process through which such goals should be achieved. ${ }^{89}$ When participants can generally agree on network goals, self-organisation may be an effective governance form. When goal consensus is intermediate, ${ }^{90}$ a lead agency or NAO governance is likely to be more effective. Goal consensus seems more likely when network members constitute an epistemic community, that is, a community of experts with recognised expertise and an authoritative claim to knowledge in a certain domain or issue area. ${ }^{91}$ The members of such communities share normative, principled, and causal beliefs; notions of validity; and common policy practices. ${ }^{92}$ Together with the common professional background of the network members, these shared beliefs mitigate disagreements amongst the network participants and function as drivers of convergence. ${ }^{93}$

Goal consensus also seems likely when the network participants have the freedom to arrive at agreements with other network members. This seems more likely for authorities that are capable of acting independently and autonomously at the national level, since this provides them with a margin of discretion that makes it possible for them to act on the basis of their own assessment, and make credible commitments to their partners. ${ }^{94}$ Extensive discretion is less probable in areas that are politically sensitive, ${ }^{95}$ since here political principals tend to watch regulatory authorities more closely.

\footnotetext{
${ }^{87}$ Provan and Kenis, 2008: 238. Similar Ostrom, 1990: 197-206.

${ }^{88}$ Ibid.

${ }^{89}$ Provan and Kenis, 2008: 239-240.

${ }^{90}$ When goal consensus is low, a point to engage in cooperation seems to be lacking; see Provan and Kenis, 2008: 240. A lack of consensus may be caused by a lack of interdependence amongst organisations, which links the discussion presented here to the discussion presented in the previous section on interdependence.

${ }^{91}$ On epistemic communities, see e.g. Haas, 1992.

${ }^{92}$ Haas, 1992.

${ }^{93}$ Eberlein and Newman, 2008: 36; similar Coen and Thatcher, 2008; Thatcher and Coen, 2008.

${ }^{94}$ Eberlein and Grande, 2005: 103.

${ }^{95}$ Eberlein and Newman, 2008: 37, 44.
} 


\subsubsection{Network-level competencies}

A fourth and final factor that determines network effectiveness relates to the issue of network-level competencies. The extent to which such competencies are needed varies according to the prevalence of internal and external pressures for coordination. For example, when network members are significantly interdependent, or when networks are under pressure from an external funder to coordinate activities, the need for network coordination will be great. In this case, central steering seems more apt than selforganisation. ${ }^{96}$

Central steering can, however, only be effective if the administrative entities set up to govern networks are given the competencies and resources needed to properly fulfil their coordination task. ${ }^{97}$ This is not self-evident, as studies on networked governance in the European Union demonstrate. Networks require a "double delegation of powers and functions: one 'upwards' from [the domestic regulatory agencies] and a second 'downwards' from the European Commission" ${ }^{98}$ Both usually agree to transfer only limited powers to newly established networks and retain control over networks. ${ }^{99}$ This is logical from the point of view of principal-agent theory, which argues that principals (national authorities and the Commission, in this case) maintain control over agents (networks, in this case) to prevent "shirking" or "bureaucratic drift"; ${ }^{100}$ that is, to inhibit an agency from opportunistically pursuing its own interests. ${ }^{101}$ Methods for exercising control include the assignment of vague mandates and limited powers to networks, and the provision of limited resources in terms of staff and money. ${ }^{102}$ When they participate in networks, public metagoverners - the Commission in this case - may choose to advance their own agendas and approaches through strategic manipulation of the network process. ${ }^{103}$

These organisational weaknesses may apply to formal networks and to informal networks alike, ${ }^{104}$ although their nature is likely to vary with the degree of formalisation of a network. The existence of informal networks alongside formal networks (and the other way around) may itself present an obstacle to cooperation, since the coexistence of cooperative arrangements may result in institutional competition and venue shopping by

\footnotetext{
${ }^{96}$ Provan and Kenis, 2008: 240-241.

${ }^{97}$ Sørensen and Torfing, 2009: 246; Schrank and Whitford, 2011.

${ }^{98}$ Coen and Thatcher, 2008: 50; italics in original.

${ }^{99}$ Ibid.: 50-51.

${ }^{100}$ Pollack, 1997: 108.

${ }^{101}$ For this definition of shirking, see Kiewiet and McCubbins, 1991: 5, quoted in Pollack, 1997: 108. For the caveats associated with principal-agent theory and a more nuanced picture, see e.g. Coen and Thatcher, 2005. For a review of and reply to critiques on principal-agent theory, see Pollack, 2007. For the argument that the delegation of powers in the EU is best captured by a multi-principals model, see Dehousse, 2007.

${ }^{102}$ See e.g. the cases presented in Coen and Thatcher, 2008.

${ }^{103}$ Sørensen and Torfing, 2009: 242.

${ }^{104}$ For the difference between formal and informal networks, see the introduction to this chapter.
} 
regulatory authorities. ${ }^{105}$ Both formal and informal networks appear to suffer from competition from comitology committees as well. Committees retain strong formal powers, relegating other networks to a lower rank in the institutional hierarchy, ${ }^{106}$ and pulling authorities away from such networks and directing authorities' attention (and resource investments) to themselves instead.

\subsubsection{Synthesis}

The above discussion suggests that the effectiveness of networks may be curtailed by two factors. The first is a mismatch between the governance form of networks and one or more of the structural contingencies of networks; this may be particularly problematic when networks are mandated rather than initiated by network members. ${ }^{107} \mathrm{~A}$ second limiting factor may be a mismatch between what networks are mandated to do and what they are capable of doing with the resources allocated to them. Where mismatches are found, the result may be that networks that are meant to offer effective methods of dealing with new governance challenges are restrained in their flexibility and comprehensiveness of action, diminishing their effectiveness. ${ }^{108}$ In this regard, particularly resource constraints of centrally-steered networks seem to demonstrate a basic reluctance of member states and EU institutions to make networks work effectively. A lack of network effectiveness should, in this case, not be understood to question the potential usefulness of networks as compliance instruments in theory, rather the willingness of principals to make their agent work in practice. ${ }^{109}$

\subsubsection{Output legitimacy: a participant-level perspective}

While the previous section outlines the factors that may reduce the usefulness of networks from an institutional design and capacity perspective, the current section addresses such limitations from a micro perspective; that is, from the perspective of the individual authorities participating in cooperation.

From this perspective, the constructive behaviour of individual civil servants who are involved in such networks is crucial for making them work. It is self-evident that noninterference and unilateral action on the part of officials are not helpful in this regard; officials must be willing to and capable of engaging in consultation and active assistance if cooperation is to deliver the benefits discussed in the previous section of this chap-

\footnotetext{
${ }^{105}$ Coen and Thatcher, 2008: 66.

${ }^{106}$ Ibid.

${ }^{107}$ Provan and Kenis, 2008: 246.

${ }^{108}$ See ibid., in relation to governance mismatches; see Kassim and Menon, 2003: 124, in relation to resource constraints.

${ }^{109}$ For the notion that these principals can also choose to make network governance more effective and democratic, and for the challenges that they may face in this regard, see Sørensen and Torfing, 2009.
} 
ter. ${ }^{110}$ This is not self-evident as networks are not above national interest and power; thus, logics of interaction within networks may express rivalry and competition rather than cooperation. ${ }^{111}$ When constructive cooperation makes room for competition, the effectiveness of networks is bound to suffer. The same applies to cases characterised by exclusive deliberation. Inclusiveness - the involvement in networks of participants other than technocrats that are affected by the outputs of networks - is important, since it facilitates the achievement of high-quality decisions. ${ }^{112}$ There seems to be a broadly shared perception that similar to the development of post-legislative guidance, ${ }^{113}$ inclusiveness in networks is not self-evident, as Section 1.2.4 on the democratic legitimacy of networked cooperation elucidates in detail.

Cooperation should not only involve constructive and inclusive participation; it should also respect the diversity within the EU. Indeed, in an early communication on administrative cooperation, the European Commission recalls:

In contrast to the relative homogeneity of administrative practice within each [member state], the organisation of administrative cooperation in the [EU] context must take account of significant differences between the [member states] in different organisation structures, organisational practice and the overall level of resources devoted to enforcement. ${ }^{114}$

In this regard, the diversity within the EU should be accepted as posing limits to the degree of coordination that networks may want to achieve. ${ }^{115}$ It has been argued, however, that attempts to balance diverse national interests amidst this diversity risk leading to the imposition of one-size-fits-all approaches that do not fit anyone (or most). ${ }^{116}$ This puts the usefulness of networks as compliance instruments for those participating in cooperation at risk, as well as the effectiveness of implementation.

A final concern regarding the usefulness of networked cooperation concerns the implementation of the outputs produced by networks; two notions seem relevant to this. The first is that the regulatory norms produced by networks do not take the form of hard law. The standards and guidelines that network participants may agree on must be considered as soft-law acts "representing good faith undertakings of participants in the network". ${ }^{117}$ Chapter 5 on post-legislative guidance shows that compliance with soft law

\footnotetext{
${ }^{110}$ Slaughter refers to this as "positive comity", see Slaughter, 2004: 250; Eberlein and Grande, 2005: 103.

111 Tshuma, 2000: 136.

${ }^{112}$ Kohler-Koch, 2009: 50-51, on rationales for involving civil society in policy-making processes.

${ }^{113}$ See Chapter 5 on post-legislative guidance, Sections 1.2 .2 and 3.2.

${ }^{114}$ COM (94) 29 final, p. vii; italics added.

${ }^{115}$ See Slaughter, 2004: 248, who labels this 'legitimate difference'. See also Sabel and Zeitlin, 2010: 4, who argue that deliberation in the EU is "driven by the discussion and elaboration of persistent difference".

${ }^{116}$ De Moor-Van Vught, 2011: 102.

117 Tshuma, 2000: 135.
} 
acts should not be taken for granted, and that the implementation of such acts across member states may be erratic.

The second issue relates to the importance of monitoring to ensure implementation. Section 1.1.1 of this chapter suggests that the opportunities for network members to monitor each others' performance are conducive to trust building, which actorcentred institutionalism argues is important for effective implementation. ${ }^{118}$ Monitoring is also important, since it brings the threat of reputational costs for those that choose to defect; this is necessary to keep unwilling member states in check. ${ }^{119}$ Thus, when monitoring mechanisms are lacking, implementation may suffer not only for member states that 'are not seen' (because the low probability of detection reduces the credibility of sanctions), but also on the part of those that 'do no see' (because of the said lack of trust).

\subsubsection{Input legitimacy: accountability, transparency, and participation}

While the previous sections reflect on possible limitations of networked cooperation in terms of output legitimacy, the current section briefly elaborates on possible shortcomings regarding the democratic legitimacy of networks. Before elaborating on the aspects that are relevant in this regard, it must be said that the manner in which the democratic legitimacy of networks is assessed partly depends on the nature of the functions assigned to these networks. ${ }^{120}$ Arguably, standards for self-initiated networks that concern themselves with the practicalities of law administration may, or should, differ from standards for mandated networks with a great influence on regulatory policy making in a certain area. Similarly, networks that receive public funding may be subject to different standards of legitimacy than networks for which this is not the case.

Considering that legitimacy assessments may be case dependent, it seems that there are three principles that must be accounted for in such assessments. The first of these principles is accountability. In order to pass the accountability test, networks should have a legal basis or be otherwise accountable. There should at least be openness about what they do and the decisions that they make. ${ }^{121}$ The second principle concerns participation. Networks should enable inclusive participation out of not only a functional belief that those who are affected have the relevant knowledge to successfully address policy issues, but also a normative belief that those who are affected should have the right to participate. ${ }^{122}$ Third, there should be transparency about the role that networks

\footnotetext{
${ }^{118}$ For the idea that transparency functions as a trust-building mechanism, see Chapter 3 on the approach and methodology of this study, Section 2.2.

${ }^{119}$ See also ibid., Section 2.1 .

${ }^{120}$ Sørensen and Torfing, 2009: 245.

${ }^{121}$ Baldwin and McCrudden, 1987, in De Visser, 2009: 258.

${ }^{122}$ Kohler-Koch, 2009: 51. For an elaboration on the increased attention in the EU to participatory governance, see Chapter 7 on civil society.
} 
play in the policy process. ${ }^{123}$ Assessed against these three principles, cooperation in the context of informal networks "naturally look[s] suspicious", ${ }^{124}$ as the following elaboration elucidates.

Networks codified in EU legislation seem to score well on accountability and legal clarity when the relevant legislation specifies the powers and duties of network members in detail. ${ }^{125}$ This, however, is not always the case. Networks may not have a strong legal basis; they may be mandated through soft-law notices or Commission decisions. This does not provide them with strong credentials in this regard. ${ }^{126}$ In addition, establishing acts may specify the objectives that networks should achieve only vaguely, leaving room for interpretation of the responsibilities of networks and leaving network members with substantial interpretative discretion to fill in technical details and societal norms that the legislature should define. ${ }^{127}$ If this is the case, or if acts that are adopted by networks do not provide the reasons on which they are based, ${ }^{128}$ judicial review of the legitimacy of contestable acts - for example of whether these acts are adopted ultra vires - will be difficult. ${ }^{129}$

Where mandates are vague or lack a basis in secondary legislation, transparency and wide participation by other stakeholders are particularly imperative. ${ }^{130}$ Transparency - for example through websites, annual reports, or meetings with stakeholders - is indispensable if networks are to be held accountable for their actions, and it is important for its potential to stimulate participation. ${ }^{131}$ There has, however, been much discussion regarding the limited degree to which information about 'what is going on inside the box' is available. It has been argued that information is not sufficiently available and that networks have remained black boxes. ${ }^{132}$ Transparency concerns seem particularly pressing in relation to informal networks, which, acting outside the EU institutional framework, are more likely to lack procedural rules for access to information. ${ }^{133}$ The lack of such rules may be explained by the alleged incompatibility between effectiveness and transparency; it has been argued that the effectiveness of informal networks is precondi-

\footnotetext{
${ }^{123}$ COM (2001) 428 final, p. 7. The good governance principles set out by the Commission have been subject to criticism, for example in relation to the lack of precision inherent therein. Filled in with understandings derived from other studies, however, they seem to be useful yardsticks for evaluation.

${ }^{124}$ Sabel and Zeitlin, 2010: 2; cf. Eberlein and Grande, 2005: 106.

${ }^{125}$ Craig, 2009: 39-40, 45-46.

${ }^{126}$ De Visser, 2009: 260.

${ }^{127}$ Ibid.: 259; Craig, 2009: 45-46.

${ }^{128}$ Reason giving is one element of due process. The second one, inclusive deliberation, is elaborated on below.

${ }^{129}$ De Visser, 2009: 259. For an elaboration the principle of effective judicial protection in relation to networks, see De Visser, 2009: 284ff.

${ }^{130}$ Craig, 2009: 45-46.

${ }^{131}$ De Visser, 2009: 276-277.

${ }^{132}$ De Moor-Van Vught, 2011: 102.

${ }^{133}$ Cf. Craig, 2009: 47.
} 
tioned to a lack of disclosure about the whereabouts of network participants. ${ }^{134}$ If this is true, there seems to be a trade-off between the degree to which networks can meet input legitimacy requirements and the degree to which they can be effective problem-solving instruments. ${ }^{135}$

The lack of transparency exacerbates another problem that is inherent in networked cooperation: that of the domination of "experts and enthusiasts"136 and that of the lack of inclusion of all affected interests, in network deliberations. ${ }^{137}$ Indeed, even though new modes of governance such as networks are widely seen as enhancing opportunities for participatory governance, these modes "are [not] by definition synonymous for more participatory policy-making". ${ }^{138}$ It has been argued that new forms of governance, while more horizontal and heterarchical, may actually raise concerns regarding technocratisation and a dominance of national administration, concerns that may have been absent under the participatory regime used under the Community method. ${ }^{139}$ While understandable from a confidentiality perspective, this lack of inclusion is problematic because it reduces the effectiveness of network outcomes, as Section 1.2.3 suggests. Moreover, it hinders the acceptability of such outcomes from the public, ${ }^{140}$ and amongst those directly affected by the outcome. This lack of acceptability may negatively affect the effectiveness of networks as compliance instruments, underlining once again the importance of inclusion from both an input and output legitimacy point of view. ${ }^{141}$

\section{Networks relevant to this study}

The introduction to this chapter defines transnational governance networks as structures of interdependence, involving cross-border, horizontal cooperation amongst multiple, operationally autonomous actors pursuing common public goals. This broad definition covers various forms of networks. ${ }^{142}$ This section presents the most prominent networked forms of cooperation existing in the context of the three directives subject to examination in this study. It outlines the formal features of each of these networks and the roles that they are supposed to play in the policy context.

\footnotetext{
${ }^{134}$ Eberlein and Grande, 2005: 106.

${ }^{135}$ For a similar argument, see Chapter 5 on post-legislative guidance, which has argued that inclusion in the guidance development processes may greatly delay the adoption of guidance and yield political compromises that may be a source of confusion for implementation actors who need to use these guidelines in practice.

${ }^{136}$ Craig, 2009: 3 .

${ }^{137}$ This type of inclusion is referred to as "global deliberate equality", in Slaughter, 2004: 246

${ }^{138}$ Smismans, 2008: 876.

${ }^{139}$ See e.g. Smismans, 2008, who uses the area of occupational health and safety as an example.

${ }^{140}$ De Visser, 2009: 271.

${ }^{141}$ For a similar argument, see Chapter 5 on post-legislative guidance, Section 1.2.2.4.

${ }^{142}$ For a schematic picture, see Figure 8 included in the introduction of this chapter.
} 
Particular attention is paid to the networks that are focused on in the analysis presented in Section 3 of this chapter. These networks include: the Consumer Safety Network (CSN) and Prosafe (the Product Safety Enforcement Forum of Europe), for the Directive on general product safety; IMPEL (the European Union Network for the Implementation and Enforcement of Environmental Law), for the area of integrated pollution prevention and control; and the European SAFA Steering Group, for the SAFA Directive. What distinguishes these networks from a material perspective is the policy domain in which they exist. What distinguishes them from a legal perspective is the degree to which they are encapsulated in the EU institutional framework. Table 16 categorises these networks with reference to both types of distinctions. The features of these networks are discussed in detail after each global review of the networked forms of cooperation in the context of each directive.

Table 16 Networks focused on in this study

\begin{tabular}{lll}
\hline & Legally formal & Legally informal \\
\hline GPS & Consumer Safety Network & Prosafe \\
IPPC & not applicable & IMPEL \\
SAFA & not applicable & European SAFA Steering Group \\
\hline
\end{tabular}

\subsection{The GPS Directive}

The implementation context of the GPS Directive features a number of networked forms of cooperation, as Figure 10 demonstrates. ${ }^{143}$

With respect to law making, we find the GPSD committee, which assists the Commission in its implementation tasks. One of the matters that requires the involvement of the committee is the adoption of urgency measures, which the Commission may propose when products pose a serious risk to consumer health and safety. Such measures may, for example, make the marketing of products subject to prior conditions that make them safe, or order that products be withdrawn from the market. ${ }^{144}$

\footnotetext{
${ }^{143}$ Note that the figures in this section are modeled on the figure in the introduction to this chapter, which has served to distinguish schematically between different forms of networks.

${ }^{144}$ Directive 2001/95/EC, Art. 13, in conjunction with Art. 15.
} 


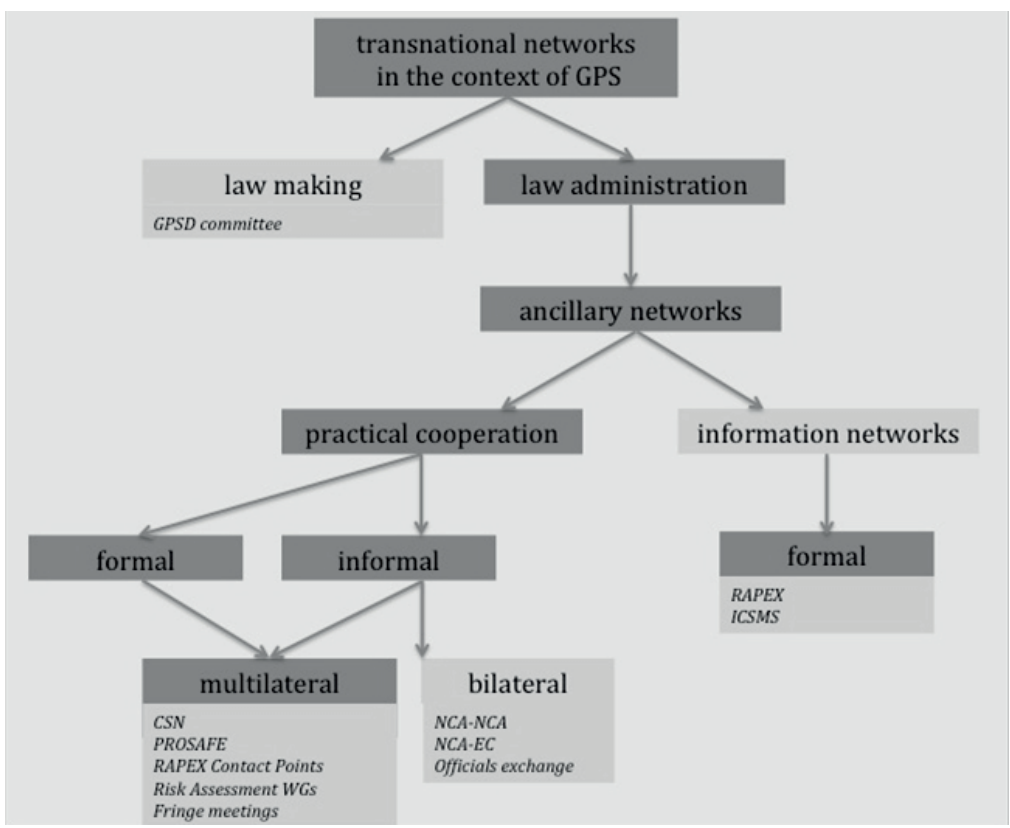

Figure 10 Networks in the context of the GPS Directive

With respect to law administration, we find a number of information networks. RAPEX, the rapid alert system for dangerous non-food products, is undoubtedly the most central of these networks. RAPEX is a formal, Commission-owned application that aims to ensure a rapid exchange of information concerning consumer products that pose a serious risk. Member states must notify the Commission of serious-risk products that they find on their territory ('RAPEX notifications'). The Commission acts as a clearinghouse; it classifies and indexes the notifications and it verifies that information received through RAPEX complies with the relevant legal provisions. It may then distribute the notifications to the other member states. These member states must then notify the Commission about whether or not the product is present at their territory and about the measures that they intend to adopt. ${ }^{145}$ The RAPEX system is also used for notifications of products that do not present a serious risk ('notifications for information'). ${ }^{146}$ The RAPEX website and publications such as RAPEX reports provide information about notifications to the public. ${ }^{147}$

\footnotetext{
${ }^{145}$ Ibid., Art. 12, in conjunction with Annex II, and Commission Decision 2010/15/EC), in particular point 3.1.1 (obligations for member states when notifying products to RAPEX), 3.4 (verification of notifications by the Commission), 3.5 (distribution of notifications by the Commission to the member states), and 3.7 and 4 (on member state follow up).

${ }^{146}$ Directive 2001/95/EC, Art. 11, in conjunction with Commission Decision 2010/15/EC, point 3.1.2.

${ }^{147}$ Commission Decision 2010/15/EC, point 1.2.
} 
A second online platform is ICSMS, the internet-supported information and communication system for market surveillance. ${ }^{148}$ ICSMS was a joint venture of a number of market surveillance authorities. The Commission took over ownership and management of the system to implement the obligation outlined in the Market Surveillance Regulation, to "develop and maintain a general archiving and exchange of information system" on issues related to market surveillance activities. ${ }^{149}$ Said to create "the basis for an effective and efficient cooperation between the market surveillance bodies in Europe", ${ }^{150}$ ICSMS aims to facilitate the exchange of test results and risk assessments, gather the contact information for the market surveillance authorities of the member states, and provide detailed information about technical products.

Regarding practical transnational cooperation, bilateral forms such as contacts between individual authorities, or between authorities and the European Commission, are juxtaposed to multilateral forms of cooperation. Regarding the latter, reference must be made to the RAPEX Contact Points Network, which is a formal network steered and organised by the Commission. The purpose of this network is to enable discussions regarding the operation of RAPEX and to help improve the communication between contact points. ${ }^{151}$ Informal networks such as risk assessment working groups have, in the past, functioned to assist the Commission in attempts to improve the quality of the RAPEX guidelines. ${ }^{152}$ Fringe meetings allow member states to 'socialise' in-between multilateral meetings that are organised in Brussels or elsewhere.

The focus of the analysis in Section 3 of this chapter is not on these networks. The introduction to this chapter states that our interest lies in understanding the usefulness of multilateral implementation networks that enable practical cooperation between national competent authorities. In view of this interest, law-making networks (the GPSD committee) and information platforms (RAPEX and ICSMS) are excluded from in-depth analysis. Two of the networks that aim to facilitate practical cooperation amongst national authorities are not targeted at product safety inspectors or are not aimed at improving inspections or risk assessments on the ground, which excludes these networks (the RAPEX Contact Points Network and risk assessment working groups) from our subsequent analysis as well. Informal bilateral and multilateral contacts may concern the street-level implementation of product safety legislation, but much has been

\footnotetext{
${ }^{148}$ See European Commission, 'ICSMS', <https://webgate.ec.europa.eu/icsms/>.

${ }^{149}$ Regulation 765/2008/EC of the European Parliament and of the Council of 9 July 2008 setting out the requirements for accreditation and market surveillance relating to the marketing of products and repealing Regulation (EEC) No 339/93 [2008] OJ L 218/30, Art. 23.

${ }^{150}$ See European Commission, 'ICSMS', <https://webgate.ec.europa.eu/icsms/>.

${ }^{151}$ Commission Decision 2010/15/EC, point 5.2.1. The national RAPEX contact points run their own RAPEX National Networks, which involve the market surveillance authorities and the authorities responsible for border controls; see point 5.2.2.

152 See European Commission, 'Consumers, Committees, networks, and working groups', $<$ http://ec.europa.eu/consumers/archive/safety/committees $>$. See Chapter 5 on post-legislative guidance.
} 
said about informal relations in the EU already. ${ }^{153}$ The survey and interviews conducted for this study merely confirm the importance of informal relations that support market surveillance activities in the member states. ${ }^{154}$

Therefore, there are two possible candidates for analysis: the Consumer Safety Network and Prosafe. It is these two networks that the in-depth analysis in Section 3 turns to and that the following subsections describe in detail.

\subsubsection{The Consumer Safety Network}

The Consumer Safety Network was developed after the merger of the Product Safety Network and the Consumer Safety Working Party, in 2008. Formally established by Article 10 of the GPS Directive and chaired by the European Commission, it is firmly anchored in the EU institutional framework. Participants in this network are experts of the competent authorities responsible for the implementation of the GPS Directive. Accession and candidate countries, business and consumer organisations, the European Parliament, external experts, and Prosafe enjoy the status of observers. Meetings of the network usually take place three times a year. ${ }^{155}$

The Consumer Safety Network gathers the named authorities and the Commission "in particular in the form of administrative cooperation". ${ }^{156}$ Its aims are, more concretely, to facilitate "the exchange of information on risk assessment, dangerous products, test methods and results, recent scientific developments as well as other aspects relevant for control activities", "the establishment and execution of joint surveillance and testing projects", "the exchange of expertise and best practices and cooperation in training activities", and "improved cooperation at Community level with regard to the tracing, withdrawal and recall of dangerous products". ${ }^{157}$ As such, it aims to support the market surveillance authorities in the street-level implementation process, which makes it interesting to examine the usefulness of cooperation taking place within this network.

\footnotetext{
${ }^{153}$ See e.g. Christiansen and Piattoni, 2003.

${ }^{154}$ All interviews carried out for this study. See Christiansen et al., 2003: 5 for a similar statement, and further contributions to this volume for the implications of informal governance in the EU.

${ }^{155}$ Some of these notions are are outlined in legislation. The GPS Directive only refers to the composition of the network and its tasks. Information on the number of meetings and the observer status of certain actors is retrieved from documents on meetings of the network, published on the Commission's website; see European Commission, 'Consumers, Committees, networks, and working groups', <http://ec.europa.eu/consumers/ archive/safety/committees $>$.

${ }^{156}$ Directive 2001/95/EC, Art. 10(1).

${ }^{157}$ Directive 2001/95/EC, Art. 10(2), sub a-d.
} 


\subsubsection{Prosafe ${ }^{158}$}

The creation of the Consumer Safety Network was preceded by the birth of Prosafe, a freestanding, informal forum for cooperation, established in 1992 by market surveillance officers from various European countries. Prosafe currently gathers officials from market surveillance authorities from 33 countries (plus Hong Kong). This means that the network comprises more than EU member states, which seems to suggest that cooperation with third countries is seen as helpful for ensuring that the objectives of European product safety legislation are achieved. Prosafe is managed by a Board, which is elected by the General Assembly, and it has a secretariat to support the functioning of the organisation. The European Commission and the European Free Trade Area (EFTA) are permitted to be present at meetings of the General Assembly, which are organised at least twice a year.

Prosafe's mission is "to facilitate the cooperation between market surveillance officers to improve product and service safety". As such, its scope extends beyond the domain of product safety. More concretely, it aims to promote the informal exchange of information, experiences and best practices "whilst employing a maximum of discretion", for example through meetings of the General Assembly and other discussion forums. It also aims to facilitate cross-border cooperation amongst market surveillance officers by acting as a link between the European Commission and the member states in the initiation and organisation of joint market surveillance actions co-funded by the Commission and EFTA. Such actions may aim to achieve a basic level of expertise and practical experience amongst market surveillance organisations ('horizontal activities'), or to increase the safety of specific products or product categories ('vertical activities'). Particularly the need to maintain more formal relations with the European Commission and EFTA has required Prosafe to undergo a degree of professionalisation. This professionalisation involved the creation, in 2005, of a Prosafe Foundation, next to the already existing Prosafe Association.

Since Prosafe aims to achieve the same objectives as the Consumer Safety Network, and since cooperation in Prosafe takes place within a different format than that charaterising the Consumer Safety Network, it is interesting to compare the extent to which both networks achieve their goals.

\subsection{The IPPC Directive}

Having reflected on the networked forms of cooperation in the domain of general product safety, the focus now shifts to providing insight into the networks in the area of

\footnotetext{
158 The following information and quotes are taken from the website of Prosafe; see Prosafe, $<w w w . p r o s a f e . o r g>$.
} 
integrated pollution prevention and control. Figure 11 pictures the networks that are relevant in this regard. ${ }^{159}$

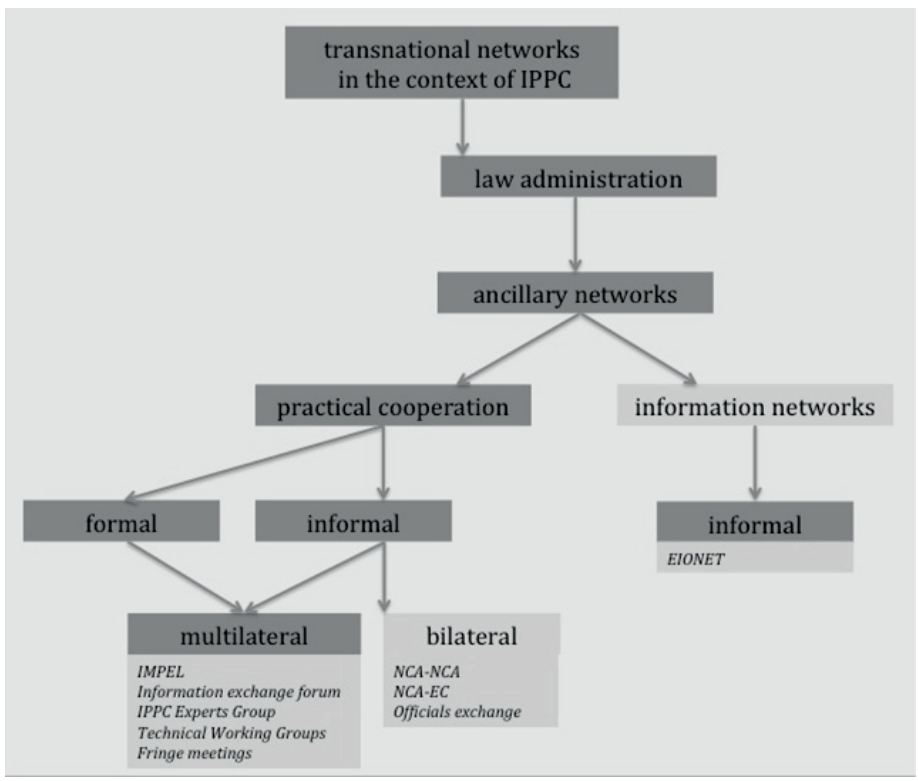

Figure 11 Networks in the context of the IPPC Directive

The IPPC Directive does not provide for the establishment of a law-making network to assist the Commission with its implementation tasks because the directive does not task the Commission with the adoption of - what are now - implementing acts. ${ }^{160}$ On the implementation side we find EIONET, the European Environment Information and Observation Network. ${ }^{161}$ EIONET is a network of the European Environment Bureau, which includes approximately 1,000 experts from 39 countries in over 350 national environment agencies and other bodies that deal with environmental information. EIONET aims to provide information and expertise about the state of the environment in Europe, allowing policy makers to monitor the effectiveness of the policies that have been implemented. ${ }^{162}$ It is used for the dissemination of information provided by member states following their reporting obligations under the IPPC Directive. ${ }^{163}$

\footnotetext{
${ }^{159}$ Note that cooperation under the IED differs from cooperation in the context of the IPPC Directive; the main differences are explained in footnotes.

${ }^{160}$ The Directive on industrial emissions, however, does require the involvement of a committee - the Article75 IED committee - in the adoption of BAT conclusions. See Directive 2010/75/EC, Art. 13, in conjunction with Art. 75. On the BAT conclusions, see Chapter 5 on post-legislative guidance.

${ }^{161}$ See European Environment Agency, Eionet, <http://www.eionet.europa.eu>.

162 Ibid.

${ }^{163}$ Directive 2008/1/EC, Art. 17 (1) and (3). National reports are available on European Environment Agency, 'Eionet: Central Data Repository', <http://cdr.eionet.europa.eu>; 'Eionet: Reporting Obligations Database:
} 
The IPPC Directive features a number of networks that enable practical cooperation amongst national competent authorities. Many of these are linked to the information exchange process for the best available techniques, which is elaborated on in Chapter 5 on post-legislative guidance. ${ }^{164}$ From Chapter 5, one may recall that the information exchange process is managed by the European IPPC Bureau (EIPPCB), which conducts its work through technical working groups. The TWGs are informal groups set up by the Commission for the development and review of each BREF. They are comprised of technical experts representing member states, industries, environmental organisations, and the Commission. The TWGs send progress reports and draft BREFs to the informal Information Exchange Forum, which involves the Commission, member states, and industry representatives as members, and environmental organisations and non EUstates as observers. The Forum steers the information exchange process and acts as a platform for the discussion of horizontal and general issues related to the information exchange process. ${ }^{165}$ It receives advice from the informal IPPC Expert Group, ${ }^{166}$ which is composed of member state representatives and the Commission. The IPPC Expert Group also exchanges information about the directive as a whole and primarily deals with the implementation and review of the directive. ${ }^{167}$

The previous section, which addresses networks in the context of the GPS Directive, has recalled that the focus of this study is on multilateral implementation networks that facilitate practical cooperation and aim to support street-level actors. With this in mind, the current study does not focus on information networks (in this case, EIONET). In addition, networks that facilitate information exchange regarding the development of the BREFs (technical working groups, the IPPC Expert Group, and the Information Exchange Forum) are not subjected to further analysis. Since much is known about informal relations amongst national and EU officials, ${ }^{168}$ and the survey and interviews carried out for this study merely confirm the relevance of informal contacts for supporting the application process, such relations are not focused on either.

The focus of the analysis in Section 3 of this chapter is on IMPEL instead. The characteristics of this network are elaborated on below.

\footnotetext{
Reporting obligation for IPPC questionnaire', <http://rod.eionet.europa.eu/ obligations/523>; and 'Eionet: Industrial Emissions Reporting Information System (IRIS)', <http://iris.eionet.europa.eu>.

${ }^{164}$ See Chapter 5 on post-legislative guidance, Section 2.2.1.

${ }^{165}$ Under the IED, the Forum has been formalised. It has been established by a Commission decision and is now known as the IED Article 13 Forum.

${ }^{166}$ Under the IED Directive, this group is known as the Industrial Emissions Experts Group. It has remained informal.

${ }^{167}$ See European IPPC Bureau, 'Who is who in the IED', <http://eippcb.jrc.ec.europa.eu/about/who_ is _who.html>.

${ }^{168}$ See Section 2.1.
} 


\subsubsection{IMPEL ${ }^{169}$}

The precursor to IMPEL, the Network of EC Environmental Enforcement Agencies, was established in 1992 by environmental authorities across European countries. Members are national, regional, and local authorities of the member states, of acceding or candidate countries and of countries in the European Economic Area that are competent in the implementation of environmental law. Currently, IMPEL has 45 member authorities in 22 countries. It has a Board and a General Assembly, which is comprised of national representatives and to which EU institutions and organisations may be admitted as observers. It also has a secretariat that is responsible for the day-to-day running of the network.

While fully informal initially, the Commission came to co-chair the network in 1994; a pragmatic answer to the recognition in the Fifth Environment Action Programme that the Commission should have a role in an environmental implementation and enforcement network. The Commission gave up this position following establishment of the independent IMPEL association, in 2008. Both the Commission's withdrawal from the network and the establishment of the association were instigated, in part, by the intention of the Commission to start funding IMPEL activities through the LIFE+ programme. While necessary from a practical point of view, the establishment of the association was meant to be a 'light touch' and to leave the informal structures of the network intact. Note that the Sixth Environmental Action Programme, launched in 2002, gave IMPEL legal recognition and a legal basis for its activities in the context of the programme.

The purpose of IMPEL is "to create the necessary impetus in the European Union to make progress on ensuring a more effective application of environmental legislation." It aims to achieve this by promoting the exchange of information and experiences between environmental authorities on the implementation of EU environmental law; identifying and developing best practices; producing guidance, tools, and common standards; contributing to improvements in permitting practices; and encouraging and facilitating capacity building and training activities. Key objectives for specific periods are outlined in IMPEL's multiannual strategic programmes. These objectives are achieved through meetings for exchanging information and experiences and enhancing consistency and best practices, and by means of projects conducting research on specific objectives. IMPEL's website refers to the implementation of a range of projects related to different aspects of environmental licensing under the IPPC Directive, which according to the website, is a "core issue" for cooperation through the network.

${ }^{169}$ The following information and quotes are taken from the website of IMPEL; see IMPEL, <http://impel.eu>. 


\subsection{The SAFA Directive}

Having discussed the networked forms of cooperation in the context of the GPS and IPPC Directives, what is left to consider are the networks existing in the area of SAFA. The relevant networks are depicted schematically in Figure 12 and discussed in detail below.

In the area of law making, we find the Air Safety Committee, which was established by the SAFA Directive with the aim of assisting the Commission in the adoption of implementation measures. ${ }^{170}$ The Commission may propose measures detailing, for example, the content and procedures of ramp inspections, the format for the storage and dissemination of data, and the nature of information collected by the member states. ${ }^{171}$

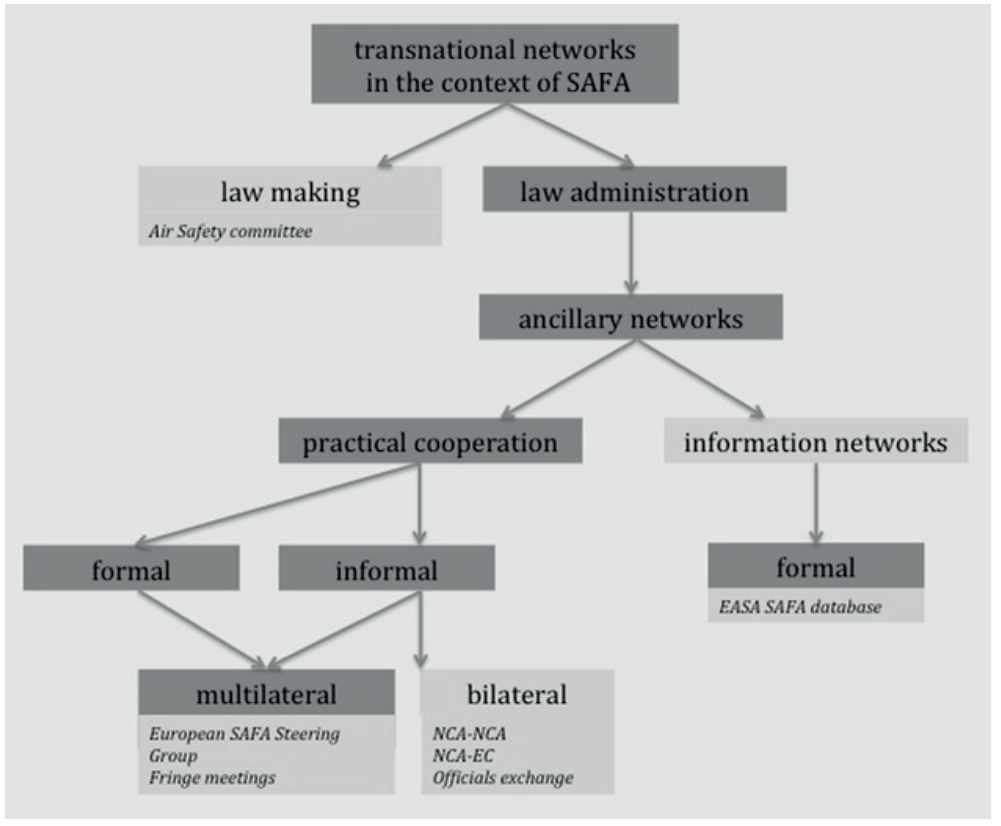

Figure 12 Networks in the context of the SAFA Directive

Regarding the domain of implementation, the SAFA Directive and the relevant implementing legislation require the establishment of a SAFA centralised database developed, maintained, and updated by the European Aviation Safety Agency, in order to facilitate the exchange of information amongst member states. ${ }^{172}$ This formal database includes reports on all SAFA ramp inspections conducted by the national aviation authorities,

\footnotetext{
${ }^{170}$ Directive 2004/36/EC, Article 10.

${ }^{171}$ Ibid., Article 8(2).

${ }^{172}$ Ibid., Article 5(1), in conjunction with Commission Regulation (EC) 768/2006, Art. 2.
} 
which member states feed into the database. ${ }^{173}$ Practical cooperation takes place informally, for example in the framework of bilateral contacts between individual authorities or between authorities and the Commission, and through multilateral fringe meetings.

In view of this chapter's focus on multilateral networks that permit practical cooperation between national competent authorities, law-making networks (the Air Safety Committee) and information databases (the SAFA centralised database) are not subject to further analysis. The same principle applies to informal relations, though for different reasons. ${ }^{174}$ In the remainder of this chapter, the focus is on the European SAFA Steering Group. The characteristics of this group are elaborated on below.

\subsubsection{The European SAFA Steering Group ${ }^{175}$}

The ESSG succeeded the Joint Aviation Authorities-National Coordinators (JAA-NC) Group, which was in place between 1997 and 2006, when the SAFA Programme, not yet outlined in EU legislation, functioned under the auspices of the Joint Aviation Authorities. The network was established in the European context - though not formally institutionalised - when the SAFA Directive entered into force and the management of the directive was submitted to the European Commission, which chairs the network, and the European Aviation Safety Agency. Currently, the ESSG gathers the SAFA national coordinators of the EU member states and the non-EU members of the European Civil Aviation Conference (ECAC), countries engaged in the SAFA Programme, and representatives from EASA and Eurocontrol. Candidate SAFA participating states are invited as observers. The ESSG meets three times a year.

The ESSG is, in principle, a technical advisory group that aims to advise the Commission about proposals from EASA before such proposals are tabled for discussion in the Air Safety Committee. The ESSG also advises the Commission regarding the safety oversight policy of the SAFA Programme and about possible actions to take in specific safety cases. Moreover, it gives recommendations for further development of the SAFA Programme and provides the Commission with feedback on the national implementation of the SAFA Programme. Finally, the ESSG reviews and responds to the safety analysis that EASA is required to carry out on the basis of the inspection reports submitted by states into the centralised SAFA database, before submission of this analysis to the Air Safety Committee. The purpose of this safety analysis is to identify carriers that pose a particular safety threat, and to check the consistency of member state findings for identical operators.

\footnotetext{
${ }^{173}$ Commission Regulation (EC) 768/2006, Art. 3.

${ }^{174}$ See section 2.1 of the current chapter.

175 The information below is based on the European Aviation Safety Agency, 'Ramp Inspection Programme (SAFA/SACA)', <http://www.easa.europa.eu/node/15629>, and on interview EASA1. Note that the ESSG has recently been renamed as Ramp Inspection Coordination and Standardisation.
} 
Note that the SAFA national coordinators partaking in meetings of the ESSG may be involved in the street-level implementation of the SAFA Directive or have an oversight function only. ${ }^{176}$ According to an EASA official, $85-90 \%$ of the national coordinators conduct SAFA ramp inspections next to the policy management tasks that they exercise. ${ }^{177}$ The notion that multilateral networks targeted at SAFA inspectors exclusively do not exist, and the idea that ESSG is as close to the street-level as one can get, explains the focus of our analysis on the ESSG.

\section{The usefulness of networks as compliance instruments}

While the introduction to this chapter states that networks are plentiful, this section suggests that there is a good reason for this. In all three policy domains, the networks included in this study are considered important compliance instruments. The way in which cooperation is useful, and the extent to which this is the case, seems to vary across countries and policy domains. Section 3.1 elaborates on the importance of the notion of interdependence for motivating cross-border cooperation. The virtues that networks are associated with, both in situations of interdependence and in situations where interdependence is weak are discussed in Section 3.2. Section 3.3 then discusses the conditions under which cooperation seems to function best. Finally, Section 3.4 examines what seem to be the most pressing weaknesses of (informal) networks as compliance instruments.

\subsection{Perceived interdependence}

Similar to post-legislative guidance, ${ }^{178}$ the usefulness of networks as compliance instruments must be evaluated stepwise: first, there is the question of whether officials are involved in cross-border cooperation and if so, why this is the case. Second, when officials are engaged in cooperation, the question is about whether or not they find this cooperation useful and if so, what they appreciate about it. The current section concerns the former aspect; the latter element is elaborated on in subsequent sections.

Interviews suggest that there may be three broad reasons for member state authorities to engage in cooperation. ${ }^{179}$ First, authorities may feel obligated to be present at network meetings, given the formal institutional framework where these meetings oc-

\footnotetext{
${ }^{176}$ Relevant to the context of this study is that while the former is the case for the Dutch and Polish SAFA national coordinators, the latter applies to the Portuguese SAFA national coordinator. See Chapter 4 on monitoring and sanctions, Section 3.1, for a discussion.

${ }^{177}$ Email from interviewee EASA1 to author

${ }^{178}$ See Chapter 5 on post-legislative guidance, Section 3.1.

${ }^{179}$ Note that these reasons are not necessarily mutually exclusive; the matches between motivational factors and particular networks outlined in the following sentences speak to the primary reasons for cooperation through these particular networks.
} 
cur. This appears to be the case for the Consumer Safety Network in particular, which is the only legally formal network in the context of this study. ${ }^{180}$ This finding is illustrated in Section 3.3 below. Second, authorities may be instigated to engage in cooperation by the perception that for each of them to perform well in the administration of the relevant measures, their colleagues must perform equally well. Officials who are involved in cooperation through Prosafe and through the European SAFA Steering Group, often refer to the notion of interdependence as a factor motivating cooperation, as we see below. Third and finally, when interdependence is low authorities may engage in networks because of particular virtues (other than those related to interdependence) that these networks are perceived to produce. The case of integration pollution prevention and control seems to be exemplary in this regard.

An elaboration on what motivates authorities to participate in transnational networks seems most interesting for cases in which such participation is not perceived as obligatory. This excludes participation in the Consumer Safety Network from our analysis at this point. Regarding the three other networks included in this study, an interesting distinction can be made between Prosafe and the ESSG, and IMPEL, as suggested above. In the areas of prod-

92\% of the GSP survey respondents indicate that the authority that they belong to participates in Prosafe: $85 \%$ once or several times a year, and $7 \%$ less often.

uct and air safety, officials explicitly refer to interdependence as an important factor that motivates cooperation with colleagues from other member states. The free movement of goods within the single European market makes product safety an issue of common concern for the market surveillance authorities of the member states. In the words of an official from Prosafe:

Product safety is a topic of which you cannot think in national terms only. I spoke with a business operator that said: "so my product is not admitted to the Antwerp port? I will take it to Hamburg and import it to Europe from there". Then I answered: "I will inform my colleagues from Hamburg that this product is coming to them". My conversation partner didn't quite like that. This shows that it doesn't work to think nationally. We are in an internal European market, so we have to co-operate - otherwise products will enter our market after we have just sent them back because they are unsafe! ${ }^{181}$

Likewise, the international nature of air traffic makes air safety an issue of common concern for all civil aviation authorities. In the words of an official involved in the implementation of the SAFA Directive:

\footnotetext{
${ }^{180}$ And to the ESSG to some extent, too. However, this does not seem the prime motivation for officials to perceive such cooperation as useful.

${ }^{181}$ Interview Prosafe1; similar Prosafe3.
} 
It is impossible to impose national boundaries on aviation. Even if it is a foreign operator, the foreign operator is flying all over the world, and he may be taking some Portuguese citizens, even between Alaska and Mongolia. There is always a Portuguese guy traveling between Alaska and Mongolia. And I can say the same about Portuguese operators; there is always some Portuguese operator operating flights to Mecca during the pilgrimage period. So aviation, because it is international, is by nature a national issue. ${ }^{182}$

The above citations suggest that for each market surveillance and civil aviation authority to be effective in the implementation process, it is important that all competent authori-

All SAFA survey respondents eligible for participation in ESSG meetings do participate in such meetings. ties perform adequately. Only one of them needs to underperform for effective implementation to be endangered; hence the perception that authorities are interdependent and that cooperation is needed if the implementation performance of each of these authorities is to be successful.

The dynamics that play a role here are illustrated in Figure 13. Picturing the mutually reinforcing effect of cooperation and mutual trust, and outlining conflict resolution as an important virtue that cooperation in situations of interdependence is associated with, this figure partly anticipates the discussion in the following sections. Note that cooperation in situations of interdependence may also be appreciated because of the efficiency gains that it produces for some authorities (see Section 3.2 below), and this figure is, therefore, not complete. It shows how appreciation of cooperation in situations of interdependence differs from appreciation in situations without interdependence, and what officials in the two policy domains where perceptions of interdependence are high hold in common.

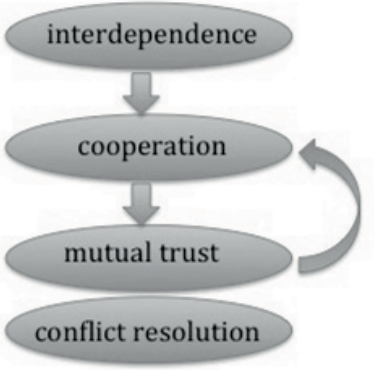

Figure 13 Incentives and prime virtues of cooperation present interdependence

${ }^{182}$ Interview PT17. Similar NL29. 
The functional argument outlined above is not accepted in the case of the IPPC Directive. While pollution crosses borders like products and airplanes, the interdependency argument generally does not come to the fore as a motivational factor for cooperation, at least not in the interviews conducted in this study. Even the suggestion that more lenient permit conditions for industrial installations in other member states may provide a competitive edge to such countries

$90 \%$ of the IPPC survey respondents indicate that they or their direct colleagues participate in IMPEL: $66 \%$ once or several times a year, and $24 \%$ less than that. The participation rate is significantly lower for permit writers.

as well as the relevant economic operators - emphasising possible economic costs associated with unequal implementation - does not seem to motivate officials to cooperate. The relatively weak perceptions of interdependence in the case of the IPPC Directive, and the resulting relatively weak perception that there is an urgent reason for cooperation to take place, are underlined by the following citation:

There is no ADCO [committee for administrative cooperation] in the IPPC Directive. This probably also depends on the topic: the cross-border element is not as strong as for example in the case of the General Product Safety Directive. There is no direct reason to create something for the IPPC Directive. ${ }^{183}$

Relatively weak levels of interdependence in the case of the IPPC Directive may explain why officials demonstrate less of a preference for administrative cooperation in this case, than in the case of the other two directives in this study. The idea that cooperation through the IMPEL network does occur suggests that there are other factors that stimulate officials to engage in cooperation. Thus, the virtues of cooperation, other than those that relate directly to interdependence, seem important, as Figure 14 suggests and as the following section demonstrates.

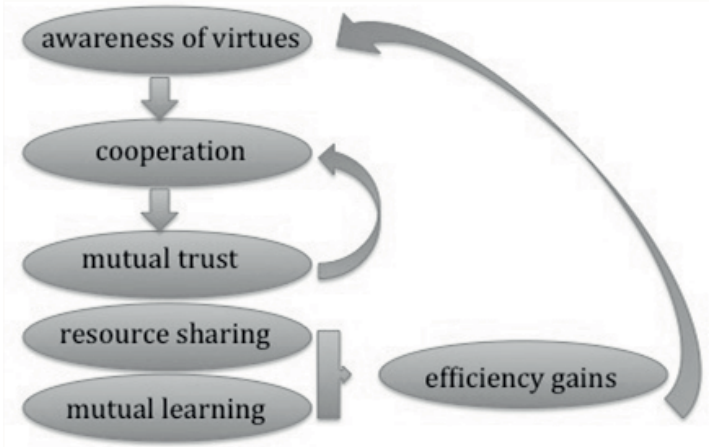

Figure 14 Incentives and perceived virtues of cooperation without interdependence

${ }^{183}$ Interview NL17. 


\subsection{The virtues of transnational cooperation}

Section 1.1 suggests that the virtues that cross-border cooperation is associated with relate to the notions of mutual learning, resource sharing, mutual trust, and conflict resolution. The importance that officials attach to these notions seems to depend, first of all, on the nature of the policy domain, and specifically on the extent to which officials feel that they are interdependent in the implementation process. Where high degrees of interdependence are perceived, officials appear to attach much importance to the conflict resolution potential of cooperation, possibly next to the other virtues that cooperation may produce. Where perceptions of interdependence are weak, these other virtues become the focus. In fact, in the latter case, it seems that awareness of networks' capability of producing these particular virtues stimulates officials to engage in cooperation from the start.

The current section elaborates on how these virtues manifest themselves in the various networks selected for study. Doing so, it demonstrates that the appreciation of the virtues produced by networks varies not only across policy domains, but across authorities as well.

\subsubsection{Mutual learning: about teachers and students}

Learning seems to be appreciated as a product of cooperation, primarily in the area of integrated pollution prevention and control and in the domain of product safety. It seems less important in the area of air safety; even though an official from EASA considers the European SAFA Steering Group to function primarily as a knowledge-sharing platform, ${ }^{184}$ national interviewees emphasise the conflict resolution potential of the ESSG as particularly important. The focus in the current section is accordingly on the perceptions of officials involved in networks that function in the context of the IPPC and GPS Directives, and on inter-country differences that can be distinguished in this regard.

These inter-country differences express themselves in an appreciation of networks as offering learning and teaching opportunities. Although officials from all three countries included in this study seem to appreciate cooperation because it allows them to exchange experiences and best practices, ${ }^{185}$ it is Polish and Portuguese officials that refer most often to the fact that cooperation allows the participants to learn from one another. This is the case both in the area of product safety and in the area of integrated pollution prevention and control, as the following quotations illustrate:

Cooperation [in the area of product safety] is particularly important because it makes it possible to see how other member states work, we find together a so-

\footnotetext{
${ }^{184}$ Interview EASA1.

${ }^{185}$ E.g. interview NL5; PT6; PL2.
} 
lution for issues, we help each other, and we learn with each other. We have to learn from each other. ${ }^{186}$

In IMPEL, everyone has the chance to learn something, because we have different legal systems, different points of view, different solutions to solve the problems. It is very interesting. It gives us knowledge about how other countries solve the problems. ${ }^{187}$

The view that cooperation enables mutual learning to take place, as expressed in the above quotations, seems to resonate less with Dutch officials. This lack of resonance relates to the idea that, whereas Polish and Portuguese officials may situate themselves as 'students' in the cooperation context, Dutch officials conceive of their role in cooperation mainly as one of 'teaching others'. These officials feel that they are rightly placed to do so, since in their view their authorities are amongst those in the lead regarding the knowledge and expertise needed for adequate implementation. This self-perception of Dutch pre-eminence in these policy areas is illustrated by the following quotations:

Central and Eastern European Countries learn how to change things for the best. We already have our ways of doing things, so we will not change. This does not mean that Prosafe is not useful for us: what we hear from countries such as Denmark, Austria, Germany, and the United Kingdom makes us think. These countries act as a mirror: are we actually on the right track? But while Prosafe is also useful for us, it is of much greater benefit to the new member states. $^{188}$

IMPEL is very useful. Other countries really don't have a clue how things are organised here. Romania, for example, takes part in projects and as a result it learns. It knows nothing at all about certain topics like waste. ${ }^{189}$

\footnotetext{
${ }^{186}$ Interview PT6. Similar PL2.

${ }^{187}$ Interview PL8. Similar PT10.

${ }^{188}$ Interview NL5; similar interview NL10; NL11; NL12; NL13. It is indeed true that the Netherlands was amongst the forerunners in the area of product safety legislation. In the 1980s, the Warenwet became applicable to all non-food products, as something close to the GPS Directive avant la lettre. The Netherlands was amongst those countries that lobbied the European Commission for a directive on general product safety and that took part in writing the first GPS Directive, which was adopted in 1992. This Directive did not have a substantial influence on Dutch legislation, which, as suggested above, already reflected the essence of the GPS Directive. See interview NL2.

${ }^{189}$ Interview NL22. It is true that Dutch permitting practices in the area of IPPC had already followed the spirit of integrated pollution prevention and control before the Directive entered into force. For both Poland and Portugal, the IPPC Directive constituted a shock in terms of principles and required working procedures. See e.g. interviews NL21; PT9; PL12. The differences amongst these countries also appeared from comparative
} 
The above citations suggest that, whereas cooperation may have a learning effect for all, it is appreciated most by authorities that position themselves as students in the cooperation context. For countries that - for whatever reason - do not particularly consider themselves in the position to learn, this learning effect is less pronounced. ${ }^{190}$

One reason why the latter countries would invest in cooperation is the idea that in particular in situations of interdependence - as in the area of product safety - cooperation pays off when learning processes take the quality of implementation in laggard countries' to a higher level, rendering implementation practices more consistent across the board. The benefit for well-performing countries is that consistency lowers the implementation costs for these countries and increases the effectiveness of their implementation efforts, as we have seen before.

Moreover, 'leading countries' may derive certain fringe benefits from cooperation. Dutch officials have long considered networks such as Prosafe and IMPEL as convenient platforms for diffusing Dutch "ways of doing things", ${ }^{191}$ and for discussing and seeking support for new approaches to implementation problems and to policy making in the respective areas. ${ }^{192}$ In fact, it seems that both networks have been used as policy-making instruments in contact with the European Commission. ${ }^{193}$ Polish and Portuguese officials do not refer to these fringe benefits. The fact that the Dutch do, seems to be explained not only by their positive self-perception, but also by the fact that they have been dominant in both networks. Despite recent moves towards more inclusion on the part of other member states, Prosafe has long been a "Dutch house", ${ }^{194}$ officials say, and the Netherlands has always had a dominant position in IMPEL as well, as we see below. Together, these paragraphs suggest that, while networks may not always effectuate $m u$ tual learning, the learning effects that they spur may be beneficial for students as well as for leaders, in different ways.

\footnotetext{
analysis of the legislative frameworks in place before and after entry into force of the IPPC Directive.

${ }^{190}$ Firms would not, it is argued; studies have found that it is unlikely for firms to enter into an alliance with partners that possess redundant technology. See Mowery et al., 1996, referred to in Podolny and Page, 1998: 69. It seems that this difference could be explained by the fact that while cooperation between firms is influenced greatly by the competitive benefits that such cooperation may bring along (these benefits are likely to be little for leading firms), this competitive element is absent for leading countries (because substandard implementation elsewhere either reduces the effectiveness of their implementation performance or negatively affects their position in the single market). For this argument, see further below.

${ }^{191}$ Interview NL4; NL8. Another official indicates that Prosafe is not a mechanism to diffuse the Dutch model since capacity problems forced the Netherlands to take a step back when it comes to cooperation. This official indicates that, whereas the Netherlands was rather dominant at first, Prosafe is more balanced now the influence of all participating countries is present. According to this official, the Netherlands is still amongst the leading countries, but it would want to be the leading partner if it had the necessary resources. See interview NL10.

${ }^{192}$ Interview NL17; NL13.

${ }^{193}$ Ibid.

${ }^{194}$ Interview NL13; also Prosafe1.
} 


\subsubsection{Mutual trust: about leaders and laggards}

The concept of (mutual) learning should not be conceived of in narrow terms, as involving the exchange of practical knowledge and experience about implementation in order to teach others how to do better or to improve one's own performance. Where cooperation allows the participants to acquire insight into how colleagues from other member states go about the administration of particular rules, it may identify the extent of compliance in other member states as well. This 'learning in the broad sense' is important, since there seems to be a certain degree of mistrust amongst officials regarding compliance in member states other than their own, and in reality this mistrust may be misplaced. Both notions are reflected in the following citations:

Cooperation is the most important thing. It creates awareness that the others aren't as bad as people may have thought. It's all about mutual trust. ${ }^{195}$

Some Central and Eastern European Countries are better than I thought - that is what you see during meetings. ${ }^{196}$

Often, the first thought is: why should we implement this here if others countries don't do it? Cooperation is used to hold a mirror to one's own performance. We may think that we are doing so well, but is this actually the case? And are they [Eastern European countries] actually so bad over there? There is a lot of rabble-rousing. Images and noises come up very quickly. Sometimes they are the truth, but no one checks whether this is indeed the case. Because of cooperation, you see that things are done the same in other countries. IMPEL contributes to the strengthening of mutual trust. ${ }^{197}$

Trust and cooperation are related: they reinforce each other. We all have the same aim. There are no competing interests. Safety is a basic principle, a basic value in the air safety domain. People that have a role to play here need to have the knowledge and expertise. And the question is whether these elements are always present. ${ }^{198}$

The notion that all citations above are from interviews with Dutch officials is not a matter of coincidence. It is Dutch officials that express most doubts about the adequacy of implementation in other countries, and it is these same officials that most connote cooperation with mutual trust. This need for reassurance is not surprising in view of the

\footnotetext{
${ }^{195}$ Interview Prosafe4.

${ }^{196}$ Interview NL11.

${ }^{197}$ Interview NL18.

${ }^{198}$ Interview NL29.
} 
self-perception of the Dutch as amongst those in the lead when it comes to the implementation of the three directives examined in this study. ${ }^{199}$

Note that mistrust has a negative effect not only for those who do not trust, but also for those who are not trusted. While countries that perceive themselves as 'more advanced' or as 'better compliers' may feel a degree of frustration (since why should they comply if others do not), feelings of frustration may be present in countries that are subject to misgivings as well. For example, Polish and Portuguese officials involved in the area of integrated pollution prevention and control indicate that they have felt a sense of misunderstanding from member states that may or may not be more advanced. ${ }^{200}$ They indicate that cooperation has made officials understand each other better and that it has made them feel more accepted by their colleagues. ${ }^{201}$ The result of this is that cooperation is enhanced not only because sceptical officials have gained trust, but also because those that were initially subject to misgivings may no longer find themselves in a position to defend themselves. This latter side of the coin does not usually surface in discussions about the importance of mutual trust for facilitating cooperation. It does, however, seem equally important. Cooperation should not only aim to benefit the sceptics amongst the participants; it should aim to benefit all those who have made the effort to engage in cooperation.

\subsubsection{Resource sharing: the importance of money}

The previous subsections address rather 'lofty' concepts associated with transnational cooperation. When it comes to cooperation in the area of product safety, however, officials highlight a rather mundane benefit of cooperation: a reduction in the financial burden of implementation. Consumer products covered by Prosafe joint projects are collected by inspectors from the participating market surveillance authorities, which forward them to the same laboratory for testing to ensure uniformity of test results. Both the labour and travel costs of the persons involved, from the partaking authorities and the costs of product testing, are largely borne by Prosafe, which is awarded EU and EFTA funding for the management of joint projects. ${ }^{202}$ While this financial benefit pertains to all participating countries, it may be particularly helpful for authorities that struggle with a lack of resources to undertake appropriate - that is, organoleptic and laboratory when needed - product tests on their own.

\footnotetext{
${ }^{199}$ See Section 3.2.1.

${ }^{200}$ Interview PL8; PT9.

${ }^{201}$ Ibid.

${ }^{202}$ The percentage of co-financing depends on the number of countries that participate. The more countries join, the higher the subsidy provided. This subsidy may finance up to $70 \%$ of the project costs. The remaining costs are paid for by the member states, either with finances or with man-hours. Information retrieved from interview Prosafe1.
} 
For Portuguese officials, this financial side appears to be an important motivating factor for partaking in cooperation projects:

Why we participate in Prosafe? For learning and for financial help. ${ }^{203}$

Cooperation is essential. Without it, it would not be possible to do much market surveillance actions, since they cost a lot of money and we don't have much budget. ${ }^{204}$

Well-functioning cooperation is the way. Just to show you how important cooperation is: you would not be able to perform so many product tests if you were not involved in a network. All these tests are very costly, and it would be more useful if all member states could get together and do more of this together. ${ }^{205}$

The importance that Portuguese officials attach to the financial benefits that they derive from cooperation is explained by the fact that budgetary constraints confront them with serious limitations regarding the opportunity to carry out laboratory tests. ${ }^{206}$ When it comes to ASAE ${ }^{207}$ which is the market surveillance authority responsible for most of consumer products, this situation does not seem to be particularly pressing. This is the case, since Portuguese legislation puts the burden of proof on the economic operator. Thus, it is not up to the market surveillance authority to prove that a particular product is unsafe, but it is for the economic operator to demonstrate the safety of that particular product. The operator can do so by submitting the results of tests that are conducted by an accredited laboratory. ${ }^{208}$ This situation alleviates the financial burden of implementation for the authority.

However, this rule does not benefit DG Consumidor, which is the formally competent authority that decides on the safety of products. ${ }^{209}$ This is because DG Consumidor is not a market surveillance authority, which means that it cannot force economic operators to submit test reports. Whenever DG Consumidor wants to verify the safety of a particular product, it must rely

$78 \%$ of the GPS survey respondents agree or strongly agree that Prosafe is useful. This percentage is similar for inspectors.

on ASAE laboratories or on other certified laboratories for testing. Officials from $D G$

\footnotetext{
${ }^{203}$ Interview PT3.

${ }^{204}$ Interview PT5.

${ }^{205}$ Ibid.

${ }^{206}$ Interview PT4; PT5; PT6; PT7.

${ }^{207}$ Full name: Autoridade de Segurança Alimentar e Económica (Food and Economic Safety Authority).

${ }^{208}$ Interview PT4.

${ }^{209}$ Note that DG Consumidor falls under the Ministry of Economy and Innovation.
} 
Consumidor indicate that participation in Prosafe joint projects helps them in the exertion of their function, since it makes it possible for them "to test products for free", as the citations above testify. In the case of ASAE, financial benefits extend beyond product testing; they cover the complete range of market surveillance actions taken in the context of joint projects.

What applies to the Portuguese authorities applies to a greater extent to the Polish authorities. ${ }^{210}$ The lack of financial resources for carrying out laboratory tests was a common theme amongst all interviews with Polish inspectors and other officials. It is worthwhile to elaborate on this theme here, since the lack of money for lab tests imposes severe constraints on how well inspectors can carry out their jobs. An official from the Polish Office for Competition and Consumer Protection (UOKiK), the central authority that decides whether products forwarded to them by the regional trade inspections are safe, outlines the problem as follows:

For several tests, it is possible to ask the state lab, which could do it for free for us. But then there is a counterargument from the market operator who says, "sorry, I don't think it was reliable". There is this specific hesitation, also from our side: from the beginning we know that the operator might object to this testing. And he is right, so to say, but we cannot afford to do anything else. So I think we are taking these labs for the financial reasons, but we know that the outcome will be that we cannot fully trust this. Well, we do trust it, but the market operator has a different story. ${ }^{211}$

If the situation is far from ideal for $\mathrm{UOKiK}$, it seems equally, or more, pressing for the regional trade inspectorates. In the regions visited for this research project, the money reserved for laboratory testing is limited; the annual number of products submitted for laboratory testing by the trade inspectorates ranges from one to three annually. ${ }^{212}$ It is self-evident that this greatly undermines the ability of inspectors to do their job proper$1 y,{ }^{213}$ and that Prosafe actions are appreciated because of their financial benefits for the Polish authorities. ${ }^{214}$ However, Prosafe actions are a drop in the ocean: joint market surveillance actions have a rather narrow focus - they apply to a small section of consumer products only - and participation of the Polish authorities in such actions is (and this may seem counterintuitive) limited, as we see below. ${ }^{215}$

\footnotetext{
${ }^{210}$ Interview PL2.

${ }^{211}$ Interview PL2.

${ }^{212}$ Interview PL3; PL4; PL5.

${ }^{213}$ Interview PL3; PL4; PL5.

${ }^{214}$ Interview PL2. Note that even though they do not formally decide on unsafe products, the trade inspectorates benefit as well, since economic operators do not have a point in challenging the evaluations of inspectors when the relevant products have already been proven to be unsafe.

${ }^{215}$ See Section 3.4.1 below.
} 
Comparable 'mundane' benefits associated with cooperation are found neither in the area of air safety nor in the domain of integrated pollution prevention and control. This

$66 \%$ of the IPPC survey respondents agree or strongly agree that cooperation through IMPEL is useful. This percentage is considerably lower for permit writers. is logical, since comparable projects involving direct subsidies for national-level implementation activities do not exist in either of these areas. In the

area of integrated pollution prevention and control, only Portuguese officials argue that cooperation has financial benefits since "you can get knowledge for free". ${ }^{216}$ In fact, this is what stimulates the relevant authority to continue participating in projects organised by IMPEL; this is testified by the great number of projects that Portugal has participated in over the years. ${ }^{217}$ Regarding cooperation in the area of air safety, the idea that cooperation brings financial benefits is completely absent from interviews with the relevant officials. This absence may occur because officials refer to the European SAFA Steering Group primarily as a vehicle for attaining technical agreements between member states, as we see in the following subsection. Any financial benefits that agreement on common approaches may be associated with are indirect at best.

\subsubsection{Conflict resolution: 'bottom-up' coordination in the presence of interdependence}

Section 3.1 suggests that the participation of officials in cooperation in the areas of product and air safety is driven by a realisation that authorities in these fields depend on each other to make implementation work for each of them individually. Officials indicate that they engage in cooperation because they find it crucial that authorities 'do the same thing the same way'. While mutual learning processes may be important mechanisms for arriving at more consistent implementation practices, the potentiality of networked cooperation to facilitate the resolution of conflict amongst member states is

All SAFA survey respondents who participate in ESSG meetings strongly agree that such meetings are useful. equally important, officials say. The importance that officials attach to this particular virtue of cooperation is unsurprising in view of the idea that consistency serves the self-interest of authorities as it reduces the costs of implementation for them, and given the fact that central arbitration mechanisms in charge of arriving at common risk assessments in both areas are lacking. Were such mechanisms to exist, neither Prosafe nor the European SAFA Steering Group would have an important role to play as conflict resolution tools.

\footnotetext{
${ }^{216}$ Interview PT10.

${ }^{217}$ See the numbers presented in Section 3.4.1 below.
} 
The below citations suggest that while there is scepticism about the attainability of complete consistency in implementation outcomes, views on the usefulness of both networks for overcoming divergent opinions amongst member states seem to be similar:

Sometimes it is difficult for all member states to arrive at similar risk assessment conclusions. When subjectivity is part of the problem, results can hardly be the same. Joint actions coordinated by Prosafe are helpful, since risk assessment is performed by member states altogether, reaching a conclusion altogether. ${ }^{218}$

Whether harmonisation is possible? Well, that's a political answer. On technical grounds, of course it is possible. Meetings of the ESSG are a very useful tool to achieve agreements on technical issues and so on. It is the only forum where we have the opportunity to express our different interpretations. I have to say that in $96-97 \%$ of the cases we reach an agreement, a very easy agreement. But there is always a margin of difficulty, you see. It is used like a political thing, because if a member state runs out of all the technical arguments, the only way out is to say: "it's a political thing and I have to stick with it". ${ }^{219}$

This latter quotation supports the view that cooperation may be particularly effective for issues that are not politically sensitive, since regulatory authorities are given the most leeway to act independently in these situations. ${ }^{220}$ Since it is unlikely for issues to be completely apolitical - if politics plays a role in highly technical issues such as aviation and product safety, one may wonder where it is absent ${ }^{221}$ - one may expect the problemsolving potential of networks to be limited to some extent.

The notion that the idea of IMPEL as a conflict resolution mechanism does not come to the fore in interviews with officials involved in the area of integrated pollution prevention and control is not surprising in view of the discussion in Section 3.1 of this chapter. The hypothesis is that this has to do not only with the perceived low degree of interdependence, but also with the incomparability of IPPC installations. Not a single installation is identical to another, which means that there are at least as many correct permitting outcomes as there are installations. Thus, cooperation is useful when it deals with the premises of environmental licensing, and when it makes it possible for officials to learn from conceptual, procedural, and operational approaches to permitting that are

\footnotetext{
${ }^{218}$ Interview PT6. About the difficulty of deciding on whether something is safe or unsafe, see also interview NL2. For the idea that Prosafe helps member states to arrive at a common view, see also interview NL10.

${ }^{219}$ Interview PT17. Similar interview PL15 and NL29. On the idea that the ESSG is meant to "reach consensus acceptable to everybody", see email from interviewee PL15 to author; on the idea that the ESSG is "very important for standardisation", see interview NL29.

${ }^{220}$ See Section 1.2.2.3 of the current chapter.

${ }^{221}$ For the idea that the issue of product safety is not entirely apolitical, see NL2.
} 
employed in other member states; however, the complexity and singularity of cases make it impossible to expect networks to act as problem-solving mechanisms for concrete cases. This explains why, instead of the problem-solving capacity of cooperation, it is the capacity of IMPEL to enable mutual learning that is referred to most emphatically by officials involved in the implementation of the IPPC Directive.

\subsection{Informality: the key to making cooperation work?}

The finding that transnational cooperation may create the virtues discussed above broadly lends support to - and, in view of the cross-country and cross-issue variations that exist in this regard, slightly nuances - the postulations about the usefulness of cooperation set out in Section 1.1. Cooperation must function well to deliver those benefits. This section suggests that the perception of cooperation amongst officials as informal is a key facilitating factor in this regard.

\subsubsection{Informality: key to openness, key to mutual trust}

The importance of informality was a common theme running through all of the interviews with officials engaged in the networks that are relevant to this study. Officials unequivocally refer to informality as the key to making cooperation work and to formality as the most effective way to stifle meaningful cooperation. In the area of product safety, this unanimous perception translates to a preference of officials for informal cooperation through Prosafe over cooperation in the framework of the formal Consumer Safety Network, at least regarding practical cooperation; both networks have aimed to facilitate this but the former network seems to be more effective than the latter. Cooperation within IMPEL is appreciated because it functions outside of the EU institutional order. ${ }^{222}$ And in the case of the European SAFA Steering Group, the perceived informality of cooperation is also referred to as a great strength.

The benefits of informality are briefly summarised in the following words of a Portuguese official: "informality is why you have so much input from the participants". ${ }^{223}$ In other words, informality translates to openness on the part of network participants. The dynamics that play a role here are illustrated by the following citations:

IMPEL started out as a network of the member states. The European Commission wanted to join in; it saw IMPEL as some sort of a threat. The Commission got to co-chair meetings et cetera. But this practice was ended, since the Commission did not feel comfortable in this position. The interests and priorities of

\footnotetext{
${ }^{222}$ Interview NL17; PT10.

${ }^{223}$ Interview PT10. See also interview NL17.
} 
member states and of the Commission diverged, and member states did not really give any openness in the presence of the Commission. ${ }^{224}$

During Commission-centred meetings [i.e. meetings of the Consumer Safety Network], if the Commission takes the floor and they facilitate some meeting, it is just the normal way that they dominate the discussions. The Commission is not interested in nuancing things, or in details, or that we have a problem with paying money for our lab because we don't have any money and we cannot afford to pay for any test report for a whole year. I think that several member states think that they cannot say it. Because that would be kind of a red spot on your table and they have a map and oops: 'we will just put a red flag on you because you are a nasty boy'. I could understand several member states, that they are afraid of being the bad guys. I would say this kind of things during Prosafe meetings. There, everything is allowed. We can just normally say that they cut our budget and we are in trouble. But there is no such kind of a red light that the EC will listen to it and they will draw some consequences from what we say, like 'your money is not satisfied'. 225

If the benefit of informality is openness about problems that authorities may struggle with, the benefit of openness is that it allows for cooperation to function as an effective learning, trust-building, and problem-solving instrument. In the words of an official from Prosafe:

The solution to problems is found only if the reason for problems is explained. If the reason is not explained, we cannot find a solution that suits the problem. And there can only be trust when the information that comes in is honest. In Prosafe, we talk out freely. ${ }^{226}$

The remainder of this subsection focuses on cooperation in the area of product safety. In this area, the Consumer Safety Network is supposed to facilitate administrative cooperation between the market surveillance authorities of the member states, as demonstrated in Section 2.1.1 of this chapter. Established by the GPS Directive, this network came into being after the member states' dismissal of the proposal for the European Commission to make Prosafe fulfil this task. Prosafe was founded a decade earlier following a shared awareness amongst market surveillance officers that in a situation of

\footnotetext{
${ }^{224}$ Interview NL17.

${ }^{225}$ Interview PL2. Similar PT6.

${ }^{226}$ Interview Prosafe1.
} 
interdependence, member states should 'get together' if efficient and effective implementation is to be ensured. ${ }^{227}$

However, the Consumer Safety Network has not been effective - at least not in the manner that was envisaged by the GPS Directive. A comparison of what the Consumer Safety Networks aims to do and $75 \%$ of the GPS survey respondents agree or strongly agree that the Consumer Safety Network is useful. This percentage is lower for inspectors. what it actually does suggests that the network rarely does what it is formally supposed to do. Section 2.1.1 outlines that it aims to exchange information on market surveillance issues, establish and execute joint projects, exchange experiences and best practices, and improve supranational cooperation regarding the tracing, withdrawal, and recall of dangerous products. According to interviewees, it constitutes a forum for reflection and discussion concerning topics related to consumer product and service safety. ${ }^{228}$ As such, its operation does not meet the objectives outlined in the GPS Directive.

Note that the mismatch between objectives and achievements does not mean that the Consumer Safety Network is useless; it only means that its potential usefulness must be derived from somewhere else. In fact, the survey conducted for this study suggests that certain respondents, particularly policy officials (rather than inspectors), appreciate cooperation through the network. Interviews suggest that this is because the network complements the work undertaken within the framework of Prosafe, by providing room for discussions of a more political nature (rather than permitting hands-on cooperation). ${ }^{229}$

Prosafe, on the other hand, has a history of organising joint market surveillance actions. ${ }^{230}$ These actions address both horizontal issues (related to the development of best practices in market surveillance in general) and vertical, product-specific issues (for example food imitation child-appealing products, and ladders). Discussions of various issues of market surveillance take place during meetings of the General Assembly. A comparison between what the Consumer Safety Network does and is supposed to do, and what Prosafe actually does, can only lead one to the conclusion that "nothing of what happens in Prosafe happens in the Article-10 network"; ${ }^{231}$ to which one may add:

This network was an attempt to establish something like Prosafe, but it has been established several times, without any real success, even though one tried in different ways. ${ }^{232}$

\footnotetext{
${ }^{227}$ Interview Prosafe/NL8.

228 See below.

${ }^{229}$ See below.

${ }^{230}$ See its website, <www.prosafe.org>

${ }^{231}$ Interview Prosafe1.

${ }^{232}$ Ibid.
} 
Also the Commission admits that while the Consumer Safety Network should have taken on the tasks stipulated in the GPS Directive, this has not happened. ${ }^{233}$ In view of the negative performance evaluations of the Network in view of the goals that are set, the Commission's proposition, outlined in the proposal for a Regulation on market surveillance of products, to establish a European Market Surveillance Forum drawn up along the lines - though extending the tasks - of the Consumer Safety Network seems neither logical nor advisable. ${ }^{234}$ What adds to the level of surprise of this proposal is a Commission official's view that the only reason that the Consumer Safety Network still exists, is because "it is, in the end, a formal body", ${ }^{235}$ which officials feel obligated to make use of.

The perceptions of the usefulness of the Consumer Safety Network that are held by the national officials interviewed for this study appear to vary. Dutch officials seem to view the Network as a redundancy. ${ }^{236}$ A Polish official indicates a clear preference for cooperation through Prosafe, relegating the Consumer Safety Network to a state of indifference. ${ }^{237}$ In the view of a Portuguese official who frequented meetings of both the Consumer Safety Network and Prosafe, the two networks complete each other. ${ }^{238}$ It is true that results of joint market surveillance actions may be discussed during meetings of the Consumer Safety Network, and those issues may be taken further by the GPSD committee for regulatory policy-making. In this sense, the Consumer Safety Network fulfils a function that Prosafe cannot perform, which seems to imbue it with a degree of added value in the implementation context. In view of the nature of the discussions and the dominance of policy officials over street-level actors in CSN meetings, the immediate added value of such discussions for street-level actors seems limited.

Whether outwardly rejected or evaluated as useful in some way, one thing is clear: regarding administrative cooperation between the market surveillance authorities of the member states, the Consumer Safety Network is not as effective as Prosafe. ${ }^{239}$ The reason that the Consumer Safety Network has failed to constitute the type of forum that it purports to be - returning to the focal issue of this section - is a simple one. In the words of a Commission official:

\footnotetext{
${ }^{233}$ Interview EC2.

${ }^{234}$ Commission, 'Proposal for a regulation of the European Parliament and of the Council on market surveillance of products and amending Council Directives 89/686/EEC and 93/15/EEC, and Directives 94/9/EC, 94/25/EC, 95/16/EC, 97/23/EC, 1999/5/EC, 2000/9/EC, 2000/14/EC, 2001/95/EC, 2004/108/EC, 2006/42/EC, 2006/95/EC, 2007/23/EC, 2008/57/EC, 2009/48/EC, 2009/105/EC, 2009/142/EC, 2011/65/EU, Regulation (EU) No 305/2011, Regulation (EC) No 764/2008 and Regulation (EC) No 765/2008 of the European Parliament and of the Council' (Market Surveillance Regulation) COM (2013) 75, Art. 25-27.

${ }^{235}$ Interview EC2.

${ }^{236}$ Interview NL7; NL12; NL11.

${ }^{237}$ Interview PL2.

${ }^{238}$ Interview PT6.

${ }^{239}$ All interviews with officials involved in cooperation through CSN and Prosafe.
} 
If government officials come to Brussels to attend, they do so as representatives of the member states. The formal character of meetings does not quite foster cooperation on a practical level and can even act as a brake on cooperation. Prosafe works better, because it is informal. ${ }^{240}$

\subsubsection{What really matters: the perception of cooperation as informal}

The above section does not leave room for doubt regarding the crucial role that informality can play as a stimulus for effective cooperation. What makes cooperation informal must still be clarified. Interviews suggest that, similar to interdependence, it is the perception of cooperation as informal that determines the behaviour of officials in networks. While legal informality - that is, the lack of codification in EU legislation seems to be an absolute precondition in this regard, this is not the case for material informality - that is, the lack of involvement in the network by the European Commission or an EU agency - as we see below.

The notion that even a network with a strong formal presence of the European Commission or an EU agency can provide a sense of informality is supported by the case of the European SAFA Steering Group. The characteristics of this group are outlined in Section 2.3.1 of this chapter. Recall that legally speaking, the group is an informal platform for cooperation; it is not codified in EU legislation. Upon closer examination, however, it appears to be strictly tied to the EU institutional framework: it is chaired by the European Commission and attended by officials from the SAFA coordination team at EASA. Moreover, notes on meetings are produced by EASA, for example in the form of training bulletins that are distributed amongst SAFA participating states. ${ }^{241}$ In brief, even though one cannot speak of a 'legal formalisation' of the network, the way in which it is managed - by EU bodies - make it, from a material point of view, appear similar to a formal EU network.

Despite the formal outlook of meetings, officials nonetheless seem to experience ESSG meetings as informal events. ${ }^{242}$ The dynamics that seem to play an important role here are illustrated by the following citation:

I have to say that on this ESSG committee, where the SAFA national coordinators have a place, the European Commission acts as the chair of those meetings. So it is the Commission representative who runs the show. But in $99 \%$ of the cases, the representative is very low profile, and it is a kind of a formal thing: he opens the meetings and thanks all of the participants before closing the meeting and so on. But I don't feel watched by the Commission, by no means. I am pretty sure that neither me nor my colleagues have ever felt con-

\footnotetext{
${ }^{240}$ Interview EC2; similar interview EC4.

${ }^{241}$ Interview EASA1. See Chapter 5 on post-legislative guidance, Section 2.3.2.

${ }^{242}$ Interview PT17; PL15; NL29.
} 
straints, say, because the Commission representative is there. On the contrary. It is a technical discussion. The Commission representative is not a technician; he's not an engineer or a pilot. So we can discuss freely between us, because the guy doesn't understand our language anyway, and that's very good. But if we, in this atmosphere amongst equals, amongst pilots and engineers, if we don't find an agreement, the last resort is to look at the Commission representative, since the Commission is the owner of the forum, and say, 'look, please find us a way to deal with those issues'. ${ }^{243}$

Experiences seem to have been completely different in the case of IMPEL. During a certain period of its existence, IMPEL resembled the ESSG in the sense that it was closely tied to the EU institutional framework as well. ${ }^{244}$ At this point, however, perceptions start to diverge. Officials indicate that when the Commission started to formally participate in the network - and, arguably, to use it to advance its own policy objectives ${ }^{245}$ member states did not provide openness. In fact, this lack of openness is referred to as one of the reasons that the Commission quit the network. ${ }^{246}$ Thus, it seems that the participation of the Commission may trigger different reactions on the part of member states. Informal networks embedded within the EU institutional framework may be experienced as informal, as in the case of the ESSG, but they may also be experienced as formal, as is the case for IMPEL. This seems to be rather paradoxical.

This paradox should be resolved, first, by eliminating the assumption that it is informality stricto sensu - meaning both legal and material informality - that is determinative for meaningful cooperation. As is the case for interdependence, it seems to be the perception of cooperation as informal that is crucial in this regard. The Commission's lack of specialist knowledge on the issues tabled for discussion, hinted at in the above excerpt from an interview with a SAFA national coordinator, appears to be one factor that leads to this perception of informality. Other factors are hinted at in the following quotations from interviews with officials involved in cooperation through Prosafe:

In contrast to the Consumer Safety Network, Prosafe is not an agent of the Commission. The Commission only finances Prosafe's work. And the Commission was never really present during Prosafe meetings. There was a representation at annual get-togethers, but it was very informal and they were not the main actors. ${ }^{247}$

\footnotetext{
${ }^{243}$ Interview PT17.

${ }^{244}$ See Section 2.2.1.

${ }^{245}$ For the notion that the Commission may come to manipulate the network process in an attempt to advance its own goals, see Section 1.2.2.4 above.

${ }^{246}$ Interview NL17.

${ }^{247}$ Interview PL2.
} 
The strong point about Prosafe is that talking out freely is possible, since we can say anything without having to cover for ourselves in order to prevent losing face. We also talk freely to the Commission, when it is present at meetings. This works very, very well, as we know there is mutual confidentiality. We hear things from the Commission about how things are cooking inside the Commission that we never hear at any other platform. Newcomers find this strange, but in the end, things are being said. ${ }^{248}$

Here, it is not a lack of knowledge from the Commission about the issues under consideration, but the minor role of the Commission or the principle of mutual confidentiality that create a sense of informality. While this seems to further complicate the situation, the following citation adds another element to the equation:

I recall that the Commission wanted to be closer to the people, and they organised some kind of get-together at the Berlaymont building with Commissioner Kuneva who was just cruising to the tables and then there were some unofficial meetings. But whenever these things take place in Brussels, it is too stiff. It is too strict, too formal, too Commission-centred. And whenever Prosafe meetings take place, because it is in different locations, everything changes. We had a Commission representative on one of our project meetings, and the meeting was on the same level of great cooperation because it was not in Brussels. It was in Warsaw and everybody felt very safe. Wherever the meeting takes place, because market surveillance authorities organising the joint action host the meetings, it is always some kind of safe haven to be kind of talking normally about everything. ${ }^{249}$

In other words, location matters, too. What all of these different elements - the Commission's perceived lack of knowledge, mutual confidentiality, and meetings away from Brussels - seem to have in common is the facilitating role that they play in reducing the attention drawn by the Commission as a monitoring and sanctioning body. ${ }^{250}$ Overall, it seems that the following two things can be said: it is not informality stricto sensu, but the perception of cooperation as informal, that facilitates such cooperation; and it is not necessarily the absence of the Commission, but the absence of the Commission as guardian of the treaties, that causes perceived informality.

\footnotetext{
${ }^{248}$ Interview Prosafe1.

${ }^{249}$ Interview PL2.

${ }^{250}$ Similar Voermans, who argues that networks emerge because of a need for feedback, and a desire to share problems and receive feedback without the risk of incrimination; see Voermans, 2014: 351.
} 


\subsection{Pitfalls of cooperation}

Although positively evaluated by officials, cooperation - and in particular cooperation that is perceived as informal - may have downsides. This section elaborates on three factors that seem particularly pressing in this regard; these factors concern incomplete participation, unequal participation and low levels of inclusiveness, and the erratic implementation of lessons learned and agreements arrived at back home.

\subsubsection{Incomplete participation}

The first of these downsides relates to the idea that since legally and materially informal networks do not function in the shadow of hierarchy (as is the case for Prosafe and IMPEL), there is no way to pressure authorities to cooperate. This means that while authorities that are willing to engage in cooperation are likely to join, authorities that are reluctant to participate are left out. The latter authorities may use some of the products produced by networks - such as shared guidance documents - but they are likely to miss out on many of the benefits that cooperation offers. While there may be understandable reasons for them to refrain from involvement in cooperation, there is a probability that it is those authorities that choose not to participate that may be well served by cooperation projects. In the product safety area, for example the adagio 'safety follows welfare' - and the associated idea that in countries with relatively low welfare levels product safety is not a priority - seems to be commonplace. ${ }^{251}$ Thus, market surveillance in such countries may take a backseat, and participation in cooperation projects - which may, for several reasons, be helpful for such countries - may not be high on the agenda. ${ }^{252}$

The idea that countries with relatively low welfare levels are not the only ones to opt out of cooperation is illustrated by the idea that Dutch officials participate less in Prosafe because of the decreasing amount of resources available for cooperation; a development that, according to them, is caused by a lack of political salience of the issue of product safety in the Netherlands. ${ }^{253}$ The importance of issue salience as a factor explaining member state responses to compliance instruments has been identified in Chapter 4 on monitoring and sanctions; its appearance at this point once again underlines its significance as a factor to be considered in examinations of the usefulness of compliance instruments. ${ }^{254}$ Note that the Netherlands, even though it claims to participate less often than in the past, is still the only country to have participated in all Prosafe

\footnotetext{
${ }^{251}$ Interview NL2.

${ }^{252}$ Participation rates of such countries in Prosafe projects suggest that this may be true in some cases indeed. Suggestion based on data received by email, from interviewee NL12.

${ }^{253}$ Interview NL12. One should, however, not forget that such perceptions are relative. Regarding the Netherlands, market surveillance in this country is still evaluated as "brilliant". Interview EC3.

${ }^{254}$ And, one may submit, in studying implementation processes in the EU. Core issues in EU implementation research are discussed in Chapter 2 on implementation in the EU: same rules, divergent practices, Section 3.2.
} 
projects organised between 2005 and 2009, and in at least an average of two out of five activities organised under joint actions between 2010 and $2013 .{ }^{255}$

Financial constraints also hamper the extent to which Portuguese officials participate in Prosafe. The relevant officials indicate that they want to participate more often, but that resource limitations make this impossible. ${ }^{256}$ Figures suggest that the participation rate of Portugal in Prosafe has, in relatively terms, been quite modest indeed. Portugal participated in three out of the eleven Prosafe projects organised between 2005 and 2009 , and in at least one activity annually for joint actions organised between 2010 and $2013 .{ }^{257}$ With a total participation in seven projects and joint actions between 2005 and 2013, Portugal falls about two projects below the average number of projects that Prosafe members participated in during these years. ${ }^{258}$ The Polish market surveillance authority participated slightly more often than the Portuguese authorities; officers took part in four projects between 2005 and 2009, in at least one activity annually for joint actions between 2010 and 2013, and in a joint action on third-country cooperation. ${ }^{259}$ Having participated in nine projects and joint actions overall, Poland is slightly more active than the average Prosafe member. ${ }^{260}$

While financial and staff constraints may be an important factor hampering participation, the main barrier for countries that are willing to participate in joint actions, but that nonetheless opt out of cooperation is, according to a Prosafe official, a mundane one: the inability on the part of officials to communicate in English. This barrier is often enhanced the more one descends the public administration hierarchy, and it is lowerplaced civil servants that cooperation in Prosafe is targeted at. ${ }^{261}$

When it comes to the participation rates of authorities in IMPEL, research shows that considerable inter-country variation exists here as well. It shows that four IMPEL members, amongst which is the Netherlands, have been the leading countries in approximately $60 \%$ of all 147 projects organised in the framework of IMPEL since 1997. The Netherlands has been significantly represented, not only as a project leader (30 projects), but also in terms of project participation (71 projects); it is second out of all countries that have participated in IMPEL projects. ${ }^{262}$ Also notable is the high number of projects (42) that Portugal has participated in. ${ }^{263}$ This is the case despite the fact that

\footnotetext{
${ }^{255}$ Data received by email, from interviewee NL12. These data show the participation of member states in individual projects between 2005 and 2009, but there is no breakdown for activities in the following years (the data only show participation in annual joint actions, which cover several product-specific projects).

${ }^{256}$ Interview PT6; PT3.

${ }^{257}$ Data received by email, from interviewee NL12.

${ }^{258}$ Between 2005 and 2013, 29 Prosafe members participated in 249 product-specific projects and joint actions. The average number of projects per member is 8.6.

${ }^{259}$ Data received by email, from interviewee with NL12.

${ }^{260}$ See above n. 258.

${ }^{261}$ Interview Prosafe3.

${ }^{262}$ BIO Intelligence Service, 2013: 19.

${ }^{263}$ Ibid.
} 
Portuguese officials indicate that a lack of resources (time, staff) has either made it impossible for them to participate at all, or forced them to prioritise projects. If more resources were present, Portuguese officials would participate more often, it seems; interviewees perceive cooperation as valuable for enhancing implementation in their country. ${ }^{264}$ Polish officials indicate that they have not taken part in IMPEL projects for "a long time", even though it would be useful for them to do so. ${ }^{265}$ The Polish participation rate in IMPEL is indeed lower (24 projects) than those of the other two countries under consideration, although it is not as low as those of most other 'new' member states. ${ }^{266}$

'Making informal cooperation formal' might at first sight seem like a potentially effective way to increase the participation rates of countries in networks. However, such formalisation does not constitute the panacea in this regard. States that, willingly or forced by circumstances, opt out of voluntary forms of cooperation may decide not to frequent meetings of formal networks as well. In fact, participant lists of network meetings such as the Consumer Safety Network and the European SAFA Steering Group show that all member states rarely attend. ${ }^{267}$ It seems that resource limitations may also be to blame for this. This is certainly the case for Portuguese officials involved in the areas of product safety and integrated pollution prevention and control. ${ }^{268}$ The following excerpt from an interview with Portuguese officials illustrates this issue and underlines how relative distance plays an important role in this regard:

IMPEL is useful. But sometimes the problem is the resources. For example, even when we are going to a committee meeting, it is usually a one-day meeting. For us it will take two or three days to attend the meeting. If the meeting is on Thursday, we need to go the day before, and we have to return the day after. Last time, the plane left at seven, and the meeting was supposed to stop at five but it stopped at six, so I missed one-and-a-half hours of the meeting. For the next meeting, I will be there until the end, but it means that I have to stay another day in Brussels. If you are in the Netherlands, you go by train and you return on the same day. ${ }^{269}$

It is important to note how a seemingly mundane issue - distance and resource limitations - may greatly impact the ability of at least some authorities to participate in cooperation projects and other get-togethers that may be of great value. Thus, the often-

\footnotetext{
${ }^{264}$ Interview PL8; PT9; PT10.

${ }^{265}$ Interview PL8.

${ }^{266}$ BIO Intelligence Service, 2013: 19-20.

${ }^{267}$ These lists are retrieved from European Commission, 'Consumers, Committees, networks, and working groups', <http://ec.europa.eu/consumers/archive/safety/committees> (on the Consumer Safety Network), and from internal EASA documents (on the ESSG).

${ }^{268}$ See PT9; PT2.

${ }^{269}$ Interview PT9. For similar remarks on the importance of distance, see interview Prosafel.
} 
heard optimistic view that voluntary cooperation ensures that officials make the most of such cooperation and that great participation rates must relate to the successfulness of this cooperation, ${ }^{270}$ must be juxtaposed against the more pessimistic view that it is not only unwilling countries, but also countries that are willing but practically unable to participate, that are left out.

\subsubsection{Low levels of inclusiveness and unequal participation}

Section 1.2.3 suggests that in order for networks to produce optimal outcomes, deliberations must allow for inclusiveness; thus, they should involve experts, as well as non-state actors who are affected by the issue that is subject to discussion. In the case of product safety, one could think of consumer organisations and business actors. In the case of air safety, it is airline operators that seem to be directly concerned. Regarding the area of integrated pollution prevention and control, the most relevant actors seem to be representatives from environmental organisations and business actors.

An assessment of the extent to which the actors referred to above participate in the networks under consideration here yields a bleak picture of the inclusiveness of cooperation. From Section 2 of this chapter one may recall that, at meetings of the Consumer Safety Network - which is the only legally formal network in the context of this study business and consumer organisations may only act as observers. The European SAFA Steering Group - which is legally informal but materially formal - does not allow any non-public actors to attend its meetings. Regarding the legally and materially informal networks included in this study - Prosafe and IMPEL - the latter seems most inclusive; it allows non-governmental organisations to attend General Assembly meetings as observers. Societal actors are not allowed to participate or act as observers, in any meetings that are organised within the framework of Prosafe. While it seems reassuring that the only legally formal network examined here enables the greatest degree of openness, the overall picture is one in which societal actors are effectively kept at bay.

The above paragraphs raise the question about the extent to which this rather exclusive nature of cooperation is problematic. It may be relevant to recall that neither of the networks discussed here have the power or duty to make decisions that are binding for regulated actors; in fact, they are far removed from having such competencies. What they do that is relevant to regulatory policy-making, is act as preparatory forums for comitology committees (which is the case for the Consumer Safety Network and the European SAFA Steering Group), or provide feedback on the practicability and enforceability of EU measures (IMPEL). Otherwise, they merely aim to support the implementation of the relevant legal provisions by exchanging information and experiences, by

\footnotetext{
${ }^{270}$ See e.g. interview EC4; EC1; Prosafe2. These officials argue that the primary advantage of Prosafe is that officials are not required to be present, and that the notion that many countries have participated in Prosafe constitutes an indication of its success. For the idea that the eb and flow of authorities to and from networks must be considered an indicator of network-level successfulness, see Provan and Milward, 2001: 418.
} 
solving disagreements between authorities, and/or by clarifying certain issues for them. The notion that these clarifications may be outlined in quasi-official documents (such as in the SAFA training bulletin) does not affect the notion that agreements and clarifications arrived at are legally not binding. ${ }^{271}$ In this sense, one may argue that the inclusion of experts alone in network meetings should not be considered problematic from a legal point of view. ${ }^{272}$

From a practical perspective, the effectiveness of informal networks may be conditional on the exclusive nature of cooperation. For example, officials in the product safety area state that, it is not only the formality of the Consumer Safety Network that makes it an ineffective vehicle for cooperation; the presence of consumer organisations and business actors at meetings is also referred to as a hindrance for truly meaningful cooperation to unfold. According to an official, the presence of these actors negatively affects the 'trust factor' amongst member states. This not only makes it difficult for officials to establish contacts; it also reduces the degree to which authorities are open about issues that they are confronted with in the implementation process. The latter is the case even in comparison to cooperation in the GPSD committee. ${ }^{273}$ The same interviewee argues that also business is less open, "although this is stupid as their input is needed and sought". Such views add doubt to the problem-solving potential of the Consumer Safety Network; they also reinforce pleas to have at least some forum permitting expert-only deliberation.

Another inclusion-related issue concerns deliberative equality amongst member state experts themselves. It is known that member states do not participate equally within networks; ${ }^{274}$ this does not seem different from the networks under consideration here. Interviewees suggest that cooperation in both the Consumer Safety Network and Prosafe is dominated by certain countries, with others remaining passive. ${ }^{275}$ This is the same for the European SAFA Steering Group, officials indicate, ${ }^{276}$ and it is seemingly not different for IMPEL. ${ }^{277}$ The noted inequality is explicable, at least in part, by the varying backgrounds of participating member states; countries with a head start in the imple-

\footnotetext{
${ }^{271}$ See Section 3.4.3 for the notion that these documents may nonetheless be considered to have a de facto binding effect. See Chapter 5 on post-legislative guidance, Section 1.2.4 for a discussion on the legal effect of soft-law documents.

${ }^{272}$ See also Section 1.2.4, which argues that standards for the democratic legitimacy of self-initiated networks (in this case, Prosafe and IMPEL) should probably differ from standards for mandated networks with a great influence on policy-making in a certain area. This study does not include any networks that fit the latter conceptualisation; while the CSN and the ESSG may act as advisory forums to the Commission before issues are tabled in the GPSD committee or in the Air Safety Committee, respectively, it is these committees - and not those networks - that have decision-making competencies.

${ }^{273}$ Interview NL13.

${ }^{274}$ See e.g. Alfé et al., 2008, on participation in committees.

${ }^{275}$ E.g. interview NL5; NL10.

${ }^{276}$ Interview NL29.

${ }^{277}$ Interview NL17.
} 
mentation of the relevant measures may, in some circumstances, be naturally placed in the position to give, while others in these same circumstances may be better positioned to receive (or perceptions may be as such). ${ }^{278}$ This alone does not seem to pose a problem. In fact, a characteristic of networks is the relative absence of quid pro quo behaviour. ${ }^{279}$ However, when countries in a learning position do not intervene, problems may occur with respect to the implementation of lessons learned or agreements arrived at (which ultimately may not be implementable), and the trust put in these authorities by other network members (which are not capable of monitoring the relevant member states).

Finally, the notion of inequality within networks seems to pose an interesting conceptual paradox: that of the existence of a hierarchy within forms of governance that are supposedly heterarchical. This paradox, and the general issue of inequality in networks, has not been examined in detail in the academic literature. A detailed discussion regarding the (conceptual) implications of this paradox is beyond the scope of this study. Future research efforts should aim to clarify the conceptual difficulties in this regard (to reconcile hierarchy with heterarchy), and provide details about the legitimacy concerns that seem to flow from this paradox (the meaning of unequal participation for the input and output legitimacy of cooperation). These questions seem particularly pressing for networks that are imbued with substantial legal competencies, since member states may be bound to dutiful implementation of the network outputs back home. It is also when networks play a substantial role in the policy context - for example because the outputs that they deliver are seen as greatly authoritative irrespective of their nonbinding nature - that ensuring equal participation seems important from a legitimacy point of view. ${ }^{280}$

These remarks remind us of our discussion in Chapter 5 on post-legislative guidance, which suggests that inclusiveness in guidance development processes is essential from a democratic perspective, and from a problem-solving point of view, particularly in view of the inherent legally binding effect or the great de facto effect that guidance documents may have for implementing authorities.

\subsubsection{External impact of cooperation}

Finally, doubts regarding informal networks relate to their external impact; that is, to the extent that cooperation may spur positive changes in the participating countries. While this issue is not the focus of this study, the discussion that follows is nonetheless helpful, since awareness amongst officials of the external impact of networks creates a feedback loop influencing perceptions of the 'internal' usefulness of networks as compli-

\footnotetext{
${ }^{278}$ See Section 3.2.1 for this argument in relation to the notion of mutual learning.

${ }^{279}$ Powell, 1990: 304.

${ }^{280}$ The ESSG may be an example of the latter type of networks: while informal, it has nonetheless been a dominant mechanism in the implementation context, and interviewees attach great importance to it, as we have seen in the previous sections. See in particular Section 3.2.4.
} 
ance instruments. For example, when officials see (or otherwise seem to know) that their colleagues do not use the lessons that are learned in the context of cooperation, mutual trust may suffer, along with the propensity of effective cooperation in the future. Refer to previous sections for the importance of trust for making cooperation work. ${ }^{281}$

Before assessing the external impact of the networks included in this study, it is important to recall that it is difficult - if not impossible - to conduct an effectiveness evaluation that aims to establish causal relationships between cooperation and (positive) changes in the implementation process. This is, first, because networks are only one out of many instruments that affect the application of EU measures. Certainly, changes in application practices may be triggered by cooperation, but they may also - and this is more likely - be caused by the interplay of several compliance instruments and/or other mediating factors. Detecting the role of cooperation in this context is not an easy endeavour. A second reason that an effectiveness evaluation is difficult to conduct, is that the benefits of cooperation are hard to quantify. The previous sections show that much of what is experienced inside networks relates to the exchange of knowledge and experiences regarding a certain issue. The effects of these exchanges are difficult to evaluate in objective terms. While these two aspects make it difficult to offer insight into the external impact of networks in objective or straightforward terms, they do not detract from the obligation to determine the extent to which the networks discussed in this study are capable of inducing change.

Let us first look at the alleged change capacity of the two informal networks subject to this study. Both Prosafe and IMPEL do not command any legal authority to enforce actions beyond those required within the context of a certain project. In the framework of Prosafe, for example, market surveillance authorities are required to collect product samples and to take the corrective measures agreed with their colleagues during project meetings. These are concrete actions that they have formally committed to because of their participation in the project. The legally binding effect of that which is exchanged or accepted as useful during such meetings is, however, null. Whether or not lessons that were learned are implemented at home depends on the willingness of officials to do something' with these lessons. While country-specific conditions may make it impossible to simply copy such lessons in the national implementation practice, emulation may encounter too many obstacles for these lessons to be 'tailored to fit'. It seems that such obstacles are likely present particularly when materialisation of the necessary changes depends on actors other than the network participants. For example, the implementation of lessons learned might require substantial organisational overhauls or the investment of (financial) resources that these actors do not control and that superior actors may not want to arrange.

Cooperation within the framework of Prosafe is said to have stimulated discussions about product safety, led to legal and practical changes in several countries, and in-

${ }^{281}$ See in particular Sections 1.1.1, 1.2.2.1, and 3.2.2. 
creased the proactivity rate of market surveillance authorities across member states. ${ }^{282} \mathrm{~A}$ Prosafe official argues that it is the low profile, depoliticised nature of cooperation in Prosafe that has facilitated these changes. ${ }^{283}$ Statements along these lines clearly emphasise the importance of informality - and voluntariness - of making cooperation deliver, not only in relation to their internal virtues (for example, mutual learning during cooperation), but regarding their external benefits (that is, changed administration practices) as well. While some agree that "there is a very big informal part that has a very large output", ${ }^{284}$ others, however, concur that Prosafe must take a great leap forward for it to be truly effective. ${ }^{285}$

Two issues should be noted in this regard. First, the contrasting perceptions outlined above represent different views on the extent to which cooperation should be formalised for it to deliver. Relevant is that while perspectives that emphasise the importance of informality are generally shared amongst officials that have participated in Prosafe projects, views that propagate further formalisation are commonplace mainly amongst Dutch officials who are further removed from the street level and amongst Commission officials. ${ }^{286}$ Recognition of this distinction brings us to the second issue of importance; namely, that there are likely more benefits of cooperation than what those who do not participate can see. In fact, the "large output" of informal cooperation that is referred to above is found partly in the implementation of concrete lessons learned or agreements arrived at. Interviews suggest that "seeing each other informally and calling each other by the first name" not only stimulates intra-network cooperation, it promotes cooperation at home as well. ${ }^{287}$ Since they get to know each other well, network participants know whom to call in case of questions, and this helps to solve these questions. These outputs are less visible, which may explain why 'outsiders' do not grasp the full benefits that officials claim to reap from informal cooperation.

A similar concept applies to IMPEL, it seems, although positive opinions about its external effectiveness are not as broadly supported as in the case of Prosafe. For IMPEL, Portuguese officials from IGAMAOT, the authority that is responsible for environmental inspections, indicate that projects have taught them many concrete working procedures that they have subsequently implemented at home. ${ }^{288}$ The relevant Polish official demonstrates uncertainty about the effects of IMPEL projects, ${ }^{289}$ and Dutch officials

\footnotetext{
${ }^{282}$ Interview Prosafe/NL8.

${ }^{283}$ Interview Prosafe/NL8.

${ }^{284}$ Interview NL10.

${ }^{285}$ Interview NL12; interview EC2.

${ }^{286}$ This seems counterintuitive in view of the Commission's appreciation of cooperation through Prosafe; cooperation that they deem more effective than (formal) cooperation in the context of the CSN. Note, however, that both networks constitute extremes on the scale of formality, and that it is possible to position networks between these extremities. ESSG is an example in this regard.

${ }^{287}$ Interview NL29.

${ }^{288}$ Interview PT10.

${ }^{289}$ Interview PL8.
} 
show considerable scepticism regarding the concrete effects that cooperation may have for the Dutch implementation practice. ${ }^{290}$ Scepticism amongst the latter officials may be prompted by the idea that they do not generally position themselves as 'students' in the cooperation context; uncertainty on the part of the former seems to be motivated, at least partly, by awareness of the differences between the legal and administrative systems of member states. ${ }^{291}$ This latter issue underlines the idea that the impact of networks is shaped in part by the transferability of lessons learned, and that some member states may reap the benefits of cooperation more than others. Note that unlike Prosafe, IMPEL's lack of legal authority does not enter discussions as a factor that hampers IMPEL's effectiveness; this might be explained by the Commission's previous unsuccessful involvement in the network and IMPEL's subsequent emancipation from the Commission. ${ }^{292}$

The above information does not imply that the degree of formality is unimportant to the effectiveness of cooperation; an issue that can be illustrated by reference to the European SAFA Steering Group. Technical agreements arrived at in this group are not legally binding; despite its close links to the EU institutional context, the ESSG is a legally informal network. These agreements do, however, seem to have some authority because they are logical and they can be confirmed through publications in a training bulletin issued by EASA. Interviews suggest that SAFA officials attach much importance to such confirmation, as the following excerpt from an interview with the Portuguese SAFA national coordinator suggests:

It [the SAFA training bulletin] is a very strong tool to disseminate some practical arrangement that we have agreed upon during our Steering Group meetings. It is not a high-level, legal, tool, but the issue is that there are always some countries that are behaving wrongly. The only thing is that I would expect these bulletins to be published more frequently, because if I remember well, the first one was published in September 2009 and the second one in November 2012. ${ }^{293}$ I would really welcome very much if EASA published these bulletins on a more frequent basis, because I consider them to be of capital importance for us to clarify some issues that we do know there are recurrent discussions on the Steering Group about, and we do expect a harmonised approach. Basically these are technical issues. The SAFA training bulletin gives us the opportunity, as the name indicates, to train our inspectors on the best way of tackling these issues and things. It's a confirmation of things we solve amongst ourselves at ESSG meetings. Once I receive this bulletin, the first thing that I do is to im-

\footnotetext{
${ }^{290}$ Interview NL21.

${ }^{291}$ Interview PL8.

${ }^{292}$ For a more comprehensive evaluation on several aspects of the work of IMPEL, see Bio Intelligence Service, 2013.

${ }^{293}$ A third one was issued in the course of 2014, after this interview was carried out.
} 
mediately upload it to our internal Internet, in order to have it available for the inspectors. I tell you that in order to illustrate how important it is for us to have this uniform way of doing things and using this platform to distribute the harmonised way and the harmonised interpretation. ${ }^{294}$

Note that these words do not apply to the Prosafe handbook 'Best Practice Techniques in Market Surveillance'. ${ }^{295}$ This handbook aims to present information about best practices in market surveillance that was gathered in the course of a multiannual project to enhance market surveillance practices across European countries. ${ }^{296}$ In contrast to EASA's training bulletin, the handbook is not supported by an authoritative framework, which does make a difference. The training bulletin may not constitute a legal document, but it is certainly considered authoritative, and it presents agreements that are to be complied with. ${ }^{297}$ When it comes to the handbook, member states are free to ignore any best practices that are outlined therein. This is logical, not only given the informal context in which such best practices came about, but also given the (limited) number of member states involved in the determination of the recommendations outlined in the handbook. ${ }^{298}$ Both issues are linked and both devalue the status of the handbook. Not considered a panacea, formalisation through confirmation by a formal network - which could be the Consumer Safety Network - could provide a partial solution here. ${ }^{299}$

\section{Concluding remarks: how and when do networks work?}

Overall, transnational networks appear to be one of the most useful instruments for supporting the application of EU law by the competent authorities of the member states; this is what the survey and the interviews conducted for this study suggest. The current section aims to summarise the factors that the previous sections have suggested make networks useful compliance instruments, and to outline the conditions that networks need to meet in order for them to deliver. These factors and conditions are listed Table 17 and recapped in detail in the following paragraphs.

\footnotetext{
${ }^{294}$ Interview PT17.

${ }^{295}$ Prosafe, n.d.

${ }^{296}$ Ibid.: 6.

${ }^{297}$ Interview PT17.

${ }^{298}$ According to the handbook, fifteen member states participated fully and "several more" contributed "actively" to the work. See Prosafe, n.d.: 6.

${ }^{299}$ Note that the consultation of member states on a fait accompli is far from ideal from an input and output legitimacy point of view; hence the idea that formalisation through confirmation by a formal network is only a partial solution. For the advantages of involving member states in the development of guidance documents and how (not) to arrange deliberation processes - see Chapter 5 on post-legislative guidance, in particular Section 1.2.2.3.
} 
Table 17 Conditions for networks to be useful compliance instruments

Authorities must be motivated to cooperate from the outset. This is likely to be the case:

- in situations of perceived interdependence. In this case, cooperation is seen as important for standardising implementation practices across the board. Here:

- the conflict resolution potential of networks is important in particular

- mutual learning and mutual trust are important for countries in different ways

- resource sharing, where possible, is more important for some countries than for others

- when authorities perceive cooperation as useful for producing virtues other than those associated directly with interdependence. In this case:

- mutual learning and mutual trust are important for countries in different ways

- resource sharing, where possible, is more important for some countries than for others

In order for cooperation to deliver, it must be perceived of as informal. This means that:

- networks must be legally informal rather than codified in EU legislation

- when networks are materially formal, the Commission should not be present as a guardian but as a facilitator

The analysis presented in this chapter suggests that the participation of officials in transnational networks may be motivated by three factors. First, participation in networks may be a matter of obligation because of the codification of networks in secondary EU legislation. This legal formality seems to be an important motivational factor for officials to engage in cooperation through the Consumer Safety Network in the area of product safety. Second, authorities may be incited to participate in networks - or to establish such networks - because of a shared perception that authorities are interdependent in the implementation of EU law. The perception that their own effectiveness in the implementation process depends on the implementation performance of authorities in other member states constitutes a strong motivational factor for officials in the area of product safety to engage in Prosafe, and for officials in the domain of air safety to engage in the European SAFA Steering Group. When feelings of interdependence are weak - as in the area of integrated pollution prevention and control - the motivation to engage in cooperation must come from somewhere else. Thus, a third motivational factor for cooperation lies in awareness of the virtues - other than those related most directly to interdependence - that may accompany cooperation. These findings remind us of Chapter 5 on post-legislative guidance, which shows similar dividing lines across policy areas regarding perceptions of interdependence and associated virtues of guidance as a compliance instrument.

The networks included in this study produce virtues that the literature has outlined as most prominent; they concern mutual learning, mutual trust, resource sharing, and conflict resolution. The importance that officials attach to such virtues seems to vary across countries and across policy domains. The conflict resolution potential of networks seems to be most appreciated in situations of interdependence; in this study, in the areas of product and air safety. Here, officials attach much importance to networks 
for 'getting member states on the same line', regarding the outcomes of safety assessments that are conducted in the implementation process. While cooperation through Prosafe aims to arrive at common risk assessment outcomes and corrective measures for specific product categories, cooperation through the ESSG has the effect of arriving at technical agreements related to the implementation of SAFA inspections. Note that officials in the area of integrated pollution prevention and control do not specifically refer to this function of cooperation.

In the area of integrated pollution prevention and control, as in the product safety domain, cooperation is appreciated for the learning effect that it has. The benefits of learning do not seem to be unidirectional, since the value of exchangeable resources knowledge and expertise - differs across member states. On one hand, there will be network participants with a relatively good performance record by virtue of the resources that they have at their disposal or (relatedly) their relatively long history in a certain policy domain. On the other hand, there are likely to be network participants with less experience in this same policy domain and with less capacity to ensure effective application. Interviewees point out that authorities take on unequal roles in cooperation, with some of these authorities taking on a position of 'students' in the cooperation context and others taking on a role as 'teachers'. It is arguably the former authorities that benefit most directly from cooperation, since cooperation teaches them how to improve. Authorities that take on positions as givers in networks may derive little benefit from cooperation in the short term. However, when authorities on the receiving end implement the lessons learned through cooperation, those that invest in cooperation as teachers benefit too, since the implementation of the law is improved overall. From a practical point of view, this benefit seems most relevant in situations of interdependence, since authorities have an immediate interest in the performance of others.

Resource sharing in the mundane understanding of the word - money - seems primarily relevant to authorities that lack resources in the implementation process. It is only useful in those fields that permit the financial burden of implementation to be shared. Cooperation through Prosafe may permit consumer products to be tested for free, at least where the safety of these products is assessed in the context of joint projects that are cofinanced by the European Commission and by EFTA. This is not the case for airplanes and industrial installations. In the latter cases, financial resources may be saved because learning processes prevent officials from having to invent the wheel individually. It is only in the area of integrated pollution prevention and control that officials refer to cooperation as a cost-saving mechanism in this regard, and this occurs to limited extent.

Finally, for all three domains subject in this study, trust is referred to as an important product of cooperation, particularly by Dutch officials. These officials indicate that cooperation has reassured them that, to speak with an official, "other authorities are not as bad as they [the Dutch] thought they were". There are also indications that authorities that are initially subject to mistrust benefit from increasing levels of trust; rele- 
vant officials indicate that they have come to feel more understood and accepted by their colleagues. Since mutual trust is necessary for cooperation to be effective and for future cooperation to take place, cooperation and trust have a mutually reinforcing effect - at least where cooperation functions to allow for trust building.

This chapter suggests that the perception of cooperation as informal is of particular importance in this regard. The case studies included in this chapter suggest that legally formal networks - networks that are codified in EU legislation - are likely to interrupt meaningful cooperation. An example of such a legally formal network is the Consumer Safety Network, which was established by the GPS Directive with the intention of ensuring administrative cooperation amongst member states. This sort of cooperation has not been successful and the network constitutes a discussion forum for policy-level officials, rather than a platform for concrete cooperation amongst street-level actors. The notion that administrative cooperation within Prosafe is referred to as effective - not only by member states, but also by the Commission - is explained in part by its informality. Informality is said to enable openness amongst the participants, which is considered a prerequisite for the potential virtues of cooperation to materialise. Note that Prosafe would have few projects to carry out if Commission and EFTA funding did not exist, and that in order for such funding to be granted, formal relations with the Commission and with EFTA must exist. Also note that the existence of such relations does not detract from the fact that Prosafe is a legally and materially informal network.

The idea that a network does not need to be materially informal for it to be effective is supported by the European SAFA Steering Group. While the Commission and EASA have important positions in the coordination of the network and during network meetings, the ESSG nonetheless seems to be perceived as informal. That the involvement of EU bodies in networks may have different effects is shown by IMPEL, which was strongly tied to the EU institutional framework for some time. In this case, the Commission's formal presence in the network was felt to be hampering meaningful cooperation; this is one of the reasons that the Commission decided to quit IMPEL, giving network coordination back to the member state authorities involved. These case studies suggest that networks do not need to be materially informal for them to deliver, but that in order for materially formal networks to be successful, the Commission should not be present as a guardian of the treaties and should play a facilitating role in the network instead.

Although they are considered useful for supporting authorities in the application of EU law, networks are not the magic bullet for removing implementation problems that street-level actors may be confronted with. This is because authorities do not always participate in networks due to unwillingness or a lack of resources. This is concerning, since it may be those authorities that would benefit most from cooperation that are left out. Second, the participation of national authorities within networks seems unequal. On one hand, a characteristic of networks is the absence of quid pro quo behaviour, which is unavoidable because of the divergent resources that network participants have 
at their disposal and is logical in view of the fact that awareness of the existence of such divergences may stimulate cooperation to start with. On the other hand, when such inequality translates to hierarchy within a form of governance that is supposedly heterarchical, legitimacy questions - in terms of inclusiveness and the implementability of network outcomes - seem to arise.

Third, the implementability of network outputs is not self-evident for other reasons as well. Street-level actors may appreciate cooperation for the lessons that it teaches them, but implementation of such lessons at home may require approval or resource endowments 'from above'. Lessons may not be easily transferable to home jurisdictions, resources may not be allocated, or network outputs may lack the authority to be implemented dutifully in member states. In other words, the internal effectiveness of networks does not necessarily translate into external effectiveness. In view of the fact that future cooperation partly depends on the extent to which network outputs are implemented in national jurisdictions, the external effectiveness of networks is important not only in 'narrow terms' - in view of the policy objectives that networks are set to achieve - but in terms of the usefulness of networks as compliance instruments for individual authorities as well.

A degree of formalisation of the outputs of legally informal networks - through member state consultation and approval in the context of more formal networks - may help solve some of the problems described above. Such formalisation could imbue network outputs with more authority to compel member states into agreed ways of doing things. Formalisation of network outputs may also motivate member states to make the most of (the preceding) practical cooperation or to participate in such cooperation in the first place. In this two-step model, the informality of street-level cooperation must be ensured; this is needed in view of the openness amongst national actors that informality facilitates. Moreover, the Commission should play a facilitating role within the network that would serve as a vehicle for more formal agreements; this may be challenging because the Commission may want to use networks to further its own interests, and these interests may not always concur with the interests of the member states.

Overall, it seems that in situations where a broadly shared consensus on network goals exists the proposed model may be useful for increasing the internal and external effectiveness of cooperation. This is most likely to be the case in domains that are not politically sensitive. These remarks remind us of Chapter 5 on post-legislative guidance, which argues that the workability of guidance is optimal in domains that are highly technical rather than highly political, since here guidance development processes are less likely to be dominated by national preferences than by a shared desire to arrive at objective guidance. Note that similar to post-legislative guidance, this chapter suggests that also when policy domains are relatively politicised, transnational networks - and in particular transnational networks that permit, what is perceived as 'informal' cooperation - may be useful instruments for supporting member states in the application of EU measures. 


\section{PART IV}

\section{NATIONAL \\ COMPLIANCE INSTRUMENTS}

The last empirical part of this study focuses on national compliance instruments. Chapter 7 examines the usefulness of civil society, which may support the application of EU measures 'from the bottom up'. Chapter 8 concentrates on domestic case law and on preliminary rulings delivered by the CJEU, both of which may support application practices 'from the top down'.

\footnotetext{
${ }^{1}$ For the rationale of including preliminary rulings in this part of the study, please refer to Chapter 3 on the approach and methodology of this study, Section 3.2.
} 



\section{Chapter 7}

\section{Civil society}




\section{Introduction}

The penultimate empirical chapter of this study focuses on the usefulness of civil society activism for supporting national competent authorities in the application of EU law. The concept of civil society is highly ambiguous; neither the European institutions, ${ }^{1}$ nor scholars, ${ }^{2}$ have reached consensus on its meaning. From an academic point of view, a distinction can be made between conceptualisations of civil society in terms of organised societal interests acting in cooperation with, or in opposition to, the state, and conceptualisations of civil society as a sphere of social interaction that contributes to deliberation, transparency, contestation, and the formation of a (European) public sphere. ${ }^{3}$ Thus, civil society has a Janus face: "it is the activated European citizenry that demands to be included in EU policy-making and it is the imaged community of Europeans". ${ }^{4}$

This study follows an organisation-based conceptualisation of civil society. In the remainder of this chapter civil society, more precisely, refers to "that arena of the polity where self-organising groups, movements, and individuals, relatively autonomous from the state, attempt to articulate values, create associations and solidarities, and advance their interests". ${ }^{5}$ This definition covers manifold types of civil society actors. For the purpose of this study, a useful distinction can be made between the average member of the general public and organised civil society ('civic organisations'). It has been argued that despite the "citizen inflation" that has permeated EU discourse ${ }^{6}$ - but in line with the institutional priorities of the $\mathrm{EU}$ institutions ${ }^{7}$ " the citizen almost entirely disappears from the picture"; ${ }^{8}$ active citizenship is nearly limited to participation in the electoral process. ${ }^{9}$ In EU parlance, the notion of 'civil society' has become synonymous with that of 'organised civil society'. ${ }^{10}$

Civic organisations may be understood to encompass "the wide range of voluntary organisations that follow a 'logic of action' that is distinct from that of the state or the market or the private sphere". ${ }^{11}$ In the context of this study, these organisations refer to

\footnotetext{
${ }^{1}$ Kohler-Koch, 2009; Smismans, 2003.

${ }^{2}$ For an overview of diverse conceptualisations of civil society in scholarship, see e.g. Heidbreder, 2012: 6ff; Kohler-Koch and Quittkat, 2009.

${ }^{3}$ Heidbreder, 2012: 8-9; Kohler-Koch and Quittkat, 2009.

${ }^{4}$ Kohler-Koch, 2009: 52.

${ }^{5}$ Definition derived from Linz and Stepan, 1996: 7.

${ }^{6}$ Smismans, 2007: 579.

${ }^{7}$ In particular it is those of the European Commission and the European Economic and Social Committee, whose discourse on civil society in the EU is most prominent. For an overview on the concept of civil society within the European Commission and the European Economic and Social Committee in particular, see Smismans, 2003.

${ }^{8}$ Smismans, 2009: 66.

${ }^{9}$ Ibid.: 61 .

${ }^{10}$ Smismans, 2009.

${ }^{11}$ Kohler-Koch, 2009: 51.
} 
general-interest associations, which aim to pursue a public good or a universal value. ${ }^{12}$ Civic organisations can be divided into formalised non-governmental organisations (NGOs) and social movement organisations (SMOs). What differentiates these two types is that, while the former tend to work through conventional political channels, the latter take grass-roots organisational approaches and tend to rely on protest. ${ }^{13}$ Both, however, act to defend civic - rather than state, private, or sectoral - interests, and they may share the same general aims and act together. ${ }^{14}$

The distinctions outlined above are depicted in Figure 15. The focus of this chapter is on the concepts and actors shown in the darkly shaded boxes.

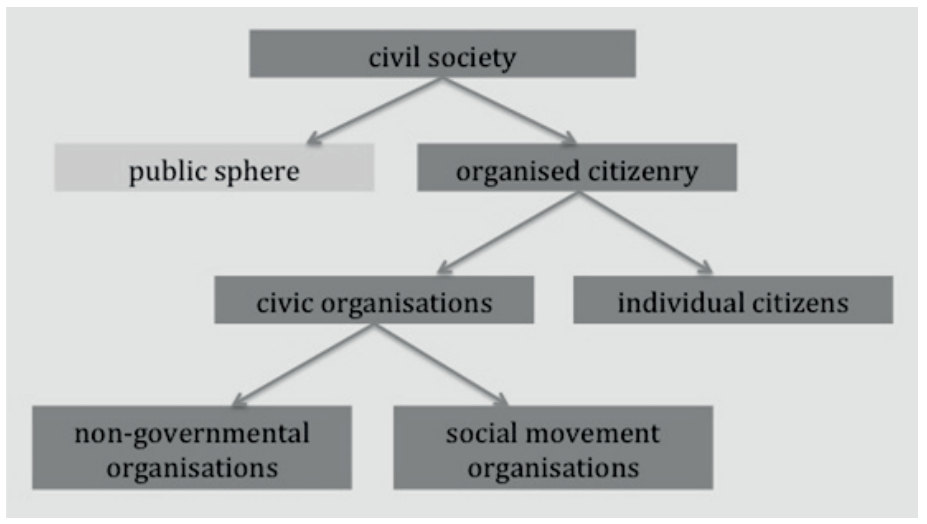

Figure 15 Conceptualisations of civil society

Attention to civil society in the EU has increased since the turn of the millennium. With the "governance turn in EU studies" 15 emerging and the permissive consensus amongst EU citizens withering, attention has shifted beyond an output-oriented conceptualisation of EU policies that emphasises effectiveness, towards an input-oriented under-

\footnotetext{
${ }^{12}$ Kohler-Koch and Quittkat, 2009: 13. This understanding seems to be in line with the notion that it is only general interest associations that are understood to qualify as civil society organisations. Dissent exists as to the inclusion of producer interests. Trade unions and professional groups are often not considered part of civil society. See Kohler-Koch and Quittkat, 2009: 13. For a different perspective, see e.g. Koopmans, 2004; Della Porta and Caiani, 2011: 47. Note that this understanding differs from the broad definition provided by the European Commission in its White Paper on European Governance, in which it considers trade unions and employers and professional organisations civil society organisations as well; see COM (2001) 428, p. 11, n. 9. For a discussion of the ever-broadening use of the concept of civil society by the Commission, sometimes to such an extent as to "include all forms of interaction between EU institutions and intermediary organisations", see Smismans, 2009: 63ff; quote on p. 65.

${ }^{13}$ Della Porta and Caiani, 2011: 26.

${ }^{14}$ See Della Porta and Caiani, 2011: 25-26. The term "civic interests" was coined by Young and Wallace, who define it as "those interests other than those of producers that are relevant to both individual items of market regulation and the broad policy impact"; see Young and Wallace, 2000: 2.

${ }^{15}$ Kohler-Koch and Rittberger, 2006.
} 
standing that underlines democratic legitimacy. ${ }^{16}$ Civil society participation in EU governance is seen as a possible solution to democratic legitimacy problems, and to efficiency and effectiveness shortcomings in the EU. ${ }^{17}$ Indeed, "the first and dominant view of and role attributed to civil society in the EU is that of an actor who contributes, or ought to contribute, to EU policy-making in order to enhance the quality and legitimacy of the substantial inputs through participation and thereby improves policy outputs." 18 The contribution that civil society could make to ensuring the correct implementation of EU measures on the ground has not been an area of focus; this is related, in part, to the notion that the EU institutions have defined civil society in a way that directly relates to their institutional interests, rather than to the various roles that civil society may play at different stages of the policy process in a multi-level polity. ${ }^{19}$

This political attention to the legitimising role that civil society may play in the policy-making process has translated into academic attention to the contribution that civil society could make, and has made, to more legitimate, effective, and efficient governance outputs. ${ }^{20}$ Studies on the role that civil society may play in the implementation of EU law seem to be lacking. ${ }^{21}$ When they exist, they seem to focus on civil society involvement in areas governed by the open method of coordination. ${ }^{22}$ Otherwise, civil society is referred to as a fire-alarm oversight mechanism providing the European Commission with information about instances of implementation failure in the member states. Chapter 4 on monitoring and sanctions instruments suggests that civil society has been acknowledged as playing "a vital role... in helping the Commission to detect infringements of Union law", ${ }^{23}$ even though the extent to which civil society acts as a whistleblowing mechanism greatly varies across policy areas and member states.

This chapter continues the discussion presented in Chapter 4. However its focus is not on the extent to which civil society may support the Commission in its monitoring activities - an issue that is addressed in Chapter 4 - but on the usefulness of activities

\footnotetext{
${ }^{16}$ Scharpf, 2003: section 2.1. For EU policy documents, see COM (2001) 428.

${ }^{17}$ E.g. Heidbreder, 2012: 8; Armstrong, 2002; De Schutter, 2002; Smismans, 2003; Kohler-Koch, 2009. For EU policy documents stressing the link between civil society involvement and legitimate governance, see the European Commission's White Paper on European Governance. For an account of the development of thinking within the European Commission, the European Economic and Social Committee, the European Parliament, and the European Committee of the Regions on the concept of civil society and on the contribution that civil society may make to democratically legitimate governance, see Smismans, 2003.

${ }^{18}$ Heidbreder, 2012: 11.

${ }^{19}$ Smismans, 2003: 490; Armstrong, 2002: 105.

${ }^{20}$ E.g. Eising, 2008; Eriksen, 2006; Finke, 2007; Føllesdal, 2011; Greenwood, 2007; Smismans, 2003, 2006; Quittkat, 2011; Magnette, 2003; Lindgren and Persson, 2010; Kohler-Koch, 2009. For issues of participation in EU bodies (comitology committees, agencies, networks, the open method of coordination, and private actor regulation), see Hofmann et al., 2011: Chapter 9.

${ }^{21}$ But see e.g. Jensen, 2007; Börzel and Buzogány, 2010.

${ }^{22}$ See e.g. De la Porte and Pochet, 2005; Trubek and Trubek, 2005; and Armstrong, 2006, for critical accounts on the actual involvement of civil society organisations in the open method of coordination.

${ }^{23}$ COM (2012) 154 final; p. 2.
} 
undertaken by citizens and civic organisations for national competent authorities in the street-level implementation of EU law. Given the virtual absence of studies on the extent to which civil society may, in this latter sense, contribute to improving the administration of EU law, ${ }^{24}$ the empirical insights provided in this chapter may add to the literature by examining this issue.

${ }^{24}$ Heidbreder, 2012. 


\section{Civil society as a compliance instrument}

This section aims to identify why civil society may be useful for competent authorities in the application of EU measures (Section 1.1), and which factors may hinder its usefulness as a compliance instrument (Section 1.2). As such, it sets the scene for the analysis presented in the subsequent sections of this chapter.

\subsection{Why civil society?}

The conceptualisation of civil society provided in the introduction to this chapter corresponds to a view of "civil society as functional participation", ${ }^{25}$ and to a perception of the EU as a regulatory political system in which civic organisations are endowed with a role in the policy process as intermediaries. ${ }^{26}$ Although discussion about the involvement of civil society in the policy process has focused on the legitimising effect of such involvement at the policy-making stage, civil society may carry out several other 'functions' in the EU policy process, "in particular providing expertise, and ensuring compliance and implementation". ${ }^{27}$ That the provision of expertise may come in useful for ensuring implementation (which means that both notions are closely intertwined) is described in Sections 1.1.1 and 1.1.2 below.

Civil society may support competent authorities in the application process through one of two avenues. The first of these is cooperation, according to which civil society "acts as a collaborator, constituent element, and integrated player in political processes". ${ }^{28}$ The second avenue is opposition, according to which civil society functions as a "counterpart and in opposition to formal governmental power". ${ }^{29}$ Table 17 shows the concrete strategies that civil society can use to cooperate with, or put pressure on, the state. These different strategies are elaborated on below. In line with the focus of the academic literature, this elaboration focuses on the role played by civic organisations, rather than by individual citizens.

Table 17 Civil society strategies

\begin{tabular}{ll}
\hline Cooperation & Multi-level pressure \\
\hline Political support & Direct contestation \\
Knowledge and expertise & Externalisation \\
\hline
\end{tabular}

\footnotetext{
${ }^{25}$ Smismans, 2003: 486.

${ }^{26}$ Kohler-Koch, 2009: 53; also Smismans, 2003: 486.

${ }^{27}$ Smismans, 2003: 486; also Kohler-Koch, 2009: 53.

${ }^{28}$ Heidbreder, 2012: 7.

${ }^{29}$ Ibid.
} 


\subsubsection{Cooperation}

The previous paragraph suggests that one way for civil society to support the application of EU law is by engaging in direct cooperation with the national competent authorities. Civil society has two types of resources at its disposal that may be useful for these authorities. ${ }^{30}$ The first of these is political support for the implementation of certain measures. Such support may be helpful not only when implementation is contested by regulated actors or by society at large, but also in a situation where awareness of the underlying policy problems is low. ${ }^{31}$ When they enjoy political support from civic organisations, state authorities are assured that if they stick to the course of action endorsed by such organisations, future conflict between the state and civic organisations is unlikely to emerge. ${ }^{32}$ When political support is visible to society at large, for example because of the use of media strategies, ${ }^{33}$ such support could create or enhance awareness and increase the acceptability of implementation measures in society as well.

A second resource that civic organisations may provide national competent authorities with is practical support in the form of specialist knowledge and expertise. Authorities may welcome the knowledge and expertise that civic organisations have to offer, since such resource endowment allows them to control the costs of implementation. ${ }^{34}$ Arguably, one may expect this function to be particularly helpful for authorities that face administrative capacity shortcomings, struggle with limited financial resources and scientific and technical expertise available for ensuring implementation, and experience difficulties in pooling and coordinating existing resources. ${ }^{35}$ It is likely that this type of support is also relevant to authorities with relatively modest implementation tasks, since it is in cases without economies of scale that resource investments are particularly costly.

Compared to authorities that are assigned a broad set of tasks and responsibilities, the interest of civic organisations in defending specific interests gives them a comparative advantage when it comes to the possession of knowledge and expertise regarding these specific interests. Furthermore, EU integration may provide additional resources in this regard. Civic organisations may, for example, have access to information through their membership in European umbrella organisations or through their EU offices. ${ }^{36}$ Indeed, the latter may not only constitute a focal point for national civic organisations for action targeted at the supranational level, ${ }^{37}$ it may also increase the capacity of such

\footnotetext{
${ }^{30}$ Note that accounts on the cooperative role that civil society may play usually refer to the policy formulation (transposition) phase of the policy process rather than to the phase during which implementing measures are put into effect on the ground.

${ }^{31}$ For an argument along these lines, see Börzel and Buzogány, 2010: 166.

${ }^{32}$ Börzel, 2006.

${ }^{33}$ See Della Porta and Caiani, 2011: 108.

${ }^{34}$ Börzel and Buzogány, 2010: 159.

${ }^{35}$ Ibid.: 166.

${ }^{36}$ Della Porta and Caiani, 2011: 98-99.

${ }^{37}$ See e.g. Della Porta and Caiani, 2011: 98-99.
} 
organisations to act independently at the national level. The participation of civic organisations in transnational regulatory networks may help these organisations build up specialist knowledge and expertise. ${ }^{38}$ The EU may support the participation of such organisations in transnational cooperation and provide them with financial and technical assistance in order to enhance their effectiveness. ${ }^{39}$ The provision of such assistance is aligned with the emphasis that the EU has put on the importance of including civic organisations as actors in the policy process. ${ }^{40}$

\subsubsection{Multi-level pressure}

While cooperation with the state may strengthen the capacity of competent authorities directly, opposition against these authorities may have the same effect indirectly. This is the case, since where civil society acts to put pressure on administrative authorities, the preferences held by these authorities may shift in favour of a certain implementation outcome, and resources may be redirected towards implementation of the relevant rules. It is this redirection of resources that has the effect of strengthening state capacity in the implementation process. Civic organisations and individual citizens have two primary techniques at their disposal to put pressure on the state: direct contestation and externalisation. ${ }^{41}$ Both of these techniques require that civic organisations and citizens act as watchdogs of the competent authorities in the implementation process, meaning that the activities of the authorities must be scrutinised and authorities must be held accountable in case of implementation failure. NGOs seem better placed to act as watchdogs of the state than SMOs and individual citizens; the former are more likely to command the resources needed to monitor the performance of the authorities and to pose a credible challenge to these authorities when necessary.

It is suggested above that one way for civil society to act as a challenger of the state is by resorting to acts of direct contestation. ${ }^{42}$ Such acts may involve the exercise of soft pressure on the state, through the use of media strategies to make implementation failure visible to a broader public and through naming and shaming the responsible authorities. From Chapter 4 on monitoring and sanctions one may recall that naming and

\footnotetext{
${ }^{38}$ E.g. Ekiert and Foa, 2011. For an account of the limited participation in the transnational networks included in this study, see Chapter 6 on transnational networks.

${ }^{39}$ See European Commission, 2012. On funding and training of civil society organisations in the latest entrants into the EU, see e.g. Kutter and Trappmann, 2010.

${ }^{40}$ Although this emphasis has been on the role that civil society could play in the policy making, rather than in the implementation, context; see the introduction to this chapter.

${ }^{41}$ Note that these two techniques relate to pressure from civil society regarding the implementation of EU legislation only. Where legislation is lacking (and it makes little sense for NGOs to act as watchdogs in the strict sense of the word - there is nothing to be enforced), NGOs are more likely to make use of other strategies. Framing, according to which NGOs use the EU as a point of reference to alter the domestic discourse, is an example of such other strategies. See Sudbery, 2010: 141.

${ }^{42}$ Sudbery, 2010: 140. This function fits into the tradition of behavioural political science, which focuses on the role of civil society as holding the government accountable through acts of direct contestation.
} 
shaming is thought to compel badly performing authorities into compliance because of the reputational costs of negative publicity.

Civil society actors may also challenge national competent authorities through administrative appeals or by initiating administrative litigation, when such actors have access to appeal procedures and access to justice. Regarding access to justice, Chapter 8 on case law shows that national procedural law provisions in this regard - for example rules on standing and court costs - differ across member states. ${ }^{43}$ It also suggests that these differences on paper translate into varying propensities for actors to initiate proceedings before administrative courts throughout the EU. Policy-specific factors amongst which is the expertise of judges regarding individual policy issues - influence the prevalence of litigation as well. ${ }^{44}$ This means that the extent to which citizens and civic organisations may engage in acts of direct contestation is expected to differ across member states and across policy domains, at least regarding the degree to which they resort to court proceedings as to hold authorities accountable for implementation failure.

A second strategy for civil society to put pressure on national authorities involves bypassing domestic institutions and using supranational channels to generate pressure on these authorities - or, more accurately, on national governments - from the outside. ${ }^{45}$ When such an "externalisation strategy" is used, ${ }^{46}$ it is not institutions at the national level (national courts in particular), but institutions at the supranational level, that are seen as potential allies of civil society. In view of the fact that NGOs command more resources than SMOs and citizens, NGOs may be expected to be more capable. One way for civic organisations to have EU bodies put pressure on national governments is by taking advantage of the multiple arenas that they may have access to. These arenas, which may come in the form of transnational advocacy networks, European umbrella organisations, and EU offices, may help NGOs gain visibility for their cause. ${ }^{47}$ It has been suggested that such arenas are used particularly by well-structured, pragmatic, and lobby-oriented organisations with relatively little leverage at the domestic level. ${ }^{48}$

Instead of, or in addition to, these non-state avenues, civil society may directly resort to the supranational institutional arena for pressure on national governments to materialise. Chapter 4 on monitoring and sanctions shows that civic organisations and citizens may act as whistle-blowers to the European Commission by submitting complaints to it regarding the implementation performance of member states. It has become

\footnotetext{
${ }^{43}$ See Chapter 8 on case law, Section 1.2.

${ }^{44}$ See ibid., Section 3.

${ }^{45}$ E.g. Imig and Tarrow, 2001: 7, who hypothesise that if the EU is to become a polity, citizens will "sooner or later" turn their claims towards the supranational level. See Sudbery, 2010: 140, for the argument that NGOs are more likely to take this course without an EU competence in the relevant policy area.

${ }^{46}$ Chabanet, 2002, in Della Porta and Caiani, 2011: 15.

${ }^{47}$ Sudbery, 2010: 140.

${ }^{48}$ Della Porta and Caiani, 2011: 17.
} 
clear that the Commission considers the role that civil society plays in this regard as vital to its monitoring function, particularly in view of the limited competencies that it has at its disposal to exercise police-patrol oversight. However, both the literature and the empirical findings presented in Chapter 4 suggest that the extent to which civil society may act as a fire-alarm mechanism greatly varies across policy domains and member states, and that the Commission has limited resources to properly act on all incoming complaints. In this sense, the support of the Commission as a 'tool' to put pressure on member states 'from the outside' is not guaranteed.

Finally, while pressure may seem - and often is - disruptive for national competent authorities initially, it may eventually be helpful because of the direction of additional resources to authorities that it may generate; these resources could strengthen the capacity of the authorities to engage in proper implementation. Authorities benefit only when the outcome of pressure mechanisms requires better implementation (which may not be the case where jurisprudence confirms a challenged course of action from the authorities), and additional resources are deemed to be needed (and allocated) to effectuate the necessary improvements (which may not be the case when an issue has low political salience). These latter remarks remind us of our discussion in Chapter 4 on monitoring and sanctions, which underlines the importance of issue salience if change in the policy process is to come 'from above' ${ }^{49}$

\subsection{Limitations of civil society as a compliance instrument}

While focused on how civil society may be of help to the authorities in the implementation of EU law, the above section incidentally discusses some of the limitations of civil society as a compliance instrument as well; limitations that (as in the case of the Commission's lack of resources to properly verify all of the complaints received by it) are not always ascribable to civil society. This section confirms this latter point. It starts by elaborating on the need for the preferences of civil society actors to be congruent with the policy objectives that are set in legislation (Section 1.2.1). It then discusses the factors that the literature identifies as prominent for shaping the interaction between state and civil society, and the persistent fault lines across member states when it comes to the nature of such interactions (Section 1.2.2). Table 18 lists the factors that are relevant to both sections.

${ }^{49}$ See Chapter 4 on monitoring and sanctions, Sections 3.1.2 and 3.2.3. 
Table 18 Factors shaping the interaction between state and civil society

\begin{tabular}{ll}
\hline Relevant domain & Determinative factors \\
\hline State & Nature of strategies adopted vis-à-vis civil society \\
& $\begin{array}{l}\text { Institutional traditions regarding openness of the administration } \\
\text { Strong or weak separation of powers }\end{array}$ \\
& Policy preferences \\
Civil society & Organisational capacity \\
& Role perception in relation to the state \\
Policy & Low or high profile \\
\hline
\end{tabular}

\subsubsection{Civil society preferences}

A precondition for civil society to act as a compliance instrument is, that the preferences of citizens and civic organisations converge with the requirements of EU legislation..$^{50}$ This is not self-evident. Citizens may be content with instances of implementation failure (such as the failure of authorities to provide economic operators with an environmental permit), and refuse to act as watchdogs when they 'should'. Civic organisations may choose to sabotage the efforts of authorities in the implementation of EU measures (such as where EU rules do, in their view, not go far enough), and refrain from lending public support to policies or providing the state with necessary knowledge and expertise. If civil society is mute, it does little to help the state meet its commitments. If civil society openly opposes the implementation of EU rules, it may become an obstacle to implementation. In the latter scenario civic organisations may appear as veto players in a multiple veto point structure that is not helpful to authorities in the implementation process. $^{51}$

\subsubsection{Strength of civil society}

The former paragraph assumes that a civil society exists and that this civil society has the strength to act. This, however, is not always the case. First, civil society is not equally present across policy areas; civic organisations are more active in certain domains namely in those regulating public goods - than in others. ${ }^{52}$ Second, the strength of civil society greatly varies across countries. The following subsections aim to explain why this is the case.

\footnotetext{
${ }^{50}$ E.g. Jensen, 2007: 472.

${ }^{51}$ Jensen, 2007.

${ }^{52}$ See also Chapter 4 on monitoring and sanctions, in which it has been shown that the extent to which civil society acts as a fire alarm mechanism varies across policy domains.
} 


\subsubsection{Between cooperation and conflict, between institutional and organisational ca- pacity}

This section begins with a slight nuance of the argument that civil society may act either in cooperation with the state or in opposition to it. First, it is self-evident that cooperation and opposition constitute two extremes of a sliding scale, and that these two extremes are not mutually exclusive. Civil society may decide to provide state authorities with knowledge and expertise to support them in the administration process and simultaneously not hesitate to put pressure on these same authorities in case of implementation failure. Second, whether civil society is observed as cooperating with the state or as acting in opposition relates more to the dynamics between the state and civil society than the role that civil society has chosen in relation to the state. This is the case, because state and civil society are mutually constitutive, at least to some extent, and the role of civil society partly depends on the attitude that state authorities have in relation to it.

A more nuanced view of the dynamics between state and civil society would discern four possible modes of interaction between both types of actors. When cooperation is well developed and levels of confrontation are low, the interaction between state and civil society follows a consensual logic. Where the opposite is the case and conflict prevents effective cooperation, the interaction between state and civil society is of a confrontational nature. There may also be situations where both the intensity of cooperation and levels of conflict are high. When this is the case, the interaction between state and civil society follows a pragmatic logic. ${ }^{53}$ Finally, when both levels of cooperation and levels of conflict are low, levels of interaction are non-existent. This may be the case when civic organisations are absent or when these organisations are too weak to act.

The strength of civil society is, however, not the only factor that determines the logic of interaction between state and civil society. As mentioned previously, state and civil society are mutually constitutive. For example, the development of a pragmatic logic of interaction not only presupposes a strong civil society, particularly a civil society possessing a great capability of self-organisation and a sufficient distance to the state; it also requires that the state demonstrate sufficient institutional capacity to deal with civil society as a partner and a challenger. ${ }^{54}$

Concretely speaking, for cooperation to occur, civil society must have resources to offer to the administration. In other words, it must be capable of providing effective symbolic support and/or the knowledge and expertise that are valuable to authorities for

\footnotetext{
${ }^{53}$ See Cinalli, 2005, in Della Porta and Caiani, 2011: 110.

${ }^{54}$ Börzel and Buzogány, 2010: 160; see also Sissenich, 2010. One may argue that both sides must also be willing to fulfil their respective tasks; organisations may be capable of acting in a certain way but not willing to do so, or vice versa. Willingness is, however, difficult to operationalise and, moreover, mirrored in capacity. This is why it will be referred to here in passing only. On the issue of willingness, see e.g. Sissenich, 2010, who emphasises the willingness of civil society in post-communist member states to exploit the new domestic opportunity structure following EU integration.
} 
the implementation process. When non-state actors are too weak to provide the administration with such resources - which is more likely for the average member of the general public and for grass-roots movements, than for formalised NGOs - a strong incentive for the authorities to engage non-state actors in the implementation process is likely to be lacking. ${ }^{55}$ Such incentive is also likely to be absent if civic organisations are too strong, since this may make authorities fear agency loss or agency capture, and result in their unwillingness to open up to the engagement of civil society. ${ }^{56}$ Unwillingness on the part of state authorities is also expected to be present if the views of civil society run counter the preferences of state authorities; the latter may tend to view what it considers to be conflicting views as illegitimate. ${ }^{57}$

For civic organisations, the incentive to engage in cooperation with the authorities lies in opportunities to influence the implementation of EU legislation. For such incentive to be credible a strong state is required; ${ }^{58}$ state actors must have the capacity to exchange resources with civil society actors without facing the threat of agency capture, and they must be able to reward them for their support. ${ }^{59}$ Interaction between the state and civil society is further framed by institutional traditions regarding the permeability of the administrative system and the nature of the strategies adopted by authorities visà-vis civil society. Access to the state is easier when administrative systems offer multiple rather than few access points - which is the case more for centralised states featuring a weak separation of powers than for states where the opposite is true $-{ }^{60}$ and for low profile rather than high-profile policy domains. ${ }^{61}$ Access is also easier when the prevailing strategies from state, in relation to civil society, are integrative or cooperative rather than exclusive or confrontational. ${ }^{62}$ This factor is shaped, in part, by historical intricacies, and it is therefore linked to the notion of path dependence discussed in the following subsection.

\subsubsection{Institutional path dependence and fault lines in the $E U$}

The previous subsection emphasises the significance of the state's institutional capacities (to respond to civil society activities) and organisational capacities of civil society (to provide support or exert pressure) as shaping the dynamics of interaction between state and civil society. The current section demonstrates that these characteristics vary not

\footnotetext{
${ }^{55}$ Börzel and Buzogány, 2010: 159; on grass-root movements versus NGOs, see Della Porta and Caiani, 2011 : 26, 103-104.

${ }^{56}$ Agency loss happens when an agent acts in a way that is opposed to the interests of the principal. On agency loss, see e.g. Pollack, 1997: 108ff. On the relation to civil society, see Börzel and Buzogány, 2010: 163.

${ }^{57}$ Kriesi, 2004: 72.

${ }^{58}$ Streeck and Schmitter, 1985: 26.

${ }^{59}$ Ibid.: $19 \mathrm{ff}$.

${ }^{60}$ Kriesi, 2004: 69-70.

${ }^{61}$ Duyvendak and Giugni, 1995, 96-98, in Kriesi, 2004: 77.

${ }^{62}$ Kriesi, 2004: 71.
} 
only across policy domains, but also across countries, and that the notion of path dependence plays an important explanatory role. The concept of path dependence may be understood to refer to the idea that institutional structures are the result of actions that create a set of institutions and that encourage these institutions to be sustained. ${ }^{63}$ Institutions are thus 'sticky'; path dependence reduces the likelihood of overnight institutional change. Applied to the subject of this chapter, the concept of path dependence may explain why some countries feature a vigorous civil society and why in other countries, civil society is observed as (still) fragile.

The extent to which democracy has been firmly entrenched in these states is an explanatory variable for the varying strength of civil society across European states; research shows clear fault lines between European democracies where communism or authoritarianism never existed or lasted only a few years, and post-authoritarian or post-communist democracies. ${ }^{64}$ Whereas the former (Western European) countries feature a tradition of participatory governance, this is not the case for post-authoritarian (Southern European) and post-communist (Central and Eastern European) countries. ${ }^{65}$ In the latter categories of countries, contemporary relations between state and civil society are more likely to be characterised by confrontational rather than cooperative patterns. ${ }^{66}$ The remainder of this section briefly elaborates on the characteristics of civil society in post-communist and post-authoritarian democracies in Europe.

Although cross-variations in the development of civil society exist, authoritarianism in Southern European countries generally featured demobilised and apathetic publics and weak oppositional civic organisations. The result was not only an incomplete civil society, but also a disconnection between civil society and the state. ${ }^{67}$ Postauthoritarian civil society in these countries shows a tendency towards politicised and clientelistic interactions. ${ }^{68}$ The influence of EU integration on the development of civil society has not been particularly positive. It has been argued that EU integration may have contributed to the weakening of civil society in these countries through an empow-

\footnotetext{
${ }^{63}$ This is one understanding of the causes of path dependence. For an overview of others and for definitions of path dependence, see Page, 2006.

${ }^{64}$ Sissenich, 2010. See Fernandes, 2012, for this argument on civil society in Portugal and Spain. See Riley and Fernandez, 2006, on Spain and Italy. See Börzel and Buzogány, 2010; Kutter and Trappmann, 2010; and Howard, 2003, on post-communist countries. Linz and Stepan, 1996 examine civil society developments in countries in, amongst others, Southern and Eastern Europe. On pre-democratic traditions of participatory governance in Europe, see Bermeo and Nord, 2000, who cover a range of European countries.

${ }^{65}$ Of course, inter-country variances in patterns of participatory governance in Western liberal democracies exist; see e.g. CIVICUS, n.d.

${ }^{66}$ On post-communist countries, see e.g. Börzel and Buzogány, 2010: 176; Kutter and Trappmann, 2010: 56. On post-authoritarian countries, see e.g. Fernandes, 2012.

${ }^{67}$ See e.g. Fernandes, 2012, on Portugal and Spain; Hamann and Manuel, 1999, on Portugal; Riley and Fernandez, n.d., on Spain and Italy; Papaioannou and Serdedakis, 2001, on Greece; Sotiropoulos, 1995, on Greece.

${ }^{68}$ CIVICUS, n.d.
} 
erment of state technocrats and a bureaucratic mode of thinking in political elites, as well as a favouring of business organisations over popular groups. ${ }^{69}$

In the case of post-communist countries in Central and Eastern Europe, EU integration seems to have produced similar results. The destruction of the traditional associational landscape during the communist period led to a marginalisation of civil society in these countries, ${ }^{70}$ where, according to some observers, a 'civil society' never actually existed; it has been said that "the lack of civil society was part of the very essence of the all-pervasive communist state" ${ }^{71}$ The marginalisation of civil society was confirmed during the transition period and by the accession strategy of the EU. While the former was driven by elites, ${ }^{72}$ the latter implied an exclusive, top-down implementation of the EU acquis that left little room for the involvement of civil society. ${ }^{73}$ This unfavourable context, together with civil society's initial emergence in opposition to the state, ${ }^{74}$ have not been conducive to shifting the self-perception of civil society away from one as an adversary, towards one as a partner, of the state. ${ }^{75}$ Moreover, the involvement of civil society actors in the policy process outside of the framework provided by majoritarian institutions is often considered clientelistic, opaque, exclusive, and thus undemocratic. ${ }^{76}$ This explains why civil society in post-communist countries has generally remained wary to act as an agent of new governance modes that favour the involvement of civil society in the public policy process. ${ }^{77}$ It also explains why strengthening civil society is considered imperative to the correct implementation of EU measures in postcommunist countries. ${ }^{78}$

Section 1.1 shows that in line with the Union's discourse, civil society ought to be involved in the policy process, and in fact the EU has made several efforts to strengthen civic organisations in post-communist countries post-accession. Accounts of the impact of such efforts are, however, mixed. While some observers argue that EU enlargement provided a "critical turn" in patterns of civil society transformations, ${ }^{79}$ others claim that

\footnotetext{
${ }^{69}$ Fernandes, 2012.

${ }^{70}$ For an overview, see e.g. Ekiert and Foa, 2011: 9-14; Kubik, 2000 (on Poland).

${ }^{71}$ Wedel 1994: 323, in Ekiert and Foa, 2011: 5.

${ }^{72}$ E.g. Howard, 2003.

${ }^{73}$ Börzel and Buzogány, 2010: 163; Kutter and Trappmann, 2010: 54.

${ }^{74}$ Ekiert and Foa, 2011: 9-14; Börzel and Buzogány, 2010: 164.

${ }^{75}$ Börzel and Buzogány, 2010; CIVICUS, n.d.

${ }^{76}$ Börzel and Buzogány, 2010.

${ }^{77}$ Not all authors agree on the vision of a weak civil society common to all post-communist countries. See e.g. Ekiert and Foa, 2011; and Rupnik, 1999, for the argument that there are great differences between postcommunist countries. For views that consider post-communist countries to have more similarities than differences when it comes to the development of civil society, see e.g Howard, 2003, who argues that there is "less variation among post-communist countries than there is between them and non-post-communist countries". See Howard, 2003: 6; emphasis in original. For similar views, see e.g. Kutter and Trappmann, 2010; Börzel and Buzogány, 2010; Sissenich, 2010; CIVICUS, n.d.

${ }^{78}$ See Chapter 2 on implementation in the EU: same rules, divergent practices, Section 3.2.4.

${ }^{79}$ Ekiert and Foa, 2011: 21.
} 
it has had a differential effect on the empowerment of civic organisations. According to the latter account, the opportunities offered by EU enlargement have empowered those that were already powerful. ${ }^{80}$ This is the case since, in order to make use of funding, networking, and other opportunities offered by the EU, civic organisations must exploit the new opportunity structure in the first place, and thus initially command considerable skills and resources. ${ }^{81}$ Moreover, EU funding for specific projects has forced civic organisations to focus on certain EU priorities rather than allowing them to build their own core activities. ${ }^{82}$ When concerned with the implementation of EU measures, these priorities have directed civic organisations to monitor formal compliance only, thus not permitting 'serious' civil society involvement in the (practical) implementation process. ${ }^{83}$ National governments are said to have acted as gatekeepers, keeping effective civil society involvement at bay. ${ }^{84}$ In this regard and in view of the strengthening of administrations in the context of the accession process, EU enlargement seems to have been of greater benefit to state actors than to civil societies. ${ }^{85}$

\section{Civil society actors relevant to this study}

The current section reflects on the associational landscape in the three policy areas and in the three countries examined in this study. The focus of this section is on the existence of civic organisations in this regard; the role that citizens may play in the implementation process is described in Section 3 of this chapter. Note that rather than providing a full picture of the presence of civic organisations in the relevant policy areas, the following subsections focus on those organisations that are specifically relevant to the policy issue regulated by the directives that are discussed in this study.

\subsection{The GPS Directive}

\subsubsection{The Netherlands}

The associational landscape in the Netherlands features a great number of consumer organisations, which may be of a professional or of a voluntary nature. The biggest and most well-known organisation is Consumentenbond (Alliance of Consumers), ${ }^{86}$ which is known for the product tests that it conducts. Note that these tests concern the quality

\footnotetext{
${ }^{80}$ Börzel, 2006; Sissenich, 2010; Kutter and Trappmann, 2010.

${ }^{81}$ Ibid.

${ }^{82}$ Kutter and Trappmann, 2010: 58, 61.

${ }^{83}$ Ibid.: 56.

${ }^{84}$ Kutter and Trappmann, 2010: 56.

${ }^{85}$ Sissenich, 2010; see also Zubek, 2008.

${ }^{86}$ See Consumentenbond, <www.consumentenbond.nl>.
} 
rather than the safety of products. Relevant to the area of product safety is VeiligheidNL (SafetyNetherlands), ${ }^{87}$ a private foundation established approximately thirty years ago, that aims to limit accidents involving consumer products by increasing the visibility of risks and stimulating and facilitating safe consumer behaviour. It does this by collecting data on injuries, implementing awareness-raising campaigns, and providing training to a variety of stakeholders. It cooperates with public and private sector actors to achieve its aims. ${ }^{88}$

\subsubsection{Poland}

Poland has two national-level consumer organisations with a general outlook: the Federacja Konsumentów (Consumer Federation) and the Stowarzyszenie Konsumentów Polskich (Association of Polish Consumers). A representative of the latter indicated that general product safety is not currently a priority topic for the association, which is why expertise on this issue within the association is absent. The reason provided for the lack of attention to the issue of product safety is that the Polish Office for Competition and Consumer Protection and other governmental bodies provide "sufficient coverage" of general product safety. ${ }^{89}$

Product safety appears to be one of many topics for the Polish Consumer Federation, the oldest and most well-known consumer organisation in Poland. ${ }^{90}$ Established in 1981 and a pro bono publico organisation since 2004, the Federation operates across the whole country, through forty-eight regional branches. It is primarily tasked with providing free consumer advice and legal assistance to individual consumers. The Federation is also involved in educational activities and consulted on national consumer policy and the implementation of EU legislation. It employs experts, but also relies on voluntary work. The Federation is a member of Consumers International (CI) and BEUC, the European Consumer Organisation.

\subsubsection{Portugal}

Portugal has five general-interest consumer organisations with a nation-wide scope, and a number of other organisations with a regional and/or specific scope. ${ }^{91}$ Most of these organisations are small and function on the basis of voluntary work. ${ }^{92}$ Two of them play a role in the issue of consumer protection: the Associação de Consumidores de Portugal

\footnotetext{
${ }^{87}$ See VeiligheidNL, <www.veiligheid.nl>.

${ }^{88}$ Interview NL1.

${ }^{89}$ Email from an expert from the Association of Polish consumers to author.

${ }^{90}$ Interview PL2. See Federacja Konsumentów, <http://www.federacja-konsumentow.org.pl>. The following information is derived from this website and from interview PL6.

${ }^{91}$ See European Commission, 'National Consumer Organisations', <http://ec.europa.eu/consumers/ eu_consumer_policy/consumer_consultative_group/national_consumer_organisations $>$.

${ }^{92}$ Interview PT8; PT6.
} 
(Consumers Association of Portugal), a small voluntary organisation, and the Associação Portuguesa para a Defesa do Consumidor (Portuguese Association for the Defence of the Consumer; DECO), the biggest and most well-known professional consumer organisation of Portugal, and the most relevant one to the context of this study. ${ }^{93}$

Established in 1974, and recognised as an institution of public interest in 1978, DECO aims to provide information to consumers and raise consumer awareness, mediate disputes between consumers and business actors, and represent the interests of consumers to public entities. While DECO does engage in activities related to the issue of product safety - it carries out product tests, the results of which are published in its magazine - the association primarily deals with economic interests and rights. ${ }^{94}$ DECO is involved in cross-border cooperation with sister organisations within and outside of Europe, and it is a member of BEUC, CI, and International Consumer Research \& Testing.

\subsection{The IPPC Directive}

\subsubsection{The Netherlands}

The Netherlands features a great number of environmental organisations at the local, regional, and national level. Many of these are grass-roots movements protesting against the establishment of industrial installations 'in citizens' backyards'. Professional organisations with a nation-wide scope act to defend a variety of general and specific interests related to nature conservation and environmental protection. Relevant to the area of integrated pollution prevention and control is Natuur \& Milieu (Nature \& Environment; N\&M) ${ }^{95}$ a small professional organisation that operates in the areas of renewable energy, sustainable mobility, and healthy food. It aims to contribute to a "substantial improvement" of nature and the environment. It does this by increasing awareness of the environment and by creating support for (more) environmental measures; by lobbying political institutions, in cooperation with other stakeholders; and by initiating, and partaking in, legal procedures against companies and state authorities. N\&M also assists citizens and local environmental organisations with expertise, for example in the area of integrated pollution prevention and control.

In addition, there is the Coöperatie MOBilisation for the Environment (MOB), ${ }^{96} \mathrm{a}$ small organisation that aims to promote nature conservation and environmental protection. It does this by increasing political and societal awareness of environmental quality in the Netherlands; by lobbying political institutions and informing the European Commission about incorrect implementation of EU directives; by concluding agree-

\footnotetext{
${ }^{93}$ Interview PT; PT2; PT3; PT5. See DECO Proteste, <http://www.deco.proteste.pt>.

${ }^{94}$ Interview PT8.

${ }^{95}$ See Natuur\&Milieu, <http://www.natuurenmilieu.nl>.

${ }^{96}$ See MOBilisation for the Environment, <http://www.mobilisation.nl>.
} 
ments with companies or starting legal procedures against them; and by advising citizens. MOB cooperates with, and provides support to, other environmental organisations as well. One of its target areas is the area of integrated pollution prevention and control.

\subsubsection{Poland}

According to the Polish environmental NGO's directory, Poland has over eighty environmental organisations. ${ }^{97}$ Some of these are professional organisations that possess the financial resources to hire expertise; many of these organisations are grass-roots organisations created as one-issue movements and are reliant on voluntary work. ${ }^{98}$ Despite the fact that integrated pollution prevention and control is "quite a hot topic" in Poland, given the manifold problems that the IPPC Directive poses, ${ }^{99}$ there seem to be few organisations that work on this issue in particular. ${ }^{100}$

The one NGO that contacts interviewed for this study recognised as having expertise on the issue of integrated pollution prevention and control is Federacja Zielonych Gaja (Green Federation Gaja). ${ }^{101}$ Gaja, which was founded in 1993, is a small professional organisation that greatly relies on voluntary work. Its activities, which come in the form of legal consultancy services, protests and demonstrations, concern diverse issues ranging from the promotion of a healthy and nature-friendly lifestyle to water and natural habitat protection. Gaja is a member of the Polish Green Network and of the Clean Baltic Network. As a pro bono publico organisation, it receives several benefits from the state that support its operation.

\subsubsection{Portugal}

Portugal has few professional environmental organisations with a nation-wide scope; many organisations are local grass-roots, and often one-issue organisations founded in areas featuring industrial activity. Amongst the most well-known national environmental organisations are the oldest environmental association of Portugal, Liga para a Proteç̧ão da Natureza (Alliance for the Protection of Nature; LPN), ${ }^{102}$ which was established in 1948, and GEOTA, Grupo de Estudos de Ordenamento do Território e Ambiente (Study Group of Spatial Planning and the Environment). ${ }^{103}$ The latter was, similar to

\footnotetext{
97 See Związek Stowarzyszeń Polska Zielona Sieć, 'Polish environmental NGOs Directory', $<$ http://www.ecolink.org.pl>.

${ }^{98}$ Interview PL14.

${ }^{99}$ Interview PL13, similar PL14.

${ }^{100}$ Interview PL13; PL14.

${ }^{101}$ Email from an expert from a Polish environmental NGO to author; interview PL13. The following information is retrieved from Federacja Zielonych GAJA, <http://gajanet.pl>.

${ }^{102}$ See Liga para a Protecção da Natureza, <www.lpn.pt>.

${ }^{103}$ See GEOTA, <www.geota.pt>.
} 
many environmental organisations in Portugal, established after the Portuguese revolution of 1974. Many of these organisations have disappeared over time.

Despite the idea that the implementation of integrated pollution prevention and control legislation in Portugal is "on stand-by", ${ }^{104}$ and that there is much left to be desired in this regard, organisations that focus on this issue are hard to find. Quercus, a national association for nature conservation, seems to be an exception. Quercus is active in various areas related to nature conservation and environmental protection. It conducts research projects aimed at educating consumers, and is consulted on environmental legislation. The association is involved in several regional, national, and international environmental platforms and networks. ${ }^{105}$

\subsection{The SAFA Directive}

Compared to the other two directives examined in this study, the SAFA Directive constitutes an atypical case regarding the presence of civic organisations in the implementation process. While the interests of air passengers fall within the scope of consumer organisations, air safety is an issue that seems to be of direct interest to airline operators and to others who are active in the aircraft industry. Civic organisations that focus on the issue of air safety do not seem to exist in any of the countries discussed in this study, and interviewees did not refer to any other sort of civic activity in relation to SAFA either.

\section{The usefulness of civil society as a compliance instrument}

This section aims to analyse the usefulness of civil society as a compliance instrument. It does this by studying the nature of civil society activism and subsequently, perceptions of its usefulness for each individual directive. Section 3.1 focuses on (the reasons for the absence of) civil society activism in the context of the SAFA Directive; Section 3.2 focuses on the role and the usefulness of civic organisations and citizens in the area of general product safety; and Section 3.3 concludes by discussing these issues for the IPPC Directive. The latter two sections address each of the three countries covered in this study separately.

\subsection{The SAFA Directive: low salience, lack of civil society involvement}

The nature of the interaction between state authorities and civil society in the three member states explored in this study shows considerable cross-country variation, as the following subsections clarify. Factors that may explain such variation have little bearing

\footnotetext{
${ }^{104}$ Email from an expert from a Portuguese environmental consultancy to author.

${ }^{105}$ See Quercus, <http://www.quercus.pt>.
} 
when it comes to explaining the presence or absence of civil society activism in policy domains in the first place. Indeed, country-specific factors may explain divergent patterns in the interaction between state and civil society where civic organisations have a role to play, which is the case for the areas of product safety and integrated pollution prevention and control. However, they do not explain why civil society activism is absent in some areas, which Section 2.3 suggests is the case for the area of air safety.

Here, the notion of issue salience seems to be an important explanatory factor. It has been noted elsewhere ${ }^{106}$ that issue salience refers to the relative importance attached to a policy subject within society. ${ }^{107}$ Civil society activism may play an important mediating role in increasing issue salience and, indirectly - because salience may trigger a direction of resources to a certain policy area - supporting the application of EU law. Facilitated by focusing events, which - justifiably or not - may be seen as an expression of implementation failure, civic organisations may turn societal attention to certain policy issues by generating debate or calling the state to account. Civic organisations may also decide to help the state, or use both opposition and cooperation strategies to secure better implementation.

While the presence of focusing events may explain civic activism, interviews suggest that the opposite is also true; that is, that the lack of focusing events may explain a lack of civil society activism in policy areas. This is the case in the area of air safety. The following excerpts from interviews with officials from all three countries included in this study establish a link between the absence of focusing events - the absence of airplane crashes - on one hand, and the absence of salience and civil society activism on the other hand:

The level of safety in aviation is very high, which makes that attention for this issue within politics and at management layers at ministries tends to fade away. There will always be competition between different modes of transportation on where to spend money to improve safety. For example, there are much more accidents with road traffic and specifically touring cars than aviation accidents, and accidents trigger thinking about priorities. This explains why it was necessary to put up a rather big fight regarding the budget for SAFA. Because of its largely preventive nature, it is difficult to measure what the effect of the SAFA Programme is on overall aviation safety - although safety findings always need to be corrected before the next flight. ${ }^{108}$

Well, SAFA is just there, it is just some programme in the civil aviation authority that we do. Only the people involved and the people in the industry know

\footnotetext{
${ }^{106}$ See Chapter 2 on Implementation the EU: same rules, divergent practices, Section 3.2.2.2.2.

${ }^{107}$ Spendzharova and Versluis, 2013.

${ }^{108}$ Interview NL27. For this quote see also earlier, Chapter 4 on monitoring and sanctions, Section 3.2.3.
} 
the programme. Citizens just want to buy cheap tickets and they want their flights to be on time. The people in the government should know, but if they do...? ${ }^{109}$

I'm pretty sure the Angola issue ${ }^{110}$ is the only example where people knew about us. Otherwise, nobody knows, nobody cares. Before Angola, even the government wasn't aware that we are doing SAFA. They asked ANAC, 'oh come on, is there a SAFA Programme? You inspect aircraft? I was not aware of that.' They became aware because of the Angola issue. No one is asking, for example the Parliament doesn't ask any clarifications, and also the media don't talk about it. And if the public is not aware, does not feel that something happened, that is good, and that is meaning that we are doing our job. But the immediate reaction in the media was that apparently we need accidents to keep the attention. ${ }^{111}$

Overall, interviewees point to the perceived safety of flying as the 'culprit' for the lack of civil society involvement regarding the application of the SAFA Directive. The question is whether or not this is problematic. Some officials suggest that the lack of 'excitement' or the absence of a watchful eye within society make it difficult for them to convince management and policy makers of the relevance of their work; a difficulty that expresses itself in turf battles when it comes to freeing human and financial resources for carrying out ramp inspections. ${ }^{112}$

Other views express the positive aspects of lacking salience. First, there is a fear that if taxpayers knew about the amount of money spent on inspections that do not directly benefit society then the public perception may turn against resource investments that are needed to ensure implementation. ${ }^{113}$ This suggests that issue

$29 \%$ of the SAFA survey respondents agree that NGOs play an active role. NGOs mainly increase citizens' awareness of unsafe airlines. They also provide the authority with information about unsafe operators, discuss safety issues with operators, and start court cases. $29 \%$ agree that NGOs play a useful role.

None of the respondents agree that citizens play an active role. $14 \%$ do, however, indicate that it would be useful if they did.

\footnotetext{
${ }^{109}$ Interview PL15.

${ }^{110}$ This issue refers to the authorisation of the Air Safety Committee for the Angolan flag carrier, which has a rather bad reputation when it comes to safety, to fly to Portugal under direct Portuguese oversight.

${ }^{111}$ Interview PT17.

${ }^{112}$ Interview NL27; PT17. For a slightly different view on the salience of SAFA rules in the Netherlands, see interview NL29.

${ }^{113}$ Interview PT17.
} 
salience may hamper implementation rather than help it, at least when it mobilises opposition against policy programmes. ${ }^{114}$ From this point of view, a lack of visibility is desirable over societal interest in the relevant policy issue. Second, a lack of visibility may also be a sign that the authority is performing well. In the words of the Portuguese SAFA national coordinator:

Our job is to have this - I would not say 'under control' - but if the public is not aware, does not feel that something happened, that is good and that is meaning that we are doing our job. ${ }^{115}$

While the above paragraphs suggest that its mere absence makes civil society a useless compliance instrument for supporting the application of the SAFA Directive, the results of the survey that was circulated in the context of this study suggest that a substantial minority of the survey respondents do agree that civil society plays an active role in the implementation process, and that this role is useful fur supporting SAFA officials in their work. It seems that this contrasting finding may be explained by the idea that business actors are - in interviews - said to play a (supportive) role in the implementation process, by acting as whistle-blowers regarding potential safety threats posed by operators, or by starting court cases against competent authorities. ${ }^{116}$ In the context of this study, business actors do not, however, qualify as civil society actors, ${ }^{117}$ which explains why this section does not focus on the role that business actors may play and, or so it seems, why the survey results differ from the results of the interviews conducted for this study.

\subsection{The GPS Directive}

While civil society activism appears to be absent in the context of the SAFA Directive, the role of civil society in the area of product safety appears to vary across member states. The following subsections aim to provide insight into the interaction between state and civil society in the three countries explored in this study, regarding the reasons for the nature of this interaction and the usefulness of civil society as a compliance instrument.

\subsubsection{The Netherlands: civil society in a complementary role}

The previous section suggests that the lack of salience of the air safety issue can be explained by the absence of air safety disasters, and that this lack of salience ensures that

\footnotetext{
${ }^{114}$ For the idea that civil society preferences need to be in line with policy objectives in order for civil society to be of potential help for the implementation process, see Section 1.2.1.

${ }^{115}$ Interview PT17.

${ }^{116}$ See e.g. Chapter 8 on case law, Section 3.1.2.3.

${ }^{117}$ See the introduction to this chapter.
} 
national competent authorities function below the radar. This section also suggests that low issue salience may be an indication that the competent authorities function well. ${ }^{118}$ When implementation is effective, there is little reason for civil society to pressure the state into compliance. There is little reason for civil society to offer symbolic support to the state when the work of the latter is invisible, supposed to stay out of the limelight, taken for granted, or where societal interests converge. Finally, there is little reason for civil society to provide the state with knowledge and expertise that the state already has.

While the state does not directly or indirectly control the extent to which civil society resorts to pressure, it does have an immediate effect on the degree to which cooperation between the state and civil society materialises; as a gatekeeper, the state may choose to embrace civil society involvement or keep civic organisations at bay. There is little reason for the state to require the symbolic support of civil society when implementation is uncontested. And there is little reason for authorities to enlist the practical support of civic organisations when these authorities already command the resources that are necessary to abide by their commitments. What these remarks seem to suggest is that while states need to possess sufficient institutional capacity to involve civil society as a partner, ${ }^{119}$ their institutional capacity should not be too high, since this might prevent cooperative relations from developing.

The Dutch case in the area of product safety seems to provide an example of this. Regarding the institutional capacity - and the implementation performance - of the Netherlands Food and Consumer Product Safety Authority (NVWA), perceptions seem to be positive, as the following excerpt from an interview with a representative of VeiligheidNL suggests:

The product safety system in the Netherlands is quite good, especially if one compares it to the situation in other member states. The NVWA is known to be a very objective risk assessor. It's not like they just do something. The expertise in the NVWA is really abundant. ${ }^{120}$

In such a situation, there seems to be little room for civil society involvement, in terms of both cooperation and pressure. Interviews suggest that product safety is not an issue within society and that civic organisations do not play a role in the area of market surveillance. ${ }^{121}$ VeiligheidNL is the only consumer organisation that is referred to as playing a relevant role in the implementation process, although to a limited extent. According to an official of the NVWA, this NGO is valuable, as its efforts to educate consumers about

\footnotetext{
${ }^{118}$ Of course, this is not always the case; it is often 'when something goes wrong' that it is not only this particular event, but a series of shortcomings that created the context in which this event could go wrong, that are brought into the limelight.

${ }^{119}$ See Section 1.2.2.1.

${ }^{120}$ Interview NL1.

${ }^{121}$ Interview NL12.
} 
responsible consumer behaviour complement state action. This suggests that true cooperation is not present; ${ }^{122}$ something that is underlined by the argument of a representative of VeiligheidNL that the NVWA should enlist the knowledge and expertise of the organisation more often:

The NVWA can only take certain product-related enforcement measures. We focus on prevention, and can hence take measures that may complement action taken by the NVWA. Cooperation could be better in the sense that we could more often be called upon to intervene in cases where the NVWA's enforcement strategy cannot be implemented, for example where the problem is related not to the product characteristics, but to consumer behaviour. ${ }^{123}$

The alleged unwillingness of the NVWA to engage in closer cooperation with this NGO might relate to the self-perception of the authority as a good performer. ${ }^{124}$ It may also relate to the idea that while officials appreciate the role played by the NGO, they do not consider its activities highly relevant to supporting the implementation of product safety legislation. Concretely speaking, the activities of VeiligheidNL may help achieve a higher level of consumer protection, but they are not directly relevant to the market surveillance tasks of the NVWA in this regard. In this situation, and since cooperation involves transaction costs, the authority may deem that such cooperation costs more than it brings. Whatever the reason for the seeming unwillingness of the authority to enlist the support of the NGO more frequently, this case seems to suggest that in situations featuring authorities with a strong implementation capacity, the role of civil society may be limited.

\subsubsection{Poland: negative perceptions of civil society}

While a strong implementation performance from the market surveillance authority may explain, in part, the low degree of cooperation between the state and civic organisations in the Netherlands, this is not the case for the other two countries included in this study. In particular, Poland seems to provide a good example of a weak civil society paralleled by a weak administration that is generally sceptical towards civil society involvement. This appears to be the case despite the existence of legal provisions that aim to ensure civil society involvement in the implementation of consumer protection policy. The relevant law in this regard - the Act on competition and consumer protection ${ }^{125}$ - lists consumer organisations amongst the entities that should perform tasks in the

\footnotetext{
${ }^{122}$ Interview NL12.

${ }^{123}$ Interview NL1.

${ }^{124}$ See Chapter 6 on transnational networks, Section 3.2.

${ }^{125}$ O ochronie konkurencji i konsumentów, Ustawa z dnia 16 lutego 2007 [2007] Dz.U. 50/33 [Act on competition and consumer protection].
} 
field of consumer protection. Generally speaking, consumer organisations must represent consumer interests before central government and self-government administration bodies, and they may participate in the implementation of the government's consumer policy. When state authorities have explicitly commissioned the implementation of government tasks to consumer organisations, the latter may apply for public funds that must be used to conduct such tasks. On the part of the state, the act requires the central government and the self-government administration bodies to consult consumer organisations on consumer protection measures. ${ }^{126}$

The problem with the Act on competition and consumer protection is that it does little to enhance the general capacity of consumer organisations to act in the public interest. State funding for consumer organisations is limited to situations in which such organisations contribute to the implementation of projects that serve the government's policy agenda. ${ }^{127}$ For example, on paper consumer organisations are entitled to perform tests on products and to publish their results. ${ }^{128}$ But since such activities are not publicly financed, this is not the type of activity that consumer organisations focus on in practice. According to an interviewee, there is one private foundation in Poland that conducts product tests, but it lacks sufficient financial means and can only assess simple products. ${ }^{129}$

The foregoing remarks explain why the focus of the biggest Polish consumer organisation - Federacja Konsumentów - is on standardisation, consumer education, and the provision of free-of-charge legal advice to individual consumers. Product safety is included in consumer education projects, but it is not focused on otherwise. What this NGO can do when it comes to product safety is to act as an information channel to UOKiK - the central Office for Competition and Consumer Protection - when it receives complaints from consumers about allegedly unsafe products. However, given the rather low degree of consumer awareness in Poland, the number of complaints is not particularly high. ${ }^{130}$

The limited involvement of civil society in the product safety domain would not, in principle, be a problem - were it not for the fact that the opportunities for the regional trade inspectorates to inspect the market and conduct proper product checks are limited. According to interviewees, the trade inspectorates primarily conduct governmental action programmes rather than their own programmes. The annual number of products submitted for laboratory testing by the trade inspectorates is less than five. ${ }^{131}$ In addition

\footnotetext{
${ }^{126}$ Act on competition and consumer protection, Arts 37 and 45.

${ }^{127}$ Ibid., Art. 45(2), sub 8 juncto 7.

${ }^{128}$ Ibid., Arts 37 and 45(2), sub 3.

${ }^{129}$ Interview PL6.

${ }^{130}$ Ibid. This low degree of awareness finds support in the fact that when citizens buy electronic equipment, only $27 \%$ of respondents indicate that they take safety into consideration when buying such products. See Urzędu Ochrony Konkurencji i Konsumentów, 2009.

${ }^{131}$ Interview PL3; PL4; PL5. Numbers range from one to three annually. See also interview PL6. This is why
} 
to financial issues, ${ }^{132}$ there are moral issues that inhibit the effective implementation of product safety legislation. Given the low salaries of inspectors, a perceived lack of appreciation from society and the state, and for business actors the disruptiveness of market surveillance actions, inspectors are easily exposed to corruption. ${ }^{133}$ In view of this situation, consumer organisations can be useful in the implementation process, by cooperating with the authorities or by watchdogging their activities.

It has already been said, however, that the capacity of NGOs to act in cooperation with the state is limited because of the nature of legal norms and practical resource constraints. This is similar to the capacity of consumer organisations to act in opposition to the state. Without suggesting that the implementation performance of the authorities should trigger pressure on the part of consumer organisations, one might question the extent to which organisations that are heavily dependent on government funding are sufficiently removed from the state, in order for such organisations to challenge the state when necessary. It seems that consumer organisations are rarely critical of the administration. ${ }^{134}$

What seems equally clear is that inspectors are rather hostile towards any sort of engagement in the implementation process of consumer NGOs and individual citizens. Of the officials interviewed for this study, only one - an official from UOKiK - refers to consumer organisations as providing useful input into the implementation process:

UOKiK sees notices from NGOs and citizens as the same as RAPEX. ${ }^{135}$ They allow market surveillance authorities to keep contact with the real world. NGOs are more helpful than citizens, because they have knowledge and expertise. NGOs provide information, they raise awareness amongst consumers, and they may be inspirational for the market surveillance authorities. ${ }^{136}$

The same official, however, indicates that NGOs and citizens are not always aware that the authorities act in the public rather than the private interest, and that "quite often" they demand UOKiK to act in a way that is not legally appropriate. ${ }^{137}$

If the remarks of this official describe a mixed message about the usefulness of civil society's involvement in the implementation process, the perceptions of inspectors must

cooperation through Prosafe may be relevant for authorities; see Chapter 6 on transnational networks, Section 3.2.3.

${ }^{132}$ And knowledge issues, interviewees from a law firm argue. See PL7.

${ }^{133}$ Email from a trade inspector to author. On salience, also interview PL3; PL4.

${ }^{134}$ See interview PL6 and Section 2.1.2 above. Case law analysis shows that none of the court proceedings started against UOKiK in the area of general product safety were started by consumer organisations. For an analysis of Polish case law in this area, see Chapter 8 on case law, Section 3.1.2.1.

${ }^{135}$ RAPEX is the EU's Rapid Alert System for dangerous non-food products. For an elaboration, see Chapter 6 on transnational networks, Section 2.1.1.

${ }^{136}$ Interview PL2.

${ }^{137}$ Ibid. 
indicate outright scepticism in this regard. Inspectors indicate that the input received from civil society is limited. Citizens are uninterested in product safety, inspectors say. ${ }^{138}$ When they are involved, such involvement is rarely helpful, since the few consumer complaints that inspectors receive - either from consumers directly, or through NGOs usually relate to issues that are not related to the safety of the relevant products. ${ }^{139}$ Since consumer organisations, as stated above, primarily function as information channels between consumers and trade inspectorates, they are depicted as "not quite vivid" at best, ${ }^{140}$ and ignored at worst:

What we think of NGOs? We are the same like you see it, we are laughing about them. Because I don't hear from them. Sometimes they cooperate with us; sometimes they call us to say that something happened with a consumer and we check every case. But we don't really value their input. ${ }^{141}$

Whether it is the alleged low-quality engagement of civil society in this policy domain in particular, or more principled hostility towards civil society activism in general that is at the root of the noted scepticism amongst inspectors is, on the basis of this case study alone, difficult to determine. It seems to be a mix of both. What can be said with a degree of certainty is that this situation appears to be a vicious circle: as long as consumer organisations do not possess the capacity to act as reliable partners in the implementation process, the administration's doors are bound to remain closed and scepticism is certain to persist. And as long as the administration does not open up to general civil society involvement - for example by funding consumer organisations rather than projects that serve the implementation of a specific government agenda - it is difficult to expect consumer organisations to build up the necessary capacity. Regardless, it seems that the key to exit this cycle lies with the government, which should also aim to socialise lower-level civil servants to a civil society appropriate discourse and rethink its funding priorities.

\subsubsection{Portugal: mixed perceptions of civil society}

If in the Polish case, capacity limitations on the part of civil society are explicitly referred to as limiting the usefulness of civil society in the implementation process, the Portuguese case highlights the institutional capacity of the state as an important determinant for perceptions of the usefulness of civil society as a compliance instrument. In compari-

\footnotetext{
${ }^{138}$ Interview PL4. This is confirmed by surveys, which show that safety is one of the last things that citizens look at when they buy a consumer product.

${ }^{139}$ Interview PL 3; PL5.

${ }^{140}$ Interview PL3; similar PL5, PL4.

${ }^{141}$ Interview PL4.
} 
son to Poland and the Netherlands, the Portuguese Consumer Protection Act $^{142}$ dedicates much importance to the role that consumer associations play in product safety regulation. Relevant to the purpose of this study is that consumer organisations are entitled to request laboratories to analyse consumer products and to make the results of such tests public. They also have the right to request, with the competent administrative or judicial authorities, that unsafe products be seized, removed from the market, or banned. ${ }^{143}$

The vehicle for the adoption of the latter types of measures used to be the Comissão de Segurança de Serviços e Bens de Consumo (the Consumer Goods and Services Safety Commission; CSSBC). ${ }^{144}$ The CSSBC, a key organ in the implementation of general product safety legislation, was presided over by DG Consumidor (DGC). ${ }^{145}$ It included ministerial experts and other public officials, and representatives from business and consumer associations. The CSSBC has, however, not survived the recent organisational overhauls in the Portuguese administration and was abolished some years ago. Its competences were shifted to DGC, which now has sole decision-making power when it comes to the adoption of investigative and corrective measures. While, formally speaking, this concentration of power makes it easier for it to make decisions, DGC has been keen to gather the expertise of the stakeholders that were previously consulted in the framework of the CSSBC under another format:

Of course, it [the shift of competences to DGC in the area of non-food product safety outside special legislation] has advantages from the point of view that here it only depends on our work. But I was keen on not losing the opinions of experts, because we don't have enough expertise. And I think it's useful, because consumer policy relies, in my view, on a number of completely different inputs. And it's the only way you can work, so you always need to be in cooperation, to engage, to actively engage, with other public bodies, with private bodies, with consumer organisations. So that's why I think this model [of cooperation] is appropriate. ${ }^{146}$

It is not only the expertise of consumer associations acquired through institutionalised consultation that is perceived to provide valuable input to the implementation process.

\footnotetext{
${ }^{142}$ Defesa do consumidor, Lei $n^{\circ}$ 24/96 de de 31 de Julho [1996] DR 1. a série A, No 176/2184 [Consumer Protection Act].

${ }^{143}$ Ibid., Art. 18(d) and (i).

${ }^{144}$ Segurança geral dos produtos, Decreto-Lei no 69/2005, de 17 de Março [2005] DR 1. ${ }^{\text {a }}$ série A, No 54/2354 [General Product Safety Act], Art. 9, 13.

${ }^{145}$ Note again that DG Consumidor is the Consumer Directorate General, which falls under the Ministry of Economy and Innovation.

${ }^{146}$ Interview PT7; similar PT6. The idea is to bundle this expertise in a Safety Working Party, which is established under the National Consumer Council. The National Consumer Council is established by the Consumer Protection Act, Art. 22.
} 
Consumer associations are also considered useful, since they aim to educate consumers about the issue of product safety. ${ }^{147}$ Moreover, NGOs may transmit information - for example, consumer complaints or results from their own research - that DGC would not otherwise receive. ${ }^{148}$ Officials from DGC may also request consumer associations to help them solve specific problems that they do not have the relevant expertise for. According to officials:

NGOs are very effective when we ask them for help. Some of them have the expertise, they study deeply, and that's what makes them useful. ${ }^{149}$

In contrast to what seems to be the case in the Netherlands and in Poland, consumer organisations in Portugal may play a role of close cooperation. Only part of the explanation for this contrast lies in the divergent legal rules that are applicable to consumer organisations in these three countries. What seems to play an explanatory role is an attitude of openness on the part of officials. While Polish inspectors show a considerable degree of scepticism towards any sort of civil society involvement, Portuguese ministerial officials seem much more open to help that (resourceful) consumer organisations offer. This openness follows, at least in part, from the idea that DGC does not have sufficient in-house expertise in the area of product safety regulation, as the above quotation suggests. Here, we observe a sharp contrast with the Dutch market surveillance authority, which as we have seen before, regards itself as a capable implementer. ${ }^{150}$

Note that the lack of expertise in the area of product safety identified by DGC officials relates to the fact that market surveillance in Portugal is split between DGC and ASAE. While the former, as noted previously, has formal decision-making power over the adoption of investigative and corrective measures in relation to economic operators, it is the latter that does the work on the ground. One of the disadvantages of this model is that one of the partners in this cooperative arrangement - DGC - lacks connections with the market and with economic operators that market surveillance authorities have. This lack of natural connectedness explains the openness on the part of DGC to the engagement of stakeholders, including that of consumer organisations that have resources to offer.

This latter remark is a sore spot: while Portugal has a number of national and regional consumer NGOs, only some of these organisations have the capacity to engage with the authorities in a way that is meaningful to the authorities. The majority of con-

\footnotetext{
${ }^{147}$ Interview PT6.

${ }^{148}$ Interview PT7; PT6; PT5.

${ }^{149}$ Interview PT6.

${ }^{150}$ See Chapter 6 on transnational networks, Section 3.2. Note that DGC is tasked with different responsibilities than the NVWA; while the NVWA spans the entire field of market surveillance for consumer products from inspections to risk assessments, risk evaluations, and the adoption and implementation of corrective measures -DGC focuses on policy making and on educating consumers; see interview PT7.
} 
sumer organisations appear to be small, regional NGOs that work with volunteers. ${ }^{151}$ These NGOs are not regarded as particularly helpful in the implementation of product safety legislation, since they lack the resources that authorities value:

I think NGOs are useful. They have a role to play in society. And we try to deal with them on the same level. But there are differences between them, some are more proactive than others, and DECO is very active and they have the capacity of doing things. I mean, they have the human resources, the financial capacity, they have lots of associates. And they receive money from the EU for programmes. I think they have the expertise. The others have less capacity. So in general we deal more with DECO. ${ }^{152}$

According to a representative of DECO, it is indeed the levels of expertise that consumer organisations bring to bear that determine the role that such organisations may play in the implementation context. However, this interviewee also indicates that consumer organisations in general play a greater role since the end of the authoritarian regime in Portugal. Both notions are expressed in the following quotation:

There are certainly developments when it comes to the participation of consumer organisations here. First of all because of democracy. The more democratic a government is, the more they ask civil society to participate. And if NGOs answer, or if the government receives feedback from consumer associations, it means that NGOs are doing a good job and the [authorities] need their expertise. So here first, it is the democratic process, and second, it is DECO itself. Indeed, it is the good feedback from DECO that makes DECO different from other consumer associations. ${ }^{153}$

While interviewees from ASAE agree that consumer organisations play an important role in society, and while they also claim to interact most often with DECO, ${ }^{154}$ their perceptions of the usefulness of this organisation are markedly less positive than those held by their colleagues from DGC. It is worthwhile to quote two interviewees from ASAE, since they illuminate this point, and the relevance of their statements extends beyond the product safety domain, as we see below:

We have a very good relationship with DECO. We normally meet three or four times a year. But they keep sending us results of their analyses, and they cannot

\footnotetext{
${ }^{151}$ Interview PT8.

${ }^{152}$ Interview PT3. Similar PT5.

${ }^{153}$ Interview PT8.

${ }^{154}$ Interview PT2; PT3; PT4.
} 
understand that we can't act on their results, that we need to have our own. I mean, they are private; they are not an authority. ${ }^{155}$

DECO sends everything to us. But if I ask about their reports, they don't answer. We never see the test reports. So for me that is nothing. And sometimes they write something in their magazine and I think it is not correct. Because they say that a product does not comply with a standard, but almost all of the time the standards they use are not harmonised and they use them in the wrong way. So they say that a product does not comply with all sorts of things that are not related to safety. Besides, my position is not that I defend the economic operator, but I don't need to punish him either. They can't write what they write, it's not correct. ${ }^{156}$

It seems that the explanation for the marked differences between the perceptions of DGC officials and perceptions of officials from ASAE lies in the different types of activities that the relevant bodies undertake and the divergent types of expertise that they possess. Since DGC does not possess the specialist expertise on product safety that ASAE commands, matters that specialists of ASAE consider incorrect might escape the attention of DGC officials. Moreover, the division of tasks between DGC and ASAE implies that the verification of consumer complaints and of other information that either body may receive is ASAE's responsibility. DGC may request that ASAE follow up on such information - at which time the matter is off DGC's table - but ASAE is legally obliged to verify each and every consumer complaint that it receives. ${ }^{157}$ Given that only half of the complaints that it checks are logical from a product safety point of view, ${ }^{158}$ the notion that ASAE officials are critical when it comes to civil society involvement is not surprising. Rising awareness amongst consumers that there may be issues with the safety of products is, ${ }^{159}$ therefore, not seen as helpful since this awareness is not coupled with knowledge about where product safety begins and where it ends. ${ }^{160}$

Overall, the Portuguese case seems to show that the usefulness of civil society - and the interaction between civil society and the state to begin with - greatly depends on the institutional capacity of the state for the specific issue at stake. It also suggests that, in order for civil society resources to be truly helpful in the implementation process, authorities must at least have some expertise to judge their value. It is difficult to expect this to be the case for authorities that rely on NGOs to provide them with expertise that they do not possess themselves. These considerations seem to be paradoxical in light of

\footnotetext{
${ }^{155}$ Interview PT3.

${ }^{156}$ Interview PT4.

${ }^{157}$ Interview PT2.

${ }^{158}$ Ibid.

${ }^{159}$ Interview PT7; PT8.

${ }^{160}$ Interview PT2.
} 
the reflections outlined in Section 1.1 above, on the basis of which one would expect NGOs to fill in where the state fails. Upon closer inspection, it seems that these theoretical considerations speak to the likelihood of cooperation between the state and civil society, while the considerations following from this particular case study speak to the expected effectiveness - in objective terms - of such cooperation of supporting that the law is applied correctly. Put concretely, what this case seems to add to the considerations elaborated on in Section 1.2.2.1 of this chapter is that the state should have some capacity in the area at stake, not only to prevent agency capture, but also to ensure that the assistance offered by NGOs is truly helping. Of course, this idea is not directly related to the perceived usefulness of NGOs as compliance instruments, but in view of its pertinence it seems worthwhile to refer to it at this point.

\subsubsection{Synthesis}

This section suggests that civil society in the area of product safety is not particularly active and that perceptions of the usefulness of societal activity vary across authorities. Generally, consumer NGOs involved in the area of product safety are relatively few. Where they exist, they do not always possess the knowledge and expertise needed to act as partners of the state in the implementation process. When consumer organisations try to cooperate with the state, state officials may denounce the input of consumer organisations as unhelpful, regard themselves as more than capable of ensuring effective

$38 \%$ of the GPS survey respondents agree (or sometimes strongly agree) that NGOs play an active role. NGOs mainly provide the authority with information about unsafe products and/or implement awareness-raising activities. They also discuss safety issues with companies. $60 \%$ agree (or sometimes strongly agree) that NGOs play a useful role. Inspectors indicate slightly different roles for consumer organisations, and more of them agree that these roles are useful.

$48 \%$ agree (or sometimes strongly agree), that citizens play an active role. $58 \%$ agree (or sometimes strongly agree) that this role is useful. These percentages, especially for appreciation, are higher for inspectors. implementation, and harbour more principled scepticism in relation to the legitimacy of civil society's involvement in the policy process. Only in some instances, do authorities actively seek and appreciate the input of consumer organisations in the implementation process. Awareness that NGOs have resources to offer that the authorities do not have at their disposal is an important impetus for authorities to enlist the support of consumer organisations. Note that since the re-

sources that authorities are endowed with may vary, not only across but also within countries, perceptions on the usefulness of the same NGO may vary across authorities within the same country, as the Portuguese example suggests. 
Note that the finding that consumer organisations do not play a particularly active role in the area of product safety broadly corresponds to the results of the survey conducted in this study; only two-fifths of the survey respondents agree that consumer organisations play an active role in the implementation process. The idea that nearly half of the survey respondents indicate that citizens play an active role in the implementation process seems bold, in view of the fact that citizens are not often mentioned in the interviews relevant to this section. Dividing lines seem to exist when it comes to the appreciation rates of consumer NGOs and citizens as actors in the implementation process as well; such rates seem to be higher for the survey respondents than for the interviewees.

\subsection{The IPPC Directive}

While the air safety domain demonstrates a lack of civil society involvement and the product safety area shows various ways in which NGOs aim to cooperate with the implementing authorities, the area of integrated pollution prevention and control shows much of the opposite. Officials from all three countries included in this study indicate that environmental organisations are active, and that this activism mainly takes the form, not of cooperation with the authorities, but of opposition against them. The following subsections aim to explain the interaction between the authorities and environmental organisations, and to discuss the usefulness of civil society activism in each of the three countries individually.

\subsubsection{The Netherlands: ambivalent perceptions of constructive pressure}

In the Netherlands - traditionally known as an environmental leader but currently classified as an average performer when it comes to the quality of the environment ${ }^{161}$ - state authorities and civil society seem to be engaged in what is best defined as a love-hate relationship'. Environmental organisations act as challengers of the state, officials say; they have persistently screened IPPC permits, pointed out what they regarded as sore points, used administrative objection and appeal procedures, and started court proceedings. On one hand, such activity leads to irritation on the part of permit writers, since it requires them to anticipate any possible criticism on the part of NGOs in the drafting process and to revise permits that are quashed upon appeal. ${ }^{162}$ On the other hand, officials value the involvement of environmental organisations for at least three reasons.

First, the notion that NGOs have won appeal procedures has the effect of increasing officials' awareness of existing problems with IPPC permits, and of triggering corrective action from supervisory authorities. ${ }^{163}$ An official from the VROM Inspectie (Public

\footnotetext{
${ }^{161}$ Börzel, 2000: 33. According to the Dutch NGO Natuur\&Milieu, the Netherlands ranks tenth amongst the EU member states See Natuur\&Milieu, 2011. Note that Yale's Environmental Performance Index ranks the Netherlands eleventh compared to the 178 countries looked at worldwide; see Hsu et al., 2014: 10.

${ }^{162}$ Interview NL21; NL23; NL25.

${ }^{163}$ Interview NL21; NL26.
} 
Health, Spatial Planning and Environment Inspectorate ${ }^{164}$ indicates that the proactive stance on the part of NGOs has boosted the vigour with which the inspectorate examines IPPC permits drafted by provincial authorities, which are responsible for permitting the majority of IPPC installations in the Netherlands: ${ }^{165}$

We were much less vigorous in this role [in the examination of permits] before NGOs were coming and winning cases now and then. When this happened, awareness arose that we needed to do more. Now we appeal [against noncomplying permits], unless we have reasons not do so. Earlier it was the other way around: we did not appeal, unless we had reasons to do so. We were always afraid to lose proceedings. For the inspectorate, carefulness was always important, and that can have a paralysing effect. NGOs have had an effect on our action capacity. We are grateful to them for this. ${ }^{166}$

Second, next to being valued for the corrective effect that it has had, the keenness with which environmental organisations have screened and appealed against IPPC permits is perceived as having worked preventively. Concretely, permit writers appear to appreciate the watchdog function of NGOs since it "keeps them sharp", which prevents sloppiness from creeping into the drafting process. ${ }^{167} \mathrm{~A}$ similar concept applies to ministerial officials, who add that it is not only legal procedures, but also discussions with NGOs that keep them focused. NGOs send out valuable signals and are not quickly satisfied, officials say, and this helps authorities make headway in the implementation process. ${ }^{168}$

Third, some officials claim to 'use' environmental organisations to strengthen their demands in relation to economic operators. The following quotation illustrates both this point and the ambivalent perceptions regarding the usefulness of environmental activism in general:

In our opinion, some organisations are sometimes an obstacle in the process, but it keeps us sharp. Some of them know what they are talking about, and sometimes we receive complaints from NGOs of which we think '!?'. We try to anticipate the thoughts of NGOs and of course we always try our utmost best to make sure everything is correct. Sometimes we can also express the opinions of NGOs in explaining their requirements to companies and suggest to consid-

\footnotetext{
${ }^{164}$ Now, together with the Inspectie Verkeer en Waterstaat (the Transport and Water Inspectorate), the Inspectie Leefomgeving en Transport (Human Environment and Transport Inspectorate).

${ }^{165}$ The Netherlands has approximately 3,000 operators that require one or more IPPC permits. Interview NL16. As a single operators can encompass more than one IPPC installation, the number of IPPC permits will be higher than the number of operators.

${ }^{166}$ Interview NL18.

${ }^{167}$ Interview NL21; NL25. Similar interview NL26; NL18.

${ }^{168}$ Interview NL18.
} 
er the improvements as suggested by NGOs in order to avoid legal proceedings. ${ }^{169}$

The above quotation highlights the idea that the extent in which environmental organisations may be regarded as useful depends on the quality of their input. Not all NGOs have the resources that are needed to make a valuable contribution; interviewees indicate that NGOs may not only lack expertise, as the quotation above suggests, but that they have little time as well, and that their action capacity may have a limited range of priorities. ${ }^{170}$ Related to this latter point is the idea that, the extent to which NGOs 'make trouble' in the implementation process partly depends on the type of IPPC installation at stake; permits for certain types of installations trigger more activism than permits for others. ${ }^{171}$ Overall, it seems that only some NGOs make a difference, and only in some circumstances.

While various national and regional environmental organisations interact with the authorities, Section 2.2.1 of this chapter suggests that officials consistently identify two organisations as significant in this regard: Natuur \& Milieu (N\&M) and Coöperatie MOBilisation for the Environment (MOB). This is not surprising if one considers that these organisations are most active in the area of litigation; a great deal of legal proceedings against permitting authorities are started by $N \& M$ or by MOB, sometimes on behalf of other environmental organisations or citizens. ${ }^{172}$ When they are not engaged in litigation, these organisations may assist other NGOs, grass-roots organisations, and citizens in legal proceedings. This is an important task in view of the difficulties that are experienced by citizens and small NGOs in areas as technically complicated as IPPC:

When it comes to big industries, the fire alarm system doesn't work so well. Citizens don't complain so much, since they think, 'we can't do anything about such a giant anyway'. This is why we cooperate with citizens who want to start legal procedures; we bring expertise and we create support for such actions. ${ }^{173}$

While environmental organisations may, thus, act autonomously at the national level or facilitate domestic opposition by ordinary citizens who are confronted with plans for the construction of industrial installations in their backyard, pressure is exercised not only at the domestic level but through externalisation as well. MOB, for example, has tried to change the domestic implementation process by taking its claims to the European level. In fact, MOB's complaints to the European Commission about the transposition and the application of the IPPC Directive are said to have led the Commission to launch in-

\footnotetext{
${ }^{169}$ Interview NL25. On the notion that involvement of NGOs legitimises permits, see interview NL26.

${ }^{170}$ Interview NL25; NL21.

${ }^{171}$ Ibid.

${ }^{172}$ For a discussion on Dutch case law in the area of IPPC, see Chapter 8 on case law, Section 3.1.2.2.1.

${ }^{173}$ Interview NL19.
} 
fringement proceedings against the Netherlands for noncompliance with the directive. ${ }^{174}$

The above paragraphs suggest that the activities of environmental NGOs represent both 'pain and gain' for the competent authorities, and that they are useful either way. While officials appear to regard the watchful eye of environmental organisations as a hindrance in the implementation process, they simultaneously appreciate them for the preventive and corrective effect that they have had - at least where such organisations dispose of the resources to make a sensible contribution to the implementation process. The complexity of the area of IPPC makes it difficult for most environmental organisations and citizens to act successfully; it is important to note that the idea that civil society in the Netherlands is feared and appreciated simultaneously is explained by the strength of a limited number of civic organisations, rather than by the action capacity of environmental organisations in general. This suggests that civil society does not have to be active or strong to have a large impact; the existence of some active and capable organisations may be more helpful than the existence of manifold organisations possessing moderate or limited resources when acting as challengers and/or as partners of the state.

\subsubsection{Portugal: negative perceptions of 'unconstructive' pressure}

How different the interaction between environmental organisations and state authorities can be is demonstrated by the Polish and Portuguese case studies. While Dutch officials indicate that there are certain environmental organisations that are particularly valuable in the implementation process for the watchdog function that they exert, Portuguese officials primarily regard the complaints that NGOs submit to them as frustrating. Interviews with officials suggest that this frustration is not caused by a principled rejection of NGO activism as potentially useful. The following excerpt from an interview with permit writers from the Agência Portuguesa do Ambiente (Portuguese Environment Agency; APA) suggests that it follows from the notion that rather than engaging in constructive cooperation with the authorities, many NGOs limit themselves to rigidly opposing them:

There are some regional and local branches that are very active, but sometimes they don't seem very well informed. We would like for NGOs to identify the problem and to be part of the solution. Sometimes it appears as if they are just against the companies, even if these companies comply with BAT and the ELVs. Because IPPC companies draw more attention - unlike small businesses, they have environmental permits available for public consultation on the Internet - they are held responsible, even when there is no reason. Smaller com-

${ }^{174}$ Interview NL20. 
panies can go unnoticed, even if most polluting, only because they are not known by the population. ${ }^{175}$

Interviewees from the Inspeção-Geral da Agricultura, do Mar, do Ambiente e do Ordenamento do Território (General Inspectorate for Agriculture, Sea, Environment and Spatial Planning; IGAMAOT) indicate that the few big environmental NGOs have the necessary technical expertise. However, this does not suffice for NGOs to be useful in the implementation process:

Recently I had a meeting with [an NGO], and they came up with a solution for something, but sometimes their ideas are not possible to put into practice. They think we can solve things in a certain way, but they are not totally aware of the legal boundaries of our powers and authority. And then we have to explain, 'no, we can't go that way, because the law doesn't allow us', or, 'we are not empowered to do it'. They have good intentions, but they are not always aware of the real context where an authority can take action. And they have expertise on the technical part of the environment, but this expertise has to be complemented with knowledge of the legal framework and the real context. ${ }^{176}$

Overall, the Portuguese officials that were interviewed for this study seem to agree that the quality of the input provided by environmental organisations often does not differ from the quality of complaints submitted by ordinary citizens. Similar to the case for the latter, part of the complaints that the authorities receive from environmental organisations are said to be "unfounded". Handling such complaints takes time that may eventually be wasted. ${ }^{177}$

The above remarks depict environmental organisations as rather useless in the implementation of the IPPC Directive, and as putting the blame for this uselessness on the oppositional - rather than constructive - attitude of such organisations and the low quality of input that they provide. Interviews with representatives from environmental NGOs support the idea that NGOs often take an oppositional stance in relation to the authorities, as the following excerpt from an interview with a representative from Liga para a Protecção da Natureza (Alliance for the Protection of Nature; LPN) confirms:

Generally, we are not very comfortable for the authorities. I mean, we have a history of placing complaints in the European Commission against decisions from the government; we have a history of challenging the government. We prevent funds from being used for the wrong projects, forcing those projects to

\footnotetext{
${ }^{175}$ Interview PT9.

${ }^{176}$ Interview PT10.

${ }^{177}$ Interview PT10; PT9.
} 
be discussed and adjusted. So generally, our relationship is not a very good one. ${ }^{178}$

The same interviewee, however, argues that some environmental NGOs also provide high-quality resources to the authorities, and that the authorities should know this as well:

Sometimes we do the work that they should do; we basically give it to them. I mean, if a government chooses to ignore it, they are ignoring good technical work, because NGOs in Portugal are very much composed of people from the universities. They don't admit it publicly, but in meetings with us they have to admit that most of the times they make political decisions, and that they agree with us technically, but that the political strategy is different. ${ }^{179}$

Although the latter quotations do not specifically concern the activity of environmental organisations when it comes to the implementation of the IPPC Directive - and the authorities' reactions - it is worthwhile to include them at this point. This is the case, since they suggest that the administration is not particularly open to NGOs even when such NGOs possess knowledge and expertise that is recognised by the administration as technically useful. Indeed, the last quotation seems to reveal a more structurally uncooperative attitude of authorities towards civil society; an attitude that interviews with public officials did not reveal. This unwillingness is implicit in the following excerpt from an interview with a representative of Quercus, the only organisation that is (particularly) relevant to the area of IPPC: ${ }^{180}$

It hardly ever happens that citizens come to us to complain about IPPC installations; it is generally too complicated. We have one case now. The citizen came to us as the authorities he went to first did not want to do anything, even though some authority recognised that there was a problem. Why nothing is happening? I have no clue. It can't be that they have too much work, because this is all there is! It is exactly this that they have to do! But when we contact them, the right people are never there. If you call them they are not present, and their colleagues never know anything. When we write to the ministry or to APA in a specific case, for example when we want to know why a certain license was granted, we always get an answer, but it takes them three months to get back to us and the answer doesn't say a lot. One would say the authorities

\footnotetext{
${ }^{178}$ Interview PT12.

${ }^{179}$ Interview PT12.

${ }^{180}$ See Section 2.2 .2 of this chapter.
} 
and NGOs are working for the same thing, for the environment. But it seems like we are competing. ${ }^{181}$

It may be that the noted lack of openness on the part of the administration is caused by resource limitations within the authorities; these resource limitations have been increasing since the latest organisational overhauls in the Portuguese administration. ${ }^{182}$ The notion that environmental policy is not traditionally a strong component of the government's policy may constitute an explanatory factor as well. It is said that the environmental department within the relevant ministry orients itself towards directions received from the finance ministry, which are not particularly green. ${ }^{183}$ The fact that IPPC is a complicated issue and environmental awareness amongst Portuguese citizens is relatively low - with citizens who are relatively passive unless an IPPC installation is planned in their backyard ${ }^{184}$ - may not help the cause of environmental organisations either.

Overall, environmental organisations are not perceived as making a useful contribution to the implementation of IPPC rules in Portugal. While officials indicate that this is the case because environmental organisations lack the capacity to act as constructive partners of, and challengers to, the state in the implementation process, interviews with representatives of environmental organisations suggest that this issue alone does not explain why authorities keep their doors closed. Other issues, including administrative capacity limitations and low societal awareness, seem to be explanatory factors as well. Overall, it seems that civil society activism could be much more useful if both environmental organisations and the state had the capacity to engage constructively with one another.

\subsubsection{Poland: negative perceptions of pressure}

The idea that capacity is problematic comes to the fore as an explanatory factor for the limited usefulness of environmental NGOs and the low levels of cooperation between environmental NGOs and the state of Poland as well. Representatives from environmental NGOs refer to the country's communist legacy as explanatory in this regard. The following excerpt from an interview with a representative from Green Federation Gaja reflects not only on this idea, but also on the idea that a strong civil society indicates a state that is capable of ensuring effective implementation:

Civil society is the key word to improving the implementation of the IPPC Directive - a stronger civil society. Because then this stronger civil society would

\footnotetext{
${ }^{181}$ Interview PT13.

${ }^{182}$ For the idea that resource limitations exist, see interview PT9.

${ }^{183}$ Interview PT13.

${ }^{184}$ Interview PT13; PT9; PT10.
} 
solve this not-skilled-enough authorities' personnel problem. It would be solved automatically, because if we had a strong civil society there would be a very strong pressure; the government would be forced to make some changes. I really don't want to go back to make some analysis based on the comparison between the communist times and democratic times. But in many cases it is impossible to speak about a problem without this background, because in Poland since 1945 until 1989 the authorities were the enemy of the society. Thus, everything connected with authorities was incorrect. It will take many years - a whole generation has to be renewed - before we can start building this strong civil society. It is impossible to do so when you think the government is against you. At the same time, we are still not recognised by governmental bodies and by society as an important partner in political processes. ${ }^{185}$

While the hostility between the state and civil society during communist times still seems apparent, it seems that the conditions for change in the interaction between the state and NGOs in the environmental domain are relatively favourable compared to those in other domains. This is the case, since the environment provides a good example of a policy area in which the involvement of civil society in the policy process has been stimulated. Most notably, environmental NGOs are given rather extensive participatory rights by virtue of the Aarhus Convention and the relevant European implementing legislation. ${ }^{186}$ These participatory rights may not strengthen the material capacity of environmental organisations, but since they highlight the legitimacy of civil society involvement in the policy process, they may pave the way for more openness towards civil society on the part of the state.

It seems that the formal significance of NGOs in the environmental policy domain may explain why, in contrast to the product safety domain, some officials involved in the area of IPPC seem relatively open to the involvement of NGOs in the implementation process - however formalistic such openness may be. The following quotation from an interview with permit writers, demonstrates the conditions under which the input from NGOs may be useful, and where environmental organisations may be a nuisance instead:

NGOs work in quite a specific way, because they usually don't want to change the conditions set out in the permit. They want cessation of the activity. They

\footnotetext{
${ }^{185}$ Interview PL13.

${ }^{186}$ The United Nations Economic Commission for Europe (UNECE) Convention on Access to Information, Public Participation in Decision-Making and Access to Justice in Environmental Matters was signed in 1998, in Aarhus. It outlines rules for citizens and for their associations regarding access to environmental information, public participation in environmental decision-making, and access to justice. Its provisions relating to the first two issues must be implemented by the EU member states by virtue of the adoption of EU legislation in this regard.
} 
want to stop it completely. So it is hard to discuss, they don't give any arguments to us, because they just don't want this landfill or installation. And the final argument is, 'would you like to live here near this landfill?' But they don't take into account that the landfill was here ten years ago. They are not really constructive. Sometimes it happens that NGOs give some feedback on the permit. They have experts from the technical universities that cooperate with those people and then participation is very useful. ${ }^{187}$

The views on the participation of NGOs in the permitting process expressed by these permit writers are similar to those held by an official from the Ministry of the Environment. The latter, however, adds that the way in which regional authorities deal with NGOs partly also depends on the historical connections between them, ${ }^{188}$ which suggests that patterns of interaction between the authorities and NGOs may vary across regions. This suggestion finds support in the following quotation, which suggests that relations between state and civil society are more 'normalised' in some regions than in others - and that permit writers are generally dismissive of societal activism:

Whether NGOs are useful [in environmental licensing processes]? It's rather the opposite. Authorities don't really like them. There were even some cases of NGOs that make money by objecting to everything. We had one of them in our region. They had this habit that they would come to operators and say, 'we're not going to formally object if you give us money'. Of course these are exceptional cases, but they exist. Usually, it is small local organisations that may do this, professional organisations are mostly ok. But for permit writers the only thing is that they have to be part of the process, so whichever remarks NGOs submit, even some very stupid ones, they add to the whole process. Sometimes we get a lot of stupid remarks, not necessarily from NGOs, but also from society. And then we need to prove that it is exactly the opposite way. It is a lot of additional work for the permit writer. ${ }^{189}$

Note that the above quotations are similar to the perceptions of Portuguese officials, who likewise refer to most civil society complaints about IPPC permits as unfounded and as time consuming, and to the participation of environmental organisations as little constructive. Also note that the sentiment that most NGOs do not have the knowledge and expertise to make themselves valuable actors in the implementation process is held

\footnotetext{
${ }^{187}$ Interview PL9. Similar PL11.

${ }^{188}$ Interview PL8.

${ }^{189}$ Interview PL12. Note that this view is based on accounts heard from permit writers.
} 
not only by the Polish official quoted above, but also by ministerial officials, permit writers from other regions, and representatives from environmental NGOs. ${ }^{190}$

According to the latter, the lack of expertise on the part of NGOs is explained by the fact that most NGOs depend on voluntary work; there are only a few professional organisations that have the resources to invest in staff and expertise. ${ }^{191} \mathrm{~A}$ representative from Green Federation Gaja indicates that it is difficult to find people with expertise on IPPC in environmental NGOs:

It's difficult to find NGOs involved in IPPC, I'm the only one at Gaja and it is a big problem actually, because we have only a few people from different NGOs working in the whole country on this issue. In Poland it's easy now to get some volunteers for hospices and when it comes to children's issues, or animal welfare. But when it comes to experts and you have to go deeper into the problem, it's very hard to get people interested. At Gaja we have two volunteers and eight staff members. I am doing IPPC voluntarily now; this is also a problem, because I have different tasks. But many people in Poland just recognise Gaja as an NGO dealing with IPPC, so I get many letters, mails, phone calls every week, so it's quite big. Those are from people that don't get any support from the authorities or from any other sources. It's like fulltime work; it's a way of doing it for life. ${ }^{192}$

The weakness of civil society in the environmental domain cannot be seen as separate from the low levels of environmental awareness within Polish society. Polish citizens traditionally do not care about the protection of public places, interviewees say; when citizens do get involved in environmental issues, it is not out of a general concern with the state of the environment, but because an IPPC installation is planned in their backyard. ${ }^{193}$ It may be argued that the low visibility of environmental issues and weak societal support for environmental organisations do not help the cause of NGOs, both in terms of capacity building and the state's (more than formalistic) openness to such organisations as legitimate partners in the implementation process.

Interviewees argue that it is not only the lack of broad societal support, but also the lack of high-level political support for green policies that mitigates the impact that environmental NGOs may have. Much industry is still owned by the state. This explains why the state has been reluctant to adopt environmental policies at the expense of industrial development - the Ministry of Environment is said to have clear directives not to hinder

\footnotetext{
${ }^{190}$ Interview PL8; PL9; PL11, PL13; PL14.

${ }^{191}$ Interview PL14; PL13.

${ }^{192}$ Interview PL13.

${ }^{193}$ Interview PL13; PL14; PL12; PL9.
} 
the implementation of construction plans - and why well-reasoned claims of NGOs are not always accepted by authorities and courts. ${ }^{194}$

In view of the above remarks, it seems that environmental organisations in Poland cannot, generally speaking, be expected to function as useful compliance instruments. Certainly, permit writers suggest that NGOs that bring in relevant knowledge and expertise may be accepted as providing valuable input in the implementation process, and a representative from Green Federation Gaja confirms that the administration has been opening up to environmental NGOs:

Culture, and legal culture in particular, is very important, but the optimistic thing is that it is improving. So there is hope for the future. It seems easier and easier for us to work as an NGO. And I see that our campaigns and projects bring something. I am still very surprised that a small expert NGO can make a change. ${ }^{195}$

Interviews do, however, also suggest that such expertised NGOs are rare. ${ }^{196}$ Moreover, despite the fact that things are changing, openness to NGOs on the part of the state is still largely formalistic. Veritable openness to civil society enabling actual cooperation between the state and environmental is partly a matter of time. However, similar to the area of product safety, it may be a task for the state to extend more efforts aimed at socialising lower-level civil servants to the idea that civil society involvement in the policy process is 'a good thing'. Moreover, if environmental organisations are to build the capacity that is needed to act as credible partners of, and challengers to the state, the government may have to contribute more financially and symbolically. Both, however, are unlikely to be provided if the environment is not a priority for the state.

\subsubsection{Synthesis}

This section suggests that environmental organisations and citizens act primarily as challengers of the state in the implementation process, and that they are - especially in the Netherlands and in Portugal - seen as active challengers. This section also suggests that few environmental organisations have the resources to act as credible opponents to

\footnotetext{
${ }^{194}$ Interview PL14. Both factors may explain why while Poland was recognised as having made great strides towards a cleaner environment in the first years after the fall of communism, such advances did later seem to have come to a halt. Note that the latest Environmental Performance Index (EPI) ranks Poland $30^{\text {th }}$ out of the 178 countries studied worldwide; see Hsu et al., 2014: 10. Poland's rank in the 2012 EPI was $22^{\text {nd }}$ out of the 132 countries covered; see Emerson et al., 2012: 10. While the latest EPI suggests the trend environmental performance of Poland to be positive (see Hsu et al, 2014: 10), the 2012 EPI still ranked Poland as $107^{\text {th }}$ out of the 132 countries covered in this regard (see Emerson et al., 2012: 10). In view of the latter ranking, pessimistic perceptions of progress in the environmental quality in Poland are not surprising.

${ }^{195}$ Interview PL13.

${ }^{196}$ See Section 2.2.2 of this chapter.
} 
(or as credible partners of) the state; this may be explained, in part, by the technically complicated nature of the issue of integrated pollution prevention and control. While some officials indicate that they appreciate environmental organisations when these organisations possess the resources needed to act constructively in the implementation process, others show a more principled rejection of civil society as rightful or desirable. It is not only principled rejection that results in limited openness, on the part of the state, to civil society involvement; adminis-

$24 \%$ of the IPPC survey respondents agree (or sometimes strongly agree) that NGOs play an active role. NGOs mainly share their views on the application of BAT in conversations with the authority. They also discuss the application of BAT with companies, start court cases, inform the public about the application of BAT, and take part in public participation processes. 52\% agree (or sometimes strongly agree) that NGOs play a useful role. These percentages are similar for permit writers.

$47 \%$ of the respondents agree (or sometimes strongly agree) that citizens play an active role. $68 \%$ agree that this role is useful. These percentages are considerably lower for permit writers. trative capacity limitations - both practical and symbolic - seem to have this effect as well. Overall, it is only in the Netherlands that environmental organisations are regarded as highly useful in the implementation process; perceptions in Poland and Portugal are generally negative.

The idea that environmental organisations play an active role in the implementation process is certainly not commonplace amongst those who responded to the survey that was circulated for this study; only a quarter of the survey respondents agree that NGOs play an active role in the implementation process. The notion that more than half of these respondents regard the role played by NGOs as useful does, in contrast, seem high in comparison to the aggregated picture that has arisen from the interviews. It also suggests that the associational landscape does not necessarily need to be very active in order for NGOs to fulfil a useful role in the implementation process; moreover, high levels of civil society activism may create frustration and irritation on the part of officials, since much of this activism may come from organisations that do not have many resources to offer. Positive perceptions of the usefulness of NGOs may be derived from an appreciation of the resources that a limited number of active NGOs have to offer in an associational landscape that is generally calm.

Note that discrepancies between the survey results and the interviews are present particularly when it comes to the role and especially the usefulness of citizens in the implementation process. While interviewees do not refer to individual citizens as useful actors in the implementation process, ${ }^{197}$ the aggregated survey results show a great ap-

${ }^{197}$ Citizens only enter the scene as useful in the Dutch implementation context, and only for the court cases that they start in association with environmental NGOs that support them in such cases. 
preciation of the role played by citizens in this regard. Note that this is particularly true for survey respondents who are not involved in environmental licensing processes; appreciation rates regarding the involvement of citizens are considerably lower amongst the latter. The survey results do not, unfortunately, enable the reason for these divergent appreciation rates to be ascertained.

\section{Concluding remarks: how and when does civil society work?}

This chapter suggests that the usefulness of civil society as a compliance instrument varies greatly across countries and across policy domains. The factors accounting for such variation are, to a considerable extent, those that the literature suggests are relevant; the case studies suggest some nuances occasionally. Table 19 outlines the conditions that these case studies suggest must exist in order for civil society to function as a useful support to authorities in the implementation process. These conditions are recapped in detail below.

Table 19 Conditions for civil society to be a useful compliance instrument

There must be something like civil society activism to begin with. This is the case where:

- an issue is salient enough for society to get engaged in the implementation process

When opposing the state, civil society must be capable of doing so credibly. This is the case when:

- civil society possess sufficient expertise regarding the relevant policy issue

When civil society aims to engage in cooperation with the state, authorities must regard this as potentially useful. This seems to be the case when:

- authorities are socialised into the idea that civil society participation is 'a good thing'

- authorities have sufficient practical resources to engage with civil society

- authorities are not too confident of their own implementation performance

- civic organisations possess the expertise to cooperate constructively with the state

In order for civil society to be a useful compliance instrument, there must be civil society activism to begin with. This is not a matter of course, as the area of air safety testifies. An explanation for the absence of civil society activism in this area seems to be the lack of societal salience of the issue of SAFA; something that is caused by the absence of focusing events -concretely speaking, these are crashes of third-country airplanes in EU member states - that are helpful to draw society's attention to a policy issue. Note that a lack of salience is not necessarily problematic. While the lack of a watchful eye may make it difficult for authorities to ensure that sufficient resources are allocated to implementation, societal awareness of the resources that authorities are endowed with may also mobilise opposition, especially if it is unclear how citizens stand to benefit from implementation. In the latter case, civil society may act as a veto player that obstructs 
the implementation of rules, rather than as a useful actor helping implementation move forward.

Where civil society is active, the extent to which this is the case and the role played by civil society vary across member states and across policy domains. In the area of integrated pollution prevention and control, interviewees (and a minority of the survey respondents) refer to civil society as playing an active role in the implementation process. In the case studies examined here, pressure seems to be the most prominent mode in which environmental organisations choose to interact with the state. This pressure is most visible in the Netherlands, where environmental organisations and (grass-roots groups of) citizens have started numerous court cases against authorities responsible for permitting IPPC installations. In the area of product safety, survey respondents seem to find civil society more active than interviewees; the latter do not generally refer to consumer organisations as playing an active role in the implementation process. Cooperation seems to be the dominant modality employed by consumer organisations across the three countries included in this study. Which of the two modalities appears dominant is partly a matter of choice for civic organisations, partly a matter of capacity of these organisations and the state, and partly a matter of state perceptions of the legitimacy of civil society involvement in the policy process.

Important for determining the choice of NGOs regarding the modality of interaction seems to be the adequacy of the implementation performance of member states. When implementation is deemed inadequate, pressure may be a necessary tool to repair implementation failure. Pressure does not seem useful when the implementation performance of the administration is deemed adequate; in this case, civic organisations may want to support the state by providing it with knowledge and expertise that may be relevant to the implementation process. The above sentences partly explain why consumer organisations in the area of product safety choose to cooperate with the state, and why environmental organisations in the area of IPPC mainly choose to put pressure on authorities.

Whether officials experience civil society activism as useful does not depend entirely on the mode of interaction chosen by civil society actors. While Polish market surveillance inspectors demise the efforts of cooperation made by consumer organisations, some Portuguese officials are positive about involving consumer organisations in risk management processes. And while Polish IPPC permit writers are generally negative about the pressure generated by environmental organisations, Dutch permit writers refer to the strongly challenging role of such organisations as amongst the most useful in supporting the implementation process. To explain these divergent perceptions the notions of capacity and legitimacy are relevant factors.

It is the balance between the organisational capacity of the state to deal with civil society and the capacity of civil society to act as a credible challenger of, and collaborator with, the state that determines the interaction between state and civil society. Civil 
society organisations need sufficient knowledge and expertise, not only to act as credible challengers of the state, but also to be regarded by the state as useful partners in the implementation process. This chapter suggests that most of the environmental organisations in all three countries included in this study do not possess such expertise; this may, to a significant extent, be blamed on the technically complicated nature of the issue of IPPC. This is also the case for Polish consumer organisations. Note that the Dutch perception of civil society activism in the area of IPPC as greatly useful is based on an appreciation of the role that a few highly expertised NGOs play, rather than on the input that authorities receive from the majority of NGOs in this field. The latter also applies to the few positive perceptions held by Polish and Portuguese officials.

Whether or not cooperation materialises not only depends on the objective levels of expertise that civil society organisations have to offer; it also depends on the degree to which the state is, or regards itself as, capacitated to ensure proper implementation. When the state regards itself as strong enough, it may be less willing to engage with NGOs than when it considers itself in need of external expertise. While the first aspect might explain, in part, why the Dutch market surveillance authority is not welcoming to the help that consumer organisations offer, the latter aspect explains why the Portuguese ministry involved in the implementation of general product safety legislation welcomes engagement with such organisations. The Portuguese case also shows that while it is true that authorities should not be too strong, they should not be too weak either; authorities must be capable of assessing whether the expertise offered by NGOs actually meets their needs. When authorities are particularly weak, they may rely on 'expertise' that these NGOs do not have. In this case, cooperation may affect the capacity of the state adversely and do little to help the effectiveness of implementation in objective terms.

Varying perceptions of the legitimacy of participatory governance explain the openness of the state to civil society participation as well. It is at this point that the fault lines suggested in the literature divide (open) Western European countries from (relatively closed) post-communist and post-authoritarian European countries are relevant. For example, despite the participation-friendly discourse in Polish consumer legislation, the spirit of this legislation is not apparent with market surveillance inspectors in the Polish regions. And despite the importance that the Aarhus Convention attaches to public participation in environmental matters, openness amongst IPPC permit writers to the participation of environmental NGOs generally remains formalistic.

It is not only Polish NGOs that seem to be confronted with a lack of openness to their participation on the part of the state; in particular Portuguese environmental NGOs indicate that they are confronted with this issue as well. In this case, however, it may be material administrative capacity limitations that are to be blamed, although the low societal and political salience of environmental issues in Portugal may not help the cause of environmental NGOs either. Note that the latter issue could be the case for 
environmental NGOs in Poland as well. As such, issue salience not only seems to explain the existence of civil society activism across member states in the same policy domain (as in the case of air safety); it may also explain the nature of the interaction between state and civil society across countries in the same policy domain.

Finally, civil society is not a quick fix to compliance problems, particularly when it is (still) feeble. This chapter suggests that the strength of civil society and the nature of the interactions between civil society and the state are highly path-dependent, which means that neither of these are expected to change instantly. The idea that a flourishing civil society cannot be conjured up clearly sets it apart from the compliance instruments discussed in the previous chapters of this study. Supranational agencies can be established following agreement about their creation, and the infringement procedure can, to some extent, be moulded to ensure its effective functioning. Post-legislative guidance can be developed on request, and networks can be created when a need for cooperation exists. However, the creation of non-governmental organisations alone cannot create a flourishing civil society, and constructive relations between civil society and the state. For these matters to materialise, a culture in which civil society defines itself not just as an adversary, but also as partner of the state is needed; a culture, moreover, in which state officials consider civil society a legitimate partner in the implementation process. If such a culture is lacking, the usefulness of civil society as a compliance instrument is bound to be limited.

When a culture similar to that described above does exist, civil society could be a useful compliance instrument, by strengthening the capacity of the state to ensure effective implementation. This idea makes it imperative to pay considerable attention to strengthening civil society - and to strengthening the capacity of the state to engage in constructive relations with civil society - in countries that have, until now, remained behind. In view of the idea that significant improvements in the latter countries are likely to materialise over time, the good news for implementation in the EU is that significant improvements may be arriving. 



\title{
Chapter 8
}

\author{
Case law
}




\section{Introduction}

The last empirical chapter of this study focuses on case law; an instrument that, in contrast to civil society activism and in view of the functional relationship between courts and parties in court proceedings, has an outspoken top-down character. In the context of this study, case law covers two components: domestic administrative case law with an EU law dimension and preliminary rulings delivered by the Court of Justice of the European Union. ${ }^{1}$ The inclusion of the latter instrument in this chapter is, as explained earlier, ${ }^{2}$ motivated by the idea that national courts are prime actors for making the EU's preliminary ruling system work. The CJEU would not deliver preliminary rulings if national courts did not submit requests to it, and preliminary rulings would not acquire meaning in the national implementation context if national courts did not loyally comply with these rulings. ${ }^{3}$

Unlike other compliance instruments examined in this study, national case law and preliminary rulings have, from the early years of EU integration played a role in ensuring member state compliance with EU law. One must only recall the famous Van Gend \& Loos and Costa $v$ Enel judgements ${ }^{4}$ that were handed down by the CJEU, following a request for a preliminary ruling submitted by national courts in the context of domestic court proceedings. These rulings have greatly increased the potential for the preliminary ruling system to support the correct implementation of EU law, since the Court developed the doctrines of direct effect and supremacy in these rulings. ${ }^{5}$ While the former principle makes it possible for individuals to assert EU rights in national courts, ${ }^{6}$ the latter imposes an obligation on national courts to disregard national law provisions that conflict with EU law provisions. ${ }^{7}$ While the Court has thus engaged national courts as allies in, what may be called, a dialogue system between the national and supranational judiciaries, national courts and the CJEU are not equal conversation partners. This is the case, since the Court perceives the purpose of the system as securing a uniform interpretation of EU measures throughout the Union "by assigning to the Court a monopoly of final interpretation", ${ }^{8}$ which national courts must respect.

\footnotetext{
${ }^{1}$ Note that CJEU case law delivered in the context of infringement proceedings is covered in Chapter 4 on monitoring and sanctions.

${ }^{2}$ See Chapter 3 on the approach and methodology of this study, Section 3.2.

${ }^{3}$ At least not in the way they are intended to do so. Where national courts do not comply with interpretations given by the CJEU in preliminary rulings, this judicial noncompliance may return to the relevant member state, for example in the form of infringement proceedings for noncompliance with EU law.

${ }^{4}$ Case 26/62 NV Algemene Transport- en Expeditie Onderneming van Gend \& Loos $v$ Netherlands Inland Revenue Administration [1963] ECR 1; case 6/64 Flaminio Costa v. E.N.E.L. [1964] ECR 585.

${ }^{5}$ Tridimas and Tridimas, 2004: 128.

${ }^{6}$ This principle was established first in the Van Gend \& Loos ruling, cited in n. 4 above.

${ }^{7}$ This principle was developed in the Costa $v$ Enel judgement, cited in n. 4 above.

${ }^{8}$ Fennelly, 1996: 672-673.
} 
The CJEU itself has often referred to both domestic case law and preliminary rulings as essential solutions to compliance problems. ${ }^{9}$ The idea that the Court's interpretations of EU law are greatly sought after is suggested by the fact that the number of preliminary questions submitted to the CJEU has increased over time, from a single preliminary question in 1961, to a record 450 questions in $2013 .{ }^{10}$ Today, preliminary ruling questions form the great majority of the Court's caseload. ${ }^{11}$

This chapter aims to analyse the usefulness of preliminary rulings and of domestic case law as compliance instruments. This involves conducting not only a legal analysis of the relevant case law, but an evaluation regarding the perceived usefulness of this case law for those who stand to benefit from it as well.

\footnotetext{
${ }^{9}$ Case C-478/93 Kingdom of the Netherlands v Commission [1995] ECR I-3081, p. 38.

${ }^{10}$ Figures from Curia (2014), Annual Report 2013. Synopsis of the work of the Court of Justice, the General Court and the Civil Service Tribunal, Luxembourg: Publications Office of the European Union, pp. 103-104.

${ }^{11}$ In 2013, 450 out of 699 cases put before the CJEU concerned preliminary questions. Court of Justice of the European Union, 2012: 96; 2014: 70.
} 


\section{Case law as a compliance instrument}

While closely intertwined in practice, domestic case law and the EU's preliminary ruling system are conceptually distinct. Thus, this section discusses each of these instruments separately. The first parts of Sections 1.1 and 1.2 begin by addressing the question of why national case law can be a useful compliance instrument (Section 1.1.1) and which factors may hinder its usefulness as such (Section 1.2.1). The second parts of these sections examine the same questions for preliminary rulings issued by the CJEU (Sections 1.1.2 and 1.2.2).

\subsection{Why case law?}

\subsubsection{Domestic case law}

While the infringement procedure, which has been discussed in Chapter 4 on monitoring and sanctions, is meant to enforce compliance from the supranational level, domestic case law is a pre-eminent decentralised enforcement mechanism. In view of its closeness to the national law administration practice, domestic case law has an advantage over infringement proceedings regarding its swiftness in responding to instances of noncompliance..$^{12}$ The complementary role that domestic case law may play in relation to the infringement procedure has been widely recognised, ${ }^{13}$ particularly in areas characterised by collective action problems, such as the environment and consumer protection. ${ }^{14}$

Of interest in this study is domestic case law that is intended to solve disputes between the public administration and natural or legal persons. Such case law fulfils two functions, both of which are closely intertwined. The first function, which is of a subjective nature, relates to the idea that case law offers redress for citizens or other actors who claim to suffer from grievances caused by public authorities. ${ }^{15}$ For example, citizens may want to challenge a decision that allows an industrial operator to construct a chemical installation in their (metaphorical) backyard, and operators may want to object to the allegedly unfair conditions outlined in this permit. Conceptually speaking, it is this subjective function of case law that most closely relates to the right to effective judicial protection, which is a general principle of EU law. ${ }^{16}$

The second function of domestic case law, which is of an objective nature, involves the desire to ensure legality, by guaranteeing that public authorities act within the limits of

\footnotetext{
${ }^{12}$ The problems associated with the infringement procedure in this regard have been discussed in detail in Chapter 4 on monitoring and sanctions. See Sections 1.2.1 and 3.3 of this Chapter.

${ }^{13}$ E.g. by the CJEU; see case C-478/93 The Netherlands v. Commission [1995] ECR I-3081, p. 38.

${ }^{14}$ Micklitz and Reich, 1996; Somsen, 1996, in Slepcevic, 2009: 378.

${ }^{15}$ De Visser, 2009: 285

${ }^{16}$ E.g. case C-222/84 Marguerite Johnston v. Chief Constable of the Royal Ulster Constabulary [1985] ECR 1651, para 18. For an elaboration on this principle, see Section 1.2.1 below.
} 
the law and ensuring that decisions made by the authorities comply with the relevant legal provisions. ${ }^{17}$ It is this function that is most relevant to this study, since it is not focused on grievances that applicants claim to suffer, but on the compatibility of the behaviour of the public administration with legal provisions. It is from a judicial evaluation of the latter issue that public authorities may draw lessons that are useful for implementation practice. This is the case when the court declares that a decision was unlawful and obliges the authority to rethink its decision, or when the court puts its decision in place of the decision made by the authority in the first instance. It is also the case when the initial administrative decision is confirmed, since such a confirmation may support the authority's entire course of action in relation to the relevant policy issue. This latter function may be as useful as the former, in particular when the authority's activities are subject to persistent out-of-court challenges by business or civil society actors; challenges that may cease once 'judicial authorisation' of a decision has been obtained.

In view of the fact that case law may have the effect of undoing wrongs committed by the public authorities, its effect is primarily ex post and corrective. Case law may, however, also have the effect of preventing instances of noncompliance from occurring. This may be the case when the court has declared a certain decision to be in violation of, or in compliance with, applicable legal provisions, and also - and even more so, one might argue - through judicial rule making, that is, through "a court's authoritative interpretation of existing rules and procedures, which results in the clarification of the law and practices in question". ${ }^{18}$ Thus, national case law may not only have an enforcement function, but also - if and when it strengthens the capacity of the administration by clarifying legal provisions - play a management-related role. ${ }^{19}$ Note that the clarifying and capacity-building effects that case law may have, remind us of the role that postlegislative guidance may play in the implementation context, which is elaborated on in Chapter 5 of this study.

\subsubsection{Preliminary rulings}

Unlike the effect of domestic case law, the effect of the preliminary ruling system on national administrative authorities is indirect. This is because, as the Court has noted, the system aims at "enabling courts and tribunals of the [member states] to ensure uniform interpretation and application of [EU] law within the European Union". ${ }^{20}$ It is only when these courts and tribunals actually 'do something' with preliminary rulings that

\footnotetext{
${ }^{17}$ De Visser, 2009: 285.

${ }^{18}$ Cichowski, 2007: 7.

${ }^{19}$ For a comparison between the rationalist school of international relations studies, which emphasises enforcement as a mechanism to achieve compliance, and the management school of international relations studies, which emphasises capacity-building as means to do so, see Chapter 3 on the approach and methodology of this study, Section 2.

${ }^{20}$ Court of Justice of the European Union, 'Recommendations to national courts and tribunals in relations to the initiation of preliminary ruling proceedings' [2012] OJ C 338/1, point I.1.
} 
national competent authorities benefit from these rulings; when courts do not comply with preliminary rulings in their own judgements, competent authorities do not stand to benefit from them, at least not in the short term. ${ }^{21}$

In order to frame the discussion on the usefulness of preliminary rulings for national authorities, a brief review of the legal design of the system is in place. Article 267 TFEU stipulates that preliminary rulings are delivered following a request from a national court or tribunal for clarification on the interpretation of EU law or the validity of acts adopted by the EU institutions. ${ }^{22}$ Note that since clarification of the latter type is not relevant to this study, it is not elaborated on in the remainder of this chapter, and attention will be paid to clarification concerning the interpretation of EU law instead. Requests for clarification may be submitted when a court or tribunal considers a preliminary ruling necessary to solve the dispute at stake. ${ }^{23}$ Whether or not the parties in the proceedings have expressed a wish for the court to do this is not relevant in this regard. ${ }^{24}$ When a question on the interpretation of EU law is pending before a court or tribunal against whose decisions there is no judicial remedy under national law, the court or tribunal is obliged to request that the CJEU provide a preliminary ruling. ${ }^{25}$ Relevant to determine in this regard, is whether a judicial remedy exists against the decision of the court or tribunal in the actual case at hand. When this is not the case, an obligation to refer does exist, ${ }^{26}$ unless the question raised is irrelevant, ${ }^{27}$ the Court has already dealt with the point of law in question, ${ }^{28}$ or the correct application of EU law is so obvious as

\footnotetext{
${ }^{21}$ See above note 3 .

${ }^{22}$ Art. 267 TFEU, first indent (a) and (b), and second indent. What constitutes a national court or tribunal is interpreted as a self-standing concept in EU law; it is for the CJEU to decide whether a body is a court or tribunal in this sense. See Court of Justice of the European Union, 'Recommendations to national courts and tribunals in relations to the initiation of preliminary ruling proceedings', point I.9. See also e.g. case 43/71 Politi v. Italy [1971] ECR 1039. References may be made not only with regard to binding legislation, but also regarding non-binding acts, such as recommendations, and irrespective of whether or not the provision is directly effective. For an elaboration, see Craig and De Búrca, 2011: 444.

${ }^{23}$ Art. 267 TFEU, second indent.

${ }^{24}$ Court of Justice of the European Union, 'Recommendations to national courts and tribunals in relations to the initiation of preliminary ruling proceedings', point I.10. See also e.g. case C-344/04 $R$ on the application of IATA and ELFAA v. Department of Transport [2006] ECR I-403, para 27 and 28; case 283/81 Srl CILFIT and Lanificio di Gavardo SpA v. Ministry of Health [1982] ECR 3415, para 9.

${ }^{25}$ Art. 267 TFEU, third indent.

${ }^{26}$ For a development of this reasoning, see case 6/64 Flaminio Costa v. E.N.E.L. [1964] ECR 585; case C-99/00 Criminal proceedings against Lyckeskog [2002] ECR I-4839; and case C-210/06 Cartesio Oktató és Szolgáltató [2008] ECR I-9641.

${ }^{27}$ In this case, no further action on the part of the court is required.

${ }^{28}$ In this case, the national court can rely on earlier rulings delivered by the CJEU, which thereby become precedents for them; see Craig and De Búrca, 2011: 451. When the national court still decides to submit a question to the CJEU, the Court may, after hearing the Advocate-General, decide to give its decision by reasoned order. The same applies where the reply to the question may be clearly deduced from existing case law or where the answer to the question referred for a preliminary ruling admits of no reasonable doubt; see Rules of Procedure of the Court of Justice of the European Union of 21 September 2012, OJ L 265/1, 29.00.2012, Art.
} 
to leave no scope for reasonable doubt (acte clair). ${ }^{29}$ Recourse to the acte clair doctrine is bound to significant constraints to curb the discretion of national courts and ensure that these courts cooperate with the CJEU on questions that raise any doubt. ${ }^{30}$

As the role of the Court in preliminary rulings is limited to providing an interpretation of EU law (or to rule on its validity), it is for national courts to use the interpretation provided by the Court to decide on issues of fact raised in the main proceedings or to resolve any differences of opinion regarding the interpretation or application of national law. ${ }^{31}$ Here, national authorities are beneficiaries from preliminary rulings. This is the case since, while preliminary rulings provide guidance for national judges to resolve the case at hand, it is national authorities involved in the proceedings that eventually benefit from the problem being solved. It is also the case since preliminary rulings may clarify issues that authorities have struggled with in the administration of the relevant legal provisions. In fact, these authorities may have asked the court to submit preliminary questions on the interpretation of EU law provisions to the CJEU in the first place.

Finally, the beneficial effect of preliminary rulings is not limited to national courts and authorities from the member state from which the question has originated. Because of the emergence of an integrated EU legal order with the CJEU at its top and national courts as the "natural allies" of the Court in the implementation of EU law, ${ }^{32}$ rulings given upon the request of one member state are now increasingly held to have either de facto or de jure impact on all other national courts as well. ${ }^{33}$ In view of the fact that the judicial interpretation of EU law shows significant differences across member states, the EU-wide impact of preliminary rulings is an important side effect of the preliminary ruling system. ${ }^{34}$

\footnotetext{
99.

${ }^{29}$ See case 283/81 Srl CILFIT and Lanificio di Gavardo SpA v. Ministry of Health [1982] ECR 3415, para 21. As to the existence of a previous ruling, this is the case in particular where the question is materially identical to a question that has already been the subject of a preliminary ruling in a similar case; see case 28-3-/62 Costa en Schaake NV, Jacob Meijer NV and Hoechst-Holland NV v. Nederlandse Belastingadministratie [1963] ECR 31. This is true also when the questions at issue are not strictly identical; see case 283/81 Srl CILFIT and Lanificio di Gavardo SpA v Ministry of Health [1982] ECR 3415, para 13-14. In this case, the court may take upon itself the responsibility for resolving the question that is raised. See case 283/81 Srl CILFIT and Lanificio di Gavardo SpA v. Ministry of Health [1982] ECR 3415, para 16.

${ }^{30}$ For a compilation of views on the strictness of these criteria, see Craig and De Búrca, 2011: 457-459.

${ }^{31}$ Court of Justice of the European Union, 'Recommendations to national courts and tribunals in relations to the initiation of preliminary ruling proceedings', point I.7-8.

${ }^{32}$ Craig and De Búrca, 2011: 443; similar Alter, 2000: 516; Prechal, 2005: 131-132. The term "natural allies" is derived from Prechal. One may argue that since they act as 'enforcers and appliers' of EU law, national courts are the natural allies of the Commission as much as they are the allies of the CJEU.

${ }^{33}$ Craig and De Búrca, 2011: 443; similar Alter, 2000: 516.

${ }^{34}$ Golub, 1996: 368-71.
} 


\subsection{Limitations of case law as a compliance instrument}

Section 1.1.1 above iterates that domestic case law may be a useful compliance instrument because of the dispute-resolution and clarifying effect that it has. For these potential benefits to materialise, two conditions must be met: judicial remedies must be perceived as effective and case law must exist in the first place. Neither of these conditions are met as a matter of course. In relation to the latter condition, reference must be made to the fact that cross-country and cross-issue variation in the prevalence of case law exists; ${ }^{35}$ this is also the case in the context of this study, as Section 2.1 of this chapter suggests. The varying prevalence of case law does not, at first glance, seem to merit particular attention in view of the question that is central to this study. Similar to the findings in Chapter 7 on civil society, ${ }^{36}$ this chapter, however, would be incomplete without an examination of the factors that may explain the observed variance in the prevalence of case law. This is the case, since the usefulness of case law as a compliance instrument cannot be fully understood by looking only at the usefulness of 'what is out there'. The absence of case law says something about the utility of case law as a compliance instrument as well; it implies that case law does not aid the implementation of EU law in all member states and in all areas. Seen from this perspective, an examination of the reasons for the prevalence of case law is of equal value to that of an evaluation of the usefulness of existing case law.

In view of the fact that procedural rules on access to justice play an important role in explaining the prevalence of domestic litigation, Section 1.2.1 below begins with a comparative evaluation of the relevant rules in the three member states that are subject to this study. It subsequently examines national rules on judicial remedies (Sections 1.2.1.1 through 1.2.1.3). In view of the potential importance of civic organisations as challengers of the authorities before national courts and the varying capacity of such actors to act as credible watchdogs of the administration - an issue that Chapter 7 on civil society discusses in more general terms - the current section focuses specifically on capacity issues in relation to litigation (Section 1.2.1.4).

What has been argued to apply to domestic case law similarly applies to preliminary rulings. For the preliminary ruling system to be a useful compliance instrument, preliminary rulings must remove interpretational problems that authorities struggle with most in the implementation process and they must exist in the first place. Section 1.2.2 highlights two factors that seem particularly relevant to mediating the usefulness of the system: the willingness of judges to refer questions on the interpretation of EU law to the CJEU (Section 1.2.2.1), and the reaction of national courts and administrations to preliminary rulings given by the Court (Section 1.2.2.2).

\footnotetext{
${ }^{35}$ E.g. Alter, 2000: 497.

${ }^{36}$ And similar to what is implied in other empirical chapters as well; for example the analysis of the varying presence of infringement proceedings across policy areas and across member states, in Chapter 4 on monitoring and sanctions.
} 


\subsubsection{Domestic case law}

Case law can exist only there where there is an administrative act that can be challenged in judicial proceedings. ${ }^{37}$ Provided that this is the case, this act can only be challenged where natural and legal persons have access to justice. While EU measures that harmonise access to justice across member states exist in some policy domains, ${ }^{38}$ member states have, by virtue of the principle of national procedural autonomy, generally remained free in the adoption of such measures. This freedom is circumscribed by the principle of effective judicial protection, according to which member states must ensure that natural and legal persons are able to enforce all of the rights conferred on them by EU law before national courts. ${ }^{39}$

The principle of effective judicial protection is comprised of a number of elements; one of which is access to justice, which includes standing, ${ }^{40}$ the length of judicial review, ${ }^{41}$ and costs of engaging in litigation. ${ }^{42}$ The effectiveness of judicial protection is also determined by the effectiveness of the final judgement delivered by the court and by the conditions under which interim relief may be obtained. In relation to judicial remedies, reference must be made to Article 19(1) TEU, which provides that " $[\mathrm{m}]$ ember [s] tates shall provide remedies sufficient to ensure effective legal protection in the fields covered by Union law" ${ }^{43}$ Moreover, in accordance with the principle of sincere cooperation outlined in Article 4(3) TEU, national courts are required, to the extent that is pos-

\footnotetext{
${ }^{37}$ Note that the types of administrative acts that can be challenged in judicial proceedings vary greatly across member states; see Eliantonio et al., 2012: 67.

${ }^{38}$ See e.g. the area of judicial cooperation in civil matters, in particular Arts 67 and 81 TFEU. In the area of environmental law, see Directive 2003/35/EC of the European Parliament and of the Council of 26 May 2003 providing for public participation in respect to the drawing up of certain plans and programmes relating to the environment and amending with regard to public participation and access to justice Council Directives 85/337/EEC and 96/61/EC [2003] OJ L 156/17.

${ }^{39}$ This right is outlined in Articles 6 and 13 of the European Convention for the Protection of Human Rights and Fundamental Freedoms. It is reaffirmed in Art. 47 of the Charter of Fundamental Rights of the European Union. Art. 6(1) TEU puts the legal value of the Charter on equal footing with that of the Treaties. The principle was earlier recognised by the Court as a fundamental right under the ECHR and the Charter of Fundamental Rights, see e.g. C-185/97 Coote v Granada Hospitality Ltd [1988] ECR I-5199.

${ }^{40}$ E.g. case 222/86 UNECTEF v. Heylens [1987] 4097; joined cases C-87/90, C-88/90 and C-89/90 A. Verholen and others v. Sociale Verzekeringsbank Amsterdam [1991] ECR I-03757; C-12/08 Mono Car Styling [2009] ECR I-6653. On access to court for individuals, see e.g. case C-237/07 Dieter Janecek v. Freistaat Bayern [2008] ECR I-6221 (in the context of an environmental directive); on access to the court for legal persons, see e.g. case C279/09 DEB v. Bundesrepublik Deutschland [2010] I-13849.

${ }^{41}$ E.g. case C-63/08 Virginie Pontin v. T-Comalux SA [2009] I-10467.

${ }^{42}$ See e.g. case C-279/09 DEB v. Bundesrepublik Deutschland [2010] ECR I-13849.

${ }^{43}$ See also European Convention for the Protection of Human Rights and Fundamental Freedoms, Art. 13, and, more extensively, Charter of Fundamental Rights of the European Union, Art.47, first indent. See also e.g. case 222/84 Johnston [1986] ECR 1651; case C-432/05 Unibet [2007] ECR I-2271; and case C-334/12 RX-II Arango Jaramillo and Others v. EIB [2013] ECR.
} 
sible, to interpret and apply national procedural rules that govern the exercise of rights of legal action in a way that achieves that result. ${ }^{44}$

National procedural rules are adequate as long as they meet the principles of equivalence and effectiveness. The principle of equivalence refers to the idea that procedural rules governing actions for safeguarding an individual's rights under EU law must be no less favourable than those governing actions for the safeguarding of rights derived from national law. ${ }^{45}$ The principle of effectiveness prohibits national rules from rendering impossible in practice or excessively difficult the exercise of rights conferred by EU law. ${ }^{46}$ The notion that member states must ensure that the rights conferred by EU law are protected by effective judicial remedies (ubi ius ibi remedium) is implied in the effectiveness principle. ${ }^{47}$

The following subsections address national procedural law provisions on access to justice (Section 1.2.1.1) and judicial remedies (Section 1.2.1.2). In view of the interest and scope of this study, this analysis is succinct, and touches on the core principles only. Moreover, country-specific features regarding these core principles are shown in tables that are intended to provide a brief overview of the discussion included in each subsection. When possible, these tables rank the member states based on the favourability of procedural rules for potential litigants (where a ranking is possible, each table starts with the country with the most favourable rules). Finally, note that in view of the intertwinement of these principles, it is impossible to draw general comparative conclusions regarding the effectiveness of judicial protection in the three countries under examination. ${ }^{48}$ An attempt to draw such conclusions will therefore not be made; the synthesis presented in Section 1.2.1.3 is limited to recapping the countries' performances regarding each of the issues discussed in the subsections below.

\subsubsection{Access to justice}

National procedural law provisions on access to justice in administrative matters vary across member states. ${ }^{49}$ It seems safe to assume that the generosity of such rules codetermines the extent to which natural and legal persons engage in litigation. Both of these notions make it useful to compare the rules on access to justice of the three legal systems included in this study. The following subsections present a comparative analysis of procedural rules on various issues related to access to justice for the three countries included in this study. These issues are broadly categorised under the headings of standing, time limits, and costs.

\footnotetext{
${ }^{44}$ Lenaerts, 2013: 2.

${ }^{45}$ See case 33/76 Rewe-Zentralfinanz and Rewe-Zentral [1976] ECR 1989, para 5; case C-312/93 Peterbroeck [1995] ECR I-4599, para 12; and case C-416/10 Križan and Others [2013] ECR, para 85.

${ }^{46}$ Ibid.

${ }^{47}$ Lenaerts, 2013: 3.

${ }^{48}$ See also Eliantonio et al., 2012: 86.

${ }^{49}$ See Eliantonio et al., 2012: Chapter 4.
} 


\subsection{Standing}

Whether an individual or legal person may participate in legal proceedings depends on whether national procedural rules grant this person locus standi. Here, a distinction must be made between standing rules for proceedings initiated under the principle of actio popularis and rules that apply to other court procedures. The following paragraphs address standing rules under both procedures.

A. Actio popularis proceedings

The principle of actio popularis offers every member of the public the right to object to public decisions, even when a personal interest is lacking. In most legal systems, this right is unknown. When it does exist, it applies to special cases only. ${ }^{50}$ In the context of this study, the principle is known only in Portugal, as Table 20 suggests.

Table 20 Existence of actio popularis principle

\begin{tabular}{ll}
\hline Portugal & Yes, in certain areas \\
Poland & No (limited implementation, only for administrative objection) \\
Netherlands & No \\
\hline
\end{tabular}

In Portugal, the principle of actio popularis applies to areas regarding the protection of public health, the environment, quality of life, consumers, cultural heritage, and the public domain. In these cases, everyone has the right to initiate actio popularis proceedings; a right that may be exercised personally or through the intervention of associations acting for the defence of the relevant interests, regardless of whether or not there is a direct interest in the case. ${ }^{51}$ Organisations and foundations must have legal personality; the protection of the interests involved in the type of action at stake needs to be included expressly in their statutory duties and objectives; and they should not exercise any professional activity in competition with companies. ${ }^{52}$

In the Netherlands, the right to actio popularis used to exist in the area of environmental and planning law; it was abolished in $2005 .{ }^{53}$ Poland has a proposals and complaints procedure, which allows anyone to lodge a complaint or submit a proposal concerning any activity (or the omission of such) of any public authority. ${ }^{54}$ Since it does not give

\footnotetext{
${ }^{50}$ Ibid.: 69.

${ }^{51}$ Constituição da República Portuguesa [Constitution of the Republic of Portugal], 7th revision, Art. 52, §3; Direito de participação procedimental e de acção popular, Lei no 83/95 de 31 de Agosto [1995] DR, 1. a série A, No 201/5464, revised version [Law on rights of participation in proceedings and actio popularis], Arts 1, 2 and 2 .

${ }^{52}$ Law on rights of participation in proceedings and actio popularis, Art. 3.

${ }^{53}$ For the proposal to abolish the right to actio popularis, see Kamerstukken 29 421, no. 3. For approval of the necessary amendments, see Handelingen Tweede Kamer 2004-2005, no. 17, pp. 953-54 and Handelingen Eerste Kamer 2004-2005, no. 26, p. 1139.

${ }^{54}$ Kodeks postępowania administracyjnego, Ustawa z dnia 14 czerwca 1960 [1960] Dz.U. 30/168, [Administra-
} 
complainants the right to bring their case before a court, this procedure must be considered a limited implementation of the actio popularis principle. In view of its administrative character, it will not be further elaborated on here.

\section{B. Concept of party in other proceedings}

The question of whether or not someone qualifies as a party in other administrative court proceedings is approached differently across member states. In some legal systems, the concept of party is underlain by an interest-based approach to legal standing, which means that an applicant needs to show a factual interest in the outcome of the case in order to be granted standing. Other systems follow a rights-based approach to legal standing, which implies that the applicant must show that his factual interest is protected by a legal provision. The requirements that must be met in order to acquire standing may vary across policy domains. Moreover, they may be different for individuals and non-governmental organisations. Table 21 summarises the core features of the three legal systems included in this study.

Table 21 Concept of party in other proceedings

\begin{tabular}{ll}
\hline Portugal & Broad, interest-based approach \\
& Requirements depend on the area of law \\
& NGOs have standing \\
Netherlands & Interest-based approach, tendency to narrow \\
& Requirements depend on the area of law \\
& NGOs have standing \\
& Narrow, formally interest-based approach; in practice close to rights-based approach \\
& Requirements differ in the area of environmental law \\
& NGOs have standing in environmental law; standing in other areas subject to conditions
\end{tabular}

A comparison of the concept of party in the three countries subject to this study suggests that the rules that apply in Portugal are most favourable to potential applicants. The consideration of who is a party in the legal proceedings depends on the administrative procedure at stake. Under the special administrative procedure, under which all administrative acts with external effects may be challenged, ${ }^{55}$ any person who claims to be the holder of a direct and personal interest, in particular those persons whose rights or legally protected interests have been damaged, have standing. ${ }^{56}$ Standing is also granted to public and private legal persons concerning the rights that they are bound to

\footnotetext{
tive Procedure Act; APC], Art. 221.

${ }^{55}$ Even if they are subject to administrative recourse, particularly when they are likely to prejudice legally protected rights or interests. Código de Processo nos Tribunais Administrativos, Lei $n^{\circ}$ 15/2001 [2001] DR 1. ${ }^{\mathrm{a}}$ série A, No 130/ 3336 [Code of Procedure of the Administrative Courts; CPAC], Art. 51(1), in conjunction with Constitution of the Republic of Portugal, Art. 268(4).

${ }^{56} \mathrm{CPAC}$, Art. 55, $\$ 1$, sub a; Art. 68, $\$ 1$, sub a.
} 
defend, and to any public or private person acting to defend the rights and values protected by the Constitution. ${ }^{57}$ Under the common administrative procedure, which guarantees that judicial protection extends to all disputes within the scope of the administrative jurisdiction that are not subject to special regulations, ${ }^{58}$ anyone who claims to be part of the disputed material relationship is considered competent to act. ${ }^{59}$ The same applies to persons and associations defending the values and rights protected by the Constitution. Public health and environment are amongst those rights and values. ${ }^{60}$

Legal standing for environmental non-governmental organisations is regulated separately and liberally. ${ }^{61}$ Most relevant to this study is that, regardless of whether they have a direct interest in the claim, environmental NGOs have the right to propose legal actions necessary for the prevention, correction, suspension, and termination of acts or omissions of such, of public or private entities that are, or could be, a factor in the degradation of the environment. ${ }^{62}$ The wide access to justice for environmental NGOs resembles the legal standing requirements for non-governmental organisations in Portugal for actio popularis proceedings.

The legal system of Poland distinguishes between the concepts of 'parties in the proceedings' and 'persons with the rights of a party'. Parties in the proceedings are the complainant and the authority whose action is the subject matter of the complaint. ${ }^{63}$ Complainants may be natural or legal persons with a legal interest, the public prosecutor, the Ombudsman, and social organisations. ${ }^{64}$ Social organisations are defined as 'professional, self-governmental, cooperative, and other social organisations' ${ }^{65}$ They must act within the scope of their statutory activity or in matters affecting the legal interest of other persons. ${ }^{66}$ Moreover, such organisations must exist formally, and they must be non-profit making and independent from political parties and the administration. ${ }^{67}$ Since the interest of complainants must be protected by a legal provision, the Polish approach is similar to a rights-based approach to standing.

\footnotetext{
${ }^{57}$ Ibid., Art. 55, $\$ 1$, sub c and f, and Art. $68, \$ 1$, sub b and d, in conjunction with Art. 9, 2 .

${ }^{58} \mathrm{CPAC}$, Art. 37, $\$ 1$. Examples are the recognition of subjective legal situations arising directly from legal regulations, and the condemnation of the adoption of certain behaviour, or the absence of it, on the part of the administration. For the complete list, see CPAC, Art. 37, $\$ 2$.

${ }^{59}$ CPAC, Art. 9, $\$ 1$.

${ }^{60}$ Ibid., Art. 9, $\$ 2$.

${ }^{61}$ Namely, in Organizações não governamentais de ambiente, Lei 35/98, de 18 de Julho [1998] DR 1. a série A, No 164/3474 [Law on environmental non-governmental organisations].

${ }^{62}$ Law on environmental non-governmental organisations, Art. 10, sub a.

${ }^{63}$ Prawo o postępowaniu przed sądami administracyjnymi, Ustawa $z$ dnia 30 sierpnia 2002 [2002] Dz.U. 153/1270 [Proceedings before Administrative Courts Act; PACA], Art. 32.

${ }^{64}$ PACA, Art. 50, $\$ 1$.

${ }^{65}$ APC, Art. 5, §1, sub 5.

${ }^{66}$ PACA, Art. 50, $\$ 1$.

${ }^{67}$ Jendróska and Bar, 2012: 16-17.
} 
Persons or organisations with the rights of a party are entitled to exercise all of the privileges pertaining to parties in the proceedings - for example, initiation of proceedings, verification of the files, issuing of statements, presentation of evidence, and lodging of appeals - but they are not subject to the duties imposed on parties in the proceedings. ${ }^{68}$ The rights of a party are granted by the court ex officio or upon request. The rights of a party are granted ex officio to persons who have not filed a complaint but who have participated in the administrative proceedings, and whose legal interest is affected by the outcome of the court case. ${ }^{69}$ The rights of a party are granted upon request to persons who have not participated in the administrative proceedings, but whose legal interests are affected by the proceedings and to social organisations, if the case relates to the scope of their statutory activity. ${ }^{70}$ Refusal to grant the rights of a party is subject to appeal. $^{71}$

Note that social organisations must have participated in the preceding administrative proceedings in order to file a complaint. ${ }^{72}$ Their participation in administrative proceedings is granted upon request only, and following a positive assessment of the public authority that participation is justified by the statutory objectives of the organisations and by the public interest. ${ }^{73}$ Authorities are obliged to inform social organisations when they find that they may be interested in participating in the proceedings, and when such organisations meet the requirements for their 'design' that are described earlier in this subsection. ${ }^{74}$

Following entry into force of the Aarhus Convention, environmental organisations enjoy wider standing rights than other social organisations, at least when public participation in environmental cases is required. In these cases - projects falling under the IPPC Directive are an example - environmental organisations may participate with the rights of a party if they are classified as 'social organisations' whose involvement is justified by their statutory objectives, and if they submit an application for participation. ${ }^{75}$ This means that they do not need to have participated in preceding administrative proceedings to file a complaint. Moreover, they do not need to prove that the public interest requires their participation.

The legal system of the Netherlands follows an interest-based approach to the definition of party. Indeed, Dutch administrative law starts from the definition of 'interested

\footnotetext{
${ }^{68}$ Email 3 from interviewee PL2 to author.

${ }^{69}$ PACA, Art. 33, $\$ 1$.

${ }^{70}$ Ibid., Art. 33, $\$ 2$.

${ }^{71}$ Ibid., Art. 33, $\$ 2$.

${ }^{72}$ Ibid., Art. 50, $\$ 1$.

${ }^{73}$ APC, Art. 31, $\$ 1$.

${ }^{74}$ Ibid., Art. 31, $\$ 4$.

${ }^{75} \mathrm{O}$ udostępnianiu informacji o środowisku i jego ochronie, udziale społeczeństwa $w$ ochronie środowiska orazo ocenach oddziaływania na środowisko, Ustawa z dnia 3 października 2008 [2008] Dz.U. 199/1227 [Act on the provision of information about the environment and its protection, public participation in environmental protection and environmental impact assessment], Art. 44.
} 
party', which covers, first of all, individuals whose interests are directly affected by a decision. The requirements that apply in this regard have been elaborated on in case law and involve the need for individuals to have a direct (rather than derived), own (rather than someone else's), personal (that is, distinguishable from others), objective (rather than subjective or emotional), and actual (rather than imaginary) interest. When it comes to environmental law cases, the spatial influence of the project determines whether the interest of individuals qualifies as a 'direct interest'. ${ }^{76}$ Also administrative authorities representing the interests entrusted to them are deemed interested parties. ${ }^{77}$ The same applies to legal persons, whose interests are considered to include those general and collective interests that they, pursuant to their objectives and as evidenced by their actual activities, represent. ${ }^{78}$ Regarding - mainly environmental - NGOs, the Council of State has recently narrowed access to justice using the activities that NGOs carry out as a separate criterion to establish whether the relevant organisations have a direct interest. ${ }^{79}$ Requirements are stricter for projects covered by the Crisis and Recovery Act as well. ${ }^{80}$

\subsection{Time limits}

All legal systems set time limits within which individuals and legal persons are allowed to challenge an administrative decision before the court. Case law of the CJEU has affirmed that these time limits must be reasonable. While these limits should not be too short so as to ensure that individuals have sufficient time (to decide whether or not) to initiate a case ${ }^{81}$ they should not be too long either in the interest of legal certainty. ${ }^{82}$ Time limits should meet the principles of effectiveness and equivalence; they must be equally favourable to those relating to similar domestic claims, and they may not be framed such that it is impossible or excessively difficult to obtain reparation. ${ }^{83}$ General

\footnotetext{
${ }^{76}$ For an elaboration, see e.g. Backes, 2012: 11.

${ }^{77}$ Algemene Wet Bestuursrecht, Wet van 4 juni 1992, houdende algemene regels van bestuursrecht [1992] Stb. 315 [General Administrative Law Act; GALA], Art. 1:2.

${ }^{78}$ GALA, Art. 1:2.

${ }^{79}$ Backes, 2012: 15-16.

${ }^{80}$ Crisis- en herstelwet, Wet van 18 maart 2010, houdende regels met betrekking tot versnelde ontwikkeling en verwezenlijking van ruimtelijke en infrastructurele projecten [2010] Stb.135 [Crisis and Recovery Act; CRA].

${ }^{81}$ See initially, case 33/76 Rewe-Zentralfinanz $e G$ and Rewe-Zentral $A G v$. Landwirtschaftskammer für das Saarland [1976] ECR 1989; case 45/76 Comet BV v. Productschap voor Siergewassen [1976] ECR 2043. Case C208/90 Theresa Emmott v Minister for Social Welfare and Attorney General [1991] ECR I-4269 imposed strict conditions on national legal systems. These conditions have been restricted in following case law. See e.g. case C-338/91 H. Steenhorst-Neerings v. Bestuur van de Bedrijfsvereniging voor Detailhandel, Ambachten en Huisvrouwen [1993] ECR I-5475. case C-410/92 Elsie Rita Johnson v. Chief Adjudication Officer [1994] ECR I-5483; case C-188/95 Fantask A/S e.a. v. Industrieministeriet (Ehrvervministeriet) [1997] ECR I-6783. For a review of this case law, see Eliantonio, 2008: 72-83.

${ }^{82}$ E.g. Case C-255/00 Grundig Italiana [2002] ECR I-8003, paragraph 34, and Case C-2/06 Kempter [2008] ECR I- 411 .

${ }^{83}$ E.g. case C-261/95 Palmisani [1997] ECR I-4025.
} 
requirements also exist regarding time limits for judges to deliver a judgement; the length of proceedings must be 'reasonable' in the light of the characteristics of the case. ${ }^{84}$

A. Time limits for persons to bring a claim

Time limits for persons to bring a claim vary greatly across the three legal systems included in this study, as Table 22 suggests.

Table 22 Time to lodge an appeal

\begin{tabular}{ll}
\hline Portugal & Three months \\
The Netherlands & Six weeks \\
Poland & Thirty days \\
\hline
\end{tabular}

In Poland, persons who want to challenge an administrative decision before an administrative court must do so within thirty days after the decision was delivered to them or published. ${ }^{85}$ This term is not extendable. ${ }^{86}$ In the Netherlands, an appeal must be lodged within six weeks after the decision has been notified. ${ }^{87}$ In Portugal, the time period for persons to appeal to a court is, in principle, three months after notification. ${ }^{88}$ In contrast to Poland, Dutch and Portuguese legislation stipulates that the time limit may be extended if justified by certain conditions. ${ }^{89}$

B. Time (limits) for courts to deliver a judgement

In none of the three legal systems included in this study do specific, commonly applicable time limits for courts to deliver a judgement exist. Practice suggests that great crosscountry differences exist regarding the time required for judges to decide. Table 23 compares the legal rules and practices for the three legal systems under examination.

\footnotetext{
${ }^{84}$ Consolidated version of the European Convention for the Protection of Human Rights and Fundamental Freedoms [1950] Art. 6(1); Charter of Fundamental Rights of the European Union [2010] OJ C 83/389, Art. 47, second indent. For EU case law, see e.g. case C-185/95 P Baustahlgewebe [1998] I-8417 (on the length of proceedings by the General Court).

${ }^{85}$ PACA, Art. 53, \$1, in conjunction with Kodeks Cywilny, Ustawa z dnia 23 kwietnia 1964 [1964] Dz.U. 16/93 [Civil Code], Arts 110 and 111, $\$ 1$ (on how the time limit is set). This time limit is different for the public prosecutor and the Ombudsman; see PACA, Art. 53, $\$ 3$.

${ }^{86}$ See case II GSK 1765/13, judgement of 25 September 2013.

${ }^{87}$ GALA, Art. 6:7 and 6:8.

${ }^{88}$ CPAC, Art. 58(2)(b).

${ }^{89}$ For Portugal, see CPAC, Art. 58(4); for the Netherlands, see GALA, Art. 6:11.
} 
Table 23 Time (limits) to decide on an appeal

\begin{tabular}{|c|c|c|}
\hline & Legal rules & Practice (2012) \\
\hline Netherlands & Generally no specific time limits & $\begin{array}{l}\text { District courts: } 37 \text { weeks } \\
\text { Council of State: } 35 \text { weeks }\end{array}$ \\
\hline Poland & $\begin{array}{l}\text { Requirement to quickly settle the matter; try to } \\
\text { resolve it at first meeting }\end{array}$ & $\begin{array}{l}\text { First instance: } 80 \% \text { within } 26 \text { weeks } \\
\text { SAC: } 60 \% \text { within } 52 \text { weeks }\end{array}$ \\
\hline Portugal & 'Reasonable period of time' & Average of 126 weeks \\
\hline
\end{tabular}

For matters falling under general administrative law in the Netherlands, no time limits exist. ${ }^{90}$ When a district administrative court has jurisdiction - that is, in the majority of first instance appeals ${ }^{91}$ - the decision will usually come within one year after the claim has been lodged. ${ }^{92}$ In 2012, administrative cases before district courts were solved in an average time period of 37 weeks. ${ }^{93}$ When the competent court was the Administrative Jurisdiction Division of the Council of State - which is the last court of appeal for all administrative cases $^{94}$ - the average length of proceedings in 2012 was thirty-five weeks. ${ }^{95}$ Sectoral legislative acts may impose specific time limits for courts to decide. An example is the Crisis and Recovery Act, which requires the Council of State to decide within six months. ${ }^{96}$

In Poland, the law stipulates that the administrative court should take actions in order to quickly settle the matter and try to resolve it at the first meeting. ${ }^{97}$ It usually takes several months for the court of first instance to deliver a judgement, and approximately one year for the court of second instance - the Supreme Administrative Court to do so. ${ }^{98}$ In 2012 , over $80 \%$ of the cases before the court of first instance were decided within six months; over $60 \%$ of the cases before the Supreme Administrative Court were decided within one year. ${ }^{99}$

\footnotetext{
${ }^{90}$ The GALA only stipulates the time limits for the administrative authority to send the documents relating to a case to the district court and file a defence (four weeks), for the parties in the case to submit their views on the expert report that the court may request (four weeks), and for the district court to give a judgement in writing (in principle six weeks after closing the inquiry). GALA, Art. 8:42, 8:47, 8:66. In principle, these provisions also apply to the Administrative Jurisdiction Division of the Council of State. GALA, Art. 8:108.

${ }^{91}$ GALA, Art. 8:6.

${ }^{92}$ Backes, 2012: 25.

${ }^{93}$ De Rechtspraak, 'De Nederlandse rechtspraak in cijfers, Hoe lang duurde de afhandeling de afgelopen jaren', $<$ http://www.rechtspraak.nl>.

${ }^{94}$ GALA, Art. 8:105.

${ }^{95}$ Number for the General Chamber; procedures take forty-two weeks for the Spatial Planning Chamber. See Raad van State, 'Jaarverslag over 2012, Bestuursrechtspraak in cijfers, Uitspraken, personeel, kosten, en doorlooptijd van Bestuusrechtspraak', <http://jaarverslag2012.raadvanstate.nl >.

${ }^{96}$ CRA, Art. 1.6(4).

${ }^{97}$ PACA, Art. 7.

${ }^{98}$ Jendróska and Bar, 2012: 22.

99 Biuro Orzecznictwa Naczelnego Sądu Administracyjnego, 'Sprawozdania roczne: 2012', $<$ http://www.nsa.gov.pl/sprawozdania-roczne-1.php>.
} 
Administrative law in Portugal states that individuals have the right to a court decision delivered within a reasonable period of time. ${ }^{100}$ In reality, the length of court proceedings in Portugal appears to be excessive, with procedures taking up 29 months on average in 2012. ${ }^{101}$ The duration of cases greatly varies across policy areas. In the environmental domain, for example, court proceedings may last up to five or ten years. ${ }^{102}$ Portugal has been condemned several times for the excessive delay in judicial proceedings, and reforms to fix this situation have been implemented recently. ${ }^{103}$

\subsection{Costs}

Litigants may incur several types of costs during court proceedings, the most important of which are court fees, attorney costs, and costs paid for experts consulted in the proceedings. In view of the principle of effective judicial protection, these costs may not bar access to the court, and legal aid to persons that are unable to bear court costs must be available. ${ }^{104}$ The current section compares the situation for the three countries included in this study.

\section{A. Court fees}

In view of the existence of the actio popularis principle in Portugal, this subsection first addresses court fees for proceedings started under this principle in Portugal. It then provides insight into court fees for other proceedings for all three countries included in this study.

\section{a. Actio popularis proceedings}

Table 24 Court fees for actio popularis proceedings

\begin{tabular}{ll}
\hline Portugal & No court fees if the request is at least partially approved \\
Poland & Not applicable (no fees for the complaints and proposal procedure) \\
Netherlands & Not applicable \\
\hline
\end{tabular}

For actio popularis cases in Portugal, neither costs of the preparation of the case nor court fees must be paid, on the condition that the request is at least partially approved by the judge. When this is not the case and the judge dismisses the entire request, the applicant is convicted by the judge to pay between a tenth and half of the costs that

\footnotetext{
${ }^{100}$ CPAC, Art. 2(1). CPAC, Art. 74 confirms that there are no concrete time limits for courts to deliver a judgement.

${ }^{101}$ Figure for cases subject to the special administrative procedure; see Direção-Geral da Política de Justiça, 'Duração média dos processos findos: 2012', <http://www.siej.dgpj.mj.pt>.

102 Aragão, 2012: 29.

103 Ibid.

${ }^{104}$ E.g. case C-279/09 DEB v. Bundesrepublik Deutschland [2010] ECR I-13849 (on legal aid to legal persons).
} 
would normally be appropriate. ${ }^{105}$ Fixing the amount, the judge must consider the economic situation of the applicant and the formal or substantive reasons for dismissal. Only when the applicant is condemned for 'bad faith litigation' are the legal costs calculated according to the general rules outlined in legislation, that is, according to the rules that apply to other cases than to actio popularis cases. ${ }^{106}$

This item does not apply to the Dutch and Polish legal systems, since the actio popularis principle does not (strictly) exist in these countries. Regarding Poland, reference may be made to the fact that the 'quasi actio popularis' complaints and proposals procedure is free of charge. ${ }^{107}$

b. Other proceedings

The Dutch legal system is relatively simple when it comes to the calculation of court fees. In the Netherlands, the law dictates fixed costs for natural and legal persons in first and second instance proceedings. This is different in Poland and Portugal. The Polish and Portuguese rules generally consider the value of the respective case as a starting point, unless the value of the case cannot be measured in monetary terms. In the latter case, fixed rates are applied. In Portugal, where the value of the accounting unit has recently been increased to support the sustainability of the judiciary, ${ }^{108}$ other factors are considered next to the value of the case. Examples are the complexity of the case, whether an electronic platform was used to file the appeal, and whether the case is an appeal. ${ }^{109}$ The latter factor is considered in the Polish system as well.

Table 25 intends to provide an idea of the court fees payable by parties in court proceedings.

\footnotetext{
${ }^{105}$ See subsection b on costs in the regular procedure, below.

${ }^{106}$ Law on rights of participation in proceedings and actio popularis, Art. 20, $\$ 1, \S 2$ and $\$ 3$.

${ }^{107}$ This could be deduced from the fact that costs are to be paid by 'parties' in the proceedings (PACA, Part IV, Art. 261ff), and the proposals and complaints procedure does not include 'parties' as such; it implements the citizens' right to petition, as guaranteed in the Constitution.

${ }^{108}$ Aragão, 2012: 21.

${ }^{109}$ These factors explain the ranges listed in the table below.
} 
Table 25 Court fees for proceedings other than actio popularis proceedings

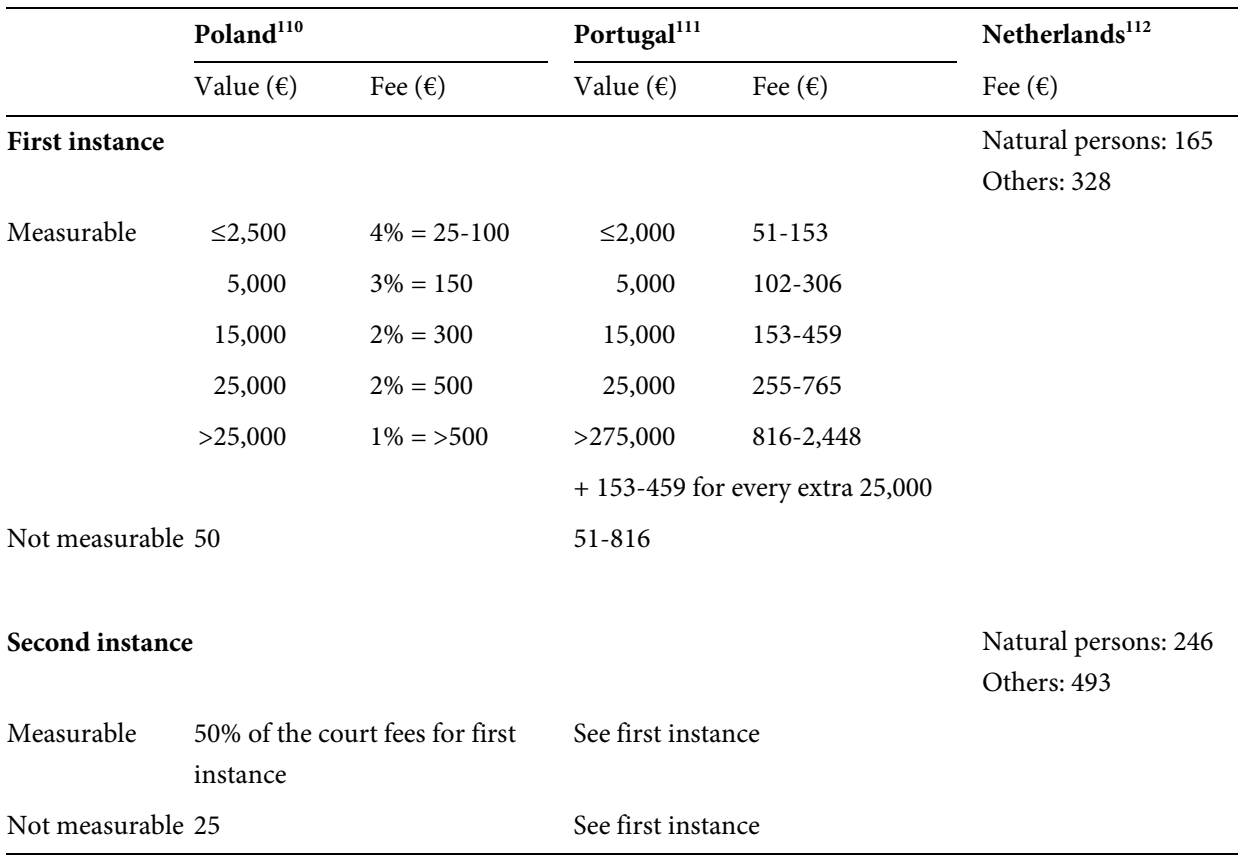

A comparison of the court fees for natural and legal persons would lead one to expect that the Dutch system, while practical in its simplicity, withholds persons whose case represents a relatively low monetary value from appealing to an administrative court. Considering the countries' gross domestic product (GDP), this problem seems urgent in Poland and Portugal as well. ${ }^{113}$ In both of these countries, and especially in Poland, the affordability of litigation does seem to be a particularly urgent problem for cases with a

\footnotetext{
${ }^{110}$ For cases the value of which can be measured, $W$ sprawie wysokości oraz szczegótowych zasad pobierania wpisu w postępowaniu przed sądami administracyjnymi, Rozporzadzenie Rady Ministrów z dnia 16 grudnia 2003 [2003] Dz.U. 221/2193 [Regulation of the Council of 16 December 2003 on the amount and the detailed rules for charging court fees in the proceedings before administrative courts; Regulation of the Council], $\$ 1$. The Regulation implements PACA, Art. 233. For cases whose value cannot be measured, see Regulation of the Council, $\$ 2$, sub 3 .

${ }^{111}$ Regulamento das Custas Processuais, Decreto-Lei $n^{\circ}$ 34/2008, de 26 de Fevereiro [2008] DR 1. a série, No 40/1261, revised version [Regulation on Process Costs], Art. 6 ff. Once the value of a case has been determined, the court fees are calculated using process accounting units (PAU); see Regulation on Process Costs, Art. 5. For cases with a measurable value, see Regulation on Process Costs, Table 1. For other cases, see Regulation on Process Costs, Art. 12, in conjunction with Table 1. The value of the case is important not only since it determines the legal and other costs, but also since it determines the form of the process (common or summary); the number of judges involved in the case; and whether there is a right of appeal to a superior court. CPAC, Art. 31, $\$ 1, \S 2$ and $\$ 3$.

${ }^{112}$ GALA, Arts 8:41(2) and 8:109(1).

${ }^{113}$ In 2012, GDP per capita in the Netherlands was 48,250 USD, compared to 12,660 USD in Poland and 20,580 USD in Portugal. Data retrieved from The World Bank Group, 'Data', <http://data.worldbank.org/>.
} 
higher value. Generally speaking, a rough comparison of court fees across the three countries suggests that, measured in terms of GDP, litigation is most affordable for Dutch litigants and least affordable for Polish litigants. ${ }^{114}$ Note that the Polish and Portuguese court fees are comparatively low in cases, the value of which cannot be measured.

Finally note that in Portugal, the rules related to court fees are more lenient for environmental NGOs than for other social organisations and for individuals. Environmental organisations are exempted from court fees as long as they act in good faith. Litigation in bad faith is, as for other persons, payable subject to the rules outlined in general law provisions. ${ }^{115}$ Comparable rules do not exist in Poland or the Netherlands.

\section{B. Experts}

In some legal systems, courts may refer to experts in order to attain impartial information that may help them arrive at an adequate assessment regarding the subject matter at stake in the proceedings. The costs of these experts may or may not be payable by parties in the proceedings.

Table 26 Expert costs

\begin{tabular}{ll}
\hline Poland & Individuals pay for experts hired on their own motion \\
Netherlands & Individuals pay for experts hired on their own motion \\
Portugal & Individuals pay for the expertise delivered and for the expert report \\
\hline
\end{tabular}

In the Netherlands, the complexity of a subject may motivate the court to consult experts on its own motion, ${ }^{116}$ although rising pressure for courts to arrive quickly at a judgement has decreased the extent to which courts ask for external expertise. In legal disputes with an environmental or planning dimension, the Foundation for Advise in Administrative Litigation provides judges, upon their request, with expertise. ${ }^{117}$ Individuals pay only for experts that they have hired on their own motion. ${ }^{118}$

\footnotetext{
${ }^{114}$ Note, first, that where ranges of court fees apply - which is the case in Portugal - the lowest point in the range is taken as a reference point. Second, note that the fees due in first instance proceedings are taken as a reference point. This is the case, since these fees are most relevant to determining access to justice in the first place. Third, for the Dutch case, the average of the costs for natural persons and legal persons has been used as a reference point. Fourth, note that it is not easy to precisely compare court fees for measurable cases, since the fees in Poland and Portugal are subject to variation depending on the value of the case and the increase in court fees is not linear. The said ranking is, thus, based on a rough comparison of court fees across the three countries.

${ }^{115}$ Law on environmental non-governmental organisations, Art. 11.

${ }^{116}$ GALA, Art. 8:34.

${ }^{117}$ Stichting Advisering Bestuursrechtspraak, <www.stab.nl>.

${ }^{118}$ GALA, Art. 8:36. Costs for experts are not compensated for by legal aid.
} 
In Poland, there is a theoretical opportunity for the court to consult experts on its own motion or at the request of a party in the proceedings. ${ }^{119}$ In practice, however, the role of experts is limited. This is because experts are consulted only when necessary and when it does not excessively prolong the proceedings. Moreover, the evidence presented by experts is regarded as supplementary only, and findings must come in the form of documentary proof. ${ }^{120}$ In practice, the court rarely resorts to experts. ${ }^{121}$ When doubt about the evidence exists, the judge would quash the authority's decision, argue that it is not a court of fact but a court of law, and order further fact finding by the authority. ${ }^{122}$ When individuals hire experts, they must pay these experts themselves. ${ }^{123}$

In Portugal, additional costs must be paid when recourse is received from an expert, regardless of whether this expert is consulted by the judge ex officio or at the request of the claimant. ${ }^{124}$ It is both the service provided that is compensated for, and the number of pages of the report prepared by the expert. ${ }^{125}$ This compensation varies between $€ 102$ and $€ 1120$ for the service, and it is set at $€ 10,20$ per page of the expert report. ${ }^{126}$

C. Attorneys

Legal systems have adopted various approaches to determine whether or not applicants are required to be represented by an attorney, as Table 27 demonstrates for the three countries included in this study.

Table 27 Attorneys

\begin{tabular}{ll}
\hline Netherlands & Attorney optional \\
Poland & Attorney optional in first instance but required in second instance \\
Portugal & Attorney generally required \\
\hline
\end{tabular}

In the Netherlands, appointment of a lawyer is optional rather than obligatory. Where plaintiffs choose to be represented by a lawyer, the costs are incurred by them. ${ }^{127}$ In Poland, appointment of an attorney is generally optional; it is obligatory in a limited number of cases only, amongst which are cassation cases submitted before the Supreme Administrative Court. ${ }^{128}$ Attorney costs are payable by the relevant party. ${ }^{129}$ The legal

\footnotetext{
${ }^{119}$ PACA, Art. 106, $\$ 3$.

${ }^{120}$ Ibid., Art. 106, $\$ 3$.

${ }^{121}$ And in the area of environmental law not at all; see Jendróska and Bar, 2012: 24.

${ }^{122}$ Email 2 from interviewee PL2 to author.

${ }^{123}$ PACA, 199. Such costs are not compensated for by legal aid.

${ }^{124}$ Regulation on Process Costs, Art. 16, $\$ 1$, sub d.

${ }^{125}$ Ibid., Art.17, $\$ 2$ and $\$ 3$.

${ }^{126}$ Ibid., Table IV.

${ }^{127}$ Unless legal aid is granted; see Section E on Financial Assistance, below.

${ }^{128} \mathrm{PACA}$, Arts $50, \$ 1$, and $175, \$ 1$. Save certain conditions, for example where the cassation appeal is brought by a professional employed in the legal domain, or when the matter concerns a tax case; see PACA, Art. 175, $\$ 2$ and $\$ 3$.
} 
system of Portugal, in contrast, generally requires litigants to be represented by a lawyer. ${ }^{130}$ The relevant costs are payable by plaintiffs. ${ }^{131}$ It is this latter system that seems least favourable to litigants from a cost-related point of view.

D. Compensation of costs for winning parties

In most legal systems, rules exist for the compensation of costs incurred by the winning party in the proceedings. Answers to the question about who compensates, and which costs are compensated vary across countries. This is also the case for the three countries included in this study, as Table 28 suggests.

Table 28 Compensation of costs for winning parties

\begin{tabular}{ll}
\hline Netherlands & One-way cost shifting \\
& Compensated are court fees and other costs \\
Poland & First instance proceedings: one-way cost shifting \\
& Second instance proceedings: the losing party pays \\
& Compensated are 'indispensable costs of the proceedings' \\
Portugal & The losing party pays \\
& Compensated are court fees, other expenses, and $50 \%$ of the attorney fees \\
\hline
\end{tabular}

The Netherlands has a one-way cost shifting approach, according to which the losing authority compensates the costs incurred by the winning claimant (and not vice versa). Dutch administrative law requires that the losing authority compensates the court fees, ${ }^{132}$ and that the court may condemn it to reimburse other costs as well. ${ }^{133}$ Amongst these costs are attorney costs, costs of an expert, travel costs of the claimant, and the income that the claimant has missed because of the need to be present at the court proceedings. $^{134}$

This is different in Poland and Portugal, where the practice of one-way cost shifting does not exist or exists to a limited extent only. The legislative framework in Poland makes a distinction between first and second instance proceedings. In first instance proceedings, a one-way cost shifting approach applies. When the complainant wins first instance proceedings, the court orders the authority to reimburse "the cost of proceed-

\footnotetext{
${ }^{129}$ PACA, Art. 199. Unless legal aid is granted; see Section E on Financial Assistance, below.

${ }^{130}$ In cases submitted before formal jurisdictional courts of the state, litigants may forfeit lawyers in civil procedure cases that do not allow appeal due to the insignificant amount of money that they involve. See Article 32 (1) of the Civil Procedure Code.

${ }^{131}$ CPAC, Art. 11, $\$ 1$. Unless legal aid is granted, see Section E on Financial Assistance, below.

${ }^{132}$ GALA, Art. 8:74.

${ }^{133}$ GALA, Art. 8:75, sub 1.

${ }^{134}$ Besluit proceskosten bestuusrecht, Besluit van 22 december 1993, houdende nadere regels betreffende de proceskostenveroordeling in bestuursrechtelijke procedures [1993] Stb. 763 [Decision on costs for administrative court proceedings], Art. 1.
} 
ings indispensable for appropriate vindication of his rights". ${ }^{135}$ The reverse does not apply. Indispensable costs include court costs incurred by the party (meaning court fees and other expenses), ${ }^{136}$ costs of travel of a party or agent, and a sum equivalent to the loss of earnings due to attending the court. ${ }^{137}$ The latter two types of costs should not exceed the salary of a lawyer or legal counsel. ${ }^{138}$ When the party is represented by a lawyer the cost includes the salary of the lawyer, which is subject to legal limits, court costs, and the costs of personal attendance of a party required by the court. ${ }^{139}$

Polish rules on compensation are different for second instance proceedings. When the judgement of the court of first instance dismissing the complaint has been reversed in granting the cassation appeal, the plaintiff may claim the costs from the authority. ${ }^{140}$ Where the second instance judgement grants the cassation appeal by reversing the first instance judgement granting the complaint, however, the authority may claim the costs from the plaintiff. ${ }^{141}$ Where a cassation appeal is dismissed, the complainant must reimburse the costs incurred by the authority if the complainant has filed the cassation appeal against the first instance judgement dismissing the complaint. ${ }^{142}$ The authority must reimburse the costs incurred by the complainant if it has filed the cassation appeal against the first instance judgement granting the complaint. ${ }^{143}$

One-way cost shifting is absent from Portuguese law; in Portugal, it is always the losing party that pays the costs incurred by the winning party. These costs include court fees, other expenses, and $50 \%$ of the attorney fees. ${ }^{144}$ In view of the cost risks that individuals incur when they engage in court proceedings, the Portuguese rules seem comparatively least favourable to individual applicants. Note that these cost risks also apply to complainants filing a cassation appeal before the Polish Supreme Administrative Court. The idea that the costs made by the other party are not controllable - and thus impossible to predict - establishes an additional hurdle for Portuguese complainants and for Polish complainants in second instance proceedings to initiate court proceedings. These remarks are not relevant to the Dutch context, since individuals do not need to fear the possibility of paying any costs in case of lost proceedings.

\footnotetext{
${ }^{135}$ PACA, Art. 200.

${ }^{136}$ Ibid., Art. $211 \mathrm{ff}$.

${ }^{137}$ Ibid., Art. 205, $\$ 1$.

${ }^{138}$ Ibid., Art. 205, $\$ 1$.

${ }^{139}$ Ibid., Art. 205, $\$ 2$.

${ }^{140}$ Ibid., Art. 203(1).

${ }^{141}$ Ibid., Art. 203(2).

142 Ibid., Art. 204(1).

${ }^{143}$ PACA, Art. 204(2).

${ }^{144}$ Regulation on process costs, Art. $26, \$ 1$ and $\$ 3$.
} 
E. Financial assistance

In all three countries, financial assistance mechanisms for persons who are unable to bear the court costs exist. Table 29 shows that the relevant rules vary significantly across countries.

Table 29 Financial assistance

\begin{tabular}{ll}
\hline Portugal & Court fees, other costs of the proceedings, and attorney costs \\
& Full compensation \\
Poland & Court costs and attorney costs \\
& Full or partial compensation \\
Netherlands & Attorney costs \\
& Partial compensation only
\end{tabular}

In Portugal, natural and legal persons and social organisations may apply for financial assistance to fully cover court fees, other costs of the proceedings, and attorney costs. ${ }^{145}$ Also in Poland, both natural and legal persons and social organisations may apply for financial assistance. Assistance may compensate fully or partially for court costs and attorney costs. ${ }^{146}$ The Dutch legal system is comparatively the least generous to applicants; in the Netherlands, financial assistance is provided for legal aid only, and litigants themselves must, in principle, bear a part of the costs. ${ }^{147}$

F. Requests for a preliminary ruling

In the Netherlands, requests of the national court for a preliminary ruling from the Court of Justice of the European Union trigger a separate procedure and additional court fees. ${ }^{148}$ This is different in Portugal and Poland, where litigants do not have to pay additional court fees when the court decides to submit a preliminary question to the CJEU.

Table 30 Costs for preliminary ruling requests

\begin{tabular}{ll}
\hline Poland & No extra costs \\
Portugal & No extra costs \\
Netherlands & Extra costs \\
\hline
\end{tabular}

\footnotetext{
${ }^{145}$ Acesso ao direito e aos tribunais, Lei $n^{\circ}$ 34/2004, de 29 de Julho [2004] DR 1. a Série, No 177/4802 [Act on Access to Justice and to the Courts], in particular Arts 7 (who may apply), 16 (what is compensated for), and 19 (how to apply).

${ }^{146}$ PACA, Section V, Chapter 3, Section 2, Arts 244, $\$ 1$ (court costs and attorneys), 245, \$1 (total or partial compensation), and 246 (conditions). Court costs cover court fees and other expenses, for example amounts due to interpreters and travel costs made by judges for the performance of judicial acts outside the court house; see PACA, Arts 211 and 213.

${ }^{147}$ Wet op de rechtsbijstand, Wet van 23 december 1993, houdende regelen omtrent de door de overheid gefinancierde rechtsbijstand [1993] Stb. 775 [Act on legal assistance], in particular Arts 24 and 35, sub 1.

${ }^{148}$ Ministerial Order on costs for administrative court proceedings, Annex, A.2.
} 


\subsubsection{Remedies}

The introduction to this section suggests that the effectiveness of judicial protection is affected partly by national rules on access to justice, which are discussed above; the effectiveness of judicial remedies for actors who engage in litigation is an important determinant in this regard as well. The principle of effective judicial protection requires member states to ensure that the rights outlined in EU law are protected by effective judicial remedies, ${ }^{149}$ and that courts are empowered to grant injunctive relief. ${ }^{150}$ Case law of the CJEU has affirmed that interim relief is an important principle in order to achieve effective judicial protection; it is seen as a bare necessity to have a mechanism to protect the rights that individuals derive from EU law, pending the judgement of the court. ${ }^{151}$ The following subsections examine national procedural rules for both interim relief and remedies if the court upholds an appeal.

\section{A. Interim relief}

Courts must be able to grant interim relief when an applicant challenges a measure that is allegedly incompatible with $\mathrm{EU} \mathrm{law}^{152}$ and in cases where an applicant challenges a national act based on an allegedly invalid EU measure. ${ }^{153}$ Interim measures may be both positive and negative. Positive measures may, for example, concern the granting of a provisional licence to conduct a certain activity. Negative interim measures (which are also referred to as injunctive relief) may concern suspension of the enforcement of a contested administrative measure until the final ruling is issued. The generosity of rules on interim relief is not easy to compare across member states, the most important reason for this is that the applicable criteria for granting interim relief are vague and judges have a wide degree of discretion in their decisions. Thus, Table 31 does not intend to provide a ranking of legal systems. Note that the focus here is on injunctive relief rather than interim relief in general.

\footnotetext{
${ }^{149}$ Lenaerts, 2013: 3.

${ }^{150}$ Ibid.

${ }^{151}$ Sharpston, 1993: 26, in Eliantonio, 2008: 226.

${ }^{152}$ Case C-213/89 R. $v$ Secretary of State for Transport, ex parte Factortame Ltd and others [1990] ECR I-2433. For a review of this case law, see Eliantonio, 2008: 226-235.

${ }^{153}$ Joined cases C-143/88 and C-92/89 Zuckerfabrik Süderdithmarschen AG v Hauptzollamt Itzehoe and Zuckerfabrik Soest GmbH v Hauptzollamt Paderborn [1991] ECR I-415; case C-465/93 Atlanta Fruchthandelsgesellschaft $m b$ Hand others $v$ Bundesamt für Ernährung und Forstwirtschaft [1995] ECR I-3761. For a review of this case law, see Eliantonio, 2008: 226-235.
} 
Table 31 Injunctive relief

\begin{tabular}{ll}
\hline Netherlands & $\begin{array}{l}\text { Suspensive effect only upon request } \\
\text { Injunctive relief given 'where speed is essential because of the interests involved' } \\
\text { Poland }\end{array}$ \\
& $\begin{array}{l}\text { Suspensive effect only upon request } \\
\text { Injunctive relief in case of a plausible threat of significant damage or effects that are difficult } \\
\text { to reverse }\end{array}$ \\
Portugal & $\begin{array}{l}\text { Suspensive effect only upon request, unless the decision involves a financial payment } \\
\text { Court needs to weigh private and public interest }\end{array}$ \\
\hline
\end{tabular}

In none of the three countries included in this study do objections against an administrative decision have an automatic suspensive effect. In the Netherlands, an automatic suspensive effect only applies to certain cases covered by the Crisis and Recovery Act. ${ }^{154}$ In all other cases injunctive relief may be granted when speed is essential because of the interests involved. ${ }^{155}$ This rather vague criterion has been fleshed out in case law, which has developed a number of sub-criteria in this regard. ${ }^{156}$

In Poland, appeal to the administrative court does not automatically suspend execution of the challenged decision. ${ }^{157}$ Claimants may ask the court for injunctive relief, which is granted when there is a risk that the execution of the decision may cause significant damage or effects that are difficult to reverse. ${ }^{158}$ It is up to the claimant to show that the threat is plausible. ${ }^{159}$

In Portugal, suspensive effect is automatic only when the purpose of the appeal or review is a financial payment that does not have a sanctioning function, and a guarantee has been given under tax law. ${ }^{160}$ In all other cases, applicants can request a suspensive effect. Portuguese case law does not define any clear criteria for when injunctive relief should be granted. While it is clear that judges should balance the private interest of the applicant and the relevant public interests, judges do, in practice, have considerable discretion in their decision making in this regard. ${ }^{161}$

B. Remedies if a claim is upheld

In all of the legal systems included in this study, rules on remedies have recently been modified in order to meet concerns regarding the effectiveness of previously existing catalogues of remedies. The remedies that are currently available to Dutch, Polish, and Portuguese judges (when a claim is upheld) are listed in Table 32.

\footnotetext{
${ }^{154}$ CRA, Art. 2:14, in conjunction with Art. 2:10(1) and 2:9(1).

${ }^{155}$ GALA, Art. 8:81.

${ }^{156}$ For a summary, see Backes, 2012: 20.

${ }^{157}$ PACA, Art. 61, $\$ 1$.

${ }^{158}$ Ibid., Art. 61, $\$ 3$.

${ }^{159}$ Jendróska and Bar, 2012: 20.

${ }^{160}$ CPAC, Art. 50(1).

${ }^{161}$ Aragão, 2012: 20.
} 
Table 32 Remedies when the appeal is upheld

\begin{tabular}{ll}
\hline Netherlands & Authority is allowed or obliged to repair the decision, or \\
Decision is quashed \\
- authority ordered to take a new decision, or \\
- legal effects may stay in place, or \\
- judgement may replace decision \\
Fortugal and second instance courts ${ }^{162}$ \\
Decision is quashed \\
- authority condemned to reconstruct situation if act had not been executed \\
- authority mandated to follow a course of action \\
- binding guidelines for authority in deciding on new act, or \\
- decision on content of new administrative decision \\
First instance courts \\
Decision is quashed in whole or in part \\
- judgement may set rules for authority to follow in the proceedings \\
Second instance courts \\
Decision is quashed in whole or in part \\
- first instance judgement reversed \\
- case referred back to first instance court \\
- binding guidelines for first instance court
\end{tabular}

In the Netherlands, the effectiveness of judicial review has recently been subject to criticism, which has triggered a number of reforms. Dutch administrative law provides the administrative judge with two possible remedies: the judge may declare the appeal well founded, or the judge may decide that the appeal is unfounded. ${ }^{163}$ Since these remedies are in fact restricted to quashing administrative decisions or to leaving them in place, they are not always sufficient to solve the dispute between the parties in the proceedings. Decisions may be quashed just because of an infringement of procedural requirements, in which case the entire administrative decision-making process must start anew, objections against this decision may be filed again, and the whole process resembles "decision-ping-pong" between courts and authorities. ${ }^{164}$

\footnotetext{
${ }^{162}$ Remedies for first instance courts (Tribunais Administrativos e Fiscais de Círculo) and second instance courts (Tribunais Centrais Administrativos). Judicial review by the Supreme Administrative Court (the thirdinstance court) is exceptional. It is open against decisions turned down by second instance administrative courts in cases of "fundamental importance" from a legal or social point of view, or when such a review is required for a "better application of the law"; see CPAC, Art. 150. Exceptional proceedings may also be brought before the Court concerning the standardisation of case law (CPAC, Art. 152), and in cases where the authorities making the decision are examined by the Court from the outset (Estatuto dos Tribunais Administrativos e Fiscais, Lei no 13/2002, de 19 de Fevereiro [2002] DR 1. ${ }^{a}$ série A, No 42/1324 (Statute of Administrative and Tax Courts), Arts 24 and 26). In such cases, the Court only reviews the legal questions of the case.

${ }^{163}$ GALA, Art. 8:70.

${ }^{164}$ Backes, 2012: 21-22.
} 
Currently, judges are obliged to resolve the dispute between the parties in the proceedings whenever possible. ${ }^{165}$ Provisions stipulating that judges may decide that the legal effects of the quashed decision remain in place, or that the judgement replaces it, ${ }^{166}$ are useful tools in this regard. These tools have existed for a long time, but they are used more frequently now than in the past. ${ }^{167}$ Moreover, and as a last option, the judge may also provide the authority with the possibility to correct the faults in the contested decision within a certain time limit, after which the court proceedings will be resumed. ${ }^{168}$ The court of last appeal can oblige the authority to repair the decision. ${ }^{169}$ Where it has been used, this shortcut (bestuurlijke lus) has generally increased the effectiveness and efficiency of judicial review. ${ }^{170}$ Finally, a recent addition to the General Administrative Law Act stipulates that a judge should not quash a decision on the grounds that it conflicts with legal provisions if these provisions do not serve to protect the interests of the person that relies on them (relativiteitsvereiste). ${ }^{171}$

In Poland, the judicial remedies differ for first and second instance courts. First instance administrative courts may quash the contested decision in whole or in part. ${ }^{172}$ While an administrative court cannot put its judgement in the place of the administrative decision, it may set rules that the administrative authority which issued the quashed decision in the first place must follow in further proceedings. ${ }^{173}$ Such rules contribute to a swift resolution of the dispute at stake. When the Supreme Administrative Court upholds an appeal, it reverses the contested decision in whole or in part, and refers it back to the relevant first instance court - whose entire judgement it reverses ${ }^{174}$ - for reexamination. ${ }^{175}$ The first instance court then re-examines the case based on the interpretation of the law by the Supreme Administrative Court, which is binding. ${ }^{176}$

The success of court judgements in solving cases satisfactorily seems questionable. It is said that Polish courts are notorious for taking a formalistic approach to the case at stake; although the law stipulates that courts should aim to resolve the matter thoroughly, case law often focuses on procedural issues only, leaving the substance of the dispute undecided. This focus is visible, for example, in the idea that the court does not consult experts to help it to decide on disputes, and that it would rather refer the matter back to

\footnotetext{
${ }^{165}$ GALA, Art. 8:41a.

${ }^{166}$ Ibid.,, Art. 8:72.

${ }^{167}$ Backes, 2012: 18.

${ }^{168}$ GALA, Art. 8:51a.

${ }^{169}$ Ibid.,, Art. 8:51d.

${ }^{170}$ Backes et al., 2014.

${ }^{171}$ GALA, Art. 8:69a.

${ }^{172}$ PACA, Art. 145, \$1, in conjunction with APC, Art. 156, \$1

${ }^{173}$ Ibid., Art. 153.

${ }^{174}$ Ibid., Art. 186.

${ }^{175}$ PACA, Art. 185, $\$ 1$.

${ }^{176}$ Ibid., Art. 190.
} 
the administration to develop new evidence supporting its claim. ${ }^{177}$ This situation seems, to a great extent, comparable to the practice in the Netherlands until approximately ten years ago.

In Portugal, legislation stipulates that an appeal should aim not only to quash an administrative act, ${ }^{178}$ but also to condemn the administration to adopt the acts and operations necessary to reconstruct the situation that would exist if the contested measure had not been executed. ${ }^{179}$ When the court condemns the practice of an administrative act, it also decides on the material interest of the claimant, mandating the authority a course of action to follow. ${ }^{180}$ If the act that the administration is required to adopt involves the formulation of administrative opinions or administrative judgements, then the court cannot determine the precise content of the action required, but must provide guidelines to be observed by the administration in the new administrative act. ${ }^{181}$

It is argued that despite the requirement outlined in the Constitution and in legislation that judges must give priority to the material questions of a case, ${ }^{182}$ judgements are nonetheless often not evaluations regarding the merits of the case, rather they are formal decisions about the admissibility of the trial and other procedural questions. As a result - and despite the favourable legal provisions - the material facts being questioned and the larger legal issues at stake often remain unresolved. ${ }^{183}$

\subsubsection{Synthesis}

As it is impossible to draw an overall comparative conclusion concerning the effectiveness of judicial protection across legal systems, Table 33 provides an overview of the relative performance of the three countries regarding each issue discussed in the previous subsections. Three points are given if the rules, from a relative perspective, provide for the highest degree of judicial protection; two points are given if the rules allow for comparable levels of judicial protection across countries; and one point is given if a country clearly ranks lowest relative to the others. Zero points are given if individuals are not given the opportunity to exercise a certain right.

Not all cases permit a ranking. This is the case for the costs of actio popularis proceedings and injunctive relief. While a comparison between national rules on injunctive relief is impossible because of the vagueness of the applicable legal provisions, it is not possible to compare the costs of actio popularis proceedings since the procedure does not exist in all countries.

\footnotetext{
${ }^{177}$ Email 2 from interviewee PL2 to author.

${ }^{178}$ CPAC, Art. 50

${ }^{179}$ Ibid., Art. 66, in conjunction with Art. 95, $\$ 3$.

${ }^{180}$ Ibid., Art. 71, $\$ 1$.

${ }^{181}$ Ibid., Arts 71, 22 and 95, $\$ 3$.

${ }^{182}$ Ibid., Art. 2, $\$ 1$

${ }^{183}$ Aragão, 2012: 2, 30.
} 
Table 33 Comparative overview of effectiveness of judicial protection

\begin{tabular}{lccr}
\hline & Netherlands & Poland & Port \\
\hline Standing & & & 3 \\
A. Actio popularis & 0 & 0 & 3 \\
B. Other procedures & 2 & 1 &
\end{tabular}

\section{Time limits}

$\begin{array}{llll}\text { A. For claimants } & 2 & 1 & 3 \\ \text { B. For courts } & 3 & 2 & 1\end{array}$

\section{Costs}

\section{A. Court fees}
a. Actio popularis
Not applicable

b. Other procedures

Measurable ${ }^{184}$
Not measurable
C. Attorneys (required?)
D. Compensation ${ }^{185}$
E. Financial assistance
F. Preliminary rulings

$\begin{array}{lll}3 & 1 & 2 \\ 1 & 2 & 3 \\ 3 & 3 & 2 \\ 3 & 2 & 1 \\ 3 & 3 & 2 \\ 1 & 2 & 3 \\ 2 & 3 & 3\end{array}$

\section{Remedies}

A. Interim relief

Not applicable

B. Remedies ${ }^{186}$

3

Total

26

1

When the points allocated to each country are added up, it appears that the Dutch and the Portuguese system score more or less equally on the scale of effectiveness, while the Polish system remains somewhat behind. Note that this outcome does not imply that Dutch and Portuguese citizens enjoy higher levels of judicial protection than Polish citizens, since the differences between the best scoring country (Portugal) and the worst scoring state (Poland) are small; there is not a single country that is particularly underperforming or excelling. Moreover, a high score regarding one factor cannot compensate for a low score concerning another factor. For example, where standing opportunities are generous, high court fees may still bar access to justice. And where court fees are low, individuals may not have legal standing to use case law as a problem-solving tool in

\footnotetext{
${ }^{184}$ For the motivations underlying this ranking, see note 114 above.

${ }^{185}$ For first-instance proceedings, considering the risk to pay incurred by the party and the costs that need to be compensated, where this is the case.

${ }^{186}$ For first-instance proceedings.
} 
the first place. In both cases, the notion that effective judicial remedies are in place is meaningless, since access to the court is barred to begin with. In other words, this table merely provides an idea of the relative performances of countries for individual principles, instead of attempting to arrive at a general comparative conclusion on the effectiveness of rules for judicial protection across the three legal systems.

\subsubsection{Capacity of civil society to engage in litigation}

Chapter 7 on civil society shows that citizens and civic organisations may be useful for supporting the application of EU law by cooperating with national competent authorities and/or by exercising pressure on these same authorities, for example by starting domestic court proceedings against them. It is clear that for civil society actors to bring a case before a national court, they need to have access to justice. In this regard, it is sufficient to refer to the previous sections, which suggest that rules on access to justice vary across member states. For civil society actors to carry through court cases effectively, however, being granted access to justice is not enough; civil society actors must also have the capacity to act as credible parties in court proceedings. Concretely speaking, what civic organisations and citizens need is information, expertise, and money. ${ }^{187}$ The problem is that what they have at their disposal does not always meet this need.

Regarding the issue of information, two matters must be established. The first is that both civic organisations and citizens are not always aware of the opportunity to turn to a national court in order to force administrative authorities into compliance with EU legislation. ${ }^{188}$ Second, when they are, they do not always have relevant or sufficient information about the application of legislation on the ground. ${ }^{189}$ The ease with which civil society may acquire such information depends, in part, on the existence of regulations for access to information for civil society. While the Aarhus Convention (and the relevant EU implementing legislation) establishes generous rules on access to environmental information for citizens and civic organisations, ${ }^{190}$ similar rights do not exist in most other policy areas. Given the resulting cross-issue asymmetry, one may, all other things being equal, expect it to be easier for civil society 'to make a case' in the environmental domain than in other policy domains. ${ }^{191}$

In reality, however, not all other things are equal. Actors throughout the EU may have access to the same information, but that they should have sufficient knowledge and

\footnotetext{
${ }^{187}$ Slepcevic, 2009; Börzel, 2006.

${ }^{188}$ Slepcevic, 2009: 381.

${ }^{189}$ Ibid.

190 The provisions on access to information in the Aarhus Convention are implemented by Directive 2003/4/EC of the European Parliament and of the Council of 28 January 2003 on public access to environmental information and repealing Council Directive 90/313/EEC [2003] OJ L 41/26.

${ }^{191}$ At least when the rules on access to information are applied effectively, one might add, which is not always the case. See Commission, 'Report on the experience gained in the application of Directive 2003/4/EC on public access to environmental information' (Report) COM (2012) 774 final.
} 
expertise to do something valuable with this information is not self-evident. Chapter 7 on civil society shows, for example, that levels of expertise of civic organisations vary greatly across the board, and that expertise is likely to be scarce in areas that are technically complicated and for organisations that depend on voluntary work. In the context of this study, this scarcity seems to apply to environmental organisations in the field of integrated pollution prevention and control in particular. Only a few NGOs can claim to have sufficient knowledge and expertise to fully grasp the essence of the authorities' legal obligations in this field, and to establish their compliance with such obligations. ${ }^{192}$

Finally, civil society must possess the financial resources that are necessary to engage in litigation and to pursue a case successfully. ${ }^{193}$ Relevant to this is the fact that NGOs and individuals must be able to pay the court fees and other costs that are due over the course of court proceedings. The crux is that neither affluence on the part of organisations nor low court costs can assure effective civil society participation in court proceedings. This is because, while rich organisations are more likely to be able to afford litigation, they may not be able to compensate entirely for high litigation costs. Low costs, on the other hand, may mitigate weak organisational capacity, but they may still not allow the poorest organisations to put pressure on the administration through litigation. ${ }^{194}$

Overall, these limitations highlight the idea that law is at the service of the privileged. ${ }^{195}$ They also suggest that as long as this is the case, the potential for civil society actors to act as watchdogs of the authorities before national courts - and the potential for domestic case law to be a useful compliance instrument - will remain underexploited.

\subsubsection{The preliminary ruling procedure}

The introduction to this section suggests that the usefulness of the EU's preliminary ruling system depends on two factors: the extent to which preliminary rulings have a clarifying effect for national judges (and administrations), and the extent to which national judges ask the CJEU to rule on interpretational issues in the first place. One may add a third factor to this discussion, which concerns the degree to which national courts (and administrations) follow through on preliminary rulings in the national implementation practice. Starting from the assumption that preliminary rulings provide clear interpretations of EU law, the focus of this section is on the extent to which such rulings are requested and the follow through of such rulings in the national implementation context.

\footnotetext{
${ }^{192}$ For a general argument along those lines, see Slepcevic, 2009: 381.

${ }^{193}$ Ibid.; Börzel, 2006: 130.

${ }^{194}$ Slepcevic, 2009: 381-382.

${ }^{195}$ Conant, 2002: 21ff.
} 


\subsubsection{Preliminary ruling requests: cross-issue, cross-country, and cross-court variation}

Preliminary ruling requests submitted by national courts to the CJEU comprise the bulk of cases put before the Court, with statistics showing a steady increase in such requests over the years. ${ }^{196}$ Statistics also show an unequal division of preliminary ruling requests across policy domains, member states, and different types of court. The following paragraphs look at each of these issues in turn, while referring to the policy domains and the member states included in this study.

The variance of preliminary ruling requests across policy areas seems partly explained by the "systematic biases in EU law that shape which national policies can be influenced by the EU legal process and which domestic actors will find EU law most helpful to promote their objectives" ${ }^{197}$ In areas where the EU has created far-reaching rights for citizens, and in areas that have been harmonised to a significant extent, actors may find it easier to find an "EU legal angle of attack" than in areas where this is not the case. ${ }^{198}$ These notions may explain why the area of freedom, security, and justice is amongst the areas with the highest numbers of preliminary ruling requests submitted by national courts annually, and why a domain such as common foreign and security policy has remained behind. Of particular relevance to this study is that national courts appear active in the areas of consumer protection and transport, and less so in the area of the environment. ${ }^{199}$

Next to cross-issue variance, statistics also show a great deal of cross-country variance regarding the numbers of preliminary ruling requests submitted to the CJEU by national courts and tribunals. In absolute terms, ${ }^{200}$ Dutch courts are amongst the mostoften referring courts of the old EU-15. ${ }^{201}$ This is different for courts in Portugal; between 2004 and 2012, the number of questions submitted by Portuguese courts was approximately one-fifth of that submitted by Dutch courts. ${ }^{202} \mathrm{With}$ approximately the same number of questions submitted as Portuguese courts, Polish courts rank highest in comparison to the other 2004 accession states. ${ }^{203}$ Variation exists, not only across member states, but also within the vertical chain of the judiciary; statistics suggest that higher courts are more reluctant to refer preliminary questions to the CJEU than lower courts. ${ }^{204}$

\footnotetext{
${ }^{196}$ For numbers, see the introduction to this chapter.

${ }^{197}$ Alter, 2000: 494-496.

${ }^{198}$ Ibid.

${ }^{199}$ See Court of Justice of the European Union, 2014: 71.

${ }^{200}$ It is self-evident that absolute numbers do not indicate the relative performance of member states; see below.

${ }^{201}$ See Court of Justice of the European Union, 2013: p. 112.

${ }^{202}$ Ibid.

${ }^{203}$ Ibid.

${ }^{204}$ Court of Justice of the European Union, 2013: 113.
} 
There are two categories of factors that seem relevant to explaining inter-country variation in the number of preliminary references submitted to the Court. The first category is of a structural nature. This category considers the idea that any explanation must be based on the number of preliminary references, relative to the number of court cases that give rise to EU law issues, in the member state in question. ${ }^{205}$ Both numbers are bound to differ across member states. Determinative for such differences are, it seems, factors such as population size, the degree of litigation in member states, the compliance performance of the public administration, ${ }^{206}$ and EU trade levels. ${ }^{207}$ While the relationship between the interplay of these factors and the numbers of preliminary references submitted to the CJEU is not clear, it seems plausible that they complement another behavioural factor that has widely been described in the literature as explaining why some member states are more prone to refer than others: the willingness of judges to refer preliminary questions to the CJEU.

The willingness of judges is a relevant explanatory factor, since judges act as gatekeepers; ${ }^{208}$ ultimately, it is up to them to decide whether or not to refer a preliminary question to the CJEU. Studies suggest that judicial support for the CJEU varies across member states and, within member states, across courts in the court hierarchy. ${ }^{209}$ Courts are more likely to be supportive of the CJEU where the net utility gains of referring preliminary questions exceed the gains from not referring questions to the Court. ${ }^{210}$ The extent to which EU law undermines the influence, independence, and autonomy of national courts plays a role here. Higher courts may feel threatened by the existence of the CJEU as the highest court for questions of EU law, or be upset because the Court undermines their own influence. This may explain why higher courts are more reluctant to refer questions to the CJEU than lower courts. For lower courts, in contrast, a reference may bolster their authority in the national legal system and be a method of challenging higher-court jurisprudence. ${ }^{211}$

Judicial identity and the complexities for national legal systems of the sometimesproblematic outcomes of preliminary rulings also affect the willingness of national courts to refer questions to the Court. ${ }^{212}$ Public opinion is argued to affect willingness as well, with negative public perceptions of EU integration producing legitimacy constraints on national courts that lead to fewer preliminary references. ${ }^{213}$ Finally, judges in

\footnotetext{
${ }^{205}$ Broberg and Fenger, 2013: 489.

${ }^{206}$ For an argument that such factors are relevant, see Broberg and Fenger, 2013. Note that it is impossible to establish which share of these proceedings give rise to issues of EU law. See Broberg and Fenger, 2013: 489.

${ }^{207}$ Stone Sweet and Brunell, 1998; Stone Sweet and Caporaso, 1998; Carrubba and Murrah, 2005.

${ }^{208}$ Alter, 2000: 499; Tridimas and Tridimas, 2004: 134ff.

209 Tridimas and Tridimas, 2004: 134ff.

${ }^{210}$ Ibid.: 135 .

${ }^{211}$ Alter, 2000: 504-505; Tridimas and Tridimas, 2004: $134 \mathrm{ff}$.

${ }^{212}$ Alter, 2000: 503-506.

${ }^{213}$ Mattli and Slaughter, 1998; Carrubba and Murrah, 2005.
} 
systems with abstract constitutional review are more likely to be cautious about submitting preliminary ruling requests than judges in systems where constitutional review does not exist at all. ${ }^{214}$ In legal systems with abstract review, the constitutionality of the law is only evaluated in abstracto (that is, not in the context of a legal dispute pending before a court) and a law that is found to be unconstitutional is invalidated with general effects. Preliminary rulings, however, determine the outcome of the proceedings in the framework of which the question was referred in concreto. Because of its influence on a concrete case, the preliminary ruling system requires judges in legal systems with abstract review to explicitly deviate from the powers given to them by national law. It is this need for deviation that explains the hesitance on the part of judges in abstract review systems to submit questions to the CJEU. Overall, there seem to be many factors that may impede preliminary rulings from being requested, even where such rulings may be useful for courts and national competent authorities in the implementation of EU law.

\subsubsection{Compliance with preliminary rulings}

When a national court has referred a question about the interpretation of EU law to the CJEU, the subsequent ruling given by the Court must be completed in order for it to be useful for administrative authorities that are parties to the proceedings. This means that the national court needs to comply with the interpretation given by the Court and carefully consider the compatibility of national law with EU law based on the guidance given by the Court in this regard. This follow through is not self-evident, given the absence of a mechanism to force national courts into compliance with CJEU judgements. While preliminary rulings are binding to national courts, compliance with such rulings depends on the court's assessment of the expected net utility gains from applying the rulings, and the utility gains from not applying them. ${ }^{215}$

When national courts do follow through on preliminary rulings, it is up to the government and administration to accept the interpretational guidance given by the CJEU as a directive for the overall administration of the relevant legislative provisions. Abidance with a decision of the CJEU is more likely to occur in a country that tends to abide by its own court decisions than in a state where this is not the case. Moreover, it has been argued that where national courts are "less legitimate, less vigilant, and a rule of law ideology is not a significant political factor, politicians would be more likely to use extralegal means to circumvent [CJEU] jurisprudence". ${ }^{216}$ An assessment of the strength of the rule of law principle in the three countries examined in study, would lead one to expect the Netherlands to be in the coalition that supports faithful implementation of

\footnotetext{
${ }^{214}$ Carrubba and Murrah, 2005: 412.

215 Tridimas and Tridimas, 2004: 135.

${ }^{216}$ Alter, 1998: 144.
} 
Court jurisprudence. For Poland and Portugal, in contrast, such support seems questionable. ${ }^{217}$

Other factors that influence the extent to which an administration is willing to comply with CJEU rulings relate to the vigilance of civil society organisations in the respective area and the costs of policy change. The more vigilant civil society organisations are - and the more these organisations engage in "repeat-player litigation" - the higher the chance of administrative compliance. ${ }^{218}$ In relation to this point, reference should be made to Chapter 7 on civil society, which suggests that the organisational strength of civil society varies across member states and across policy areas. This means that civil society cannot always be relied on to keep a watchful eye on the administration or to challenge the administration when necessary. Regarding the effect of the costs of policy change, it is argued that a higher concentration of the benefits of change and a wider distribution of the costs bring a higher probability of administrative acceptance of CJEU rulings. ${ }^{219}$ This means that compliance with CJEU judgements is most likely to occur in areas where 'everyone pays for the benefit of some'. This is advantageous to clearly defined societal groups that are set to benefit from policy change, but not for amorphous groups of beneficiaries.

Together, these factors indicate that the usefulness of preliminary rulings for the public administration depends on the follow up of such rulings by national courts, and on the acceptability of interpretative guidance provided by the CJEU amongst political actors and the higher echelons of the administration. If the outcome at both stages of the implementation process is negative, the usefulness of preliminary rulings for street-level implementation actors may be doubted. It seems that this may also be the case when the political principals are divided about the desirability of interpretations outlined in rulings and cannot enforce compliance on the part of the administration, enabling the administration to disregard such interpretations in the application practice and follow its own course. ${ }^{220}$

\section{Case law relevant to this study}

This section aims to examine, in brief, the case law that is relevant in the context of this study. Section 2.1 focuses on national case law; preliminary rulings are the subject of Section 2.2.

\footnotetext{
${ }^{217}$ According to the World Bank, in 2013, the Netherlands scores highest on the 'rule of law' indicator, at least in comparison with Poland and Portugal. On a scale from -2.5 (weak rule of law) to 2.5 (strong rule of law), the Netherlands scores 1.84 points. The scores for Portugal and Poland are 1.04 and 0.74, respectively. See World Bank Group, The World Bank Group, 'Worldwide Governance Indicators', <www.govindicators.org >. ${ }^{218}$ Alter, 2000: 508.

${ }^{219}$ Ibid.; Conant, 1998.

${ }^{220}$ See Chapter 2 on implementation in the EU: same rules, divergent practices, Section 3.2.2.2.3.
} 


\subsection{National case law}

Regarding the prevalence of national case law concerning the three directives included in this study, the following arguments must be established from the outset. First, for all three directives, potential challengeable acts must concern administrative acts. In line with the interest of this study in the core provisions of the directives, ${ }^{221}$ these acts must, in general terms, concern market surveillance activities in the area of general product safety; ramp inspections in the domain of SAFA; and environmental licenses in the area of integrated pollution prevention and control.

Table 34 lists the authorities in the Netherlands, Poland, and Portugal, whose acts are potentially relevant to this study. Note that these authorities are not necessarily those against which court proceedings may be started. While the acts of some of these bodies are directly challengeable in court, claimants do in most cases, first need to resort to administrative objection and appeal procedures that may involve, as challenged entities, authorities other than those responsible for issuing the administrative act in the first place.

Table 34 Relevant administrative authorities

\begin{tabular}{|c|c|c|c|}
\hline & Netherlands & Poland & Portugal \\
\hline \multirow[t]{4}{*}{ GPS } & Netherlands Food and Consumer & \multicolumn{2}{|c|}{ Office for Competition and Directorate-General for } \\
\hline & \multirow[t]{3}{*}{ Product Safety Authority ${ }^{222}$} & Consumer Protection ${ }^{223}$ & Consumer Protection ${ }^{225}$ \\
\hline & & Provincial trade & Food and Economic Safety \\
\hline & & inspectorates ${ }^{224}$ & Authority 226 \\
\hline \multirow[t]{4}{*}{ IPPC } & Provincial administrative & Regional administrative & Portuguese Environment \\
\hline & authorities 227 & authorities $^{229}$ & Agency $^{231}$ \\
\hline & Municipal administrative & \multirow{2}{*}{\multicolumn{2}{|c|}{$\begin{array}{l}\text { County administrative } \\
\text { authorities }^{230}\end{array}$}} \\
\hline & authorities $^{228}$ & & \\
\hline
\end{tabular}

\footnotetext{
${ }^{221}$ See Chapter 3 on approach and methodology, Section 4.1.1.

${ }^{222}$ Nederlandse Voedsel en Waren Autoriteit.

${ }^{223}$ Urząd Ochrony Konkurencji i Konsumentów. This Office is responsible for taking corrective measures regarding economic operators.

${ }^{224}$ Wojewódzki Inspektorat Inspekcji Handlowej. The regional trade inspectorates carry out the preparatory work for the Office to adopt the respective corrective measures.

${ }^{225}$ Direção-Geral do Consumidor. DGC is responsible for the adoption of corrective measures in relation to economic operators. It may ask ASAE to conduct certain inspections, and it may resort to laboratories to conduct product checks.

${ }^{226}$ Autoridade de Segurança Alimentar e Económica. ASAE is responsible for the 'practical' part of the market surveillance process, that is, for everything except the decision on the safety of the product.

${ }^{227}$ Gedeputeerde Staten, for certain categories of installations covered by the IPPC Directive.

${ }^{228}$ College van Burgemeester en Wethouders, for certain categories of installations covered by the IPPC Directive.

${ }^{229}$ Urząd Marszałkowski Województwa, for installations with a significant impact on the environment.

${ }^{230}$ Urzad Starostwo Powiatu, for installations without a significant impact on the environment.

${ }^{231}$ Agência Portuguesa do Ambiente.
} 


\begin{tabular}{llll}
\hline & Netherlands & Poland & Portugal \\
\hline SAFA & Transport and Human & Civil Aviation Authority $^{233}$ & National Civil Aviation \\
& Environment Inspectorate & & Authority $^{234}$ \\
\hline
\end{tabular}

Second, it is clear that the case law that is relevant to this study must concern jurisprudence from Dutch, Polish, and Portuguese administrative courts. Table 35 below shows which courts are relevant in this regard.

Table 35 Administrative courts relevant to the context of this study

\begin{tabular}{llll}
\hline & Netherlands & Poland & Portugal \\
\hline First instance & $\begin{array}{l}\text { District courts, administrative } \\
\text { law division }\end{array}$ & $\begin{array}{l}\text { Regional administrative } \\
\text { courts }^{236}\end{array}$ & $\begin{array}{l}\text { Administrative and Tax } \\
\text { Courts at the district level }\end{array}$ \\
Second instance & Administrative Jurisdiction & Supreme Administrative & Administrative Courts of \\
& Division of the Council of State & Court & \\
Third instance & Not applicable & Not applicable & Appeal $^{240}$ \\
& & & $\begin{array}{l}\text { Supreme Administrative } \\
\text { Court }^{241}\end{array}$ \\
\hline
\end{tabular}

The relevant case law has been searched using the available online national databases. For ramp inspections under the SAFA Directive, the universally used term 'SAFA' was used. For environmental licences under the IPPC Directive, the implementing legislation and/or a combination of key words were used. The latter applies to market surveillance actions under the GPS Directive as well. The relevant search terms are listed in Table 36. Translations of, and explanations for, the use of these terms are given in the footnotes.

\footnotetext{
${ }^{232}$ Inspectie voor Leefomgeving en Transport.

${ }^{233}$ Urząd Lotnictwa Cywilnego.

${ }^{234}$ Autoridade Nacional de Aviação Civil.

${ }^{235}$ Rechtbanken.

${ }^{236}$ Wojewódzki sq̨d administracyjny, for all first-instance cases apart from those in which the Supreme Administrative Court is competent; see Ustawa $z$ dnia 25 lipca 2002 r. prawo o ustroju sądów administracyjnych (Administrative Courts Act; ACA), Art. 3; PACA, Art. 13, \$1.

${ }^{237}$ Tribunais Administrativos e Fiscais de Círculo.

${ }^{238}$ Afdeling Bestuursrecht van de Raad van State.

${ }^{239}$ Naczelny Sąd Administracyjny.

${ }^{240}$ Tribunais Centrais Administrativos. Unless the case at hand concerns a civil liability case with a value exceeding the amount of three million euros and if the parties raise questions of law only; in this case, the Supreme Administrative Court has jurisdiction. See CPAC, Art. 151(1).

${ }^{241}$ Supremo Tribunal Administrativo. Judicial review by the Supreme Administrative Court is exceptional; see n. 162 above.
} 
Table 36 Search terms used for finding relevant jurisprudence

\begin{tabular}{|c|c|c|c|}
\hline & Netherlands ${ }^{242}$ & Poland ${ }^{243}$ & Portugal $^{244}$ \\
\hline \multirow[t]{4}{*}{ GPS } & 18 onder a Warenwet & ogólnym bezpieczeństwie produktów & Decreto-Lei $69 / 2005^{247}$ \\
\hline & 21 Warenwet & AND Prezes Urzędu Ochrony & \\
\hline & Warenwetbesluit Algemene & Konkurencji i Konsumentów AND & \\
\hline & Productveiligheid ${ }^{245}$ & Inspektor Inspekcji Handlowej ${ }^{246}$ & \\
\hline \multirow[t]{4}{*}{ IPPC } & BBT IPPC ${ }^{248}$ & prawo ochrony środowiska AND & Decreto-Lei 194/2000 AND \\
\hline & & najlepsze dostępne techniki $i^{249}$ & melhores técnicas disponíveis ${ }^{250}$ \\
\hline & & & Decreto-Lei 73/2008 AND \\
\hline & & & melhores técnicas disponíveis ${ }^{251}$ \\
\hline SAFA & SAFA & SAFA & SAFA \\
\hline
\end{tabular}

For Portuguese first instance courts, it was impossible to retrieve the available case law online; the online database does not include jurisprudence issued by such courts. In this case, it was necessary to rely on the triangulated statements on this issue of Portuguese respondents (both national officials and civil society representatives). While the statements of these interviewees are not further verifiable in the context of this study, two factors are in favour of relying on them. First, the authorities responsible for the administration of the legislation are singular and centralised. They may have regional branches

\footnotetext{
${ }^{242}$ Database: De Rechtspraak, 'Uitspraken', <uitspraken.rechtspraak.nl>.

${ }^{243}$ Database: Naczelny Sąd Administracyjny, 'Centralna Baza Orzeczeń Sądów Administracyjnych', on $<\mathrm{http}: / /$ orzeczenia.nsa.gov.pl>.

${ }^{244}$ Database: Instituto de Gestão Financeira e Equipamentos da Justiça, I.P., 'Bases Jurídico-Documentais', on $<$ http://www.dgsi.pt $>$.

${ }^{245}$ The Dutch database only allows one to search for relevant key words. The terms 18 onder a Warenwet and 21 Warenwet stand for Article 18, sub a, and Article 21 of the General Food and Product Safety Act (Wet van 28 december 1935, houdende voorschriften betreffende de hoedanigheid en aanduiding van waren [1935] Stb. 7930. Warenwetbesluit Algemene Productveiligheid (Besluit van 28 september 1993, houdende regelen betreffende de algemene produktveiligheid [1993] Stb. 499) is the Ministerial Order on general product safety.

${ }^{246}$ The Polish database allows one to fill in the party against which the complaints must be filed (Prezes Urzędu Ochrony Konkurencji i Konsumentów translates as the President of UOKiK; Inspektor Inspekcji Handlowej is the Inspector of the Trade Inspectorate), and the law that is concerned (ogólnym bezpieczeństwie produktów translates as general product safety).

${ }^{247}$ The Portuguese database only allows one to search for key terms in judgements. Decreto-Lei 69/2005 lays down rules on general product safety.

${ }^{248} \mathrm{BBT}$ stands for beste beschikbare technieken (best available techniques); IPPC is a term that is generally used (also in Dutch) to denote national legislation implementing the IPPC Directive.

${ }^{249}$ The law that is concerned is Prawo ochrony środowiska, Ustawa $z$ dnia 27 kwietnia 2001 [2001] Dz.U. 62/627 [Environmental Protection Act]; the relevant key words in the text of the judgement are najlepsze dostępne techniki (best available techniques).

${ }^{250}$ Decreto-Lei no 194/2000 de 21 de Agosto [2000] DR 1. a série A, № 192/4116 formerly implemented the IPPC Directive. Melhores técnicas disponiveis stands for best available techniques.

${ }^{251}$ Decreto-Lei $n^{\circ} 173 / 2008$ de 26 de Agosto [2008] DR 1. a série, № 164/5967 is the successor act to Decreto-Lei 194/2000 implementing the IPPC Directive.
} 
(which is the case for ASAE), but if anything 'goes wrong' in these branches, the close connections between them and the main office is expected to guarantee that this information is not lost. Thus, the relevant information is concentrated rather than dispersed, which makes claims of officials regarding the absence of case law more plausible. Second, interviews were conducted, not only with street-level actors, but also with higherlevel officials from these authorities. Had court proceedings been ongoing, it could be assumed that some of these officials would have known about such proceedings.

The numbers of court cases that have been arrived at are shown in Table 37. For the sake of clarity and readability, the contents of these cases are not elaborated on here but in Section 3 of this chapter, in conjunction with the discussions regarding the usefulness of these cases.

Table 37 National case law

\begin{tabular}{lccc}
\hline & GPS & IPPC & SAFA \\
\hline Netherlands & $0^{252}$ & 8 & 2 \\
First instance courts & 0 & 76 & 2 \\
Council of State & 51 & $61^{253}$ & 0 \\
Poland & 6 & 9 & 0 \\
First instance courts & & 0 & 0 \\
Supreme Administrative Court & 0 & 0 & 0 \\
Portugal & 0 & 0 & 0 \\
First instance courts & 0 & & \\
Second instance courts of appeal & & & \\
Supreme Administrative Court & & & \\
\hline
\end{tabular}

\subsection{Preliminary rulings}

As to preliminary rulings delivered by the CJEU, the Court's official website was used. ${ }^{254}$ The search terms that were used are 'Directive 2001/95/EC' (for the GPS Directive), 'Directive 61/96/EC' and 'Directive 2008/1/EC' (for the IPPC Directive), and 'Directive 2004/36/EC' (for the SAFA Directive). The results were filtered further based on an assessment of whether the preliminary questions submitted to the CJEU include a focus on provisions in the directives discussed in this study, rather than a mere reference to the directive. This search delivered one ruling on the GPS Directive, six on the IPPC

\footnotetext{
${ }^{252}$ Case law search delivered one result, but the relevant case addresses general product safety rules only incidentally. Since also interviewees indicate that case law is not present/useful, this case is not considered relevant.

${ }^{253} 29$ out of 61 cases in first-instance courts in the three regions that were visited for this research. It is these 29 cases that were examined in detail for the analysis in Section 3 of this chapter.

${ }^{254}$ Court of Justice of the European Union, <curia.europa.eu>.
} 
Directive, and none on the SAFA Directive. Also the contents of these rulings are elaborated on in Section 3 below.

Table 38 Preliminary rulings

\begin{tabular}{lll}
\hline GPS & IPPC & SAFA \\
\hline 1 & 6 & 0 \\
\hline
\end{tabular}

\section{The usefulness of case law as a compliance instrument}

This section aims to examine the usefulness of case law as a compliance instrument. Following the structure in the previous sections of this chapter, this section first discusses the usefulness of national case law for supporting the national competent authorities in the implementation process (Section 3.1). It then reviews the usefulness of preliminary rulings as compliance instruments (Section 3.2). The structure of these two sections is further elucidated at the beginning of each of them.

\subsection{National case law}

This section consists of three parts. In line with the idea that national case law can act as a compliance instrument only when jurisprudence on the implementation of the relevant provisions exists, it first discusses a number of legal and extra-legal factors that explain the prevalence of national case law in the three domains and the three countries examined in this study (Section 3.1.1). Section 3.1.2 analyses the contents of the national case law that is relevant to this study, and evaluates the usefulness of this case law for supporting the application of the relevant legal provisions. Section 3.1.3 recaps the findings presented in the previous two sections.

\subsubsection{Explaining the prevalence of case law}

Section 2.1 suggests that the amount of national case law varies greatly across countries and across policy domains. On a country level, Portugal seems to be an outlier, with case law being absent in all three areas in this study. The lack of litigation in Portugal is particularly striking in the area of integrated pollution prevention and control, since case law in this area in Poland and in the Netherlands is relatively abundant. In the area of general product safety, on the other hand, the many cases in Poland stand out compared to the absence of cases in the Netherlands and Portugal. The only area where some cross-country similarity exists is the area of air safety, where case law is absent apart from a mere two cases in the Netherlands. 
The following subsections aim to explain the patterns observed in litigation by discussing a number of legal and extra-legal factors that seem to have explanatory potential in this regard.

\subsubsection{Capacity and motivation of potential litigants}

The extent to which litigation exists is determined, first of all, by the existence of actors that could, in theory, challenge the administration in court. Using the area of integrated pollution prevention and control as an example, there must be companies that apply for IPPC permits, and there must be civil society actors that are active as watchdogs of the administration in the implementation process. Moreover, these actors must have the resources to start court proceedings and to carry them through successfully. This is not always the case, as is discussed in Chapter 7 on civil society and in Section 1.2.1.4 above. Non-governmental organisations may be few; they may not have sufficient expertise in, and knowledge of, the relevant policy area; and they may be dependent on the government for funding. While it may be unwise for the latter organisations to bite the hand that feeds them, organisations (and citizens) that lack the resources to make a credible claim in court may be deterred from engaging in litigation as well. It seems that the latter issue withholds actors from engaging in litigation in the - technically complicated - area of IPPC. ${ }^{255}$

The idea that there must be someone to identify when the administration does not comply presumes the presence of a second condition: that the administration does not comply, or that there is 'a point' for actors to engage in litigation. Of course, this is not always the case. While environmental organisations in all three countries that are included in this study are critical of the compliance performance of the authorities that are competent for granting IPPC permits, ${ }^{256}$ consumer organisations appear positive or neutral when it comes to the market surveillance activities carried out by the competent authorities. ${ }^{257}$ While one would expect case law to be present in the area of IPPC, the area of product safety may be expected to be less litigious - at least as far as legal challenges from the part of civil society are concerned. An analysis of the case law that is relevant in this study proves these expectations to be true. ${ }^{258}$

The interests of business actors in litigation are not strictly tied to the question of whether authorities comply or defect. In fact, business actors may be content when authorities defect, as long as this defection affects their own position in a positive way. This may be the case when market surveillance authorities turn a blind eye to noncompliance with the general product safety requirement, or when the competent authorities require companies to implement techniques that do not conform to the legal require-

\footnotetext{
${ }^{255}$ These issues of have been referred to in Chapter 7 on civil society, Sections 3.2 and 3.3.

${ }^{256}$ See ibid., Section 3.3 .

${ }^{257}$ See ibid., Sections 3.1 (on air safety) and 3.2 (on general product safety).

${ }^{258}$ Note that analysis demonstrates that none of the Polish court cases started in the area of product safety were initiated by consumer organisations.
} 
ment for them to use the best available techniques in their installation. Such defection may be intentional or advertent. Interviewees indicate that Polish authorities have, in the past, simply copied IPPC permit applications, because officials lacked the knowledge and expertise to make their own critical assessment. ${ }^{259}$ The compliance performance of some municipal authorities that are competent to decide on IPPC permits in the Netherlands is thought to be substandard because of similar capacity limitations. ${ }^{260}$ Market surveillance authorities throughout the EU miss instances of noncompliance with the general product safety requirement, partly because of a lack of capacity. ${ }^{261}$ And SAFA inspectors may refrain from reporting risks because they are afraid to make mistakes or to 'make difficulties' with operators, ${ }^{262}$ because they are under time pressure ${ }^{263}$ or because of knowledge limitations. ${ }^{264}$

Whereas underperformance of the authorities may defy any motivation for economic operators that benefit from such performance to challenge the administration in court, the administration's compliance - and awareness on the part of operators that they would not have a case in court - may have the same effect. Airline operators, for example, do complain about SAFA inspection results, but it is said that they simply do not have enough evidence to substantiate an appeal against a decision in court. ${ }^{265}$ Officials claim that this is the case since the authorities "play by the book", ${ }^{266}$ and since operators know that the applicable legislation provides little room for discriminatory treatment given the clear guidelines that exist. ${ }^{267}$

As far as the latter element is concerned, the opposite is true for the area of IPPC, where the vagueness of rules leaves considerable room for diverse interpretations, ${ }^{268}$ and where the administrative discretion granted to authorities facilitates challenges to the way in which the authorities have made use of this discretion. In this case, economic operators may exploit loopholes in the law or challenge the administration's interpretation of legal requirements in order to have the authorities agree on more lenient permit conditions. ${ }^{269}$ Something similar applies to general product safety, where the difficulty of assessing whether a product is 'safe' provides room for operators to challenge the veracity of the administration's risk assessment and risk evaluation and the appropriateness of the corrective measures adopted by it. ${ }^{270}$ An assessment of case law in the areas of IPPC

\footnotetext{
${ }^{259}$ Interview PL13.

${ }^{260}$ Interview NL16; NL23.

${ }^{261}$ Interview NL12; NL10; PL2; PT7.

${ }^{262}$ Interview PL15.

${ }^{263}$ Interview PT16.

${ }^{264}$ Interview NL28.

${ }^{265}$ Interview PT17.

${ }^{266}$ Interview NL29.

${ }^{267}$ Interview NL29; PT17.

${ }^{268}$ See e.g. Section 3.3.2, sub B, below.

${ }^{269}$ On companies that try to negotiate more lenient conditions, see e.g. interview NL21; NL23; NL24; NL25.

${ }^{270}$ On the difficulty of assessing the safety of a product, see Chapter 5 on post-legislative guidance, Section
} 
and GPS shows that operators often try to challenge the standards set by the authority or the product safety evaluation that the authority has arrived at. ${ }^{271}$

\subsubsection{The performance of prejudicial problem-solving mechanisms}

While the existence of actors who are capable of making a credible claim in court - and that see a point in opposing the administration to begin with - is a necessary factor for litigation, it is not sufficient for case law to exist. This is the case, since actors may choose alternative avenues to 'get what they want'. Civil society actors, for example, may choose not to take the conflictual road towards problem resolution, but to act in cooperation with the state instead. ${ }^{272}$ This is true for Polish environmental NGOs, some of which have even been asked by permitting authorities, to help these authorities in the application of the law. ${ }^{273}$ Dutch environmental organisations not only seek to achieve their objectives by going to court, but also by bringing across their viewpoints informally. ${ }^{274}$ Dutch consumer NGOs perceive their role as one of complementing the state, ${ }^{275}$ and Portuguese consumer NGOs claim to support the administration by providing it with information and expertise. ${ }^{276} \mathrm{~A}$ cooperative approach seems strategically logical, when authorities are willing (but unable) to ensure proper implementation, and when the administrative system is open to civil society participation. Cooperation may be effective since 'punishment' may not provide guidance for authorities on how to do things better, ${ }^{277}$ and (and partly related to this), since support may lead to a quicker resolution of problems than opposition.

Business actors may, for a variety of reasons, try to solve disagreements through mechanisms other than litigation. ${ }^{278}$ In order for such other - prejudicial and cooperative - mechanisms to work, at least two conditions must be met. The first is the existence of a culture of cooperation between the administration and business actors. Interviews suggest that the existence of such a culture of cooperation is not evident. Of the three countries included in this study, the Netherlands seems to provide the best example of this. Let us use the area of product safety as an example. Dutch officials of the Netherlands Food and Consumer Product Safety Authority pride their authority on the "compliance assistance approach" that it takes towards economic operators. This approach, which sees compliance as a horizontal rather than a top-down issue, basically

\footnotetext{
3.4.2.

${ }^{271}$ See Sections 3.1.2.1 and 3.1.2.2 below.

${ }^{272}$ See Chapter 7 on civil society, Section 1.1.

${ }^{273}$ See Ibid., Section 3.3.3.

${ }^{274}$ See Ibid., Section 3.3.1.

${ }^{275}$ See Chapter 7 on civil society, Section 3.2.1.

${ }^{276}$ See ibid., Section 3.2.3.

${ }^{277}$ On the inappropriateness of sanctions where noncompliance results from a lack of capacity (and on other methods of enforcing compliance), see Chapter 3 on the approach and methodology of this study, Section 2.

${ }^{278}$ See Section 3.1.1.3 below.
} 
consists of a three-step model towards tackling issues of noncompliance. It puts the emphasis on informing operators about their obligations and, when necessary, persuading them into compliance. It is only when information and persuasion do not work that coercion is resorted to. ${ }^{279}$ In this context, informal discussion between authorities and business actors plays an important role in resolving disputes between them. ${ }^{280}$

While, in the words of an inspector, the Dutch market surveillance authority "tries to solve things with companies instead of looking what exactly the letter of the law says", ${ }^{281}$ the opposite seems to be true for the Portuguese authorities to some extent and for the Polish authorities in particular. For one, Portuguese interviewees from the Food and Economic Safety Authority emphasise their police powers. They indicate that they do not know how authorities in other member states without similar powers can cope with their tasks, and that they themselves "never negotiate": 282

We are a police authority. We arrest. We don't negotiate anything. Either they comply, or they don't. ${ }^{283}$

Their colleagues from DG Consumidor, the authority that is formally responsible for the adoption of measures in relation to operators, indicate that ASAE's public image is indeed that of an "economic police", ${ }^{284}$ which is not stimulating for companies who would like to solve matters informally. Officials from DGC seem to maintain different relations with business operators. They emphasise that relations with businesses are positive, that they appreciate the input of economic operators, and that they cooperate with them in the resolution of problems. ${ }^{285}$ Such cooperation seems particularly appreciated in view of the length of judicial proceedings in Portugal, which - as outlined in Section 1.2.1.1.2, sub $B$ above - is excessive. ${ }^{286}$

While experiences in Portugal seem mixed, the Polish market surveillance authorities appear at the bottom of the list for the possibility of informal, prejudicial problem solving. Interviewees from the regional trade inspectorates claim to "threaten with UOKiK" when companies disagree with the assessment conducted by the inspectorates. ${ }^{287}$ The reluctance of inspectors to engage into a dialogue with operators or their representatives seems to be explained by the notion that these inspectors generally seem afraid to make mistakes and be punished. This fear has earlier been referred to as ex-

\footnotetext{
${ }^{279}$ Interview NL8; NL12.

${ }^{280}$ Interview NL2; NL4.

${ }^{281}$ Interview NL4.

${ }^{282}$ Interview PT2; PT4.

${ }^{283}$ Interview PT4.

${ }^{284}$ Interview PT7.

${ }^{285}$ Interview PT5; PT6; PT7.

${ }^{286}$ See also further below, Section 3.1.1.4.2.

${ }^{287}$ Interview PL3, similar PL4.
} 
plaining why inspectors attach great importance to formal guidance that leaves little room for discretion. ${ }^{288}$

Business operators seem critical of the attitude of UOKiK in particular. This criticism is about the idea that UOKiK does not provide business operators with formal explanations of the law, that it is strict in the application of legal provisions, that companies are seen as enemies, and that it is not interested in agreeing with companies but in starting proceedings instead. ${ }^{289}$ According to an interviewee from UOKiK, however, the authority cannot engage in informal problem resolution for the following reasons:

Firstly, we are obliged to obey the law and the question may arise, 'in which legal form did you carry out this resolution?' We cannot simply give formal guidance and a safety certificate, because we do not have the legal power to do so. Secondly, 'informal negotiations' may have negative connotations as the business operators may charge us for corruption. Therefore, we are quite careful with this. Thirdly, my experience with informal consultations is always bad, as business operators want some kind of official umbrella for their activity that is not completely legal and they want to impose something on us that does not agree with the role that both parties have. Fourthly, business operators only pass this information that is favourable for them, sometimes leaving too much space for guessing on our part. There is no trust towards us. And finally, my feeling about what we agreed upon was often completely different from their feelings on this. So they would say, 'we're ok, UOKiK approved it', but what we said was, 'we have no right to prove or disapprove anything as it is not us, but the business operators, who place the products on the market'. ${ }^{290}$

In other words, business operators are seen as often unreliable and wanting to shift the responsibility for the safety of their products to the authority for informal cooperation to be possible. What underlies these problems is a lack of mutual trust; UOKiK cannot trust the information provided by business operators, and business operators do not trust the authority's intentions. This case once again proves the importance of mutual trust for (informal) cooperation to work; ${ }^{291}$ it shows that without such trust, cooperation is bound to be an ineffective problem-solving mechanism. In this case, the result of this ineffectiveness is that the only way for companies 'to get their right' is by initiating formal proceedings against the authority. It is this reason that may explain, in part, why there is relatively much case law on the administration of general product safety regulations in Poland.

\footnotetext{
${ }^{288}$ See Chapter 5 on post-legislative guidance, Section 3.4.2.

${ }^{289}$ Interview PL7.

${ }^{290}$ Interview PL2.

${ }^{291}$ This notion is identified in Chapter 6 on transnational networks as a key factor for making networks work.
} 
For informal dispute resolution to work, a culture of cooperation based on mutual trust is not sufficient; clear legislative provisions, or at least, converging views on the interpretation of these provisions, are also important. The existence of post-legislative guidance may be an important supportive tool for this. Section 3.1.1 above hints at the importance of the SAFA guidance materials for facilitating agreement on inspection results between civil aviation authorities and business operators. ${ }^{292}$ The RAPEX guidelines in the area of product safety help to narrow the margin of discretion for market surveillance authorities when implementing risk assessments and risk evaluations, and they are appreciated as such. However, in view of the remaining room for subjectivity, ${ }^{293}$ it is not certain that the guidelines have prevented court proceedings. ${ }^{294}$

Preventing court proceedings does not seem to have been an effect of the BREF guidance documents. Given their much criticised vagueness and the leeway that they grant the administration in the setting of emission limit values, ${ }^{295}$ the BREFs must be expected to be of little help in supporting authorities and operators to solve disagreements informally. When they take on a concrete legal meaning in the implementation context - as is the case in the Netherlands - the BREFs are likely to give rise to court proceedings, since here vagueness becomes a problem in particular. ${ }^{296}$ In fact, the use of the BREFs in IPPC permits does appear to be the focus of some court proceedings in the Netherlands, as we see in Section 3.1.2.2.1 below.

\subsubsection{Interests of potential litigants}

The previous sections assume that motivated actors will go to court when they have the capacity to do so and when prejudicial problem-solving mechanisms fail to deliver results. However, business operators and civil society must also have sufficient interest in experiencing possibly lengthy and costly court proceedings. One may expect them to be willing to do so only where the benefits of litigation outweigh the costs. ${ }^{297}$ Cost-benefit considerations may have several dimensions, as the following

$34 \%$ of the IPPC survey respondents agree or strongly agree that court cases regarding the application of BAT in IPPC permits regularly take place in their country. paragraphs clarify.

\footnotetext{
${ }^{292}$ See Chapter 5 on post-legislative guidance for more detail, Section 3.2.2.

${ }^{293}$ And their perception as being non-binding, one may add; see Chapter 5 on post-legislative guidance, Section 3.3.3.

${ }^{294}$ The fact that court cases in the area of product safety do exist, suggests that they are at least not fully successful in this regard.

${ }^{295}$ See Chapter 5 on post-legislative guidance, Section 3.2.2.

${ }^{296}$ See ibid., Section 3.4.1.

${ }^{297}$ See also Tridimas and Tridimas, 2004, on the expectation that private litigations invoke EU law if they expect a net gain, financial or otherwise, from doing so (p. 132ff).
} 
Cost-benefit considerations may have a financial dimension, which consists of the idea that where the monetary costs of litigation are high, high-value cases (that is, cases in which a lot of money is at stake) are more worthwhile to pursue than low-value cases. Concretely speaking, this dimension may explain why an IPPC operator may be willing to exhaust all of the legal possibilities that are open to it; for business operators applying for an IPPC permit, great financial interests are at stake. Such interests relate to the question of whether a planned installation may be constructed, and to the size of the financial investment that is needed for the implementation of the techniques that an IPPC permit requires operators to implement. In the words of a Dutch official involved in environmental licensing processes:

Compared to, for example, product safety, huge interests and enormous amounts of money are involved when it comes to IPPC permitting. That's why we do have a lot of litigation here. There are also a lot of interests connected to this. It is very important for companies to get the most out of the process. ${ }^{298}$

If this is true, the idea that only one-third of the respondents that took part in the IPPC survey confirm that court cases regularly take place in their country seems surprising. Note, however, that Dutch case law focuses on the use of the BREFs in environmental licensing processes; this may be motivated by the fact that the BREFs have a concrete legal meaning in the Netherlands. ${ }^{299}$ When the BREFs are seen as a mere 'help' in the implementation process - rather than as documents that are to be complied with - and authorities take a more casual approach to their application in practice, there may be less of a reason for companies to resort to administrative litigation in an effort to exercise 'damage control'.

Financial interests are not the only interests that mediate the prevalence of case law. While financial interests may weigh heavy, fears of reputational damage may compel companies to relinquish the legal route, at least where public image is important. The latter may not apply to companies that do not particularly pride themselves as environment friendly; for such companies, the visibility of court cases and the reputational damage that litigation may entail is likely to weigh less than the financial benefits that may be gained by challenging an act in court. ${ }^{300}$ It seems, however, rather unwise for 'green companies' to challenge stringent permit conditions in court. Receiving free publicity by appealing a case before a court is certainly not in the interest of airlines that are sanctioned for safety deficits, or of companies that have been found to put unsafe products on the market. Overall, business actors for whom public image is important have an

\footnotetext{
${ }^{298}$ Interview NL24.

${ }^{299}$ See Chapter 5 on post-legislative guidance, Section 3.3.1.

${ }^{300}$ This may be the case in particular where environmental awareness within society is low and the watchdog function of NGOs and citizens is weak, which is the case in Poland and Portugal. See Chapter 7 on civil society, Section 3.3.
} 
interest in solving problems at a maximum discretion, and court proceedings do not seem to be the best strategy in this regard ${ }^{301}$ - unless the potential financial gains are so considerable as to offset potential reputational costs.

The area of air safety may serve as an illustration in this regard. The consequences of a 'bad' SAFA inspection report are generally limited, unless the findings are extraordinarily heavy. ${ }^{302}$ Broadly speaking, these consequences range from the verbal debriefing of findings to the airplane crew, to the adoption of corrective actions by the airline, and finally, the grounding of the aircraft. ${ }^{303}$ Ultimately, airline operators may be subject to an EU-wide operating ban ('black listing'), ${ }^{304}$ or to a territorial operating ban imposed by individual member states. ${ }^{305}$ The latter measure was an issue in the only two (Dutch)

None of the SAFA survey respondents agree that court cases regarding SAFA inspections regularly occur in their country. court cases on SAFA. ${ }^{306}$ It is imaginable that the benefits that the relevant operators could gain by challenging the

respective decision - the lifting of the operating ban and the award of compensation were deemed to outweigh the reputational damage that could be incurred by the airlines. Otherwise, court cases seem to be few, or at least that is what Section 2.1 of this chapter and the survey results, which are shown elsewhere in this subsection, suggest is the case. The fact that operators have an interest in solving issues discretely is likely the most important variable accounting for this result. However, other factors - for example, the absence of civil society activism in this area, or, for airlines, favourable performances of civil aviation authorities in individual countries - might be explanatory as well.

\subsubsection{Rules for access to justice}

While they help to explain the presence of case law in the three countries and in the three policy domains included in this study, the intertwinement of the factors discussed above cannot fully account for the varying prevalence of case law observed in Section 2.1 of this chapter. Next to the extra-legal factors that have been discussed, legal factors must be considered important for explaining the prevalence of litigation as well. These legal factors broadly concern national procedural rules for access to justice and judicial remedies, which are discussed in Section 1.2.1 above. This section identifies those fac-

\footnotetext{
${ }^{301}$ Interview PL15; PT6; PT17; NL12.

${ }^{302}$ Interview NL27.

${ }^{303}$ Directive 2004/36/EC, Annex II, point 6; also Directive 2004/36/EC, Article 7.

${ }^{304}$ Regulation (EC) 2111/2005 of the European Parliament and of the Council of 14 December on the establishment of a Community list of air carriers subject to an operating ban within the Community and on informing air transport passengers of the identity of the operating air carrier, and repealing Article 9 of Directive 2004/36/EC [2005] OJ L 344/15.

${ }^{305}$ Regulation (EC) 2111/2005, Art. 6.

${ }^{306}$ For a discussion, see Section 3.1.2.3 below.
} 
tors that interviewees indicate are particularly important for mediating the prevalence of case law that is relevant to this study.

\subsection{Standing}

Section 1.2.1.1.1 has clarified that rules for standing differ across member states. Relevant to this study, is that these rules are most liberal in Portugal and least generous in Poland. The legal system of the Netherlands finds itself in between these two extremes, although there is an increasing tendency to narrow access to the administrative court. This tendency concerns non-governmental organisations in particular, whose qualification as interested parties, since recently, depends not only on their statutory goals, but also on the nature of their activities. Note that Dutch environmental NGOs had already suffered because of the abolishment of the actio popularis principle, which formerly existed in the area of environmental and planning law, until approximately ten years ago. In combination with this fact, the strengthening of rules on standing can be seen as a fast deterioration of standing opportunities for environmental NGOs in the Netherlands.

Limitations regarding standing are referred to as problematic by Polish interviewees as well, although here citizens seem to experience most problems in this regard. A representative from an environmental organisation highlights that the centrality of the concept of ownership in the Polish approach to standing is problematic for citizens, since it restricts access to the court to a limited class of citizens. Moreover, it creates extra work for environmental NGOs. The following quotation illustrates both problems:

The neighbours whose parcel is not directly linked to a farm will not automatically be informed of the installation, because they are not a party in the proceedings. According to the law, they are not neighbours. Even if they want to be involved and ask for this, the commune can refuse them. With NGOs the situation is different, since our constitution says that being a party in such proceedings is a normal part of our work and that we do that just for pro bono publico. And that makes that we can become a party of such proceedings at any stage. Very often we use this privileged position and we try to help these neighbours, because they can then participate in the process through us. It is very complicated and I am not very happy about it. Because it is extra work. We get cases from the whole of Poland. For example, when the case is in Malopolska or wherever, for me it is impossible to go there and visit the place. So we are just officially there. But all of the documents - and this is very important 
for me - are going to us. It is extra work; I have to check all of these documents sent by these people and then re-send them to the commune office. ${ }^{307}$

These issues do not play a role in Portugal, where standing rules are, as we have seen, lenient. This is the case not only because everyone may, by virtue of the actio popularis principle, start legal proceedings in relation to certain issues, but also because of the wide standing rules in cases pursued under other procedures. In view of this leniency, one would expect litigation to be a popular dispute-resolution tool for Portuguese citizens and NGOs. Reality does, however, prove such expectations incorrect. The following factors seem to explain the mismatch between expectations and reality.

\subsection{Length of proceedings}

The first of these factors relates to the duration of judicial proceedings. Portuguese officials indicate that the courts are overloaded with work, and that the length of proceedings poses a hurdle for societal actors to engage in litigation:

The general perception of the functioning of the judicial system in Portugal is extremely negative, meaning that you would only go to court to get leverage to preferably settle out-of-court. Actually threatening somebody to take him or her to court is an added reason for you to settle. Because the courts are overloaded with pending cases, and therefore work in a very slow way. Obviously there are a lot of exceptions, but the system is perceived as being very, very heavy, and working very, very slowly. So that is always an issue, whenever we talk about case law, in any area. ${ }^{308}$

The idea that the length of proceedings in Portugal is excessive has come to the fore previously in this Chapter; Section 1.2.1.1.2, sub B, indicates that the average duration of court proceedings in Portugal is a staggering 29 months. While it is possible that the length of court proceedings is an issue that withholds actors from engaging in litigation more generally - court proceedings do not, in the majority of cases offer quick solutions to disputes $-{ }^{309}$ Dutch and Polish officials do not explicitly refer to this issue as a great barrier for persons to engage in litigation. Here, it is in combination with the financial gain that actors forsake by entering into court proceedings - instead of earning money by immediately agreeing with the requirements imposed by the administration - that the length of proceedings seems to prevent actors from engaging in litigation. ${ }^{310}$

\footnotetext{
${ }^{307}$ Interview PL13.

${ }^{308}$ Interview PT7; on the length of proceedings, also PT6; PT10.

${ }^{309}$ E.g. interview PL2.

${ }^{310}$ For this issue, see Section 3.1.2.2.1 below.
} 


\subsection{Costs}

Present in both Polish and Portuguese interviews is the idea that litigation is relatively expensive. Section 1.2.1.1.3 shows that measured against GDP, court fees in both countries are relatively high compared to the fees that apply to the Netherlands - at least where the value of the case can be measured, and in particular for cases with a higher value. The following example may serve as an illustration in this regard. While an applicant for an IPPC permit with a value of one million euros in the Netherlands would be required to pay $€ 328$ for first instance court proceedings, the same applicant would need to pay $€ 10,000$ in Poland and at least $€ 5,253$ (but up to $€ 15,759$ ) in Portugal. For cases with a lower value, the differences are less considerable, but they are still pronounced. This leads one to expect that economic operators in Poland and Portugal that are not sure of their case, may tend to resort to the court less often than operators in the Netherlands; financially speaking, the former have more to lose. The notion that Portuguese claimants who lose court proceedings are liable to pay the costs incurred by the winning authority adds to the risks that Portuguese operators face when engaging in court proceedings.

What applies to business operators, applies to civil society actors as well. A representative from a Dutch environmental NGO refers to the then planned (but eventually not implemented) increases in court fees that were set to make litigation more costly, and thus more difficult for civil society. ${ }^{311}$ Court fees in the Netherlands are, however, still relatively affordable in comparison to those that Polish citizens and NGOs, and Portuguese citizens must pay. ${ }^{312} \mathrm{~A}$ representative from a Portuguese environmental NGO indicates that court cases are generally rare, "since it costs too much and you never know the result". ${ }^{313}$ Similar considerations apply to Poland, as the quotation below illustrates:

Litigation is possible, for some at least. But you need to be very, very determined. Those people that I just told you about were very assertive; they just got married and they had a little child and this farm was very problematic. They had good jobs, and they could pay for a lawyer, and it was possible for them to go to court. But if you are just a normal person living in the village you cannot even defend your family. So this is a problem. ${ }^{314}$

Overall, only in cases where the value cannot be measured (and possibly in low-value cases) may Portuguese and Polish claimants have an edge over Dutch citizens and or-

\footnotetext{
${ }^{311}$ Interview NL19.

${ }^{312}$ Note that Portuguese environmental NGOs are exempted from court fees as long as they act in good faith; see Section 1.2.1.1.3, sub A, sub b.

${ }^{313}$ Interview PT13; also PT10.

${ }^{314}$ Interview PL13.
} 
ganisations. This edge quickly disappears where measurable cases are concerned; ${ }^{315}$ in such cases, court fees may be seen as hindering access to justice for the less privileged, as the above quotations suggest.

\subsection{Remedies}

While rules for access to justice significantly influence the extent to which actors engage in court proceedings, prior expectations of these actors as to the outcome of such proceedings appear to mediate the prevalence of jurisprudence as well. Judicial remedies thus, not only reflect the usefulness of existing rulings; they also indicate the likelihood of actors resorting to litigation in the first place. The following subsections focus on two issues that interviewees suggest are particularly relevant in this regard.

\section{A. Expertise of judges}

One issue that comes to the fore as a factor that mediates the amount of case law in the areas of general product safety and integrated pollution prevention and control is the lack of expertise on the part of judges in these domains. An interviewee in the area of general product safety puts the problem bluntly:

The courts understand nothing at all. They are lawyers, you know. ${ }^{316}$

The perceived lack of expertise of judges in the areas of product safety and integrated pollution prevention and control is experienced as focusing courts on procedural issues rather than on the merits of the case. ${ }^{317}$ The consequences of this focus regarding the probability of litigation taking place are ambiguous. Dutch interviewees in the area of product safety indicate that since the issue that is central to the dispute is not solved which is why "no one is helped with case law anyway" 318 - case law is resorted to only if all other possibilities are exhaust-

$25 \%$ of the GPS survey respondents agree that court cases on market surveillance for GPS products take place regularly in their country. ed. Note that Dutch case law in the area of product safety does not exist. In Poland, on the other hand, companies are said to eagerly exploit the lack of expertise on the part of judges by using court proceedings to challenge the administration's compliance with procedural rules. It seems that in this case, the lack of expertise may have led to more court cases.

The opposite pattern was observed for Dutch case law in the area of integrated pollution prevention and control. Here, the notion that Dutch judges may resort to out-

\footnotetext{
${ }^{315}$ Apart from for Portuguese environmental NGOs; see note 312 above.

${ }^{316}$ Interview PT4.

${ }^{317}$ See Section 3.1.2 below.

${ }^{318}$ Interview NL2.
} 
of-court expertise is said to contribute to the relatively great number of court proceedings on IPPC in the Netherlands. ${ }^{319}$ The lack of case law on IPPC permit conditions in Portugal, on the other hand, might be explained by a lack of expertise on the part of judges on the technicalities of IPPC permits, in combination with the fact that out-ofcourt experts are rarely consulted. ${ }^{320}$ This may be the case for Poland as well. ${ }^{321}$ Note that issues of expertise do not come to the fore in interviews with officials in the area of air safety.

\section{B. Relativiteitsvereiste}

As stated above, a relatively recent addition to the Dutch General Administrative Law Act concerns the rule that judges do not quash a decision if this decision violates norms that do not serve to protect the interests of the claimants (relativiteitsvereiste). ${ }^{322}$ While some have argued that the introduction of this principle would counter misuse by claimants of judicial protection procedures, others have pointed out principled and practical concerns regarding its implementation. ${ }^{323}$ The alleged adverse consequences for NGOs that want to use court proceedings as instruments to enforce compliance with the law on the part of the administration are shown in the following excerpt from an interview with a representative from an environmental NGO:

What if NGOs want to make a case against a decision that concerns antibiotics in livestock farming? NGOs can then be left out, since the judge can say that antibiotics are maybe not an environmental issue, but a health issue or something like that. ${ }^{324}$

This sort of consequence not only applies to NGOs; it applies to claimants in general. Whether these consequences have significantly affected the work of environmental NGOs in the Netherlands - as the above quotation seems to suggest - has not yet been studied. One may argue that, since environmental organisations defend the environmental interest - and the relativiteitsvereiste does not subject them to any limitations in this regard - the extent to which such organisations are hindered in their work may be expected to be small.

\footnotetext{
${ }^{319}$ Interview NL24.

${ }^{320}$ Interview PT10.

${ }^{321}$ See Section 3.1.2.2.2 below.

${ }^{322}$ See Section 1.2.1.2, sub B.

${ }^{323}$ Commissie Scheltema, 2007.

${ }^{324}$ Interview NL19.
} 


\subsubsection{Litigation culture}

Finally, even when the characteristics of the issues discussed in the previous sections are in favour of litigation, the intangibles of culture may decrease the amount of litigation. This is certainly the case in Portugal, as the following quotation testifies:

That we have low levels of litigation is not only a question of costs or time. It is also a question of tradition. Since 1995 we have had an interesting representative action - actio popularis - equivalent to a class action. I have received scholars from a lot of countries in the world who are doing studies comparing the possibilities for representative actions in the EU. And they always come to Portugal, because we have this almost perfect law that seems very favourable for consumer associations to actually launch actions, and nobody can understand why there are so few court cases, in particular for compensatory redress. It is not just a question of costs, or of not having privileged legal standing, so to speak, it is also a cultural question... If you are a consumer association you may have key principles and a set of cases to stand for. But if you are a consumer, it's different; I think you don't see it that way. And I think in a way you can apply this to product safety. ${ }^{325}$

In addition, Polish society does not seem litigious; in terms of relative numbers of pending cases in the area of administrative law, Poland ranks seventeenth out of the nineteen EU member states for which data are available. ${ }^{326}$ That some areas may be more litigious than others - or at least, that subjective perceptions may not concur with the picture arising from objective (aggregated) data - becomes clear from an interview with an official from UOKiK, who perceives the area of product safety as litigious:

I can assess this also from our experience, as in some cases even when the party won in second instance and the first instance decision was quashed, they go to the court and lodge a plea. Why? 'Because it is possible'; as there was a legal notice on the possibility of going to the court. And so they did it! ${ }^{327}$

\footnotetext{
${ }^{325}$ Interview PT7. On the fact that citizens are not assertive enough 'to go get their right', see also interview PT13.

${ }^{326}$ Communication from the Commission to the European Parliament, the Council, the European Central Bank, the European Economic and Social Committee and the Committee of the Regions, The 2014 EU Justice Scoreboard, COM (2014) 155 final, p. 13. Note that data are available for nineteen countries. Also note that figures for Portugal are not available. In 2013, 75,372 case were lodged before an administrative court in Poland; see Supreme Administrative Court, http://www.nsa.gov.pl/index.php/pol/Media/Files/roczna-17.

${ }^{327}$ Interview PL2.
} 
The Netherlands, finally, enters the picture as rather litigious compared to Poland (and undoubtedly compared to Portugal too); ${ }^{328}$ the country ranks seventh out of the nineteen countries for which data are available. ${ }^{329}$ Note that the Netherlands was formerly known for its low administrative litigation rates; statistics show a steady increase in administrative litigation between 2000 and 2012, during which the number of administrative cases doubled. ${ }^{330}$ The fact that the increased administrative litigation is not felt in the domain of product safety (and in the area of air safety, for that matter) could be explained by the factors that are discussed above.

\subsubsection{Synthesis}

The above paragraphs discuss the legal and extra-legal factors that interviewees indicate are particularly important for mediating the prevalence of case law in their countries and in their policy domains. Note that these factors have explanatory power only in combination with one another. For example, Portugal may have liberal standing rules for NGOs and litigation may in some cases be free of charge, but the absence of a true litigation culture is an important factor preventing actors from going to court. Standing rules for environmental NGOs in Poland may be liberal too, but capacity problems inhibit many organisations from actually enjoying their rights. And while standing opportunities for environmental NGOs in the Netherlands tend to become more limited, NGOs still go to court more often than environmental organisations in Poland and Portugal, because they possess the resources to do so.

This section shows that case law cannot always be relied on as a compliance instrument and explains why this is the case; it also demonstrates that, similar to the case for civil society, case law cannot simply be conjured up. As the creation of nongovernmental organisations alone cannot make for a flourishing civil society, the establishment of legal and practical tools that facilitate access to the court only cannot make case law a popularly-used dispute-resolution mechanism. For case law to be such a mechanism, another condition must be met, and that condition is a culture that is receptive to litigation. If such a culture is lacking, litigation is bound to be limited, and with it the potential of case law as a compliance instrument. ${ }^{331}$

\subsubsection{The usefulness of national case law}

While the discussion in the foregoing section attempts to explain the prevalence of case law across countries and across policy domains, the current section turns to a discussion of the usefulness of the national jurisprudence that Section 2.1 finds relevant to this

\footnotetext{
${ }^{328}$ Note that the Commission's EU Justice Scoreboard does not include any data on Portugal in this regard.

${ }^{329}$ Commission, 'The 2014 EU Justice Scoreboard' (Communication) COM (2014) 155 final, p. 13.

${ }^{330}$ Centraal Bureau voor de Statistiek, 'Bestuursrecht: procedures bij rechtbanken', <http://statline.cbs.nl $>$.

${ }^{331}$ Of course, little case law may deliver great insights. Thus, the usefulness of case law might be much higher if more cases were to exist.
} 
study. Section 3.1.2.1 discusses the usefulness of case law concerning market surveillance in the area of general product safety; Section 3.1.2.2 deals with case law on the application of BAT in IPPC permits; and Section 3.1.2.3 completes the discussion by addressing case law on SAFA inspections. In order to frame the discussion, each section starts with a succinct analysis of the contents of the case law, before it analyses its usefulness.

\subsubsection{The GPS Directive}

In the area of product safety, case law is only present in Poland. Possible reasons for the contrast with Portugal and the Netherlands in this regard are elaborated on in Section 3.1.1 above. Note that case law in the area of product safety does not seem prevalent in other countries either; as stated previously, only a quarter of the respondents to the survey that was circulated for this study agree that court proceedings on market surveil-

$65 \%$ of the GPS survey respondents agree (or sometimes strongly agree) that case law is helpful, and $50 \%$ agree (or sometimes strongly agree) that case law addresses the relevant questions. lance for products covered by the GPS Directive regularly occur in their country. Also note that approximately twothirds of these respondents indicate that case law is useful, and that about half of them agree that case law addresses the questions that are relevant to supporting the market surveillance authorities in the application process. Unfortunately, the survey does not permit conclusions to be drawn about the reasons underlying such evaluations.

The following subsection elaborates on the usefulness of case law for Polish officials involved in the application of general product safety regulations. In order to situate the perceptions of these officials, it first outlines the contents of the case law and then offers insight into the extent to which this case law is regarded as useful for supporting officials in their work.

\subsection{Poland}

\section{A. Contents}

Analysis suggests that there are two strands of case law on the administration of the General Product Safety Act (GPSA), ${ }^{332}$ which implements the GPS Directive in Poland. The first strand concerns administrative sanctions imposed on business operators for noncompliance with the general product safety requirement or with other provisions outlined in the GPSA. ${ }^{333}$ Since this study does not focus on whether or not authorities

\footnotetext{
${ }^{332}$ O ogólnym bezpieczeństwie produktó, Ustawa z dnia 12 grudnia 2003 [2003] Dz.U. 229/2275, as amended.

${ }^{333}$ Cases that are at least partly about the imposition of a fine: VI SA/Wa 3522/13, judgement of 3 April 2014; VI SA/Wa 1229/09, judgement of 26 January 2010, and II GSK 881/10, judgement of 7 September 2011; VI SA/Wa 1391/11, judgement of 10 November 2011, and II GSK 936/12, judgement of 22 October 2013; VI SA/Wa 2423/10, judgement of 8 February 2011 and II GSK 1416/11, judgement of 17 October 2012; VI
} 
comply with rules on the imposition of sanctions, ${ }^{334}$ this strand of jurisprudence is not directly relevant to the context of this study. Rather, our interest lies in a second strand of jurisprudence, which concerns the administration's compliance with rules on investigative and corrective measures that are outlined in general product safety regulations. Note that the two strands are not always easy to disentangle; questions on the legality of the safety evaluation conducted by UOKiK, or the corrective measures adopted by it may be present in cases that deal with the legality of sanctions imposed on economic operators. If cases of the latter type include an evaluation of provisions on investigative and corrective measures, they are included in the analysis below.

Case law analysis suggests that courts emphasise the authority's compliance with applicable procedural rules. An example is a case concerning the safety of a product that inspectors, based on an organoleptic test, evaluated as unsafe because it could be mistaken for a food product. The court restated the applicable legislation and then posited that the authority failed to explain whether and why the consumption of the product causes a threat to "the health and life of human beings", whereas such "is an essential prerequisite for considering a product to be safe or dangerous". The court considered that UOKiK was entitled to resort to an expert but failed to, and that in the reexamination of the case it should consider, "first of all, whether and what kind of [food product] [the products] represent, whether and why their consumption may cause a threat to the health or life of people; and whether these products are safe or dangerous". It also said that a hearing did not need to be held for this purpose. ${ }^{335}$ In this case, the court clearly applied a 'hands-off approach' by looking into the procedural aspects of the case, as it had done in a number of other cases. ${ }^{336}$

In a number of cases, the court did (also) 'dive into' the substantive legislative provisions relevant to the context of the case at hand. In most of these cases, the court sided with the authority and accused the business operator. One such case concerned the classification of products - an important issue, since the classification of a product determines which standards are appropriate for the safety assessment. Relevant to this case was that the court maintained that it is not the declaration of the manufacturer of the

\footnotetext{
SA/Wa 2414/10, judgement of 4 February 2011, and I GSK 1404/11, judgement of 16 October 2011; VI SA/Wa 1967/10, judgement of 23 December 2010; VI SA/Wa 58/10, judgement of 8 April 2010, and II GSK 1089/10, judgement of 18 October 2011; II GSK 2062/09, judgement of 2 March 2010, and II GSK 882/10, judgement of 29 September 2011; VI SA/Wa 1855/09, judgement of 13 January 2010; VI SA/Wa 1603/0, judgement of 6 October 2008.

${ }^{334}$ See Chapter 3 on approach and methodology, Section 4.1.1.1.

${ }^{335}$ II GSK 882/10, judgement of 29 September 2011 (in conjunction with VI SA / Wa 2062/09, judgement of 2 March 2010, and VI SA / Wa 2390/11, judgement of 6 February 2012).

${ }^{336}$ E.g. case VI SA/Wa 1855/09, judgement of 13 January 2010; VI SA/Wa 1902/07, judgement of 21 February 2008 (in conjunction with VI SA/Wa 1714/06, judgement of 17 January 2007); VI SA/Wa 2073/07, judgement of.21 February 2008.
} 
nature of the product, but the appearance of the product and its purpose, that should determine the classification of the product. ${ }^{337}$

In another case on standards, the question was about which product standard applied: the standard that was adopted after the product was put on the market, or the standard that was previously in force. The court did not decide on the applicability of the standards; it stated that regardless of which standard was applicable, the product was unsafe since, while it did not comply with the current standard, it did not comply with the (stricter) previous standard either. The court also ruled that the company's claim that it had accidentally put a detective batch of products on the market did not reduce its liability as a producer; it argued that since the company had not indicated the specific batch of allegedly accidentally defective products, the negative lab test result applied to all products on the market. ${ }^{338}$ One may argue that while this judgement solved the dispute at stake, it did not clarify the questions that underlie the dispute, namely those on the applicability of standards. Indeed, it may have been helpful if the court had reviewed the legal rules on the applicability of standards and provided clarity through a legal interpretation about which rules apply to what situations.

Business operators often challenge the validity of the evidence underlying the administrative decision. In one such case, the court confirmed that the authority could come to the conclusion that the product was not safe by relying on lab tests indicating that the product poses a health threat. ${ }^{339}$ The same was maintained in another case, in which the court indicated that the authority was not required to consult an additional expert, which was requested by the company. In this case, the court also confirmed the authority's interpretation of 'manufacturer' ${ }^{340}$ Both these cases clearly undermine attempts of economic operators to have administrative decisions quashed on the basis of arguments that invalidate the evidence presented by the authority, and that challenge their own responsibilities as business operators.

The responsibilities of business operators also were confirmed in a case where a company argued that it could not execute the order of UOKiK to withdraw products from the market, as it could not identify the buyers of the products. The court stated that withdrawal had to be possible, since an operator introducing products to the market should take diligent action to avoid all hazards, and "an element of due diligence is undoubtedly to maintain business files that identify the recipient of the particular type and model of the goods placed on the market". ${ }^{341}$

In another case, the court addressed the more conceptual question of what constitutes a 'safe product'. The court first made a distinction between the notion of 'danger-

\footnotetext{
${ }^{337}$ II GSK 936/12, judgement of 22 October 2013 (in conjunction with VI SA/Wa 1391/11, judgement of 10 November 2011).

${ }^{338}$ VI SA/Wa 2414/10, judgement of 4 February 2011.

${ }^{339}$ VI SA/Wa 58/10, judgement of 8 April 2010.

${ }^{340}$ VI SA/Wa 1855/09, judgement of 13 January 2010.

${ }^{341}$ II GSK 1089/10, judgement of 18 October 2011.
} 
ous product' and the idea of 'a product that does not meet the safety requirement'. It maintained that the concept of a product not being 'safe' is broader than the idea of 'a product that does not meet the safety requirement'. In other words, a product that does meet the general safety requirement may be unsafe. At the same time, the court said that one could not talk about 'degrees of noncompliance' with the general safety requirement: a product is safe or it is not. ${ }^{342}$ This evaluation quashes attempts of business operators to avoid the imposition of (high) fines by arguing that their product is 'not entirely unsafe', and it may be useful for the authority in the justification of corrective measures.

The only case that resulted in a clear victory for market operators was one that disputed whether the trade inspectors could rely on organoleptic testing only while carrying out a safety assessment for a certain product. The court agreed with the economic operator and stated that where product standards exist, organoleptic tests or the experience of inspectors cannot substantiate a conclusion that the product is unsafe. In such cases, the safety of the product should be assessed using the test methods outlined in the relevant standard, and the authority must, on that basis, rule whether the product is safe or not. ${ }^{343}$ In view of the fact that it imposes strict requirements for the authority when assessing the safety of products, this ruling has been referred to as a "breakthrough ruling". ${ }^{344}$

\section{B. Usefulness}

In relation to the usefulness of national case law, two findings seem important: that court rulings do not need to be 'world changing' to be useful, and that most rulings are regarded as far from that. This section elaborates on whom court rulings are useful for, why this is the case, and how and why the problem-solving potential of jurisprudence in terms of clarification of substantive issues is limited.

The fact that court proceedings exclusively involve UOKiK - rather than the trade inspectorates ${ }^{345}$ - as the party representing the state does not mean that jurisprudence in the area of general product safety is relevant only for the former. According to an interviewee, the cases are significant to both UOKiK and the trade inspectorates, since, "even though UOKiK is more connected to the court case as we [UOKiK] lodge the claim, the inspectorates are interested in how the case was resolved, as it sometimes affects their day-to-day routine as well". ${ }^{446}$ Moreover, this same interviewee indicates that court

\footnotetext{
${ }^{342}$ VI SA/Wa 2423/10, judgement of 8 February 2011. Similar VI SA/Wa 2073/07, judgement of 21 February 2008

${ }^{343}$ II GSK 881/10, judgement of 7 September 2011 (in conjunction with VI SA/Wa 1229/09, judgement of 26 January 2010, and VI SA/Wa 2183/11, judgement of 24 January 2012).

${ }^{344}$ Interview PL2.

${ }^{345}$ One of the reasons for the absence of case law involving the trade inspectorates is that the tasks of the inspectorates are quite limited; it is not for the trade inspectorates, but for UOKiK, to decide whether products are safe or not.

${ }^{346}$ Interview PL2.
} 
rulings are covered in guidelines and training programmes for inspectors, ${ }^{347}$ which means that such rulings are meant to have a direct impact on the work of the trade inspectorates.

When asked whether court rulings might be useful for them, trade inspectors indicate that they solve issues with uncooperative companies by "threatening with UOKiK" and that they have not faced complicated issues that would merit judicial review. ${ }^{348}$ Inspectors also indicate that in cases where they are confronted with unclear legislative provisions, UOKiK provides interpretations that are, by inspectors, seen as authoritative. ${ }^{349}$ While such interpretations are, as suggested above, partly based on jurisprudence, trade inspectors indicate that they are not familiar with any court rulings in the area of general product safety. ${ }^{350}$ It is unclear why this is the case; a reading of guidelines issued by UOKiK proves that such guidelines do, in fact, explain and refer to court rulings. ${ }^{351}$

Interviewees indicate that case law does not always clarify the underlying questions; an issue that the case law analysis reported above hints at. A number of factors seem explanatory in this regard. The first relates to knowledge limitations of judges when evaluating the substantive questions at stake, for example whether a safety assessment is valid or not. These knowledge limitations are derived from the idea that "the court is as wise as the evidence is". ${ }^{352}$ Unless the balance is clearly in favour of UOKiK - for example because the product safety tests submitted by the manufacturer are blatantly suspicious - courts have a difficult time determining which party is correct and, therefore, whether the disputed product is safe (as the manufacturer would argue) or unsafe (as UOKiK would submit). As a result, it is only when the court resorts to an external expert to verify the validity of the product tests submitted by the company and the authority that a decision in favour of one or the other party is made. ${ }^{353}$ This does not happen often, since when possible judges will choose to close the case on the basis of procedural arguments to avoid exploring the issue further. This emphasis on the authority's compliance with procedural rules does not elucidate what is truly important; that is, the compliance of the authority with the substantive provisions of the General Product Safety Act.

Second, this lack of expertise creates spin-offs that further deteriorate the problemsolving potential of jurisprudence (and, one may argue, the trust in courts as disputeresolution institutions). One of them is that UOKiK tries to solve things by resorting to impartial experts from technological institutes or other bodies - in order for such ex-

\footnotetext{
${ }^{347}$ Interview PL2.

${ }^{348}$ Interview PL3.

${ }^{349}$ Ibid. The importance that inspectors attach to formal guidance is also identified in Chapter 5 on postlegislative guidance; see Chapter 5 on post-legislative guidance, Section 3.4.2.

${ }^{350}$ Interview PL3; PL4; PL5.

${ }^{351}$ See e.g. Nawrocki, 2011.

${ }^{352}$ Interview PL2.

${ }^{353}$ Interview PL2. This expert is appointed by the court and may, for example, work for a technological institute.
} 
perts to review the validity of product tests - rather than to a court. ${ }^{354}$ Note that since such an exercise pre-empts court judgements that might clarify the obligations of businesses and of the administration - and that are certain to do so authoritatively - it is bound to provide an indefinite solution to issues that are encountered in the implementation process. Another spin-off is that business operators realise that it is beneficial to get the courts ruling in their favour by systematically undermining the authority's compliance with procedural rules:

There's quite a popular trick on the part of business operators: if they cannot undermine the test result, they undermine the procedure and the court will rule in favour of them, since it will be more familiar with the procedure than with the test result. The judges do by definition not understand the essentials of the case, so it is far more complicated for them to quash the case from the substantive side. And when procedural shortcomings are detected, the whole case goes to the dustbin, so operators use it. ${ }^{355}$

As a result, the issue that led to the proceedings is not solved, either because court proceedings are avoided altogether, or because the courts focus on the procedural side of the case. This links to a third factor; namely, the idea that the courts do not only focus on procedures, they are in fact "very strict on procedures". ${ }^{356}$ Officials' concerns in relation to this issue are expressed in the following excerpt from an interview with an official from UOKiK:

I remember the courts were undermining several issues when they were not totally familiar with the facts and they didn't care about the factual situation. They did care if the article was fulfilled and if the other party was present and so on. I think the courts are just lacking the general knowledge of the construction of products, but they don't need this knowledge at all, since they are courts of law. Where there is no lab, no test report, or the lab is not accredited - that is the only source for the court. They just want to cover for themselves: No test report? No lab? Go home! ${ }^{357}$

A fourth and final factor that is referred to as playing a role in case law is that courts are "generally hesitant, not clear-cut, and perhaps very reserved in far-reaching opinions"; it

\footnotetext{
${ }^{354}$ Interview PL2. Note that this scenario differs from the scenario outlined in Section 3.1.1.2 above, which involves informal cooperation between business actors and UOKiK only (that is, without the involvement of an impartial expert).

${ }^{355} \mathrm{Ibid}$.

${ }^{356}$ Ibid.

${ }^{357}$ Interview PL2.
} 
is said that "because judges do not really provide bold interpretations that help us to act in relation to business operators, rulings do not really solve the issue". ${ }^{358}$

Note that the above remarks on the role of case law may, at first glance, seem rather paradoxical in view of the earlier referred-to relevance of court rulings for UOKiK. This paradox is solved if one considers the fact that there are some cases that have been useful for solving substantive issues, and that court rulings may be used to draft guidelines for business actors since "at least judgements are not undermined by operators". ${ }^{359}$ In a country where business operators try to exploit the courts' lack of knowledge by challenging everything - from material issues to procedural rules - even court rulings that seem unenlightened may be useful as reference points for the state in interactions with business operators. In other words, however enlightening or unenlightening they are, court rulings make life easier for the authorities in charge of the implementation of general product safety rules.

One final remark should be made at this point. While the 'products' of rulings may be easily incorporated into guidelines, their implementation in the day-to-day administration of the law may not be that easy. This is the case for rulings that, however clarifying they may be, require the channelling of additional (financial) resources to market surveillance activities. In concrete terms, while the "break-through ruling" discussed above may have been useful for the elucidating effect that it has had, the fact that the administration is now, in many cases, required to carry out lab tests to prove that products are unsafe is problematic in view of the scarce financial resources available to the authority. In the words of an interviewee:

Sometimes it is possible to ask a state lab, and this lab will do it for free for us. But then there is the counterargument of the market operator, who says, 'sorry, but I don't think it is reliable, because...' There is always this specific hesitation, also from our side - from the beginning we know that the operator might object to this testing. And he is right, so to say, but we cannot afford to do anything else, since we don't have the money. We are quite open about this. What we can do is the visual check and that's it. We may ask the producer to come to us with counterevidence and then we can assess the evidence. I remember that if we had two counter-opinions, and they had totally different outcomes, and we were to make a decision if the product is safe, what we did was not to make a check of the product itself, since it was too expensive, but to hire an expert to compare the two tests. And then we rely on the expert opinion. We are trying; we are doing our best. ${ }^{360}$

\footnotetext{
${ }^{358}$ Interview PL2.

${ }^{359}$ Interview PL2.

${ }^{360}$ Interview PL2.
} 
In other words, when the - otherwise valuable - lessons learned from court rulings are not easily implementable in practice, it is questionable how useful these rulings actually are. Rulings that require the administration to do something that it cannot practically do may hinder rather than support the administration in its efforts to ensure that policy objectives - in this case, the protection of consumer safety - are achieved, since the administration may have to see how potentially unsafe products are marketed as safe.

\subsubsection{The IPPC Directive}

Section 2.1 shows that case law on the application of the best available techniques (BAT) in IPPC permits is only present in the Netherlands and in Poland. From Section 3.1.1, one may recall that the results of the survey that was circulated for this study suggest that case law on this issue is not prevalent; only about one third of the survey respondents agrees, or strongly agrees, that court cases on the application of BAT in IPPC permits regularly take place in their country. The survey results also show that over half of the respondents agree that case law is useful, and that nearly half of them agree that case law addresses questions that are relevant to supporting their authority in the application of BAT in permits for IPPC instal-

$55 \%$ of the IPPC survey respondents agree (or sometimes strongly agree) that this case law is helpful, and $48 \%$ agree (or sometimes strongly agree) that case law addresses relevant questions. These percentages are somewhat higher for permit writers.

lations. While the survey results suggest that national case law addresses a variety of issues, they do not allow insight into the precise extent that this case law revolves around the application of BAT in IPPC permits.

The following subsections elaborate on the contents of the Dutch and Polish case law that is relevant to this study, and on the perceptions of national officials regarding the usefulness of this case law for supporting the application of BAT in IPPC permits. Note that for the discussion on the contents of Dutch case law, the (rather abundant) literature on this jurisprudence has served as a starting point. Also note that the discussion in the Polish section is limited to case law delivered by the Supreme Administrative Court and by the first instance courts in the regions that were visited for this research. ${ }^{361}$ The possibility that important case law was missed seems unlikely in view of the fact that significant cases would, in all likeliness, have made it to the Supreme Administrative Court. Moreover, if cases from other courts were important, interviewees would have referred to these cases, and this did not happen. Finally, the following analysis only considers case law delivered under the IPPC regime, which was in force until January 2013. Jurisprudence issued following entry into force of the Industrial Emissions Directive falls outside of the scope of this study.

\footnotetext{
${ }^{361}$ Note that a similar concept does not apply to our case law analysis in the area of GPS; here, case law was limited to jurisprudence issued by the administrative court in Warsaw.
} 


\subsubsection{The Netherlands}

\section{A. Contents}

In order to understand the contents of case law delivered by Dutch courts, one must know that Dutch legislation takes a rather strict approach towards the application of the best available techniques in permits for IPPC installations. ${ }^{362}$ The law stipulates that "at least" BAT must be applied, which means that a balancing act involving the technical characteristics of the installation concerned, its geographical location, and the local environmental conditions may not lead to emission limit values that are more lenient than those achievable by BAT. ${ }^{363}$ In other words, and unlike other member states, BAT is the absolute minimum requirement for Dutch IPPC permits.

While it is questionable whether this rather strict approach conforms to the guiding philosophy of the IPPC Directive that a high level of protection for the environment "as a whole" must be achieved, ${ }^{364}$ Dutch judges have consistently and thoroughly judged whether the best available techniques are indeed applied in IPPC permits. At the same time, the courts are reluctant when, in the range of BAT-ELVs, ${ }^{365}$ the permit requirements are set. ${ }^{366}$ Some interviewees perceive the courts as unambitious in this regard. In fact, representatives from environmental NGOs regard the legal requirement to apply "at least" BAT as a dead letter:

The Council [of State] finds whatever emission limit values are set perfectly fine as long as they find themselves somewhere in the BAT range. So what does this very term 'at least' actually mean? We do not have to go beyond BAT anyway! ${ }^{367}$

The reluctance of judges to review the correctness of emission limit values (ELVs) set in IPPC permits may be explained by the fact that the judge allows the authorities a considerable degree of administrative discretion in setting permit conditions. ${ }^{368}$ In-depth

\footnotetext{
${ }^{362}$ For the legislative provisions on the application of BAT outlined in the IPPC Directive, see Chapter 3 on approach and methodology, Section 4.1.1.2.

${ }^{363}$ Wet algemene bepalingen omgevingsrecht, Wet van 6 november 2008, houdende regels inzake een vergunningstelsel met betrekking tot activiteiten die van invloed zijn op de fysieke leefomgeving en inzake handhaving van regelingen op het gebied van de fysieke leefomgeving [2008] Stb. 496 [Act laying down General Conditions for Environmental Law], Article 2.14(1), sub a, $1^{\circ}$ and $2^{\circ}$ and sub c, $1^{\circ}$ in conjunction with Besluit omgevingsrecht, Besluit van 25 maart 2010, houdende regels ter uitvoering van de Wet algemene bepalingen omgevingsrecht [2010] Stb. 143 [Ministerial Order Environmental Law], Article 5.3.

${ }^{364}$ See e.g. Peeters and Oosterhuis, 2010, who argue that the minimum requirement regarding the application of BAT restricts the opportunities for authorities to make a truly integrated decision in the permitting process (p. 49).

${ }^{365}$ Best available techniques - associated emission levels.

${ }^{366}$ E.g. RvS 29 November 2006, ECLI:NL:RVS:2006:AZ3264; 27 August 2008, ECLI:NL:RVS:2008:BE9313; 28 January 2009, ECLI:NL:RVS:2009:BH1132.

${ }^{367}$ Interview NL20; similar NL19.

${ }^{368}$ See e.g. Knijff, 2010.
} 
review of the merits of the case may be seen as difficult to reconcile with this discretion; it may be considered undue intrusion on the part of the judge in what is actually the area of competence of the administration.

It seems, however, that the reluctance of the court to rule on the merits of the case may also be explained by the fact that the judge "is simply not enough of an expert". ${ }^{369}$ Certainly, judges may consult experts in the area of environmental law - the Netherlands even has a specific foundation for this purpose, as suggested previously ${ }^{370}$ - but this is not possible for every case, and it speaks for itself that an expert report does not replace a judgement. Evaluating the motivation underlying the permit decision issued by the authorities requires less technical insight than an assessment of whether the emission limit values set in the permit are correct. This may explain why the motivation of contested decisions has generally played a crucial role in court cases concerning IPPC permits. This is not only true for cases in which ELVs requiring the implementation of measures exceeding BAT (BAT-plus measures) are set, but also for permits including ELVs within the BAT-AELs range outlined in the BREFs. ${ }^{371}$ The problem with this case law is that it does not actually solve the case, and that the same decision may be appealed several times. Note that the resulting phenomenon of "decision-ping-pong" 372 may be a matter of the past, since the General Administrative Law Act currently makes it possible for the court to enable or oblige the authority to repair the decision before the court proceedings are resumed. ${ }^{373}$

Chapter 5 on post-legislative guidance shows that important benchmarks for the administration in determining BAT should be - and are - the relevant guidelines outlined in the BREFs. ${ }^{374}$ Although Dutch legislation does not endow the BREFs with legal status, jurisprudence shows that the courts do endow such documents with a rather concrete legal meaning. ${ }^{375}$ The court has judged that where IPPC permits meet the requirements outlined in the relevant BREF documents, compliance with the requirement to apply the

\footnotetext{
${ }^{369}$ Interview NL24.

${ }^{370}$ See Section 1.2.1.1.3, sub B.

${ }^{371}$ According to Dutch law, BAT-plus measures are needed where national environmental quality standards are likely to be exceeded, where there is a location-specific accumulation of environmental problems, or where attaining national environmental goals requires particular efforts on the part of economic operators. See Kamerstukken II [Parliamentary Reports of the Second Chamber], 2003/04, 29711, no. 3, p. 11, and no. 8. In practice, the Court quashed many decisions requiring the implementation of measures stricter than BAT. See e.g. RvS 28 September 2005, ECLI:NL:RVS:2005:AU3398; 27 August 2008, ECLI:NL:RVS:2008:BE9313; and (under the IED) 3 April 2013, ECLI:NL:RVS:2013:BZ7545. Exceptions are, for example, RvS 16 March 2011, ECLI:NL:RVS:2011:BP7775., and 22 July 2009, ECLI:NL:RVS:2009:BJ3426.

${ }^{372}$ Backes, 2012: 22.

${ }^{373}$ The court of last appeal can oblige the authority to repair the decision, other courts can enable the authority to do so. See GALA, Art. 8:51d (bestuurlijke lus). See further section 1.2.1.2, sub B.

${ }^{374}$ See Chapter 5 on post-legislative guidance, Section 2.2.1

${ }^{375}$ E.g. RvS 26 April 2006, ECLI:NL:RVS:2006:AW3976; 25 January 2006, ECLI:NL:RVS:2006:AV0295.; 22 April 2009, ECLI:NL:RVS:2009:BI1839; 22 July 2009, ECLI:NL:RVS:2009:BJ3426; 16 March 2011, ECLI:NL:RVS:2011:BP7775; 5 October 2011, ECLI:NL:RVS:2011:BT6639. See also Oosterhuis et al., 2007.
} 
best available techniques is presumed. ${ }^{376}$ Moreover, deviation from the BREFs is possible, only if motivated adequately. ${ }^{377}$

In line with the "at least" requirement in Dutch legislation, judges have maintained that when it comes to techniques that are not listed as the best available techniques in the BREF documents, only those techniques that facilitate the achievement of a similar or further reduction of emission levels are permitted. ${ }^{378}$ Moreover, when BREF documents are out-dated by the time of permitting an installation, the courts have judged that a draft BREF should be used as an indication of whether or not techniques are BAT. ${ }^{379}$ It is particularly in out-dated cases or when BREFs do not provide guidelines on the determination of BAT - for example when an activity is not covered by the BREFs that searching for information besides that included in the BREF documents is considered imperative. ${ }^{380}$

\section{B. Usefulness}

Dutch officials involved in the determination of IPPC permits indicate that of all the compliance instruments included in this study, case law ranks amongst the most useful instruments for supporting them in the application of BAT in IPPC permits. Jurisprudence is experienced as providing clarity on the interpretation of the concept of BAT and, therefore, as helping the authorities to construct well founded permits. ${ }^{381}$ To say that case law provides clarity, however, does not mean that all interpretational difficulties are solved through case law. In fact, interviewees identified several issues that pose interpretational questions. Examples include national regulations for the revision of IPPC permits; the relationship between rules on integrated pollution prevention and control and other (non-environmental) legislation; and the 'bubble concept', according to which the performance of an installation that exceeds the applicable ELVs is compensated for by the performance of an installation that applies measures that are stricter than BAT. ${ }^{382}$ In other words, case law clarifies, but because of its incomplete coverage, it is not a cure-all instrument.

\footnotetext{
${ }^{376}$ E.g. RvS 14 November 2007, ECLI:NL:RVS:2007:BB7828; 4 April 2007, ECLI:NL:RVS:2007:BA2227; 16 May 2007, ECLI:NL:RVS:2007:BA5207; 21 December 2007, ECLI:NL:RVS:2007:BC1397; 21 December 2007, ECLI:NL:RVS:2007:BC1400; 22 July 2009, ECLI:NL:RVS:2009:BJ3426; 7 April 2010, ECLI:NL:RVS:2010: BM0215; 7 July 2010, ECLI:NL:RVS:2010:BN0430.

${ }^{377}$ Van den Broek, 2007. E.g. RvS 30 November 2011, ECLI:NL:RVS:2011:BU6362.

${ }^{378}$ RvS 23 February 2005, ECLI:NL:RVS:2005:AS7235; 17 February 2010, ECLI:NL:RVS:2010:BL4140.

${ }^{379}$ E.g. RvS 26 April 2006, ECLI:NL:RVS:2006:AW3976; 5 January 2007, ECLI:NL:RVS:2007:AZ5854; 25 January 2006, ECLI:NL:RVS:2006:AV0295; 23 February 2005, ECLI:NL:RVS:2005:AS7235.

${ }^{380}$ RvS 17 January 2007, ECLI:NL:RVS:2007:AZ6395. See RvS 7 October 2009, ECLI:NL:RVS:2009:BJ9530, for an evaluation by the Council of State that the assessment of the permitting authorities that the BREFs relied on outdated information was wrong. See also e.g. Borgers, 2007: 34-41; discussion amongst several stakeholders, in Ramnewash-Oemrawsingh, 2005: 81; Bröring, 2007: 21-22. This happens in practice as well. See interview NL24; NL23.

${ }^{381}$ Interview NL22; NL24; NL21; NL25. See also Uylenburg, 2010.

${ }^{382}$ But, see (under the IED) Rechtbank Den Haag, 5 March 2014, case AWB-12_6042. This judgement (on the
} 
Because of the clarifying effect that it has had, jurisprudence is also experienced as useful for preventing future conflict between authorities and economic operators and environmental NGOs. In the words of a permit writer:

In the end, it is jurisprudence that brings us further. For example, when we win a case against an oil terminal, we can refer to that one in the future. Companies need to comply with that judgement, and they know it. As a result, they know that it does not make sense anymore to discuss things with us. And companies also consider the length of proceedings: a court procedure takes a year, and many want to prevent that as it is relatively cheaper to meet a requirement than to be involved in a court proceeding and to earn nothing for a whole year. ${ }^{383}$

In contrast to what the following subsection identifies as the case for Poland, in the Netherlands, it is primarily environmental organisations that initiate legal proceedings, sometimes in cooperation with citizens or grass-roots organisations. From Chapter 7 on civil society one may recall that, while such organisations are few - IPPC is a technically complicated issue, and only few organisations can claim substantial expertise in this area - Dutch officials generally attach great value to civil society for the watchdog function that it has had. ${ }^{384}$ At this point it must be added that NGOs are in fact appreciated because of the court cases that they initiate. ${ }^{385}$ Awareness that NGOs have been winning court cases has made officials view environmental licensing practices in a different manner, interviewees say. ${ }^{386}$ An interviewee from the former VROM Inspectie indicates that the proactive stance of NGOs has boosted the vigour with which this body pursues poorly drafted permits from the provincial authorities:

We were much less vigorous in this role before NGOs were coming and winning cases now and then. When this happened, awareness arose that we needed to do more... NGOs have had an effect on our action capacity. We are grateful to them for this. ${ }^{387}$

Permit writers indicate that regardless of how legal action taken by environmental NGOs may frustrate them, they generally appreciate the critical role of NGOs in keeping them focused. ${ }^{388}$ Moreover, the possibility that NGOs may go to court is said to be useful for persuading unwilling companies into more stringent standards and for preventing

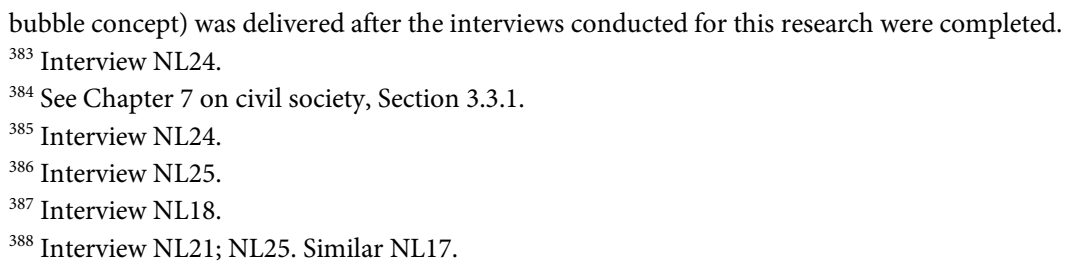


sloppiness from creeping into the permit drafting process. ${ }^{389}$ As such, both case law and the possibility of court cases being started are said to help officials in the implementation process.

\subsubsection{Poland}

\section{A. Contents}

The contents of Polish case law on BAT are of a completely different nature than those of Dutch case law. This is the case, since the concept of the best available techniques and the BREFs do not generally have a pivotal position in judgements issued by Polish administrative courts. When they appear, they are usually referred to formalistically, as described in the following paragraphs. Three, partly intertwined, factors seem to explain the lack of centrality of BAT and of the BREFs in Polish case law.

First, in the majority of cases, neither BAT nor the BREFs seem to be the cause of contention to begin with; claimants do not generally challenge the compliance of an IPPC installation with BAT or with the BREFs. Instead, NGOs and business operators often challenge the authority's compliance with procedural rules or general principles of law. ${ }^{390}$ An example is a case in which an operator claimed a breach of the principle of equality because of the authority's requirement for him to apply stricter pollution control measures than his neighbour. The first instance court judged that the authority had justified its decision by demonstrating that such measures were necessary from an environmental point of view. ${ }^{391}$ In this case, as in cases in which procedural rules are the focus of the dispute, an evaluation of whether the respective installation complies with BAT does not enter the picture in court proceedings.

NGOs do not only challenge procedural rules, they also - and often - challenge the validity of the environmental impact assessment (EIA) report on the basis of which the decision granting an environmental permit was made. ${ }^{392}$ In one such case, the Supreme Administrative Court said that since the court only evaluates the legality of administrative decisions, marginal review is in place. It remarked that it could not conduct a full analysis of the report, since this would require external expertise, and external experts are consulted by the court only exceptionally and in a limited fashion. ${ }^{393}$ The court said that the report contained the required analysis, including an analysis of whether or not the installation complies with the environmental protection requirements associated with $\mathrm{BAT}$, and a request that the applied technologies meet the recommendations out-

\footnotetext{
${ }^{389}$ On this issue, see further Chapter 7 on civil society, Section 3.3.1.

${ }^{390}$ This follows from case law analysis, and from interview PL13.

${ }^{391}$ Case IV SA/Wa 1768/08, judgement of 8 April 2009.

${ }^{392}$ E.g. cases IV SA/Wa 1486/07, judgement of 20 November 2007; IV SA/Wa 1395/07, judgement of 20 November 2007; IV SA/Wa 1498/11, judgement of 9 December 2012; IV SA/Wa 2324/12, judgement of 6 February 2013; II OSK 776/12, judgement of 22 August 2013.

${ }^{393}$ For the relevant rules, see Section 1.2.1.1.3, sub B.
} 
lined in the BREFs. On the basis of these facts, the report was deemed accurate enough to serve as a foundation for the administrative decision. ${ }^{394}$ The focus of civil society actors on issues with EIA reports (and on other easy-to-spot faults, such as noncompliance with procedural rules) is logical in view of the fact that most ordinary citizens and environmental organisations do not have the expertise that is necessary to substantiate a claim of noncompliance with BAT. ${ }^{395}$ However, it does not make case law particularly interesting from a substantive point of view.

A second explanation for the lack of centrality of the concept of BAT in Polish case law is that even when an elaboration on the concept of BAT would be logical in view of the dispute at stake, the courts do not explore this issue. ${ }^{396}$ This is only partially explained by the fact that the courts exercise marginal judicial review, ${ }^{397}$ according to which they must grant the administration a considerable degree of decisional discretion and refrain from judging the merits of the case. This practice exists in the Netherlands as well, but Dutch courts do, in many cases, go beyond the authority's declaration that the proposed techniques are BAT by comparing the proposed techniques with the contents of the BREFs and other relevant provisions. Polish courts would merely verify whether or not the environmental impact assessment report includes a comparison with BAT, as the previous paragraph hints, without considering the question of which emission limit values or which techniques qualify as BAT.

The reluctance of judges to investigate the concept of BAT, and their tendency to rush to an evaluation of the procedural side of the case instead, seems explicable by the idea that judges lack expertise on the topic of integrated pollution prevention and control. When a decision has been quashed for noncompliance with procedural rules or general principles of law - particularly the motivation of the administrative decision, ${ }^{398}$ the reasoning of the complaint, ${ }^{399}$ or other legal principles ${ }^{400}$ - a decision about the mer-

\footnotetext{
${ }^{394}$ Case II OSK 776/12, judgement of 22 August 2013 (and the relevant first-instance judgement, case IV SA/Wa 1498/11 judgement of 9 December 2012).

${ }^{395}$ See Chapter 7 on civil society, Section 3.3.2.

${ }^{396}$ It seems that there is only one case in which the court actually attempted to clarify BAT, amongst others, by referring to the relevant literature in this regard, namely case IV SA/Wa 1471/11, judgement of 30 November 2011. In other cases, such an elaboration is absent. See in particular e.g. cases II SA/Łd 247/07, judgement of 2 March 2007; IV SA/Wa 2036/09, judgement of 12 October 2010; IV SA/Wa 1226/12, judgement of 4 October 2012; IV SA/Wa 1190/11, judgement of 26 October 2011; OSK 233/11, judgement of 25 April 2012; I OSK 577/12, judgement of 2 July 2013; IV SA/Wa 1768/08, judgment of 8 April 2009

${ }^{397}$ E.g. cases IV SA/Wa 1486/07, judgement of 20 November 2007, and IV SA/Wa 1395/07, judgement of 20 November 2007.

${ }^{398}$ E.g. case OSK 1560/08, judgement of 29 April 2009; OSK 233/11, judgement of 25 April 2012; IV SA/Wa 2036/09, judgement of 12 October 2010; IV SA/Wa 1226/12, judgement of 4 October 2012.

${ }^{399}$ E.g. case IV SA/Wa 1199/11, judgement of 7 November 2011. Here, the Minister of the Environment challenged that the governor's decision granting an integrated permit complied with BAT; the court said that the minister had not explained why this should be the case, since the minister "confined itself to citing vague regulations... without a precise application which provisions where violated by the decision of the governor". The court did not further elaborate on the notion of BAT.
} 
its of the case is not necessary. Thus, the court would not need to burn its fingers on the complicated issue of BAT. Furthermore, while Dutch courts frequently rely on external expertise in technically complicated cases, the role of experts in the Polish administrative legal system is limited, both in theory and in practice. ${ }^{401}$

A third and final factor explaining the lack of centrality of the BREF guidance documents relates to the value that Polish courts attach to the BREFs. Whereas the BREFs have a concrete legal meaning in the Netherlands, Polish officials only need to take the BREFs into account in the permitting process. For example, in a case in which an environmental organisation complained that an IPPC permit did not comply with BAT because it was not based on the techniques outlined in the relevant BREF, the SAC quashed the complaint by referring to the 'soft status' of the BREFs. The court stated that the BREFs "give opinions on the best available techniques" and that "these studies are not official and not binding to the administrations of the member states". 402

This perception was confirmed in another case that focused on whether the environmental impact assessment report should only include a comparison of the proposed techniques with BAT, or also include a decision about the conditions to be met by the installation. The SAC agreed with the former suggestion and argued that the decision specifying the environmental conditions must take place in the process of determining the IPPC permit, that this decision should be based on environmental legislation, and that it should consider the requirements outlined in the BREFs - "of course as guidelines" - and other statutory provisions. ${ }^{403}$

While BREFs do not, according to Polish case law, need to be complied with in environmental decisions, compliance with the proposed techniques outlined in the BREFs does, in principle, lead to a presumption of compliance with BAT. In a case where the administration claimed that a technique was not BAT, the court rejected the complaint because the technique was included in the relevant BREF and the authority did not sufficiently explain why the proposed technique would not be an appropriate pollution control method. ${ }^{404}$ In this regard, Polish case law seems similar to Dutch case law, which

\footnotetext{
${ }^{400}$ Case IV SA/Wa 1768/08, judgement of 8 April 2009 (on the principle of equality); the court quashed a complaint lodged by an operator claiming a breach of the principle of equality following the authority's demand for him to apply stricter measures than his neighbour. The court judged that the authority had justified its decision by demonstrating that such measures were necessary from an environmental point of view. See also case IV SA/Wa 1908/08, judgement of 5 February 2009, in which the operator complained about the imposition of fees because of pollution emitted without an integrated permit. The company argued that it had applied for a permit and the fact that he did not have it yet was to be blamed on sluggishness of the administration. Moreover, the installation had already used BAT during the period over which the fees had to be paid. The court ruled that the authority had violated the principle of justice.

${ }^{401}$ For the procedural provisions on this issue, see Section 1.2.1.1.3, sub B.

${ }^{402}$ Case OSK 874/10, judgement of 15 May 2011; IV SA/Wa 1205/09, judgement of 26 November 2009.

${ }^{403}$ Case OSK 1246/12, judgement of 2 October 2012;. IV SA/Wa 1757/11, judgement of 12 January 2012. Similar IV SA/Wa 543/08, judgement of 23 May 2008.

${ }^{404}$ Case I OSK 577/12, judgement of 2 July 2013; IV SA/Wa 1471/11, judgement of 30 November 2011. In
} 
has (also) confirmed that compliance with the requirements outlined in the BREFs leads to a presumption of compliance with BAT.

\section{B. Usefulness}

Polish officials involved in the domain of IPPC do not seem to give case law credit; in none of the interviews conducted for this study was case law described as an important compliance instrument. It seems that this may be explained, first - and as could be derived from the above paragraphs - by the fact that court judgements are rarely enlightening when it comes to the interpretation of core issues concerning the implementation of BAT in IPPC permits. The above paragraphs suggest that this is the case because courts focus on procedural issues rather than on the merits of the case. This is not something that should only be blamed on a lack of expertise from judges ${ }^{405}$ As we have seen, environmental organisations in particular usually challenge the authorities' compliance with procedural rules, rather than the prescription by the authorities of specific ELVs. It is not surprising that in such cases, the judgement is of little help with the interpretation of substantive aspects of national legislation, or with the relationship between national legislation and EU legislation. Interviewees argue that it is particularly in relation to this latter issue that interpretational problems have persisted. ${ }^{406}$

The absence of case law on essential interpretational questions is not that problematic, it seems - at least not in the eyes of officials. Permit writers indicate that they rely on the Ministry of the Environment for guidance. ${ }^{407}$ In fact, they argue that it is not jurisprudence, but ministerial guidance, that solves interpretational problems. While undoubtedly experienced as useful in this regard, it seems that the extent to which the ministry provides guidance that advances environment-friendly solutions over economy-friendly solutions might be doubted. The ministry has traditionally been weak in view of the government's preoccupation with social and economic issues. ${ }^{408}$ If it is true that, in the words of an interviewee, "economy will always come first", ${ }^{409}$ the absence of objective court judgements seems all the more problematic.

The second reason for the perception that case law is not useful as a compliance instrument is derived from the fact that case law does not always seem consistent:

\footnotetext{
another range of cases in which the question of whether a material was a raw material or waste was at stake, the regional court used a BREF as a reference point to define whether a certain material could qualify as a raw material. The court concluded that while the material was indeed referred to in the BREF as a raw material, the operator did not have the technology to use it in the production process, as a result it must be qualified as waste. See cases IV SA/Wa 889/09; IV SA/Wa 888/09; IV SA/Wa 886/09; IV SA/Wa 885/09, all judgements of 12 January 2010.

${ }^{405}$ Interview PL8.

${ }^{406}$ Interview PL8; PL9; PL12.

${ }^{407}$ Interview PL9; PL11; PL12.

${ }^{408}$ Millard, 1998; Curtis, 1992: 61-64. For the idea that the implementation of environmental policy has been a continuous challenge, see OECD, 2003: 1; Karaczun, 2005: 245-246.

${ }^{409}$ Interview PL12.
} 
Usually, the ministry wins this kind of court cases. Sometimes in similar cases you have yet two different decisions from the court. It's the legal system. The judges have the right to their own decisions. ${ }^{410}$

The fact that the judges have the right to their own deliberation should not have to imply that jurisprudence is 'random'. However, if this is the case, case law must be expected to be a suboptimal instrument for civil servants because it is unclear what is considered 'right', and it makes it difficult to defend judgements as authoritative in relation to economic operators. On a side note, where case law is random, it is also an inappropriate instrument for the harmonisation of implementation practices within the same country.

\subsection{Synthesis}

The previous sections clearly suggest that there are great differences between Dutch and Polish case law on the implementation of BAT in IPPC permits, and specifically on the role that the BREFs should play in this regard. In view of these differences, the following two points may be made. First, the fact that case law that is experienced as useful by implementation actors does not necessarily mean that it constitutes an effective tool for ensuring the uniformity of implementation practices across the board. As the purpose of this study is not to analyse the correctness of national case law in the light of EU law provisions, an assessment of whether Dutch or Polish jurisprudence on BAT is 'correct' goes beyond the scope of this study. What must be said, however, is that loose (judicial) interpretations on the use of the BREFs similar to those set out in Polish case law were amongst the triggers for the European Commission to start a revision process of the IPPC Directive.

This brings us to a second point that should be noted; namely, that diverging judicial interpretations may indicate legislative vagueness, a need for legislative clarification, and - if and where such clarification ensues - improve the implementation of EU measures indirectly. The IPPC Directive constitutes a clear example of this as far as the former two aspects are concerned. As suggested above, interpretational diversity regarding BAT and the use of the BREFs in IPPC permits has been a major motivational factor for legislative revision. In its proposal for the Directive on Industrial Emissions (IED), the Commission refers to "significant shortcomings in the implementation of best available techniques due to vague provisions on BAT in the current legislation, the large degree of flexibility left for competent authorities to deviate from it in the permitting process and the unclear role of the BREFs". ${ }^{411}$ Empirical reports on the implementation

\footnotetext{
${ }^{410}$ Interview PL8.

${ }^{411}$ Commission, 'Proposal for a Directive of the European Parliament and of the Council on industrial emissions (integrated pollution prevention and control) (Recast) (Industrial Emissions Directive) COM (2007) 844 final, p. 9.
} 
of BAT and the use of the BREFs in IPPC permits underline these shortcomings. ${ }^{412}$ To ensure that the guidelines on BAT outlined in the BREFs are used as yardsticks in environmental licensing processes, the IED dictates that the "BAT conclusions [which outline conclusions on the best available techniques] shall be the reference for setting the permit conditions". ${ }^{413}$ This not only means that competent authorities must use them in permitting processes, but also that courts are not in the position to relegate the BAT conclusions to nonbinding guidelines, as some of them had done with the BREFs. It also means that case law, however ineffective it might be for harmonizing implementation practices directly, may have the same effect indirectly, by triggering legislative clarifications that remove interpretational problems, and by aligning judicial (and administrative) interpretations. It must be noted that the extent to which the IED has had this effect remains to be seen.

\subsubsection{Case law on SAFA inspections}

Finally, case law in the area of SAFA only exists in the Netherlands, and to a limited extent. The idea that case law in the area of SAFA is not a regular phenomenon is supported by the results of the survey that was circulated amongst SAFA officials; from

$14 \%$ of the SAFA survey respondents agree that this case law is helpful, and $28 \%$ agree or strongly agree that case law addresses the relevant questions.
Section 3.1.1 one may recall that none of the survey respondents refer to court proceedings as a regular phenomenon in the area of SAFA. One

out of seven respondents indicate that such case law is useful, and two out of seven agree that case law addresses the questions that are relevant to supporting the civil aviation authorities in the law application process.

The current section discusses the contents of the two Dutch cases in the area of SAFA and the usefulness of these cases in the eyes of implementation actors. Note that these cases do not concern aircraft inspections under the SAFA Directive; rather, they concern inspections conducted under the SAFA Programme, which preceded the directive. Since the directive merely turned the programme from an international, voluntary framework into a supranational, binding instrument, ${ }^{414}$ these court cases might also be relevant for SAFA officials to the implementation of SAFA inspections conducted under the directive.

\footnotetext{
${ }^{412}$ E.g. Entec, 2007, 2010.

${ }^{413}$ Directive 2010/75/EU, Art. 14(3) (emphasis added).

${ }^{414}$ At least as far as SAFA inspections are concerned.
} 


\subsection{The Netherlands}

\section{A. Contents}

Central to the first court case was whether or not, in her evaluation on the safety of an airline operator, the Minister of Transport and Water Management could rely on the norms that are used in the framework of the European Civil Aviation Conference and outlined in the SAFA Programme, and whether the imposition of a temporary territorial operating ban was proportional to the SAFA inspection results. The airline also accused the minister for acting in contradiction to the principle of equality, because she had, for a long time, failed to act against another airline that received negative safety evaluations. In relation to the first set of points, the Council of State considered the motivation of the decision of the minister, which it evaluated as reasonable. As to the second point, it judged that the minister had made plausible that the cases relevant in the proceedings were not equal. ${ }^{415}$

In another case before the Council of State, the central question was whether or not the findings of SAFA inspections, on the basis of which the minister had imposed a temporary territorial operating ban, provided sufficient reason to do so, and more specifically whether the safety findings for this particular airline needed to be compared to those for other airlines. The airline also challenged the proportionality of the decision. Examining also this second case by exercising marginal review, the Council of State considered the decision that was adopted by the minister legitimate. ${ }^{416}$

\section{B. Usefulness}

The two cases discussed above concern the motivation of decisions adopted by the minister rather than the validity of SAFA inspection results or the manner in which these inspections are conducted. As such, they may be more relevant for policy officials involved in the drafting of ministerial decisions than for SAFA inspectors. This explains why SAFA inspectors do not refer to this case law as relevant or useful.

\subsubsection{Synthesis}

The preceding sections depict a mixed picture of the usefulness of case law for supporting the application of EU law provisions. On the negative side, we find that case law often does not exist. This is the case for Portugal in particular, and for Poland and the Netherlands in certain policy areas. In addition, when case law does exist, it is often limited to solving procedural questions, as established particularly for Polish case law in the areas of GPS and IPPC. Moreover, when case law is perceived as enlightening, it may require the competent authorities to follow a course of action that they cannot afford to implement. Polish case law in the area of general product safety provides an example of this. Finally, diverging judicial interpretations of the same issue, as in the use of the

\footnotetext{
${ }^{415}$ RvS 6 February 2008, ECLI:NL:RVS:2008:BC3585.

${ }^{416}$ RvS 3 September 2008, ECLI:NL:RVS:2008:BE9687.
} 
BREFs in IPPC permits, question the extent to which case law is an effective instrument for ensuring correct implementation practices across the board.

Next to these negative notions, is the positive fact that case law may be experienced as useful for solving interpretational questions and for solidifying the stance of authorities in relation to NGOs and business operators. Polish officials in the area of general product safety claim to draw much authority from court judgements, however limited the clarifying effect of these judgements may be. Dutch officials involved in environmental licensing processes consider case law one of the most important compliance instruments because case law clarifies and consolidates the position of authorities in relation to (difficult to deal with) NGOs and business operators. Both cases suggest that the usefulness of case law is determined as much by the clarifying effect of judgements as by the context in which competent authorities must ensure compliance with the law, particularly by the nature of the interaction between the authorities, and business and civil society actors.

\subsection{Preliminary rulings}

While Section 3.1 focuses on the prevalence and the usefulness of domestic case law as a compliance instrument, this section shifts our attention to the usefulness of preliminary rulings for supporting national officials in the implementation process. Section 2.2 outlines that preliminary rulings exist only in relation to the GPS Directive (one ruling) and in the context of the IPPC Directive (six rulings). The fact that preliminary rulings in the domain of SAFA are absent might be caused by the limited presence of domestic case law in this domain, as preliminary questions can be asked only when such case law exists.

The following subsections elaborate on the essence of the preliminary rulings in the areas of product safety and integrated pollution prevention and control, and on the extent to which national officials consider these rulings useful for supporting the national competent authorities in the application process.

\subsubsection{Preliminary rulings for the GPS Directive}

\section{A. Contents}

The only preliminary ruling that may be relevant for officials involved in the area of general product safety is a ruling delivered by the CJEU following the submission of a preliminary question from the Hungarian Fövárosi Bíróság. ${ }^{417}$ Relevant to the GPS Directive was the question of whether a distributor of radio equipment may, pursuant to the provisions of the said directive, be regarded as the producer of that product without having participated in its production, and even though its activities do not affect the

${ }^{417}$ Case C-132/08 Lidl Magyarország Kereskedelmi bt v Nemzeti Hírközlési Hatóság Tanácsa [2009] ECR I03841. 
safety properties of the product. The national court also asked whether the distributor may be required to issue a declaration of conformity related to the radio equipment concerned, or whether the distributor may be made subject to the obligations imposed on the producer when the producer does not market the relevant products.

The CJEU recalled that the GPS Directive does not apply when specific rules governing the safety of products exist, and that Directive 1999/5 on radio equipment and telecommunications terminal equipment, and $58 \%$ of the GPS survey respondents agree or strongly agree that preliminary rulings on market surveillance for GPS products are helpful. 55\% respondents agree or strongly agree that these rulings address the relevant questions. These percentages are considerably higher for inspectors. the mutual recognition of their conformity (R\&TTE Directive), provides such rules for radio equipment. ${ }^{418}$ The Court also stated that in order to determine the obligations of an operator arising from the GPS Directive, it must be held that a person who markets a product may be regarded as the producer of that product only under the conditions outlined in Article 2(e) of this directive (which defines the term 'producer'), and as the distributor thereof only under the conditions set out in Article 2(f) (which defines the term 'distributor'). The Court also held that the producer and the distributor are only bound by obligations that the GPS Directive imposes on each of them respectively.

\section{B. Usefulness}

None of the officials interviewed for this study refer to this ruling as useful. In fact, national officials do not seem to be familiar with it in the first place. This unfamiliarity may be explained by two factors. The first is that the preliminary question was raised in proceedings on the conformity of a product covered by the R\&TTE Directive, which is a new approach directive. ${ }^{419}$ Reference to the GPS Directive is made only because the provisions of this directive apply insofar as the regulated issues are not governed by the R\&TTE Directive. Second, in none of the three countries included in this study are the interviewed authorities responsible for the implementation of the R\&TTE Directive. ${ }^{420}$

\footnotetext{
${ }^{418}$ Directive 1999/5/EC of the European Parliament and of the Council of 9 March 1999 on radio equipment and telecommunications terminal equipment and the mutual recognition of their conformity [1999] OJ L $91 / 10$.

${ }^{419} \mathrm{New}$ approach directives only harmonise the essential requirements of products. Harmonised standards developed by experts are used to attest the conformity of a product with the essential requirements outlined in the relevant directive. Compliance with the presumption of conformity is attested by the CE-marking. In order to ensure the free movement of goods, the principle of mutual recognition applies in relation to declarations of conformity. Impetus to the increased use of the new approach to technical harmonisation was given by Council, 'A new approach to technical harmonisation and standards' (Resolution) [1985] OJ C 136/1. See Europa, 'A new approach to technical harmonisation', <http://europa.eu/legislation_summaries/internal_ market/single_market_for_goods/technical_harmonisation/>.

${ }^{420}$ In the Netherlands, the competent authority is Agentschap Telecom (Telecommunications Agency); in Poland, the Urzad Komunikacji Elektroniczne (Office of Electronic Communications) is competent; and in Portugal, the competence lies with the Autoridade Nacional de Comunicações (National Communications
} 
Both of these factors explain why awareness of this ruling is absent, and why the only ruling that may, in theory, be relevant for officials in the area of general product safety is in fact not useful at all for supporting them in their work. In view of these findings, the idea that nearly $60 \%$ of the survey respondents indicate that preliminary rulings on market surveillance for GPS products are helpful seems remarkable. This number seems explicable only if one assumes that these results indicate the desirability of having such rulings, rather than appreciation of the single ruling that exists.

Note that a desire to have the CJEU interpret provisions included in the GPS Directive is not something that appears in interviews with national officials. Portuguese officials, for one, do not seem to be confronted with any particular interpretational problems. ${ }^{421}$ This also applies to Dutch officials, who explain the said absence of problems of interpretation by the 'good fit' between the directive and pre-existing Dutch legislation:

From a legal perspective, the GPS Directive does not really mean anything. The first directive comprised what was already laid down in the Warenwet. So the changes that the GPS Directive brought about to national legislation and to ways of thinking and doing were very few and very little. Both legally and from an operationalisation point of view, the Netherlands already had a lot of experience in dealing with product safety. ${ }^{422}$

This is completely different for Poland, which is a newcomer in the area of general product safety. ${ }^{423}$ Polish market surveillance officials indicate that they have struggled with numerous interpretational questions. ${ }^{424}$ To solve these questions, inspectors tend to look at the Office of Competition and Consumer Protection to provide them with guidance. UOKiK then resorts to the European Commission to provide it with interpretational support; ${ }^{425}$ it has certainly not considered requesting that the national court submit preliminary questions on issues that UOKiK has struggled with. The following quotation elucidates why this is the case:

Firstly, the preliminary ruling procedure needs the relevant court's willingness to pose such questions to the CJEU, and that can be done only when the legislation is unclear. Please note that we are talking about the GPS Directive, so

\footnotetext{
Authority).

${ }^{421}$ Interview PT4; PT6; PT7.

${ }^{422}$ Interview NL13; similar NL2.

${ }^{423}$ It was EU accession that fuelled the adoption of consumer protection legislation in Poland; the General Product Safety Act was adopted, in 2003, to implement the GPS Directive. Earlier legislation in the same spirit did not exist.

${ }^{424}$ Interview PL2; PL3.

${ }^{425}$ See Chapter 5 on post-legislative guidance, Section 3.4.2.
} 
there might be considerations on national law and not EU law, so there is no reason to ask the questions to the CJEU. Secondly, for me it was quite obvious that we are the enforcement agency and it is us, who should do the control and provide interpretations of the law that would favour the safety and interests of consumers. I didn't need the CJEU to do this job for me. From time to time we needed an interpretation from the Commission, and sometimes its guidance is quite good. But often the Commission was reluctant to do this and they pushed the job to the member states. My reasoning was the following: if the Commission sees no serious trouble, we could deal with the case on our own basing ourselves on some consultations with other member states regarding how they understand the same provisions. Usually it works, so if it ain't broke, why fix it and engage the CJEU? ${ }^{426}$

While the system outlined above may not require fixing as far as national officials are concerned, ${ }^{427}$ it is unclear to what extent it truly - or optimally - supports national officials in the implementation process. It is likely the case that informal problem solving amongst member states has the advantage of yielding relatively speedy solutions to issues of interpretation. However, preliminary rulings handed down by the CJEU are unquestionably more authoritative than solutions arrived at amongst member states. It is pointed out earlier that authoritative interpretations of EU law may add value, not only because they may ease relations with regulated entities, ${ }^{428}$ but also because they may be used more uniformly across member states. Since the usefulness of guidance on the interpretation of EU law provisions is, in part, determined by its faithful implementation across the board, such uniformity becomes directly relevant to national authorities in the implementation process. ${ }^{429}$ When interpretations are not supported by an authoritative framework, their usefulness to authorities in the implementation process might be limited.

In addition, officials may not be willing to share problems with their colleagues although everyone knows that these problems exist:

Not everyone wants to talk about that, since it may look like they don't know how to solve the problem. So in that light the better answer for me would be to

\footnotetext{
${ }^{426}$ Email 1 from interviewee PL2 to author.

${ }^{427}$ Also Dutch and Portuguese officials indicate that informal problem-solving is important, see e.g. interviews NL6; PT4.

${ }^{428}$ See e.g. Chapter 5 on post-legislative guidance, Section 3.4.2, and Section 3.1.2.1.1, sub B, of this chapter, on Polish case law in the area of GPS.

${ }^{429}$ See Chapter 5 on post-legislative guidance, Section 1.2.3.3.
} 
say: 'we have no problems with interpreting the law', and to avoid further comments on Poland. But that would not be true. ${ }^{430}$

While they may be unwilling to share the difficulties they encountered with others, or they may indicate that they were not confronted with any difficulties to begin with, officials may be quick to indicate that interpretational divergences across member states exist. ${ }^{431}$ The notion that officials implicitly shift the blame for interpretational mistakes to others is not the primary concern here. The primary concern is that, as long as openness about interpretational issues faced by member states in the implementation process does not exist, such issues are likely to persist. This is the case not only because informal problem-solving mechanisms are not used, but also because it is unlikely that authorities ask national courts to request that the CJEU submit a preliminary ruling on the interpretation of provisions that pose problems.

Note that while Polish interviewees are alone in indicating that they have faced interpretational problems in the implementation of the GPS Directive, such problems do seem to be faced by other member states as well. One source of such problems is the New Legislative Framework (NLF) ${ }^{432}$ which aims to reinforce and harmonise market surveillance throughout the EU. ${ }^{433}$ Interpretational problems particularly relate to the definitions of the terms 'placing on the market' and 'making available on the market'. Whereas the NLF provides a definition for each notion, ${ }^{434}$ the GPS Directive refers to the notion of 'placing on the market' without defining it. ${ }^{435} \mathrm{~A}$ reading of the directive seems to suggest that the concept of 'placing on the market' covers both 'placing on the market' and 'making available on the market' in the sense defined by the NLF. However, the lack of explicit definitions in the GPS Directive, and the resulting misalignment

\footnotetext{
${ }^{430}$ Email 1 from interviewee PL2 to author.

${ }^{431}$ E.g. interview NL7; NL8; NL9; NL13.

${ }^{432}$ The NLF consists of sectorial harmonizing legislation and three newly-adopted horizontal legislative acts, namely Regulation (EC) No 764/2008 of the European Parliament and of the Council of 9 July 2008 laying down procedures relating to the application of certain national technical rules to products lawfully marketed in another Member State and repealing Decision No 3052/95/EC [2008] OJ L 218/21; Regulation 765/2008/EC of the European Parliament and of the Council of 9 July 2008 setting out the requirements for accreditation and market surveillance relating to the marketing of products and repealing Regulation (EEC) No 339/93 [2008] OJ L 218/30; and Decision No 768/2008/EC of the European Parliament and of the Council of 9 July 2008 on a common framework for the marketing of products, and repealing Council Decision 93/465/EEC [2008] OJ L 218/82.

${ }^{433}$ Conclusion of the author's observation of stakeholder contributions during the International Product Safety Week of December 2010.

${ }^{434}$ According to the NLF, 'placing on the market' refers to "the first making available of a product on the [EU] market". 'Making available on the market' refers to "any supply of a product for distribution, consumption or use on the $[\mathrm{EU}]$ market in the course of a commercial activity, whether in return for payment or free of charge"'(Regulation 765/2008/EC, Art. 2(1) \& (2); Decision 768/2008/EC, Art. R1 \& R2).

${ }^{435}$ E.g. Directive 2001/95/EC, Art. 1(1).
} 
between the directive and the NLF, has been problematic for at least some market surveillance authorities.

The legal complexity caused by the lack of alignment between the NLF and the GPS Directive has produced a situation of ambiguity fostering divergent interpretations of whether (and how) the notions 'placing on the market' and 'making available on the market' are applicable to non-harmonised consumer products, and what they mean. ${ }^{436}$ This confusion has, amongst other consequences, resulted in different answers to the question of which norms must be applied to consumer products: the norm that applied at the moment the product was 'placed on the market', or the norm applicable when the product was 'made available on the market', and only in the framework of purchasing transactions, or also in the context of the provision of a service.

National interpretations do not always concur with the answer to this question provided by the European Commission; ${ }^{437}$ as a result, different norms may be applied to the same product throughout the EU. While these differences do not necessarily lead to legal problems - in principle, compliance with norms established under the GPS Directive is voluntary - it does lead to legal uncertainty for economic operators and to unequal levels of consumer protection. An authoritative interpretation by the CJEU may, in this regard, be useful for ensuring that legal provisions are interpreted uniformly throughout the EU, and for helping member states understand their obligations in the implementation process.

\subsubsection{Preliminary rulings for the IPPC Directive}

\section{A. Contents}

Six preliminary rulings have been delivered on questions that have arisen in the context of the implementation of the IPPC Directive. Three of these rulings concern questions related to the rules for access to justice that are outlined in the Aarhus Convention and implemented in, amongst others, the IPPC Directive. ${ }^{438}$ These rulings are not relevant to

\footnotetext{
${ }^{436}$ Given that Regulation 765/2008/EC covers all harmonised products and the principle of lex specialis vis-àvis the GPS Directive applies where the notions of 'placing on the market' and 'making available on the market' are concerned. The definitions outlined in this regulation apply to all harmonised consumer products that may for other purposes be subject to the GPS Directive. Thus, harmonised consumer products may be subject to (at least) three legal acts: the relevant sector directive (for product-category-specific provisions), Regulation 765/2008/EC (for accreditation and market surveillance provisions), and the GPS Directive (for more specific measures compared to those provided by the Regulation, and, in certain cases, for RAPEX notifications).

${ }^{437}$ The EC has maintained that every time a product is supplied on the market in the course of a commercial activity, which includes the provision of services, the then-applicable norm shall apply. This means that in theory, products traded in any type of commercial transaction shall always be in conformity with the latest norms relevant for that specific product.

${ }^{438}$ Case C-260/11 The Queen, on the application of David Edwards and Lilian Pallikaropoulos $v$ Environment Agency and Others [2013] not yet published; case C-416/10 Jozef Križan and Others v Slovenská inšpekcia životného prostredia [2013] not yet published; and case C-24/09 Djurgården-Lilla Värtans Miljöskyddsförening $v$ AB Fortum Värme samägt med Stockholms stad [2010] ECR 2010, I-00035.
} 
the subject matter of this study and therefore are not elaborated on here. The remaining rulings do seem potentially useful for officials in environmental licensing processes; it is, therefore, these rulings that are discussed in the remainder of this paragraph.

Two judgements concern the interpretation of terms that are used in Annex I of the IPPC Directive, which lists the installations subject to an IPPC permit. One judgement concerned the reference for a preliminary ruling submitted by the Danish Vestre Landret on the interpretation of the expression 'places for sows'; ${ }^{439}$ in particular whether this expression must be interpreted as covering places for gilts. The Court stated that this expression must indeed be interpreted as such. ${ }^{40}$ Another ruling, submitted by the French Conseil d'État, ${ }^{441}$ concerned the interpretation of the term 'poultry'. The Court stated that this term must be interpreted to include quails, partridges and pigeons. Regarding the system to calculate the number of different types of poultry authorised for a farm for the intensive rearing of poultry, the Court stated that the relevant provision precludes national legislation that calculates the number of poultry by considering the amount of nitrogen excreted by the various bird species. ${ }^{442}$

The third and final relevant ruling concerns a request submitted by the Dutch Raad van State about whether the national emission ceilings for $\mathrm{SO}_{2}$ and for $\mathrm{NO}_{\mathrm{x}}$ outlined in the Directive on national emission ceilings (NEC Directive) ${ }^{443}$ must be included in the conditions for granting an environmental permit, in particular in the determination of emission limit values based on BAT. The CJEU stated that member states are not obliged to do this. The Court recalled that none of the relevant articles of the IPPC Directive refer to those emission ceilings. Article 9(4) of this directive merely states that emission limit values must be based on the application of BAT, without prescribing the use of any technique or specific technology. Moreover, the NEC Directive states that its

$66 \%$ of the IPPC survey respondents agree (or sometimes strongly agree) that preliminary rulings on the interpretation of the IPPC Directive are helpful. $62 \%$ agree (or sometimes strongly agree) that such rulings address the relevant questions. These numbers are considerably lower for permit writers.

IPPC Directive is to achieve integrated pollution prevention and control in order to attain a high level of environmental protection as a whole, the (quantitative) objective of

\footnotetext{
${ }^{439}$ Directive 96/61/EC, Annex I, subheading 6.6.(c), as amended by Regulation (EC) No 166/2006.

${ }^{440}$ Case C-585/10 Niels Møller v Haderslev Kommune [2011] ECR 2011 I-13407.

${ }^{441}$ Case C-473/07 Association nationale pour la protection des eaux et rivières-TOS and Association OABA $v$ Ministère de l'Ecologie, du Développement et de l'Aménagement durables [2009] ECR 2009 I-00319.

${ }^{442}$ Directive 96/61/EC, Annex I, subheading 6.6.(a), as amended by Regulation (EC) No 1882/2003.

${ }^{443}$ Directive 2001/81/EC of the European Parliament and of the Council of 23 October 2001 on national emission ceilings for certain atmospheric pollutants [2001] OJ L 309/22.
} 
the NEC Directive is to limit emissions in order to improve the protection of the environment and human health, with the long-term purpose of not exceeding critical levels and loads. ${ }^{44}$ Put briefly, what the Court said in this judgement is that member states may take the NECs into consideration in the determination of permits, but that this is not obligatory.

\section{B. Usefulness}

Familiarity with the preliminary rulings discussed above appears incomplete. A Polish ministerial official claims only to be familiar with the ruling requested by the Vestre Landsret on the rearing of pigs, which is referred to as "quite useful and technical in terms of rearing methods, although it did not refer to the BREFs" ${ }^{445}$ Dutch officials are generally familiar with the ruling on the relation between the NEC Directive and the IPPC Directive. This is explicable in view of the fact that this ruling was submitted the request of the Dutch Council of State, and officials were made aware of it through a verbal debriefing organised by InfoMil. ${ }^{46}$ The relevance of this ruling for the Dutch permitting practice is underlined by the fact that interviewees refer to the "failure of the Netherlands" to deal with the relevant issue and the resulting "legal tensions" in this regard. ${ }^{447}$ Interviewees indicate that this ruling has helped them arrive at adequately motivated permits and has made it easier for them to justify the prescription of strict permit requirements. ${ }^{448}$ Note that InfoMil only follows preliminary ruling proceedings that are relevant to the Dutch permitting practice - which may be the case when permit writers have indicated that they struggle with the issues at stake in such proceedings and that this has until now only been the case for the NEC ruling. ${ }^{449}$ In view of this situation, and in view of the fact that officials seem unlikely to look for such rulings alone, the incomplete familiarity amongst officials with preliminary rulings is not surprising.

The fact that the issues addressed in preliminary rulings do not include those that are particularly relevant for authorities to the implementation process does not necessarily make preliminary rulings 'useless'. This seems clear from the survey results, which are shown elsewhere in this section; about two-thirds of the survey respondents (strongly) agree that preliminary rulings on the interpretation of the IPPC Directive are useful. However, had preliminary rulings addressed the core issues that actors struggle with in the implementation process, it is likely that more officials would have known about such rulings and perceived them as useful. Such core issues concern the status of the BREF

\footnotetext{
${ }^{444}$ Joined cases C-165/09 to C-167/09 Stichting Natuur en Milieu and Others v College van Gedeputeerde Staten van Groningen (C-165/09) and College van Gedeputeerde Staten van Zuid-Holland (C-166/09 and C-167/09) [2011] ECR 2011 I-04599.

${ }^{445}$ Email from interviewee PL8 to author.

${ }^{446}$ InfoMil, the Dutch Knowledge Centre for Environmental Legislation and Policy, acts as the information channel between the Commission and the European IPPC Bureau and permitting authorities.

${ }^{447}$ Interview NL23.

${ }^{448}$ Interview NL21; NL22.

${ }^{449}$ Interview NL31.
} 
guidance documents and the way in which authorities ought to deal with the ranges of emission limit values outlined in the BREFs; issues that were earlier referred to as having created problems in the implementation practice. ${ }^{450}$ Studies also identify numerous other interpretational issues that concern the implementation of an integrated approach' to pollution prevention and control; ${ }^{451}$ the scope of the terms 'air', 'water', and 'soil'; ;52 and the precise weight to be attached to raw materials and to energy efficiency in decisions on permit applications. ${ }^{453}$

It is possible that the considerations outlined in Section 1.2.2 of this chapter, which identify manifold behavioural factors that may withhold national courts from referring questions to the CJEU, explain why such issues are not referred to the CJEU for clarification, at least for some courts and some member states. What may also have explanatory potential is the idea that some issues that do cause confusion are "not heavy enough" for preliminary rulings to be requested. ${ }^{454}$ It is only when national courts cannot solve the case on their own and guidance provided by the European Commission does not provide clarity that the Court is potentially useful, officials say. ${ }^{455}$ If this is true, one must assume that national courts have not felt the need to look for external guidance and that guidance provided by the Commission, which all officials indicate that they resort to when legislative provisions are unclear, ${ }^{456}$ is sufficient to solve problems of interpretation. While the former aspect might be doubted in view of the fact that courts do not always possess sufficient expertise in the area of IPPC, ${ }^{457}$ the latter aspect may be questioned in view of the fact that there are problems associated with Commission guidance.

One of these problems is that the Commission does, in fact, not always provide guidance, as Chapter 5 on post-legislative guidance suggests. ${ }^{458}$ Second, while Commission guidance may be useful for the author of the questions, it is not necessarily useful across the board. This is the case, since there is no guarantee that Commission guidance is disseminated to other member states as well - unless it is published on the Commission's website and such publication is known to authorities throughout the EU. Third is the question of whether or not Commission guidance would stand in court if the CJEU were to rule on the relevant issues. ${ }^{459}$ And fourth - and partly related to the latter point while officials refer to Commission guidance as useful, ${ }^{460}$ some of them also say that it is

\footnotetext{
${ }^{450}$ See Chapter 5 on post-legislative guidance, Section 3.4.1.

${ }^{451}$ Bohne and Dietze, 2004: 199; Doppelhammer, 2000: 199-200.

${ }^{452}$ Oosterhuis et al., 2007: 25.

${ }^{453}$ Ibid.: 23.

${ }^{454}$ Interview NL31.

${ }^{455}$ Ibid.

${ }^{456}$ Interview NL26; PL8; PT9.

${ }^{457}$ For this notion, see Section 3.1.2.2 above.

${ }^{458}$ Chapter 5 on post-legislative guidance, Section 3.4.1.

${ }^{459}$ Interview NL31.

${ }^{460}$ Ibid.; PT9; PL8.
} 
"not binding and in many cases very general" ${ }^{461}$ This latter issue leads us back to a point that has been made before, namely that guidance that is not seen as 'binding' may not be regarded as authoritative by authorities and regulated entities alike; thus, such guidance may not actually solve the problems that officials struggle with in the implementation process. This might be a problem for Poland in particular, since calls for binding guidance in the area of IPPC - and in other areas for that matter - have been loudest here. ${ }^{462}$ In the Netherlands, in contrast, Commission guidance in the area of IPPC is considered authoritative and is 'sold' to companies as something that authorities and companies must follow. ${ }^{463}$

The lack of preliminary rulings on issues that have created considerable interpretational diversity is said to be one of the causes for "the many complaints" that citizens seem to submit to the European Commission on the implementation of the IPPC Directive. ${ }^{464}$ Dealing with these complaints requires the implementation of significant resources on the part of the Commission; resources that the Commission is not thought to have at its disposal, at least not sufficiently so. ${ }^{465}$ Preliminary rulings may mitigate the pressure on the Commission, because member states would have to resort to the Commission for guidance less often - guidance that, given the vagueness of the directive, is often difficult to develop - and because citizens would have no reason to complain if the administration implemented the lessons learned from preliminary rulings. It seems that the key to improving the preliminary ruling system lies with national authorities and national courts, which should (point out the need to) ask the CJEU for guidance more often.

\subsubsection{Synthesis}

The foregoing analysis of the usefulness of preliminary rulings suggests that the potential for the preliminary ruling system to act as a compliance instrument is underexploited. This is because, while existing rulings may be experienced as useful for clarifying legislative provisions, provisions that are the source of a great deal of confusion and the cause of interpretational diversity across member states remain unaddressed. Of course, this is not an issue that the CJEU can solve; it is an issue that is first and foremost up to national authorities and national courts to address. While it is the former that can request that national courts ask the CJEU for a preliminary ruling, it is the latter that act as gateways to the Court in Luxembourg.

\footnotetext{
${ }^{461}$ Email from interviewee PL8 to author.

${ }^{462}$ See Chapter 5 on post-legislative guidance, Section 3.4.

${ }^{463}$ Interview NL31.

${ }^{464}$ Interview NL17. Chapter 4 on monitoring and sanctions suggests that the Commission received 60 complaints on the implementation of the IPPC Directive that were eligible to be taken forward by formal infringement proceedings. The numbers for the GPS Directive and the SAFA Directive are three and zero, respectively. See Chapter 4, Section 2.1 .

${ }^{465}$ For a discussion of this issue, see Chapter 4 on monitoring and sanctions, in particular Section 1.2.1.2.
} 
The foregoing sections suggest that there are several factors that prevent (more) preliminary rulings from being requested. One of these is that national case law is not always present; a fact that Section 2.1 suggests applies to the majority of cases examined in this study. When national case law is absent, opportunities for national authorities and national courts to indicate a need for preliminary rulings are, self-evidently, lacking. A second factor that prevents preliminary rulings from being requested is that national administrative authorities and national courts involved in domestic proceedings may not see a purpose to asking the CJEU for support. Courts may prefer to solve issues by themselves, for a variety of reasons that Section 1.2.2 suggests may be relevant, but which the verification of is beyond the scope of this study. Authorities appear to have a preference for resorting to the Commission for guidance or to other member states for informal problem resolution. In view of the problems associated with these two strategies, both are imperfect for ensuring that interpretational problems are eliminated, and preliminary rulings may be helpful for implementing actors in the implementation process.

\section{Concluding remarks: how and when does case law work?}

This chapter suggests that the usefulness of case law as a compliance instrument is variable. This applies to both case law issued by national administrative courts and to preliminary rulings issued by the Court of Justice of the European Union. The following two subsections aim to summarise the findings presented in the preceding sections of this chapter and to outline the conditions that these sections suggest make case law work (better) as a compliance instrument.

\subsection{National case law}

National case law may be a useful compliance instrument for national officials in the administration of EU law, by solving legal disputes and in particular, by clarifying legal provisions that have triggered problems of interpretation. The usefulness of national case law is, however, conditioned on so many 'ifs' that it is difficult to speak of it as a reliable compliance instrument. Table 39 summarises the factors that, according to the empirical sections of this chapter, explain the usefulness of national case law as a compliance instrument. These factors are recapped further below. 
Table 39 Conditions for national case law to be a useful compliance instrument

Case law must exist in the first place. This is the case when:

- there are capable actors that see a point in engaging in administrative litigation

- prejudicial problem-solving mechanisms do not exist or fail to deliver results

- interests in a positive outcome of the case outweigh (possible) financial or reputational costs

- rules for access to justice do not pose insurmountable obstacles for actors to engage in litigation

- the outcome of judgements is expected to be useful

- litigation is commonly used as a dispute-resolution tool

Case law must solve the dispute at stake and provide clarity. This is most likely to be the case when:

- claimants challenge the administration's compliance with substantive rather than procedural rules

- judges posses sufficient expertise to solve the substantive issue at stake

Case law must be implementable in practice. This is the case when:

- authorities have the resources to implement the judgement

The empirical sections of this chapter demonstrate significant variance regarding the prevalence of case law across member states and across policy domains. While Portugal is conspicuous because of the absence of case law in all of the three policy areas subject to this study, Poland is unique because of the presence of case law in the area of general product safety. The area of IPPC has created case law in both Poland and the Netherlands. In the domain of SAFA, finally, case law is virtually absent across countries; there are only two cases in the Netherlands.

This chapter suggests several factors that may, together, explain the varying prevalence of national case law across countries and across policy domains. Regarding crosscountry variance in the prevalence of case law within the same policy domain, national procedural law provisions regulating access to justice and the intangibles of litigation culture seem to be relevant mediating factors. The existence of regulated actors that see 'a point' in engaging in litigation, financial and reputational interests of potential litigants, and expectations on the usefulness of judgements to be delivered by the court seem to account for the cross-issue variance that is observed. The presence of civic organisations, and the capacity of such organisations to act as watchdogs of the state in the implementation process, explains the variation across policy domains and across states. The noted variance in the prevalence of case law suggests that while case law might be a useful instrument in some countries and in some policy areas, it is bound to be much less of a useful mechanism in other countries and in other policy areas.

This chapter also suggests that evaluations of the usefulness of case law are determined by the extent to which court rulings go beyond an 'easy' solution for the dispute at stake in the proceedings. For case law to be truly helpful, jurisprudence must include clarifications of substantive legal provisions relevant to the legal dispute. That such clarifications do not always ensue is shown by each case studied in this chapter. That such clarifications do not need to be 'world changing' to be useful for implementation actors is shown by the Polish case on jurisprudence in the area of general product safety. 
Here, the authoritative nature of court rulings is referred to as making such rulings useful for easing relations with regulated entities, regardless of the limited clarifying effect that these rulings have produced in many cases. The Polish case also shows that resource limitations may make it difficult for the administration to comply with (more far-reaching) judicial interpretations in practice. In this case one may wonder to what extent such interpretations constitute a help - rather than an obstacle - for authorities in the implementation process.

The notion that judicial interpretations may make national jurisprudence one of the most important compliance instruments is illustrated by the Dutch case of jurisprudence in the area of integrated pollution prevention and control. While case law has not solved each and every instance of a lack of clarity, its effect on the implementation practice has been considerable, in a positive way. Many of the court proceedings in the area of IPPC were initiated by environmental NGOs, sometimes in cooperation with citizens or grass-roots organisations; this underlines the link between the current chapter and Chapter 7 on civil society, and the relevance of civic organisations to engaging in litigation in areas that regulate public goods, of which the environment is a prime example. Indeed, had Dutch environmental organisations not been as active in starting court proceedings as they have been, court proceedings in the area of IPPC would have occurred much less frequently. Furthermore, had such organisations not been as knowledgeable and expertised as they (or at least some of them) were, jurisprudence would have been much less helpful for implementing authorities from a substantive point of view.

The idea that case law may rarely be enlightening from a substantive point of view was suggested by the Polish case of jurisprudence in the area of GPS, and it is confirmed by case law in the area of IPPC as well. Polish case law in this latter area does not generally touch upon substantive issues. The idea that judgements, in many cases, fail to do so is explained as much by the failure of business and civil society actors to challenge the substantive issues at stake, as it is explained by a lack of expertise on the part of judges that rule on such issues. Both factors are intertwined, since what motivates actors to challenge the administration's compliance with procedural rules is a lack of expertise for these actors to challenge the substance of the case, and awareness that judges do not possess sufficient expertise to rule on the merits of the case. While the Polish case of jurisprudence in the area of IPPC particularly exemplifies the first notion, Polish case law in the area of general product safety specifically illustrates the second idea.

The Dutch case on jurisprudence in the area of IPPC highlights the value of the availability and consultation of out-of-court expertise that is required for case law to be useful, and for litigation to be used as a dispute-resolution mechanism in the first place. The area of product safety, on the other hand, demonstrates that case law may be lacking because of awareness, on the part of potential litigants, of the lack of knowledge of judges. Together, the Dutch and Polish cases question the extent that jurisprudence 
issued in highly technical areas can be helpful as a compliance instrument; they also mitigate expectations of the degree to which case law in such areas is used as a problemsolving instrument in the first place, at least where judges are known to lack the expertise to solve the substantive issues at stake and the consultation of external experts in court proceedings is not likely.

In view of the multiplicity of factors that should come together in order to make case law work - and given the fact that the case studies show that such a situation does in many cases not materialise - it seems that rife optimism on the usefulness of case law as a compliance instrument is misguided. This is unfortunate, in particular where national guidance that may not be considered authoritative or that may, inadvertently or on purpose, not represent a correct interpretation of EU law provisions is relied on. The problem is that an easy solution to this situation does not exist; case law does not simply 'spring up', and unlike other compliance instruments (bar, markedly, a flourishing civil society) case law cannot be created at will. Rules for access to justice may be broadened, but as long as there are no (civil society) actors that are capable of bringing a case to court, and litigation is not commonly seen as a way to stand up for one's rights, it is unlikely that litigation will become a popularly-used dispute-resolution mechanism in policy sectors and/or member states. In addition, if judges are not provided the tools that are required to solve the substantive legal tensions underlying disputes, case law is not expected to be useful, beyond providing momentary relief to parties in the proceedings and constituting an authoritative point of reference. When case law does function in such a way as to clarify substantive legal provisions that authorities have struggled with in the implementation process, however, case law may be a very useful instrument for supporting authorities in the application process.

\subsection{Preliminary rulings}

The picture of the usefulness of the EU's preliminary ruling system for supporting national competent authorities in the law administration process seems as mixed as the picture that is depicted in relation to the usefulness of national case law. This is, first, because national officials that could, in theory, benefit from existing rulings are not always familiar with them. Second, while some preliminary rulings are referred to as useful for the implementation practice, existing rulings do not address those issues that seem to have caused the greatest degree of confusion amongst implementing authorities across member states. The status of the BREFs is a prime example of this.

From a policy-effectiveness point of view, preliminary rulings would, in the latter type of cases, be desirable for ironing out differences in the interpretation of the relevant provisions and for harmonizing implementation practices across member states. Note, however, that the harmonizing potential of preliminary rulings is not necessarily at the forefront of officials' minds (nor is it the focus of this study). Preliminary requests are not necessarily motivated by concerns about a lack of uniform law administration prac- 
tices across member states; rather, they are motivated by an appreciation of the potential usefulness of Court rulings for providing the competent authorities in the member state that issued the request to the CJEU with much-needed clarification. While this fact does not rule out the submission of requests following awareness of different administrative and/or judicial interpretations across member states, it does mean that what matters first and foremost is whether or not national judges find the law to be clear. When the answer to this question is positive, preliminary requests are unlikely to be submitted.

All of this suggests that it is too easy to say that recourse to the CJEU should be had in all cases in which judicial interpretations across member states happen to diverge. However, there are cases in which such recourse would have been logical in view of the insecurities that national officials themselves claim to be confronted with. In these cases, the fact that recourse to the CJEU did not occur is concerning. This is the case, since other mechanisms that officials may resort to do not constitute true alternatives to preliminary rulings. Certainly, post-legislative guidance may be helpful for addressing problems in the implementation of the law, as this chapter and Chapter 5 on postlegislative guidance suggest. However, both chapters also suggest that guidance has several downsides, and that one of them - its soft-law nature - may be problematic if a binding interpretation is what officials need most and nonbinding guidelines is what they get. Downsides apply to problem-solving strategies that are used by member states acting in concert as well; these downsides include not only the informal nature of agreements, but also the questionable willingness of member states to share their problems with their colleagues to begin with. Both post-legislative guidance and informal problem-solving arrangements are, thus, clearly suboptimal mechanisms for solving interpretational difficulties

It is particularly in view of the downsides of alternative instruments, that preliminary rulings may be very useful for supporting officials in their daily work. The idea that some officials say it would be useful if (more of) such rulings existed, might be seen to highlight the veracity of this idea. That it is national courts that act as gatekeepers in the EU's preliminary ruling system, and that national authorities often prefer to resort to alternative mechanisms - even when they have the opportunity to share their doubts in court proceedings - suggest that the key to making the system work better is first and foremost in the hands of the member states. 



\section{PART V \\ CONCLUSIONS \\ AND RECOMMENDATIONS}





\section{Chapter 9}

What works to make EU law work?

Conclusions and recommendations 



\section{What this study set out to do}

This study aims to provide insight into what works to make EU law work. This objective was set out of awareness that EU law does not always work as it should; member states do not always comply with EU measures, as a result of which the policy objectives set are not always achieved, and the beneficiaries of EU measures do not by definition enjoy the rights granted to them by these measures. While all legal systems are bound to suffer from a certain rate of noncompliance - achieving full compliance is therefore an illusion and, one may argue, even undesirable - the relatively novel nature of the EU as a political system makes compliance problems more urgent. This is because the Union still needs to prove its credibility as an effective problem-solving system, and the effective implementation of EU measures throughout the Union is nothing less than essential in this regard. Indeed, the added value of the EU is uncertain if its measures do not benefit those whom they are intended to benefit. ${ }^{1}$

In view of their adverse consequences, compliance problems are serious enough to merit political and scholarly attention. In fact, both in the political and in the academic world, the idea that the EU has a compliance deficit - and the related idea that compliance problems must be solved - has become much of a platitude. The past two decades have seen the appearance of numerous EU documents outlining the need to improve the implementation of EU law. Focusing mainly on the transposition phase of the implementation process, the increasing body of scholarly literature has not only shown that compliance problems exist, it has also identified a variety of structural and circumstantial factors underlying such problems. From veto players to issue salience, from misfits to Chinese Walls, and from government preferences to administrative capabilities explanations for transposition problems are plentiful. ${ }^{2}$

While EU implementation research has delivered valuable insight into the problems encountered by member states in the transposition of EU directives, three notable lacunae exist. The first is that this research provides little insight into member states' behaviour during the application phase of the implementation process; that is, the phase during which the provisions of EU measures are - or must be - applied to concrete cases on the ground. We know little about compliance, and about the problems experienced by street-level implementing actors, at this stage of the implementation process. This lack of attention to the application phase of the implementation process may be explicable by the fact that it is difficult to monitor the application of EU law on the ground. However, since the application of EU rules is essential if these rules are to achieve their full effect, this lack of attention causes concern.

Second, EU implementation research has done little to establish a general theory of implementation in the EU. Rather than aiming to identify possible causes of a phenom-

\footnotetext{
${ }^{1}$ See Chapter 1 on making EU law work: a problem in need of a solution, Section 1.

${ }^{2}$ Ibid. and Chapter 2 on implementation in the EU: same rules, divergent practices, Section 3.2.
} 
enon, theory building should aim to establish causal relationships between variables that are generalised explanations of this phenomenon. From this point of view, the abundance of factors proposed as explaining implementation processes or outcomes have not contributed to the formulation of a generally applicable, straightforward explanation for implementation in the EU. ${ }^{3}$ The question is whether ambitions to arrive at such a theory of implementation are realistic. It seems difficult to find a common denominator amongst cases that may serve as a starting point for theory building. What seems certain is that trying to explain divergent implementation records by reference to another set of case studies - and possibly another set of explanatory variables - is likely to fail to fulfil this ambition. In view of the questionable added value of such an endeavour in terms of theory building, this study has opted not to take this route.

A third limitation of EU implementation research is its excessive focus on implementation failure - as though all policies are bound to fail, and as though member states act in a vacuum when implementing EU rules. The majority of studies seem to have overlooked the fact that instruments that are designed to offer solutions to compliance problems, or that may otherwise be expected to support member states in the implementation of EU measures, do exist. While knowledge about variables explaining implementation problems may be relevant for practitioners attempting to close implementation gaps, it seems that practitioners may benefit not only from knowledge on 'what goes wrong' in the implementation of EU law, but also from knowledge on 'what goes right'. More concretely, they may benefit from insight into the functioning of tools that may be helpful for making EU law work better.

In view of the considerations outlined in the previous paragraphs, this study suggests that it may be promising to reverse our perspective on implementation and compliance in the EU. Thus, instead of focusing on the transposition phase of the implementation process, this study directs its attention to the phase during which EU measures must be applied in concrete situations on the ground. And rather than concentrating on problems that member states may encounter in the application of EU measures, this study takes a solution-oriented approach. It does this by evaluating the usefulness of compliance instruments for supporting the competent administrative authorities of the member states in the application of EU law.

\section{Approach and methodology}

Compliance instruments are conceptualised as those mechanisms that are designed to improve the application of EU measures by the national competent authorities, or that may otherwise be expected to have the effect of supporting the authorities' work in this regard. In view of the idea that existing taxonomies of policy instruments - and other

\footnotetext{
${ }^{3}$ Chapter 2 on implementation in the EU: same rules, divergent practices, Sections 3.2.4 and 3.3.
} 
models that appear natural or suitable for the categorisation of such instruments - do not seem to provide an adequate framework for studying compliance instruments, this study categorises compliance instruments based on an appreciation of the institutional context embedding the main actors involved in making these instruments work. Since these actors may be found within the national, transnational, or supranational institutional context, the compliance instruments that were found are categorised as belonging to either of these levels. ${ }^{4}$ These levels, which have been used as the basic structure of the empirical core of this study, and the accompanying instruments, which are discussed in separate chapters, are shown in Figure 16. Explanations as to why these instruments might be expected to support the application of EU law by the authorities of the member states are provided in Section 4.2 below, which summarises the findings of this study as to the usefulness of each compliance instrument.

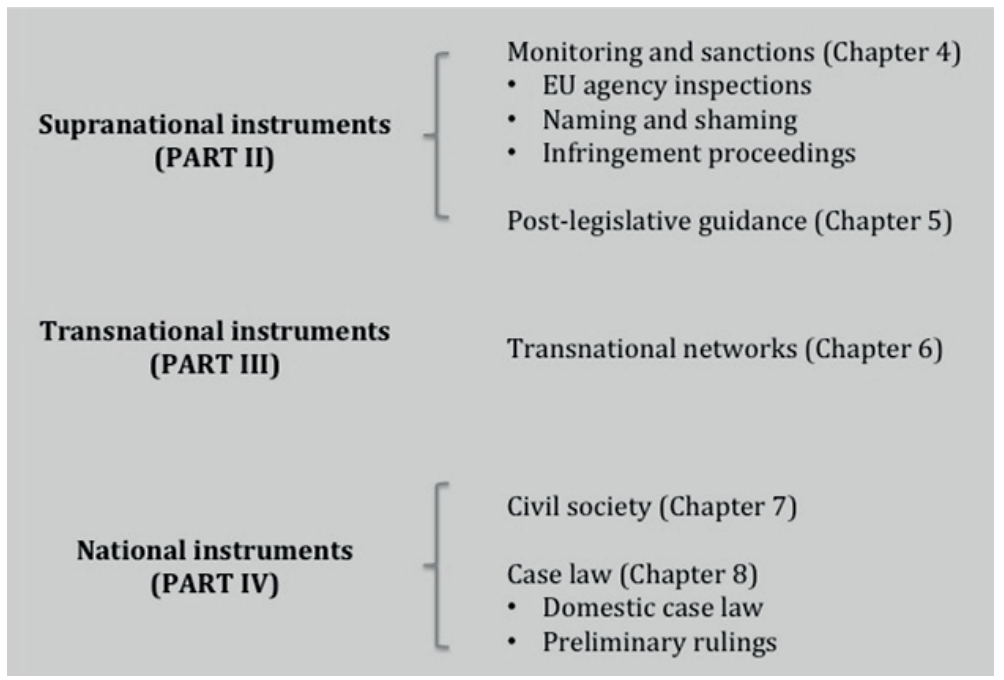

Figure 16 Compliance instruments: categorisation and specification

Since an evaluation of the usefulness of compliance instruments involves more than meets the lawyer's eye, this study takes an interdisciplinary approach, combining perspectives from legal science with those pertaining to political science, and in particular public administration. More concretely, the methods used in this study include case law analysis, literature and policy document analysis, survey methodology (77 completed surveys), and qualitative interviewing (91 interviewed officials). The combination of these methods is well suited to analysing the usefulness of compliance instruments. Case law analysis and literature and policy document analysis were needed to obtain insight into the conceptual, practical, and political frameworks in which compliance instru-

\footnotetext{
${ }^{4}$ See Chapter 3 on the approach and methodology of this study, Section 3.
} 
ments exist, and into the design of these instruments. A survey and qualitative interviews were needed to acquire insight into the perceptions of actors involved in the law administration practice. The perceptions of these actors are relevant because it is impossible to evaluate the usefulness of compliance instruments objectively, by establishing causal relationships between concrete compliance instruments and (improved) application practices. This impossibility arises not only because instruments interact with each other, but also because they interact with, and are influenced by, factors of a circumstantial nature. In addition, the perceptions of actors, who compliance instruments are supposed to affect, play an important mediating role in the how these instruments are used and the impact that they have. It is for these reasons that the preferences and beliefs of actors involved in the application of EU measures on the ground are helpful tools for assessing the usefulness of compliance instruments. ${ }^{5}$

In order to arrive at valid and in-depth insight into the usefulness of compliance instruments, this study uses a case-study methodology involving three EU directives and three EU member states. The directives selected for study are the Directive on general product safety, the Directive on integrated pollution prevention and control, and the Directive on the safety of third-country aircraft using Community airports. ${ }^{6}$ Table 40 shows that these directives demonstrate a variety of compliance instruments that may support national authorities in the implementation of the key provisions included in these directives. These key provisions require member states to assess the safety of nonfood consumer products and to adopt corrective measures when such products are evaluated as posing a risk to consumer health and safety (GPS Directive); to determine environmental permits for large industrial installations based on the best available techniques (IPPC Directive); and to conduct ramp inspections of third-country aircrafts suspected of noncompliance with international safety standards. ${ }^{7}$

\footnotetext{
${ }^{5}$ See Chapter 1 on making EU law work: a problem in need of a solution, Section 3.

${ }^{6}$ Directive 2001/95/EC on general product safety; Directives 96/61/EC and 2008/1/EC on integrated pollution prevention and control (now replaced by Directive 2010/75/EU on industrial emissions); and Directive 2004/36/EC on the safety of third-country aircraft using Community airports (repealed by Regulation (EC) No 216/2008 on common rules in the field of civil aviation and establishing a European Aviation Safety Agency and, since late 2014, substituted by generally-applicable implementing rules).

${ }^{7}$ See Chapter 3 on the approach and methodology of this study, Section 4.1.1.
} 
Table 40 Compliance instruments for the directives and member states included in this study

\begin{tabular}{llccc}
\hline Level & Instrument & GPS & IPPC & SAFA \\
\hline Supranational & Monitoring and sanctions & & & + \\
& EU agency inspections & - & - & + \\
& Naming and shaming & + & + & - \\
& Infringement proceedings & + & + \\
& Post-legislative guidance & + & + & + \\
Transnational & Transnational networks & + & + & + \\
National & Civil society & + & + & + \\
& Case law & & + \\
\hline
\end{tabular}

Note that in contrast to supranational and transnational instruments, the existence of national compliance instruments greatly depends on the institutional and societal arrangements within individual member states. The member states selected for study are the Netherlands, Poland, and Portugal, which are categorised as belonging to different worlds of compliance, and which are, thus, believed to face different problems in the application of EU law on the ground. While the effectiveness of administration and judiciaries is thought to ensure that application works well in the Netherlands, this is not the case for Poland and Portugal. Shortcomings in the court system and a weak civil society are thought to explain why application processes are weak in Poland; administrative inefficiencies may produce a mixed effect on implementation processes in Portugal. Including countries faced with a variety of obstacles in the process of applying EU law is essential if one aims to study what makes EU law work better across the board; when problems encountered in the application process are different, answers to what works to make application work better are expected to vary as well. ${ }^{9}$

\section{What this study has not done}

In order to frame the findings of this study on what works to make EU law work (better), the reader should be aware of the limitations inherent in this study. These limitations mainly constitute downsides of the in-depth nature of this study; they predominantly follow from the fact that this study includes only a limited number of countries and a limited number of policy domains. The following limitations are singled out as important in this regard.

\footnotetext{
${ }^{8}$ Actual infringement proceedings started for 'bad application'.

${ }^{9}$ See Chapter 2 on implementation in the EU: same rules, divergent practices, Section 3.2.4, and Chapter 3 on the approach and methodology of this study, Section 4.1.2.
} 
The first limitation of this study is that its intention to provide in-depth qualitative insight into the usefulness of compliance instruments comes at the expense of quantity concerning the national and EU officials interviewed for this study. The seventy-six national and EU civil servants interviewed for this study represent a small share of the numerous actors who are involved in the implementation of EU measures. ${ }^{10} \mathrm{~A}$ similar concept applies to the sixteen representatives of non-governmental actors who were interviewed. The limited number of interviewees poses the risk that idiosyncrasies are singled out rather than a picture of generally valid perceptions. Attempts to reduce the probability of such idiosyncrasies were made by sampling interviewees wisely, and by comparing the contents of the interviews to the responses of the officials who completed the survey that was circulated for this study. ${ }^{11}$

Second, while this study incorporates countries that the literature suggests face different obstacles in the implementation process, it seems incorrect to assume that countries categorised as belonging to the same world of compliance are equal. For example, while the Netherlands is classified as belonging to the same country cluster as Germany and Spain, one may argue that there are pronounced differences between these countries (for example regarding their territorial-administrative structure) that may affect the obstacles faced by actors in the application of EU law. When there are different obstacles, ways around these obstacles - or tools to remove these obstacles may be different as well. In other words, it is not necessarily the case that perceptions of civil servants from countries that find themselves in the same world of compliance are aligned. Unfortunately, the survey conducted for this study does not allows us to verify whether the views expressed by Dutch, Polish, and Portuguese officials are idiosyncratic or in line with the perceptions of officials from other countries belonging to the respective worlds of compliance; the number of survey responses for individual member states must be higher in order for such verification to be feasible. However, since it includes responses from seven to nineteen other member states per directive, ${ }^{12}$ the survey does allow us to verify whether the perceptions of officials from the three member states focused on in this study deviate (too much) from the aggregated views of officials from a larger number of member states.

A third limitation of this study relates to the number of EU measures covered. Concretely speaking, conclusions regarding the usefulness of compliance instruments for

\footnotetext{
${ }^{10}$ Note that this is less the case for the area of SAFA, where the number of officials responsible for carrying out ramp inspections is limited, and where either the great majority of SAFA inspection teams (in the case of Poland) or a relatively large share of inspectors (which is the case for the Netherlands and Portugal) were interviewed.

${ }^{11}$ A total of 77 completed responses were received: 40 responses for the survey on the GPS Directive, 30 for the survey on the IPPC Directive, and 7 for the survey on the SAFA Directive. For an explanation of these numbers, see Chapter 3 on the approach and methodology of this study, Section 4.2.1.

${ }^{12} 17$ for the survey on the GPS Directive, 15 for the survey on the IPPC Directive, and 7 for the survey on the SAFA Directive.
} 
making the three directives examined in this study work are not necessarily generalisable to other policy domains. The problems encountered by authorities in the implementation of norms in areas other than those included in this study may be of a different nature, which means that different mechanisms may be in place - or other or additional instruments needed - to make application work better. In policy areas in which the mechanisms examined in the current study are absent, the conclusions presented in the following sections might serve as a source of inspiration for practitioners in these areas. Where similar mechanisms to those discussed in this study exist in other policy domains as well, the perceptions of officials in such domains would need to be examined in order to achieve more certainty on the validity of findings across domains. Such an endeavour is beyond the scope of this study and might be undertaken in future research.

Finally, note that the analysis in this book does not necessarily indicate the effectiveness of compliance instruments for improving the application of EU law by the member states. For sound conclusions of this nature to be drawn, one must establish causal relationships between the presence of a compliance instrument and (changed) implementation practices. This is not possible, not only because compliance instruments do not act in isolation, but also because there are circumstantial factors that influence implementation processes. Moreover, it seems difficult to acquire precise insight into the state of application on the ground, particularly where the quality of the process (rather than the quantitative output) is concerned. For example, counting the number of industrial installations that have been granted an IPPC permit is easier than establishing whether or not all of these installations have been licensed in accordance with legislative requirements. In fact, the latter is an endeavour that is not feasible.

The explanatory remarks outlined in the previous sentences do not necessarily remove concerns about the problematic nature of using subjective perceptions as tools to assess the usefulness of compliance instruments. One cannot be sure that perceptions match reality. However, perceptions, when measured adequately, are useful tools for understanding phenomena. Since perceptions are general guidelines for action, they increase the likelihood that the behavioural dynamics of actors are connected to the perceptional patterns that they display. ${ }^{13}$ Note that the validity of officials' perceptions was verified by triangulation, both through interviews and through the survey that was circulated amongst authorities. In addition, the interviews and the survey that were conducted for this study are not the only sources of evidence; other methods - namely, case law analysis, and literature and policy document analysis - were used to assess the validity of perceptions as well. In other words, attempts to compensate for possible concerns regarding the subjectivity of perceptions were made.

${ }^{13}$ See Chapter 1 on making EU law work: a problem in need of a solution, Section 3. 


\section{What works to make EU law work?}

While the above sections outline the approach and methodological framework of this study and the limitations inherent therein, this section provides insight into what works best to support the application of EU law on the ground. It is by virtue of its multiinstrument focus - which has from the outset been thought of as indispensable in view of the variety of compliance instruments that exist - that this study allows us to bring several arguments to substantiate the conclusion that compliance problems can be addressed successfully only when the 'right' mix of compliance instruments is employed; the 'right' mix meaning a combination of tailor-made solutions when possible, and a harmonised approach when necessary. A mix must be employed, since compliance problems have different roots and since compliance instruments are interdependent (Section 4.1). Flexibility must exist in view of the fact that there is considerable cross-country and cross-issue variation in the usefulness of compliance instruments, as the empirical chapters of this study demonstrate (Section 4.2). Together, these chapters also suggest that there is a lot to be gained, for both the Commission and the member states, when it comes to the functioning of compliance instruments. Recommendations on how this twofold conclusion could be taken forward by the European Commission and by the member states are presented in Section 5 below. The remainder of this section aims to summarise the conclusions from the empirical chapters and explain why compliance instruments should be combined if compliance problems are to be solved effectively.

\subsection{Mixing compliance instruments}

Compliance problems are complex. This complexity is poorly addressed by the 'either/or approach' that perspectives on implementation and compliance have often propagated in the past. Such perspectives have suggested that compliance problems must be solved by resorting to enforcement tools (rationalism), capacity-building instruments (management perspectives), or socialisation strategies (constructivism). These suggestions follow from different assumptions regarding the roots of compliance problems; while rationalists argue that such problems are caused by unwillingness on the part of states to comply, managerialists maintain that states are willing to comply and that problems appear without rule clarity or present insufficient knowledge, expertise, or money on the part of implementing authorities. Constructivists, who are less concerned with whether compliance problems are intentional or capacity related, hold that compliance problems are caused by a lack of awareness or acknowledgement of 'what is the right thing to do' in a certain situation. ${ }^{14}$

It has become more accepted that while each of these sets of assumptions about the causes of compliance problems may have explanatory power in specific cases, neither of

\footnotetext{
${ }^{14}$ See Chapter 3 on the approach and methodology of this study, Section 2.
} 
them can individually account for the compliance gap in the EU. If this gap is to be closed, a combination of enforcement, capacity building, and socialisation strategies must be attempted. ${ }^{15}$ Sanctions, for example, may be efficient when authorities refuse to apply norms correctly, but they are doomed to be ineffective when authorities struggle with a lack of clarity about what must be implemented in the first place. And networks may be effective at socialising partaking officials into appropriate norms, but they may not be as effective at ensuring that the lessons that these officials take away from cooperation are implemented at home. It is from this point of view that using a combination of compliance instruments is indispensable if compliance problems are to be addressed successfully.

Combining compliance instruments is also necessary since compliance instruments are interdependent. Such interdependencies are explored in Chapter 3 on the approach and methodology of this study and examined in detail in the empirical chapters. ${ }^{16}$ From these chapters it is clear that compliance instruments may require each other in order for each of them to function effectively, or that they may reinforce one another. In this regard, reference may be made to the interdependencies that exist between preliminary rulings, national case law, and civil society activism. National courts are prime actors for making the EU's preliminary ruling system work; the CJEU would not deliver preliminary rulings if national courts did not submit requests to it, and preliminary rulings would not acquire any meaning in the national implementation context if national courts did not loyally comply with such rulings. National judges have little to refer to the CJEU where domestic case law giving rise to EU law questions does not exist. The latter may be the case when rules on standing are so strict, court costs so high, or court proceedings so lengthy, as to preclude potential litigants from resorting to the court in the first place.

When it is difficult for individual persons to gain access to the court or when such persons do not have any interest in challenging administrative acts, civic organisations may be indispensable for initiating domestic court proceedings against the administration. Such organisations may, however, lack the knowledge and expertise to successfully engage in court proceedings, or they may be absent in the first place. When the latter is the case, litigation may be non-existent. When the former is the case, the extent to which civic actors engage in litigation may be limited and the quality of their input may be substandard. In the latter situation, civic organisations may resort to challenging the administration's compliance with procedural rather than substantive norms, which means that the possibilities for national judges to address what should be the (substantive) core of the case may be few. If such core provisions cause much confusion at the

\footnotetext{
${ }^{15}$ See e.g. Van der Heijden, forthcoming; Börzel et al., 2010; Tallberg, 2002. The implications of this study for thinking on compliance are elaborated on in the Intermezzo below.

${ }^{16}$ See Chapter 3 on the approach and methodology of this study, Section 1.2, and in particular Sections 1 and 4 of the empirical chapters of this study.
} 
street level, such confusion is bound to persist because national judges are unlikely to give judicial interpretations of such provisions, and because such provisions are bound to escape potentially helpful preliminary ruling proceedings. Clearly, multiple instruments may reinforce each other's functioning or even require each other in order for each of them to work well individually; this suggests that the chain of compliance instruments may only be as strong as its weakest link. Thus, interdependencies are both a blessing and a curse. If individual instruments work well, the effect is an increased effectiveness of the entire 'package' of compliance instruments. If they do not, the effectiveness of the package is compromised.

Interdependencies similar to those described in the foregoing paragraph exist for other combinations of compliance instruments. Guidelines, for example, may help the Commission sustain infringement cases, particularly when these guidelines have been developed jointly with the member states. The elaboration of guidelines may be triggered by the Commission's monitoring activities that highlight diverging interpretations the same legal provision across the board. The initiation of infringement proceedings and the implementation of naming and shaming strategies depend on the information gathered by the European Commission through its monitoring activities. Complaints submitted to the Commission by civic actors are recognised as valuable in this regard, but for such complaints to be truly helpful, civic actors must possess the knowledge and expertise to assess the implementation performance of member states in the first place. It is also in these cases that the effective functioning of certain compliance instruments is conditioned on the effective functioning of others.

Note that the effective functioning of certain compliance instruments may also have the opposite effect and reduce the necessity or prevalence of others. For example, when national case law is successful at solving instances of noncompliance, infringement proceedings may be avoided. When guidelines effectively clarify questions regarding the interpretation of EU law, domestic court proceedings may be prevented and preliminary rulings regarded as unnecessary. While these cause-effect relationships are not always optimal (guidelines are, for example, not by definition an adequate substitute for preliminary rulings), they might produce positive effects in other cases. When violations of EU law are prevented or solved by instruments other than the infringement procedure this may be the case when such violations are caused not by a lack of willingness to comply, but by a lack of capacity or rule internalisation - the burden on the Commission as guardian of the treaties is reduced. The result is that the Commission may channel its resources to those cases that really require 'hard' action in the form of infringement proceedings, and such cases may be solved more effectively and more efficiently. This is advantageous not only for the Commission, but for the end users of EU norms - that is, citizens and businesses in the internal market - as well. Note that the extent to which compliance instruments do indeed have this effect is not explicitly focused on in this study; it seems useful for future research to focus on analysing this issue in more detail. 


\subsection{Flexibility: why a one-size-fits-all approach may not fit anyone}

While the above section suggests that a combination of compliance instruments is needed because the dynamics underlying compliance problems vary and because compliance instruments are interdependent, this section goes further and suggests that such combinations should be flexible to fit specific situations. Such flexibility is needed, since the usefulness of compliance instruments varies across policy areas and member states. The following subsections clarify the extent to which such variations exist, by summarising the findings of this study for each compliance instrument covered in the empirical chapters. Each subsection, subsequently, addresses the questions of why the relevant instrument may be expected to support the application of EU measures in the first place; how useful the instrument appears to be for supporting authorities in the application process and why this is the case; how officials' perceptions are confirmed or contradicted by the literature, policy documents, and case law analysed for this study; and under which conditions the instrument seems to work best.

\subsubsection{Monitoring and sanctions (Chapter 4)}

Chapter 4 on monitoring and sanctions broadly examines the usefulness of three compliance instruments: inspections conducted by EU regulatory agencies, naming and shaming strategies implemented by the European Commission and EU agencies, and infringement proceedings launched by the Commission. The following subsections address each of these instruments.

\subsubsection{Inspections}

Inspections carried out by EU regulatory agencies are primarily aimed at monitoring the implementation performance of member states and correcting existing instances of noncompliance detected in the course of inspections. In the context of this study, such inspections are conducted only in the area of SAFA; here, the national competent authorities responsible for the implementation of the SAFA Directive are subjected to regular standardisation inspections carried out by the European Aviation Safety Agency. While Commission officials maintain that such inspections offer them precise insight into the application performance of national authorities, EASA officials argue that inspections not only have a monitoring, but also an educational function. This means that their effect is meant to be the enforcement of EU law and the facilitation of national authorities in their work.

The usefulness of EASA inspections for officials involved in the implementation of the SAFA Directive appears to vary across member states. Polish SAFA inspectors seem to perceive such inspections exclusively as compliance monitoring tools and regard EASA as a 'police authority' only. The implication of the perception of the agency as being there merely to test and try the performance of the inspectors and to correct them 
when justified, makes it difficult for a fruitful learning environment to develop - no matter how much the EASA team may try to establish a 'classroom situation' as it intends to do. Note that this does not mean that officials are not willing to learn; it only means that the context in which learning is supposed to take place may not be the 'right' one.

In contrast to the Polish perceptions outlined above are the perceptions held by Dutch inspectors. These inspectors do not seem too impressed by the policing aspect that accompanies inspections; an attitude that may partially be explained by the fact that Dutch inspectors perceive their own implementation performance as adequate. Perceptions of standardisation inspections amongst Dutch officials are generally appreciative; Dutch inspectors indicate that such inspections are useful because of the learning opportunities that they offer and because the inspection results can be used as a safeguard in relation to managers who may be eager to cut resources. The irony is that in order for inspection results to be used in the latter way, implementation should not be 'too good', since if EASA were to establish perfect compliance, inspection results might provide managers with sufficient grounds to cut resources.

Finally, Portuguese SAFA inspectors indicate that they would like to learn from the EASA inspection team, but that learning often fails to materialise. This is the case because SAFA inspectors are not allowed to be sufficiently open about problems encountered by them in the implementation process; it is the case also because of the alleged insufficient knowledge and expertise demonstrated by the EASA inspection team that visited Portugal. The Portuguese case also shows that the relevance of agency inspections may differ depending on the position of officials in organisations. In contrast to the perceptions of street-level actors stands the appreciation of inspections held by the Portuguese SAFA national coordinator, who, acting as a manager only, appears to value the reassurance function of inspections in particular. These perceptional differences highlight the importance of studying not only the perceptions of higher-level civil servants who are formally responsible for ensuring correct application, but the perceptions of street-level actors involved in the application of EU law on the ground as well.

It seems that for inspections to be useful compliance instruments it is required, first, that they have a monitoring function and aim to offer learning opportunities for inspected authorities. Second, members of the inspection team should possess sufficient knowledge and expertise to act as teachers in relation to national officials. Finally, the (organisational) culture of member states (or national authorities) should enable learning to occur. The case studies included in this study suggest that meeting the two latter conditions is not a matter of course.

\subsubsection{Naming and shaming}

Naming and shaming basically consists of benchmarking the implementation performance of member states and showcasing those countries whose performance is sub- 
standard. Naming and shaming can take place en plein public, in reports published by the Commission or by an EU agency on the implementation of EU measures by the member states. Naming and shaming can also be a 'secretive' exercise, which is the case where information on the implementation performance is shared 'amongst intimae'; that is, with national representatives gathering in Council working groups, expert groups, or implementation networks. Whichever the degree of openness, naming and shaming is usually associated with 'soft' enforcement, since rather than imposing 'hard' sanctions - penalties or fines - on laggard states, it is the (threat of) reputational costs following from bad rankings that should compel member states into compliance.

This study suggests that EU reports are rarely considered useful instruments for supporting national officials in the application of EU law. This is the case, since streetlevel actors are not familiar with such reports or because they do not see how such reports should benefit their daily work. Higher-level civil servants mainly express frustration regarding the limited meaningfulness of information presented in EU reports. Complaints concern the objectivity of the information that reports are based on (the extent of which, given that most reports are based on self-reporting by member states, is doubted), the understandability of member state performances for members of the public in particular (the limited extent of which may lead to a situation in which member states that are famed should be shamed and vice versa), and the indicators used to measure compliance (the nature of which is often quantitative rather than qualitative). An examination of such reports suggests that the information contained therein is often not specific about the performances of individual member states, and that it is generally difficult for outsiders to 'make sense' of this information even where a high degree of specification exists. As a result, such reports rarely include information that may 'bite' member states; something that greatly reduces the extent to which such reports may put pressure on laggard states.

The weaknesses of EU reports outlined above seem explicable in part by resource limitations on the part of the European Commission (which does not have access to precise information on the application of EU law on the ground), and in part by the wish of the Commission "to send positive, forward-looking messages" and to maintain good relationships with member states in the Council (which it depends on if it wants to push through legislation). These latter notions are not new; the idea that factors of this sort limit the extent to which the Commission can act as an effective guardian of the treaties are well established in the literature. The cautious way in which the Commission makes use of naming and shaming strategies suggests that EU reports are not always (or not even) meant to function as naming and shaming instruments. Such reports may be seen as providing authorities with immediate benefits (rather than as imposing costs on them); some officials refer to such reports as providing them with learning opportunities or offering them other forms of support. In other words, EU reports may have a capacity building rather than an enforcement function. 
What seems to work better than naming and shaming in EU reports is naming and shaming 'amongst intimae', or that is what the case of the SAFA Directive seems to suggest. This is the case, since information shared within the European SAFA Steering Group - which gathers, as national representatives, the SAFA national coordinators of the member states - is more telling than the rather superficial information presented in EU reports. As a result, it has a greater capacity to 'bite' those that underperform. Note that the manners in which member states respond to naming and shaming exercises vary. In the Portuguese case, for example, the threat of reputational damage from having to account to colleagues gathering within the ESSG for a bad ranking, serves as a driver for the SAFA national coordinator to have his authority perform as well as possible, at least in the fields that are subject to evaluation. In this case, naming and shaming seems to work as it should from a theoretical point of view.

The Dutch case shows that naming and shaming can be useful in another way, too. Dutch officials indicate that they are reluctant when it comes to the threat of reputational costs being imposed by negative rankings; a stance that is explained in part by the Dutch self-perception of their implementation performance as adequate. This reluctance is, however, also explained by the idea that overly positive evaluations might have adverse consequences when it comes to the allocation of resources to the authority. If scoreboards, similar to inspection results, are to be used as safeguards in relation to management echelons that may be looking for opportunities to cut resources, it is better to be criticised in some way than to exclusively receive praise. Thus, in order to maintain given resource levels, the implementation performance of the authority should not be too close to perfect. The Dutch case also shows that those responsible for the distribution of resources should attach a degree of salience to the policy issue in order for them to be persuaded into the necessity of ensuring the necessary resource flows. The degree to which an issue enjoys salience has, in earlier research, been identified as explanatory for implementation patterns; the current study thus confirms its relevance in this regard.

For naming and shaming to work it is required that information about the implementation performance of member states is meaningful; it should be objective, allow for truly comparative and comprehensible insight to be gained, and indicate the quality of implementation. In addition, information must bite. It is only when this is the case that member states may fear the potentiality of reputational costs, or that scoreboards may be used as safeguards in relation to managers who may want to cut resources. Moreover, where positive domestic change needs to come 'from above', the relevant policy issue must enjoy salience amongst those who are in the position to bring about such change. When these conditions are met, naming and shaming could be a powerful instrument for supporting the application of EU measures. However, since these conditions are not met as a matter of course, the effect of naming and shaming is considered rather erratic and its usefulness for implementing actors variable. 


\subsubsection{Infringement proceedings}

Infringement proceedings, which the European Commission may initiate against member states under Article 258 TFEU, mainly aim to correct (alleged) violations of EU law. These violations may have come to the Commission's attention by virtue of its policecontrol oversight mechanisms, which include member state reports on the implementation of specific EU measures, expert studies, and agency inspections. Fire-alarm oversight, which consists in the submission of complaints - for example by citizens and civic organisations - to the Commission may point out EU law violations as well. When agreement on the existence of an infringement and on corrective action to be taken does not ensue during the administrative stage of infringement proceedings, the Commission may take the matter to the CJEU. When member states fail to implement a subsequent CJEU judgement requiring them to take the necessary measures to comply with EU law, the Commission may, under Article 260 TFEU, bring the matter before the Court once again - this time to demand the imposition of financial sanctions on the culprit member state.

While referred to as effective for ensuring that violations of EU law are eventually remedied, perceptions of the usefulness of (the threat of) infringement proceedings for supporting the daily application of EU law are generally negative. Street-level actors are not always aware of the competencies of the European Commission in this regard, and when they are aware they seem to consider infringement proceedings an issue for the central government to address. Some officials indicate that the procedure might, similar to agency inspections and naming and shaming exercises 'amongst intimae', be used as a safeguard in relation to upper management echelons, were it not that the considerable time lapse between the finding of an infringement by the European Commission and sanctions imposed on member states, makes the procedure a rather incredible stick.

The time lapse between the finding of an infringement and the imposition of sanctions is well documented. In 2007, the Commission noted that the time between the reception of a complaint and the start of Article 258 TFEU proceedings - by means of the sending of a letter of formal notice to member states - was nineteen months. Infringement proceedings currently take an average of about twenty-eight months to be solved, with an extreme 'low' of about fourteen months and an extreme 'high' of almost a staggering forty-three months. Article 260 TFEU proceedings take an average of between twenty and twenty-four months to complete. In the light of these numbers, the credibility of the infringement procedure as an efficient tool for solving noncompliance cases is low.

What does not seem helpful either is the idea that the probability of infringements being detected is, because of the limited extent to which the Commission can see what is going on on the ground, rather low. The fact that application is difficult to monitor translates to the fact that of all infringement proceedings started against member states, a relatively small share concerns the application of EU law on the ground. In the context 
of this study, infringement proceedings for 'bad application' were, as far as can be confirmed, initiated only in the area of IPPC. The fact that the Commission's database reveals a number of instances of noncompliance in this area seems to be the case only because environmental organisations were active in submitting complaints to the Commission, and information presented in member state reports could be easily checked for compliance with the quantitative targets that were to be achieved.

The idea that establishing compliance is not always easy - which is the case, in part, because many IPPC provisions leave much room for interpretation - explains, at least in part, why of all the 111 alleged instances of noncompliance in the application of the IPPC Directive, only seventeen cases made it to the reasoned opinion stage and eleven cases were brought before the Court. Political and pragmatic reasons may have made the Commission refrain from starting proceedings as well, as interviews suggests is the case in the context of the GPS and SAFA Directives. The idea that such reasons may play a role in the Commission's exercise of discretion about whether or not to initiate infringement proceedings is not new; earlier studies have identified them as important factors mediating the way in which the Commission exercises its tasks as guardian of the treaties.

The idea that the erratic use of the infringement procedure may cause a degree of frustration on the part of member states is suggested by the Dutch case in the area of IPPC in particular. While they claim to respect the Commission's enforcement competencies, Dutch officials also indicate that they feel frustration regarding the incomprehensible way in which the Commission makes use of those competencies. The notion that the Commission bases its decisions on information reported by member states on their own performance - information that is not necessarily accurate - is one reason for this frustration. Another reason relates to the use of indicators by the Commission that may not say anything about the quality of compliance (instead of, for example, about progress towards certain quantitative goals). National officials also express a degree of frustration regarding the idea that the Commission sues member states in cases where compliance is, allegedly, 'close to complete'.

Amidst concerns discussed above, considerations regarding the effectiveness of recent reforms that should improve the infringement procedure - reforms that, for example, aim to decrease the time between an Article 260 TFEU case being initiated and financial sanctions being imposed - are not relevant for officials. Regardless, the question is to which extent Article 260 TFEU is an effective 'stick in the cupboard' for member state administrations. Existing research indicates that the Commission is hesitant in starting Article 260 TFEU proceedings, that only few of the cases brought before the Court resulted in the imposition of financial sanctions - twelve between 2000 and 2010, to be precise - that the height of the few fines that were imposed was relatively low, and that such fines were not always enforced. This means that even if the Article 258 TFEU procedure were resorted to more consistently, and if this procedure were to function 
more speedily, the question remains as to whether the theoretical threat of a fine being imposed on perpetrators would threaten member states enough to render Article 260 TFEU a true deterrent.

The above paragraphs do not depict a positive picture of the usefulness of infringement proceedings; a picture that corresponds to the rarely smooth functioning of the procedure in practice. Drawing on why infringement proceedings do not work as well as they could, what seems to make them work better is a reduced period of time between the finding of an infringement by the Commission and the imposition of sanctions. The shortening of the duration of Article 260 TFEU proceedings may not be sufficient in this regard, since it does nothing to reduce the time lapse between the detection of a violation of EU law and the start of Article 258 TFEU proceedings in the first place. Second, for the Commission to be perceived, by national officials, as an impartial and reasonable guardian of the treaties, it should have access to objective and relevant information about the quality of implementation in member states. This is a call that this study is certainly not alone in putting forward; indeed, this study merely highlights the urgency of improving the Commission's information base. Third, it seems that there is a lot to be gained if existing competencies - of both the Commission and the Court were to be resorted to more consistently, more vigorously, and more wisely. Concrete recommendations on how to improve the functioning of the infringement procedure, and regarding how to increase the acceptability of the exercise of the Commission's enforcement competencies amongst national officials and within society are provided in Section 5 below.

\subsubsection{Post-legislative guidance (Chapter 5)}

The discussion shifts from predominantly coercive supranational instruments, to postlegislative guidance, an instrument that aims to facilitate the administration of EU measures by the competent authorities of the member states. It is meant to do this by clarifying how EU law must, or will, be applied. Guidance may broadly come in three forms; it may come as interpretative rules, as decisional acts, and as compliance templates. The benefits of post-legislative guidance for implementing actors vary with the type of guidance at stake. Decisional rules may be useful for these actors, since they stipulate how the Commission or another EU body will make use of its implementing powers. Familiarity with these rules allows member states to anticipate the behaviour of the issuing body and to adapt to it when necessary. Interpretative rules and compliance templates, on the other hand, inform member states of how EU measures are to be applied by the national competent authorities. Interpretative rules do this, either by making a legislative framework more accessible through consolidation of the relevant rules and existing CJEU case law, or by clarifying legislative terms through interpreting them. Compliance templates concretise legislative provisions. Guidelines may not only support national competent authorities in the daily law application practice, but also con- 
tribute to the resolution of infringement cases by smoothing infringement proceedings. Finally, guidance may have a 'reassurance function'; when authorities comply with guidance, these authorities rest assured that they are also acting in conformity with the underlying norms.

Guidance is generally seen as one of the most useful compliance instruments, for various reasons. This variation is expressed, in part, in the different motivations that underlie the use of guidance in the implementation practice. In the areas of product safety and air safety, an appreciation of the usefulness of guidelines for standardising implementation practices in a context in which national authorities are interdependent in making implementation work for each of them individually, appears to be an important motivation for the use of the RAPEX guidelines and the SAFA guidance materials, respectively. The RAPEX guidelines include clarifications of the obligations for member states under the RAPEX information exchange system and risk assessment guidelines that are to steer market surveillance authorities in product safety assessments. The SAFA guidance materials clarify the scope and method of inspection for each of the inspection items on the SAFA checklist, the categorisation of findings, and the relationship between categorisations and corrective actions.

While pollution crosses borders just as product and airplanes do, interdependence does not seem to be a factor motivating the use of the best available techniques reference documents, which provide guidance on the application of the best available techniques in permits for IPPC installations. What triggers the use of the BREFs seems to be a mix of an appreciation of the binding effect of these documents, their helpfulness for individual authorities involved in environmental licensing processes, and awareness of the prominence accorded to the BREFs by the Commission.

While referred to as one of the most useful instruments in the implementation of EU legislation, the quality of guidance may be inadequate. Inadequacies may follow from the hasty, exclusive nature of the deliberation process leading up to the adoption of the guidelines, as the first versions of the SAFA guidance materials and RAPEX guidelines seem to attest to. In relation to (highly) politicised domains - the area of IPPC is an example - inadequacies may follow (also) from member state attempts to influence the drafting process to ensure that the resulting guidelines reflect national preferences, instead of by a wish to commonly agree on guidance that is as objective and as workable as possible. In other domains, such as those of product safety and air safety, the difficulty of arriving at adequate guidance may relate more to the question of whether scientific objectivity can, from a theoretical point of view, be attained. This may not be the case, and as a result guidelines may leave much room for subjectivity on the part of national implementing officials. This partly defies the meta (harmonizing) purpose of guidance; it also reduces the usefulness of guidelines for implementing actors, particularly in situations where such actors attach much value to guidance for 'getting member states on the same line' in situations of interdependence. 
While the quality of guidance appears to constitute an important determinant for the usefulness of guidance for national officials across the board, perceptions of the importance of other factors appear to vary across countries and across policy domains. One of these factors is the 'binding' nature of guidance, the desirability of which implementing actors may have different ideas about. The idea that the status that guidelines are endowed with may vary across member states is clear in the area of IPPC in particular. While Dutch case law accords the BREFs limited binding effect - deviation is possible only when adequately motivated - Portuguese legislation and, in particular, Polish legislation and jurisprudence show a less committal stance. The result is that the use of the BREFs varies greatly across member states, with some member states having to 'stick to them' and others having to use them as a source of inspiration only. In view of this situation, calls to make guidance on the best available techniques 'binding' have not come as a surprise. Such calls have led to an 'upgrade' of guidance on BAT in the Directive on industrial emissions, which has replaced the IPPC Directive; the BAT conclusions "shall" be the reference for setting the permit conditions for industrial installations covered by the directive. Appreciations of this upgrade following which vary across member states; while some officials highlight the undesirability of the reduced flexibility that accompanies bindingness, others emphasise the idea that bindingness is useful for reducing the room for discussion between the public administration, and economic operators and civic organisations.

The idea that guidance does not have to be (seen as) binding in order for it to be used across member states is shown by the case of the SAFA guidance materials. While Polish officials indicate that they use the guidance materials (also) because EASA insists that they do so, Dutch and Portuguese officials indicate that it is the validity and the usefulness of the guidance materials that stimulate their use. For the latter officials, the guidance materials are empathically nonbinding, and the association of these materials with bindingness, seems to have the effect of creating aversion amongst these officials. Views on the status of the RAPEX guidelines have much in common with perceptions on the nature of the SAFA guidance materials in the sense that the RAPEX guidelines are also considered nonbinding. However, while the SAFA guidance materials are indeed nonbinding - and, thus, have a de fact effect only - the RAPEX guidelines seem to have limited binding effect, meaning that their use is not as voluntary as officials believe. In view of the room for subjectivity that the RAPEX guidelines leave for member state officials, some officials reject the idea of the guidelines as binding. Others, in contrast, would applaud more binding guidelines in view of the easing effect on relations between the administration and economic operators that bindingness is thought to produce.

The potentially problematic nature of the unclear legal effects of guidance is an issue that the literature has addressed from a legal perspective, by underlining the factual lack of clarity regarding the precise obligations for authorities in the implementation of interpretative rules and the fact that such rules cannot be reviewed by the CJEU. This 
study underlines the reduced usefulness of guidance for implementation actors that accompanies the unclear nature of its legal effects. When member states interpret their obligations differently, the use of guidance is prone to be inconsistent. Such inconsistency hinders the efficiency of implementation when authorities are interdependent in the implementation of EU law; it may also lead to uncertainty on the part of authorities that act in good faith regarding the implementation performance of authorities that are seen as having less of a strict stance on the use of guidelines. Uncertainty may create a vicious circle of mis- and distrust, which may lead to defection and cause guidelines to have the opposite effect of what they intend to do.

While guidance is commonly regarded as one of the most useful compliance instruments, it is clear that it is not easy to make it work equally well for everyone. Certainly, guidelines should be qualitatively adequate in order for them to be useful in the implementation process. For such adequacy to be attained, inclusive deliberation involving, in particular, street-level actors that are supposed to use the guidelines - is essential. However, adequacy is easier to attain in some policy areas than in others, and what works for some officials may not work for others. It is in view of the fault lines across member states that a flexible approach differentiating amongst member states seems desirable from a utilitarian point of view. However, a relevant question is about whether or not such a flexible approach is feasible; for example, it is unclear if guidance can be 'binding' for member states that indicate a preference for bindingness and be nonbinding for others. When there are objective reasons that enable differentiation between member states - for example, the existence of unequal implementation performances - flexibility may belong to the realm of possibilities, legally speaking. However, when such objective reasons are absent, a flexible approach seems difficult to justify. In such situations it may be particularly difficult for the European Commission to serve all member states equally well. Note again that all national officials refer to post-legislative guidance as indispensable for supporting the application of EU law on the ground, and that it seems essential to explore ways to make guidance fit the needs of individual member states as well as possible.

\subsubsection{Transnational networks (Chapter 6)}

While monitoring and sanctioning mechanisms and post-legislative guidance constitute supranational compliance instruments, the governance networks discussed in this study exemplify transnational instruments. Networks may broadly be conceptualised as structures of interdependence involving horizontal cooperation of multiple, operationally autonomous actors pursuing common public goals. The adjective 'transnational' implies that these networks constitute a vehicle for officials of national authorities to act directly with their counterparts in other countries. In this study, the focus is on networks allowing for practical cooperation (rather than for the 'mere' exchange of information) amongst national authorities. From a theoretical point of view, the virtues of networks 
for supporting the implementation of norms are diverse. Cooperation through networks is said to facilitate mutual learning and resource sharing, both of which reduce information and transaction costs for participating authorities. Networks may also increase mutual trust amongst participating authorities, which leads to a decreased risk of defection on the part of these authorities and stimulates further cooperation. Finally, networks may socialise national officials to shared norms; this facilitates norm internalisation and conflict resolution amongst network members.

The extent to which officials consider transnational networks useful compliance instruments seems to depend on two matters: whether there is a motivation for officials to become engaged in transnational cooperation and if this is the case, whether such cooperation is useful and what officials appreciate in this regard. Network participation may be motivated by three factors. First, it seems that authorities may feel obligated to be present at network meetings given the formal institutional framework of these meetings, as the Consumer Safety Network, which is formally established by the GPS Directive and chaired by the European Commission, demonstrates. One aim of the CSN is to facilitate the exchange of information, expertise, and best practices amongst member states.

Second, authorities may be instigated to engage in cooperation because levels of interdependence are perceived as high; that is, because authorities feel that the effectiveness of their own implementation performance depends on the activities of authorities in other member states. The interdependence argument explains why officials in the areas of product safety and air safety consider transnational networks essential instruments for supporting them in the application of relevant measures. It explains why market surveillance authorities from several European countries established the Prosafe network, and why officials involved in the implementation of the SAFA Directive greatly appreciate cooperation through the European SAFA Steering Group. Prosafe is an informal forum for cooperation that, similar to the CSN, aims to promote the exchange of information, experiences and best practices amongst member states, for example through the organisation of joint actions. The ESSG is a technical advisory group chaired by the Commission that aims to advise the Commission about SAFA and give feedback to the Commission about the national implementation of the SAFA Directive.

Third, when interdependence levels are perceived as low, as in the case of integrated pollution prevention and control, something else must motivate officials to take part in transnational cooperation. Here, awareness of the virtues of transnational cooperation other than those related most directly to interdependence - is particularly relevant. One of these virtues - the conflict resolution potential of networks - seems to be of lesser importance in this regard; this virtue is relevant particularly in areas featuring high degrees of interdependence, for its potential to harmonise implementation practices across the board. Mutual learning, on the other hand, is a virtue that seems to motivate cooperation even when levels of interdependence fail to act as such. The effect of mutual 
learning is not unidirectional, since the value of exchangeable resources - knowledge and expertise - varies across member states. Authorities that are lagging behind in a certain policy field - and that position themselves as 'students' in cooperation - may benefit most directly from cooperation, since cooperation may teach them how to improve. For authorities that act as 'teachers', the benefits of cooperation may present themselves in the longer term when 'student authorities' implement the lessons at home and the administration of the relevant measures is enhanced overall. This potential effect seems to be of practical benefit particularly for 'teachers' that find themselves in situations of interdependence.

Closely related to mutual learning is resource sharing, which, in the mundane version of the word - money - seems relevant mainly for authorities that are confronted with a particular lack of financial resources. This virtue is limited to fields that allow the financial burden of implementation to be shared. For example, while risk assessments of consumer products may be carried out centrally, this does not apply to aircraft inspections or to processes of licensing industrial installations. In cases of the latter type, financial resources may, officials argue, be saved because mutual learning processes prevent those officials from having to invent the wheel individually.

Finally, what applies to all policy domains included in this study is the importance that officials attach to mutual trust as a product of cooperation. Dutch officials in particular indicate that cooperation has reassured them that "other authorities are not as bad as they [that is, Dutch officials] thought they were". Authorities that were initially subject to mistrust may benefit from the trust-building function of networks as well; officials from such 'other' authorities indicate that they feel better understood and more accepted by their colleagues. While not usually highlighted as a product of cooperation, this side of the mutual trust coin seems important, since feelings of being accepted may stimulate 'other' authorities to engage in further cooperation, as much as increased trust in those 'other authorities' may stimulate 'leaders' to do the same. Cooperation and trust do, thus, have a mutually reinforcing effect.

Cooperation needs to function well to deliver the virtues outlined in the previous paragraphs, and it seems that the perception of cooperation as informal is crucial in this regard. If the benefit of informality is openness about problems that authorities may struggle with, the benefit of openness is that it allows for cooperation to function as an effective learning, trust-building, and problem-solving instrument. Openness is unlikely to materialise in networks that are legally formal; that is, in networks that are consolidated in EU legislation and that are subject to regular, publicly sanctioned exchanges. Such networks - in this study, the Consumer Safety Network in the area of general product safety - are likely to interrupt meaningful cooperation. This may be different for materially formal networks, which may be perceived as informal despite the presence of the European Commission (or an EU agency) as a network participant. An important precondition for such networks to be perceived as informal is that the Commission is 
not present as a guardian, but as a facilitator. In the context of this study, the European SAFA Steering Group best exemplifies this type of network. The perception of cooperation as informal seems to apply unconditionally to networks that are informal in both a legal and a material sense, such as Prosafe in the area of general product safety and IMPEL in the area of environmental law.

While interviews suggest that cooperation should be informal for it to work, doubts regarding informal networks relate to their external impact; that is, the extent to which cooperation may spur positive changes in the participating countries. Even when national officials appreciate cooperation for the lessons that they learn, whether these lessons are implemented back home is - because of the lack of an 'authoritative framework' in which such lessons were learned - not a matter of course. When positive domestic change requires the allocation of resources 'from above' the effects of networks depend on the willingness and capacity of those other than the network participants to make that change happen. The extent to which the policy issue at stake has salience amongst such actors is an important mediating factor in this regard. Note that the lack of enforceability of network outputs does not mean that informal networks cannot be effective at bringing about positive change; in some cases, it is exactly by virtue of their informal nature that such networks are capable of effectuating such change. Moreover, the outputs of networks encompass much more than what is possible to see and evaluate in objective terms.

While cooperation must be perceived as informal in order for it to work well, completely informal cooperation - cooperation through networks that do not have any links with the EU institutional framework - may not be most appropriate option. This is because the success of networks may, to a considerable extent, depend on the resources that are allocated to them by the European Commission. This is the case for both Prosafe and IMPEL. It is Commission funding that has greatly facilitated the participation of 'willing but unable' member states in Prosafe, and that has made it possible for Prosafe to organise joint projects on a scale that goes beyond what would have been possible if the financial burden of cooperation was exclusively on the member states. In order for the Commission to play this facilitating role, a formal framework structuring relations between Prosafe and the Commission must exist. A similar concept applies to the IMPEL network as well.

For networks to work as compliance instruments, there must be an intrinsic motivation for officials to engage in cooperation. This motivation should ideally follow from the perception that authorities are interdependent in the implementation of $\mathrm{EU}$ measures, and/or from awareness of the virtues (other than those that most directly relate to interdependence) that cooperation may bring for the network participants. Second, for cooperation to be useful and continue, networks need to deliver. Concretely speaking, they must increase mutual trust amongst the participating authorities and, depending on the needs of the participants, facilitate mutual learning, resource sharing, 
and the resolution of conflicts. Third, the key to making networks deliver these virtues seems to lie in 'informality in formality', that is, in a hybrid structure featuring interstate cooperation within a facilitating EU institutional framework. It seems that when all of these conditions are met, networks can be very useful compliance instruments.

\subsubsection{Civil society (Chapter 7)}

From the supranational and transnational compliance instruments discussed in the three previous sections, the discussion now moves to instruments situated at the national level, namely, to civil society and in the following section to case law. In the context of this study, civil society is understood as comprised of civic organisations (nongovernmental organisations and social movement (grass-roots) organisations) and members of the general public. Civil society may support national authorities in the administration of EU measures through one of two avenues: through cooperation with the authorities, or through the exercise of multi-level pressure on these authorities. Cooperation may come in the form of political support for the implementation of a particular policy programme or exist in the provision of specialist knowledge and expertise to the authorities. The exercise of pressure requires civil society to act as a watchdog of the administration, by scrutinising the activities of the competent authorities and attempting to bring non-compliers into line. Pressure may be exercised at the domestic level, for example by means of the initiation of court proceedings against the administration. Civil society may also 'take the European route' and generate pressure on national governments 'from the outside', for example by submitting complaints about the implementation performance of member states to the European Commission. Cooperation and pressure are not mutually exclusive; civil society may choose to act according to both dynamics interchangeably or at the same time. Either dynamic may have the effect of strengthening the capacity of the state to engage in implementation, which is why both cooperation and pressure may be useful for authorities in the law application process.

For civil society to be a useful compliance instrument there must be civil society activism to begin with. Relevant to this, is the extent to which a policy issue has societal salience; that is, the degree to which an issue is a 'hot topic' within society. For an issue to be salient, society must be aware of the existence of this issue, and concerns about the implementation performance of the authorities must exist. Both conditions are related; awareness of a policy issue often comes with the occurrence of 'disasters' that serve to focus society's attention on that policy issue, and that may create the image that the authorities that are in charge of managing the issue are not in control. When civil society consequently 'cares' about implementation being adequate, there seems to be a fertile ground for civil society to get active in one way or the other. In the context of this study, the notion of issue salience explains why civil society in the area of air safety is mute, 
and why civil society in the area of integrated pollution prevention and control is relatively active.

When civil society is active, both the extent to which this is the case and the roles played by civil society vary across member states and policy domains. In the area of integrated pollution prevention and control, pressure seems to be the most prominent mode in which environmental organisations choose to interact with the state. This pressure is most visible in the Netherlands, where environmental organisations and (grassroots groups of) citizens have started numerous court cases against authorities responsible for permitting IPPC installations. In the area of product safety, in contrast, cooperation seems to be the dominant modality employed by consumer organisations across the three countries included in this study. Which of the two modalities appears dominant is partly a matter of choice for civic actors, partly a matter of the capacity of these actors and the state, and partly a matter of state perceptions of the legitimacy of civic actors as participants in the policy process.

Determining the choice of civic actors regarding the modality of interaction seems to be the adequacy of the implementation performance of member states. Where implementation is deemed inadequate, pressure may be seen as a necessary tool to repair implementation failure. This may be because pressure may be more effective and efficient than cooperation, particularly - but not only - when the state is capable but unwilling to comply. Note that pressure rarely seems useful when the implementation performance of the administration is deemed adequate; in this case, civic organisations may want to support the state by delivering information and expertise that are relevant to the implementation process. The above statements partly explain why consumer organisations in the area of product safety choose to cooperate with the state, and why environmental organisations in the area of IPPC mainly choose to put pressure on the administration. Note that the idea that Polish and Portuguese organisations do not by definition choose to act in opposition to the state, seems to reduce the validity of the adagio in the literature that civic organisations in post-authoritarian (Southern European) and post-communist (Central and Eastern European) countries consider themselves to be adversaries to, rather than partners of, the state. Apparently, progress in this regard, while maybe slow, is taking place.

Whether public officials experience civil society activism as useful does not depend on the mode of interaction chosen by civil society actors. While Polish market surveillance inspectors denounce the efforts of cooperation made by consumer organisations, some Portuguese officials are positive about involving consumer organisations in risk management processes. And while Polish IPPC permit writers are generally negative about the pressure generated by environmental organisations, Dutch permit writers refer to the strongly challenging role of such organisations as amongst the most useful in supporting the implementation process. To explain these divergent perceptions the notions of capacity and legitimacy are relevant factors. 
It is in particular the balance between the organisational capacity of the state to deal with civil society and the capacity of civil society to act as a credible challenger of, and collaborator with, the state that constitutes a relevant factor determining the interaction between state and civil society. On one hand, civil society organisations need to possess sufficient expertise if they are to act as credible challengers of the state, and be seen by the state as useful collaborators in the implementation process. Expertise is something that (a number of) Dutch environmental organisations do seem to possess, but that (most) Polish environmental and consumer organisations, and (many) Portuguese consumer and environmental organisations, seem to be lacking. This finding seems to broadly correspond to the literature on civil society insofar as it depicts a fault line between Western European countries featuring a strong civil society and postauthoritarian and post-communist countries that have much to gain regarding the strength of civil society.

Whether or not cooperation materialises not only depends on the objective levels of expertise that civic organisations have to offer; the degree to which the state is capacitated to ensure proper implementation is also relevant. When the state regards itself as strong enough in this regard, it may be less willing to engage with civic organisations than when it considers itself in need of external expertise. While the first aspect seems to explain, in part, why the Dutch market surveillance authority is not very welcoming to help from consumer organisations, the latter aspect explains why the Portuguese ministry involved in the implementation of general product safety legislation welcomes the input of such organisations. The Portuguese case also shows that while authorities should not be too strong to engage in cooperation with civil society, they should not be too weak either since authorities must be capable of assessing whether or not the expertise offered by civic actors meets their needs. If authorities are particularly weak, they may end up relying on 'expertise' that these actors do not have. In this case, cooperation may negatively - but unknowingly - affect the capacity of the state to act.

Varying perceptions of the legitimacy of participatory governance explain the openness of the state to civil society participation as well. At this point the fault lines that the literature suggests divide (open) Western European countries from (relatively closed) post-communist and post-authoritarian European countries are relevant. Despite the participation-friendly discourse in Polish consumer legislation, the spirit of this legislation is not apparent with market surveillance inspectors in the Polish regions. And despite the importance that the Aarhus Convention attaches to public participation in environmental matters, openness amongst IPPC permit writers to the participation of environmental organisations generally remains formalistic. It is not only Polish organisations that seem to face a lack of openness to their participation on the part of the state; in particular Portuguese environmental organisations indicate that they are confronted with this issue as well. In the latter case, practical resource constraints on the part of the 
state seem to account, to a considerable extent, for the limited openness of the administration to environmental organisations.

What is required for civil society to work is societal salience, meaning that society should be aware of a policy issue and attach a degree of importance to the state's efforts towards making implementation work. Second, civil society actors must be capacitated to act as credible challengers and as useful partners of the state. And third, state authorities must consider civil society actors as 'rightful actors' in the implementation process. While the input of both civil society and state actors is required in order for these conditions to be met, it seems that the key to making civil society a useful compliance instrument lies with the government. This is the case, since there is an important task for the government not only when it comes to strengthening civil society organisations, but also when it comes to socialising lower-level officials to a civil society friendly discourse and providing the administration with the practical resources that are needed to deal with civil society as a partner rather than as an adversary. A positive evolution of the relationship between the state and civil society will also occur in time; a flourishing civil society and veritable openness on the part of authorities cannot simply be conjured up. The divergent perceptions of the usefulness of civil society activism highlighted in this chapter are, most of all, a reminder of the current unreliable nature of civil society as a compliance instrument. If civil society functions well, it may be a useful compliance instrument; if it still does not, the path ahead may be challenging and problematic.

\subsubsection{Case law (Chapter 8)}

The last empirical chapter of this study focuses on case law; an instrument that, in contrast to civil society activism and in view of the functional relationship between courts and parties in court proceedings, has an outspoken top-down character. In the context of this study, case law is understood to cover two components: domestic administrative case law with an EU law dimension, and preliminary rulings delivered by the Court of Justice of the European Union. The findings regarding both types of case law are summarised below.

\subsubsection{Domestic case law}

Of interest in the context of this study is domestic case law that is intended to solve disputes between the public administration, and natural or legal persons. This case law fulfils two functions, both of which are closely intertwined. The first function, which is of a subjective nature, relates to the idea that case law offers redress for citizens or other actors who claim to suffer from grievances caused by the public authorities. The second, objective function of domestic case law involves the desire to ensure legality, by guaranteeing that public authorities act within the limits of the law and ensuring that decisions taken by the authorities comply with the relevant legal provisions. It is this second function that is most relevant to this study, since it puts at its centre not the grievances that 
applicants claim to suffer, but the compatibility of the behaviour of the public administration with legal provisions. It is from a judicial evaluation of this latter issue that public authorities may draw lessons that are useful in the law administration practice. In view of the fact that case law may have the effect of undoing wrongs committed by the public authorities, its effect is primarily ex post and corrective. Case law may, however, also have the effect of preventing instances of noncompliance from occurring. This may be the case when the court has declared a certain decision to be in violation of, or in compliance with, applicable legal provisions, and when judgements include clarification of legislative provisions.

For domestic case law to be a useful compliance instrument there must - similar to the case for civil society - be something like case law to begin with. This is not selfevident, as the cases included in this study suggest. Case law is absent in Portugal; in the Netherlands, it is present only in the areas of IPPC (approximately eighty cases) and SAFA (two cases); and litigation in Poland is limited to the domains of general product safety (nearly thirty cases) and IPPC (over sixty cases). The varying presence of case law across countries and across policy issues is explained by the interplay of a number of factors, which may be of a legal or of an extra-legal nature. On the legal side, we find that rules for access to justice should not pose insurmountable obstacles for actors to engage in litigation; for example, actors must be able to acquire standing and court costs should not be too high. In addition to this, judicial remedies should be regarded as helpful for solving the case speedily and effectively. Relevant to this latter point is that judges should have sufficient expertise to evaluate the merits of the case when they have the legal competence to do so.

On the extra-legal side, reference must be made to the idea that for jurisprudence to exist, capable actors that 'see a point' in engaging in administrative litigation must exist. These actors may be civic organisations that are aware that the performance of the administration is insufficient and that are capable of opposing the administration in court. The probability of domestic court proceedings increases, too, when prejudicial problemsolving instruments do not exist or fail to deliver results, and when the interests of litigants in a positive outcome of the case outweigh (potential) adverse financial or reputational costs associated with litigation. Finally, litigation must be commonly used as a dispute-resolution tool. While some of these factors are makeable (think of rules on access to justice), this does not apply to others (think in particular of factors that are culture-bound, such as litigation culture). What applies to civil society does, thus, apply to case law as well: unlike other instruments, case law is not an instrument that can simply be conjured up.

Its mere existence does not necessarily make case law a useful compliance instrument; in order for case law to be particularly useful, judges should not only solve the legal dispute at stake in the proceedings, but also provide clarity on substantive legislative provisions that pose problems of interpretation. In order for such clarity to be pro- 
vided, it seems that two conditions must be met: claimants must challenge the administration's compliance with substantive (rather than procedural) rules, and judges must possess sufficient expertise to solve the substantive issue at stake. The cases examined here suggest that it is not self-evident that such conditions are met. In Polish case law in the area of IPPC, for example, civic actors and business operators often challenge the administration's observance of procedural rules or general principles of law instead of the compliance of permits with the best available techniques. Moreover, even when an elaboration on the concept of BAT would be logical in view of the dispute at stake, the courts simply do not address this issue. The reluctance on the part of judges to address the concept of BAT, and their tendency to quickly rush to an evaluation of the procedural side of the case instead, seems explicable by the idea that judges lack expertise on the topic of integrated pollution prevention and control. Relevant to this fact, is that the role of experts in the Polish administrative legal system is limited, both in theory and in practice. When it comes to the usefulness of case law as a compliance instrument, Polish officials do not seem to give the courts credit.

This is different in the Netherlands; while case law is said to have left some interpretational questions unresolved, Dutch permit writers refer to case law as one of the most useful compliance instruments overall. In contrast to Polish judges, Dutch judges have consistently and thoroughly judged whether the best available techniques are applied in IPPC permits; this has been possible because judges may - and often do - resort to out-of-court expertise in the area of IPPC, and because environmental organisations with the expertise to credibly challenge authorities before national courts do exist. The idea that the latter conditions are not met in each and every case has left some gaps, though. For example, where courts do not resort to external expertise, they may stick with the procedural side of the case at hand and be reluctant to review the merits of the case. Overall, however, Dutch case law is seen as useful for having provided clarifications and prevented conflicts between the state administration, and civil society and business actors.

That case law does not have to be 'world changing' in order for it to be useful for authorities is shown by perceptions concerning Polish case law in the area of general product safety. A reading of this case law suggests that most rulings are not enlightening when it comes to the interpretation of substantive legislative provisions; this conclusion is supported by interviews. Explanatory in this regard are the fact that business operators usually challenge the administration's compliance with procedural rules and a lack of expertise on the part of judges to evaluate the material questions at stake. Both factors lead courts to focus on procedural questions rather than the substantive side of the case.

Regardless of their often unenlightening nature, the authoritativeness of court judgements makes such judgements relevant for the central supervising authority, which can use them as reference points in relations with business actors and as input in guidelines for inspectors. The latter is useful for these inspectors, since they attach im- 
portance to having 'authoritative guidance', amongst others in view of the alleged habit on the part of economic operators to consistently challenge decisions taken by the competent authorities. While court judgements may be easily incorporated into guidelines, compliance with such judgements may be more difficult to achieve when this requires substantial changes in the day-to-day administration of the law. Such changes may require that additional (financial) resources are employed; resources that authorities may not have at their disposal. When this is the case, case law may hinder rather than facilitate the work of the authorities.

The answer to what makes domestic case law work seems easier to give than to implement, because similar to civil society activism, case law is not an instrument that can be created at will. First, for case law to exist, a considerable number of (partially interdependent and not always makeable) conditions must be met. Second, for court judgements to be truly useful, it is required that judges do not only solve the dispute at stake, but also provide a clarification of legal provisions that authorities deem unclear. In order for this to happen, judges should possess sufficient expertise, procedural rules should allow judges to look into the merits of the case, and litigants should challenge more than the administration's compliance with procedural rules to begin with. Finally, authorities must be able to 'do something' with these judgements, which, given the resources that authorities might have to put to use, is not a matter of course. If the above conditions are not met, the usefulness of case law as a compliance instrument is expected to be suboptimal. However, if they are met, case law can be a particularly powerful compliance instrument.

\subsubsection{Preliminary rulings}

Preliminary rulings, which are governed by Article 267 TFEU, are meant to clarify the interpretation of EU law or the validity of acts adopted by the EU institutions. They are delivered by the CJEU upon the request of a national court or tribunal from a member state. When a question on the interpretation of EU law is pending before a court or tribunal against whose decisions there is no judicial remedy under national law, the court or tribunal is required to request that the CJEU provide a preliminary ruling. Unlike the case for domestic case law, the effect of preliminary rulings on national administrative authorities is rather indirect. This is because interpretations given by the CJEU are first and foremost meant for national courts, which are to use them in domestic court proceedings to decide issues of fact or to resolve any differences of opinion regarding the interpretation or application of national law. Preliminary rulings may clarify issues that authorities have struggled with in the administration of the relevant legal provisions; in fact, these authorities may have asked the court to submit preliminary questions on the interpretation of EU law provisions to the CJEU in the first place.

Similar to the case of civil society and that of domestic case law, to be a useful compliance instrument, preliminary rulings should exist in the first place. This is not a mat- 
ter of course. In the context of this study, it is only in the areas of general product safety (one) and IPPC (six) that preliminary rulings are present. Analysis suggests that the usefulness of these rulings for public officials involved in the implementation of the relevant directives is limited. This is the case, first, because awareness of these rulings seems to be incomplete, not only amongst lower-level officials who generally feel little connection with what happens at the EU level, but also amongst ministerial officials, who one may expect to be more familiar with what happens at the supranational level. Awareness amongst the latter officials seems to be present in particular when the ruling was delivered upon the request of a national court from the 'own' member state, and when rulings are otherwise deemed relevant for the national implementation practice. If this is not the case, chances are great that ministerial officials do not take an interest in 'what is going on at the Court', and subnational authorities are unlikely to be briefed about preliminary rulings.

It is not only incomplete awareness of preliminary rulings that makes many rulings irrelevant for implementation actors; it is also the (partly related) idea that such rulings do little to address the core issues that authorities struggle with in the implementation process that limits their usefulness in practice. While existing rulings may be experienced as useful for clarifying certain legal provisions, provisions that are the source of great confusion - and a great deal of interpretational diversity across member states remain unaddressed. A prominent example is the status of the BREFs in the area of integrated pollution prevention and control. Widely known to be interpreted differently across the board - and to stir confusion within member states as to their supposed use none of the preliminary rulings that are present touch on how the BREFs ought to be used by implementing authorities in environmental licensing processes. The same applies to the way in which authorities ought to deal with the range of emission limit values outlined in the BREFs and numerous other interpretational issues, which concern for example, the implementation of an 'integrated approach' to pollution prevention and control, and the scope of the terms 'air', 'water', and 'soil'.

Critical remarks also are in place when it comes to the single ruling that exists in the area of general product safety, which does in fact, address the GPS Directive only incidentally. Questions following the adoption of the New Legislative Framework, which aims to reinforce and harmonise market surveillance throughout the EU, and questions regarding the interpretation of product norms have remained unaddressed. One may argue that in order for the preliminary ruling system to be truly helpful for implementation actors, it is exactly such (core) issues that should be addressed.

Since the extent to, and the way in, which recourse is taken to the CJEU is in the hands of national courts, who act as gatekeepers, the key to making the system more useful for implementing authorities seems, at first glance, to lie with national judges. Note, however, that there are few questions to refer to the CJEU when national case law is absent; an issue that is not impossible, as the analysis on national case law shows. 
Moreover, when national case law is present, judges may not see a point in referring questions to the CJEU, for example because the matter concerns the interpretation of only national - rather than also EU - legal provisions. The fact that public authorities may resort to alternative means to solve interpretational issues (for example, Commission guidance or consultation with other member states) may prevent these officials from bringing up the matter in domestic court proceedings.

The conclusion is that the preliminary ruling system seems greatly underexploited as a compliance mechanism. This is concerning, both because interpretational problems do exist, and because alternative mechanisms may be suboptimal for solving such problems. Member states, for example, may not want to share problems encountered by them with others. And post-legislative guidance may confuse rather than clarify; it may, by authorities and regulated entities, be seen as optional rather than (in principle) obligatory; and it may not exist in the first place. When interpretations that are commonly seen as binding are absent, the willingness to comply may plummet and mutual mistrust may rise. It seems that the underuse of the preliminary ruling system is, thus, a missed opportunity, not only for supporting the administration of EU law within individual member states, but also for contributing to the uniform administration of EU law provisions throughout the Union.

How the preliminary ruling system can be made to work better seems difficult to determine, because obvious solutions (for example, 'judges should refer more questions to the CJEU') would be overly simplistic. One may argue that where national case law does exist and national administrative authorities are aware of cross-country variation in the interpretation of (core) EU law provisions, it may be advisable for these authorities to outline their concerns before national judges, and for these judges to resort to the CJEU if they deem these concerns to be justified. In order for this suggestion to be considered, it seems that authorities should not only be better aware that preliminary rulings may be beneficial for them; they should also be prepared to cast aside their pride or their confidence as to the rightfulness of their own interpretation.

\subsubsection{Synthesis}

From a general perspective, transnational networks and post-legislative guidance clearly top the list of compliance instruments in terms of their usefulness for supporting the application of EU law; regardless of policy domain or member state, national officials value those two instruments for supporting national competent authorities in the law application practice. What networks and guidance have in common is that their use is stimulated in particular by high degrees of interdependence, or at least by the perception amongst officials that national authorities are interdependent when making the implementation of EU legislation work for each of them individually. Without interdependence, virtues other than those related to interdependence are important for persuading officials to use these instruments. Note that while perceptions on what makes networks 
work converge, perceptions on what makes guidance useful diverge, in particular across member states (rather than across policy domains). This suggests that functioning cooperation is easier to achieve than quality guidance.

The extent to which the 'purely' national instruments examined in this study - civil society and domestic case law - are useful as compliance instruments varies greatly, both across countries and across policy domains. What both mechanisms have in common is that the implementation performance of public authorities plays an important role in mediating the role that they play. Where the implementation performance of the authorities is inadequate, civil society actors may choose not to cooperate with the state, but to put pressure on it instead. One way of exercising pressure is by initiating court proceedings against the competent authorities. The extent to which civil society initiates court proceedings - and generally the extent to which it acts as a watchdog of the state does, in part, depend on the societal salience enjoyed by the respective policy issue. Salience appears to be an important determinant for the functioning of other compliance instruments - for example, naming and shaming strategies and transnational cooperation - as well, particularly when the potentially positive effect of such instruments depends on actions taken by actors other than street-level actors.

What both civil society and case law share is the idea that neither of them can simply be conjured up. Post-legislative guidance may be developed upon request, and networks can be created where a need for cooperation exists. EU agencies can be established following agreement about their creation, and the infringement procedure can to some extent be moulded to ensure its effective functioning. However, just as the creation of non-governmental organisations alone cannot make for a flourishing civil society, the establishment of legal and practical tools facilitating court access alone cannot make case law a popularly-used dispute-resolution mechanism. For this, a culture that is open to civil society involvement or to the use of litigation as a dispute-resolution mechanism is needed. As long as such a culture is absent or weak, the existence of civil society activism and national case law is bound to be limited, and with it the potential of both of these instruments to act as effective compliance mechanisms.

Even when the existence of compliance instruments is not immediately mediated by country-specific cultural preconditions - which is the case for all compliance instruments that are not found at the domestic level - the importance of culture for mediating (perceptions of) the functioning of such instruments should not be underestimated. For example, what is needed for guidance to be seen as 'adequate' is greatly a question of culture. Whether officials learn from inspections carried out by an EU agency is, in part, a question of (organisational) culture. And what network participants take away from transnational cooperation is, partly, a question of culture, too. The importance of culture for determining the usefulness of compliance instruments makes us aware that what works for one member state may not work for another member state. And since cultures "cannot be harmonised", to speak with an interviewee - they are 'sticky' - 
cross-country differences in perceptions of the usefulness of compliance instruments are likely to persist.

The picture that emerges is thus, one featuring some commonalities, and simultaneously, great cross-issue and cross-country variation in perceptions of the usefulness of compliance instruments. This variation underlines the idea that a one-size-fits-all approach towards compliance problems may not fit anyone. It calls for tailor-made solutions to compliance problems when possible, and a harmonised approach when (legally) needed. The above sections also underline that the functioning and the use of compliance instruments are frequently suboptimal; an observation which suggests that there is much to be gained by making these instruments work better. How these suggestions could be taken forward by practitioners involved in making EU law work is discussed in Section 5, which aims to provide practical recommendations to these same practitioners.

\section{Intermezzo: Implications for EU implementation research}

Before we provide recommendations on how the application of EU law by the competent authorities of the member states could be made to work better, this section reflects on the relevance of this study for EU implementation research, particularly for research on the application of EU law. It first discusses the links between the findings of this research and thinking about implementation and compliance in international relations studies and studies on application in the EU. It then suggests how researchers could approach the subject of the application of EU law.

Note that the current section must be read with the following caveat in mind: that this study is neither deductive nor inductive. Instead of testing theories or formulating hypotheses, this study aims to attain a deep understanding of a specific case; namely, the usefulness of compliance instruments for supporting the national competent authorities in the application of EU law. This does not mean that theory is absent; a reflection on EU implementation research was necessary to clarify how the current study fits in amongst and differs from existing studies - and theoretical thinking infused our expectations of why compliance instruments are expected to support the daily application of EU law. ${ }^{17}$ As such, the case studies examined in this study are interpretative rather than a-theoretical. Moreover, while the collection of the empirical material was not guided by the objective of contributing to theory building on implementation in the EU, it seems that this material may nonetheless reflect the validity of variables that the literature has

\footnotetext{
${ }^{17}$ For the use of theory in relation to individual compliance instruments, see each first section of the empirical chapters. For a review of the literature on implementation in the EU, see Chapter 2 on implementation in the EU: same rules, divergent practices, Section 3.2. For an overview of the schools of rationalism, managerialism, and constructivism of international relations studies, see Chapter 3 on the approach and methodology of this study, Section 2.
} 
put forward as explaining application in the EU. It is, as suggested above, to this issue that this section turns.

\section{The findings of this study and international relations studies}

As reiterated in one of the previous sections, international relations scholars have thought of compliance as being caused by (one of) three sources: unwillingness, a lack of capacity, or a lack of norm internalisation. It has also been said that neither of these theoretical logics can account for compliance problems in the EU alone. Given this fact, and in view of the interdependencies between compliance instruments, it is suggested that compliance problems can be 'fixed' only when compliance instruments are mixed. Moreover, if these instruments are to have a positive impact on the application of EU law, they must be used effectively - both individually, and combined. It may be interesting to examine how the EU 'compliance system' scores in this regard. Looking at the compliance instruments that are included in this study and at the way in which they are used, five issues must be identified in particular.

The first of these issues is that compliance issues in the EU are mainly approached from an enforcement perspective. This is natural in view of the - recently reinforced competencies that the European Commission is endowed with as guardian of the treaties, and it is supported by the fact that the Commission has underlined its intention to make vigorous use of the enforcement instruments that it has at its disposal, in particular the infringement procedure. ${ }^{18}$ While there is little against the Commission acting as a (wise) guardian of the treaties, the great attention to the Commission's use of the infringement procedure makes one wonder what the Commission thinks about the use of other, more management-related, instruments; instruments that scholars agree must be used in concert with enforcement instruments if compliance is to be attained. While the heterogeneous nature of application across policy areas may make it difficult to create a neat and simple plan on implementation in the EU, strategic thinking must aim to yield helpful ideas regarding the most effective (combined) use of enforcement and management instruments in the EU.

Second, despite the Commission's intention to make effective use of its enforcement competencies, there are pragmatic and political reasons that withhold the Commission from exploiting the infringement procedure and naming and shaming strategies to their fullest extent. The picture that the empirical chapters of the current study depict is one of an inconsistent and sometimes even feeble enforcer indeed. The lack of enforcement is unproblematic - and managerialists would argue even commendable when compliance problems derive from a genuine lack of capacity to implement EU norms, rather than from a lack of willingness to meet the commitments engaged in under EU law. It does, however, become problematic in the opposite scenario; when

\footnotetext{
${ }^{18}$ See Chapter 4 on monitoring and sanctions, Section 1.1.2.2.3.
} 
Commission enforcement crumbles in the face of politically powerful member states that would, from an administrative capacity perspective, be capable of implementing EU law effectively, there seems to be little reason to expect such member states to comply. It is here where the weakness of Commission enforcement does, one may argue, become problematic.

Third, while the Commission does not fully exploit the enforcement instruments that it is formally in control of, it seems that it engages in attempts to exercise too much influence in relation to mechanisms that it does not - or should not - control. Transnational networks may serve as an example of this. It seems that because it has a natural interest in monitoring member state behaviour in the implementation of EU law, the Commission is naturally inclined to manoeuvre itself inside a network in such a way as to allow it to monitor what is going on at the member state level. The empirical chapters of this study show that this tendency does, however, impair the functioning of transnational networks as compliance instruments; networks could be much more useful if the Commission were to adopt a hands-off approach concerning the exercise of control over such networks. While instruments that are primarily aimed at enforcing compliance may have managerial aspects - bringing in a capacity-building element may even be a precondition for their success ${ }^{19}$ - endowing instruments that are mainly aimed at managing compliance with an enforcement element is, thus, a bad idea. Apparently, enforcement can accompany management, but management cannot accompany enforcement.

Fourth, and in relation to previous statements, while conceptually distinct, the notions of willingness and capacity are difficult to disentangle. Willingness is mirrored in capacity, and capacity is mirrored in willingness. Member states may not have the resources to comply with certain EU norms because governments are unwilling to endow the relevant implementing authorities with more resources at the expense of others, for example because policy issues lack salience. Or member states may be willing to increase the effectiveness of competent authorities but genuinely lack the necessary knowledge. The intertwinement between willingness and capacity may, in some cases, create a 'chicken and egg problem', and it puts (additional) doubt on the extent to which the sharp conceptual border between rationalist and management perspectives on compliance is helpful for analysing implementation problems. It also makes it difficult to understand why member states do not comply and to decide on the most effective remedy to solve instances of noncompliance.

Fortunately - and fifthly - many of the available remedies combine elements of both enforcement and management approaches within them, which is practically help-

\footnotetext{
${ }^{19}$ See the analysis on the usefulness of EU agency inspections, in Chapter 4 on monitoring and sanctions, Section 3.1. Also national case law is much more useful when it does not simply solve a case in favour of one party or the other, but provides legal interpretations as well. See Chapter 8 on case law, Section 3.1.2.
} 
ful as various dynamics may be responded to at the same time. ${ }^{20}$ For example, inspections undertaken by EU agencies may be first and foremost aimed at monitoring the performance of national authorities in the application of EU measures, but they may at the same time have a learning effect for street-level actors. Domestic case law may be aimed at forcing national authorities into compliance, but jurisprudence may also include clarifications of legal rules that enhance the capacity of these authorities in the implementation of the law. Networks may socialise partaking officials to shared norms, and they may at the same time be aimed at sharing best practices and drawing up guidelines for implementing actors. Such suggestions provide further ammunition to those advocating the abolishment of the borders between rationalist, management, and constructivist perspectives on compliance.

In conclusion, it seems that the above paragraphs suggest two things. First, there should be reflection on how to effectively approach compliance issues in the EU. It is important to consider how enforcement and management strategies to solving compliance issues could be combined, and how the respective instruments could be used most effectively and most efficiently. The empirical findings of this study may provide some guidance in this regard. Second, it seems that the roots of compliance problems may be much more entangled than we presume. Certainly, studies examining the interconnections between the three schools of thinking on compliance do exist. ${ }^{21}$ But these studies do not seem to touch on the issues that this section suggests may be relevant to examine in detail. Implementation research could help clarify the manner in which the tenets of these three schools interconnect and what this should mean for the design of the EU compliance system.

\section{The findings of this study and EU application research}

One may recall that the variables that EU implementation research suggests explain application processes and outcomes aim either to explain variation in application processes and outcomes across member states (the worlds of compliance typology), or to account for variation across cases (goodness of fit, issue salience, and preferences). ${ }^{22}$ While this study has - as reiterated above - not aimed at testing the validity of these (and other) theoretical variables, the empirical material collected in its context seems to enable to say the following in this regard.

\footnotetext{
${ }^{20}$ Note again that it is because of this combination of elements in individual instruments that this study has chosen not to classify compliance instruments as following one or the other logic of compliance and to use the pragmatic - and rather a-theoretical - actor-based typology of compliance instruments described in Section 2 above and in Chapter 3 on the approach and methodology of this study, Section 3.2.

${ }^{21}$ The most notable of these studies is probably the one by Börzel et al., 2010.

${ }^{22}$ These variables are discussed in Chapter 2 on implementation in the EU: same rules, divergent practices, Section 3.2.
} 
The worlds of compliance typology categorises countries as belonging to one of four worlds of compliance, each showing a specific pattern in the transposition of EU directives, and the application and enforcement of EU measures. The typology not only suggests the problems that may inhibit smooth implementation in each of these worlds; it also identifies the remedies that must be implemented to effectively solve such problems. In relation to the tenets of the typology, two main points may be made.

The first of these points is that the typology depicts a rather narrow picture of the range of remedies that may be useful for ensuring compliance with EU law. On the part of the supranational institutions, the remedies referred to are pressure, information campaigns to promote whistleblowing and domestic litigation, and (speedy) initiation of infringement proceedings; each of these is associated with different worlds of compliance. The other remedies that the typology refers to as necessary for inducing compliance - effective administration, adequate cooperation between national decision makers and implementing agencies, and effective court systems and civil societies - are matters for institutions at the national governance level to arrange. With supranational enforcement mechanisms and national compliance instruments having found their place in the worlds of compliance typology, the question of concern is about why supranational and transnational mechanisms that are primarily aimed at managing compliance - instruments that the current study suggests may be greatly useful for supporting the application of EU law - are not included as relevant for remedying compliance problems. Following the logic of the worlds of compliance typology, transnational cooperation may be a useful compliance instrument for countries belonging to the world of dead letters and for (certain) countries classified as belonging to the world of transposition neglect; the current study has, in fact, suggested that this is the case. ${ }^{23}$ Since EU norms are of an equally open nature for every member state, post-legislative guidance should be considered useful regardless of the world of compliance that countries are classified as falling into. This study has broadly confirmed this as well. ${ }^{24}$

The worlds of compliance typology not only seems incomplete as far as the remedies for compliance problems are concerned; it also seems static in the sense that it assumes that application processes in individual countries follow similar patterns regardless of the policy area at stake. This assumption is proven wrong by the current study, which - based on an examination of three EU directives in three different policy domains - suggests that the dynamics underlying application may vary greatly across policy areas. ${ }^{25}$ This variation also explains, in part, why the presence and the functioning of compliance instruments differ across policy areas. It has appeared, for example, that the

\footnotetext{
${ }^{23}$ Note that the manner in, and the extent to, which cooperation may be useful may vary for states across cases; for this point, see further below.

${ }^{24}$ Note that there may be cross-case variation in the degree of usefulness of guidance across cases; for this point, see further below.

${ }^{25}$ For an elucidation, see below, in the context of the discussion regarding the validity of the variables that have been said to account for variation in application processes across cases.
} 
(more or less technical) nature of a policy issue co-determines the usefulness of postlegislative guidance as a compliance instrument, and that the usefulness of transnational cooperation varies with the extent to which administrations are 'juniors' or 'seniors' in the implementation of specific rules. While useful to countries across the board, the degree and nature of the usefulness of these remedies do, thus, vary across cases. ${ }^{26}$

Such case-specific variation also applies - and now we arrive at the mechanisms included in the worlds of compliance typology - to the role that civil society and national judiciaries may play. Recall that while civil society is seen as functioning well in countries belonging to the world of domestic politics, it is seen as ineffective in countries belonging to the world of dead letters. One would, therefore, expect civil society to play a vigorous role in implementation processes in countries such as the Netherlands, and to be less capable of doing so in a country such as Poland. The cases included in this study do, however, suggest that the strength of civil society varies greatly across policy domains and that one cannot simply speak of the strength of civil society across member states. For example, civil society is likely to be more active when issues enjoy some degree of salience than when issues are invisible to society; civic organisations may be more capable in areas that require less technical expertise than in domains that are technically complicated; and the stance of the administration may be more open to civic engagement when national officials need external expertise than when they regard themselves as capable implementers. Thus, the role of civil society varies across policy domains and a more nuanced picture - than that conveyed by the worlds of compliance typology - is needed.

A similar concept applies to the role of national judiciaries in the application process. While countries belonging to the world of domestic politics are thought to have few problems in the application of EU measures owing to effective judiciaries, the Dutch case shows that these judiciaries do in some cases have a small role to play - not because disputes between the administration and regulated entities are absent, but because courts are not seen as effective problem-solving mechanisms, for example because of a lack of issue-specific expertise on the part of judges. Given that the effectiveness of case law as a problem-solving mechanism may vary across cases, it seems that the worlds of compliance typology may overplay the meaningfulness of national case law as a compliance instrument in countries belonging to the world of domestic politics. Similar to the effectiveness of civil society as a compliance instrument, it seems that it is also regarding national case law that reality is a bit more complex than the postulations of the worlds of compliance typology convey.

As to the case-specific variables that EU implementation research suggests influence application processes and outcomes - goodness of fit, salience, and preference heterogeneity of political principals - the following can be said. While not a focal issue

\footnotetext{
${ }^{26}$ Note that since the worlds of compliance typology does not include these two instruments, these remarks do not strictly concern the validity of its postulations.
} 
in interviews with national officials, the empirical material of this study does suggest that the goodness of fit between new EU norms and pre-existing domestic practices plays a role in the way in which national authorities apply EU law - and in the way in which they make use of compliance instruments. For example, national authorities with substantial experience in a policy domain seem more likely to act as teachers in transnational cooperation arrangements than authorities facing substantial requirements for domestic change. While this role conception allows the former authorities to diffuse their own ways of doing things - which is practical if one aims to limit the costs of adaptation - it allows the latter 'to fill in the blanks'. And while the latter authorities may regard (preliminary) rulings by the CJEU as potentially useful for solving any interpretational difficulties that they may be confronted with, authorities with a longer history and well-established administrative routines - in a policy domain may refer to such rulings as not useful, or even as obstacles, in the application of EU law. The latter view seems to underline the idea that authorities with well-established 'ways of doings things' may not be open to mechanisms triggering change, whether they are newly adopted norms, rule interpretations, or working practices that do not fit the status quo.

The concept of salience slightly contradicts the concept of goodness of fit, since it presupposes that rules that are given more societal attention to will be applied more effectively than rules for which this is not the case, regardless of the degree of fit between these rules and pre-existing domestic practices. The current study does (nonetheless) find some evidence for the relevance of salience as a factor mediating application. The low societal - and thus political - salience of the issue of product safety is said to account for the limited resources that the administrations of all three countries responsible for applying product safety regulations are endowed with. The relevance of salience as a factor influencing application does, as suggested above, become clear from the case of air safety as well; officials from all three countries indicate that accidents are needed to trigger political attention and, with it, the resource endowments necessary for effective application. Without airplane crashes, governmental priorities are said to be directed towards policy issues that are more visible to society; this, one may argue, means that implementation has, in a certain way, fallen prey to its own success.

Salience influences perceptions regarding (the usefulness of) compliance instruments as well. In the Netherlands, for example, the relatively low political salience of environmental issues is said to make government parties insensitive to low rankings in EU scoreboards that benchmark the implementation performance of member states. If we assume that such scoreboards are meant to put pressure on member states because of the reputational costs that they intend to impose on laggards, their effectiveness for coercing positive domestic change seems limited in cases that lack salience. The relevance of issue salience regarding the usefulness of scoreboards as compliance instruments is supported by the Dutch case of air safety as well. The same concept applies to the link between salience and civil society activism, which is hinted at above. 
Finally, in relation to the argument that application is less likely to be effective if heterogeneous preferences on the part of political principals are present and - consequently room for discretion on the part of the administration, there is little that the empirical material of this study can say in this regard. What this material does seem to suggest is that there are factors other than heterogeneous preferences on the part of the government that may cause a lack of control over the administration in the application of (EU) measures. The alleged independent course fared by the Dutch authority responsible for the application of general product safety regulations, for example, seems facilitated by the limited expertise of product safety issues on the part of the relevant supervising ministry. Political turf battles seem absent; something that may be explained, in part, by the low salience of the issue of product safety in the Netherlands. Had product safety been a societally important issue, it would have stirred up political debate, provided profiling options for politicians, and possibly exposed preferential heterogeneity. Whether the suggested interconnections between the variables of preferences and salience do indeed exist is a matter for future research to analyse; given the focus of the current study, conclusions in this regard cannot be drawn.

What does seem to be capable of being concluded is that several of the variables both state and case specific - that EU implementation research proposes as explanatory for variation in application are either contradictory or interconnected, and that future research should aim to test their validity and to gather them under a 'theoretical umbrella'. This study suggests that such research does not necessarily need to focus on the problems underlying application failure, and that studies concentrating on the usefulness of mechanisms for making EU law application work better could be equally useful for making progress in these matters. More focused attention to testing the validity of the suggested explanatory variables is indispensable in this regard. What is also indispensable is openness to any variables that the empirical material suggests may have potential for explaining variation in application; such openness is necessary in view of the understudied nature of application in the EU to date and the limited number of variables that have been advanced as explaining variation in application in the EU.

\section{Understanding and theorizing EU law application: what way to go?}

The answer to how researchers should approach the topic of law application in the EU depends on the aim of the researcher. If the researcher wants to truly understand application processes and outcomes in specific cases, ${ }^{27}$ interpretative research is appropriate; purely deductive or inductive research may not be useful in this regard. This is the case, since deductive and inductive research aim to confirm theories or formulate hypotheses, respectively, rather than understand the case at hand. This makes this sort of research

\footnotetext{
${ }^{27}$ Calls for a better understanding of application problems have been expressed in the EU implementation literature; see e.g. Voermans, 2015.
} 
suboptimal for building a deep understanding of the phenomenon of implementation in the EU. While deductive research may speak to this phenomenon, starting from hypotheses formulated on the basis of theoretical perspectives is likely to allow for partial insight only. In inductive research, the data-finding process may enable the collection of accurate data, but useful details may get lost in the process of trying to draw generalisable conclusions from these data. Note that while not aimed at generating hypotheses or at confirming theories, interpretative research may nonetheless reflect the validity of concepts or theories, as this research does. ${ }^{28}$

A considerable challenge for EU implementation research lies in developing a theory of EU law application. Next to openness to potential factors that may explain application in the EU, four factors seem important to bear in mind in this regard. The first is that a clear distinction must be made between the different phases of the implementation process. Researchers must be aware that the dynamics underlying implementation processes differ not only between the legal (transposition) and practical (application and enforcement) phases of the implementation process, but also between the application phase and the enforcement phase. While the distinction between legal and practical implementation has increasingly been made, application and enforcement are often viewed together. A closer look at studies examining practical implementation suggests that these studies generally focus on enforcement rather than application; this may be explained by the fact that it is even more difficult to attain proper insight into application processes than in the enforcement of EU law in practice. ${ }^{29}$ While the lack of a distinction between application and enforcement is, thus, understandable, it is also problematic in the sense that it means that existing research may have 'polluted' our thinking about what makes application fail and what makes it work. It is only by studying application separately that a 'clean' image of the dynamics underlying failure or success can be attained.

Second, while scholars from various disciplines have conducted valuable research, it seems that EU application research may benefit greatly from (more) interdisciplinary cooperation. Just as the act of applying a law involves more than meets a lawyer's or a political scientist's eye, studying law application requires more than a single disciplinary perspective. If researchers from relevant disciplines were to combine their substantive knowledge and their experience with different research methodologies in joint projects, such projects could lead to a more precise understanding of the dynamics underlying application and of the remedies that are needed to address application issues successfully. Note that cooperation as such would make it more feasible to study the - resource

\footnotetext{
${ }^{28}$ Note that links between explanatory variables and the empirical material have been established not only above, but also in each of the empirical chapters. The concepts and models relevant in the latter are not necessarily those that have been advanced as explaining application processes across countries and across policy domains; this is why the links established in the empirical chapters are not reiterated in the current section.

${ }^{29}$ These points have also been made by Treib, 2014.
} 
intensive - issue of application more comprehensively than individual researchers are able to do.

Third, as the dynamics of application may vary across policy issues, across countries, and across legal instruments, research projects should take a more inclusive approach to these issues. Indeed, since implementation studies have tended to focus on some policy areas at the expense of others, attempts should be made to select currently understudied policy areas for analysis. Since research displays a structural focus on certain member states at the expense of others, efforts must be made to examine the 'underdogs' amongst the member states as well. ${ }^{30}$ And because application may pose different problems in the case of directives than in the case of regulations - the latter of which have remained understudied in EU implementation research - it seems advisable for researchers to divide their attention and to select regulations for examination as well.

Fourth, since the application of original EU norms is said to have much in common with the application of original domestic norms, it may be helpful for EU application research to return to domestic implementation studies and build on the perspectives advanced by these studies. ${ }^{31}$ It is, as explained above, particularly the various variables that are advanced as explaining cross-case variation in the application of EU norms that have not found a theoretical umbrella yet; attempting to understand the interconnections between them and to situate them within domestic implementation research perspectives may be helpful for finding this umbrella. Whereas the variables that the worlds of compliance typology suggests explain application across member states are situated within a more coherent conceptual framework, establishing clear links with the perspectives advanced by domestic implementation research - and with case-specific variables, both those explored and those yet unexplored - may help forge a better understanding of application in the EU. After three decades of transposition-related research, the time for attaining such a better understanding seems ripe.

\section{Recommendations}

From the empirical chapters of this study it is clear that a one-size-fits-all approach to compliance may not fit anyone, and that a mix of compliance instruments - consisting of tailor-made solutions when possible, and a harmonised approach when needed - may be appropriate if EU law is to work better. It is also clear that there is much to be gained when it comes to the functioning of existing compliance instruments, which calls for attempts to make such instruments work better. The current section aims at providing practical recommendations about how this twofold conclusion can be implemented by practitioners.

\footnotetext{
${ }^{30}$ These points have also been made by others, see e.g. Angelova et al., 2012.

${ }^{31}$ For an overview, see Chapter 2 on implementation in the EU: same rules, divergent practices, Section 3.2.1.
} 
Note that implementation of these recommendations does not guarantee effective application. This is the case, since our overall conclusion is based not on an objective evaluation of the effect of compliance instruments on the application of EU law on the ground - carrying out such an evaluation is not possible - but on the perceptions of implementation actors as to what works to make EU law work better and on literature, policy document, and case law analysis. While our findings are likely to reflect the effectiveness of the examined compliance instruments for supporting the application of EU measures as well - perceptions shape behaviour as they are guidelines for action - cause-effect relationships cannot be ascertained. The recommendations that follow from our conclusion must, thus, be read with this word of caution in mind. Since they are more likely than not to have a positive effect on the application of EU law, these recommendations may, nevertheless, be useful for practitioners who aim to close the compliance gap in the EU.

\subsection{The Commission should gain more insight into the functioning of compliance in- struments}

The European Commission does not have a 'master plan' for implementation and compliance; this makes it difficult to attain insight into the variety of mechanisms that exist to support the application of EU law across policy domains. This study has attempted to put some of the pieces together, by making an inventory of the compliance instruments in place in the context of three EU directives and three member states. This study suggests that the Commission needs to gain more insight into the functioning of compliance instruments to ascertain where flexibility is possible and harmonisation is needed, and to verify how the functioning of individual compliance instruments can be improved. Specific recommendations as to the second suggestion are the subject of the following sections; this section aims to discuss what the Commission could do to make the 'compliance toolbox' a better match for the sometimes-divergent needs of member states.

Gaining insight into what works to make EU law work better in different situations has both a practical and a legal component. As to the former element, it must be said that while this study provides initial insight into what may work to make EU law work better, an examination of this issue should ideally take place in each policy domain in which improvements are needed. Moreover, lessons could be learned - and possibly transferred to other policy domains - from studying 'best practice' policy areas as well. A (better) notion of the impact of culture, which the empirical chapters underline as important in shaping member state responses to compliance instruments, seems to bear considerable importance in this regard. It goes without saying that any such examination - and any discussion on how to do better - should be framed by the general principles of EU law, notably the general principle of equality of member states before the treaties. This principle, which is outlined in Article 4(2) TEU, protects against distinc- 
tions between member states where such distinctions are arbitrary rather than justified by objective reasons. This means that the Commission does, thus, need to treat member states equally unless objective grounds for discrimination exist; hence the need for a harmonised approach to member states where tailor-made solutions are not legally possible. It seems that it may be useful for the Commission to first identify situations in which application would benefit from discrimination between member states, and then to assess whether discriminatory treatment could be implemented within the limits of the treaties.

The latter may not be an easy endeavour to undertake. Certainly, the Commission's hands are not always tied; there are situations in which discrimination amongst member states is a well-accepted phenomenon. This is the case where unequal implementation performances of member states serve as the reason for differentiation. Here, one only needs to think of the infringement procedure, which is only used when the implementation performance of member states is substandard. In addition, the contents of guidelines may vary with the implementation performance of member states, as is the case in the area of economic policy. A flexible approach in the adoption of guidelines is certainly feasible, although is not particularly attempted outside the area of economic policy.

Flexibility would, in other cases, be more difficult to defend in view of the limitations imposed by the treaties and by CJEU case law. For example, when member states are known to violate the same EU law provision, it seems from a legal point of view, difficult for the Commission to sue one state but not the other; such differentiation would not be underlain by objective reasons. This is the case even when the 'objective' situation within these member states differs, for example in terms of the resources available for implementation; the Court has maintained that the alleged adverse internal situation of member states is not a valid excuse for their infringing EU law. ${ }^{32}$ This case law creates a situation in which, what would be desirable from a theoretical point of view - namely, differentiating amongst member states based on the roots of compliance problems - is legally impossible in reality. This seems to lead to a situation in which the general principle of equality and CJEU case law may, in some cases, obstruct compliance rather than facilitate it. But as long as the current legal framework stands strong the Commission will need to manoeuvre within the room that is available.

\subsection{The Union's enforcement strategy must be reformed}

The empirical chapters of this study suggest that the effectiveness of the infringement procedure, and the way in which the Commission uses its powers under this procedure, leave much to be desired. This suggestion is not novel; it has, as underlined before, been put forward in other research as well. Although reforms to the infringement procedure have been introduced lately, these reforms do not seem sufficient to ensure the effective

\footnotetext{
${ }^{32}$ See Chapter 4 on monitoring and sanctions, Section 1.1.2.1.1, sub C.
} 
functioning of the procedure. Thus, the current section recommends the implementation of further reforms to the Union's enforcement strategy.

\subsubsection{The problem of double-hatting}

Ideally speaking - at least from a theoretical point of view - the Commission should not act as guardian of the treaties; there are simply too many obstacles that prevent the Commission from functioning effectively in this regard. These obstacles flow from the fact that the Commission wears two hats at the same time - that of policy initiator and broker in the Council, and that of guardian of the treaties - and that it is difficult to juggle the responsibilities that accompany these tasks. An independent agency could alleviate the burden placed on the Commission and ensure a more objective handling of infringement cases.

The problem with this suggestion is, however, that the system has great advantages as it is for the Commission and for (certain) member states. The Commission could use the threat of infringement proceedings as a means to acquire member state approval for EU measures in the Council; reversely, member states could threaten to block a Commission proposal if infringement proceedings are launched or continued. In this sense, both the Commission and (benefitting) member states would be foolish to agree on having an independent agency tasked with guarding the treaties. Moreover, the EU integration process as a whole might grind to a halt, since if an important part of the Union's law-making machine - the Council - were to falter, the EU will not function as a problem-solving system. From a political perspective, taking away the Commission's hat of guardian of the treaties does, thus, seem undesirable.

\subsubsection{A call for increased transparency}

The current situation is equally undesirable, as the Commission cannot ensure that member states are dealt with impartially, and as the power of a member state may determine the Commission's response to an infringement committed by that member state. While the establishment of an independent agency may be out of reach, the Commission can increase the transparency of its enforcement strategy, which is likely to lead to a degree of de-politicisation of the manner in which the Commission exercises its tasks as guardian of the treaties. Granted, enforcement is never a fully 'objective' activity; a good enforcement policy is selective by nature, and every enforcement body faces a choice of what to focus on. However, one may argue that the societal acceptability of an enforcement regime hinges on transparency about the choices that are made, and that political bodies (in this case, the European Parliament) should be involved in discussions on how this enforcement policy should be shaped. Such transparency is not currently present. If it were, the acceptance within society and amongst member states of the Commission's exercise of its tasks as guardian of the treaties - the degree of objectivity of which it would, because of this transparency, probably have to enhance - might 
be increased. Given today's discussions about bringing the EU closer to the citizen, such increased transparency seems important.

\subsection{3. $100 \%$ compliance?}

It seems that it may be advisable for the Commission to rethink the $100 \%$ compliance standard that is formally used by it in relation to member states. There are practical and normative reasons that support such advice. Practically speaking, one may argue that a smart enforcement policy overlooks instances of noncompliance that are minor. Smart enforcement requires more than priority setting as to which policy areas to focus on; it also requires leniency where violations do not have a significant impact on the lives of citizens or the competitiveness of business actors, regardless of whether or not an area is of priority. While it is known that the Commission does, in some cases, decide not to sue member states even where it has sufficient legal grounds to do so, the reasoning underlying such decisions is not clear. The Commission's refrainment might well be motivated by considerations of the type discussed in the previous sentences, but whether or not this is the case is not made public. Note that it is, therefore, also in this context that more transparency on how the Commission exercises its enforcement competencies would help.

From a normative point of view, it should be noted that it seems generally accepted that full compliance is an illusion; a notion that seems to seriously question the reasonableness of the $100 \%$ compliance standard. Achieving full compliance seems difficult particularly in areas that require a substantial mobilisation of resources; resources that may be limited in times of economic adversity. The path from 'full compliance' to 'acceptable compliance levels' is a slippery one, which means that it is not easy to draw the line between what is 'good enough' and what borders on the unacceptable. In view of the practical problems associated with the $100 \%$ compliance standard and the normative reservations in this regard, a discussion on the reasonableness of the rather radical stance of the Commission that full compliance should be attained nonetheless, seems to be an important endeavour to undertake.

\subsubsection{A call for increased efficiency}

The previous years have seen several reforms to the infringement procedure; reforms that have had an effect in particular on Article 260 TFEU proceedings and on Article 258 TFEU proceedings started for non-notification of transposition measures by member states. Under the 'new' Article 260 TFEU, the Commission does not, as was previously the case, have to submit a reasoned opinion before bringing a member state before the Court for noncompliance with an Article 258 TFEU judgement; it only needs to formally notify the member state concerned of its infringement. Following Article 260(3), the Commission may seek financial sanctions against member states that failed to notify measures transposing a directive at the stage of infringement proceedings initi- 
ated pursuant to Article 258 TFEU. While potentially helpful to speed up the reparation of infringements in certain situations, these reforms do little to increase the efficiency of infringement proceedings started for 'bad application'. Legally speaking, nonnotification has nothing to do with incorrect application, and the shortening of the duration of Article 260 TFEU proceedings does not reduce the time lapse between the finding of an infringement by the Commission and the start of Article 258 TFEU proceedings in the first place.

In order for the speediness of Article 258 TFEU proceedings to increase, one may consider providing the Commission with more resources to conduct its work as guardian of the treaties, or establishing binding time limits for Article 258 TFEU proceedings. While implementation of the former suggestion requires member state approval - approval that is, for many reasons, unlikely to ensue - this does not apply to the latter suggestion. When to start an infringement action is a matter for the Commission to decide, and "there is nothing in the Court's case law from preventing the Commission in adopting a set of binding time-limits for action in relation to Article $258 \mathrm{TFEU}$ ". ${ }^{33}$ It seems that improvements regarding the excessive duration of infringement proceedings may therefore be sought in the implementation of such binding time limits. In order for such time limits to affect the speediness of proceedings, they should not only be established but also be enforced.

While the above suggestions do not require treaty amendment, the extension of Article 260(3) TFEU to include also 'bad application' cases would, self-evidently, require revision of the treaties and therefore necessitate approval from the member states. Such reform may be expected either to lead to member states reacting more quickly to Article 258 TFEU judgements, or to result in more Article 260(2) TFEU cases. In either case, the result of extending the applicability of Article 260(3) TFEU to 'bad application' cases is expected to be positive. In fact, some officials interviewed for this study do refer to the threat of punishment as potentially useful, if proceedings were faster.

It goes without saying that in order for reforms along those lines to bear fruit, the Commission should use its competencies effectively. The idea that this is not a matter of course is shown by the manner in which it has dealt with Article 260 TFEU proceedings. The past has shown that the Commission has not always started such proceedings when it had the power to do so; that when it did initiate proceedings, the Commission did in some cases refrain from asking the Court for the imposition of a penalty; and that fines were not always enforced. Such refrainment on the part of the Commission does not help the credibility of the Article 260 TFEU procedure as a 'stick in the cupboard'. Were the necessary reforms undertaken and complied with, the infringement procedure would gain much credibility in the eyes of implementation actors, who may use it to their benefit in the application of EU law.

\footnotetext{
${ }^{33}$ Smith, 2011: 9.
} 


\subsection{The Commission should be more of a guide of the treaties}

While the Commission as guardian of the treaties may not be directly meaningful for street-level actors, the Commission as 'guide of the treaties' seems pivotal for the daily administration of EU law. It is also in relation to the functioning of the Commission in this latter role that much seems to be capable of being improved. This is the case, for example, since the Commission may not answer calls for guidance (or do so fast enough), and since guidance may confuse rather than clarify. While the quality of guidance is in some cases - notably, in areas that are highly politicised and in domains in which scientific objectivity is hard to attain - bound to remain suboptimal, the involvement of street-level actors in the guidance development process seems imperative in order for the workability of guidance to be maximised. This is not a novel suggestion; decreasing the distance between 'Brussels' and the implementation practice has, in earlier studies, been suggested as useful for law-making processes as well.

Since post-legislative guidance is not necessarily regarded as authoritative by authorities and regulated entities alike, it may be a suboptimal way to solve interpretational difficulties compared to judicial interpretations provided by the CJEU. The problem, however, is that preliminary rulings do not necessarily address the core issues that actors struggle with in the implementation of EU law, thus leaving many interpretational questions in place. The result is that officials resort to the Commission to obtain clarity regarding the interpretation of legal norms. It seems that the Commission may partially compensate for the lack of authoritativeness of guidance by involving all member states in the guidance development process, for example by establishing formal working groups gathering member state experts, or by organising formal - and inclusive - consultation opportunities otherwise.

The adoption of guidance in the form of a Commission decision - rather than as a Commission service opinion - might in some circumstances seem useful to enhance the authority of guidance amongst national competent authorities and regulated actors. At the same time one should be aware of the downsides associated with the adoption of guidance as a Commission decision. One of these downsides it that Commission decisions require a legal basis, which is not always present or may be difficult to introduce. Moreover, the consultation of member states in 'comitology' committees, which assist the Commission in the exercise of its implementing powers, by presenting these states with a fait accompli does not permit veritable deliberation. If the legitimacy of guidelines is to be ensured, such deliberation is imperative. The downside of deliberation processes is, however, that they might - in view of the 'binding' nature of the guidance documents that they should give rise to - eventually yield guidance documents that represent weak political compromises that are far removed from (being useful to) the street-level implementation practice. In addition to this, the question remains as to what extent guidelines adopted through committee procedures enable flexibility in the face of quickly 
changing situations that require clarification; situations that the adoption of soft-law guidance was, in principle, meant to provide the ideal solution for.

It is clear that straightforward recommendations are not always easy to provide, particularly since what works to make post-legislative guidance work is case dependent. What may work for one member state may not work as well for another, and what may be desirable in one policy domain may be counterproductive in another. Since guidance is amongst those instruments that implementation actors need and appreciate most, it is case-specific considerations taking into account the recommendations outlined above that seem essential to make guidance work optimally to support the application of EU law on the ground.

\subsection{The Commission should facilitate 'informal' transnational cooperation}

The emphasis that national officials put on the usefulness of transnational cooperation for supporting the application of EU legislation on the ground calls for recommendations on what type of cooperation to pursue. This study strongly suggests that such cooperation should be perceived as informal. Legally formal networks - networks that are consolidated in EU legislation and subject to publicly sanctioned exchanges - seem poorly suited to this purpose. What seems to work better is cooperation in legally informal, and possibly materially formal, networks. While networks of the former type are 'member state only' configurations that function completely outside the EU institutional order, networks of the latter type are materially embedded in the EU institutional framework and are characterised by a strong presence of the European Commission or an EU agency. Essential for materially formal networks to be perceived as informal is that the Commission is not present as a guardian but as a facilitator. Whether and how this is possible is likely to depend on the nature of the policy domain, which means that Commission participation in a network may be a difficult matter to 'get right'.

Note that networks without any material links to the EU institutional framework are likely to function sub-optimally because they may lack the vigour to act. What seems most effective for making cooperation function well is 'informality in formality', or more concretely, informal cooperation within a facilitating framework that enables formal relations between the network and EU bodies to be sustained. Such a framework should allow for a structural flow of resources from the EU budget to the network and involve agreements on the output to be delivered by the network. In order to ensure member state commitment back home, the continued flow of resources to cooperation projects could be made dependent on the implementation of network outputs.

Note that the Commission may need to stimulate member state participation in networks by outlining participation thresholds and by (financially) facilitating participation where it is needed; the latter being an important mechanism to get the 'willing but unable' involved in cooperation. Attention must be given to the possible event of hierarchy within networks that are supposedly heterarchical. Ensuring equal participation 
seems particularly pressing for networks with substantive legal competences (since it is here that member states may be bound to dutiful implementation of the network outputs) and where networks play a substantial role in the policy context otherwise (for example because the outputs that they deliver are seen as greatly authoritative irrespective of their nonbinding nature).

Finally, at a time that is brimming with belief in the virtues of quantitative measurement, awareness should exist that networks may deliver outputs that cannot be measured, and that networks encompass much more than meets the observer's eye. Thus, networks should not be regarded as useless for the few concrete outputs that they might seem to produce; moreover, what happens on an immaterial level may be equally significant to, or more important than, the concrete outputs that networks may bring about.

\subsection{Member states should take responsibility and make the most of compliance instru- ments}

It seems too simplistic to lay responsibility for making compliance instruments work on the Commission alone. As the users of compliance instruments, it is also up to the member states to indicate what they need and to improve the functioning of compliance instruments that may, or do already, work well. For example, the fact that the preliminary ruling system may sometimes fail to be a truly effective support for authorities in the application process is the case, not because the CJEU is not available to give preliminary rulings, but because essential questions of interpretation are not submitted to the Court in the first place. In some cases, national officials would need to set aside their pride and ask the national court to request that the CJEU give a preliminary ruling on the interpretation of EU law provisions. There may also be cases in which national judges must be made aware of the opportunities that EU law offers and of the obligations that it imposes in this regard.

Member states may complain about the quality of guidance, but they should also try to contribute to making such guidance work better, for example by taking part in guidance development working groups where such groups exist. When transnational networks are found useful for supporting law application, street-level actors should be encouraged, by their superiors, to participate in cooperation projects and be made aware of the benefits for both 'leaders' and 'laggards' that such cooperation may bring along. Moreover, the 'products' of cooperation should be distributed to actors that have not personally participated in such cooperation, in order for these same actors to reap some of the benefits of cooperation as well. Something similar applies to preliminary rulings and to guidelines; where they may come in useful for the street-level implementation practice, national ministries or other bodies that (should) act as information channels between 'Brussels' and the domestic implementation practice must distribute such in- 
formation to street-level actors and provide training to them, so that these actors are aware of, and understand how to implement existing norms.

In some states, there is a task for the central administration to socialise implementing actors into the idea that civil society participation in the implementation process is 'a good (or at least a legitimate) thing'. There may also be a responsibility for the legislature to open access to the court for citizens and civil society organisations in particular, or to outline rules to improve the effectiveness of judicial remedies. The (technical) complexity of policy areas may require judges to follow (additional) training or call for the establishment of centres of expertise that judges may resort to when such expertise is needed, if more than momentary relief to the parties in the proceedings is to be provided. And, where national case law is relevant for implementation actors, there should be a body to effectively inform these actors about the impact of judgements on their work. Since it is hard to expect street-level actors to look for such information alone, and since case law may constitute a valuable help for such actors in the implementation of the law, the importance of such a body is not to be underestimated.

The above information does not mean that the relevant mechanisms are, by definition, not in place in the member states or that the relevant efforts are, by definition, not undertaken. However, it seems that member states are quick to place responsibility on the Commission (or on other member states) when it comes to making application work better, and that they should examine themselves before others. Good faith efforts on the part of individual member states are just as indispensable for making compliance instruments work as efforts on the part of 'the others'; this study suggests that there is much to be gained in this respect as well. 


\section{Summary}

\section{Purpose, relevance, theory, and methodology (Chapters 1-3)}

What works to make EU law work? This may be one of the most important questions facing the European Union, in view of the nearly axiomatic implementation deficit with which it is confronted; a deficit that is problematic not only because it prevents the beneficiaries of EU measures from enjoying the rights granted to them by these measures, but also because the Union's credibility and legitimacy greatly depend on the effective implementation of EU measures throughout the Union. Problems with the implementation of EU law do not only concern the transposition of EU directives into national measures, but also the consecutive application and enforcement of such measures on the ground. In view of the adverse consequences of problems in the application of EU law, the EU institutions have attached great priority to ensuring that EU law is applied effectively throughout the Union. EU documents show that there is a clear recognition that the application of EU law is often inadequate and that continuous attention to application issues is therefore needed. They also show that the approach towards solving application issues requires review and, where necessary, improvement.

This study addresses the question posed at the beginning of this summary, by studying the usefulness of compliance instruments in supporting the correct application of EU law by the competent authorities of the member states. With its focus on application rather than transposition, this study clearly departs from the majority of EU implementation research. The research in this area offers insight into the manifold variables that may cause transposition problems, but the phase during which EU measures must be applied to concrete situations on the ground is understudied. This study is novel, too, given its concentration on solutions rather than problems that member states may encounter in the implementation of EU measures. While knowledge about variables explaining implementation problems may be relevant for practitioners who are attempting to close implementation gaps, it seems that these same practitioners may benefit from knowledge on 'what goes wrong' in the implementation of EU law, as well as from knowledge on 'what goes right' in this regard. More concretely, they may benefit from insight into the usefulness of tools that may be helpful for making EU law work better.

The compliance instruments that were selected for study are categorised as belonging to the supranational, transnational, or national governance level. On the supranational level, we find monitoring and sanctions (including EU agency inspections, naming and shaming, and the infringement procedure) and post-legislative guidance. Net- 
works for administrative cooperation amongst member states are understood to be transnational instruments. In view of the lack of a veritable European civil society and the entrenchment of non-governmental organisations at the national level, civil society activism belongs to the national level. The same concept applies to national case law and preliminary rulings. While preliminary rulings are issued by the Court of Justice of the European Union, they are requested by national courts, and they acquire meaning within the national implementation context by virtue of the compliance of national courts with such rulings.

The usefulness of the selected compliance instruments was studied using a casestudy methodology that involved three EU directives, each regulating different policy issues (general product safety, integrated pollution prevention and control, and safety assessment of foreign aircraft) and three EU member states, each featuring different implementation processes (the Netherlands, Poland, and Portugal). These cases were analysed using an interdisciplinary approach that combines perspectives from legal science with those pertaining to political science, particularly public administration. Case law, literature, and policy document analysis are required to obtain insight into the design of compliance instruments and into the conceptual, practical, and political frameworks in which these instruments exist. A survey and qualitative interviews were required to acquire insight into the perceptions of actors involved in the (street-level) application practice. Studying perceptions is useful not only because it is impossible to evaluate the usefulness of compliance instruments objectively (by establishing causal relationships between concrete compliance instruments and application practices), but also because the perceptions of the 'target group' of compliance instruments play an important mediating role in how these instruments are used and the impact they have on implementation practices.

\section{Empirical findings (Chapters 4-8)}

The first main finding of this study is that a mix of compliance instruments must be employed in a manner that is flexible towards member states when possible, and harmonised when needed. A mix must be implemented because compliance problems may have different roots (namely, unwillingness, a lack of capacity, and a lack of norm internalisation), and because compliance instruments are interdependent (which means that they require each other in order for each of them individually to function effectively). Flexibility is necessary because a one-size-fits-all approach to compliance management may not fit anyone (which means that uniformity towards member states may be counterproductive rather than supportive in terms of ensuring compliance). The second main finding of this study is that much is to be gained regarding the functioning of existing compliance instruments; this calls for attempts to make such instruments work better. The conclusions of the empirical chapters as to what works to make compliance instruments work are summarised below. 


\section{A. Monitoring and sanctions (Chapter 4)}

Included in Chapter 4 on monitoring and sanctions, are inspections of national competent authorities conducted by EU regulatory agencies, naming and shaming exercises, and infringement proceedings.

\section{a. EU agency inspections}

Inspections conducted by EU regulatory agencies primarily aim to monitor the implementation performance of member states and correct existing instances of noncompliance detected in the course of inspections. In the context of this study, such inspections are conducted only in the area of air safety; here, the national competent authorities responsible for daily implementation are subject to regular standardisation inspections conducted by the European Aviation Safety Agency. While Commission officials maintain that such inspections offer them a precise insight into the application performance of national authorities, EASA officials argue that inspections have a monitoring and an educational function. Thus, they are intended for the enforcement of EU law and the facilitation of national authorities in their work.

The usefulness of EU agency inspections for officials involved in the application process appears to vary across and within member states, and across professional positions. For such inspections to work as compliance instruments, they should have a monitoring function and aim to offer learning opportunities for inspected authorities. Second, members of the inspection team should possess sufficient knowledge and expertise to act as teachers in relation to national officials. Finally, the (organisational) culture of inspected authorities should enable learning to occur. The case studies included in this study suggest that, in particular, meeting the two latter conditions is not a matter of course.

\section{b. Naming and shaming}

Naming and shaming consists of benchmarking the implementation performance of member states and showcasing countries whose performance is substandard. Naming and shaming can occur in public, in reports published by the Commission, or by an EU agency. Naming and shaming can also be a 'secretive' exercise, when information on the implementation performance is shared 'amongst intimae', namely, with national representatives gathering in Council working groups, expert groups, or implementation networks.

This study suggests that EU reports are rarely useful for supporting national officials in the application of EU law, and that naming and shaming 'amongst intimae' may be more useful in this regard. For naming and shaming to work, information about the implementation performance of member states should be meaningful: it should be objective, enable truly comparative and comprehensible insight to be gained, and indicate 
the quality of implementation. Second and partly related to the first condition, information must bite. It is only when this is the case that member states may fear the potentiality of reputational costs, or that scoreboards may be used as safeguards in relation to managers who may want to cut resources. Third, where positive domestic change needs to come 'from above', the relevant policy issue must enjoy salience amongst those who are in a position to bring about such change. If these conditions are met, naming and shaming could be a powerful instrument for supporting the application of EU measures. Since these conditions are not met as a matter of course, the effect of naming and shaming is considered erratic and its usefulness for implementing actors varies.

\section{c. Infringement proceedings}

Infringement proceedings, which the European Commission may start against member states under Article 258 TFEU, primarily aim to correct (alleged) violations of EU law. These violations may have come to the Commission's attention by virtue of its policecontrol oversight mechanisms, which include member state reports on the implementation of specific EU measures, expert studies, and agency inspections. Fire-alarm oversight, which consists of the submission of complaints to the Commission, may also identify EU law violations. When agreement on infringement and corrective action to be taken does not ensue during the administrative stage of infringement proceedings, the Commission may address the matter with the CJEU. When member states fail to implement a subsequent CJEU judgement requiring them to take the necessary measures to comply with EU law, the Commission may, under Article 260 TFEU, bring the matter before the Court once again; this time, to demand the imposition of financial sanctions on the culprit member state.

Perceptions of the usefulness of (the threat of) infringement proceedings in supporting the daily application of EU law are generally negative. What may improve the infringement procedure is, first, a reduced period of time between the Commission finding an infringement, and the imposition of sanctions. Second, for the Commission to be perceived as an impartial and reasonable guardian of the treaties, it should have access to more objective and more relevant information about the quality of implementation in member states. Note that this study is not alone in putting forward this call. Third, it seems that there is much to be gained, too, if existing competencies - of both the Commission and the Court - were used more consistently, vigorously, and wisely.

\section{B. Post-legislative guidance (Chapter 5)}

Post-legislative guidance is aimed first and foremost at facilitating the administration of EU measures by the competent authorities of the member states. It intends to do this by clarifying how EU law must, or will, be applied. Guidance may broadly come in three forms: as interpretative rules, as decisional acts, and as compliance templates. The benefits of post-legislative guidance for implementing actors vary with the type of guidance 
at stake. Decisional rules may be useful for these actors, since they stipulate how the Commission or another EU body will make use of its implementing powers. Familiarity with these rules allows member states to anticipate the behaviour of the issuing body and to adapt to it when necessary. Interpretative rules and compliance templates, on the other hand, inform member states of how EU measures are to be applied by the national competent authorities. Interpretative rules do this either by making a legislative framework more accessible through consolidation of the relevant rules and existing CJEU case law, or by clarifying legislative terms by interpreting them. Compliance templates concretise legislative provisions. Guidelines may support national competent authorities in daily law application practice, and contribute to a quick resolution of infringement cases by smoothing infringement proceedings. Finally, guidance may have a 'reassurance function'; when authorities comply with guidance, these authorities are assured that they are also acting in conformity with the underlying norms.

Guidance is generally seen as one of the most useful compliance instruments, both across member states and across policy domains. At the same time, it is clear that it is not easy to make guidance work equally well for everyone. Certainly, guidelines should be qualitatively adequate for them to be useful in the implementation process. For such adequacy to be attained, inclusive deliberation in the guidance development process is essential. However, adequacy is easier to attain in some policy areas than in others; in policy areas that are highly politicised or where scientific objectivity is difficult to attain, arriving at adequate guidance is challenging. Moreover, what works for some officials may not work for others; here, what is particularly relevant is whether or not guidance should be 'binding'. It is in view of the fault lines across member states that a flexible approach differentiating amongst member states seems, from a utilitarian point of view, desirable. However, it is unclear if such a flexible approach is feasible; for example, it is uncertain whether or not guidance can be 'binding' for member states that indicate a preference for binding, and be emphatically nonbinding for others. When there are objective reasons that enable differentiation between member states - for example, the existence of unequal implementation performances of member states - flexibility may be possible, legally speaking. However, when such objective reasons are absent, a flexible approach seems difficult to justify. It is particularly in these situations that it may be difficult for the European Commission to serve all member states equally well.

\section{Transnational networks (Chapter 6)}

Networks may be conceptualised as structures of interdependence involving horizontal cooperation of multiple, operationally autonomous actors pursuing common public goals. The adjective 'transnational' implies that these networks constitute a vehicle for national officials to act directly with their counterparts in other countries. In this study, the focus is on networks that enable practical cooperation (rather than the 'mere' exchange of information) amongst national authorities. From a theoretical point of view, 
the virtues of networks for supporting the implementation of norms are diverse. Cooperation through networks may facilitate mutual learning and resource sharing, both of which reduce information and transaction costs for participating authorities. Networks may also increase mutual trust amongst participating authorities, which leads to a decreased risk of defection and stimulates further cooperation. Finally, networks may socialise national officials into shared norms; this facilitates norm internalisation and conflict resolution.

Transnational networks appear to be one of the most useful compliance instruments. For transnational networks to work there must, first, be an intrinsic motivation for officials to engage in cooperation. This motivation should ideally follow from the perception that authorities are interdependent in the implementation of EU measures, or from awareness of the virtues (other than those that most directly relate to interdependence) that cooperation may bring for the network participants. Second, for cooperation to be useful and continue, networks must deliver. They must increase mutual trust amongst the participating authorities and, depending on the needs of the participants, facilitate mutual learning, resource sharing, and the resolution of conflicts. Third, the key to making networks deliver these virtues seems to lie in 'informality in formality'; that is, in a hybrid structure featuring interstate cooperation within a facilitating EU institutional framework. It seems that particularly when all of these conditions are met, networks can be useful compliance instruments.

\section{Civil society (Chapter 7)}

In this study, civil society is understood to be comprised of civic organisations and members of the general public. Civil society may support national authorities in the administration of EU measures through (one of) two avenues: cooperation with the authorities, or the exercise of multi-level pressure on these authorities. Cooperation may come in the form of political support or in the provision of specialist knowledge and expertise. The exercise of pressure requires civil society to act as a watchdog to the administration, by scrutinising the activities of the competent authorities, and attempting to bring non-compliers into line. Pressure may be exercised at the domestic level, for example by means of the initiation of court proceedings against the administration. Civil society may also 'take the European route' and generate pressure on national governments 'from the outside', for example by submitting complaints about the implementation performance of member states to the European Commission. Both cooperation and pressure may have the effect of strengthening the capacity of the state to engage in implementation.

Perceptions regarding the usefulness of civil society vary greatly across countries and policy domains. For civil society to be a useful compliance instrument, a policy issue must be societally salient; meaning that society should be aware of the issue and attach a degree of importance to the state's efforts towards making implementation 
work. Second, civic actors must be capacitated to act as credible challengers and useful partners of the state. Finally, state authorities must consider civic actors 'rightful actors' in the implementation process. While the input of both civil society and state actors is required for these conditions to be met, it seems that the key to making civil society a useful compliance instrument lies with the government. This is the case, because of the important tasks for the government of strengthening the capacity of civic organisations, socialising lower-level officials to a civil society friendly discourse, and providing the administration with the practical resources required to deal with civil society as a partner rather than an adversary. As perceptions on civil society are culturally entrenched and thus 'sticky', a flourishing civil society cannot simply be conjured up, with a positive evolution of the relationship between the state and civil society occurring over time. If civil society functions well, it may be a useful compliance instrument; if it still does not, the path ahead may be challenging and problematic.

\section{E. Case law (Chapter 8)}

Chapter 8 on case law includes two compliance instruments: domestic case law and preliminary rulings given by the Court of Justice of the European Union.

\section{a. Domestic case law}

Of interest to this study is domestic case law that is intended to solve disputes between the public administration and natural or legal persons. It is particularly case law that focuses on the compatibility of the behaviour of the public administration with legal provisions - rather than the grievances that applicants claim to suffer - that is relevant, since it is from a judicial evaluation of this issue that public authorities may draw lessons which may be useful for law administration practice. Given that case law may have the effect of undoing wrongs committed by the public authorities, its effect is primarily ex post and corrective. Case law may, however, also have the effect of preventing instances of noncompliance. This may be the case when the court declares a certain decision to be in violation of, or in compliance with, applicable legal provisions, and particularly when judgements include clarification of legislative provisions.

The usefulness of domestic case law varies across countries and across policy domains. Determining what works to make domestic case law work as a compliance instrument seems easier to answer than to implement because, similar to civic activism, case law is not an instrument that can be created at will. First, for case law to exist, a considerable number of (partially interdependent and not always makeable) conditions must be met. Second, for court judgements to be truly useful, it is required that judges solve the dispute at stake and provide a clarification of legal provisions that authorities deem unclear. In order for this to happen, judges should possess sufficient expertise, procedural rules should allow judges to examine the merits of the case, and litigants should challenge more than the administration's compliance with procedural rules ini- 
tially. Finally, authorities must be able to 'do something' with these judgements, which, given the resources that authorities might have to put to use, is not a matter of course. If the above conditions are not met, the usefulness of case law as a compliance instrument is expected to be suboptimal; if they are met, case law can be a powerful compliance instrument, as the empirical findings of this study suggest.

\section{b. Preliminary rulings}

Preliminary rulings, which are governed by Article 267 TFEU, are meant to clarify the interpretation of EU law (or the validity of acts adopted by the EU institutions). They are delivered by the CJEU, upon the request of a national court or tribunal from a member state. Unlike domestic case law, the effect of preliminary rulings on national administrative authorities is rather indirect. This is the case, since interpretations given by the CJEU are first and foremost meant for national courts, which are to use them in domestic court proceedings to decide issues of fact or to resolve any differences of opinion regarding the interpretation or application of national law. Preliminary rulings may clarify issues that authorities have struggled with in the administration of the relevant legal provisions. These authorities may have asked the court to submit preliminary questions to the CJEU in the first place.

With existing preliminary rulings inadequately addressing the core issues that actors struggle with in the application process, the preliminary ruling system is underused as a compliance instrument. How the preliminary ruling system can be made to work better seems difficult to determine because obvious solutions (for example, 'judges should refer more questions to the CJEU') would be overly simplistic. One may argue that where national case law does exist and competent administrative authorities are aware of cross-country variation in the interpretation of (core) EU law provisions, it may be advisable for national officials to outline their concerns before national judges, and for these judges to resort to the CJEU if they deem these concerns appropriate. In order for this suggestion to move forward, it seems that authorities and courts should be aware that preliminary rulings may be beneficial for them, and be prepared to cast aside their pride or their confidence as to the rightfulness of their own interpretation.

\section{Conclusions and recommendations (Chapter 9)}

Chapter 9 recaps the purpose, relevance, and methodology of this thesis and summarises the findings of the empirical chapters (as above). Since this study is of an interpretative nature and extensive use has been made of theory (notably in Chapter 2 and in each empirical chapter), the chapter also reflects on the links between this study and scholarly thinking about implementation and compliance. It examines the links between the empirical material and the tenets of the three schools of international relations studies (rationalism, managerialism, and constructivism), and it suggests that implementation research should clarify how these tenets interconnect and what this means for the design 
of the EU compliance management system. It also reflects on the links between the empirical material and the variables that EU implementation research proposes as explanatory for variation in application, and it argues that research should aim to gather them under a 'theoretical umbrella'. This theoretical section concludes by providing suggestions on how researchers could, from a practical perspective, approach the subject of the application of EU law.

The thesis concludes by providing recommendations that the European Commission and the member states may consider in order to make the application of EU law work better. It recommends that the Commission gains insight into the functioning of compliance instruments to ascertain where flexibility towards member states is possible and where a harmonised approach is needed, and to verify how the functioning of individual compliance instruments can be improved. In relation to the latter point, it is suggested that (and how) the Union's enforcement strategy must be further reformed, that the Commission should be more of a guide (and not only a guardian) of the treaties, and that the Commission should facilitate informal transnational cooperation. Finally, it argues that since they are the target group of compliance instruments, it is also up to the member states to take responsibility and make use of such instruments. Good faith effort from individual member states is as indispensable for making compliance instruments work as effort from 'the others'. This study suggests that there is much to be gained also in this respect. 



\section{Annex I Valorisation}

\section{Societal relevance}

This study aims to provide insight into what works to make EU law work. It does this out of awareness that EU law does not always work as it should; member states do not always comply with EU measures, as a result of which policy objectives are not always achieved, and the beneficiaries of EU measures do not always enjoy the rights granted to them by these measures. While all legal systems are bound to suffer from a certain rate of noncompliance - achieving full compliance is therefore an illusion and, one may argue, even undesirable - the relatively novel nature of the EU as a political system makes compliance problems more urgent. This is the case, since the Union still needs to prove its credibility as an effective problem-solving system, and the effective implementation of EU measures throughout the Union is essential in this regard. Indeed, there is no added value of the EU if its measures do not benefit those whom they are intended to benefit.

In view of their adverse consequences for the credibility of the EU and for society, compliance problems are serious enough to merit political and scholarly attention. In fact, both in the political and in the academic world, the idea that the EU has a compliance deficit - and the related idea that compliance problems must be solved - has become a platitude. The past two decades have seen the appearance of numerous EU documents outlining the need to improve the implementation of EU law. Focusing primarily on the transposition phase of the implementation process, the increasing body of scholarly literature has shown that compliance problems exist, and identified a variety of structural and circumstantial factors underlying such problems.

While EU implementation research has delivered valuable insight into the problems encountered by member states in the transposition of EU directives, two lacunae that limit its practical relevance - for national and EU officials involved in 'making EU law work', and resultantly for citizens and businesses in the internal market - seem to exist. The first, which is hinted at above, concerns the fact that in contrast to the emphasis that EU institutions have put on the issue of (effective) law application, the phase during which the provisions of EU measures are applied to concrete cases on the ground has remained understudied in EU implementation studies. The weak presence of application studies is understandable, given that reliable information regarding the application performance of member states is difficult to gather. However, since applying EU rules is essential, if these rules are to achieve their full effect, and since we cannot under- 
stand member state behaviour in the implementation of EU law by examining the transposition of directives alone, this lack of attention is a cause for concern.

The second factor that reduces the relevance of EU implementation research for practitioners and citizens alike is its excessive focus on implementation failure - as though all policies are bound to fail and all member states act in a vacuum when implementing EU rules. The majority of studies seem to overlook the fact that instruments that are designed to offer solutions to compliance problems, or that may otherwise be expected to support member states in the implementation of EU measures do exist. While knowledge about variables that explain implementation problems is certainly relevant for practitioners attempting to close implementation gaps, it seems that practitioners may benefit from knowledge about 'what goes wrong' in the implementation of EU law, as well as from knowledge about 'what goes right' in this regard. More concretely, they may benefit from insight into the functioning of tools that may be helpful for making EU law work better.

In view of the considerations outlined in the previous paragraphs, this study suggests that it may be valuable, from a relevancy point of view, to reverse the perspective on implementation and compliance in the EU. In the context of this study, this 'reversed angle' means the following. First, instead of focusing on the transposition phase of the implementation process, this study has directed its attention to the phase during which EU measures must be applied in concrete situations on the ground. And second, rather than concentrating on problems that member states may encounter in the application of EU measures, this study takes a solution-oriented approach by evaluating the usefulness of compliance instruments for supporting the competent administrative authorities of the member states in the application of EU law. Yielding insight into the usefulness of the studied compliance instruments for supporting national actors in the application of EU rules on the ground and providing recommendations on how the application of EU rules can be improved, this study is helpful for national and EU practitioners who are directly involved in the application of EU law and for those who are set to benefit from the rights and obligations outlined in this law.

\section{Target group}

The focus of this study on the usefulness of compliance instruments for supporting the application of EU law makes the research results interesting for practitioners involved in the implementation of EU law. The first and most important target group of this study is EU officials, in particular those officials who are assigned implementation-related responsibilities within the European Commission. Commission officials may benefit, first, from the finding that the effectiveness of compliance instruments depends to a great extent on the perceptions of their usefulness held by the target group of these instruments; that is, (the competent authorities of) the member states. This finding, and the finding that perceptions often vary across member states and across policy domains, 
may be valuable for the Commission to account for in considerations regarding the design of compliance instruments in relation to individual member states and regarding specific policy domains.

Second, Commission officials may also benefit from the insight offered by this study into the conditions that may make specific compliance instruments work (better), ${ }^{1}$ and from the relevant recommendations that this study presents. ${ }^{2}$ Suggesting how the Commission could make better use of the compliance instruments that it has at its disposal as guardian of the treaties (e.g. the infringement procedure) and how it could facilitate the functioning of others (e.g. transnational networks), these recommendations aim to provide concrete ideas as to how the Commission could exercise its supervisory tasks more effectively and efficiently. In view of the shift in the EU, away from law making and towards implementation, these recommendations may be timely.

In addition to being potentially useful for EU officials, this study may be beneficial for national officials involved in the street-level implementation of EU rules (e.g. inspectors or civil servants responsible for licensing activities), and for those officials who are responsible for the coordination of implementation tasks at higher government levels (e.g. ministerial officials). This study may have an awareness-raising effect with regard to the variety of compliance instruments that exist - which may lead to a better use of such instruments by national authorities - and may shed light on the different ways that national authorities make use of compliance instruments and the motivations underlying the relevant dynamics. This type of knowledge may be valuable for enhancing mutual understanding and mutual trust amongst member states, both of which are not selfevident in a Union that is 'united in diversity'.

\section{Research products}

At the time of writing, the most tangible products of this study are the recommendations that it has arrived at as to how the application of EU law on the ground can be improved. These recommendations, which are presented in Chapter 9, follow from two findings that the empirical research has given rise to. The first of these findings is that a mix of compliance instruments must be employed in a manner that is flexible towards member states when possible and harmonised when needed. A mix must be implemented because compliance problems may have different roots (namely, unwillingness, a lack of capacity, or a lack of norm internalisation) and because compliance instruments are interdependent (which means that they require each other in order for each of them to individually function effectively). Flexibility is needed because a one-size-fits-all approach to compliance management may not fit anyone (which means that uniformity towards member states may be counterproductive rather than supportive in terms of ensuring compliance). The second main finding of this study is that much is to be

\footnotetext{
${ }^{1}$ See Sections 4 of Chapters 4 until 8 of this study.

${ }^{2}$ See Chapter 9, Section 5, of this study (and see Section 3 below for a synthesis).
} 
gained regarding the functioning of existing compliance instruments, which calls for attempts to make such instruments work better.

The remainder of this subsection briefly recaps the recommendations on how this twofold conclusion can be implemented by practitioners involved in the implementation of EU law presented in Chapter 9 of this study.

\section{A. The Commission should gain more insight into the functioning of compliance instruments}

This study suggests that the Commission must gain more insight into the functioning of compliance instruments, in order to ascertain where flexibility towards member states is possible and where a harmonised approach is needed, and to verify how the functioning of individual compliance instruments can be improved. Gaining more insight into what works to make EU law work better in different situations has both a practical and a legal component. Regarding the former element, while this study provides some initial insight into what may work to make EU law work better, an examination of this issue should ideally take place in each policy domain where improvements are needed. Any such examination should be framed by the general principles of EU law; notably, the general principle of equality of member states before the treaties. It seems that it may be useful for the Commission to first identify situations in which application would benefit from discrimination between member states, and then to assess whether discriminatory treatment could be implemented within the limits of the treaties.

\section{B. The functioning of existing compliance instruments should be improved}

Besides these general recommendations and based on the findings of each empirical chapter included in this study, this research provides concrete recommendations on how the functioning of the compliance instruments examined in context can be improved. These recommendations are briefly recapped below.

\section{a. The Union's enforcement strategy must be reformed}

The empirical chapters of this study suggest that the effectiveness of the infringement procedure and the manner in which the Commission uses its powers under this procedure are inadequate. This suggestion is not novel; it has been put forward in other research as well. Despite the fact that reforms to the infringement procedure have been introduced recently, these reforms do not seem sufficient to ensure the effective functioning of the procedure. Thus, this study recommends the implementation of further reforms to the Union's enforcement strategy.

First, while the establishment of an independent enforcement agency may be out of reach, the Commission could increase the transparency of its enforcement strategy, which is likely to lead to a degree of de-politicisation of the manner in which the Commission exercises its tasks as guardian of the treaties. This would increase the acceptance 
rate, within society and amongst member states, of the Commission's exercise of its tasks as guardian of the treaties. Given the current discussions about bringing the EU closer to the citizen, such increased transparency seems important.

Second, it seems that it may be advisable for the Commission to rethink the $100 \%$ compliance standard that is formally used in relation to member states. There are practical and normative reasons for such advice. Practically speaking, one may argue that a smart enforcement policy overlooks instances of noncompliance that are minor. From a normative point of view, it seems generally accepted that full compliance is an illusion; a notion that seems to question the reasonableness of the $100 \%$ compliance standard. In view of the practical problems associated with the $100 \%$ compliance standard and the relevant normative reservations, a discussion on the reasonableness of the rather radical stance of the Commission that full compliance should nonetheless be attained, seems an important endeavour to undertake.

Third, it seems that improvements regarding the excessive duration of infringement proceedings may be sought in the implementation of binding time limits for member states, and for the Commission to act in infringement proceedings. Moreover, Article 260(3) TFEU - which makes it possible for the Commission to seek financial sanctions against member states that have failed to notify measures transposing a directive at the stage of infringement proceedings initiated pursuant to Article 258 TFEU - should be extended to include 'bad application' cases. In order for reforms along those lines to bear fruit, the Commission should use its competencies effectively. If the necessary reforms are undertaken and complied with, the infringement procedure could gain much credibility in the eyes of implementation actors, who may use it to their benefit in the application of EU law.

\section{$b$. The Commission should be more of a guide of the treaties}

The Commission as 'guide of the treaties' seems pivotal for the daily administration of EU law. It is also in relation to the functioning of the Commission in this latter role that much seems to be gained. This is the case, for example, since the Commission may not answer calls for guidance (or do so fast enough), and since guidance may confuse rather than clarify. Straightforward recommendations to improve matters are not always easy to provide, since what works to make post-legislative guidance work is case dependent. What may work for one member state may not work as well for another, and what is desirable in one policy domain may be counterproductive in another. Since guidance is amongst those instruments that implementation actors need and appreciate most, it is the case-specific considerations that account for the recommendations outlined in this study that seem essential to make guidance work optimally for supporting the application of EU law on the ground. 


\section{c. The Commission should facilitate 'informal' transnational cooperation}

The emphasis that national officials put on the usefulness of transnational cooperation for supporting the application of EU legislation on the ground calls for recommendations on what type of cooperation to pursue. This study strongly suggests that such cooperation should be perceived of as informal. Legally formal networks - networks that are consolidated in EU legislation and subject to publicly sanctioned exchanges seem poorly suited to this purpose. What seems more effective is cooperation in legally and materially informal networks or in materially formal networks. While networks of the former type are member state only configurations that function outside of the EU institutional order, networks of the latter type are materially embedded in the EU institutional framework and are characterised by a strong presence of the European Commission or an EU agency. For materially formal networks to be perceived as informal it is essential that the Commission is not present as a guardian, but as a facilitator.

Whether and how this is possible is likely to depend on the nature of the policy domain, which means that Commission participation in a network may be a difficult matter to 'get right'. The Commission may need to stimulate member state participation in networks by outlining participation thresholds and by (financially) facilitating participation when necessary; the latter is an important mechanism to get the 'willing but unable' involved in cooperation. Finally, at a time that is brimming with belief in the virtues of quantitative measurement, awareness should exist that networks may deliver outputs that cannot be measured, and that networks encompass much more than meets the observer's eye.

\section{d. Member states should take responsibility and make the most of compliance instruments} It is too simplistic to place responsibility for making compliance instruments work on the Commission alone. As the users of compliance instruments, it is also up to the member states to indicate what they need and improve the functioning of compliance instruments that they say work well. This is not to say that the necessary efforts are not being undertaken by the member states. However, it seems that member states are quick to place responsibility on the Commission (or on other member states) when it comes to making application work better, and that they should examine themselves before others. Good faith effort from individual member states is as indispensable for making compliance instruments work as effort from 'the others'. This study suggests that there is much to be gained in this respect as well.

\section{Innovation}

While firmly set within the context of EU implementation research, this study departs from this research -thus, it is innovative in relation to it - for four reasons. The first is that EU implementation studies have focused primarily on explaining divergent performance records of member states regarding the transposition of EU directives. The 
phase during which EU rules are administered in concrete situations has remained a black box; we know little about the extent to which such rules are applied and about the problems that street-level actors experience in the application process. This lack of attention to the application phase of the implementation process may be explicable in view of the fact that it is difficult to monitor the application of EU rules on the ground. However, since applying EU rules is essential if these rules are to achieve their full effect, and since we cannot understand member state behaviour in the implementation of EU law by examining the transposition of directives alone, this lack of attention is a cause for concern. It is this concern that has motivated the focus of this study to be on the application of EU directives in practice rather than their transposition on paper. As such, this study has a different perspective than the majority of EU implementation studies.

Second, the excessive focus of implementation studies on implementation failure has created a bias in the implementation research product - as though all policies are bound to fail and member states act in a vacuum when they implement EU law. The majority of implementation studies seem to overlook the fact that mechanisms to support the correct implementation of EU law exist. Moreover, when studies do suggest remedies for implementation problems, the respective proposals usually mirror the nature of the implementation problems that must be solved. 'Civil society does not function well. What we need to improve implementation is more civil society activism'. 'The administration does not function effectively. What we need is a more effective administration.' And this continues. Such proposals do not provide concrete tools for taking implementation to a higher level. Because of the limited attention to 'what is out there' to remedy compliance problems, there is little knowledge about the functioning of existing 'could-be solutions'. Thus, by making an inventory of the multitude of compliance instruments in place, and by examining the usefulness of existing compliance instruments - instead of the dynamics underlying compliance problems - that the current study departs from, and is novel in relation to, existing implementation research.

Third, this study is innovative in its focus on the perceptions regarding the usefulness of compliance instruments held by the target group of these instruments - and therefore, by its recognition that the effectiveness of the EU compliance management system depends on the design of this system and on how national officials perceive the functioning and the usefulness of compliance instruments. Recognition of the importance of perceptions as mediating variables in making compliance instruments work seems weak in the few studies that assess the effect of specific (in particular legal) instruments on compliance.

Fourth and partly related to the previous point, this study is innovative because of the variety of methods used to achieve triangulation. Documentary, literature, and (EU and national) case law analysis was complemented with qualitative interviewing (91 interviewed officials) and a survey (77 survey respondents). Such a variety of data 
sources are not often employed. It is because of this combination of sources that this study can provide both comprehensive insight into the functioning of compliance instruments, and concrete recommendations on how the application of EU law can be improved.

\section{Planning and realisation}

In order for the recommendations of this study to have an impact on the implementation of EU law in practice, the concluding chapter of this study - which includes these recommendations - will be circulated to a selection of national and EU officials. This selection includes those national and EU officials who were interviewed for this study and the national officials who responded to the survey that was circulated. The conclusions of this study will also be sent to the Commission's Secretariat General division responsible for compliance issues, to the cabinet of Commissioner Timmermans, to the relevant committees of the European Parliament, in particular the Committee on Legal Affairs, and to the European Parliamentary Research Service. 


\section{Annex II List of interviews}

\section{Member States (governmental and non-governmental)}

\section{The Netherlands}

Interview NL1. Interview with an official from a consumer organisation. Amsterdam, 25 October 2010.

Interview NL2. Interview with a representative from the Confederation of Netherlands Industry and Employers/Royal Association MKB Nederland (VNO-NCW/MKB Nederland). The Hague, 29 October 2010.

Interview NL3. Interview with a representative from VNO-NCW/MKB Nederland. The Hague, 29 November 2010.

Interview NL4. Interview with an inspector from the Dutch Food and Consumer Product Safety Authority (Nederlandse Voedsel en Waren Autoriteit, NVWA). Zwijndrecht, 21 January 2011.

Interview NL5. Interview with a specialist from the NVWA. The Hague, 8 October 2010.

Interview NL6. Interview with a policy officer from the NVWA. The Hague, 8 June 2010.

Interview NL7. Interview with a policy officer from the NVWA. Utrecht, 7 January 2011.

Interview Prosafe/NL8. Interview with a Prosafe board member/an official from the NVWA. Zwijndrecht, 22 June 2010.

Interview Prosafe/NL9. Interview with a Prosafe board member/an official from the NVWA. Zwijndrecht, 21 October 2010.

Interview NL10. Interview with an inspector from the NVWA. Zwijndrecht, 3 January 2011.

Interview NL11. Interview with an official from the NVWA. Utrecht, 12 January 2012.

Interview NL12. Interview with a policy officer from the NVWA. The Hague, 21 June 2010.

Interview NL13. Interview with a policy officer from the NVWA. The Hague, 28 October 2010.

Interview NL14. Interview with a policy officer from the Ministry of Health, Welfare and Sports (Ministerie van Volksgezondheid, Welzijn en Sport, VWS). The Hague, 29 November 2010.

Interview NL15. Interview with a representative from a sectorial business association. The Hague, 16 January 2012.

Interview NL16. Interview with three officials from the Knowledge Centre for Environmental Legislation and Policy (InfoMil). The Hague, 12 January 2012.

Interview NL17. Interview with an official from the Ministry of Infrastructure and the Environment (Ministerie van Infrastructuur en Milieu, MIenM). The Hague, 4 November 2011.

Interview NL18. Interview with an official from the former Inspection of the Ministry of Housing, Spatial Planning, and the Environment (VROM-Inspectie). The Hague, 16 January 2012.

Interview NL19. Interview with a representative from an environmental organisation. Utrecht, 2 November 2011.

Interview NL20. Interview with a representative from an environmental organisation. Amsterdam, 15 December 2011.

Interview NL21. Interview with a representative from a permitting authority. Schiedam, 23 January 2012.

Interview NL22. Interview with an official from a permitting authority. Maastricht, 16 February 2012.

Interview NL23. Interview with two permit writers from a permitting authority. Maastricht, 11 January 2012.

Interview NL24. Interview with a permit writer from a permitting authority. Amsterdam, 16 December 2011.

Interview NL25. Interview with two officials from a permitting authority. Den Bosch, 13 January 2012.

Interview NL26. Interview with an official from MIenM. The Hague, 13 February 2012.

Interview NL27. Interview with an official from MIenM. Utrecht, 6 juli 2012.

Interview NL28. Telephone interview with an official from the Human Environment and Transport Inspectorate (Inspectie Leefomgeving en Transport, ILenT). 5 April 2012. 
Interview NL29. Interview with two officials from ILenT. Hoofddorp, 22 May, 2012.

Interview NL30. Telephone interview with an official from ILenT. 12 February 2014.

Interview NL31. Telephone interview with an official from InfoMil. 23 October 2014.

\section{Poland}

Interview PL1. Interview with two officials from the Ministry of Foreign Affairs (Ministerstwo Spraw Zagranicznych, MSZ). Warsaw, 22 October 2012.

Interview PL2. Interview with an official from the Office for Competition and Consumer Protection (Urząd Ochrony Konkurencji i Konsumentów, UOKiK). Warsaw, 8 November 2012.

Interview PL3. Interview with three officials from a regional trade inspectorate. Warsaw, 7 November 2012.

Interview PL4. Interview with five officials from a regional trade inspectorate. Lodz, 5 November 2012.

Interview PL5. Interview with three officials from a regional trade inspectorate. Szczecin, 30 October 2012.

Interview PL6. Interview with a representative from a consumer organisation. Warsaw, 24 October 2012.

Interview PL7. Interview with two representatives from a law firm. Warsaw, 8 November 2012.

Interview PL8. Interview with an official from the Ministry of the Environment (Ministerstwo Środowiska, $\mathrm{MoS})$. Warsaw, date removed on the request of the interviewee.

Interview PL9. Interview with two officials from a permitting authority. Warsaw, 26 October 2012.

Interview PL10. Interview with an official from the MoS. Warsaw, 26 October 2012.

Interview PL11. Interview with an official from a permitting authority. Szczecin, 30 October 2012.

Interview PL12. Interview with an official from a provincial environmental inspectorate (Wojewódzki Inspektorat Ochrony Środowiska, WIOS). Lodz, 5 November 2012.

Interview PL13. Interview with a representative from an environmental organisation. Szczecin, 29 October 2012.

Interview PL14. Interview with an official from a university/a representative of an environmental organisation. Warsaw, 24 October 2012.

Interview PL15. Interview with four officials from the Civil Aviation Authority (Urzad Lotnictwa Cywilnego, ULC). Warsaw, 25 October 2012.

\section{Portugal}

Interview PT1. Interview with an official from the Ministry of Foreign Affairs (Ministro de Estado e dos Negócios Estrangeiros). Lisbon, 7 December 2012.

Interview PT2. Interview with an official from the Food and Economic Safety Authority (Autoridade de Segurança Alimentar e Económica, ASAE) and with an official from a regional inspectorate of ASAE. Lisbon, 22 January 2013.

Interview PT3. Interview with an official from ASAE. Lisbon, 14 January 2013.

Interview PT4. Interview with an official from ASAE. Lisbon, 4 December 2013.

Interview PT5. Interview with two officials from the Directorate-General for Consumers (DG Consumidor, DGC). Lisbon, 14 January 2013.

Interview PT6. Interview with an official from DGC. Lisbon, 18 January 2013.

Interview PT7. Interview with two officials from DGC. Lisbon, 14 December 2012.

Interview PT8. Interview with a representative from a consumer organisation. Lisbon, 10 December 2012.

Interview PT9. Interview with two officials from the Portuguese Environmental Agency (Agência Portuguesa do Ambiente, APA). Lisbon, 17 December 2012.

Interview PT10. Interview with an official from the Inspectorate for Agriculture, Sea, Environment, and Spatial Planning (Inspeção-Geral da Agricultura, do Mar, do Ambiente e do Ordenamento do Território, IGAMAOT). Lisbon, 18 December 2012.

Interview PT11. Interview with a former official from the Ministério da Agricultura, do Mar, do Ambiente e do Ordenamento do Território (Ministry for Agriculture, Sea, Environment, and Spatial Planning). Lisbon, 17 January 2013.

Interview PT12. Interview with a representative from an environmental NGO. Lisbon, 11 January 2013. 
Interview PT13. Interview with a representative from an environmental NGO. Lisbon, 5 December 2012.

Interview PT14. Interview with two officials from the National Civil Aviation Authority (Autoridade Nacional da Aviação Civil, ANAC). Lisbon, 23 January 2013.

Interview PT15. Interview with an official from ANAC. Lisbon, 24 January 2013.

Interview PT16. Interview with two officials from ANAC. Lisbon, 24 January 2013.

Interview PT17. Interview with an official from ANAC. Lisbon, 15, 16, 23, and 25 January 2013.

\section{EU institutions and agencies}

\section{European Commission ${ }^{1}$}

Interview EC1. Telephone interview with an official from the European Commission, DG Health and Consumers (DG SANCO). 25 March 2010.

Interview EC2. Telephone interview with an official from the European Commission, DG SANCO. 17 January 2011.

Interview EC3. Interview with an official from the European Commission, DG SANCO. Brussels, 30 November 2010 .

Interview EC4. Interview with an official from the European Commission, DG SANCO. Brussels, 22 October 2010.

Interview EC5. Interview with two officials from the European Commission, Directorate-General for the Environment (DG ENV). Brussels, 20 January 2012.

Interview EC6. Interview with two officials from the European Commission, Directorate-General for Mobility and Transport (DG MOVE). Brussels, 3 July 2012.

Interview EC7. Interview with an official from the European Commission, DG ENV. Amsterdam, 15 December 2011.

Interview EC8. Interview with an official from the European Commission, Secretariat General. Brussels, 10 December 2014.

\section{European Aviation Safety Agency}

Interview EASA1. Telephone interview with an official from the EASA SAFA Standardisation Team. 9 March 2010.

Interview EASA2. Interview with an official from the EASA SAFA Standardisation Team. Cologne, 6 December 2011.

Interview EASA3. Interview with an official from the EASA SAFA Coordination Team. Cologne, 10 July 2012.

\section{Non-governmental organisations (non-national)}

Interview Prosafe1. Telephone interview with a Prosafe board member. 18 January 2011.

Interview Prosafe2. Interview with a Prosafe consultant. Brussels, 3 December 2010.

Interview Prosafe3. Interview with a Prosafe board member. Brussels, 15 November 2010.

Interview Prosafe4. Interview with a Prosafe consultant. Brussels, 15 November 2010.

\section{Written communication (by date)}

Email from an expert of a Polish environmental organisation to author (23 August 2012.

Email from an expert from the Association of Polish Consumers to author (21 September 2012).

Email from an expert from a Portuguese environmental consultancy to author (14 September 2012).

Email from a Polish trade inspector to author (21 November 2012).

\footnotetext{
${ }^{1}$ Names for the Commission's DGs as under the Barroso Commission.
} 
Email 1 from a Commission official to author (10 February 2014).

Email 2 from a Commission official to author (14 February 2014).

Email 1 from interviewee PL2 to author (2 September 2014).

Email 2 from interviewee PL2 to author (10 September 2014).

Email from interviewee PL8 to author (date removed on the request of the correspondent).

Email 3 from interviewee PL2 to author (17 September 2014).

Email from interviewee EASA1 to author (8 January 2015).

Email from interviewee NL12 to author (26 February 2015).

Email from interviewee PL15 to author (3 March 2015).

Email from interviewee NL30 to author (9 July 2015). 


\section{Literature}

Adam, H., and Winter, G. (1996), 'Commission guidance addressed to member state agencies', in G. Winter (ed.), Sources and Categories of European Union Law: A comparative and reform perspective, BadenBaden: Nomos Verlagsgesellschaft, pp. 629-644.

Adriaanse, P.C., Barkhuysen, T., Boswijk, P., Habib, K., De Kruif, C., Luchtman, M.J.J.P., Den Ouden, W., Prechal, S., Steunenberg, B., Vervaele, J.A.E., De Vries, S., Voermans, W.J.M., and Widdershoven R.J.G.M. (2008), 'Implementatie van EU-handhavingsvoorschriften: tussen Europese regie en nationale praktijken', RegelMaat, 2008/5, 180-191.

Alfé, M., Christiansen, T., and Piedrafita, S. (2008), 'Implementing Committees in the Enlarged European Union: Business as Usual for Comitology?', in E. Best, T. Christiansen, and P.Settembri (eds), The Institutions Of The Enlarged European Union - Continuity and Change (Cheltenham: Edward Elgar), pp. 205221.

Alter, K.J. (1998), 'Who Are the "Masters of the Treaty"? European Governments and the European Court of Justice', International Organization, 52(1): 121-147.

Alter, K.J. (2000), 'The European Union's legal system and domestic policy: spillover or backlash?', International Organization 54(3): 489-518.

Andersen, S.S., and T. Burns (1996), 'The European Union and the erosion of parliamentary democracy: A study of post-parliamentary governance', in S.S. Andersen and K.A. Eliassen (Eds) The European Union: How Democratic Is It?, Sage: London, pp. 227-251.

Angelova, M., Dannwolf, T., and König, T. (2012), 'How Robust Are Compliance Findings? A Research Synthesis', Journal of European Public Policy, 19(8): 1269-1291.

Aragão, A. (2012), 'The implementation of Article 9.3 of the Aarhus Convention on access to justice in Portugal', in J. Darpö (ed.), Effective Justice? Synthesis report of the study on the Implementation of Articles 9.3 and 9.4 of the Aarhus Convention in the Member States of the European Union, Brussels: European Commission.

Armstrong, K.A. (2002), 'Rediscovering civil society: the European Union and the White Paper on Governance', European Law Journal, 8(1): 102-132.

Armstrong K.A. (2006), 'Inclusive governance? Civil society and the open method of co-ordination', in S. Smismans (ed.), Civil society and legitimate European governance, Cheltenham: Edward Elgar, pp. 42-67.

Ayres, I.W.K., and Braithwaite, J. (1992), Responsive Regulation: Transcending the Deregulation Debate, Oxford: Oxford University Press.

Backes, C.W. (2012), 'The implementation of Article 9.3 of the Aarhus Convention on access to justice in the Netherlands', in J. Darpö (ed.), Effective Justice? Synthesis report of the study on the Implementation of Articles 9.3 and 9.4 of the Aarhus Convention in the Member States of the European Union, Brussels: European Commission.

Baker\&McKenzie (2006), General Product Safety Directive (GPSD) - Comparative Inventory, report prepared for the European Commission.

Baldwin, R., and McCrudden, C. (1987), Regulation and Public Law, London: Weidenfeld.

Ballesteros, M., Mehdi, R., Eliantonio, M., and Petrovic, D. (2013), Tools for Ensuring Implementation and Application of EU Law and Evaluation of their Effectiveness [report for the European Parliament's Committee on Legal Affairs], Brussels: European Parliament.

Baratta, R. (2014), 'Complexity of EU law in the domestic implementation process', The Theory and Practice of Legislation, 2(3): 293-308.

Bardach, E. (1977), The Implementation Game: What Happens After a Bill Becomes a Law, Cambridge and London: MIT Press. 
Barrett, S.M. (2004), 'Implementation studies: time for a revival? Personal $\quad$ reflections on 20 years of implementation studies', Public Administration, 82(2): 249-262.

Batta, D. (2007), Comparative Study on the Transposition of EC Law in the Member States. Internal Study in Cooperation with the ECPRD, Brussels: European Parliament.

Beach, D. (2005), 'Why governments comply: an integrative compliance model that bridges the gap between instrumental and normative models of compliance', Journal of European Public Policy, 12(1): 113-142.

Bemelmans-Videc, M.-L. (1998), 'Introduction: Policy instrument choice and evaluation', in M.-L. Bemelmans-Videc, R.C. Rist, and E. Vedung (eds) (1998), Carrots, stick and sermons. Policy instruments and their evaluation, New Brunswick: Transaction Publishers, pp. 1-20.

Bennett, C.J., and Howlett, M. (1992), 'The lessons of learning: reconciling theories of policy learning and policy change', Policy Sciences 25: 275-294.

Berglund, S., Dimitrova, A., Kaeding, M., Mastenbroek, E., Meeuwse, A., Romeijn, M., Steunenberg, B., and Voermans, W. (2006a), The Transposition of EC Directives. A Comparative Study of Instruments, Techniques and Processes in Six Member States, Nijmegen: Wolf Legal Publishers.

Berglund, S., Gange, I., and Van Waarden, F. (2006b), 'Mass production of law. Routinization in the transposition of European directives: A sociological-institutionalist account', Journal of European Public Policy, 13(5): 692-716.

Berman, P. (1978), 'The study of macro- and micro- implementation', Public Policy, 26(2): 157-184.

Bermeo, N.G., and Nord, P.G. (2000), Civil Society before Democracy: Lessons from Nineteenth-century Europe, Lanham: Rowman and Littlefield Publishers.

BIO Intelligence Service (2013), Evaluating the IMPEL Network and Its Work [report prepared for IMPEL], Paris: BIO Intelligence Service.

Birkland, T.A. (1997), After Disaster: Agenda Setting, Public Policy, and Focusing Events, Washington: Georgetown University Press.

Biuro Orzecznictwa Naczelnego Sądu Administracyjnego, Sprawozdania roczne: 2012, available on $<$ http://www.nsa.gov.pl/sprawozdania-roczne-1.php >.

Boh, T. (2004), 'Shielding implementation from politicisation? Implementation of the Habitats Directive in Slovenia', OEUE Phase II. Occasional Paper.

Bohne, E., and Dietze, D. (2004), 'Pollution prevention and control in Europe revisited', European Environmental Law Review 13(7): 198-217.

Borgers, H.C. (2007), 'De beste beschikbare technieken voor het bepalen van de beste beschikbare technieken', in H.C. Borgers, J.H.G. van den Broek, H.E. Bröring, T.C. Leemans and I.P. Sievers (eds), Nederlandse Milieurichtlijnen en Beste Beschikbare Technieken. Verslag van de 95e ledenvergadering van de Vereniging voor Milieurecht op 28 maart 2007, Den Haag: Bju Uitgevers, pp. 27-45.

Borghetto, E., and Franchino, F. (2010), 'The role of subnational authorities in the implementation of EU directives', Journal of European Public Policy, 17(6): 759-780.

Borghetto, E., Franchino, F., and Giannetti, (2006), 'Complying with the transposition deadlines of EU directives: evidence from Italy', Rivista Italiana di Politiche Pubbliche 5: 7-38.

Börzel, T.A. (2000), 'Why there is no 'southern problem': on environmental leaders and laggards in the European Union', Journal of European Public Policy, 7(1): 141-162.

Börzel, T. (1999), 'Towards convergence in Europe? Institutional adaptation to Europeanization in Germany and Spain', Journal of Common Market Studies, 39(4): 573-596.

Börzel, T.A. (2001), 'Non-compliance in the European Union: pathology or statistical artefact?', Journal of European Public Policy, 8:5, 803-824.

Börzel, T. A. (2002), 'Pace-setting, foot-dragging and fence-sitting: member state responses to Europeanization', Journal of Common Market Studies, 40(2): 193-214.

Börzel, T.A. (2003), 'Guarding the treaty: the compliance strategies of the European Commission', in T.A. Börzel and R.A. Cichowski (eds), The State of the European Union, Oxford: Oxford University Press, pp. 197-220. 
Börzel, T.A. (2006), 'Participation through law enforcement: the case of the European Union', Comparative Political Studies, 39(1): 128-152.

Börzel, T.A., and Buzogany, A. (2010), 'Environmental organizations and the Europeanization of public policy in Central and Eastern Europe: the case of biodiversity governance', Environmental Politics, 19(5): 708735 .

Börzel, T.A., \& Heard-Lauréote, K. (2009), 'Networks in EU multi-level governance: concepts and contributions', Journal of Public Policy, 29(2): 135-152.

Börzel, T.A. and Hofmann, T. (2012), 'Caving in or sitting it out? Longitudinal patterns of non-compliance in the European Union', Journal of European Public Policy 19(4): 454-471.

Börzel, T.A., Hofmann, T., and Panke, D. (2011), 'Policy matters but how? Explaining non-compliance dynamics in the EU', KFG Working Paper Series, No 24.

Börzel, T.A., Hofmann, T., Panke, D., and Sprungk, C. (2010), 'Obstinate and inefficient: why member states do not comply with European law', Comparative Political Studies, 43(11): 1363-1390.

Börzel, T.A., and Knoll, M. (2012), 'Quantifying non-compliance in the EU. A database on EU infringement proceedings,' Berliner Arbeitspapiere zur Europäischen Integration, No 15.

Börzel, T. A. and Risse, T. (2000), 'When Europe hits home: Europeanization and domestic change', European Integration Online Papers, 4, No. 15.

Börzel, T.A., and Risse, T. (2003), 'Conceptualizing the domestic impact of Europe', in K. Featherstone and C.M. Radaelli, The Politics of Europeanization, Oxford: Oxford University Press, pp. 57-80.

Broberg, M. and Fenger, N. (2013), 'Variations in member states' preliminary references to the Court of Justice. Are structural factors (part of) the explanation?', European Law Journal, 19(4): 488-501.

Bröring, H.E. (2007), 'Richtlijnen, beleidsregels, BREF's: mooi, mooier, mooist?', in H.C. Borgers, J.H.G. van den Broek, H.E. Bröing, T.C. Leemans and I.P. Sievers (eds), Nederlandse Milieurichtlijnen en Beste Beschikbare Technieken. Verslag van de 95e ledenvergadering van de Vereniging voor Milieurecht op 28 maart 2007, Den Haag: Bju Uitgevers, pp. 11-26.

BSI Development Solutions (2011), The Future of Market Surveillance in the Area of Non-food Consumer Product Safety under the General Product Safety Directive [report prepared for the European Commission, DG Health and Consumers], Reading: BSI Development Solutions.

Bugdahn, S. (2005), 'Of Europeanization and domestication: the implementation of the Enviromental Information Directive in Ireland, Great Britain and Germany', Journal of European Public Policy, 12(1): 177199.

Buller, J. and Gamble, A (2002), 'Conceptualizing Europeanization', Public Policy and Administration, 17(2): 4-24.

Bulmer, S., and Burch, M. (2001), 'The Europeanization of central government: the UK and Germany in historical institutionalist perspective', in G. Schneider and M. Aspinwall (eds), The Rules of Integration: Institutional Approaches to the Study of Europe, Manchester: Manchester University Press, pp. 73-98.

Bursens, P. (2002), 'Why Denmark and Belgium have different implementation records: on transposition laggards and leaders in the EU', Scandinavian Political Studies, 25(2), 173-195.

Bursens, P., and Deforche, J. (2008) 'Europeanization of subnational polities: the impact of domestic factors on regional adaptation to European integration', Regional \& Federal Studies, 18(1): 1-18.

Chabanet, D. (2002), 'Les marches européennes contre le chômage, la précarité et les exclusions', in R. Balme, D. Chabanet and V. Wright (eds), L'action collective en Europe. Collective Action in Europe, Paris: Presses de Sciences Po, pp. 461-493.

Carrubba, C.J., and Murrah, L. (2005), 'Legal integration and the use of the preliminary ruling process in the European Union', International Organization, 59(2): 399-418.

Centraal Bureau voor de Statistiek, Bestuursrecht: Procedures bij Rechtbanken, available on $<$ http://statline.cbs.nl>.

Chayes, A., and Chayes, A.H. (1993), 'On compliance', International Organization, 47(2): 175-205.

Chayes, A., and Chayes, A.H. (1998), The New Sovereignty: Compliance with International Regulatory Agreements, Cambridge, MA: Harvard University Press. 
Chayes, A., Chayes, A.H., and Mitchell, R.M. (1998), 'Managing compliance: a comparative perspective', in E. Brown Weiss (ed.), Engaging countries: strengthening compliance with international environmental accords, Cambridge: MIT Press, pp. 39-62.

Checkel, J. (1999), 'Why comply? Constructivism, social norms and the study of international institutions', ARENA Working Papers, 99/24.

Chisholm, D. (1989), Coordination Without Hierarchy: Informal Structures in Multiorganizational Systems, Berkeley/Los Angeles: University of California Press.

Chiti, E. (2013), 'European Agencies’ rulemaking: powers, procedures and assessment', European Law Journal, 19: $93-110$

Christiansen, T., and Kirchner, E.J. (2000), Committee Governance in the European Union, Manchester: University Press.

Christiansen, T., and Piattoni, S. (2003), Informal Governance in the European Union, Cheltenham: Edward Elgar Publishing.

Christiansen, T., Føllesdal, A., and Piattoni, S. (2003), 'Informal governance in the EU: an introduction', in T. Christiansen and S. Piattoni (eds), Informal Governance in the European Union, Cheltenham: Edward Elgar Publishing, pp. 1-21.

Ciavarini Azzi, G. (1988), 'What is this new research into the implementation of Community legislation bringing us?', in H. Siedentopf and J. Ziller (eds), Making European Policies Work: The Implementation of Community Legislation in the Member States (vol. I), London: Sage, pp. 190-201.

Ciavarini Azzi, G. (2000), 'The slow march of European legislation: the implementation of directives', in K. Neunreither and A. Wiener (eds), European Integration after Amsterdam: Institutional Dynamics and Prospects for Democracy, Oxford: Oxford University Press, pp. 52-67.

Cichowski, R.A. (2007), The European Court and Civil Society. Litigation, Mobilization and Governance, Cambridge: University Press.

Cinalli, M. (2005), 'Below and beyond power sharing: relational structures across institutions and civil society', in I. O'Flynn and D. Russell (eds), Power-Sharing: New Challenges for Divided Societies, London: Pluto Press, pp. 172-187.

Coen, D., and Thatcher, M. (2005), 'The new governance of markets and non-majoritarian regulators', Governance, 18(3): 329-346.

Coen, D., and Thatcher, M. (2008), 'Network governance and multi-level delegation: European networks of regulatory agencies', Journal of Public Policy, 28, 49-71.

Commissie Scheltema (2007), Advies Commissie Scheltema over relativiteitsvereiste, available on $<$ http://www.rijksoverheid.nl/documenten-en-publicaties/>.

Commission (2001), Assessment of Plans and Projects significantly affecting Natura 2000 sites, regarding the implementation of Article 6(3) and (4) of the 'Habitats' Directive 92/43/EEC, available on $<$ http://ec.europa.eu/environment/nature/natura2000/management/guidance_en.htm>.

Commission (2003), Guidance Document on the Relationship between the General Product Safety Directive (GPSD) and Certain Sector Directives with Provisions on Product Safety, available on $<$ http://ec.europa.eu/consumers/consumers_safety/product_safety_legislation/general_product_safety_ directive/index_en.htm $>$.

Commission (2003), Integrated Pollution Prevention and Control (IPPC). Reference Document on Best Available Techniques for Intensive Rearing of Poultry and Pigs (BREF), available on $<$ http://eippcb.jrc.ec.europa.eu/reference/>.

Commission (2006), Special Eurobarometer 252. Consumers protection in the internal market, available on $<$ http://ec.europa.eu/public_opinion>.

Commission (2007), Guidance on Interpretation of 'Installation' and 'Operator' for the Purposes of the IPPC Directive, available on <http://ec.europa.eu/clima/policies $>$.

Commission (2008), Special Eurobarometer 298. Consumer Protection in the Internal Market, available on $<$ http://ec.europa.eu/public_opinion>. 
Commission (2008), Eurobarometer 299. Consumers' Attitudes towards Cross-border Sales and Consumer Protection, available on <http://ec.europa.eu/public_opinion $>$.

Commission (2010), Flash Eurobarometer 282. Consumers Attitudes towards Cross-border Sales and Consumer Protection, available on <http://ec.europa.eu/public_opinion>.

Commission (2010), Guidance Document on the Relationship between Directive 2001/95/EC and the Mutual Recognition Regulation, available on <http://ec.europa.eu/enterprise/policies/single-market-goods/freemovement-non-harmonised-sectors/mutual-recognition $>$.

Commission (2010), Working Paper on the Relationship between the General Product Safety Directive 2001/95/EC and the Market Surveillance Provisions of Regulation (EC) No 765/2008, not anymore available online.

Commission (2012), Beginners' Guide to EU Funding. Overview of the Financial Rules and Funding Opportunities 2007-13. 2012 Edition, Luxembourg: Office for Official Publications of the European Communities.

Commission (2012), Flash Eurobarometer 332. Consumers' Attitudes Towards Cross-border Trade and Consumer Protection, available on <http://ec.europa.eu/public_opinion>.

Commission (2013), Flash Eurobarometer 358. Consumer Attitudes towards Cross-border Trade and Consumer Protection, available on <http://ec.europa.eu/public_opinion $>$.

Commission (2013), Internal Market Scoreboard 26, <http://ec.europa.eu/internal_market/score

Commission (2013), Keeping European Consumers Safe. 2012 Annual Report on the Operation of the Rapid Alert System for Non-Food Dangerous Products RAPEX, Luxembourg: Publications Office of the European Union.

Conant, L.J. (2002), Law and Politics in the European Union, Ithaca: Cornell University Press.

Constantelos, J. (2004), 'The Europeanization of interest group politics in Italy: business associations in Rome and the regions', Journal of European Public Policy, 11(6): 1020-1040.

Court of Justice of the European Union (2012), Annual Report 2011. Synopsis of the Work of the Court of Justice, the General Court and the Civil Service Tribunal, Luxembourg: Publications Office of the European Union.

Court of Justice of the European Union (2013), Annual Report 2012. Synopsis of the Work of the Court of Justice, the General Court and the Civil Service Tribunal, Luxembourg: Publications Office of the European Union.

Court of Justice of the European Union (2014), Annual Report 2013. Synopsis of the Work of the Court of Justice, the General Court and the Civil Service Tribunal, Luxembourg: Publications Office of the European Union.

Craig, P. (2009), 'Shared administration and networks: global and EU perspectives', Oxford Legal Studies Research Paper, No. 6/2009.

Craig, P., and De Búrca, G. (2011), EU Law: Text, Cases, and Materials, Oxford: Oxford University Press.

Cremona, M. (ed.) (2012), Compliance and the Enforcement of EU Law, Oxford: University Press.

Curtin, D., and Heukels, T. (eds) (1994), Institutional Dynamics of European Integration. Essays in Honour of Henry G. Schermers (Volume II), Dordrecht: Martinus Nijhoff Publishers.

Curtis, G.E. (ed.) (1992), Poland: a Country Study, Washington DC: GPO for the Library of Congress.

DeLeon, P. (1999), 'The missing link revisited: contemporary implementation research', Policy Studies Review $16: 3 / 4$.

Della Porta, D., and Caiani, M. (2011), Social Movements and Europeanization, Oxford: University Press.

Demmke, C. (2001), 'Towards effective environmental regulation: innovative approaches in implementing and enforcing European environmental law and policy', Jean Monnet Working Paper, No. 5/01.

De la Porte, C., and Pochet, P. (eds) (2002), Building Social Europe through the Open Method of Co-ordination, Brussels: Peter Lang.

De la Porte, C., and Pochet, P. (2005), 'Participation in the open method of coordination. The cases of employment and social inclusion', in J. Zeitlin and P. Pochet (eds), The Open Method of Coordination in Action. The European Employment and Social Inclusion Strategies, Brussels: Peter Lang, pp. 353-389. 
De Moor-Van Vugt, A.J.C. (2011), 'Netwerken en de Europeanisering van het toezicht', SEW, Tijdschrift voor Europees en Economisch Recht, 2011/3: 94-102.

De Rechtspraak, De Nederlandse Rechtspraak in Cijfers, Hoe Lang Duurde de Afhandeling de Afgelopen Jaren, available on $<$ http://www.rechtspraak.nl>.

De Schutter, O. (2002), 'Europe in search of its civil society', European Law Journal, 8(2): 198-217.

De Visser, M. (2009), Network-based Governance in EC Law. The example of EC competition and EC communications law, Oxford: Hart Publishing.

Dehousse, R. (1997), 'Regulation by networks in the European Community: the role of European agencies', Journal of European Public Policy, 4(4): 246-61.

Dexter, L.A. (2006), Elite and Specialised Interviewing, Colchester: ECPR Press.

DiMaggio, P.J., and Powell, W.W. (1991), 'Introduction', in W.W. Powell and P.J. DiMaggio (eds), The New Institutionalism in Organizational Analysis, Chicago: University of Chicago Press, pp. 1-38.

Dimitrakopoulos, D. (2001), 'The transposition of EU law: "post-decisional politics" and institutional economy', European Law Journal, 7(4): 442-458.

Dimitrakopoulos, D., and Richardson, J. (2001), 'Implementing EU public policy', in J. Richardson (ed.), European Union: Power and Policy-Making [ $2^{\text {nd }}$ edition], London: Routledge, pp. 335-356.

Dimitrova, A., and Rhinard, M. (2005), 'The power of norms in the transposition of EU directives', European Integration online Papers, 9, No 16.

Dimitrova, A., and Steunenberg, B. (2000), 'The search for convergence of national policies in the European Union: An impossible quest?', European Union Politics, 1(2): 201-226.

Dimitrova, A., and Steunenberg, B. (2013), 'Living in parallel universes? Implementing European movable cultural heritage policy in Bulgaria', Journal of Common Market Studies, 51(2): 246-263.

Dimitrova, A., and Toshkov, D. (2009), 'Post-accession compliance between administrative co-ordination and political bargaining', European Integration Online Papers 13(2), No. 19.

Direção-Geral da Política de Justiça, Duração média dos processos findos: 2012, available on $<$ http://www.siej.dgpj.mj.pt $>$.

Doppelhammer, M. (2000), 'More difficult than finding the way round Chinatown? The IPPC Directive and its implementation', European Environmental Law Review 9(7): 199-206.

Dore, R. (1983), 'Goodwill and the spirit of market capitalism', British Journal of Sociology 34: 459-482.

Downs, G.W, and Jones, M.A. (2002), 'Reputation, compliance, and international law', Journal of Legal Studies 31(1), S95-S114.

Downs, G.W., Rocke, D.M., and Barsoom, P.N. (1996), 'Is good news about compliance good news about cooperation?', International Organisation 50(3): 379-406.

Duina, F.G. (1997), 'Explaining legal implementation in the European Union', International Journal of the Sociology of Law, 25(2): 155-179.

Duina, F. G. (1999), Harmonizing Europe: Nation-States within the Common Market, Albany: State University of New York Press.

Dunsire, A. (1978), Implementation in a Bureaucracy, New York: St Martin's Press.

Duyvendak, J. W., and Giugni, M. (1995), 'Social movement types and policy domains', in H. Kriesi, R. Koopmans, J. W. Duyvendak and M. Giugni, New Social Movements in Western Europe. A Comparative Analysis, Minneapolis: University of Minnesota Press, pp. 82-101.

Eberlein, B., and Grande, E. (2005), 'Beyond delegation: transnational regulatory regimes and the EU regulatory state', Journal of European Public Policy 12(1): 89-112.

Eberlein, B., and Newman, A.L. (2008), 'Escaping the international governance dilemma? Incorporated transgovernmental networks in the European Union', Governance, 21(1): 25-52.

Egeberg, M., and Trondal, J. (2011), 'EU-level agencies: new executive centre formation or vehicles for national control?', Journal of European Public Policy, 18( 6): 868-887.

Ehnert, T. (2015), 'The legitimacy of new risk governance: a critical view in light of the EU's approach to nanotechnologies in food', European Law Journal, 21(1): 44-67.

Eising, R. (2008), 'Interest groups in EU policy-making', Living Reviews in European Governance, 3(4). 
Eliadis, P., Hill, M.M., and Howlett, M. (eds) (2005), Designing Government. From Instruments to Governance, Ithaca: McGill-Queen's University Press.

Eliantonio, M. (2008), Europeanisation Of Administrative Justice? The Influence Of The Ecj's Case Law In Italy, Germany and England, Groningen: Europa Law Publishing.

Eliantonio, M., Backes, C.W, Van Rhee, C.H., Spronken, T.N.B.M., and Berlee, A. (2012), Standing Up for Your Right(s) in Europe. A Comparative Study on Legal Standing (locus standi) before the EU and Member States' Courts [report prepared for the European Parliament, Committee on Legal Affairs], Brussels: European Union.

Ekiert. G., and Foa, R. (2011), 'Civil society weakness in post-communist Europe: a preliminary assessment', Carlo Alberto Notebooks No. 198.

Emerson, J.W., Hsu, A., Levy, M.A., de Sherbinin, A., Mara, V., Esty, D.C., and Jaiteh, M. (2012), 2012 Environmental Performance Index and Pilot Trend Environmental Performance Index, New Haven: Yale Center for Environmental Law and Policy.

Entec UK Limited (2007), Assessment of the Implementation of the IPPC Directive [report prepared for the European Commission, DG Environment], London: Entec UK Limited.

Entec UK Limited (2010), Assessment of the Implementation of the IPPC Directive [report prepared for the European Commission, DG Environment], London: Entec UK Limited.

Entec UK Limited (2011), Assessment of the Implementation of the IPPC Directive Phase 3, Final Technical Report [report prepared for the European Commission, DG Environment], London: Entec UK Limited.

European Parliament, Council, and Commission (2013), Joint Practical Guide of the European Parliament, the Council and the Commission for Persons Involved in the Drafting of European Union Legislation, available on $<$ http://eur-lex.europa.eu/techleg/>.

EU Forum of Judges for the Environment (2009), 'Questionnaire on the IPPC Directive for the Annual Conference in Stockholm 2009 [country report for Poland]', available on <http://www.eufje.org/index. $\mathrm{php} / \mathrm{en} /$ conferences/ stockholm-2009>.

Eriksen, E.O. (2006), 'Deliberation and the problem of democratic legitimacy in the EU: Are working agreements the most that can be expected?', ARENA Working Paper, No. 08.

Etheredge, L.S. (1981), 'Government learning: an overview', in S.L. Long (ed), The Handbook of Political Behaviour, Vol 2., New York: Pergamon.

Etheredge, L.S., and Short, J. (1983), 'Thinking about government learning', Journal of Management Studies, 20: 41-58.

European Aviation Safety Agency, 'Comment Response Document to Guidance Material on Inspectors Qualification, Explanatory Note', not anymore available online.

European Aviation Safety Agency (2013), The EU SAFA Programme (Safety Assessment of Foreign Aircraft). Aggregated Information Report 2011-2012 (01 January 2011 to 31 December 2012)', available on $<$ www.easa.europa.eu>.

Evans, T., and Harris, J. (2004), 'Street-level bureaucracy, social work and the (exaggerated) death of discretion', The British Journal of Social Work, 34(6): 871-895.

Fairbrass, J., and Jordan, A. (2002), 'The Europeanization of interest representation: the case of United Kingdom environment policy', in A. Warleigh and J. Fairbrass (eds), Influence and Interests in the European Union: The New Politics of Persuasion and Advocacy, London: Europa.

Falkner, G. (2007), 'Time to discuss: data to crunch or problems to solve? A rejoinder to Robert Thomson', West European Politics, 30(5): 1009-1021.

Falkner, G. (2010), 'Compliance with EU social policies in old and new member states: different worlds, different remedies', EIF Working Papers No. 06/2010.

Falkner, G., Hartlapp, M., Leiber, S., and Treib, O. (2004), 'Non-compliance with EU Directives in the member states: opposition through the backdoor?', West European Politics, 27(3), 452-473.

Falkner, G., Hartlapp, M., Leiber, S., and Treib, O. (2005), Complying with Europe EU harmonization and soft law in the member states, Cambridge: Cambridge University Press. 
Falkner, G., Hartlapp, M., and Treib, O. (2007a), 'Worlds of compliance: why leading approaches to European Union implementation are only "sometimes-true theories", European Journal of Political Research, 46(3): 395-416.

Falkner, G., Hartlapp, M., Leiber, S., and Treib, O. (2007b), 'In search of the worlds of compliance: promises and pitfalls of quantitative testing', Reihe Politikwissenschaft 113.

Falkner, G., and Treib, O. (2008), 'Three worlds of compliance or four? The EU-15 compared to new member states', Journal of Common Market Studies, 46(2): 293-313.

Falkner, G., Treib, O., and Holzleithner, E. (2008), 'Introduction: The challenge of implementation research in the new member states', in G. Falkner, O. Treib and E. Holzleithner, Compliance in the Enlarged Union. Living Rights or Dead Letters?, Aldershot: Ashgate Publishing, pp. 1-26.

Fearon, J. (1998), 'Enforcement, and international cooperation', International Organization, 52(2): 269-305.

Featherstone, K. (1998), 'Europeanization and the centre periphery: the case of Greece in the 1990s', South European Society and Politics, 3(1): 23-39.

Featherstone, K. and Kazamias, G. (2001), Europeanization and the Southern Periphery, London: Frank Cass.

Fennelly, N. (1996), 'Legal interpretation at the European Court of Justice', Fordham International Law Journal, 20(3): 656-679.

Fernandes, T. (2012), 'Civil society after Dictatorship: a Comparison of Portugal and Spain, 1970s-1990s', Kellogg Institute Working Paper No. 384.

Finke, B. (2007), 'Civil society participation in EU governance', Living Reviews in European Governance 2(2).

Flyvberg, B. (2001), Making Social Science Matter: Why Social Inquiry Fails and How It Can Succeed Again, Cambridge: Cambridge University Press.

Føllesdal, A. (2011), 'The legitimacy challenges for new modes of governance: trustworthy responsiveness', Government and Opposition, 46(1): 81-100.

Franchino, F. (2004), 'Delegating powers in the European Community', British Journal of Political Science, 34(2): 269-293.

From, J., and Stava, P., 1993, 'Implementation of Community law: the last stronghold of national control?', in S.S. Andersen and Eliassen, K.A. (eds), Making Policy in Europe: The Europeification of National PolicyMaking, London: Sage, pp. 55-67.

Geradin, D., and Petit, N. (2004), 'The development of agencies at EU and national levels: conceptual analysis and proposals for reform', Jean Monnet Working Paper 01/04.

Giuliani, M. (2003), 'Europeanization in comparative perspective: institutional fit and domestic adaptation', in K. Featherstone and C.M. Radaelli (eds), The Politics of Europeanization, Oxford: Oxford University Press, pp. 134-155.

Giuliani, M. (2005), 'EU policies and domestic compliance: between international relations, implementation, and Europeanization', URGE Working Paper 5/2005.

Goetz, K.H. (1995), 'National governance and European integration: inter-governmental relations in Germany', Journal of Common Market Studies, 33(1): 91-116.

Goetz, K.H. (2005), 'The new member states and the EU: responding to Europe', in S. Bulmer and C. Lequesne (eds), The Member States of the European Union, New York: Oxford University Press, pp. 254-80.

Goetz, K.H., and Hix, S. (eds) (2000), 'Europeanised politics? European integration and national political systems', West European Politics, 23, Special Issue 4.

Goggin, M.L. (1986), 'The "too few cases/too many variables" problem in implementation research', The Western Political Quarterly 39(2): 328-347.

Goldstein, K. (2002), 'Getting in the door: sampling and completing elite interviews', Political Science and Politics, 35(4): 669-672.

Golub, J. (1996), 'The politics of judicial discretion: rethinking the interaction between national courts and the Eurpean Court of Justice', West European Politics 19(2): 360-385.

Granovetter, M.S. (1995), 'Coase revisited: business groups in the modern economy', Industrial and Corporative Change 4(1): 93-130. 
Green Cowles, M., Caporaso, J. and, Risse, T. (2001) (Eds), Transforming Europe: Europeanization and Domestic Change, Ithaca and London: Cornell University Press.

Greenwood, J. (2007), 'Organized civil society and democratic legitimacy in the European Union', British Journal of Political Science, 37(2): 333-357.

Groenleer, M., Kaeding, M., and Versluis, E. (2010), 'Regulatory governance through agencies of the European Union? The role of the European agencies for maritime and aviation safety in the implementation of European transport legislation', Journal of European Public Policy, 17(8): 1212-1230.

Haas, P.M. (1992), 'Introduction: epistemic communities and international policy coordination', International Organization, 46(1): 1-35.

Haas, P.M. (1998), 'Compliance with EU directives: insights from international relations and comparative politics', Journal of European Public Policy, 5(1): 17-37.

Haggard, S., and Moravcsik, A. (1997), 'The Political Economy of Financial Assistance to Eastern Europe, 1989-91', in R.O. Keohane, J.S. Nye and S. Hoffman (eds), After the Cold War: International Institutions and State Strategies in Europe, 1989-1991, Cambridge: Harvard University Press, pp. 246-285.

Haggard, S., Levy, M.A., Moravcsik, A., and Nicolaidis, K. (1997), 'Integrating the two halves of Europe: theories of interests, bargaining, and institutions', in R.O. Keohane, J.S. Nye and S. Hoffman (eds), After the Cold War: International Institutions and State Strategies in Europe, 1989-1991, Cambridge, MA: Harvard University Press, pp.173-195.

Hamann, K., and Manuel, P.C. (1999), 'Regime changes and civil society in twentieth-century Portugal', South European Society and Politics, 4(1): 71-96.

Hanf, K., and Scharpf, F.W. (1978), Interorganizational Policy Making: Limits to Coordination and Central Control, London and Beverly Hills: Sage Publications.

Harding, C., and Swart, B. (1996), Enforcing European Community rules, Brookfield/Singapore/Sidney: Aldershot.

Hartlapp, M., and Falkner, G. (2009), 'Problems of operationalization and data in EU compliance research', European Union Politics, 10(2): 281-30.

Haverland, M. (2000), 'National adaptation to European integration: the importance of institutional veto points', Journal of Public Policy, 20(1): 83-103.

Haverland, M., and Romeijn, M. (2007), 'Do member states make European policies work? Analysing the EU transposition deficit', Public Administration, 85(3): 757-778.

Haverland, M., Steunenberg, B., and Van Waarden, F. (2011), 'Sectors at different speeds: analyzing transposition deficits in the European Union', Journal of Common Market Studies, 49(2): 265-291.

Heidbreder, E.G. (2012), 'Civil society participation in EU governance', Living Reviews in European Governance, $7(2)$.

Héritier, A. (1999), Policy-Making and Diversity in Europe. Escape from Deadlock, Cambridge: Cambridge University Press.

Héritier, A. (2001), 'Differential Europe: national administrative responses to Community policy', M. Green Cowles, J. Caporaso, and T. Risse (eds), Transforming Europe: Europeanization and Domestic Change, Ithaca: Cornell University Press, pp. 44-59.

Héritier, A., Kerwel, D., Knill, C, Lehmkuhl, D., Teutsch, M., and Douillet, A-C (2001) Differential Europe: New Opportunities and Restrictions for Policymaking in the Member States, Lanham: Rowman and Littlefield.

Hille, P., and Knill, C. (2006), “It's the bureaucracy, stupid": the implementation of the acquis communautaire in EU candidate countries, 1999-2003', European Union Politics, 7(4): 531-552.

Hjern, B., and Porter, D.O. (1981), 'Implementation structures: a new unit of administrative analysis', Organization Studies, 2(3: 211-227.

Hofmann, H.C.H, Rowe, G.C., and Türk, A.H. (2011), Administrative Law and Policy of the European Union, Oxford: University Press.

Hood, C. (1976), The Limits of Administration, London and New York: Wiley.

Hood, C. (1983), The Tools of Government, London: Macmillan. 
Hood, C., and Margetts, H. (2007), The Tools of Government in the Digital Age, London: Palgrave Macmillan.

Hooghe, L. (2001), The European Commission and the Integration of Europe. Images of Governance, Cambridge: Cambridge University Press.

Howard, M.M. (2003), The Weakness of Civil Society in Post-Communist Europe, Cambridge: University Press.

Howell, K. (2002), 'Developing conceptualizations of Europeanization and European integration: mixing methodologies', ESRC Seminar Series/UACES Study Group on the Europeanization of British Politics, 29 November 2002, Sheffield.

Hsu, A., Emerson, J., Levy, M., de Sherbinin, A., Johnson, L., Malik, O., Schwartz, J., and Jaiteh, M. (2014), The 2014 Environmental Performance Index, New Haven: Yale Center for Environmental Law and Policy.

Hupe, P.L. (2011), 'The thesis of incongruent implementation: revisiting Pressman and Wildavsky', Public Policy and Administration 26: 63-80.

Howlett, M. (2000), 'Managing the "hollow state": procedural policy instruments and modern governance', Canadian Public Administration, 43(4): 412-431.

Howlett, M. (2005), 'What is a policy instrument? Policy tools, policy mixes, and policy-implementation styles', in P. Eliadis, M.M. Hill, and M. Howlett (eds), Designing Government. From Instruments to Governance, Ithaca: McGill-Queen's University Press, pp. 31-50.

Howlett, M., and Ramesh, M. (2009), Studying Public Policy: Policy Cycles and Policy Subsystems [ $3^{\text {rd }}$ edition], Toronto: Oxford University Press.

Hurd, I. (1999), 'Legitimacy and authority in international politics', International Organization, 53(2): 379408.

Hurd, I. (2008), Constructivism, in C. Reus-Smit and D. Snidal (eds), The Oxford Handbook of International Relations, Oxford: University Press, pp. 298-316.

Gil Ibáñez, A. (1999) The Administrative Supervision and Enforcement of EC Law: Powers, Procedures and Limits, Oxford: Hart Publishing.

Imig, D., and Tarrow, S. (2001), 'Studying contention in an emerging polity', in D. Imig and S. Tarrow (eds), Contentious Europeans: Protest and Politics in an Emerging Polity (Rowman and Littlefield), pp. 3-26.

Jans, J.H., Prechal, S., De Lange, R., and Widdershoven, R. (2007), Europeanisation of Public Law, Groningen: Europa Law Publishing.

Jendrośka, J., and Bar, M. (2012), 'The implementation of Article 9.3 of the Aarhus Convention on access to justice in Poland, in J. Darpö (ed.), Effective Justice? Synthesis report of the study on the Implementation of Articles 9.3 and 9.4 of the Aarhus Convention in the Member States of the European Union, Brussels: European Commission.

Jensen, C. (2007), 'Implementing Europe. A question of oversight', European Union Politics, 8(4): 451-477.

Joachim, J., Reinalda, B., and Verbeek, B. (2008), 'Enforcers, managers, authorities? International organizations and implementation', in J. Joachim, B. Reinalda and B. Verbeek eds), International Organizations and Implementation: Enforcers, Managers, Authorities?, London: Routledge, pp. 177-190.

Joerges, C., and Neyer, J. (1997), 'From intergovernmental bargaining to deliberative political processes: the constitutionalisation of comitology', European Law Journal 3(1): 273-299.

Joerges, C., and Vos, E. (eds) (1999), EU Committees: Social Regulation, Law and Politics, London: Hart Publishing.

Jordan, A. (1999), 'The implementation of EU environmental policy: a policy problem without a political solution', Environment and Planning C: Government and Policy, 17: 69-90.

Kaeding, M. (2007), 'Better regulation in the European Union: lost in translation or full steam ahead? The transposition of EU transport directives across member states', Dissertation defended at Leiden University, 25 October 2007.

Kaeding, M. (2008), 'Lost in translation or full steam ahead? The transposition of EU transport directives across EU member states', European Union Politics 9(1): 115-144.

Kaeding, M., and Hardacre, A. (2013), 'The European Parliament and the future of comitology after Lisbon', European Law Journal, 19(3): 382-403. 
Kaeding, M., and Voskamp, F. (2011), 'Better Implementation of EU Legislation is not just a question of taking Member States to Court. SOLVIT - Street-level EU law enforcement through an effective free-ofcharge out-of-court dispute settlement mechanism for a better functioning of the Single Market', EIPA Working Paper W/01.

Karaczun, Z. (2005), 'Preparing for EU environmental policy in Poland: the case of the nitrates directive', Land Use Policy 22(3): 245-253.

Kassim, H., and Menon, A. (2003), 'The principal-agent approach and the study of the European Union: promise unfulfilled?', Journal of European Public Policy, 10(1): 121-139.

Keast, R.L., Mandell, M. \& Brown, K.A. (2006), 'Mixing state, market and network governance modes: the role of government in "crowded" policy domains', International Journal of Organization Theory and Behavior, $9(1): 27-50$.

Keck, M.E., and Sikkink, K. (1998) Activists beyond Borders: Advocacy Networks and World Politics, Cambridge: MIT Press.

Kelemen, R.D. (2002), 'The politics of "eurocratic" structure and the new European agencies', West European Politics 25(4), 93-118.

Keohane, R.O. (1984), After Hegemony: Cooperation and Discord in the World Political Economy, Princeton: University Press.

Keohane, R.O. (2001), 'Governance in a partially globalized world "Presidential Address", "American Political Science Association, 2000”', American Political Science Review 95(1): 1-13.

Kiewiet, D.R., and McCubbins, M.D. (1991), The Logic of Delegation: Congressional Parties and the Appropriation Process, Chicago: University of Chicago Press.

Kingdon, (1995), Agendas, Alternatives, and Public Policies, London: Longman.

Klamert, M. (2014), The Principle of Loyalty in EU Law, Oxford: University Press.

Knijff, C.L. (2010), 'Beste beschikbare technieken. Jurisprudentie: toetsingskader, termijnen, beste en "light" technieken', Milieu en Recht 2010/3: 151-158.

Knill, C., and Lenschow, A. (1998), 'Coping with Europe: the impact of British and German administrations on the implementation of EU environmental policy', Journal of European Public Policy, 5(4): 595-614.

Knill, C., and Tosun, J. (2009), 'Post-accession transposition of EU law in the new member states: a crosscountry comparison', in F. Schimmelfennig and F. Trauner (eds), Post-accession compliance in the EU's new member states, European Integration online Papers, 13(2): No. 18.

Koh, H.H. (1997), 'Why do nations obey international law?', The Yale Law Journal, 106(8): 2599-2659.

Kohler-Koch, B. (2009), 'The three worlds of European civil society. What role for civil society for what kind of Europe?', Policy and Society, 28(1): 47-57.

Kohler-Koch, B., and Rittberger, B. (2006), 'Review Article: The "Governance Turn" in EU Studies', Journal of Common Market Studies, 44(1): 27-49.

Kohler-Koch, B., and Quittkat, C. (2009), 'What is civil society and who represents civil society in the EU? Results of an online survey among civil society experts', Policy and Society, 28(1): 11-22.

Koliev, F. (2015), 'Understanding the power of shaming in international politics', Paper presented at the International Studies Association's 56th Annual Convention, 18-21 February 2015, New Orleans.

König, T. (2013), 'Non-conformable, partial and conformable transposition: A competing risk analysis of the transposition process of directives in the EU15', European Union Politics, 14(1): 46-69.

König, T., and Luetgert, B. (2009), 'Troubles with transposition? Explaining trends in member-state notification and the delayed transposition of EU directives', British Journal of Political Science, 39(1): 163-194.

König, T., and Mäder, L. (2013), 'Non-conformable, partial and conformable transposition: A competing risk analysis of the transposition process of directives in the EU15', European Union Politics, 14(1): 46-69.

König, T., and Mäder, L. (2014), 'The strategic nature of compliance: an empirical evaluation of law implementation in the central monitoring system of the European Union', American Journal of Political Science, 58(1): 246-263.

Koopmans, R. (ed) (2004), 'The transformation of political mobilisation and communication in European public spheres', Integrated Report: Cross-national, cross-issue, cross-time, Europub.com research project. 
Korkea-aho, E. (2014), 'Watering down the Court of Justice? The dynamics between network implementation and Article 258 TFEU litigation', European Law Journal 20(5): 649-666.

Kriesi, H. (2004), 'Political context and opportunity', in S. Snow, S.A. Soule, and H. Kriesi (eds), Blackwell Companion to Socialem Movements, Oxford: Wiley Blackwell, pp. 67-91.

Krislov, S., Ehlermann, C.-D. , and Weiler, J. (1986), 'The political organs and the decision-making process in the United States and the European Community', in M. Cappelletti, M. Seccombe and J. H. H. Weiler (eds), Integration Through Law, Methods, Tools and Institutions: Political Organs, Integration Techniques and Judicial Process, Berlin, Walter de Gruyter, pp. 3-112.

Kröger, S. (2009), 'The open method of coordination: underconceptualisation, overdetermination, de- politicisation and beyond', European Integration online Papers, 13, Special issue 1, No. 5.

Kubik, J. (2000), 'Between the state and networks of "cousins": the role of society and noncivil associations in the democratization of Poland', in N. Bermeo and P. Nord (eds), Civil Society before Democracy, Lanham: Rowman and Littlefield, pp. 181-207.

Kurcz, M.B., and Lazowski, A. (2006), 'Two sides of the same coin? Framework decisions and directives compared', in P. Eeckhout and T. Tridimas (eds) Yearbook of European Law 2006, Oxford: Oxford University Press, pp. 177-203.

Kutter, A., and Trappmann, V. (2010), 'Civil society in Central and Eastern Europe: the ambivalent legacy of accession', Acta Politica, 45: 41-69.

Kvale, S., and Brinkmann, S. (2009), InterViews: Learning the Craft of Qualitative Research Interviewing [ $2^{\text {nd }}$ edition], London: Sage Publications.

Ladrech, R. (1994), 'Europeanization of domestic politics and institutions: the case of France', Journal of Common Market Studies, 32(1): 69-88.

Lampinen, R., and Uusikylä, P. (1998), 'Implementation deficit - why member states do not comply with EU directives?', Scandinavian Political Studies, 21(3): 231-251.

Lange, B. (2006), 'Searching for the best available techniques. Open and closed norms in the implementation of the EU Directive on integrated pollution prevention and control', International Journal of Law in Context 2(1): 67-88.

Lange, B. (2008), Implementing EU Pollution Control: Law and Integration, Cambridge: Cambridge University Press.

Latour, B. (2010), 'Networks, societies, spheres: reflections of an actor-network theorist', Keynote speech for the International Seminar on Network Theory: Network Multidimensionality in the Digital Age, Annenberg School for Communication and Journalism, Los Angeles, $19^{\text {th }}$ February 2010.

Lefevre, S (2004), 'Interpretative Communications and the Implementation of Community Law at National Level', European Law Review 29(6): 808-822.

Leiber, S. (2007), "Transposition of EU social policy in Poland: are there different "words of compliance" in east and west?', Journal of European Social Policy, 17(4): 349-360.

Lenaerts, K. (2013), 'Effective judicial protection in the EU', Intervention at Assises de la Justice 2013, What role for justice in the European Union?, Brussels, 21-22 November 2013.

Lester, J.P., and Goggin, M.L. (1998), 'Back to the future: the rediscovery of implementation studies', Policy Currents, 8: 1-9.

Lijphart, A. (1971), 'Comparative politics and the comparative method,' The American Political Science Review, 65(3): 682-693.

Linos, K. (2007), 'How can international organizations shape national welfare states? Evidence from compliance with European Union directives', Comparative Political Studies, 40(5): 547-570.

Linz, J.J., and Stepan, A. (1996), Problems of Democratic Transition and Consolidation. Southern Europe, South America, and Post-Communist Europe, Baltimore: The John Hopkins University Press.

Ludlow, P. (1991), 'The European Commission', in R. Keohane \& S. Hoffmann (eds), The New European Community, Boulder: Westview Press.

Luetgert, B. (2011), 'A comprehensive analysis of the enforcement and application of European Union law', Paper presented at Drei-Länder-Tagung, Basel, January 13 to January 14, 2011. 
Luetgert, B., and Dannwolf, T. (2009), 'Mixing methods: a nested analysis of EU member state transposition patterns', European Union Politics, 10(3): 307-334.

Leech, B. (2002a), 'Interview methods in political science', Political Science and Politics, 35(4): 663-664.

Leech, B. (2002b), 'Asking questions: Techniques for semi-structured interview's, Political Science and Politics, 35(4): 665-668.

Leeuw, F.L. (2011), 'Can legal research benefit from evaluation studies?', Utrecht Law Review 7(1): 52-65.

Leventon, J. (2015) 'Explaining implementation deficits through multilevel governance in the EU's new member states: EU limits for arsenic in drinking water in Hungary', Journal of Environmental Planning and Management, 58(7): 1137-1153.

Leventon, J. and Antypas, A. (2012), 'Multi-level governance, multi-level deficits: The case of drinking water management in Hungary', Environmental Policy and Governance, 22(4): 253-267.

Lindgren, K.-O., and Persson, T. (2010), 'Input and output legitimacy: synergy or trade-off? Empirical evidence from an EU survey', Journal of European Public Policy, 17(4): 449-467.

Lipsky. M. (1980), Street-level Bureaucracy. Dilemmas of the Individual in Public Service, New York: Russel Sage Foundation.

Magnette, P. (2003), 'European governance and civic participation: beyond elitist citizenship?', Political Studies, 51(1): 144-160.

Majone, G. (1994), 'The rise of the regulatory state in Europe', West European Politics, 17(3): 77-103.

Majone, G. (1996). Regulating Europe. London: Routledge.

Maniokas, K. (2009), 'Conditionality and compliance in Lithuania: the case of the best performer', European Integration Online Papers, 13(2), No. 20.

March, J.G., and Olsen, J.P. (1989), Rediscovering Institutions: The Organizational Basis of Politics, New York: The Free Press.

March, J.G., and Olsen, J.P. (1995), Democratic Governance, New York: Free Press/McMillan.

March, J.G. and Olsen, J.P. (2006) 'The logic of appropriateness', in M. Moran, M. Rein and R.E. Goodin (eds), Oxford Handbook of Public Policy, Oxford: Oxford University Press.

Marks, G.M., Hooghe, L., and Blanks, K. (1996), 'European integration from the 1980s: state-centric v. multilevel governance', Journal of Common Market Studies, 34(3): 341-378.

Mastenbroek, E. (2003), 'Surviving the deadline. The transposition of EU directives in the Netherlands', European Union Politics, 4(4): 371-395.

Mastenbroek, E. (2005), 'EU compliance: still a "black hole”?', Journal of European Public Policy, 12(6): 11031120.

Mastenbroek, E., and Kaeding, M. (2006), 'Europeanization beyond the goodness of fit: bringing domestic politics back in', Comparative European Politics, 4(4): 331-354.

Mastenbroek, E., and Van Keulen, M. (2006), 'Beyond the goodness of fit: a preference-based account of Europeanization', in R. Holzhacker and M. Haverland (eds), European Research Reloaded: Cooperation and Integration among Europeanized States, Dordrecht: Springer, pp. 19-42.

Matthews, D. (1993), 'Enforcement of health and safety law in the UK, Germany, France and Italy', Economic \& Social Research Council Working Paper, No. 18.

Mattli, W. and Slaughter, A. (1998), 'Revisiting the European Court of Justice', International Organization 52(1): 177-209.

Maynard-Moody, S.W., and Musheno, M.C. (2003), Cops, Teachers, Counselors: Stories from the Front Lines of Public Service, Ann Arbor: University of Michigan Press.

Mazmanian, D.A., and Sabatier, P.A. (1981), Effective Policy Implementation, Lexington: Lexington Books.

McAdam, D. (1999), Political Process and the Development of Black Insurgency. 1930-1970 (2 ${ }^{\text {nd }}$ edn), Chicago: the University of Chicago Press.

Mbaye, H.A.D. (2001), 'Why national states comply with supranational law? Explaining implementation. Infringements in the European Union, 1972-1993', European Union Politics, 2(3): 259-281.

McCauley, D. (2011), 'Bottom-up Europeanization Exposed: social movement theory and non-state actors in France', Journal of Common Market Studies, 49(5): 1019-1042. 
McCubbins, M.D., and Schwartz, T. (1984), 'Congressional oversight overlooked: police patrols versus fire alarms', American Journal of Political Science, 28(1): 165-179.

McEvily, B., Perrone, V., and Zaheer, A. (2003), 'Trust as an organizing principle', Organization Science 14(1): 91-103.

McNally, T. (2009), 'Overview of the EU Water Framework Directive and its implementation in Ireland. Biology and environment', Proceedings of the Royal Irish Academy, 109B: 131-138.

Meier, K.J. (1999), 'Are we sure Lasswell did it this way? Lester, Goggin and implementation research', Policy Currents 9(1): 5-8.

Mendrinou, M. (1996), 'Non-compliance and the European Commission's role in integration', Journal of European Public Policy, 3(1): 1-22.

Micklitz, H., and Reich, N. (eds) (1996), Public Interest Litigation before European Courts, Baden-Baden: Nomos.

Millard, (1998), 'Environmental policy in Poland', Environmental Politics 7(1): 145-161.

Mitchell, R.B. (1996) 'Compliance theory: an overview', in Cameron, J. (ed.) Improving Compliance with international environmental law, London: Earthscan, pp. 3-28.

Moravcsik, A. (1998), The Choice for Europe: Social Purpose and State Power From Rome to Maastricht, Ithaca NY: Cornell University Press.

Mowery, D.C., Oxley, J.E., and Silverman, B.S. (1996), 'Strategic alliances and interfirm knowledge transfer', Strategic Management Journal, 17(Special Issue: Knowledge and the Firm): 77-91.

Munoz, R. (2006), 'The monitoring of the application of Community law: the need to improve the current tools and an obligation to innovate', Jean Monnet Working Paper No. 04/06.

Natuur\&Milieu (2011), Ranking the stars. Nederland in vergelijking met andere Europese lidstaten op het gebied van milieu, natuur en klimaat, Utrecht: Natuur\&Milieu.

Nawrocki, T. (2011), Postępowanie przed Prezesem UOKiK w świetle ustawy o ogólnym bezpieczeństwie produktów [Proceedings before the President of UOKiK in the light of the General Product Safety Act], Warsaw: UOKiK.

Neyer, J., and Zürn, M. (2001) 'Compliance in comparative perspective. The EU and other international institutions', InIIS-Arbeitspapier, nr. 23/01, Universität Bremen.

OECD (2003), OECD Environmental Performance Reviews: Poland 2003, Paris: OECD Publishing.

Oliver, D. G., Serovich, J. M., and Mason, T. L. (2005), 'Constraints and opportunities with interview transcription: Towards reflection in qualitative research', Social Forces, 84(2): 1273-1289.

Oosterhuis, F.H., Peeters, M.G.W.M., and Uylenburg, R. (2007), 'Het beoordelingskader van de IPPC richtlijn. Implementatie, interpretatie en toepassing', STEM-publicatie 2007/1, Arnhem: Structurele Evaluatie Milieuwetgeving.

Ostrom, E. (1990), Governing the Commons: The Evolution of Institutions for Collective Action, Cambridge University Press.

O’Toole, L. J. (1986), 'Policy recommendations for multi-actor implementation: An assessment from the field', Journal of Public Policy, 6(2): 181-210.

O'Toole, L. J. (2010), 'The ties that bind? Networks, public administration, and political science', PS: Political Science and Politics, 43(1), 7-14.

Ottow, A.T., and De Weers, K. (2011), 'Towards a European enforcement toolkit?', The Europe Institute Utrecht Working Paper 01/11.

Page, S.E. (2006), 'Path dependence', Quarterly Journal of Political Science, 1: 87-115.

Panke, D. (2010), The Effectiveness of the Court of Justice. Why Reluctant States Comply, Manchester: University Press.

Papaioannou, S., and Serdekakis, N. (2001), 'Civil society and its enemies: the case of Greece', in A. Bron and M. Schemmann (eds), Civil Society, Citizenship and Learning, Münster: LIT Verlag, pp. 204-222.

Peers, S. (2012), 'Sanctions for infringement of EU law after the Treaty of Lisbon', European Public Law 18(1): 33-64. 
Perkins, R., and Neumayer, E. (2007), 'Do membership benefits buy regulatory compliance? An empirical analysis of EU directives 1978-99', European Union Politics, 8(2): 180-206.

Peters, G.B. (1997), 'The Commission and implementation in the European Union: is there an implementation deficit and why?', in N. Nugent (ed.), At the Heart of the Union: Studies of the European Commission, London: Macmillan, pp. 187-202.

Peeters, M.G.W.M., and Oosterhuis, F. (2010), Integrale Afweging bij Vergunningverlening (STEM publicatie 2010/08), Arnhem: STEM.

Pierson, P. (2000), 'Increasing returns, path dependence, and the study of politics', American Political Science Review, 94(2): 251-267.

Podolny J.M., \& Page K.L. (1998), 'Network forms of organization', Annual Review $\quad$ of Sociology 24, 57-76.

Polak, J., and Versluis, E. (forthcoming), 'The virtues of interdependence and informality: an analysis of the role of transnational networks in the implementation of EU directives', in S. Drake and M. Smith (eds), New Directions in Effective Enforcement of EU Law and Policy, Cheltenham: Edward Elgar.

Pollack, M.A. (1997), 'Delegation, agency and agenda setting in the European Community', International Organization, 51(1): 99-135.

Pollack, M.A. (2007), 'Principal-agent analysis and international delegation: red herrings, theoretical clarifications and empirical disputes', Bruges Political Research Paper No. 2.

Powell, W.W. (1990), 'Neither market nor hierarchy: network forms of organization', Research in Organizational Behaviour, 12, 295-336.

Prechal, S. (2005), Directives in EC Law [2 ${ }^{\text {nd }}$ edition], Oxford: Oxford EC Law Library.

Pressman, J.L., and Wildavsky, A., (1973), Implementation: How Great Expectations in Washington are Dashed in Oakland: Or, why It's Amazing that Federal Programs Work at All, this Being a Saga of the Economic Development Administration as Told by Two Sympathetic Observers who Seek to Build Morals on a Foundation of Ruined Hopes, Berkeley: University of California Press.

Pressman, J.L., and Wildavsky, A., (1984), Implementation: How Great Expectations in Washington are Dashed in Oakland: Or, why It's Amazing that Federal Programs Work at All, this Being a Saga of the Economic Development Administration as Told by Two Sympathetic Observers who Seek to Build Morals on a Foundation of Ruined Hopes [ $3^{\text {rd }}$ edn], Berkeley: University of California Press.

Prete, L., and Smulders, B. (2010), 'The coming of age of infringement proceedings', Common Market Law Review, 47(1): 9-61.

Prosafe (n.d.), Best Practice Techniques in Market Surveillance, available on <www.prosafe.org>.

Prottas, J.M. (1979), People Processing: the Street-level Bureaucrat in Public Service Bureaucracies, Lexington: Lexington Books.

Provan, K.G., and Kenis, P. (2008), 'Modes of network governance: structure, management, and effectiveness', Journal of Public Administration Research and Theory, 18(2): 229-252.

Provan, K.G., and Milward, H.B. (2001), 'Do networks really work? A framework for evaluating public-sector organizational networks', Public Administration Review, 61(4): 414-423.

Putnam, R.D. (1993), Making Democracy Work. Civic Traditions in Modern Italy, Princeton: University Press.

Rothstein, B. (1998), Just Institutions Matter: the Moral and Political Logic of the Universal Welfare State, Cambridge University Press.

Quaglia, L., Neuvonen, M., Miyakoshi, M., and Cini, M. (2007) 'Europeanization', in M. Cini (ed.) European Union Politics [2 ${ }^{\text {nd }}$ edition], Oxford: Oxford University Press, pp. 405-420.

Quittkat, C. (2011), 'The European Commission's online consultations: a success story?', Journal of Common Market Studies, 49(3): 653-674.

Raad van State, Jaarverslag over 2012, Bestuursrechtspraak in cijfers, Uitspraken, personeel, kosten, en doorlooptijd van Bestuusrechtspraak, on

$<$ http://jaarverslag2012.raadvanstate.nl $>$. 
Radaelli, C.M., and De Francesco, F. (2007), Regulatory Quality in Europe: Concepts, Measures and Policy Processes, Manchester: University Press.

Radaelli, C. M. (2000), 'Whither Europeanization? Concept stretching and substantive change', European Integration online Papers 4, No. 8.

Radaelli, C. (2003), 'The open method of coordination: a new governance architecture for the European Union?', SIEPS Reports, No. 1.

Radaelli, C.M. (2006), 'Europeanization: solution or problem?', in M. Cini and A.K. Bourne (eds) Palgrave Advances in European Union Studies, Basingstoke: Palgrave, pp. 56-76.

Ramboll Management Consulting (2009), Market Surveillance in the Member States [report prepared for the European Parliament, Internal Market and Consumer Protection Committee], Brussels: European Parliament.

Ramnewash-Oemrawsingh, S.T. (2005), IPPC: in Wetgeving en Praktijk, Den Haag: Boom Juridische Uitgevers.

Raustiala, K., and Slaughter, A. (2002), 'International law, international relations and compliance', in W. Carlnaes, T. Risse, and B. Simmons (eds), Handbook of International Relations, London: SAGE Publications, pp. 538-558.

Raustiala, K., and Victor, D.G. (1998), 'Conclusions', in D.G. Victor, K. Raustialia, and E.G. Skolnikoff (eds), The Implementation and effectiveness of International environmental commitments: Theory and evidence, Cambridge: MIT Press, pp. 659-707.

Reale, M. (1993), 'Le comunicazioni interpretative della Commissione della Comunità europea', Rivista di diritto europeo, 3: 507-523.

Riley, D., and Fernandez, J.J. (2006), 'The authoritarian foundations of civic culture: Spain and Italy in comparative perspective', IRLE Working Paper No. 135/06.

Risk \& Policy Analysts (2006), Establishing a Comparative Inventory of Approaches and Methods Used by Enforcement Authorities for the Assessment of Safety of Consumer Products covered by Directive 2001/95/EC on General Products Safety and Identification of Best Practices [report prepared for the European Commission, DG Health and Consumers], Loddon: Risk \& Policy Analysts Limited.

Risse, T., Green Cowles, M., and Caporaso, J. (2001), 'Europeanization and domestic change: introduction', in M. Green Cowles, J. Caporaso, and T. Risse (eds), Transforming Europe: Europeanization and Domestic Change, Ithaca: Cornell University Press, pp. 1-20.

Rose, R. (1991), 'What is lesson-drawing', Journal of Public Policy, 11(1): 3-30.

Rupnik, J. (1999), 'The post-communist divide', Journal of Democracy, 10(1): 57-62.

Sabatier, P.A. (1986), 'Top-down and bottom-up approaches to implementation research: a critical analysis and suggested synthesis', Journal of Public Policy, 6(1), 21-48.

Sabatier, P.A. (1988), 'An advocacy coalition framework of policy change and the role of policy-oriented learning therein', Policy Sciences, 21(2/3): 129-168.

Sabatier, P.A., and Mazmanian, D.A. (1981), 'The implementation of public policy. A framework of analysis', in D.A. Mazmanian and P.A. Sabatier (eds), Effective Policy Implementation, Lexington: Lexington Books, pp. 3-35.

Sabel, C., and Zeitlin, J. (2008), 'Learning from difference: the new architecture of experimentalist governance in the EU', European Law Journal, 14(3): 271-327.

Sabel, C.F., and Zeitlin, J. (2010), 'Learning from Difference: the new architecture of experimentalist governance in the EU', in C.F. Sabel and J. Zeitlin (eds) (2010), Experimentalist Governance in the European Union. Towards a New Architecture, Oxford: University Press, pp. 1-28.

Scharpf, F.W. (1997), Games Real Actors Play: Actor-Centered Institutionalism in Policy Research, Boulder: Westview.

Scharpf, F.W. (1999), Governing in Europe: effective and democratic?, Oxford: University Press.

Scharpf, F.W. (2000), 'Institutions in comparative policy research', Comparative Political Studies, 33: 762-790.

Scharpf, F.W. (2003), 'Problem-solving effectiveness and democratic accountability in the EU', MPIfG Working Paper 03/1. 
Schoenberger, H. (2009), 'Integrated pollution prevention and control in large industrial installations on the basis of best available techniques - the Sevilla process', Journal of Cleaner Production, 17 (16): 15261529.

Schout, A. (2008), 'Inspecting aviation safety in the EU: EASA as an administrative innovation?' in E. Vos (ed.), European Risk Governance. Its Science, its Inclusiveness and its Effectiveness [CONNEX Report Series No. 06], pp. 257-294.

Schout, A., and Jordan, A. (2005), 'Coordinated European governance: self-organizing or centrally steered?', Public Administration 83: 201-220.

Schrank, A., and Whitford, J. (2011), 'The anatomy of network failure', Sociological Theory, 29(3): 151-177.

Scott, J. (2011), 'In legal limbo: post-legislative guidance as a challenge for European administrative law', Common Market Law Review, 48(2): 329-355.

Scott, J., and Trubek, D.M. (2002), 'Mind the gap: law and new approaches to governance in the European Union', European Law Journal, 8(1): 1-18.

Senden, L.A.J. (2004), Soft law in European Community law, London: Hart Publishing.

Senden, L.A.J. (2013), 'Soft post-legislative rulemaking in the EU: a time for more stringent control', European Law Journal, 19(1): 57-75.

Schimmelfennig, F., and Sedelmeier, U. (2005), 'Introduction: conceptualizing the Europeanization of Central and Eastern Europe', in F. Schimmelfennig and U. Sedelmeier (eds), The Europeanization of Central and Eastern Europe. Ithaca: Cornell University Press, pp. 1-28.

Sinclair, T.A.P. (2001), 'Implementation theory and practice: uncovering policy and administration linkages in the 1990s', International Journal of Public Administration, 24(1): 77-94.

Sissenich, B. (2007), Building States without Society. European Union Enlargement and the Transfer of EU Social Policy to Poland and Hungary, Lexington: Lexington Books.

Sissenich, B. (2010), 'Weak states, weak societies: Europe's east-west gap', Acta Politica 45: 11-40.

Somsen, H. (ed.) (1996), Protecting the European Environment: Enforcing EC Environmental Law, London: Blackstone Press.

Sørensen, E., and Torfing, J. (2005), 'The democratic anchorage of governance networks', Scandinavian Political Studies, 28: 195-218.

Sørensen, E., and Torfing, J. (2007), 'Introduction: governance network research: towards a second generation', in E. Sørensen and J. Torfing (eds), Theories of democratic network governance, London: Palgrave Macmillan, pp. 1-24.

Sørensen, E., and Torfing, J. (2009), 'Making governance networks effective and democratic through metagovernance', Public Administration, 87(2): 234-258.

Sharpston, E. (1993) Interim and Substantive Relief in Claims under Community Law, London: Butterworths. Shaw, J., and More, G. (1995) (eds), New Legal Dynamics of the European Union, Oxford: Clarendon Press.

Siedentopf, H., and Ziller, J. (1988), Making European Policies Work: the Implementation of Community Legislation in the Member States', Newbury Park: Sage.

Simmons, B. (1998), 'Compliance with international agreements', Annual Review of Political Science, 1998(1): 75-93.

Slaughter, A. (2004), A New World Order. Princeton: University Press.

Slepcevic R (2009), 'The judicial enforcement of EU law through national courts: possibilities and limits', Journal of European Public Policy, 16(3): 378-394.

Smismans, S. (2003), 'European civil society: shaped by discourses and institutional interests', European Law Journal, 9(4): 482-504.

Smismans, S. (ed.) (2006), Civil Society and Legitimate European Governance, Cheltenham: Edward Elgar, Cheltenham.

Smismans, S. (2007), 'New governance - the solution for active European citizenship, or the end of citizenship?', Columbia Journal of European Law, 13(3): 595-622.

Smismans, S. (2008), 'New modes of governance and the participatory myth', West European Politics, 31(5): 874-895. 
Smismans, S. (2009), 'European civil society and citizenship: complementary or exclusionary concepts?', Policy and Society, 28(1): 59-70.

Smith, M. (2011), 'Administrative procedures linked with Article 258 TFEU proceedings: an academic perspective', Briefing note prepared for the European Parliament, Committee on Legal Affairs.

Snyder, F. (1993), 'The effectiveness of European Community law. Institutions, processes, tools and techniques', The Modern Law Review 56(1): 19-54.

Snyder, F (1994), 'Soft law and institutional practice in the European Community', in S. Martin (ed.), The Construction of Europe. Essays in Honour of Emile Noël, Dordrecht: Springer, pp. 197-225.

Sotiropoulos, D. (1995), 'The remains of authoritarianism: bureaucracy and civil society in post-authoritarian Greece', Estudio Working Paper 66.

Spendzharova, A. and Versluis, E. (2013), 'Issue salience in the European policy process: what impact on transposition?', Journal of European Public Policy, 20(10): 1499-1516.

Stefan, O.A. (2013), Soft Law in Court. Competition Law, State Aid and the Court of Justice of the European Union, Alphen aan den Rijn: Kluwer.

Steiner, J., and Woods, L. (2009), EU Law [10 ${ }^{\text {th }}$ edition], Oxford: Oxford University Press.

Steunenberg, B. (2006), 'Turning swift policy-making into deadlock and delay. National policy coordination and the transposition of EU directives', European Union Politics, 7(3): 293-319.

Steunenberg, B., and Toshkov, D. (2009), 'Comparing transposition in the 27 member states of the EU: the impact of discretion and legal fit', Journal of European Public Policy, 16(7): 951-970.

Stone Sweet, A., and Brunell, T.L. (1998), 'Constructing a supranational constitution: Dispute resolution and governance in the European Community', American Political Science Review, 92(1): 63-81.

Stone Sweet, A., and Caporaso, J.A. (1998), 'From free trade to supranational polity: the European Court and integration', in W. Sandhotz and A. Stone Sweet (eds), European Integration and Supranational Governance, Oxford: University Press, pp. 92-133.

Stone Sweet, A., and Sandholtz, W. (eds) (1998), Supranational Governance: The Institutionalization of the European Union, Oxford: Oxford University Press.

Strauss, A., and Corbin, J. (1990), Basics of Qualitative Research: Grounded Theory Procedures and Techniques, Newbury Park: Sage Publications.

Streeck, W., and Schmitter, P.C. (1985), 'Community, market, state - and associations? The prospective contribution of interest governance to social order', in W. Streeck and P.C. Schmitter (eds), Private Interest Government. Beyond Market and State, London: Sage, pp. 1-29.

Sudbery, I. (2010), 'The European Union as political resource: NGOs as change agents?', Acta Politica 45: 136157.

Sverdrup, U. (2004), 'Compliance and conflict management in the European Union: Nordic exceptionalism', Scandinavian Political Studies, 27(1): 23-43.

Sverdrup, U. (2007), 'Implementation', in P. Graziano and M.P. Vink (eds) Europeanization: New Research Agendas, Houndmills: Palgrave, pp. 197-211.

Tallberg, J. (1999), 'Making states comply. The Eurpean Commission, the European Court of Justice \& the enforcement of the internal market', Lund Political Studies 109. .

Tallberg, J. (2002), 'Paths to compliance: enforcement, management and the European Union', International Organization 56(3): 609-643.

Tarrow, S. (2001), 'Contentious politics in a composite polity', in D. Imig and S. Tarrow (eds), Contentious Europeans: Protest and Politics in an Emerging Polity (Lanham: Rowman and Littlefield), pp. 233-251.

Thatcher, M. and Coen, D. 2008. 'Reshaping European regulatory space: an evolutionary analysis', West European Politics 31(4): 806-36.

Theodossiou, M.A. (2002), 'An analysis of the recent response of the Community to non compliance with Court of Justice judgments: Article 228(2) E.C.', European Law Review 27(1): 25-46.

Thomann, E. (2015), 'Customizing Europe: transposition as bottom-up implementation', Journal of European Public Policy, forthcoming. 
Thomson, R. (2007), 'Time to comply: national responses to six EU labour market directives revisited', West European Politics, 30(5): 987-1008.

Thomson, R. (2009) 'Same effects in different worlds: the transposition of EU directives', Journal of European Public Policy, 16(1): 1-18.

Thomson, R. (2010), 'Opposition through the back door in the transposition of EU directives', European Union Politics, 11(4): 577-596.

Thomson, R., Torenvlied, R., and Arregui, J. (2007), 'The paradox of compliance: infringements and delays in transposing European Union directives', British Journal of Political Science, 37(4): 685-709.

Toshkov, D. (n.d.), 55 years of EU Legislation, available on <http://www.dimiter.eu/Eurlex.html>.

Toshkov, D. (2007a), 'In search of the worlds of compliance: culture and transposition performance in the European Union', Journal of European Public Policy 14, 933-959.

Toshkov, D. (2007b), 'Transposition of EU social policy in the new member states', Journal of European Social Policy, 17(4): 335-348.

Toshkov, D. (2008), 'Embracing European Law Compliance with EU Directives in Central and Eastern Europe', European Union Politics, 9(3): 379-402.

Toshkov, D., Knoll, M. and Wewerka, L. (2010), 'Connecting the dots: case studies and EU implementation research', Institute for European Integration Research Working Paper 10/2010.

Treib, O. (2003), 'EU governance, misfit, and the partisan logic of domestic adaptation: an actor-centered perspective on the transposition of EU directives', Paper presented at the 8th Biennial International Conference of EUSA, Nashville, Tennessee.

Treib, O. (2008), 'Implementing and complying with EU governance outputs', Living Reviews in European Governance, 3(5).

Treib, O. (2014), 'Implementing and complying with EU governance outputs', Living Reviews in European Governance, 9(1).

Treib, O., and Falkner, G. (2008), 'Conclusions: the state of EU social standards in Central and Eastern European practice', in G. Falkner, O. Treib and E. Holzleithner, Compliance in the Enlarged Union. Living Rights or Dead Letters?, Aldershot: Ashgate Publishing, pp. 157-182.

Tridimas, G., and Tridimas, T. (2004), 'National courts and the European Court of Justice: a public choice analysis of the preliminary reference procedure', International Review of Law and Economics, 24(2): 125145 .

Trubek, D., and Mosher, J. (2003), 'Alternative approaches governance in the EU: EU social policy and the EU employment strategy', Journal of Common Market Studies, 41(1): 63-88.

Trubek, D., and Trubek, L. (2005), 'Hard and soft law in the construction of social Europe: the role of the open method of coordination', European Law Journal, 11(3): 343-364.

Tshuma, L. (2000), 'Hierarchies and Government Versus Networks and Governance; Competing Regulatory Paradigms in Global Economic Regulation', Social Legal Studies 9(1), 115-142.

Underdal, A. (1998), 'Explaining compliance and defection: three models', European Journal of International Relations, 4(1): 5-30.

Urzędu Ochrony Konkurencji i Konsumentów (2009), Znajomość praw konsumenckich oraz analiza barier utrudniajacych konsumentom bezpieczne i satysfakcjonujace uczestnictwo $w$ rynku [UOKiK Report], Warsaw: UOKiK.

Uylenburg, R. (2010), 'Beste beschikbare technieken en juridische procedures', Milieu \& Recht, 37(6): 351-351

Van Boetzelaer, K., and Princen, S. (2012), 'The quest for co-ordination in European regulatory networks', Journal of Common Market Studies 50(5), 819-836.

Van den Bossche, P. (1996), 'In search of remedies for non-compliance: the experience of the European Community', Maastricht Journal of European and Comparative Law, 1996(3): 371-398.

Van den Broek, J.H.G. (2007), 'IPPC-proof op 30 oktober 2007', Milieu en Recht, 34(2): 83-87.

Van der Doelen, F.C.J. (1998), 'The "give-and-take" packaging of policy instruments: optimising legitimacy and effectiveness', in M.-L. Bemelmans-Videc, R.C. Rist, and E. Vedung (eds), Carrots, stick and sermons. Policy instruments and their evaluation, New Brunswick: Transaction Publishers, pp. 129-148. 
Van der Heijden, J. (forthcoming), 'The long, but promising, road from deterrence to networked enforcement', in S. Drake and M. Smith (eds), New Directions in Effective Enforcement of EU Law and Policy, Cheltenham: Edward Elgar.

Van Evera, S. (1997), Guide to methods for students of political science, Ithaca: Cornell University Press.

Van Waarden, F. (1995), 'Persistence of national policy styles: a study of their institutional foundations', in B. Unger and $\mathrm{F}$. Van Waarden (eds), Convergence or diversity? Internationalization and economic policy response, Aldershot/Brookfield USA/Hong Kong, Singapore, Sidney: Avebury.

Versluis, E. (2003), Enforcement matters. Enforcement and Compliance of European Directives in Four Member States, Delft: Eburon.

Versluis, E. (2004), 'Explaining variations in implementation of EU directives', European Integration online Papers, 8, No. 19.

Versluis, E. (2007), 'Even rules, uneven practices: opening the 'black box' of EU law in action', West European Politics, 30(1): 50-67.

Versluis, E. (2012) 'Catalysts of compliance? The role of European Union agencies in the implementation of EU legislation in Poland and Bulgaria', in M. Busuioc, M. Groenleer, and J. Trondal (eds), The agency phenomenon in the European Union, Manchester: Manchester University Press, pp. 172-190.

Vink, M.P., and Graziano, P. (2007), 'Challenges of a new research agenda', in P. Graziano and M.P. Vink (eds), Europeanisation: New research agendas, Houndmills: Palgrave Macmillan.

Voermans, W. (2015), 'Implementation: the Achilles heel of European integration', The Theory and Practice of Legislation, 2(3): 343-359.

Vos, E. (2000), 'Reforming the European Commission: what role to play for EU agencies?', Common Market Law Review, 37(5): 1113-1134.

Versluis, E., and Tarr, E. (2013) 'Improving compliance with European Union law via agencies: The case of the European Railway Agency', Journal of Common Market Studies, 51(2): 316-333.

Von Homeyer, I. (2010), 'Emerging experimentalism in EU environmental governance', in C.F. Sabel and J. Zeitlin (eds), Experimentalist Governance in the European Union. Towards a New Architecture, Oxford: University Press, pp. 121-151.

VROM-Inspectie (2011), IPPC Vergunningen Verouderen, Den Haag: VROM-Inspectie.

Wallace, H., and Wallace, W. (eds) (1996), Policy-Making in the European Union, Oxford: Oxford University Press.

Warleigh, A. (2001), "'Europeanizing” civil society: NGOs as agents of political socialization', Journal of Common Market Studies, 39(4): 619-639.

Wedel, J.R. (1994), 'US aid to Central and Eastern Europe, 1990-1994: an analysis of aid model and responses', in J.P Hardt and R.F. Kaufman (eds), East Central European Economies in Transition [Study papers submitted to Joint Economic Committee, Congress of the United States], Washington, US Printing Office, pp. 299-335.

Weiler, J.H.H. (1994), 'A quiet revolution: the European Court of Justice and its interlocutors', Comparative Political Studies, 26(4): 510-534.

Wennerås, P. (2006), 'A new dawn for Commission enforcement under Articles 226 and 228 EC: general and persistent (GAP) infringements, lump sums and penalty payments', Common Market Law Review, 43(1): 31-62.

Wennerås, P. (2012), 'Sanctions against member states under Article 260 TFEU: alive, but not kicking?', Common Market Law Review 49(1): 145-175.

Williams, G. (2005), 'Monomaniacs or schizophrenics? Responsible governance and the EU's independent agencies', Political Studies, 53(1): 82-99.

Xanthaki, H. (2014), 'Quality of legislation: focus on smart EU and post-smart transposition', The Theory and Practice of Legislation, 2(3): 329-342.

Yataganas, X.A. (2001), 'Delegation of regulatory authority in the European Union the relevance of the American model of independent agencies', Jean Monnet Working Paper 3/01. 
Yesilkagit, K., and Danielsen, O.A. (2011), 'Transnational regulatory networks as a solution to the Community credibility crisis? The case of the European Competition Network', Jerusalem Papers in Regulation and Governance, No. 31.

Young, A.R., and Wallace, H. (2000), Regulatory Politics in the Enlarging Union: Weighing Civic and Producer Interests, Manchester: University Press.

Young, OR (1979), Compliance and Public Authority: A Theory with International Applications, Baltimore: Johns Hopkins University Press.

Young. O.R. (1992), 'The effectiveness of international institutions: hard cases and critical variables', in J.N. Rosenau and E. Czempiel (eds), Governance without government. Order and change in world politics, Cambridge: Cambridge University Press, pp. 160-194.

Zeitlin, J., and Pochet, P. (2005), The Open Method of Co-ordination in Action: The European Employment and Social Inclusion Strategies, Brussels: Peter Lang.

Zhelyazkova, A. (2013), 'Complying with EU directives' requirements: the link between EU decision-making and the correct transposition of directives', Journal of European Public Policy, 20(5): 702-721.

Zhelyaskova, A., and Yordanova, N. (2015), 'Signalling "compliance": the link between notified EU directive implementation and infringement cases', European Union Politics, forthcoming.

Zhelyazkova, A., and Torenvlied, R. (2009), 'The time-dependent effect of conflict in the Council on delays in the transposition of EU directives', European Union Politics, 10(1): 35-62.

Zubek, R. (2005), 'Complying with transposition commitments in Poland: collective dilemmas, core executive and legislative outcomes', West European Politics, 28(3): 592-619.

Zubek, R. (2008), 'Parties, rules and government legislative control in Central Europe: the case of Poland', Communist and Post-Communist Studies, 41(2): 147-61.

Zubek, R., and Staroňová, K. (2010), 'Ministerial transposition of EU directives: can oversight improve performance?', EIF Working Papers, No. 9.

Zürn, M., and Checkel, J. (2005), 'Getting socialized to build bridges: constructivism and rationalism, Europe and the nation-state', International Organization, 59(4): 1045-1079.

Zürn, M., and Joerges, C. (2005), Law and Governance in Postnational Europe: Compliance Beyond the Nation-State, Cambridge University Press. 


\section{International, EU, and national measures and documents}

\section{International treaties}

Consolidated version of the Convention for the Protection of Human Rights and Fundamental Freedoms [1950], Strasbourg: Council of Europe.

United Nations Economic Commission for Europe (UNECE) Convention on Access to Information, Public Participation in Decision-Making and Access to Justice in Environmental Matters (Aarhus Convention) [1998], Herndon: United Nations Publications.

\section{EU treaties, secondary legislation, and other measures}

\section{Treaties}

Charter of Fundamental Rights of the European Union [2010] OJ C83/389.

Consolidated version of the Treaty on European Union [2012] OJ C326/13.

Consolidated version on the Treaty on the Functioning of the European Union [2012] OJ C326/47.

Consolidated version of the Treaty establishing the European Community [2002] OJ C 325/33.

Treaty establishing the European Economic Community [1957], Luxembourg: Office for Official Publications of the European Communities.

Treaty of Amsterdam amending the Treaty on European Union, the Treaties establishing the European Communities and certain related acts: Declaration No 39 on the quality of the drafting of Community legislation [1997], Luxembourg: Office for Official Publications of the European Communities.

Treaty on European Union - Declaration on the implementation of Community law, OJ [1992] OJ C191/102.

\section{Secondary legislation}

Council Directive 96/61/EC of 24 September 1996 on integrated pollution prevention and control [1996] OJ L $257 / 26$

Directive 1999/5/EC of the European Parliament and of the Council of 9 March 1999 on radio equipment and telecommunications terminal equipment and the mutual recognition of their conformity [1999] OJ L $91 / 10$.

Directive 2001/81/EC of the European Parliament and of the Council of 23 October 2001 on national emission ceilings for certain atmospheric pollutants, OJ L 309/22.

Directive 2001/95/EC of the European Parliament and of the Council of 3 December 2001 on general product safety [2001] OJ L 11/4.

Regulation (EC) No 1592/2002 of the European Parliament and of the Council of 15 July 2002 on common rules in the field of civil aviation and establishing a European Aviation Safety Agency, OJ [2002] L 240/1.

Directive 2003/4/EC of the European Parliament and of the Council of 28 January 2003 on public access to environmental information and repealing Council Directive 90/313/EEC [2003] OJ L 41/26.

Directive 2003/35/EC of the European Parliament and of the Council of 26 May 2003 providing for public participation in respect of the drawing up of certain plans and programmes relating to the environment and amending with regard to public participation and access to justice Council Directives 85/337/EEC and 96/61/EC [2003] OJ L 156/17.

Directive 2004/36/EC of the European Parliament and of the Council of 21 April 2004 on the safety of thirdcountry aircraft using Community airports [2004] OJ L 143/76. 
Regulation (EC) 2111/2005 of the European Parliament and of the Council of 14 December on the establishment of a Community list of air carriers subject to an operating ban within the Community and on informing air transport passengers of the identity of the operating air carrier, and repealing Article 9 of Directive 2004/36/EC [2005] OJ L 344/15.

Regulation (EC) No 166/2006 of the European Parliament and of the Council of 18 January 2006 concerning the establishment of a European Pollutant Release and Transfer Register and amending Council Directives 91/689/EEC and 96/61/EC [2006] OJ L 33/1.

Directive 2008/1/EC of the European Parliament and of the Council of 15 January 2008 concerning integrated pollution prevention and control (codified version) [2008] OJ L 24/8.

Regulation (EC) No 764/2008 of the European Parliament and of the Council of 9 July 2008 laying down procedures relating to the application of certain national technical rules to products lawfully marketed in another Member State and repealing Decision No 3052/95/EC [2008] OJ L 218/21.

Regulation 765/2008/EC of the European Parliament and of the Council of 9 July 2008 setting out the requirements for accreditation and market surveillance relating to the marketing of products and repealing Regulation (EEC) No 339/93 [2008] OJ L 218/30.

Decision No 768/2008/EC of the European Parliament and of the Council of 9 July 2008 on a common framework for the marketing of products, and repealing Council Decision 93/465/EEC [2008] OJ L 218/82.

Directive 2010/75/EU of the European Parliament and of the Council of 24 November 2010 on industrial emissions (integrated pollution prevention and control) [2010] OJ L 334/17.

Regulation (EU) No 182/2011 of the European Parliament and of the Council of 16 February 2011 laying down the rules and general principles concerning mechanisms for control by Member States of the Commission's exercise of implementing powers [2011] OJ L 55/13.

\section{Commission measures}

Commission Decision 2004/418/EC laying down guidelines for the management of the Community Rapid Information System (RAPEX) and for notifications presented in accordance with Article 11 of Directive 2001/95/EC [2004] OJ L 151/83.

Commission Regulation (EC) No 768/2006 of 19 May 2006 implementing Directive 2004/36/EC of the European Parliament and of the Council as regards the collection and exchange of information on the safety of aircraft using Community airports and the management of the information system [2006] OJ L $134 / 16$.

Commission Directive 2008/49/EC amending Annex II to Directive 2004/36/EC of the European Parliament and of the Council regarding the criteria for the conduct of ramp inspections on aircraft using Community airports [2008] OJ L 109/17.

Commission Decision of 16 December 2009 laying down guidelines for the management of the Community Rapid Information System 'RAPEX' established under Article 12 and of the notification procedure established under Article 11 of Directive 2001/95/EC (the General Product Safety Directive) [2010] OJ L22/1.

\section{Agency decisions}

European Aviation Safety Agency, ED Decision N ${ }^{\circ}$ 2008/001/S of the Executive Director of the European Aviation Safety Agency of 29 September 2008 on the guidance material for the qualification of SAFA inspectors, available on $<$ www.easa.europa.eu $>$.

European Aviation Safety Agency, ED Decision N ${ }^{\circ}$ 2009/001/S of the Executive Director of the European Aviation Safety Agency of 22 July 2009 on the guidance material for SAFA ramp inspections, available on <www.easa.europa.eu $>$.

European Aviation Safety Agency, ED Decision N ${ }^{\circ}$ 2012/001/S of the Executive Director of the European Aviation Safety Agency on the guidance material for SAFA ramp inspections, available on $<$ www.easa.europa.eu $>$.

European Aviation Safety Agency, 'Inspection instructions on the categorisation of ramp inspection (SAFA/SACA) Findings, Doc \# INST.RI.01/001’ [2014] available on <www.easa.europa.eu>. 


\section{Documents of EU institutions}

\section{Interinstitutional}

Interinstitutional Agreement of 22 December 1998 on common guidelines for the quality of drafting of Community legislation [1999] OJ C 73/1.

\section{Commission}

\section{COM/SEC documents}

Commission, 'Reinforcing the effectiveness of the Internal Market. Working Document of the Commission on a Strategic Programme on the Internal Market' (Sutherland Report) COM (93) 256 final.

Commission, 'Communication on the development of administrative cooperation in the implementation and enforcement of Community legislation in the internal market' (Communication) COM (94) 29 final.

Commission, 'Cooperation between Administrations for Enforcement of Internal Market Law: A Progress Report' (Report) COM (96) 20 final.

Commission, 'European Governance' (White Paper) COM (2001) 428 final.

Commission, 'Toward a reinforced culture of dialogue and consultation - General principles and minimum standards for consultation of interested parties by the Commission' (Communication) COM (2002) 704 final.

Commission, 'Better Monitoring of the Application of Community Law' (Communication) COM (2002) 725 final.

Commission, 'On the road to sustainable production. Progress in implementing Council Directive 96/61/EC concerning integrated pollution prevention and control' (Communication) COM (2003) 354 final.

Commission 'Report of the Commission on the implementation of Council Directive 96/61/EC' (Communication) COM (2005) 540 final.

Commission, 'Application of Article 228 of the EC Treaty' (Communication) SEC (2005) 1658.

Commission, 'A strategic review of better regulation in the European Union' (Communication) COM (2006) 689 final.

Commission, 'A Europe of results - applying Community law' (Communication) COM (2007) 502 final.

Commission, 'Proposal for a Directive of the European Parliament and of the Council on industrial emissions (integrated pollution prevention and control) (Recast) (Industrial Emissions Directive) COM (2007) 844 final.

Commission, 'Monitoring Consumer Outcomes in the Single Market: the Consumer Markets Scoreboard' (Communication) COM (2008) 31 final.

Commission, 'European Agencies: The way forward' (Communication) COM (2008) 135 final.

Commission, 'Report on the Implementation of Directive 2001/95/EC of the European Parliament and of the Council of 3 December 2001 on General Product Safety' (Report) COM (2008) 905 final.

Commission, 'Report on the European Community SAFA Programme (Safety Assessment of Foreign Aircraft)' (Report) [2008] OJ C42/1.

Commission, 'Report on the European Community SAFA Programme (Safety Assessment of Foreign Aircraft)' (Report) [2008] OJ C231/1.

Commission, 'Safety of third-country aircraft using Community airports (Report on the application of Directive 2004/36/EC of the European Parliament and of the Council)' (Report) [2008] OJ C 244/4.

Commission, 'Staff working paper accompanying the report from the Commission to the European Parliament and the Council: European Community SAFA Programme (Safety Assessment of Foreign Aircraft) Aggregated information report (01 January 2007 to 31 December 2007)' (Staff Working Paper), SEC (2008) 2484 final.

Commission, 'Impact Assessment Guidelines' (Guidelines) SEC (2009) 92.

Commission, '26 $6^{\text {th }}$ Annual report on monitoring the application of EU law' (Report) COM (2009) 675 final. 
Commission, 'Staff working paper accompanying the report from the Commission to the European Parliament and the Council: European Community SAFA Programme (Safety Assessment of Foreign Aircraft) Aggregated information report (01 January 2008 to 31 December 2008)' (Staff Working Paper) SEC (2009) 1576 final.

Commission, 'EU Pilot Evaluation Report' (Report) COM (2010) 70 final.

Commission, '2 $7^{\text {th }}$ Annual report on monitoring the application of EU law' (Report) COM (2010) 538 final.

Commission, 'The implementation of Directive 2008/1/EC concerning integrated pollution prevention and control and Directive 1999/13/EC on the limitation of emissions of volatile organic compounds due to the use of organic solvents in certain activities and installations' (Report) COM (2010) 593 final.

Commission, 'Smart Regulation in the European Union' (Communication) COM (2010) 543 final.

Commission, 'Implementation of Article 260(3) of the Treaty' (Communication) SEC (2010) 1371 final.

Commission, 'European Union SAFA Programme (Safety Assessment of Foreign Aircraft)' (Report) COM (2011) 159 final.

Commission, 'Staff working paper accompanying the report from the Commission to the European Parliament and the Council: European Union SAFA Programme (Safety Assessment of Foreign Aircraft) Aggregated information report (01 January 2009 to 31 December 2009)' (Staff Working Paper) SEC (2011) 301 final.

Commission, 'Second Evaluation Report on EU Pilot' (Report) COM (2011) 930 final.

Commission, '28 $8^{\text {th }}$ Annual report on monitoring the application of EU law' (Report) COM (2011) 588 final.

Commission, 'European Union SAFA Programme (Safety Assessment of Foreign Aircraft)' (Report) COM (2012) 91 final.

Commission, 'Staff working paper accompanying the report from the Commission to the European Parliament and the Council: European Union SAFA Programme (Safety Assessment of Foreign Aircraft) Aggregated information report (01 January 2010 to 31 December 2010)' (Staff Working Paper) SWD (2012) 38 final.

Commission, 'Updating the handling of relations with the complainant in respect of the application of Union law' (Communication) COM (2012) 154 final.

Commission, 'Better governance for the single market' (Communication) COM (2012) 259 final.

Commission, 'EU regulatory fitness' (Communication) COM (2012) 746 final.

Commission, '29 $9^{\text {th }}$ Annual report on monitoring the application of EU law' (Report) COM (2012) 714 final.

Commission, 'Report on the experience gained in the application of Directive 2003/4/EC on public access to environmental information' (Report) COM (2012) 774 final.

Commission, 'Product safety and market surveillance package. More product safety and better market surveillance in the single market for products' (Communication) COM (2013) 74 final.

Commission, 'Proposal for a regulation of the European Parliament and of the Council on market surveillance of products and amending Council Directives 89/686/EEC and 93/15/EEC, and Directives 94/9/EC, 94/25/EC, 95/16/EC, 97/23/EC, 1999/5/EC, 2000/9/EC, 2000/14/EC, 2001/95/EC, 2004/108/EC, 2006/42/EC, 2006/95/EC, 2007/23/EC, 2008/57/EC, 2009/48/EC, 2009/105/EC, 2009/142/EC, 2011/65/EU, Regulation (EU) No 305/2011, Regulation (EC) No 764/2008 and Regulation (EC) No 765/2008 of the European Parliament and of the Council' (Market Surveillance Regulation) COM (2013) 75.

Commission, 'Proposal for a Regulation on consumer product safety and repealing Council Directive 87/357/EEC and Directive 2001/95/EC' (Product Safety Regulation) COM (2013) 78 final.

Commission, 'The EU Justice Scoreboard. A tool to promote effective justice and growth' (Communication) COM (2013) 160 final.

Commission, 'The Consumer Conditions Scoreboard - Consumers at home in the single market' (Working Document) SWD (2013) 291.

Commission, '30th Annual Report on Monitoring the Application of EU Law' (Report) COM (2013) 726 final.

Commission, 'The 2014 EU Justice Scoreboard' (Communication) COM (2014) 155 final.

Commission, '31st Annual Report on Monitoring the Application of EU Law' (Report) COM (2014) 612 final.

Commission, 'Commission Work Programme 2015 - A New Start' (Working Programme) COM (2014) 910 final.

Commission, 'Monitoring the application of EU law. 2014 Annual Report' (Report) COM (2015) 329 final. 


\section{Other Commission documents}

Commission, 'Information from the Commission - Memorandum on applying Article 171 of the EC treaty' [1996] OJ C 242/6.

\section{Council}

Council, 'A new approach to technical harmonisation and standards' (Resolution) [1985] OJ C 136/1.

Council, 'Making the Single Market work' (Resolution) [1992] OJ C334/1.

Council, 'Effective implementation and enforcement of Community legislation in the area of social affairs' (Conclusions) [1993] OJ C 49/6.

Council, 'The effective uniform application of Community Law and on the penalties applicable for breaches of Community law in the internal market' (Resolution) [1995] OJ C 188/1.

\section{Court of Justice}

Court of Justice of the European Union, 'Rules of Procedure' [2012] OJ L 265/1.

Court of Justice of the European Union, 'Recommendations to national courts and tribunals in relations to the initiation of preliminary ruling proceedings' [2012] OJ C 338/1.

\section{National measures and parliamentary documents}

\section{National Measures ${ }^{1}$}

\section{The Netherlands}

Algemene Wet Bestuursrecht, Wet van 4 juni 1992, houdende algemene regels van bestuursrecht [1992] Stb. 315. Besluit omgevingsrecht, Besluit van 25 maart 2010, houdende regels ter uitvoering van de Wet algemene bepalingen omgevingsrecht [2010] Stb. 143.

Besluit proceskosten bestuusrecht, Besluit van 22 december 1993, houdende nadere regels betreffende de proceskostenveroordeling in bestuursrechtelijke procedures [1993] Stb. 763.

Crisis- en herstelwet, Wet van 18 maart 2010, houdende regels met betrekking tot versnelde ontwikkeling en verwezenlijking van ruimtelijke en infrastructurele projecten [2010] Stb.135.

Regeling omgevingsrecht, Regeling van de Minister van Volkshuisvesting, Ruimtelijke Ordening en Milieubeheer van 30 maart 2010, nr. BJZ2010008979, houdende nadere regels ter uitvoering van de Wet algemene bepalingen omgevingsrecht en van het Besluit omgevingsrecht [2010] Stcrt. 5162.

Warenwet, Wet van 28 december 1935, houdende voorschriften betreffende de hoedanigheid en aanduiding van waren [1935] Stb. 793.

Warenwetbesluit algemene productveiligheid, Besluit van 28 september 1993, houdende regelen betreffende de algemene produktveiligheid [1993] Stb. 499.

Wet algemene bepalingen omgevingsrecht, Wet van 6 november 2008, houdende regels inzake een vergunningstelsel met betrekking tot activiteiten die van invloed zijn op de fysieke leefomgeving en inzake handhaving van regelingen op het gebied van de fysieke leefomgeving [2008] Stb. 496.

Wet op de rechtsbijstand, Wet van 23 december 1993, houdende regelen omtrent de door de overheid gefinancierde rechtsbijstand [1993] Stb. 775.

\section{Poland}

Kodeks Cywilny, Ustawa z dnia 23 kwietnia 1964 [1964] Dz.U. 16/93.

Kodeks postępowania administracyjnego, Ustawa z dnia 14 czerwca 1960 [1960] Dz.U. 30/168.

O ochronie konkurencji i konsumentów, Ustawa z dnia 16 lutego 2007 [2007] Dz.U. 50/331.

\footnotetext{
${ }^{1}$ Versions of September 2014.
} 
O ogólnym bezpieczeństwie produktó, Ustawa z dnia 12 grudnia 2003 [2003] Dz.U. 229/2275.

O udostępnianiu informacji o środowisku i jego ochronie, udziale społeczeństwa w ochronie środowiska oraz o ocenach oddziaływania na środowisko, Ustawa z dnia 3 października 2008 [2008] Dz.U. 199/1227.

Prawo o postępowaniu przed sądami administracyjnymi, Ustawa $z$ dnia 30 sierpnia 2002 [2002] Dz.U. $153 / 1270$.

Prawo ochrony środowiska, Ustawa z dnia 27 kwietnia 2001 [2001] Dz.U. 62/627.

W sprawie wysokości oraz szczegótowych zasad pobierania wpisu w postępowaniu przed sądami administracyjnymi, Rozporzadzenie Rady Ministrów z dnia 16 grudnia 2003 [2003] Dz.U. 221/2193.

\section{Portugal}

Acesso ao direito e aos tribunais, Lei $n^{\circ} 34 / 2004$, de 29 de Julho [2004] DR 1. a Série, No 177/4802

Código de Processo nos Tribunais Administrativos, Lei no 15/2001, de 05 de Junho [2001] DR 1.a série A, No 130/ 3336.

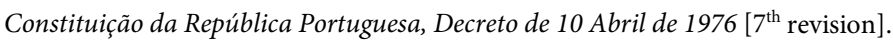

Decreto-Lei $n^{\circ}$ 194/2000, de 21 de Agosto [2000] DR 1. a série A, No 192/4116.

Decreto-Lei no 173/2008, de 26 de Agosto [2008] DR 1. a série, № 164/5967.

Defesa do consumidor, Lei no 24/96, de 31 de Julho [1996] DR 1. a série A, No 176/2184.

Direito de participação procedimental e de aç̧ão popular, Lei no 83/95, de 31 de Agosto [1995] DR 1. a série A, № 201/5464.

Estatuto dos Tribunais Administrativos e Fiscais, Lei no 13/2002, de 19 de Fevereiro [2002] DR 1.a série A, No $42 / 1324$.

Organizações não governamentais de ambiente, Lei 35/98, de 18 de Julho [1998] DR 1.a série A, No 164/3474.

Regulamento das Custas Processuais, Decreto-Lei no 34/2008, de 26 de Fevereiro [2008] DR 1. a série, No $40 / 1261$.

Segurança geral dos produtos, Decreto-Lei no 69/2005, de 17 de Março [2005] DR 1. a série A, No 54/2354.

\section{Parliamentary documents}

\section{The Netherlands}

Handelingen Eerste Kamer 2004-2005, no. 26.

Handelingen Tweede Kamer 2004-2005, no. 17.

Kamerstukken II, 2003/04, 29711, no. 3. 


\section{Case law}

\section{Court of Justice of the European Union}

Case 29/59 Netherlands v. High Authority [1960] ECR 355.

Case 26/62 NV Algemene Transport- en Expeditie Onderneming van Gend \& Loos v. Netherlands Inland Revenue Administration [1963] ECR 1.

Cases 28-30/62 Da Costa en Schaake NV, Jacob Meijer NV and Hoechst-Holland NV v. Nederlandse Belastingadministratie [1963] ECR 31.

Case 6/64 Flaminio Costa v. E.N.E.L. [1964] ECR 585.

Case 28/67 Mölkerei-Zentrale Westfalen v. Hauptzollamt Paderborn [1968] ECR 00211.

Case 5/68 Commission v. Italy [1968] ECR 423.

Case 7/68 Commission v. Italy [1968] ECR 00617.

Case C-22/70 Commission v. Council (ERTA) [1971] ECR 263.

Case 43/71 Politi v. Italy [1971] ECR 1039.

Case 34/73 Variola v. Amministrazione delle Finanze [1973] ECR 981.

Case 41/74 Van Duyn v. Home Office [1974] ECR 1337.

Case 33/76 Rewe-Zentralfinanz eG and Rewe-Zentral AG v. Landwirtschaftskammer für das Saarland [1976] ECR 1989.

Case C-45/76 Comet BV v. Produktschap voor Siergewassen [1976] ECR 2043.

Case 8/77 Sagulo, Brenca, and Bakhouce [1977] ECR 1495, 12-13.

Case 148/78 Pubblico Ministero v. Tullio Ratti [1979] ECR 1629.

Case 96/81 Commission v. Netherlands [1982] ECR 1791.

Case 230/81 Luxembourg v. European Parliament (Seat and Working Place of the Parliament) [1983] ECR 255. Case 283/81 Srl CILFIT and Lanificio di Gavardo SpA v. Ministry of Health [1982] ECR 3415.

Case 74/82 Commission v. Ireland [1984] ECR 317.

Case 14/83 Von Colson and Kamann v. Land Nordrhein-Westfalen [1984] ECR 1891.

Case 280/83 Commission v. Italy [1984] ECR 2361.

Case 29/84 Commission v. Germany [1985] ECR 1661.

Case 146/84 De Santis v. Court of Auditors [1985] ECR 1723.

Case 152/84 Marshall v. Southampton and South-West Hampshire Area Health Authority (Teaching) [1986] ECR 723.

Case C-222/84 Marguerite Johnston v. Chief Constable of the Royal Ulster Constabulary [1985] ECR 1651.

Case 293/85 Commission v. Belgium [1988] ECR 305.

Case 416/85 Commission v. United Kingdom [1988] ECR 3127.

Case 222/86 UNECTEF v. Heylens [1987] 4097.

Case 247/87 Starfruit v. Commission [1989] ECR 291.

Case C-339/87 Commission v. The Netherlands [1990] ECR I-851.

Case C-68/88 Commission v. Greece (Greek Maize) [1989] ECR 2965.

Case C-103/88 Fratelli Costanzo SpA v. Comune di Milano [1989] ECR 1839.

Case C-131/88 Commission v. Germany [1991] ECR-I 825.

Joined cases C-143/88 and C-92/89 Zuckerfabrik Süderdithmarschen AG v. Hauptzollamt Itzehoe and Zuckerfabrik Soest GmbH v Hauptzollamt Paderborn [1991] ECR I-415.

Case C-322/88 Grimaldi [1989] ECR I-4407.

Case C-96/89 Commission v. Netherlands [1991] ECR 2461.

Case C-106/89 Marleasing [1990] ECR I-4135. 
Case C-146/89 Commission v. United Kingdom [1991] ECR I-3533.

Case C-213/89 R. v Secretary of State for Transport, ex parte Factortame Ltd and others [1990] ECR I-2433.

Joined cases C-87-89/90 A. Verholen and others v. Sociale Verzekeringsbank Amsterdam [1991] ECR I-03757.

Case C-208/90 Theresa Emmott v. Minister for Social Welfare and Attorney General [1991] ECR I-4269.

Case C-338/91 H. Steenhorst-Neerings v. Bestuur van de Bedrijfsvereniging voor Detailhandel, Ambachten en Huisvrouwen [1993] ECR I-5475.

Case C-410/92 Elsie Rita Johnson v. Chief Adjudication Officer [1994] ECR I-5483.

Case C-312/93 Peterbroeck, Van Campenhout \& Cie SCS v. Belgian State [1995] ECR I-4599.

Case C-465/93 Atlanta Fruchthandelsgesellschaft mb Hand others v. Bundesamt für Ernährung und Forstwirtschaft [1995] ECR I-3761.

Case C-478/93 Kingdom of the Netherlands v. Commission [1995] ECR I-3081.

Case C-311/94 IJssel-Vliet [1996] ECR I-502.

Case C-57/95 France v. Commission [1997] ECR I-1627

Case C-169/95 Spain v. Commission [1997] ECR I-315.

Case C-185/95 Baustahlgewebe GmbH v. Commission of the European Communities [1998] ECR I-08417.

Case C-188/95 Fantask A/S e.a. v. Industrieministeriet (Ehrvervministeriet) [1997] ECR I-6783.

Case C-261/95 Palmisani [1997] ECR I-4025.

Case C-265/95 Commission v. France (Spanish strawberries) [1997] ECR I-6959.

Case C-442/97 Spain v. Commission [1999] I-08093

Case C-88/96 Germany v. Commission [2000] ECR I-823.

Case C-129/96 Inter-Environnement Wallonie ASBL v. Région Wallone [1997] ECR I-7411.

Case C-43/97 Commission v. Italy [1997] ECR I-4671.

Case C-387/97 Commission v. Greece [2000] ECR I-5047.

Case C-442/97 Spain v. Commission [1999] ECR I-8105.

Case C-361/99 Commission v. Germany [1991] ECR I-2576.

Case C-1/00 France v. European Commission [2001] ECR I-09989.

Case C-62/00 Marks \& Spencer plc v. Commissioners of Customs \& Excise [2002] ECR I-6325.

Case C-94/00 Roguette Frères [2002] ECR I-9011.

Case C-99/00 Criminal proceedings against Lyckeskog [2002] ECR I-4839.

Case C-112/00 Schmidberger [2003] ECR I-5659.

Case C-255/00 Grundig Italiana [2002] ECR I-8003.

Case C-29/01 Commission v. Spain [2002] ECR I-02503.

Case C-39/01 Commission v. United Kingdom [2002] ECR I-02513.

Case C-64/01 Commission v. Greece [2002] ECR I-02523.

Case C-173/01 Commission v. Greece [2002] ECR I-6129.

Case C-218/01 Henkel KGaA [2004] ECR I-1725.

Case C-278/01 Commission v. Spain [2003] ECR I-14141.

Case C-394/01 Commission v. Ireland [2005] ECR I-3331.

Case C-304/02 Commission v. France [2005] ECR I-6263.

Case C-441/02 Commission v. Germany [2006] ECR I-3449.

Case C-508/03 Commission v. United Kingdom [2006] ECR I-3969.

Case C-511/03 Ten Kate Holding [2005] ECR I-8979.

Case C-519/03 Commission v Luxembourg [2005] ECR I-3067.

Case C-78/04 Commission v. Austria [2004] ECLI:EU:C:2004:735.

Case C-144/04 Mangold $v$ Helm [2005] ECR I-9981.

Case C-212/04 Konstantinos Adeneler et al v Ellinikos Organismos Galaktos (ELOG) [2006] ECR I-6057.

Case C-344/04 R on the application of IATA and ELFAA v Department of Transport [2006] ECR I-403.

Case T-374/04 Germany v. Commission [2007] ECR-II 4441.

Case C-84/05 Commission v. Italy [2005] ECLI:EU:C:2005:505.

Case C-247/05 Commission v. Netherlands [2006] ECLI:EU:C:2006:84. 
Case C-308/05 Commission v. Netherlands [2006] ECLI:EU:C:2006:343

Case C-310/05 Commission v. Luxembourg [2006] ECR I-00039.

Case C-323/05 Commission v. United Kingdom [2006] ECLI:EU:C:2006:157.

Case C-432/05 Unibet [2007] ECR I-2271.

Case C-2/06 Willy Kempter KG v. Hauptzollamt Hamburg-Jonas [2008] ECR I-411.

Case C-210/06 Cartesio Oktató és Szolgáltató [2008] ECR I-9641.

Case C-121/07 Commission v. France [2008] ECR I-9159.

Case C-226/07 Flughafen Köln/Bonn GmbH v Hauptzollamt Köln [2008] ECR I-5999.

Case C-237/07 Dieter Janecek v Freistaat Bayern [2008] ECR I-6221.

Cases C-261 and 299/07 VTB-VAB NV v. Total Belgium NV [2009] ECR I-2949.

Case C-263/07 Commission v. Luxembourg [2007] ECR I-00180

Case C-271/07 Commission v. Belgium [2008] ECR I-00078.

Case C-412/07 Commission v. Ireland [2008] ECLI:EU:C:2008:72

Case C-417/07 Commission v. Luxembourg [2008] ECR I-00051.

Case C-449/07 Commission v. Italy [2008] ECLI:EU:C:2008:199.

Case C-473/07 Association nationale pour la protection des eaux et rivières-TOS and Association OABA $v$. Ministère de l'Ecologie, du Développement et de l'Aménagement durables [2009] ECR 2009 I-00319.

Case C-562/07 Commission v Spain [2009] ECR I-9553.

Case C-12/08 Mono Car Styling [2009] ECR I-6653.

Case C-63/08 Virginie Pontin v. T-Comalux SA [2009] ECR I-10467.

Case C-72/08 Commission v. Poland [2009] ECLI:EU:C:2009:412.

Case C-109/08 Commission v. Greece [2009] ECR I-4657.

Case C-132/08 Lidl Magyarország Kereskedelmi bt v. Nemzeti Hírközlési Hatóság Tanácsa [2009] ECR 2009 I03841.

Case C-24/09 Djurgården-Lilla Värtans Miljöskyddsförening v AB Fortum Värme samägt med Stockholms stad [2010] ECR 2010, I-00035.

Joined cases C-165/09 to C-167/09 Stichting Natuur en Milieu and Others v. College van Gedeputeerde Staten van Groningen (C-165/09) and College van Gedeputeerde Staten van Zuid-Holland (C-166/09 and C167/09) [2011] ECR 2011 I-04599.

Case C-258/09 Commission v. Belgium [2010] ECR I-00029.

Case C-279/09 DEB v Bundesrepublik Deutschland [2010] ECR I-13849.

Case C-534/09 Commission v. Republic of Greece [2010] ECR I-00160.

Case C-33/10 Commission v. Kingdom of Denmark [2010] ECLI:EU:C:2010:750.

Case C-44/10 Commission v. Republic of Portugal [2010] ECLI:EU:C:2010:657.

Case C-48/10 Commission v. Kingdom of Spain [2010] ECR I-00151.

Case C-49/10 Commission v. Slovenia [2010] ECR I-00128.

Case C-50/10 Commission v. Republic of Italy [2011] ECR I-00045.

Case C-416/10 Jozef Križan and Others v. Slovenská inšpekcia životného prostredia [2013] not yet published.

Case C-585/10 Niels Møller v. Haderslev Kommune [2011] ECR 2011 I-13407.

Case C-607/10 Commission v. Kingdom of Sweden [2012] ECLI:EU:C:2012:192.

Case C-260/11 The Queen, on the application of David Edwards and Lilian Pallikaropoulos $v$ Environment Agency and Others [2013] (not yet published).

Case C-352/11 Commission v. Republic of Austria [2012] ECLI:EU:C:2012:315.

Case C-369/11 Commission v. Italy [2013] not yet published.

Joined Cases C-514/11 P and C-605/11 P Liga para a Protecção da Natureza (LPN) and Republic of Finland v. European Commission [2013] not yet published.

Case C-158/12 Commission v. Ireland [2013] ECLI:EU:C:2013:234.

Case C-334/12 RX-II Arango Jaramillo and Others v. EIB [2013] ECR. 


\section{Opinions of Advocates General}

Case 7/61 Commission v. Italy [1961] ECR 317, opinion of AG Langrange.

Case 240/86 Commission v. Greece [1988] ECR 01835, opinion of AG Lenz.

Case C-494/01 Commission v. Ireland [2005] ECR I-03331, opinion of AG Geelhoed.

Joined Cases C-387/02, C-391/02 and C-403/02 Berlusconi and Others [2005] ECR I-3565, opinion of AG

Kokott.

\section{National case law}

\section{The Netherlands}

\section{Raad van State (Council of State)}

\section{Integrated pollution prevention and control}

RvS 23 February 2005, ECLI:NL:RVS:2005:AS7235.

RvS 28 September 2005, ECLI:NL:RVS:2005:AU3398.

RvS 25 January 2006, ECLI:NL:RVS:2006:AV0295.

RvS 26 April 2006, ECLI:NL:RVS:2006:AW3976.

RvS 29 November 2006, ECLI:NL:RVS:2006:AZ3264.

RvS 5 January 2007, ECLI:NL:RVS:2007:AZ5854.

RvS 17 January 2007, ECLI:NL:RVS:2007:AZ6395.

RvS 4 April 2007, ECLI:NL:RVS:2007:BA2227.

RvS 16 May 2007, ECLI:NL:RVS:2007:BA5207.

RvS 14 November 2007, ECLI:NL:RVS:2007:BB7828.

RvS 21 December 2007, ECLI:NL:RVS:2007:BC1397.

RvS 21 December 2007, ECLI:NL:RVS:2007:BC1400.

RvS 27 August 2008, ECLI:NL:RVS:2008:BE9313.

RvS 28 January 2009, ECLI:NL:RVS:2009:BH1132.

RvS 22 April 2009, ECLI:NL:RVS:2009:BI1839.

RvS 22 July 2009, ECLI:NL:RVS:2009:BJ3426.

RvS 7 October 2009, ECLI:NL:RVS:2009:BJ9530.

RvS 17 February 2010, ECLI:NL:RVS:2010:BL4140.

RvS 7 April 2010, ECLI:NL:RVS:2010:BM0215.

RvS 7 July 2010, ECLI:NL:RVS:2010:BN0430.

RvS 16 March 2011, ECLI:NL:RVS:2011:BP7775.

RvS 5 October 2011, ECLI:NL:RVS:2011:BT6639.

RvS 30 November 2011, ECLI:NL:RVS:2011:BU6362.

RvS 3 April 2013, ECLI:NL:RVS:2013:BZ7545.

\section{SAFA}

RvS 6 February 2008, ECLI:NL:RVS:2008:BC3585.

RvS 3 September 2008, ECLI:NL:RVS:2008:BE9687.

\section{Rechtbanken (District Courts)}

\section{Integrated pollution prevention and control}

Rb. Den Haag 5 March 2014, ECLI:NL:RBDHA:2014:3068. 
Naczelny Sąd Administracyjny (Supreme Administrative Court)

\section{General product safety}

II GSK 881/10, judgement of 7 September 2011.

II GSK 882/10, judgement of 29 September 2011.

II GSK 1089/10, judgement of 18 October 2011.

II GSK 1404/11, judgement of 16 October 2011.

II GSK 1416/11, judgement of 17 October 2012.

II GSK 936/12, judgement of 22 October 2013.

Integrated pollution prevention and control

II OSK 1560/08, judgement of 29 April 2009.

II OSK 874/10, judgement of 15 May 2011.

II OSK 233/11, judgement of 25 April 2012.

II OSK 577/12, judgment of 2 July 2013.

II OSK 776/12, judgement of 22 August 2013.

II OSK 1246/12, judgement of 2 October 2012.

\section{Other areas}

II GSK 1765/13, judgement of 25 September 2013.

Wojewódzki Sąd Administracyjny w Warszawie (Regional Administrative Court in Warsaw)

\section{Integrated pollution prevention and control}

IV SA/Wa 1395/07, judgement of 20 November 2007.

IV SA/Wa 1486/07, judgement of 20 November 2007.

IV SA/Wa 231/08, judgement of 9 May 2008.

IV SA/Wa 543/08, judgement of 23 May 2008.

IV SA/Wa 1908/08, judgement of 5 February 2009.

IV SA/Wa 1768/08, judgement of 8 April 2009.

IV SA/Wa 885/09, judgement of 12 January 2010.

IV SA/Wa 886/09, judgement of 12 January 2010.

IV SA/Wa 888/09, judgement of 12 January 2010.

IV SA/Wa 889/09, judgement of 12 January 2010.

IV SA/Wa 1205/09, judgement of 26 November 2009.

IV SA/Wa 2036/09, judgement of 12 October 2010.

IV SA/Wa 1190/11, judgement of 26 October 2011.

IV SA/Wa 1199/11, judgement of 7 November 2011.

IV SA/Wa 1471/11, judgement of 30 November 2011.

IV SA/Wa 1498/11, judgement of 9 December 2012.

IV SA/Wa 1650/11, judgement of 23 January 2012.

IV SA/Wa 1757/11, judgement of 12 January 2012.

IV SA/Wa 1226/12, judgement of 4 October 2012.

IV SA/Wa 2324/12, judgement of 6 February 2013.

IV SA/Wa 771/13, judgement of 5 July 2013.

\footnotetext{
${ }^{1}$ ECLI not available.
} 


\section{General product safety}

VI SA/Wa 1714/06, judgement of 17 January 2007.

VI SA/Wa 1902/07, judgement of 21 February 2008.

VI SA/Wa 2073/07, judgement of 21 February 2008.

VI SA/Wa 1603/08, judgement of 6 October 2008.

VI SA/Wa 1855/09, judgement of 13 January 2010.

VI SA/Wa 1229/09, judgement of 26 January 2010.

VI SA/Wa 2062/09, judgement of 2 March 2010.

VI SA/Wa 58/10, judgement of 8 April 2010.

VI SA/Wa 1967/10, judgement of 23 December 2010.

VI SA/Wa 2414/10, judgement of 4 February 2011.

VI SA/Wa 2423/10, judgement of 8 February 2011.

VI SA/Wa 1391/11, judgement of 10 November 2011.

VI SA/Wa 2390/11, judgement of 6 February 2012.

VI SA/Wa 3522/13, judgement of 3 April 2014.

Wojewódzki Sąd Administracyjny w Szczecinie (Regional Administrative Court in Szczecin)

Integrated pollution prevention and control

II SA/Sz 816/09, judgement of 4 November 2009.

Wojewódzki Sąd Administracyjny w Lodzi (Regional Administrative Court in Lodz)

Integrated pollution prevention and control

II SA/Łd 247/07, judgement of 2 March 2007. 


\section{Websites}

Consumentenbond, <www.consumentenbond.nl $>$.

Court of Justice of the European Union, <curia.europa.eu $>$.

De Rechtspraak, 'Uitspraken', <uitspraken.rechtspraak.nl>.

DECO Proteste, <http://www.deco.proteste.pt $>$.

Europa, 'A new approach to technical harmonisation', <http://europa.eu/ legislation_summaries/internal_ market/single_market_for_goods/technical_harmonisation/>.

European Banking Authority, 'Missions and tasks', <http://www.eba.europa.eu/about-us/missions-and-tasks > . European Commission, 'Annual reports on monitoring the application of EU law', <http://ec.europa.eu/ atwork/applying-eu-law/infringements-proceedings/annual-reports>.

European Aviation Safety Agency, 'Ramp Inspection Programme (SAFA/SACA)', <http://www.easa.europa. $\mathrm{eu} /$ node/15629>.

European Commission, 'Consumer Scoreboard', <http://ec.europa.eu/consumers/archive/consumer_research/ cms_en.htm>

European Commission, 'Consumers, Committees, networks, and working groups', <http://ec.europa.eu/ consumers/archive/safety/committees $>$.

European Commission, 'EU Pilot', <http://ec.europa.eu/internal_market/scoreboard/performance_by_governance_tool/eu_pilot>

European Commission, 'Eurobarometer Surveys', <http://ec.europa.eu/consumers/archive/strategy/facts_ eurobar_en.htm>

European Commission, 'ICSMS', <https://webgate.ec.europa.eu/icsms/>.

European Commission, 'Infringement decisions', <http://ec.europa.eu/atwork/applying-eu-law/infringements-proceedings/infringement_decisions $>$.

European Commission, 'National Consumer Organisations', <http://ec.europa.eu/consumers/eu_consumer_ policy/consumer_consultative_group/national_consumer_organisations $>$.

European Commission, 'Rapid Alert System for non-food products posing a serious risk (RAPEX)', $<$ http://ec.europa.eu/consumers/safety/rapex/index_en.htm>.

European Commission, 'RAPEX: Statistics and Reports', <http://ec.europa.eu/consumers/archive/safety/ rapex/stats_reports_en.htm>.

European Commission, 'Single Market Scoreboard', <http://ec.europa.eu/internal_market/scoreboard/> .

European Commission, 'Solvit', < http://ec.europa.eu/solvit/>.

European Commission, 'The Internal Market Scoreboard', <http://ec.europa.eu/internal_market/score>.

European Environment Agency, Eionet, <http://www.eionet.europa.eu>.

European Environment Agency, 'Eionet: Central Data Repository', <http://cdr.eionet.europa.eu>.

European Environment Agency, 'Eionet: Industrial Emissions Reporting Information System (IRIS)', $<$ http://iris.eionet.europa.eu>.

European Environment Agency, 'Eionet: Reporting Obligations Database: Reporting obligation for IPPC questionnaire', <http://rod.eionet.europa.eu/obligations/523>.

European Environment Agency (n.d.), 'Eionet Forum: Thematic reporting guidelines: IPPC reporting', $<\mathrm{http}$ ://forum.eionet.europa.eu/x_reporting-guidelines/library/ippc $>$.

European Environment Agency, 'The European Pollutant Release and Transfer Register (E-PRTR)', $<$ http://prtr.ec.europa.eu>.

European IPPC Bureau, 'References', <http://eippcb.jrc.ec.europa.eu/reference/>.

European IPPC Bureau, 'Who is who in the IED', <http://eippcb.jrc.ec.europa.eu/about/who_is_who.html>.

${ }^{1}$ All accessed 15 April 2015. 
European IPPC Bureau, 'Working procedures to elaborate BREFs', <http://eippcb.jrc.ec.europa.eu/about/ working_procedures.html>.

European Securities and Markets Authority, 'ESMA in short', <www.esma.europa.eu/page/esma-short>.

European Union, 'Agencies and other EU bodies', <http://europa.eu/about-eu/agencies>.

Federacja Konsumentów, <http://www.federacja-konsumentow.org.pl>.

Federacja Zielonych GAJA, <http://gajanet.pl >.

GEOTA, <www.geota.pt $>$.

IMPEL, <http://impel.eu $>$.

Instituto de Gestão Financeira e Equipamentos da Justiça, I.P., 'Bases Jurídico-Documentais', on $<$ http://www.dgsi.pt $>$.

Liga para a Proteç̧ão da Natureza, <www.lpn.pt>.

MOBilisation for the Environment, $<$ http://www.mobilisation.nl $>$.

Natuur\&Milieu, <http://www.natuurenmilieu.nl>.

Naczelny Sąd Administracyjny, 'Centralna Baza Orzeczeń Sądów Administracyjnych', on $<$ http://orzeczenia.nsa.gov.pl $>$.

Prosafe, <www.prosafe.org $>$.

Quercus, <http://www.quercus.pt $>$.

Stichting Advisering Bestuursrechtspraak, <www.stab.nl>.

The World Bank Group, 'Data', <http://data.worldbank.org/>.

The World Bank Group, 'Worldwide Governance Indicators', <www.govindicators.org $>$.

VeiligheidNL, < http://www.veiligheid.nl>.

Związek Stowarzyszeń Polska Zielona Sieć, 'Polish Environmental NGOs Directory', $<$ http://www.ecolink.org.pl $>$. 



\section{Curriculum vitae}

Josine Polak (Raamsdonksveer, 2 March 1985) attended grammar school at Lyceum Oudehoven in Gorinchem between 1997 and 2003. She went on to study European Studies (Bachelor of Arts cum laude) and European Public Affairs (Master of Arts cum laude), both at Maastricht University, Faculty of Arts and Social Science (FASoS). During her studies, she undertook internships at ICODA European Affairs in Brussels and at the European Institute of Public Administration in Maastricht. In 2008 and 2009, Josine was a research and teaching assistant at FASoS, where she taught bachelor and master students in the area of European Studies. From 2010 until 2014, she carried out her Ph.D. research at the Law Faculty of Maastricht University and alongside taught courses on Dutch administrative law and comparative government. 
What works to make EU law work? This may be one of the most important questions facing the European Union in view of the nearly axiomatic implementation deficit with which it is confronted. This study addresses this question by analysing the usefulness of compliance instruments in supporting the correct application of EU law by the competent authorities of the member states. These instruments - supranational monitoring and sanctions, post-legislative guidance, transnational networks, civil society, and case law - were studied using a case-study method that involved three EU directives (on general product safety, integrated pollution prevention and control, and safety assessment of foreign aircraft) and three EU member states (the Netherlands, Poland, and Portugal).

The cases were examined using an interdisciplinary approach that combines perspectives from legal science with those pertaining to political science, in particular public administration. Particularly important to this analysis were the perceptions of the 'users' of the studied compliance instruments; namely, national officials involved in the (street-level) application of EU law. Yielding insight into the usefulness of the studied compliance instruments for supporting national actors in the application of EU rules on the ground - and providing recommendations as to how the application of EU rules could be elevated to a higher level - this study will be helpful for national and EU practitioners who are directly involved in the application of EU measures, and for those who stand to benefit from the rights and obligations outlined in these measures. 